$1+x, y=2, k$

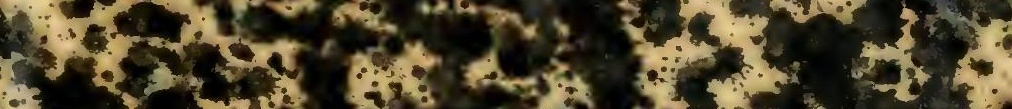

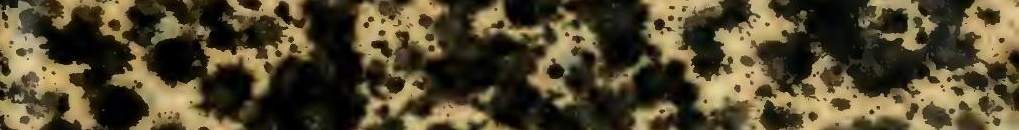

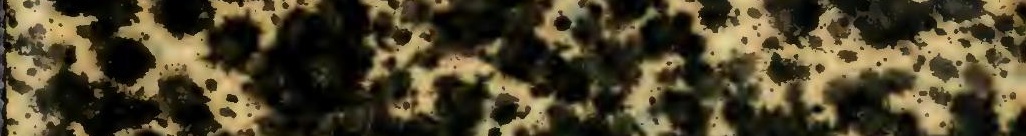

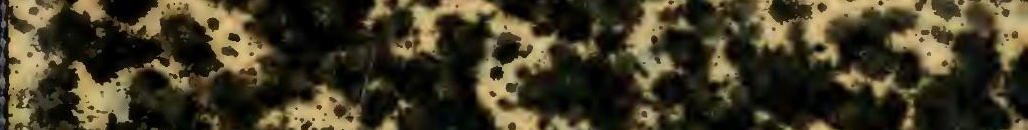
(3)

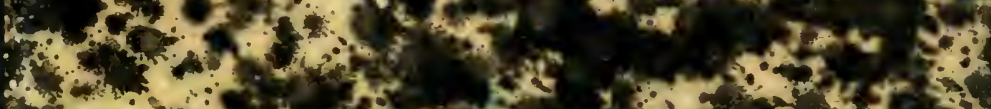
(1)

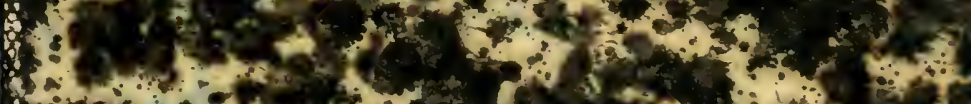
2.

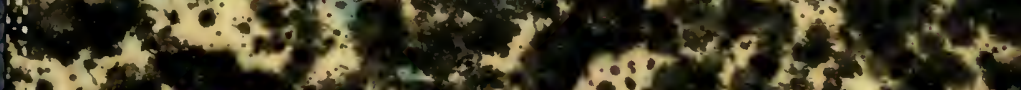

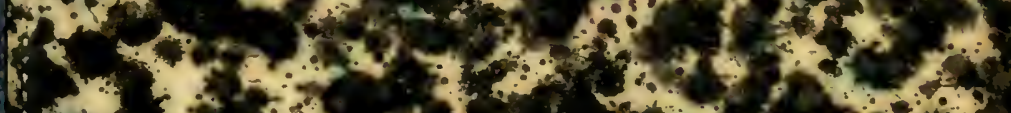

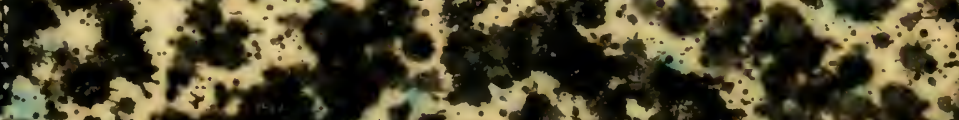

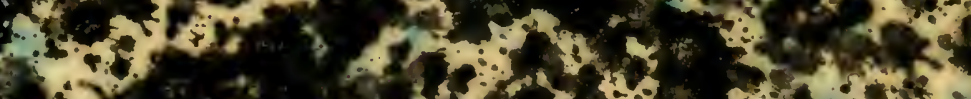

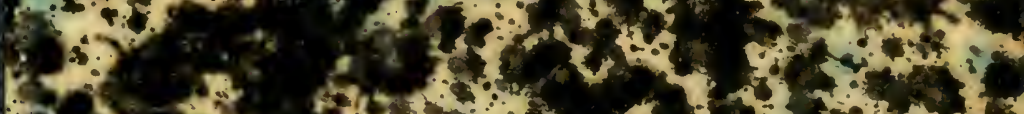

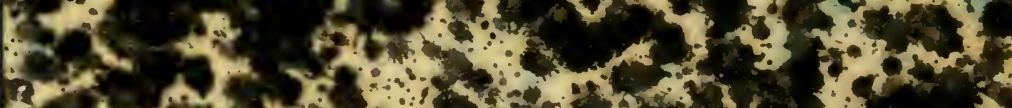

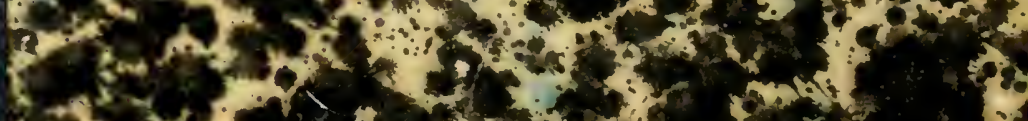

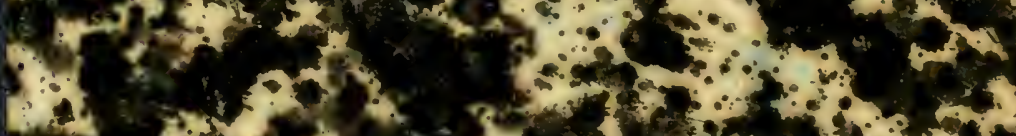

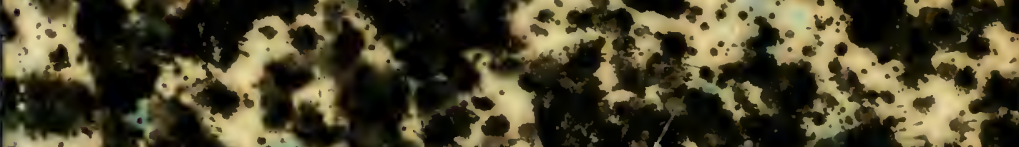

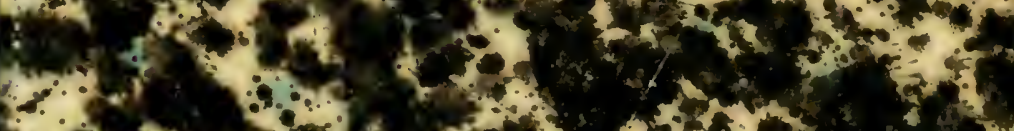

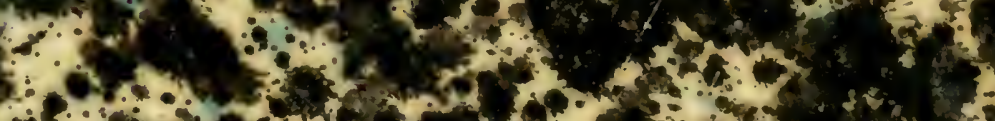

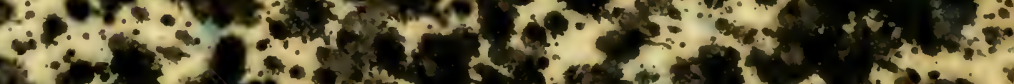

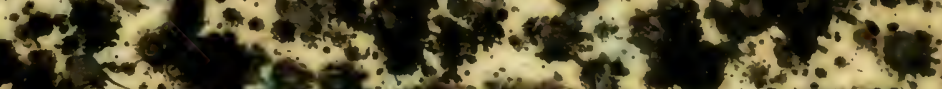

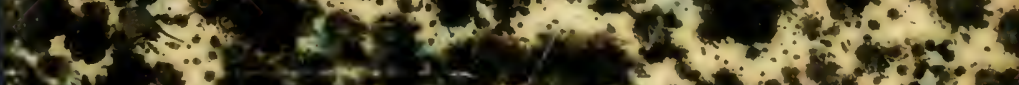

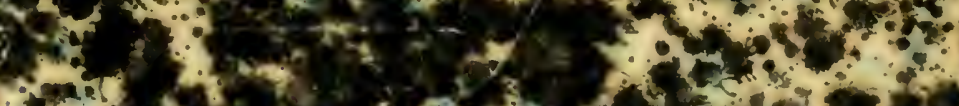

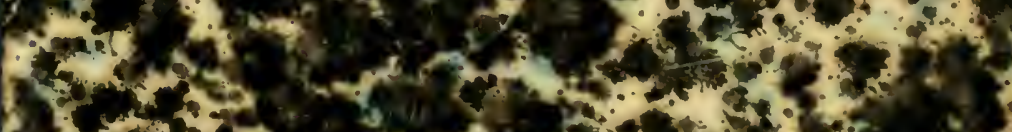

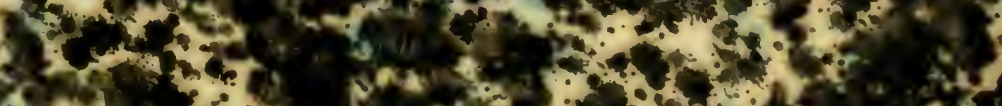

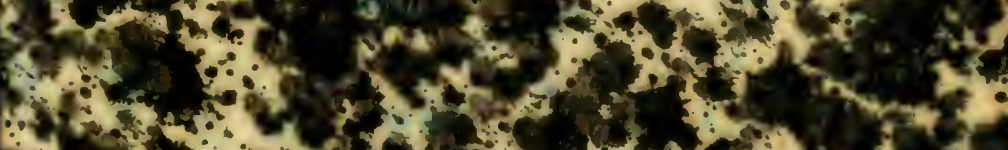

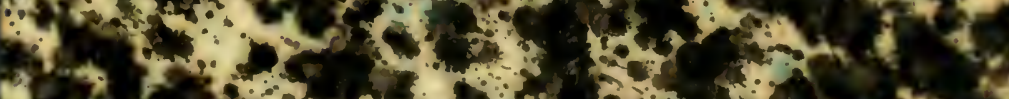

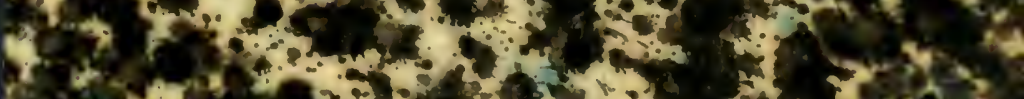

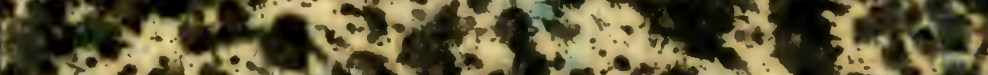

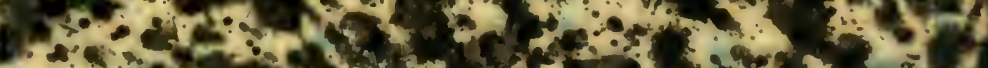

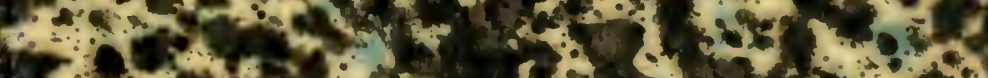

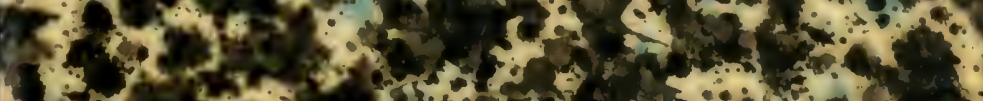

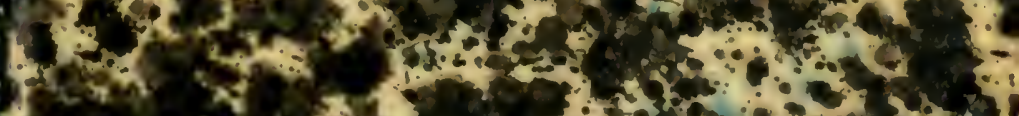

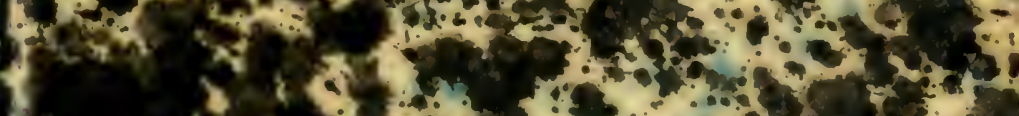

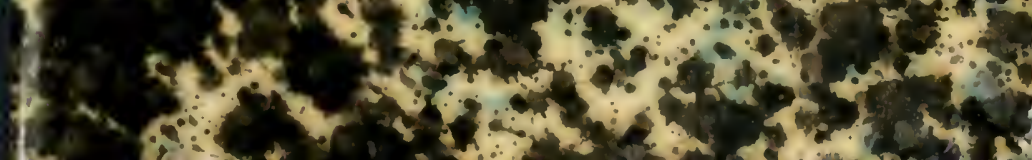


Digitized by the Internet Archive in 2009 with funding from University of Ottawa 







A mon davout couprei in le t:

Callamang

2 verawe

Lacase aly gucriol loos. 


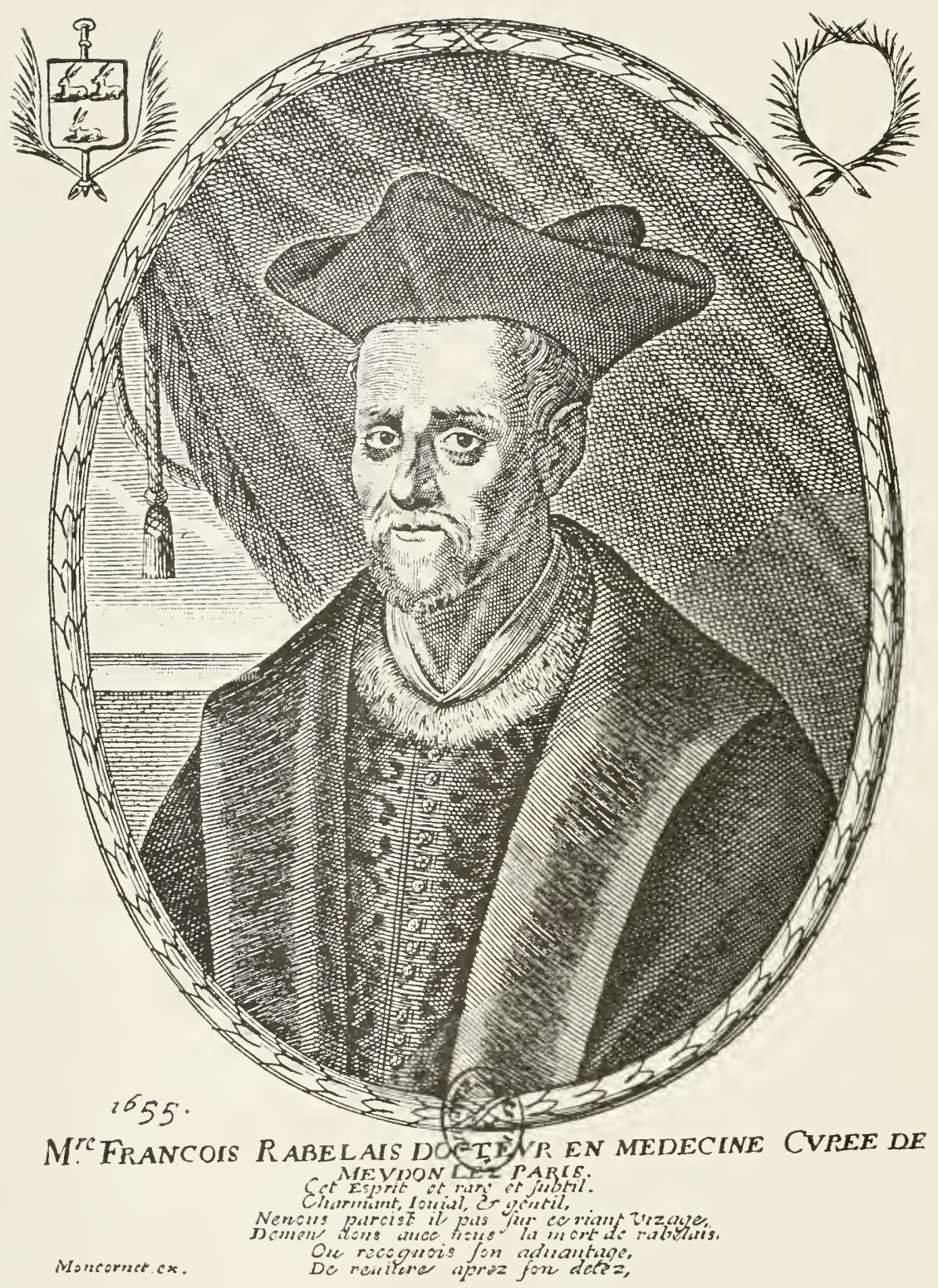




\section{RABELAIS}

\section{ANATOMISTE ET PHYSIOLOGISTE}

$\mathrm{P} \perp \mathrm{R}$

\section{Le Docteur A.-F. LE DOUBLE}

PROFESSETR D'AXITOMIE A L'ÉCOLE DE MÉDECIXE DE TOURS

MEMBRE CORRESPONDAXT DE L ACADEMIE DE MEDECINE

L.IURÉAT DE L'IXSTITLT (ACADÉ.MIE DES SCIEXCES)

AVEC UNE PRÉFACE

DE

\section{Mathias DUVAL}

PROFESSLER A LA FACULTÉ DE MÉNECINE DE P.ARIS MLMBRE DE L'ACAHËMIE DE MÉDECIXE

32 fac-similés el 17f illustrations par M. Louis D.xty-Colbas

Ouvrage couronné par la Ville de Tours

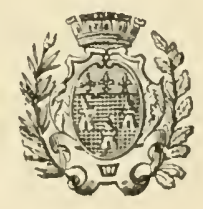

PMIIS

ERNEST LEROLX, ETTELR

2N, HUE BOXAPARTE, 28 

PAVEGYRISTE DE DESCARTES

\section{A M. L. LIARD}

DIRECTELR DE L'ENSEICANMENT SUPPERIECR

MEMBRE DE 'IXSTITUT, CONSEILLER D'ÉTAT CUMMAXEUL DE LA LÉGION D'HONXEUR

Je dédie ce livre.

$D^{r}$ A. - F. LE DOUBLE.

Tours, le $2 \mathrm{~s}$ Décembre rsps. 



\section{PREFACE}

Combien détudes ont déjà élé publiées sur Rabelais! Combien de volumes déjà consacrés à linterprélation de l'anlent de Crargantua! Il semblail impossible de lronver dans ce sujel quelque chose qui n’ềt pas élé dil déjà, et cependant nous voici bien en présence d'un livere entièrement nonveau, qui nous monlre Rabelais ì un point de vue encore complètement inédit: il nons révèle Rabelais.s sérieusement analomisle.

Au live II, Tenomanes anulomise Onaresmeprenant par une longue énumération on, pour mienx dire, une lonfue série de comparaisons qui, an premier abord, fait l'effet din fastidien.r el interminable chapelel de mols. Il avail : - les os, comme cassemuseaulx ; - les sponlyjles, comme une rornemuse; - lallialim, comme un billarl; elc., elc.

(Mne signifient ces énuméralions qui, par instant. ne semblent viser que la cocasserie de lemihainement de mols barognes? Est-ce moquerie? Rabelais a-t-il rouln tourner en ridicule les andomistes qui de tous lemps ont rherche' it romparer les arganes al les parlies doryanes ander des objets plus vulgairement connus?. Cierles la chose élait pent- 
être déjà lentante de son lemps; elle le serait plus encore anjourdhui, alors que ces comparaisons sont devenues, après l'époque de Rabelais. de plus en plus fréquentes el sonvent de plus en plus singulières. On ne s'étonne pas de voir une saillie de l'extrémité externe de l'omoplate comparée à un bec de corbean (apophyse coracoüde), ou la cavité articulaire de l'os des îles comparée à nne ruvelte (cavité cotyloüde): que l'ensemble des deux trapèzes rappelle le capuchon d'un moine, et que celle ressemblance ait valu à ce muscle le nom de cucullaris, cela paraît encore naturel, et ces comparaisons s'imposent si bien que les arlistes enx-mèmes, cenx qui s'occupent d'anatomie des formes, donnent à la figure du trapèze le nom de fichu du dos par assimilation an costume des femmes de la campagne. Le nom de morsus diaboli appliyué anx franges du pavillon tubaire est déjà d’une fantaisie plus piquante. Mais, que penser de létat psychologique de ceux qui ont établi la nomenclature des parties intra-cérébrales et qui ont tronvé des orifices qu'ils ont appelés anus et vulve, des saillies qu'ils ont qualifiées de nates (Jesses) et de testes (testicules), un oryane quils ont dit le thalamus (couche nupliale, couche optique) avec son coussin on pulvinar. Comme l'a dit je ne sais plus quel grand anatomisle, la nomenclature de ces régions cérébrales suffirait pour défrayer tout un... lupanar, puisque nons n'osons mellre ici le mol propre donl se serail servi Rabelais. Certes celle manie des comparaisons plus ou moins convenables existait déjà du temps de Rabelais, et on poumait se demander si son anatomie de Quaresmeprenant niest pas une mordante satire, comme tant d'antres jetées dans l'épopée pantagruélique.

La lecture de ce livre montrera qu'il n'en est rien.

Toujours est-il que jusqu'à présent personne n'avait pris au sérieux les chapitres relatifs à l'analomie de Ouaresmeprenant. Le bibliophile Jacob n'y voyail quine insipide énumération, n'ayant d'autre but que de rassembler la 
lechnique analomique; et Burgaud des Marels el Rathery pensaient qu'il y aurail puérilité à la prendre an sérieux el it en chercher ane interprélation rationnelle.

Eh bien! il n'en est rien. Il n'y a lì ni sative, ni puérile oslentation, ni assemblage de mots bizarres el incompréhensibles. Le tont étail de comprendre. C'est ce à quoi est arrivé. Ir. Le Donble. Celle anatomie est nne énnmération sériense; tonles les comparaisons qui la forment sont merveillensement jusles et valent une description. Le tout élait de retronver le véritable sens de certains termes analomiques et de faire connaitre les objets anciens auxquels sont comparés les organes désignés par ces termes. Le résultat de ce travail de bénédictin est de jeter une vive lueur sur la question de l'étal des connaissances anatomiques à cetle époqne et de nons faire sentir ì quelles dissections nombrenses et minulienses raval diu se liver Rabelais pour arriver it connaille si bien la forme et la disposition des parties.

Noublions pas, en effet.quaver Rabelais nous sommes à l'époque où s'oume l'ère de l'onseignement analomique. La dissection du corps humain était ì peine organisée ì l'Ecole de I'aris; depuis déjù un cerlain lemps, elle était pratiquée it Honlpellier. L'histoire recueille avee soin les différents indices de ces premières investigations anatomiques. Pont" notre part, nous arons eu oceasion, dans différentes publications, de montrer comment, à cette époque. les artistes et les médecins italiens avaient uni leur's efforls pour pénétrer dans la connaissanee du corpss humain. La publication des manuserits de Lérnard de linci a élé, à eet ésgurd, une véritable révélation; ses Ciahier's d'anntomie, qui datent de 1.jo, nous onl monlvé des dissections tress heruensement conduiles el qui abonlissent à des notions lrès exactes. Léonard de lïnci nous a laissós ses noless sous forme de dessins: Rabelnis nous laisse less sienness sons forme de comprarnisons: lan comme lante ont procéde par inages. 
Les comparaisons que nous donne Rabelais sont tontes merveilleusementexacles, commelepronvela lecture de cevolume: - les spondyles, comme une cornemuse; mais encore faul-ilsavoirque spondyles venl dive verlèbres (colonne vertébrale) el que la cornemuse en question est une sorte de long luyau avec denx on trois légères courbures comme celles du rachis; - l'alkatim, comme un billart; mais l'alkalim, c'est le sarrum, et, à l'époque de Rabelais, on appelait billarl une certaine crosse recourbée el lérjèrement concave comme l'est le sacrum; - le frontal, comme une relumbe; mais la relumbe est un vase rond, une sorte de tasse, semblable à une coquille de pèlerin, el sa ressemblance est frappante aver le fronlal.

On le voil, dans ces comparaisons, rien ne vise an comique; si an premier abord on croil elre en présence dine fanlaisie qui aurail arcumulé des mots bizarres el sans signification, celle idée disparail bientot devant la réalité des faits.

Pont arriver à la démonstration de sa these, I. Le Double a employjé le moyjen le plus propre i frapper l'esprit en parlant anx yenx: il a employé le dessin; pour chaque comparaison. il a représenté cote à côte la partie anatomique d'une part et d'autre part l'objet auquel est comparée celle partie. De ces fignres ainsi assemblées parpaires il n'en est pas une quine porte anssitat la convictiondans lesprit, tant les ressemblances sont vraies el frapjantes. Quelques-unes sont étonnantes parce qu'elles montrent combien Rabelais arait bien saisi les caractères morphologiques des parties anatomiques. Toyez par exemple: "l'os pétrenx, comme un plumail; les crémastères, comme une raquetle; le tympane (le lympan), comme un moulinet; les ventricules (du cerveun), comme un lirefond; la nuque (le bulbe), comme un fallol, etc."

C'est en cecisurtont que l'antenr a fait tune ornore entiorement nouvelle, un linre qui n'est pas fait avec d'antres lives, mais avec des materianx originanx grace it des 
recherches dans des voies non frayées encore. Il a pu ainsi élablir que Maîlre François a fait un des premiers, sinon le premier, des démonstrations publiques sur le cadave el qu'il a été l'émule de l'ésale.

Pour mener à bien de pareilles recherches, il fallail rénnir des aplitudes el des connaissances qu'on lronve rarement chez un même homme.

Il fallail d'abord étre anatomiste, cela va sans dire, el bon anatomiste. A cet égard, le culte que depuis longtemps il a voné à l'anatomie, sa silnation dans l'enseignement el ses remarquables travanx sur l'anatomie, notamment sur. les anomalies musculaires, étaient de sûrs garants de ses compétences. Mais il ne fallail passeulement connaître l'anatomie actuclle; il fallait ètre également familier avec l'anatomie des siècles passés, el spécialement de l'époque de la Renaissance; il fallait posséder à fond les wnwes de Mundinus, de Béranger de Carpi, de Gabriel de Zerbis, de Vésale, afin d'exposer la science de ces temps el refaire les coupes indiquées par Rabelais, el rendre indisculables, même pour les jrofanes, toutes ses comparaisons.

I'antre part, il fallait être linguiste ou, pour mienx rlire, philologne, afin de retronver la véritable siynification d'expressions qui avaient été mal interprétées jusqu'ici. De ces termes, les uns dérivés des langues élrangères anaient élé mulcompris; les antres, demenrés dans le langage français actuel, n'y conservaient plus le mème sens qu'ils avaient dans le vieux français. C'est ainsi que le mot spondyle, dérivé du grec, signifie vertère el non insecte coléoptère. comme on la prétendu; que les motsalkialim el nuque, dérivés de larabe, venlent dire le sacrum et le bulbe rachidien; que le mot rabot, dérivé du latin, signifie rave; que le motbillart siynifie une crosse (la crosse it crosser); cle.

Enfin, il fallait avoir des connaissances étendues en ar-

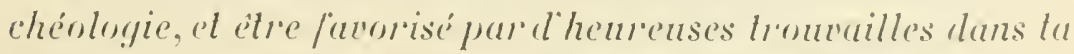
lecture des vienx 'mannscrits. comme dans tinspection des 
musées, des églises, des anciens monuments. En effet, après avoir déterminé la signification de mots mal interprétés ou dont le sens a changé avec les lemps, il élait indispensable de rechercher les objets anxquels Rabelais comparait les divers organes el, pour cela, fouiller les vieux manuscrits, compulser de vicilles estampes, éludier les musées el y retronver ces objels soit en nature, soit représentés dans des peintures ou des sculplures anciennes. Il a même fallu étudier de très près les personnages sculptés en ronde bosse sur les pilier's des maisons du $\mathrm{xVI}^{\mathrm{e}}$ siècle ou des cathédrales golhiques; étudier les personnages figurés dans les vitraux de ces mêmes cathédrales, etc. C'est ainsi qu'il a retrouvé le soulflet, anquel Rabelais compare le muscle, sur le chapileau d'un des piliers de l'église de Vézelay; la vèze (le sac de la cornemuse poitevine), à laquelle est comparée la glande pinéale, sur un chapitean des piliers d'une des portes de la maison Adam, à Angers (xvi siècle), el sur le tablean Concert de famille de Jordaens; la harpe, à laquelle esl comparée la langue, sur un vase du Musée du Lonvre; la doloire, comparée à la vésicule biliaire, sur un des vitraux de la cathédrale de Bourges; la chalamie (flute champêtre), comparée à la colonne vertébrale, dans la collection d'instruments anciens de $\mathbf{M}$. Tolbecque, de Niort; la crémaillère, comparée anx uretères, dans une des salles de l'Art rétrospectif à l'Exposition nationale de Tours de 1892 ; etc., etc.

Ces recherches, exposées avec les deux figures mises chaque fois en regard l'une de l'antre, nous présentent parfois des résullats singulièrement surprenants sur létendue el la précision des connaissances analomiques de Maitlre François; nous recommandons particulièrement à cet égard (page 181) le chapitre intitulé : "La plèvre, comme un bec de corbin. "Évidemment, à l'époque de Rabelais, on pratiquait déjà des coupes totales du tronc pour démontrer la forme el les rapporls des organes.

Aussi, à chaque page, l'auleur laisse-t-il éclater hantement 
son admiration pour celui qu'il considère comme l'émule de Vésale. Parfois peut-être va-t-il un peu loin, et le lecteur. pourra-l-il hésiter à le suivre, lont en demenranl singulièremenl pensif el perplexe au sujet des problèmes sonlevés. Tel est an moins le cas, nous semble-t-il, punr la question des spermatozoüdes el du microscope, el quon tronera exposée paye 215, au chapilre intilulé : "La génilure, comme un cenl de clous à lalle. El me contoit sa nourrice, quil, estant marié avec la Miquaresme, engendra senlement nombre de adverbes locaulx, el certains jensnes doubles."

Dans loul ce qui précède, nous auons fail allusion surlont anx faits qui relevent de l'anatomie descriptire; mais Rabelais avait anssi éludié l'analomie des régions el .I. Le Double n'a pas de peine à démontrer que le médecin ordinaire du cardinal du Bellay possédail assez bien son anatomie chirurgicale pour pouvoir indiquer d'avance le degré de gravité d'une blessure, d'après son siège el sa profondeur, el qu'il savail mème se placer au poinl de vae spécial de l'anatomie des formes. Enfin, sons le litre d'anatomie comparée, un chapitre spécial, anquel nous ne ferons que celle courle allusion, nous montreque, à une époque où les conles les plus ridicules élaient universellemenl acceplés sur cerlains monstres el animanx étranges, Rabelais a fait prenve d'un esprit scientifique sérieux en n'acceptant pour vrai que ce qui avail élé vu par lui ou par des auteurs dignes de foi.

Nous en avons dit assez pour mettre en évidence le caraclère original, nonveau, absolument inallendu de ce livre; il sera une argréable surprise pour les innombrables arlmiralenr's de Rabelais, anxquels il montrera le Maître sons une face nonvelle. Ils y tronveront, non senlement le Rabelais analomiste et physiologiste jusqu'ici méconnu, mais encore le liabelais pro/essionnel, médecin, savanl, espril universel el fécond. Il sera anssi nne surprise pour les analomislés, car il vient ajouler an nouveau chapilre à lhistone de l'ana- 
tomie. Enfin, il plaira à tous, car chacun sentira, en le lisant, et partagera le grand souffle de patriotisme dont était inspiré lanteur en l'écrivant. Il fant voir avec quel enthonsiasme M. Le Donble glorifie la Touraine en la personne de Rabelais, l'un de ses plus illustres enfants. En élevant ce monument à Rabelais, c'est an génie même de la France qu'il rend hommage dans la personne de "cet inventenr précoce de tontes les idées et de tontes les curiosités modernes, cet esprit universel et fécond qui a ponssé ses devinations an delà de son siècle, jusqu'à rejoindre le nótre ".

MATIIAS DUVAL. 


\section{AVERTISSEMEN'T}

En 18 ge, a l'occasion de l'Exposition nationale de Tom's, la municipalité tourangelle, anssi soucieuse des progres des lethes el des seiences que de cenx de l'agriculture, de löndustrie, du commerce et des arts, a inslibé un conconts ayanl pour bul de mellre en lumiere cerlains points concernant les lellres, les sciences, lhistoire, lethnographie, la géologie, la géographie, la biographie, les culles, ele., de l'ancienne Touraine, el anssi de rechercher, expliquer el commenter lonl ou parlie des lravanx el des acles des grands hommes lourangeanx, depuis Crrégoire de Tours jusqu'ì Balzac, dans les parties reslées inconnues on obscures de lentrs arumes.

J'ai pris part a ce concours, et jail cu la bonne forlune

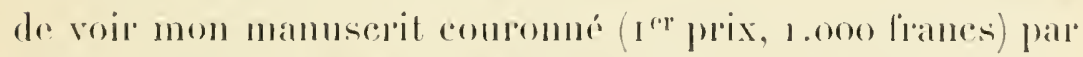
le jury, présidé par $\Lambda$ de Montaighon, membere de l'Insti-

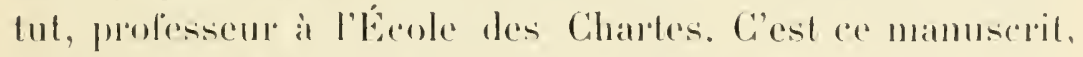
déposé depuis six ans i la Bibliotheque municipale de la ville de Tours, dont il est la proprielé, que je soumets aujourdhui, après avoir obtenu l'autorisation de le remanier et de le faire imprimer, i l'appréciation du grand public. Puisse-t-il ratifier le choix dont il a été l'objet! 



\section{INTRODUGTION}

Il est peu d'hommes dont la vie ed less opures aient inspiríatant de doetes commentaires à l'érudition contromporaine que la vie el les oemres de Francois Rabelais. On a peint Rabelais moraliste. Rabedais légiste. Rabelais pédagonue, Rabelais botaniste, Rabelais méderin, Rabelais chirmogien, ete. On na pas parté, on on na a parté püincidenment (1), de Rabelais anatomiste ef phrsiologiste. Et eependant l'auteur de Grargantua ot de P'antagrnel mórite

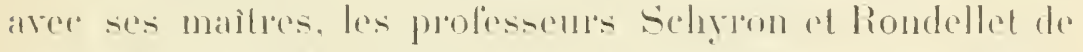
I'Université de Montpellier, antant que Vésale el Mlelsel servet, d’avoir son nom inserit en tète du livere d'or de l'analomie el de la phrsiologie.

Nir lit-on pas dans te lanití Ile Ponderibus (2), de Guil-

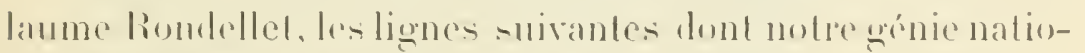

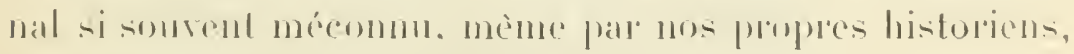

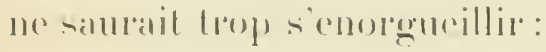

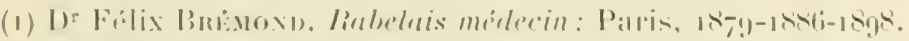

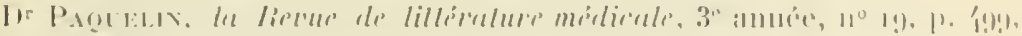
achulipe 18-5.

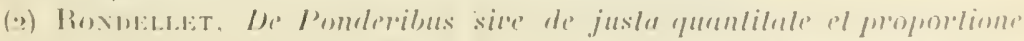

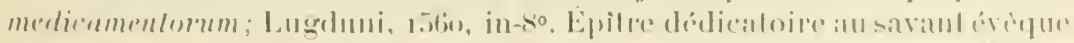

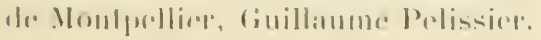


Cum autem prima sese offerel milhi ea pars qux naturam corporis humani decel exigitanda; vidi ab antiquis lam negligenter factum, ut quantum ad anatomen perlinel, me primum fuisse in hac academia existimem, qui myolomen diligenter pervestigaveril et exacte quod dum faciebam librum, qui aulopsiz responderet, evulgare necessarium duxi itlico fecissemque, ni V'essalius nunquam in eâ parte laudandus, desiderium meum aliquantum explevisset; non ila tamen quin etiam multum superstit spei meam in ei methodum non fore gregarium...

La partie qui enseigne la Nature du corps humain étant la première ‘ui se soit oflerte à mes investigations, je l'ai vue si négligée par les Anciens, que pour lanatomie jestime ètre le premies qui dans celte unirersité ait poursuivi la dissection des muscles avec soin et exactitude. Je jugeai alors nécessaire de publier sur-le-champ un livre qui Iraitât de l'autopsie, et je l'eusse fait si V'ésale, dont on ne proclame jamais trop la louange dans cette branche, n’eût suffisamınent répondu à mon désir; ce n'est pas an point cependant d'anéantir le ferme espoir que jai d’y aroir dignement contribué par ma méthode.

Au dire de Posthius, dère comme Rabelais de Guillaume Rondellet, ce dernier aurait même poussé si loin l'amour de l'anatomie qu'il aurait instamment prié son collègue et ami Fontanus, gravement malade, d'ordonner dans son testament qu'après sa mort son corps resterait la propriété de l'École de Montpellier pour ètre disséqué.

Est modus in rebus. Maître François a-t-il été possédé d'une telle ardeur pour les dissections? Il est impossible de l'affirmer. Ce qui est incontestable, c'est que ses connaissances anatomiques ont égalé, sinon dépassé, celles de ses deux maîtres Schyron et Rondellet.

C'est le 17 septembre 1530 que Rabelais s'est inserit en ces termes sur les registres de la Faculté de médecine de Montpellier:

Ego Franciscus Rabelæsus Chinonensis, diocesis Turonensis, huc adpuli, studiorum medicina gratia, delegique mihi in patrem egregium, dominum Joannem Scurronum, doctorem regentemque in hac alma Lniversilate. Polliceor autem me omnia observaturum, qux in pradicta 


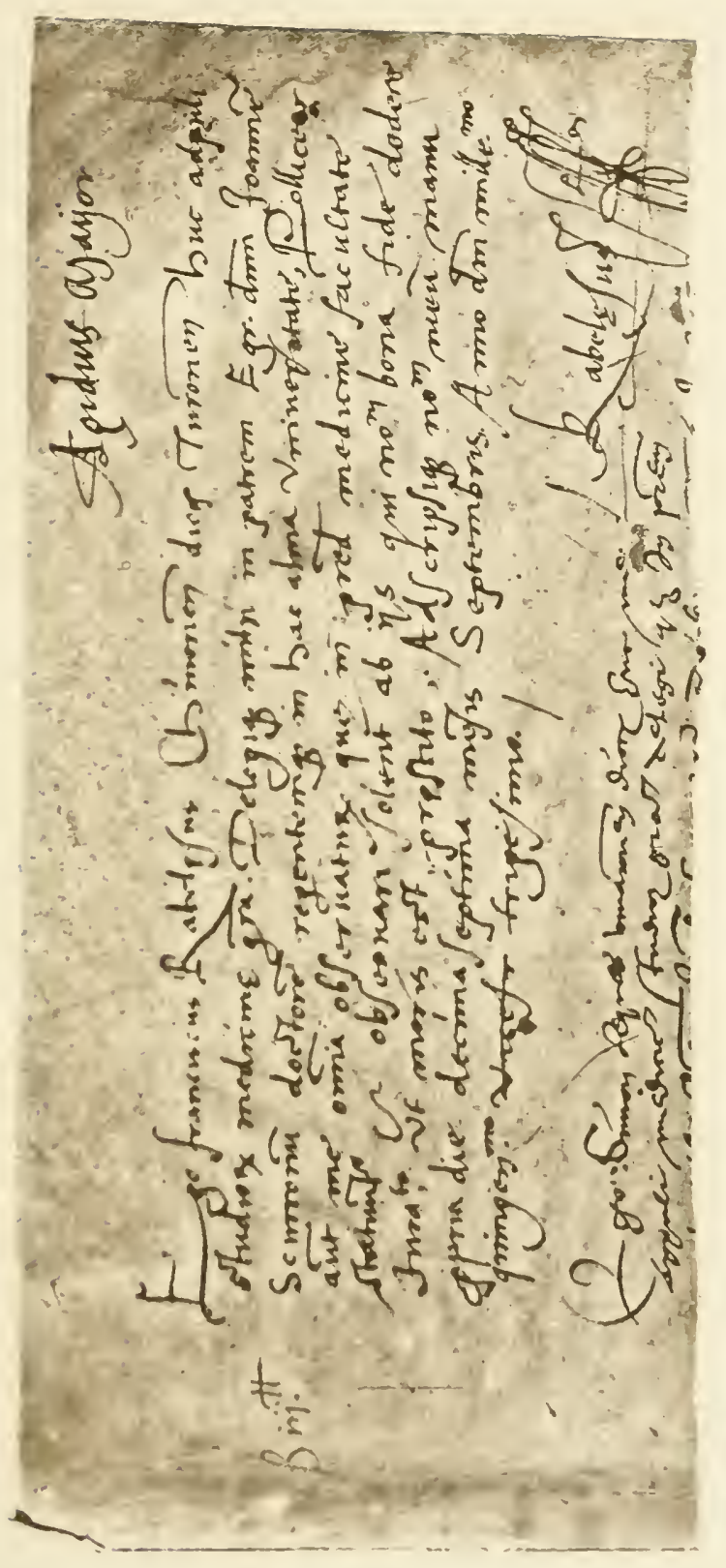



merlicine facultale staluuntur, el observari solent ab iis qui nomen bonn ficle alelere, juramento, ut moris est, praslito: adscripsique nomen meum mann propria, die decima septima mensis septembris, anno Domini millesimo quingentesimo lrigesimo.

\section{F. RABELESLS.}

Sur la marge de cet autographe, que l'Université de Ilontpellier (1) conserve avee un soin pieux ainsi que les

(1) II. E. Nö̈l raconte tu ces termes lanpive de Rabelais a Montpellier:

"... Il avait suivi la toule dans une salle on avait lien une disenssion sur la botanique... Sa r'éputation l’avait derancé ì l'école ; personne n’ignorat son prodigieux savoir... Le doyen lengagea ì prende part à la discussion... Rabelais sexcuse : on insiste, on le pousse vers la chaire ; il y monte: alor's il prorle des plantes aver tant de charme, d'éloquence et de clarté et prisente la plupart des questions sous un aspect si nomveau que fes applaulissements colatend de toutes les parties de la salle ef que lauditoire

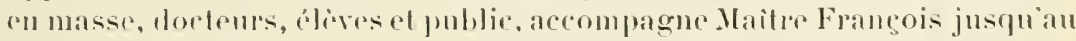

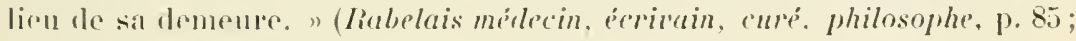
iédil. Paris, 1850.)

La notice hiographique de Louis Barró ajoute:

" Dans la discussion de cette these de botanique, il obtint un succes

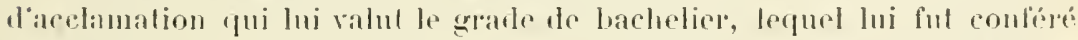

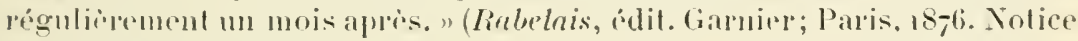
par L. liakri. j. xir.)

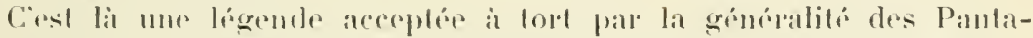

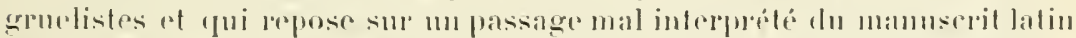

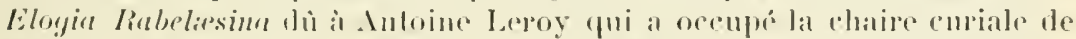
Memolon un pen moins de cent ans apres llaitre Francois. Co mannserit porte que larementation dre Ralbelais lut si hrillante : ul ab omnibus summo c'um plansu conchamatum sil eum dochoris dignitate dignandum sit; ce

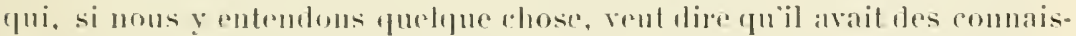

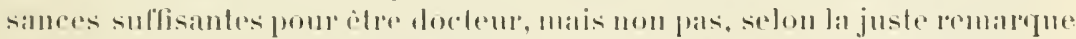

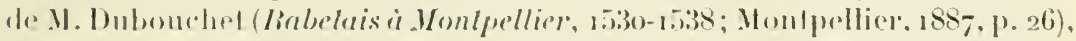
"quion lui en conl'éra le titre. Il y a loin du doctoris dignilule diynandum de

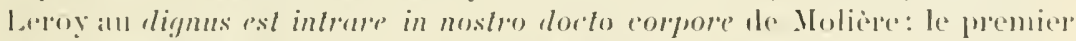

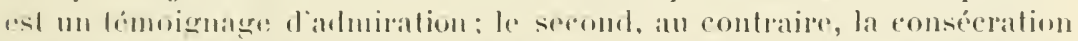
oflicielle el mérité de travaux passós al le eouromement le longues anmés dialuiles. "

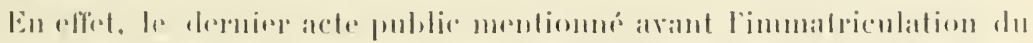

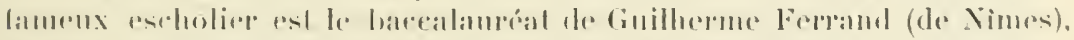

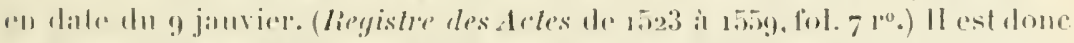

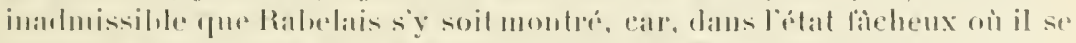

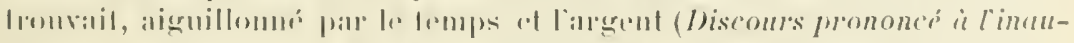

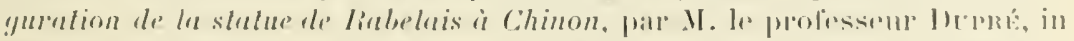

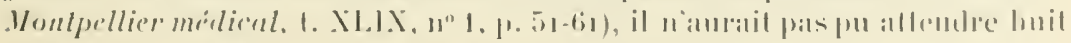

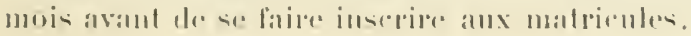




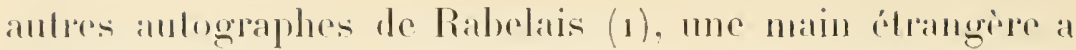
écril les mols:

Solvil tres libras.

Quelpues jours apres cette immatriculation le philiatre tourangean assistait a la première "anatomic " dirigéce par Rondellet et signait sur une feuille ad hoc: "Rabelesus quiu presens fui. " Les expressions "quia prosens fui" domt notre compatriote a lait suive sa signature sur le document ei-joint ainsi que ceux très explicites " in congregalione s, qui prócèdent sur le même docunent le nom de Caruel, démontrent que les reglements des frais de cours s'élablissaient sur le vu du compte sommis par le procureur ¿ une assemblée dans laquelle figuraient les élères qui avaient été présents à la lecon et pouraient dés lors attester de la sincérité des dépenses qu'elle avait occasionnexes $(2)$.

Serquitur yuod expositum fuit per me, procuraloris vices gerentem, consensu omninm scolasticorum, pro anatome faciendu, in yua mulhs studentium dedit, preter lonsures, a quibus hahui. XLIII solidos. Deali pro scribe promotia, quo supplicationibus

suis impetravimus. . . . . . . . . . X I sol.

Pro portaritus el comilantibus . . . . . . . Illl sol. fideniers.

Pro linteo dissecantium corpus . . . . . . . V sol.

Proteda............... Ill sol.

Proture.

Pro slupis.

11 sol. 6 denier's.

Pro candelis .

Pro carbone el filo. . . . . . . . . X X den.

Pro v'asculo. . . . . . . . . . . V den.

(1) Il avait alorstente-ciny ans suivant les uns, quarante ef meme plus suivant les autres. Dr Ponte, Discours prononcé í la sérance publique de lAdminislvalion du chef-lien du Rhone, 1 mai 1825 , et R. P. leuillant Pierre de Samt-Romulad, Thésor chronologique.

(2) Dr Gonoox, François Rabelais ì la Faculté de méderine de .Wonlpellier; Montpellier, 1876, p. 34. 


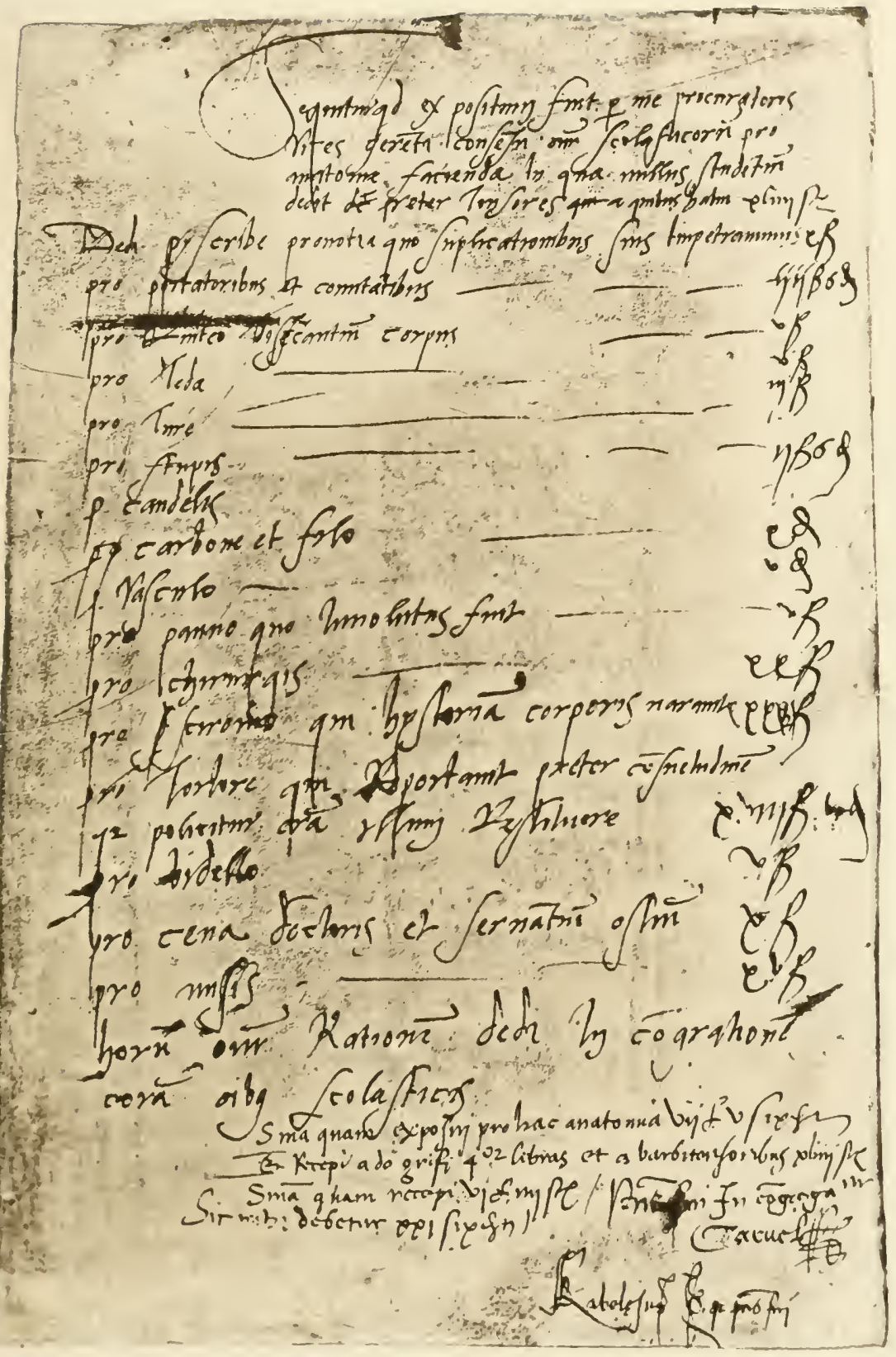



Pro panno quo inuolutus fuil. . . . . . . $\mathrm{V}^{\top}$ sol.

Pro chirurgis. . . . . . . . . . . . . XX sol.

Pro Je. Scironio, quihistoriamenrporisnararit. XXX sol.

Protortore, qui reporlavil preter consuetu-

dinem, qui policitus eram illum restiluere. XIII sol. VI den.

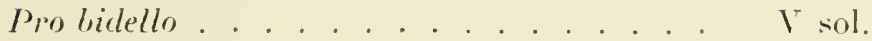

Pro cena doctoris el servantium ostium. . . X X sol.

Promissis . . . . . . . . . . . . . $\mathrm{XV}$ sol.

Inorum omnium rationem dedi in congrega-

lione, coram omniluns scolasticis.

Summa quam exposui pro hac anatomia, VII libr. V sol. IX Ien.

Et recepi a domino Cirifi quatuor libras, el

"bavbitonsoribus. . . . . . . . . . XLIIII solidos.

Summa quam recipi, VI libr. IIII sol.

Sic mihi debetur. . . . . . . . . XXI soI. IX den.

Prasens fui in conyregatione, CiliLEL.

RABEL.ESLS, quire presens fui.

(Liber Procuratoris, and ann. 1ribo.)

Parmi ces humanistes et ces savants de la Renaissance que dérolatitl'ardente soif d'apprendre et d'enseigner: Rabelais occupa le premice rang. Il ful "expert en toute clergicen el culassa dans son vaste cervean toute l'encyclopédic de son lemps (1). Ouand il commenga sa médecine, il élait si

(1) "Il est certain, dit Collefel, qüil chait tress sarant humanisle of tris probond philosophe, mathémalicien, médecin, jurisensulte, musieien, griomidre, astronome voire mème, peintre el poc̀le tont ensemble. Mais, comme la science des choses maturelles álait celle qui rerenait le plus it son humeur, il résolut de s'y appliquer enlierenent, el, a cet effet, il sen alla droit ì Montpellier."

11 est nou moins certain, on en aura la premse plus loin, qu'il était mn execllent grérengiplue.

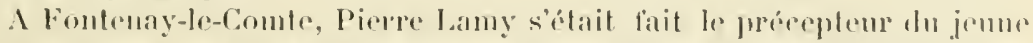

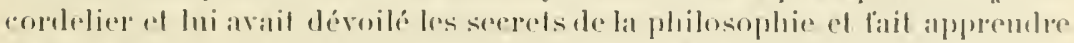

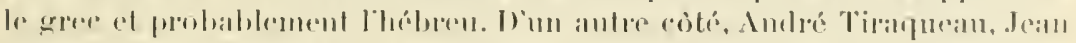

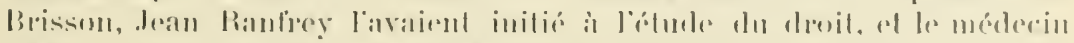

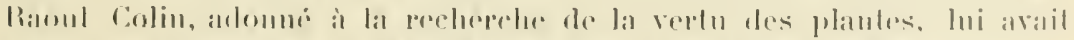

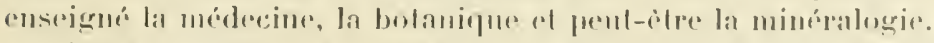

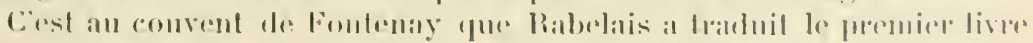

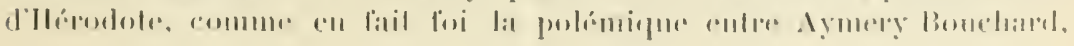


instruit dans la connaissance des maladies et de leurs peniedes qu'il put faire en deux mois environ le chemin fur los btuliants faisaient en trois ans. Devenu bachelier et obligé par le reglement d'ouvrir des cours publics, comme tous les aspirants à la lieence et au doctorat, il attira un nombreux auditoire en commentant les. Aphorismes d'Mlippoerate of l'Ars parva de Galien (1). Pour devenir un maître de la science, il n'avait pass altendu les diplòmes.

Vers la lin de l'année 15i3, ou an commencement de l'annce $15 \% 2$, il quilta Montpellier pour se rendre à Lyon où il avait déjì fait, pensons-nous, une première apparition pour publier les Cirandes el Estimables Croniques du granl et énorme géant Graryantua (2). Un petit poème latin d'Étienne Dolet, imprimé à Lỵon en s.i3s. célibre Rabelais, devenu médecin en chef du grand hôpilal du Pont-duPhòne, expliquant, après aroir disséfué magistralement le cadave d'un pendu devant un cerele nombreux d'atudiants, " comment la nature, mère des choses, a fabriqué le corps de l'homme, arec quelle beauté, avee quel all, avee quelle. parlaite harmonie ".

On comprendra l'importance que celte dissection a eue pour les contemporains de Maitre Francois " quand on saura, dit M. le Dr Brémond (3), quén 1:376 la Faculté

président á Saintes, el André Timarpueau au sujet du lirpe de ce dernier, intitule : De Legibus connubialis, sur les bois dumariage. (Voy. F. Aldourer, liabeluis à Fonlenay-le-Comle, Tours, juillet 1886, et Benjamin Fuldox, Poitou et Vendée, art. Fontenaty.)

(1) "Peut-ètre lutece il cette ćpoque yn'il instifua, dit Louis Barré, une érémonie burlesque qui lui était attribuée ì Montpellier, oì elle est restée on usage jusqu's̀ la fin du dernier siecte. Le candidat reecrait la robe rouge, conservis depuis sons le nom de robe de Rubelais; il nonlait en chaire pour rendre grâce à ses maîtres; puis, en se relirant par la salle du conclave, il recevait de ses auciens camarades quelques coups de poing qui étaient comme leurs adienx ì un condisciple deremu leur supérieur." (L. Barré, loc. cit. suprit, p. NmIr.)

(2) Voy. Aimé Vingtriner, Questions lyonnaises, Courrier de Lyon, numíro dı 2 juillet 1886.

(3) Dr Brénoxo, loc. cil. suprì, Notice p. xil. 
de Montpellier en était encore à se féliciler d'avoir obtenu de Louis d'Anjou un cadare de rriminel par chaque année pour faire des démonstrations. A la tin du xive siècle, l'École de Montpellier était plus riche, elle pouvait disiéquer deux eadaryes par an. Elle n'en disséquait pas une demi-douzaine cent ans plus tard."

Un passage des (Eknves anatomiques de Jean Riolan, complétées et mises en françois par I'ierre Constant, publiées a Paris en 1 li:g, montre que les sujets d'amphithéàtre étaient aussi rares à Paris qu'à Montpellier, quand parut Pantagruel. "An temps de Vesalius, a éerit Riolan, Charles-Quint fit meltre en question dans son mniversité de Salamanque s'il estoit permis aux médecins chrestiens de dissépuer les copps humains. Il luy fut respondu que cela chant ulile el nécessaire à la médecine, il leur devoit estre permis. C'estoit en l'année 1.5.ti (1). O que l'escole de Paris est bien plus heureuse que cela, car elle a grandement adrancé ceste science, et, par le moỵen de son Sylvius l'a libéralement communiquér anx estrangers of quielle a bien de ladvantage sur loutes les aultres, ear chle a tout autant de eorps quielle en désire, de sorte qu'en moins de dix mois clle en a ru quelquefois plus de quinze."

(1) Hippocrale a disséfue senlement des animanx el a conchu par anaIngie de la disposition des organes des quadrupreles à la disposition des

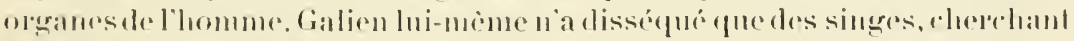

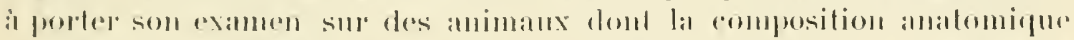

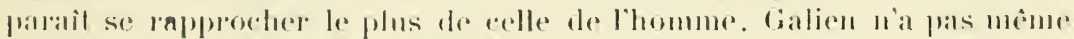

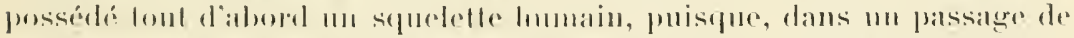

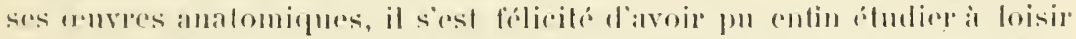

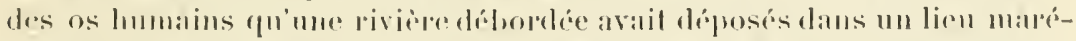

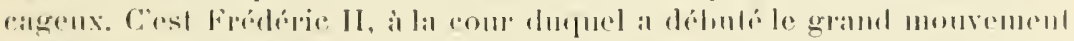

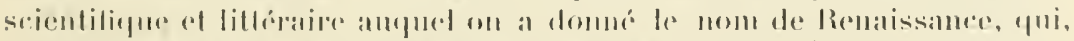

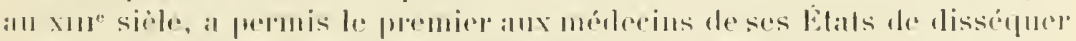

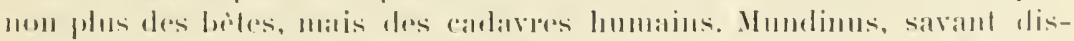

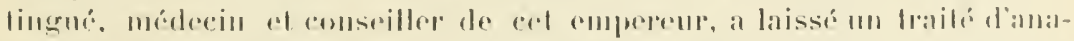

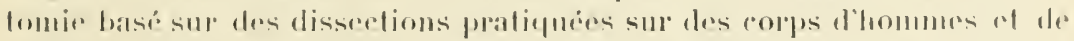

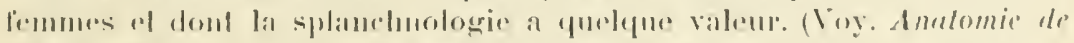

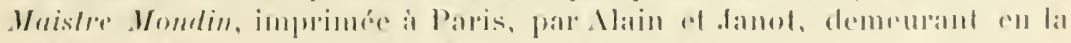

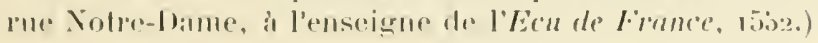


Dans lis registres de la Faculté de médeciue de Paris (Reg. m. s. dela Fac., t. V1, fol. 149, $\mathrm{r}^{\circ}$ ) il est lait mentionpropreler raritatem casĥs, à cause de la rareté du cas - de l'autopsie du corps d'une femme, morte en travail puerpéral, pratiquér dans les premiers jours de mars, 15.51, à l'HôtelDieu de Paris, sous la présidence de Jacques Goupil.

En dehor's des cadavres de criminels ou de suppliciés, les médecins de cette époque ne pouraient gù̀e, en effet, disséquer que cemx qu’ils avaient dérobés la nuil dans les cimetières, en bravant la hart et la répulsion publique. Un médecin bâlois, Félix Platner, qui a étudié à Montpellier, nous a laissé dans ses mémoires un récit curieux de sa première expédition à la recherche de "sujets d'expériences $n$.

"Elle date, dit-il, du 11 décembre 1554. La nuit était déjà sombre quand Gallotus (1) nous mena hors de la ville, au monastère des Auguslins. Nous y trouvâmes un moine qui s'était déguisé et nous prêta son aide. Nous entrons furtirement dans le cloìtre et nous restons à boire jusqu’à minuit. Puis, bien armés et observant le plus profond silence, nous nous rendons an cimetière Saint-Denis. Nous déterrons le mort en nous aidant des mains senlement, car li terre n'avait pas eu le temps de s'affermir; une fois le cadavre à déconvert, nous hui passons me corde, et tirant de toutes nos forces nous l'amenons en haut. Après l'avoir enveloppé de nos manteaux, nous le portons sur deux bâtons, jusqu'ä l'entrée de la ville. Il pourait être trois heures du matin; nous déposons notre fardeau dans un coin et frappons an guichet. Un vieux portier se présente et oure; nous le prions de nous 'donner à boire, prétextant que nous mourons de soif. Pendant qu'il va chereher le vin, trois d'entre nous introduisent le cadave et ront le porter dans la maison de Gallolus. Le portier ne se donta

(1) Un des collegues et amis de Félix Platner. 
de rien. Ouant aux pooleres de Saint-Denis, ils se riment ohligés de garder le cimetiore, el de lenr cloftre ils décoehaient des trails d'arbalide sur lous les étudiants qui s'y préscntaicnt. "

Quand les médecins ont eu acquis le droil de disséquer, ils l'ont refusé aux chirurgiens (1). Les chirmogicns de Saint-

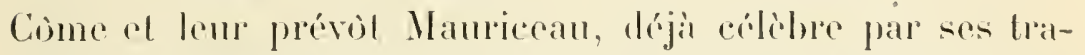

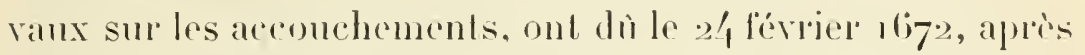
avoir vu foreer les portes de leme collige par un sermerice llampuc de plusicurs archers, remeltre à P’uylon, doyen des fécoles de médecine, un cadave qüils avaient recu plusiones jours ampalavant de l'exéculem de la laule justice. Ene sentence du lientenant de police rendue le 16 avril 16 is:3. contre de Blégny, chimrgien du duc d'Orláms ot de Lal Noue, son complice, prouve, an supplus, mienx que toules les paroles que mons pomprions ajouler, quelle valem la Far culté a altaché primitivement aux moindres sujets et avee. quelle conergie elle a entendu s'en réserver la proprété, mème

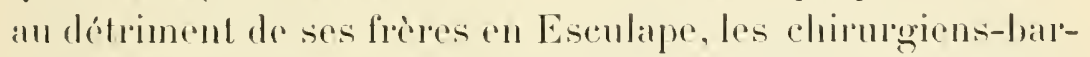
biers. Cedte sentenee "condamme par contumace de Blégny"

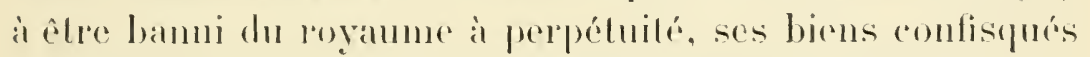
an protit du roj, et le eompliee de La Nour a de be battu ot

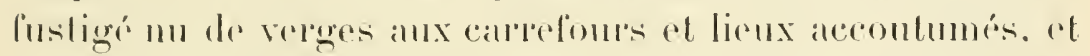
de plus a trente liveres d'ammole. El cela.... pome avoir arhede du lils du lossoyeme de simul-Sulpier plusiems cadaveres exhmmis.

Disons bien vile yue eolle abominable sentence ne regut

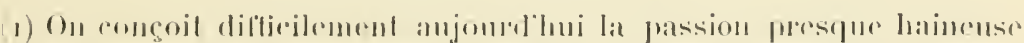

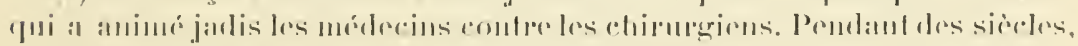

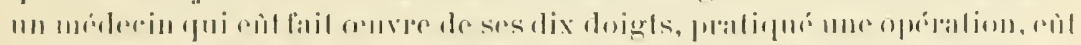

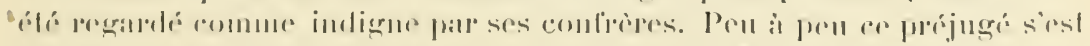

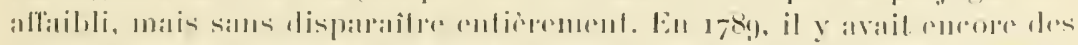

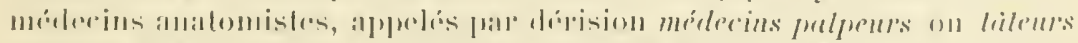

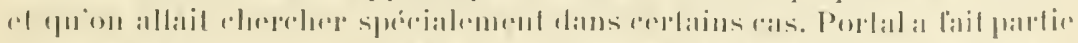

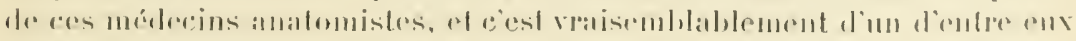
y menluires sur Gui-P'uliu.) 
pas son exécution: que. sur l'appel de Blégny et de La Noue qui sétaient constitués prisonniers à la Conciergerie de Paris, le Parlement se contenta d'admonester les délinquants ef de les condamner à des peines pécuniaires assez forles.

Je reviens à Rabelais. Il est non seulement un des premiers, - sinon le premier,_- qui aient fait des démonstrations sur le cadarre (1), mais encore qui aient vanté l'utilité des dissections. Le pendu dont il est question dans le poème d'Étienne Dolet est censé avoir la parole et se félicite "du spectacle honorable et instructif auquel il a servi; lui qui élait destiné à ètre le jonet et la pàture des corbeaux, il est exposé dans un amphithéatre, entourí de personnages distingués, il est l'objet de l’allention générale, il est comblé d'honneur et de gloire."

(1) Waprès la Retue scientifique (t. I, 1886, p. 4-8), l'Lnniversité de Bàle possede une préparation anatomique attribuée à Vésale. Le rédacteur de cette revue donne it ce sujet les intéressants renseignements suivants :

"Il s'agit d'un squelette préparé par l’illustre anafomiste ef portant la tate de 1.r.3. Ce squelette représente me des plus anciennes préparations anatomiques comnues, si re n'est mème la plus aueienne. Vésale n’a passé ¿ Bàle ef n'y a résidé, contrairement ì l'opinion généralement acceptée, qu'une seule fois, et cela en 1543.11 stait renu pour surveiller l'impression de son live De humani corporis fabrich, par Oporinus, et mullement pour sy adonner à lenseignement. 11 était trís difficile à cette éporpe de se proeurer des catavres pour la dissection, les autorités établies élant tout a fait opposées a la dissection des eadarees humains: en fait, il nétait

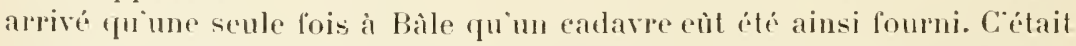
en 1531. En 15y3, pendant le séjour de Vésale, il arriva que l'on condamna ¿ la peine le mort un eertain Jacob Harrer, yui avait attenté a la vie de sa femme; il fut exéeuti. ct Vésale obtint que le corps lui fut remis. Ce fut une grande satisfaction pour le maitre, fui, pentant plusiems jours, scalpel en main, fit aux maitres et aux élèves de l'Université la demonstration de lanatomie humaine, et, fuand la dissection fut achevée. il prépara le squelette, dont il fit don à l'Universite: Arlis el industrix sux specimen, dit linscription. C'était pour l'éfoque un catleau de haute valeur."

In éruclit bâlois, II. Roth, aurait, paraît-il, publié une brochure 
Voici le poème complet de Dolet. Je le lais suivre d'une traduction libre en vers français due à l'auteur des Soir's, II. Horace Hennion (H. de Consthenn), un jeune poète tourangeau de talent et d'avenir:

détailléc relative à cette préparation de Vésale. Je nai pu me la procurer.

Rabelais, dit d'autre part Louis Barré (loc. cit. supri, p. xw), "lit au grand loópital de Lyon, oì il était métecin, un cours public d'anatomie sur le cadarre mème, chose encore peu ordinaire et dont l'honneur est attribué au Bruxellois Vésale, bien que celui-ci, néen 1514, u’ait guère pu devancer le professeur de la Faculté de Montpellier et de Lyon. "

Conclusions: Vésale est né en ıว̄ı́, el c’est entre 1532 el 1538 que Mailre François a fait sa première leçon publiqué d’anatomie. La première édition te la grande analomie De corporis humani fabricr, de Tésale, illustrée par Jean Calcar, élève du Titien, a parn, d'autre part, i Bale, en 153 , et lequalrieme livre de Garyanlua elde Panlagracl, où est décrile lanalomie de Guaresmeprenant, le 28 janvicr 1552. 


\title{
STEPHANI DOLETI
}

\section{CARMEN.}

\author{
CLJLSDAM EPITAPIILU
}

QII EXEMPLO EDITU STRAXGLLATIS.

PLBLICO POSTEX SI'ECTACLLO LIGIUNI SECTLS EST,

FRANCISCO RABELESO MEDICO DOCTISSIMO FABRICAM CORPORIS INTERPRETANTE.

Slygem (1) palualem, el quicquid aler Orcus (:2) hatiel, Forluna jurarat furens,

Jamnum mihi omne se reperturam, et probram.

Ouod dum studet, atrue nitilur.

Et virilues lotis suum in me dirum odium

Explet, saturatque, ut collibilum est:

Tibi ecce, puncto temporis claudor carcere:

Educor, et laruen miser

Hox strangulatus penden. It quid non potest

Fati imperium contrarii ?

It lemporis puncto perieram lupiter,

Pari celerilate assequor,

(unol vix liceal cuipuram a Jove summo poscere,

Speclaculo lato expositus

Secor: Medicus doctissimus planum facil.

Onam pulchrè, el affabre. ordinerque

Faluicata corpus est hominis rerum Parens.

Sectum frerguens circunspicit

Corona, miralurque molem corporis

Tanto arlificio comditi.

Quare quid agal potius, quàm ad extensum laqueum

Fortana frendens convolet,

El morle finem odin semel qurerat suo.

Non invidia diulius

Rumpenda: Tolus arl extremum cumulor

Honoribus, circunfluoque

Jam gloria, quem Monstrum atrox voluit rapidis

Corvis cibum esse, el flantibus

Luelibriam ventis. Fural Sors, jam fural:

Honoritus circunfluo.

(1) Le Styx, fleure des Enlers.

(2) Pluton, tes Enfers en crínéral. Lorsque les dieus araient juró par les raux ، lu Styx, ils nosaient plus ètre parjures; ou, sils mançuaient it leur serment, ils blaimb privés pendant cent ans de la dirinilé. 


\section{POÉSIE D'ÉTIENNE DOLET}

Epitaphe diun pendu rui, après avoir servi de laut exemple, fut, pour lenseignement du public. disséfué à Lyon pal le très savant médecin Francois Rabelais, expliquant la structure du corps lumain.

Par le Slyx et l'Oreus, la Fortune ennenic

Avait juré clans sa fureur

De combiner pour moi le plus complet malheur

La plus extrème ignominie.

Tandis que tout enlier à cela s'étudie

L'etlort de son ernel génie,

Comme à plaisir sa haine est enfin assouvic.

Ln mème instant me voit emprisonné,

Dévant le jugge traîné,

Et déjà, miséricorde!

Pendant an bont d'une corle!

Mais yue ne peurent les destins?

Quand de cette manière infìme

En un moment jeus rendu l'ame,

Dans un temps aussi court jobtins

Ce que pas un ne se permethait mime

De demander an Dien suprome:

On me dissépue en grand spectacle! Un mérlecin,

Des plus doctes, démontre avec gnel art divin

Le sage Anteur de la Nature

Du corps de l'homme a su disposer la structure

Dans forde le plus merveilleux.

Formant rercle, un public nombreux,

Une fois dissépure, landmire,

Ce bean comps, si parfait, quion vient de lui dererire.

()naurait donc la fortune a faire alors de mienx

(be dr voler, gringant des dents, en frénésie,

Droil an lare desserre, pour melle fin d'un coup

I sal haine romme a sa vie,

El n'avoir plus le corm déchiré par l'envie?

Call, pour moi, je suis, apres lonl,

Comble d'hennenrs; en plein dins la grloire je nage,

Moi que ce momstre saluvage

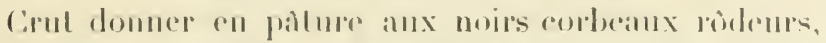

Comme en jomal anx vents. Le Sort enrage, enrage!

Moi, je nage daus les homnemps! 
En 10.39 el en risiti. Rabelais quitta Lyon pour aller deux fois a Rome, séjourna ensuite quelque lemps a Paris et revint enfin conquérir ses derniers grades universitaires à Montpellier.

Les cours publies terminés, les bacheliers avaient le droit de se présenter anx quatre examens per intentonem adipiscendi licentiam. Il fallait (I) soutenir quatre theses successivement, de deux en deux jours, sur un sujet donné la veille, et chacune de ces épreures durait au moins une heure. Au bout de huit jours, on soutenait denx autres theses appelées points rigonrenx. Le premier point roulait sur une maladie et le second sur un aphorisme d'Hippocrate, tirés au sort vingt-quatre heures seulement arant la sontenance. En conséquence, le postulant piquait dans deux livres, dans l'un chez le chancelier, dans l'autre chez le doyen. Cet acte durait de midi a quatre heures à la chapelle Saint-Michel de l'église Notre-Dame-des-Tables. Une fois admis, le candidat allait an palais épiseopal, dans la huitaine, recevoir la licence des mains de l'évếfue ou de son vicaire général, en présence de deux prolesseurs délégués par la Faculté.

Le père de Ciargantua a passí ees examens. Lui-même a pris soin de nous apprendre que sa première these de licence a porté sur un sujet de physiologie dont le chapitre IV du live III, " il la louange des presteurs et debleurs, " est un résumé succinct. "Et pensoỵs véribablement, a-t-il noté, en debtes consister la montaigne de vertu héroïque, descripte par llésiode (2), en

(1) Germax, la Renaissance il Montpellier. Mém. de la Soc. archéol. de Montpellier, 1871 .

(2) Elle habile au sommet d'un roe inaccessible,

Elle est de nos sueurs le fruit lent et pénilsle.

(HÉsIODE, les Travaux et les Jours.)

"Lycinus. - Je crois donc que vousn'ètes pas éloigné du bonheur auquel vous aspirez, si vous lien jouissez pas déjì.

"Hermotine - Eh! mon cher, je ne fais quentrevoir la route. La vertu, 


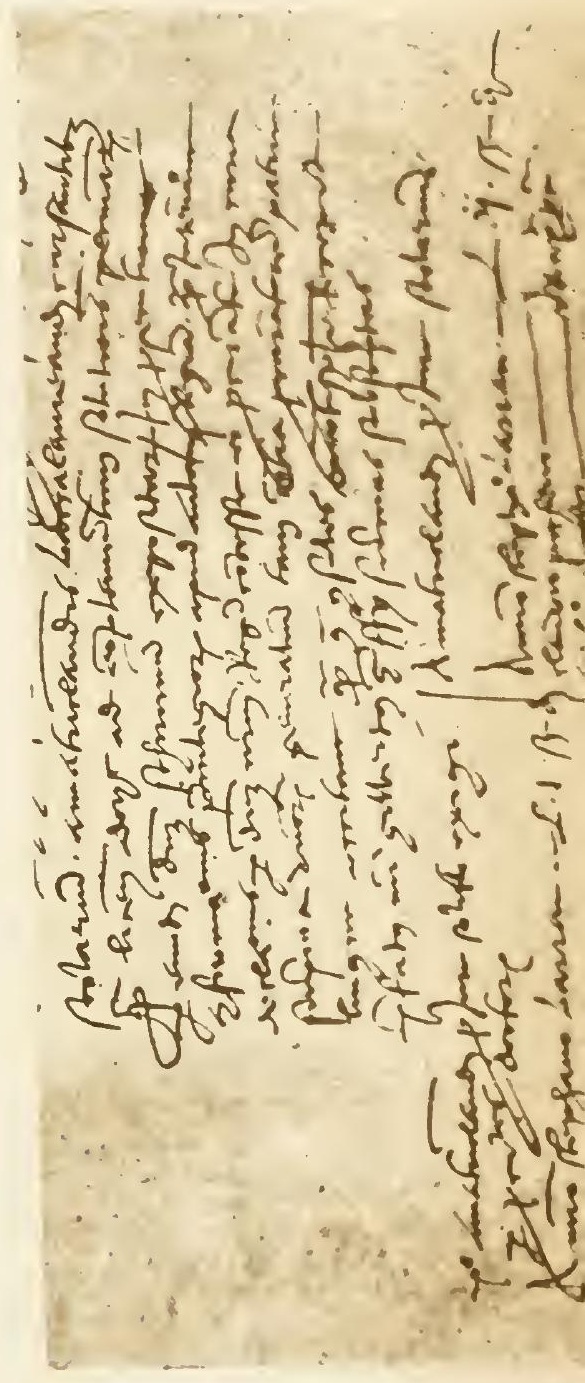




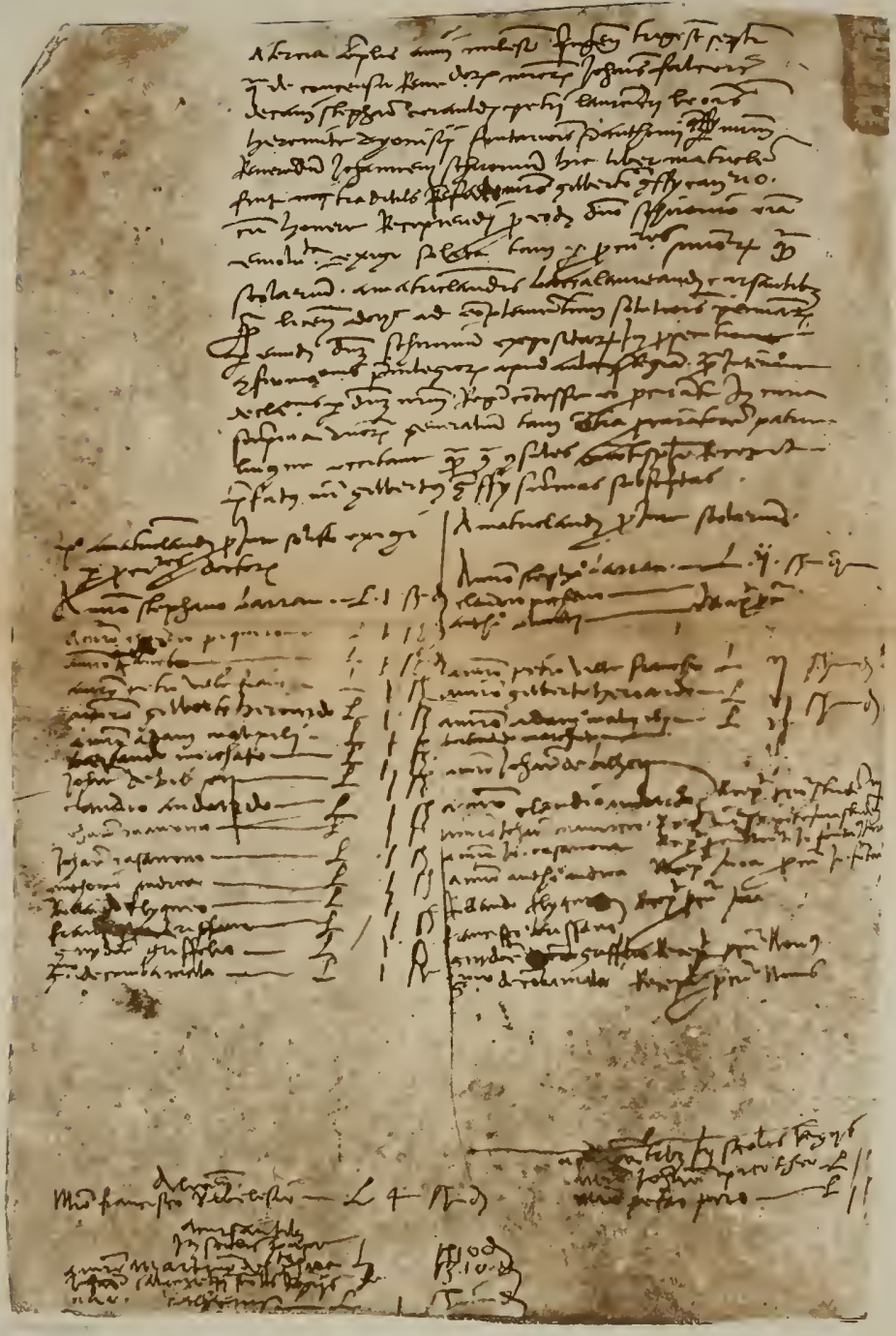


larpuelle je tenois dengé premier de ma licence (I) ".

On nia pas trouvé, il est rai. lacte de licence dans les registres de la Faculté, mais cette absence tient évidemment a ce que les thesess de licence étaient, comme nous renons de le dire, soutenues ordinairement dans ume église et le titre de lieencié conféréa an donnicile duprélat. La mention de paiement des droits de cet acte est consignéce en cestermes

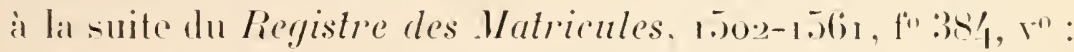

A Licentiandis: Magistro Francisco Rabelesio, libr. IV vil den.

Ce document important, que nous peprodnisorrs, a dé démenvert par. Ir. Germain, prolesseur et doyen de la Fareulté des Lettres de Moutpellier, correspondant de l'Institut.

Die terrin aprilis anni millesimi quingentesimi lrigesimi septimi, quum, de concensu reverendorum mag istrorum. Johannis Faleonis decani, Stephani Corruldi, Petri Laurentii, Lennis Iteremite, Dyonisii Fontanonis. Anthonii Grifly, per magistrum reverendum Johannem Schironium hic liber matricule fuit traditus prefato magistro Gilberto Girifly cancellario, cum honore recipiendi pro eodem domino Schironio omnia emo. lumentra exigi solita, lam per procuralores magistrorum. quam scolarium, a malriculandis, bacealaureandis, cursanlibus pro licentia, donec ad complementun solulionis pecuniarum per eumdem dominum schironium exposilarum in prosecutione confirmalionis privilegionum apud anlam regiam, pro inlerinalione declarationis per dominum nostrum regem concesse, eo procuranle in curia suprema dominorum generalium, tam contra procuratorem patrie lingue Occilane, quam contra consules Iontispessuli, recepil prefalus magisler Gillerlus Grifly summas subseriplas.

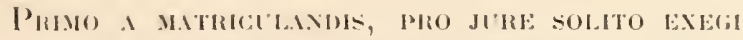

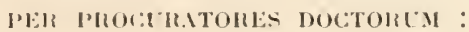

A mugistro stepheno Barruu, libr. 1.

1 mregistro Cluudir, Piquivo, lilır. 1.

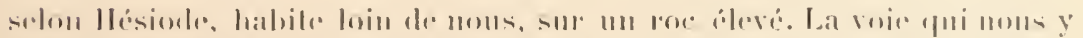

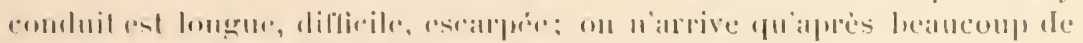

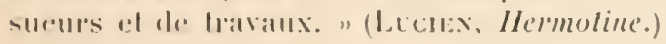

(1) I.. III, ch. III. 
1 magistro Anthonio Amelo, libr. I.

1 mayistro Pelro Villefranche, libr. I.

1 magistro Gilberto Heroardo, libr. I.

I mayistro Adam Malipili, libr. 1, ete. ete. etc.

A Licestinids :

Mayistro Francision Rabelesio, libr. IV VII den.

A Cunsanthes:

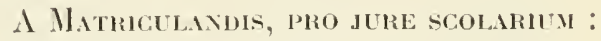

1 magistro Stephano Barrau, libr. II.

$\left.\begin{array}{l}\text { A magistro Claudio Picherio, } \\ .1 \text { magistro Anthonio Ameti, }\end{array}\right\}$ Recepil procurator.

A magistro Petro Tillefranche, libr. II.

A magistro Gillrerto Heorardo, libr. II.

1 magistro Adamo Malipili, libr. II, ele. elc. etc.

(Reyistre des Matricules, 1502-1561, fol. 384 vo.)

Cette date du : arril s5:37 ne fixe nullement, remarquons-le, le jour où Maitre Francois fut recu licencié. Celte réception remonte à une époque beaucoup plus éloignéce, puisque notre compatriote se qualilie implicitement de docteur dans sa supplique au pape Paul III et que ce pape lui attribue aussice titre dans son indult du 17 janvier 1536 (1).

Eoque lempore Facultati Medicine diligenter operam dedit, et in ea yradus ad hoc requisitos suscepit, pullice professus est el arlem huius modi praticando pluries exercuil, elc., elc. (Rabelais.)

Ac interim litteris in Facultale Medicine diligenter operam dedisti, et in ea ad Bachalariatus, Licentialive et Docloralus gradus promotus, nec non artcm medicinix publice professus fuisti et exercuisti.» (Paul III.)

(i) Voy. Anat. chirurgicale et A. LE Ror, Florelum philosophicum, reuille $g, \mathrm{r}^{0}$ et $\mathrm{r}^{\circ}$, et teuille $, \%, i i j, \mathrm{r}^{\circ}$. 



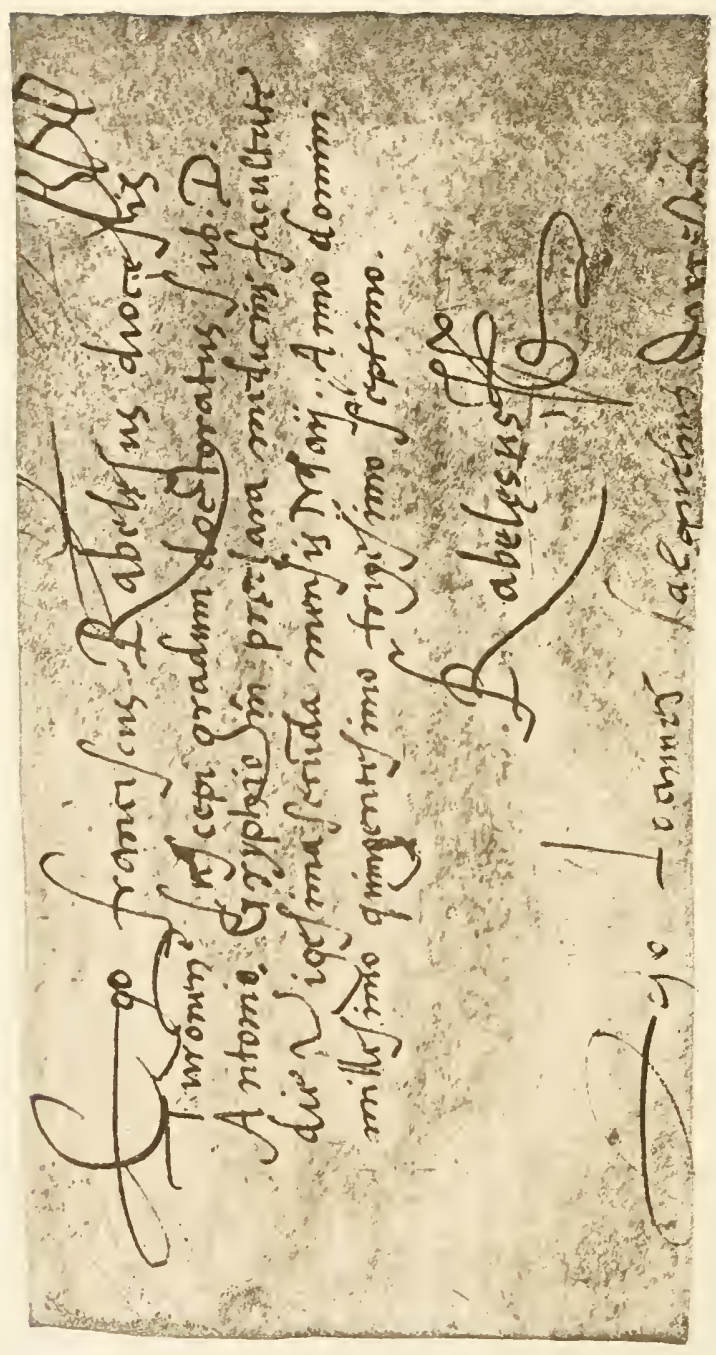


En dépit de la rubrique d'usage 1 Licentiandis, nom croyons donc que Rabelais solda seulement a son retour de Rome, pour pouvoir être proclamé doctenr, les frais de sil licence et que sa promotion au doctorat ne lut quine rérémonie en son homneur.

Quoi qu’il en soit, le 22 mai 15i3-, le savant toumgeau. coiffé du bonnet noir à houple cramoisie (1), dénoncait, sur le Cahier des actes de l'L 'niversité. son entrée oflicielle dims le corps midical par les lignes ci-jointes:

Eigo Franciscus Rabeliesus, diocesis Turonensis, suscepi yradum doctoralus, sub I). Antonio Gryphio in præclara medicinxe facullale, die vigesima secunda mensis maii, anno Domini millesimo quingenlesimo trigesimo seplimo.

RABELESES.

Rabelais demental me partie de l'année 1.3ist et de lannée 1.jis a Montpellier. Une note du registre des ma-

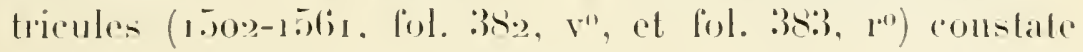
que le proeureur en charge regut de sehyron, professeur. " un écen d'or" pour l'honoraire de l'analomie que Rabelais avait interprétée. Céest la dernière fois que le nom de lillustre Chinonais ligure sur les registres de la Faculté.

\section{LA LECON IOANATOMIE}

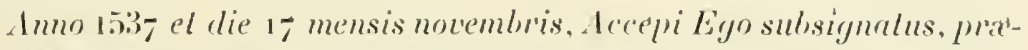
sente Magistro Anthonion Pellitario, Antiquo procuratore, a domino Schironio summam decem solidorum turonensium, pro stjudicalo el copia litlerarum regiar'um, seruendo consensum el deliheralionem domi= norum doctorum el sludentium, qui coluerunt ul processus contra Verseille ageretur communi omnium doctorum el studentium pecunia, ul constat per actus acceptos a labellione universilatis.

FuNTANCS, mocurulur.

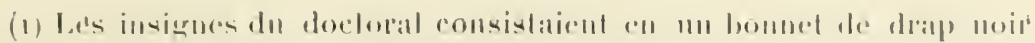

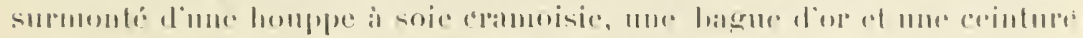

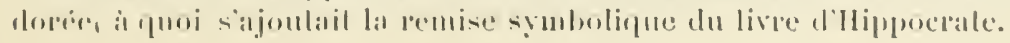


Anno eodem el die 18, accepi ego sulsignatus, prasente Magistro Anlhonio Pellitario, hic quoque sulscripto, a domino Squironio summan XXI solidorum, pro procuratore se presentanle, nostra canssa, Tholose.

Anto PELLITAIIISS.

FONTANCS, mROCurator.

Exhibuit proterea dominus Schyronius labellario, pro mercede requisila, dum Tholosum detuleril syndicalum, quinque solidos, idque anno supralicto, el die decima mensis decembris. Hoc fatern ego subscriplus.

FONTANCS, procurator.

A baille mon dil sieur. Schyronis au dil porteur, lequel a porlé le conget lev'é contre leseilles, la somme de cing soulz lournois pour son labeur, lesquels a baillé ì ma présence, lan 1538 el le neufiesme de jantier.

Anloine PELLETIER.

Accepi praterea adomino Schyronio aureum unum solis, pro analome quam interpretalus est dominus Franciscus Rabelais.

FONTANL"S, procuralor.

Item acceperam, pro solvendis chirurgis et aliis negoliis in anatome exponi solitis, duas libras, ex uno bacchalaureo, quas fatebatur accepisse dominus Schyromis.

FONTANL'S, procuralor (1).

(1) L'Tniversité de Moulpellier a temu à homenr dr conserver la robe de Rabelais. Celle robe est en dralp pouge aree une épiloge ef a manches fris comrtes. Les luturs docteurs la meltaient jadis pour passer leurs examens. Elle a été penouselón en 1612 , par le chancelier F. Ranchin; on en lail me troisiène en 1720 (Astwc, Mémoires pour servir à lhisloire de In Fréllé de médecine de Montpellier, Paris, 1767, p. 85).

"Ne serait-ce point la robe de l'escorcheur de verut dont Pamurge, dil M. Dubouchel, s'affubla pour réclaner el laire restilum les privileges de IUniversile?

"On a bean s'érertuer à nier la chose, il est cerlain que les privileges ont été enlevés en 1531, el nous en avons la preure dans un inventaire de pirces concernant la Faculté de médecine: "Sentence contre Jean Boyer, lientenant au gourernement de Montpellier en restilution des privilèges

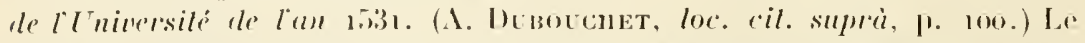
portrat de Rabedais ligure regalement dans la première collection dr porlraits de prolessentrs que possiode la liaculté de médecine de Moilpedlien et qui s'etend depuis H. de Guintonia, en 1239, jusquà nos jours. 



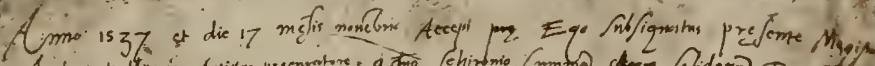

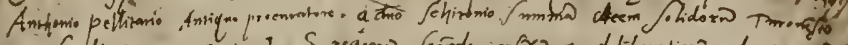

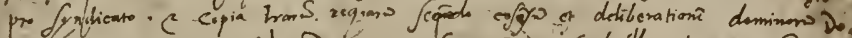

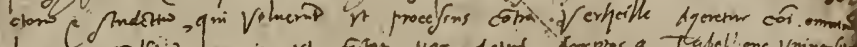

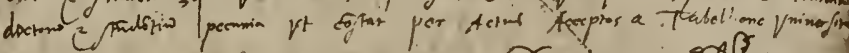

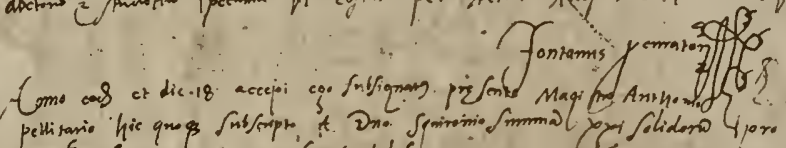

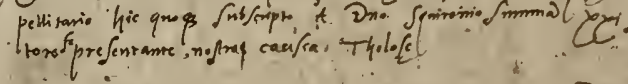

\section{of temocturinus th?}<smiles>CCCCC</smiles>

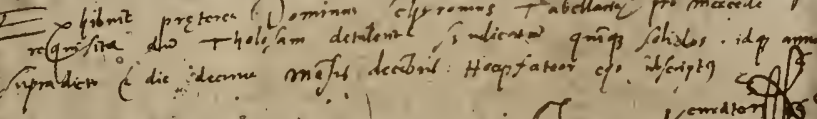

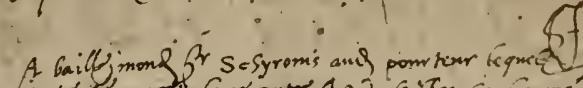

Sforinms

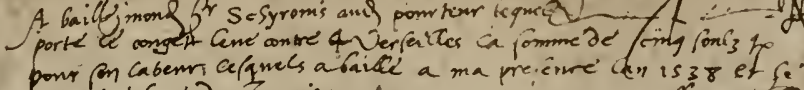

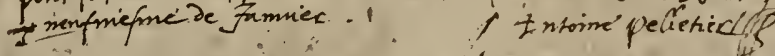

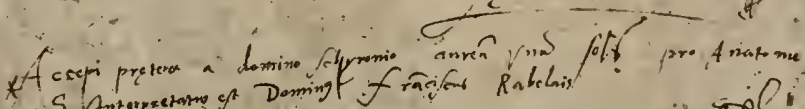

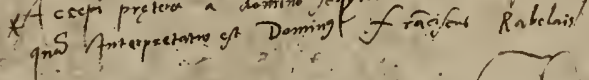

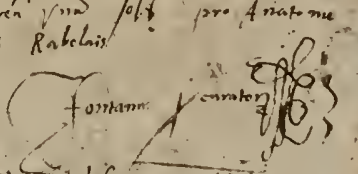

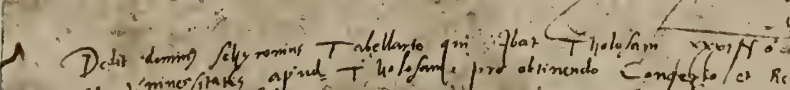

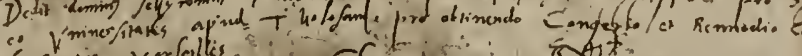

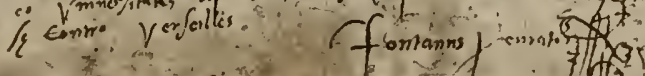

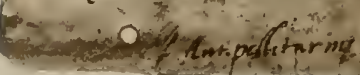


Plusieurs commentateurs, ot parmi emx te bibliophile Jacob (P. Lacroix), onl prétendu que Rabelais, al l'imitation de divers hommes marquants du XVI" sieclequi signatent lantot en français, tantòt en latin, a orthographite son nom de différentes facons. Je ne saurais clore ee pelevé de pieces justificatives sans rectifier cette nouvelle erreur. Le doete médecin chinonais a tonjoms signé Rabelais en français et liabelasus en latin. Le tablean suivant des signalunes du Maitre que nous avons pur lassembler, B. Fillon, F'. Andiger el moi, en fait foi (1).

\section{SIGNATURES DE RABELAIS}

$1519 .-$ Au dos d'un acte de rente consenti an profit des Condeliers de Fontenay-le-Comte (.) arril) (2).

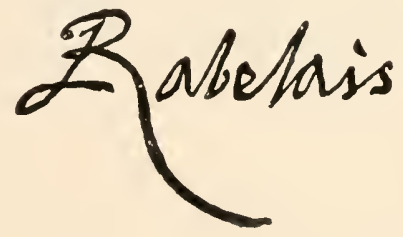

1.52:2 ou 1.5.3.-Au bas d'une lettre adressie à Guillaume Budí (4 des nones de mars).

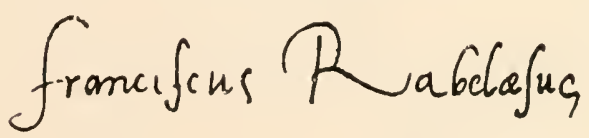

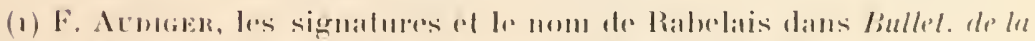

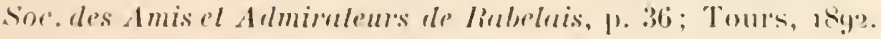

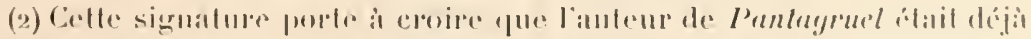

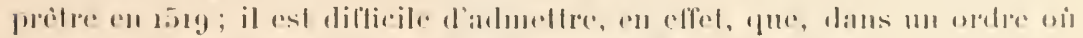

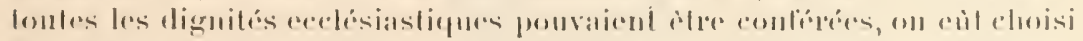

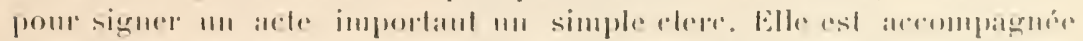

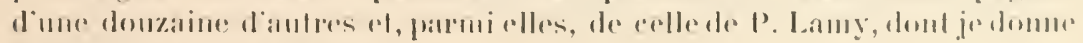
ansi phus loin lo lak--imile. 
1530. - Sur les registres de la Faculté de médecine de Ionfpellier. (17 septembre. - Immatriculation.)

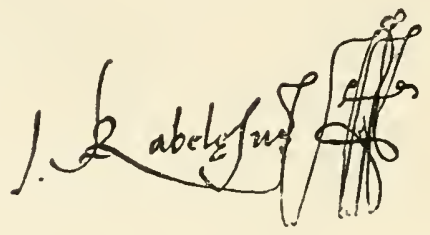

15.3o. - Ihidem. (18 octobre. - Lecon d'anatomie dirigée par Rondellet.)

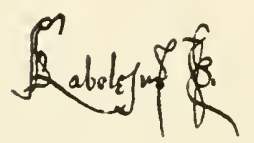

1530. - Ibirlem. (1 er novembre. - Baccalauréat.)

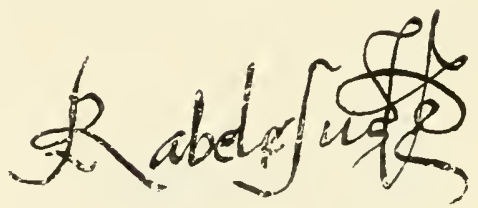

15i3o. - Ilidem. (1.5 novembre. - Reddition de comptr.)

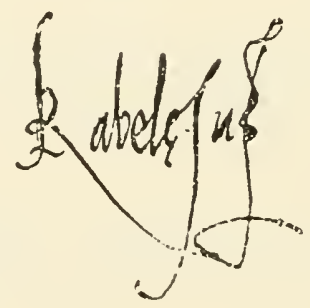

1031. - Itidem. (19 mar's. - Reddition de compte.)

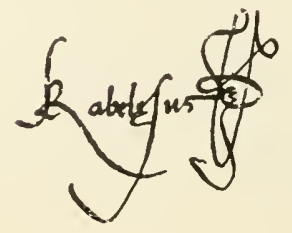


1.3.1. - Ibidem. ( 23 octobre. - Reddition de compte.)

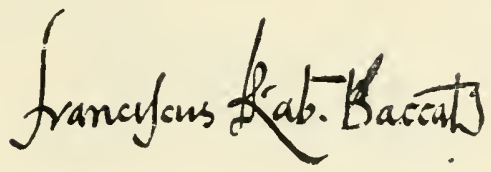

15.31. - Au bas d'un document à moitié rongé par les rats et se rapportant an premier séjour de Maître François $\therefore$ Montpellier (1).

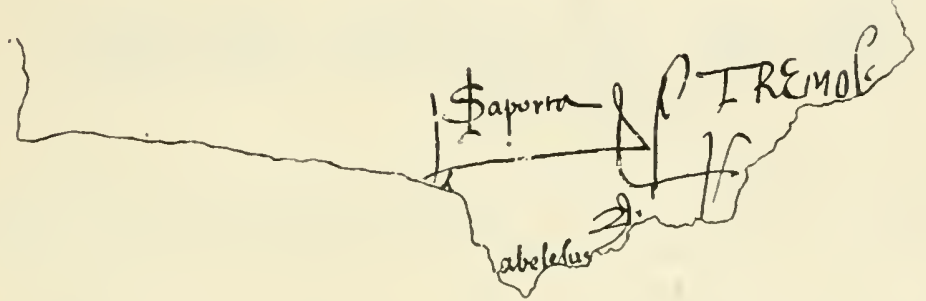

15:36. - Au bas d'unc lettre adressón a Geoffroy d'Estissac, érèque de Maillezais.

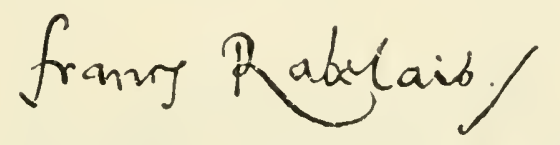

10ij. - Sur les registres de la Faculte de médecine de

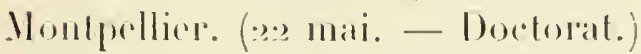

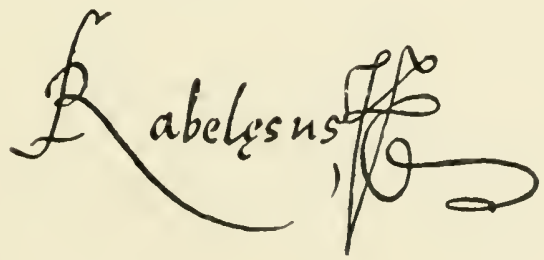

(1) Ainsi quil appert do la signature de Sapoldal an bas de ee mime

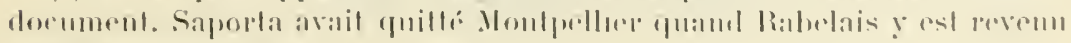
pont lat sereomble lois. 
15:37. - Ibidem. (7 novembre. - Reddition de compte.)

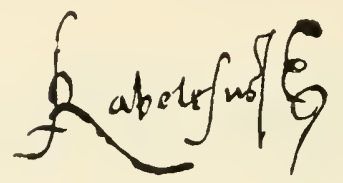

1598. - Au bas d'une quiltance de trente-deux écus d'or donnée, à Rome, à l’intendant du cardinal Du Bellay (18 juin).

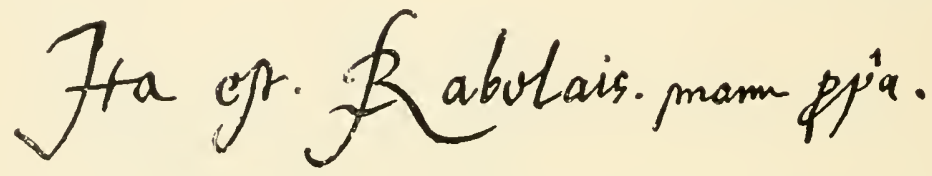

La fameuse lettre adressée à B. Salignac, la reille des calendes de décembre 1532, n'est point signée Rabelresins. comme on l'a imprimé par erreur; mais bien Rabelesus.

Dans toutes les pièces qu'il a dù foumir pendant le comrs de ses études módicales el que détient l'Université de Montpellier, le philiâtre tourangeau a orthographié son nom de la mème manière :

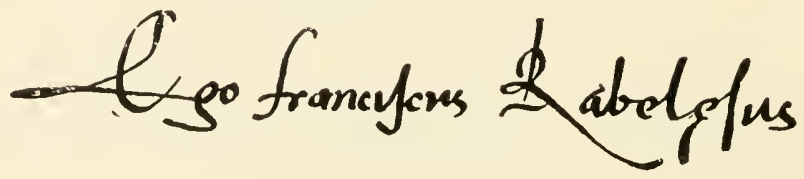

On trouve encore le nom de Rabelais écrit par lui-même el sans variation :

1" Au bas de la première page d'un exemplaire des opuscules de P. Bembo, imprimé à Lyon en 15:3.), et que l'on conserve a la Faculté de médecine de Montpellier;

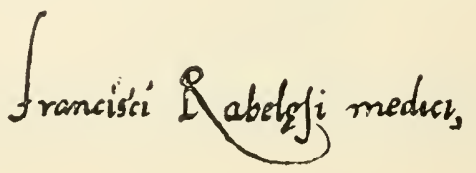


2" All bas de la première page d'un Théophilacle,imprimé en $153 \%$, et que M. A. Dubouchel a signalé dans son Rabelais a Monlpellier:

$$
\text { frarcisci }=5,9 \text { abelfit }
$$

:30 Sur un Platon imprimé en $151: 3$ i Venise, par Alde et André, exemplaire laisant achellement partie de la bibliothiogue de M. Cavalier, le mème pent-être que le savant médecin a réclancé à $\mathrm{V}$. Le Secteur, par l'intermédiaire de II tre A. Hullel (1);

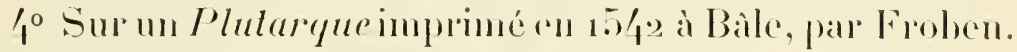
Cie volume appartient it 11 . Ernest Leroux;

5" Enfin sur lrois autres volumes que Rathery a découverts à la Bibliothèque nationale.
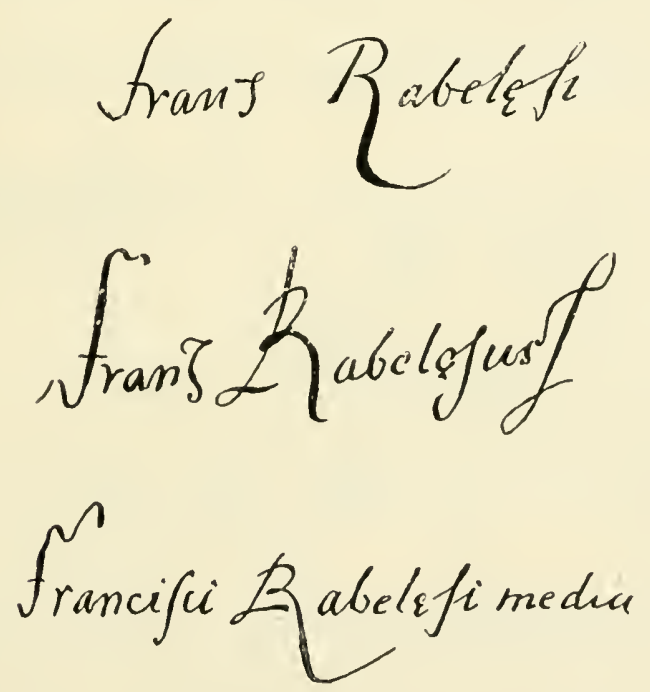

Colle fiegon milorme el réguliore de signer de Rabelais lla pas prónenpé ses conlempmains. Boyssoné el Gr. Budé ont écrit tambit Rabaliesus ot tantiot Rabelesus.

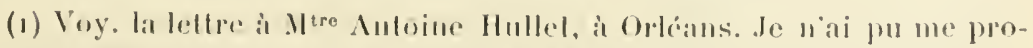

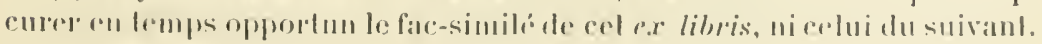


Sussanneau, Étienne Dolet, Pierre Lamy (dans un quatrain reproduit par Marty Laveaux). Cl. Marot, G. Pelissier, ainsi que le poète Bourbon ont orthographié réguliirement Rabelais, Rabelrsus.

Salmon Macrin a icrit Rabliesus; Gabriel de Puits-Ilerbaut. Rabelesius et Rabelesus: le cardinal de Tournon, Rabelezus.

On lit, d'antre part, avee de nombrenses variantes:

1" Dans différentes pièces des arehives du département d'Indre-et-Loine se rapportant soil aux ascendants de Rabelais, soit ì ses neveux: Rabellais, Rabelays, Rabelais;

$2^{\circ}$ Dans l'acte de provision de la cure de Meudon: Rabeleitus ;

30 Sur les registres du secrétariat de l'Archevèché de Paris: Rabelays ;

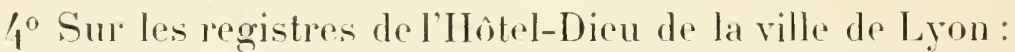
Rabellet, Rabellais, Rabellese, Rabellaise, Rabelays, Rabellays :

5 Dans l'acte de résignation de la cure de Saint-Christophe-du-Jambet: Rabelays :

6. Dans l'acte de résignalion de la eure de Meudon: Rabeloys.

En dépit de ces divergences, il faut s'en tenir ì l'orthographe qui a été adoptée sans aucun changement pendant vingt-neuf années consécutives par le sareastique écrivain $(1)$.

(1) Apres les signatures de Rabelais, il me semble intéressant de donner celles de P. Lamy, J. Boyssoné, Ronsard, Jean Bouché, Francois Garasse, Budé, Ramus et Rondellet, ses antis ou sesennemis. On peut s'assurer de suite que, contrairement à ce qui est grénéralement admis, Boyssonća śrit son nom arec un seul $n$ et que le pricepteur de lauteur de Pantagruel à Fontenay-le-Comte, le moine érudit Petrus Amicus, sappelait Lamy et non Amy. C'est anx óditeurs du roman rabelaisien et non à l'aulemr quion doit de lire Pierre Amy dans lo chapitre x du livre lll ef P. Lamy dans le chapitre xxun tu live $V$. Une depriepe preuve de res affirmations est la quittance ci-jointe dóliwér à P. Lamy far un des royagenrs en 
librairic de Henti Eslienne: "Je, Octave Folpape, ronfesse avoir pecen en nom de Jte Estienue, inpuneur à Paris, la somme do sept rscuz an soleil, par les maiss de Fre Pierre Lamy, sur et th didur-tion de ce pui est deu an dist Estienne à eause des lives rendus re jourdturi il

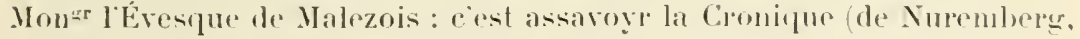
sans doute), Aristoteles, Querela pacis (d'Erasme), Homerus, Cicoro. Carrara, la Voye Cibste et lo Trimmple de Mantuene; de la quell. somme je me tiens pont content et bien jayr ef en quicte le diet Fre Lamy et tous aullies, et, en tesmoing, de ce, jai signe ces prósentes. Faict ì Fontenay-le-Comte ce denier jom de juing mil ciny cens dix el neut. -

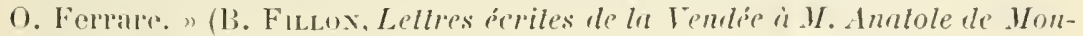
laiglon, 1861.)

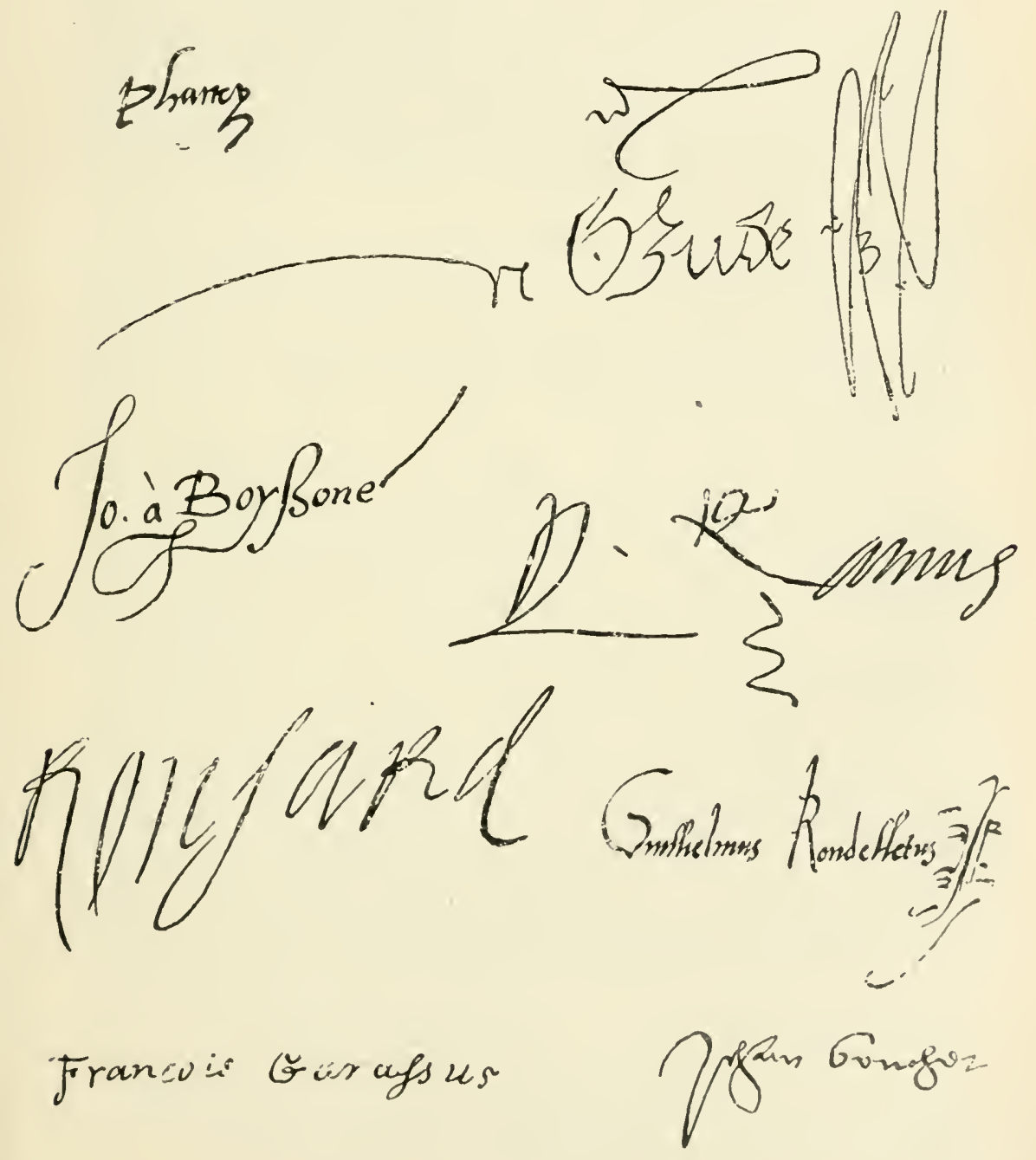


Celui que la légende a accusé sans raison d'une intempélance moins avouable liut un véribable "goinfre de livres ". Mais il ne les dévolait pas (et éest la un des laaits essentiels de son génic) pour s'emplir d'une vaine science de mots et de formules, pour citer et répéter ce que les Anciens avaient dit ot s'asservir a la tradition. Il avait an plus haut degré le goul de l'observation et de l'expérimentation. L'étude des secrets de la nature avait pour lui eneore phus de charme que celle des manuscrits et des imprimés.

"Vos philosophes qui se complaignent (1), observe Bacbue (2), toutes choses estre par les Anciens escriptes, rien ne leur estre laissé à inventer, ont tort trop évident. Ce que du ciel vous apparoyst et appelez phénomènes, ce que la terre vous exhibe, ce que la mer el les aultres flenves contiennent, n'est comparable a ce qui est en terre caché." Cherchez " ì investiguer comme est le naturel des humains. "Et surtout ne rous découragez pas. "Par temps ont esté et par temps seront toutes choses latentes (3) inventées."

Rabelais a été sous ce rapport un précurseur, un initiateur de la méthode expérimentale, e'est-ì-dire de la méthode sans laquelle il n'y a pas de vérité possible dans les sciences, surtout en médecine, un des ennemis les plus méprisants de la discipline scolastique. Quelle différence entre les docteurs du Collìge de Montaigu, "les précepteurs sophistes " qu'Érasme a raillés et le pédagogue de Gargantua, Ponocrates (4), qui se rit de tous le fatras des pédants scolastiques, des bestiaires, des lapidaires, des miroirs et autres barbouillamenta Scoti! Ponocrates qui recommande, il est vrai, à son élève la lecture des poètes, des historiens et des philosophes de l'antiquité, mais principalement

(1) Se plaignent.

(2) Mot hébreu qui signifie bouteille. On y trouve mue onomatopée.

(3) Secrètes, cachées, du latin latens.

(4) Homme laborieux, du grec róvos, travail, et \%ó́tos, force. 
l'étude "des faiels de nature " (I) et de "l'estat humain "! Chaque jour Garganulua el som maitre "devisojent ansemble de la rertu, poprićlé, eflicare el nature de tout co yui leur estoit servi à table: du pain, du vin, de l'eau, du sel, des riandes, poissons, liuicts, herbes, racines, et de l'apperst dicelles (2)... Passant par quelyues prós ou aultres lieux herbus, risitoient les arbres et plantes, les conlorants $(: 3)$ aree les lives des Anciens qui en ont escript conmone Theophraste (1), Dioseoride (.) ), Marinus (b), Pline (7), Nicander (s), Macer (y) et Galen (10) el com emportoicut leurs pleines mains au logis : despuels avoil la charge

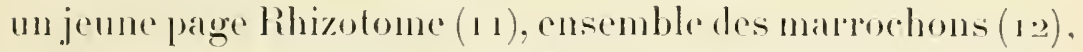

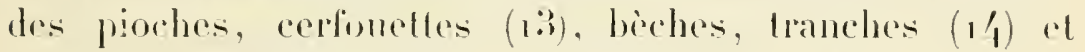
aulles instruments requis a bien artoorizer (1.j) ).

(1) "Et quanl à la cognoissance des finets de nature je veuls que lu

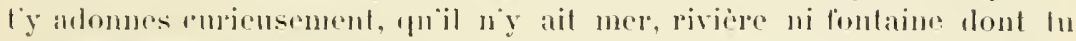

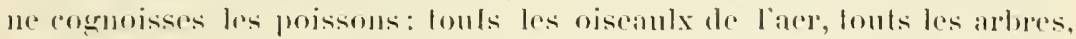

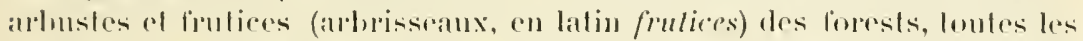
herbes de la leme, lons les molanlx caches an ventre des abysmes, les

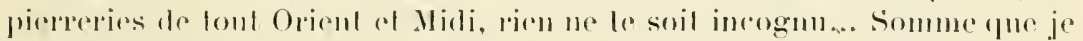

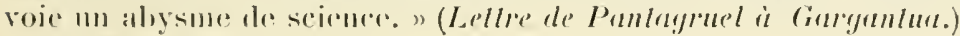

(2) I)r colles-cit.

(3) Les eomparant, les meltant en parallele, du latin conferene.

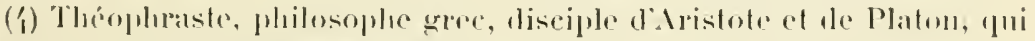
a enlereu la sexualiti des planles.

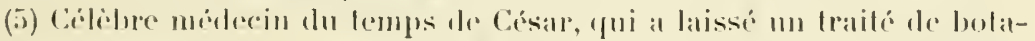
nique médicille.

(6) Disciple de Proclus.

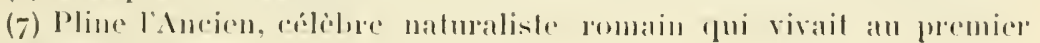
siecle de notre ine.

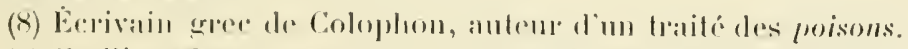

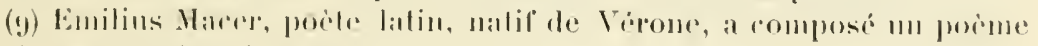
sur les virlus des simples.

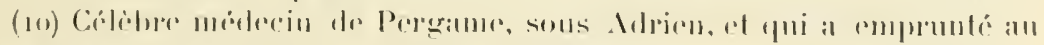

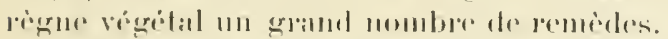

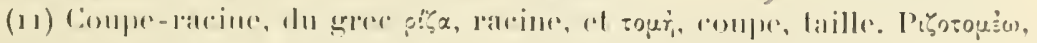

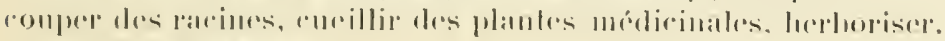

(1:2) Proliless lomeres.

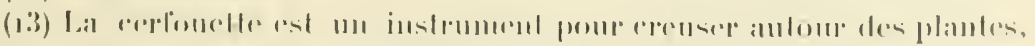

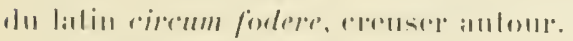

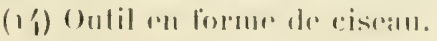

(15) Hriborisism.

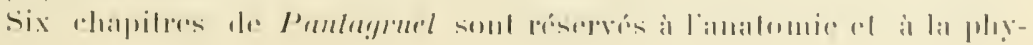


Si le temps était défavorable, au lieu d'herboriser, ils entraient dans " les boutiques des droguemrs (1), herbiers (2) et apothecaires et soigneusement considéroient les fruicts, racines, feuilles, gommes, semences, axunges pérégrines (:3), ensemble aussi comment on les adulteroit (4) $).$

Et Gargantua, "si bien et entièrement retinct en sa mémoire les choses dictes par son précepteur que pour lor's n'estuit médicin qui en sceust la moitié fout comme il faisoit n, qu'il roulut plus tard que son fils reçit la même éducation et lui manda par lettre : "Soigneusement revisite les livres des médicins grees, arabes et latins sans contemner (.) les talmudistes et les liabbalistes et par fré.

siologie (1. III, ch. 15, xxx, xxiı, of l. IV, elı, xxx, xxx, xxxis), quate ¿ la botanique (1. 11I, ch. xhix et suiv.).

Mầtre Francois a en cure du nom, de lopigine, de la cullure, de l'organographie, de l'emploi industriel ef des propriétés médicinales de beaucoup de plantes et de l'enneni naturel (animal ou régilal) de plusiems d'entre elles. Il a reconum la sexualité des plantes, mais en prenant i tort pour le mâle la lemelle qui porte la graine. Il a parlé de "l'aristolochia qui aide les femmes en mal d'mfint, du lichen qui guérit les malaties de

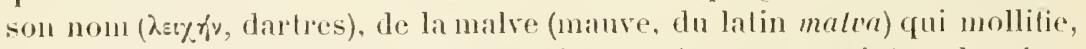
de la grainc de fougère qui est contraire anx femmes enceintes, du némular, de la semence du saule qui glacent et mortitient le germe prolitique, de lellebole qui neltoye loute alteration et habitude perverse du cervau, du glateron on herbe anx teignemx, de la racine duchanve (panfagrusion) yui, cuicte en ean, remollist les nerts retirés, les joinctures contraclées, les podagres schirrotiques el les goutles nouŕrs, cte."

Dans son Elude sur le XYI siécle, Alfred Mayrargues a consacré a Rabelais botaniste plusiem's linnes élogieuses. Léon Faye, auteur d'une brochure publiée a Angers en 1854, a cerit que, "le prenier en France. Rabelais "te vaiment digne du nom de botanisten.

(1) Doroguistes.

(2) Herboristes.

(3) Graisses changères, du latin axungin, graisse, ot du latin peregrinus śtranger, royageur. On réserve aujourd hui plus specialement le nom d'axouge à la graisse de pore.

(4) Altérait, latsifiait. Henri Estienne, daus son Apologie pour llérodote, a consacré de longs passages aux fraudes des apothicaires de son temps. Un médecin tourangean, Sébastien Collin, a écrit, ver's 1553, une Déchration de's abus el lromperies que font les apolhicaires.

(5) Mépriser, du latin contemnere. 
quentes anatomies acquicrs-toi la parfaicte cognoissance (1) de l'aultre monde qui est l'homme."

Le conseil, pour n'ètre pas nomvean - c'est le rvö́o osxutór de la sagesse antique, - est encore bon is suive. Ce que l'homme connaît toujours le moins, c'est lui-mème. Nous n'arons toujours que des motions imparfaites sur notre corps, notre carur, notre intelligence, le principe de vie qui nous anime; nous ignorons notre origine, notre berceau, notre histoire. Or savoir tout cela, ne serait-ce pas savoir le comment et le pourquoi des choses?

Bien habile était an XvI siècle celui qui pourait dire. ce que Cornelius Agrippa regardait comme vrai. Paracelse dans ses assertions positives était nébuleux ou avait la naïreté d'un enlant. L'avenir était à l'observation directe, à l'étude des " laiets de nature ". C'était par l'anatomie qu’il fallait commencer. C"est ce qu'a fait Pantagroul. et. s’il n’a pas emblassé la médecine, éest parce que. "l'eshat ast lascheux el par trop mélancholique el que les médicins sentent les elystères comme vientx diables ".

Le eorps de l'homme offre nu ensemble de combinatisons dont les mathines les phos complipuées ne donnent qu'une idée imparlaite. On y troure des modides sans nombre de constructions ingénieuses dont les architectes antaient

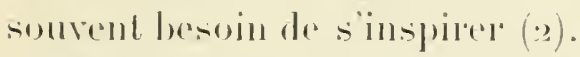

Les londenents de nos phares et de nos monolithes étahlis daprès les principes d'une géométrie savante - laissent a désirer puand on comprend les riggles yui ont présidé à la distribution des os du pied.

(1) Commaissance.

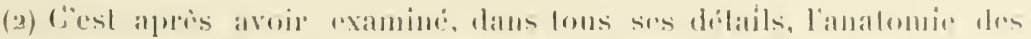

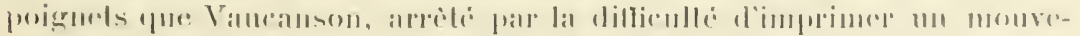

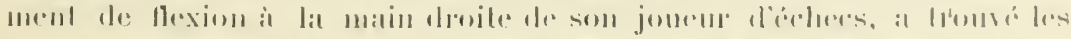

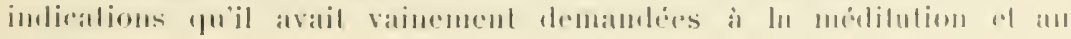
rilcul. 
Linsertion d'un mat de vaisseau dans son emplanture ne peut se comparer ì l'articulation de la colonne rertébrale arec le bassin.

Les tendons et lemrs poulies de réflexion ont une perfection quion chercherait en vain dans les cordages les plus habilement disposés.

Nul instrument de musique ne peut rivaliser aree l'appareil vocal.

L'hydrodynamique retroure ses pompes et ses soupapes dans le cour el les canaux cireulatoires. Et quelques progrès que les physiciens aient lait liare de nos jours à la construction des télescopes. des microseopes et des chambres obscures, l'oeil demeure toujours le plus merveilleux de nos instruments doptique.

A la vue de celte étomnante organisation, oi tout a ité si bien prérn el coordonné, Galien s’est écrié (1) " qu'un live d'anatomie était le plus bel hỵme quil ait été donné a lhomme de chanter an Críatem! " Ciréron, Fénelon, Bossuet, ont poussé te mème eri d'enthousiasme.

Lamatomie serait eneore la plus belle de toutes les scinces si elle neen élait la phos éminemment utile! Quoi de plus réconfortant pour une àne généreuse que cette idée: chafue connaissance que jalequiers est whe conquète que je fais pour le soulagement de l'humanité souffrante?

Sans anatomic, il ny a pas de chirmorge, de médecine, de physiologie ni même de psyrehologie possil)les (2). La connaissance des fonctions d'un organe déconle, en effet, prespue néressairement de la connaissaner de son morle de confor-

(1) Sucrum sermonem ego conditoris noslri rerum hymnem compono, e.rislimoque in hoc repram esse pielatem, non si latrorum hecalomba ei plurimas statificarerim, sed si noterim ipse prinuss casias aliatue sescenla orloramenta ac onguenta sufflumigatrerim, sed si noverim ipse primas, deinde et aliis exposuerim quenam sil ifsius sapientiu, que virlus, qux bonilas. (Gistex, De Lsu protium, lib. lll.)

(2) Tous les grands philosophes out manic le scalpel, à conmencer par Descarles, pui a decomert les actions réllexes. 
mation. Pourquoi ignorons-nous les usages du thrmus, du corps thyroüde, des capsules surrénales, ete. ? Paree que leur structure nous est encore peu connue. Il en est de mème du cerveau. Du jour où nous saurons exactement comment it est constitué, la philosophie ne flottera plus entre le spiritualisme et le matérialisme, ou le sensualisme. pour me servir d'une expression rajeunie. L'avenil moral, comme l'avenir physique de l'humanité, est subordomné aux progrès de l'anatomie et de la phrsiologie.

Ciest done a ces deux scionces qu'il fiunt appliquen l'exclamation de Homenaz (1) : Hólas, quand sera ce dori de grace particulière faict és (2) humains, qüils désistent de toutes aultres estudes et négoces (:3) pour vous lire, vous entende, vous scavoir, vous user, practiquer, incorporer, sanguifier (份) el incentriquer (5) és plofunds rentricules (6) de lenrs cerveaulx, és internes mouelles $(7)$ de leurs os, és perplex (s) labyinthes de leurs artìres? O lor's, et non plustost, ne (g) aultrement, heurens le monde (10)!"

Oue la grénération qui s'élère, plus versée dans l'étude des seiences naturelles, módite ees paroles: elle améliorera sa destinée, si elle n’en déchiffre pas l'obscur. le déconcertant rébus:

(1) Ce mot signifie ici, comme dans Merlin Coceaïe (Mistoire macaronique, 1. XIX) (et dans le patois langaulocien acturl, un homme grand, gros, mal bili.

(2) $111 x$.

(3) Affaires, du latiu negolium.

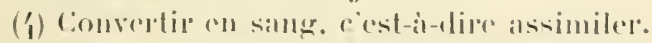

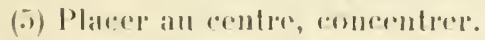

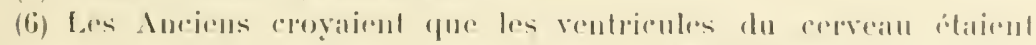

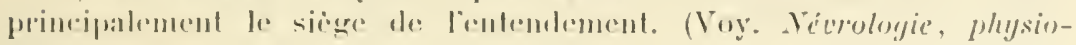
logit?.)

(7) Muellis.

(8) sinucus, tortuens, du latin perplexus.

(y) $\mathrm{Ni}$.

(10) L. IV, clı. L. 
Il y a plusieus espèces d'anatomie:

L'anatomie descriptive, qui étudie la situation, la forme, la direction, ete., tes organes et les groupe par appareil;

L'anatomie chirurgicale ou des régions, qui indique au chirurgien ee quil ne saurat impunément trancher ;

L'anatomie des formes ou artistique, qu'on jeut délinil : la connaissance de la surface extérieure du corps, soit dans les diverses altitudes du repos, soit dans les divers mourements;

L'anatomie comparée ou zoologique, yui compare ct classe tous les etres vivants:

L'anatomie pathologique, qui renseigne sur les modifications que subissent les tissus et les humeurs pendant les maladies.

Puis : L'anatomie embryogénique ou d'évolution (1), l'anatomie tératologique $(: 2)$, l'anatomie paléontologique (3), l'anatomie philosophique (4), ele.

Toutes ont été grreffées sur l'anatomie descriptive comme sur un trone commun. Celle-ci comprend:

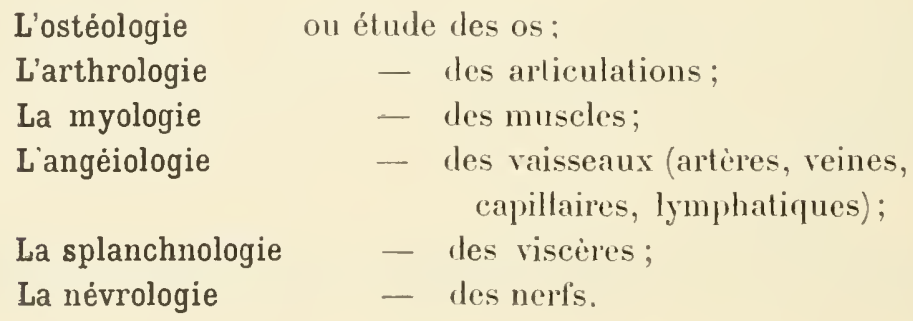

Dans les propos des héros de l'immortel romancier. on démèle une connaissance certaine de l'anatomie descrip-

(1) Elle soccupe des transformations que subit l'embryon daus le sein maternel.

(2) Elle a four objet liótude des monstres.

(3) Elle détermine les caraclères des espèces animales éteintes.

(4) De la réunion et de la comparaison de faits particuliers elle déduit des lois générales d'organisation. 
live, de l'anatomie chirurericale, de l'anatomice des lontmes, de l'anatomie comparée, de l'anatomic pathologique et de la physiologie. Je rais suceessivement reproduire el commenter ces propos en commencant par cenx qui ont trait a l'anatomie descriptive el à la phroiologie.

I ai interealé dans los pages qui suivent des dessins dus ¿ $u n$ jemne artiste tourangean réputé. M. Lonis DantyCollas. Ils angmentent la valeur de ce volume en mème temps qư̈ils rendent évidentes et compróhensibles pour lous les comparaisons dr Maitre Francois.

Pour terminer, qu'il me soil permis de dommer un sonvenir ému a la mémoire de F. Audiger. fondateur de la Soriélé des Amis et Admiraleurs de Rabelais. yui a mis a ma disposition des doemments rares et preciens qui ont romlu ma tache plus lacile. el de remereier mon éminent conflère et ami, le Dr Durean, bibliothécaire de l'Academie de médecine. dont jai mis sonvent il contribution la grande érudition el l'inépuisable complaisance. 

ANATOMIE DESGRIPTIVE 



\title{
ANATOME DESGRIPTIVE
}

\author{
OSTEOLOGL OU ETUDE DES OS
}

Dans l'oente énorme el louflue, etrange, composiose de maison profonde, d’imaginalion folle, desentiments généprox

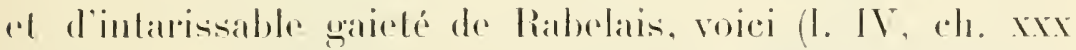
(et suiv.) " comment par Xenomanes (1) est anatomisé al descript Quaresmeprenant (2).

"Quaresmeprenant, dist Xenomanes, quant and parties internes ha, an moins de mon temps avoil (:3):

Les os, comme cassemuseaulx.

Les spondyles, comme une cornemuse.

L'alkatim, comme un billart.

(1) Xenomanes: qui a la manir des voyages, de \%evós ol pavix. Gest dean

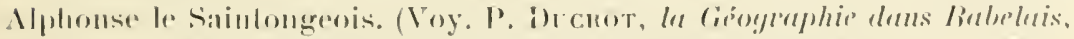

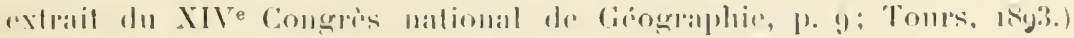

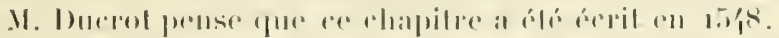

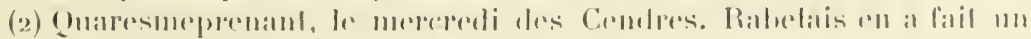

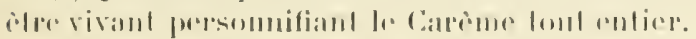

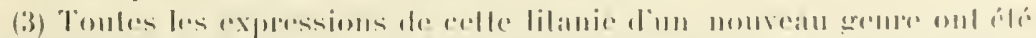

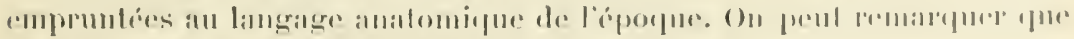

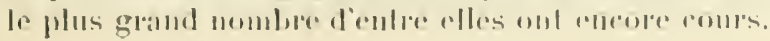


Le crane, comme une gibessière.

Les coustures, comme un anneau de pescheur.

Le frontal, comme une retumbe.

Les os pétreux, comme un plumail.

Les costes, comme un rouet.

Le breschet, comme un baldachin.

Les omoplates, comme un mortier.

Les hanches, comme un vibrequin.

Les genoils, comme un escabeau.

Les fociles, comme faucilles.

Les rassettes, comme des èchasses.

\section{Les os, comme cassemuseaulx.}

Cassemuseaulx, gâteanx tris friables, de forme variée, a pate broyée, cest-i-dire à cassure nette, que l'on fabriquait autrefois sultout a Poitiers. Ces gàteaux étaient ainsi nommés par antiphrase.

\section{LE SOT}

\section{Cassemuseaulx}

\section{Chaulx! Cassemuseaulx chaulx!}

(Farce des cris de Paris, Ancien Théatre français, 1. I1, p. 313.)

Les os, par conséquent, aróolaires, secs, peu résistants. Ciest principalement chez les vieillards que s'observe ce mode de conformation des os. Chez quelques-me ils se réduisent même à une simple coque qui se brise à la moindre chute.

On sait (1. II, ch. v) que Pantagruel "vint i Poictiers pour estudice, et proficta beancoup ".

\section{Les spondyles, comme une cornemuse.}

Les spondyles, les vertibres (1) (arovíuina). Les rertibres

(1) Dans ládition de Rabelais de Pierre Dupont, illustrée par Gustave Doré, et dans celle de Rabelais de Garnier, annotée par L. Barré, le mot 
superposées constituent la colonne vertóbrale, lige creuse. incurvée plusieur's fois sur elle-mème. plus volumineuse 'n bas quien haut, analogue à une cornemuse, cest-ì-dire a une chalamie (1) (flùte champètre), ou plutòt ì un hautbois. "Plust me plaist, déclare Panurge, le son de la rustique
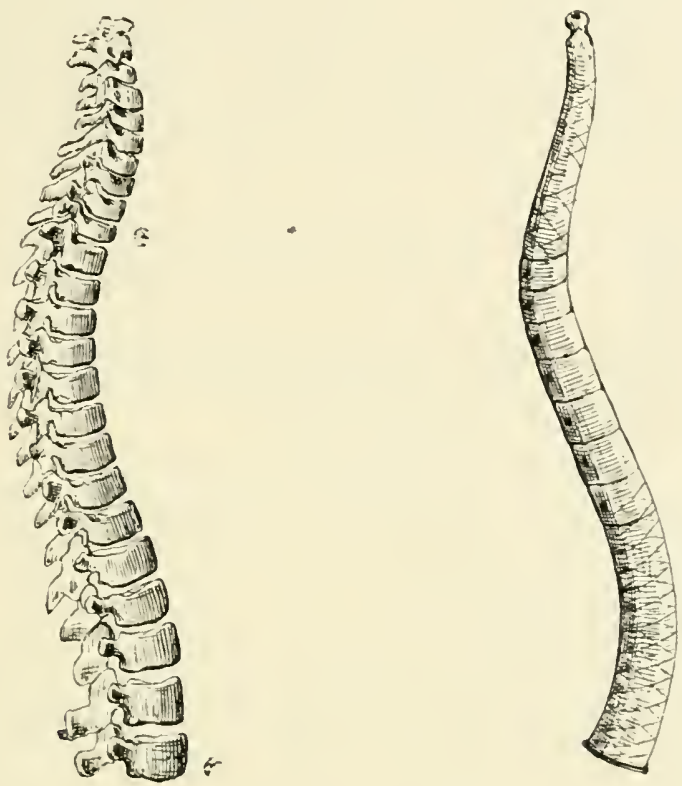

Les spondylis, comme une cornemuse.

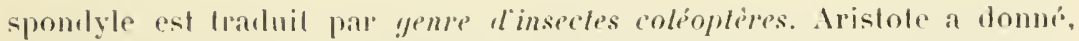

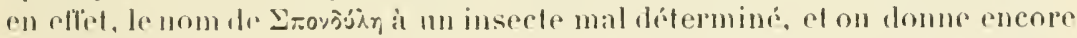
anjourdhui le nom de spondyles it les Cérambyeides aberrants appartenant is lopdre des Colíopteres of dont le lype est le Spondyle bupreste

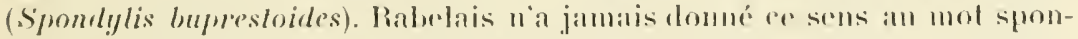

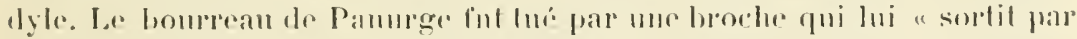

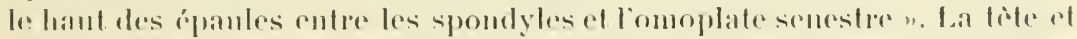

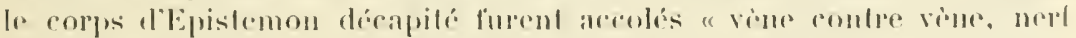

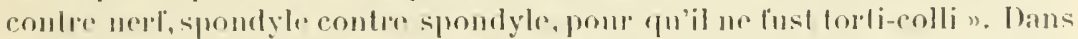

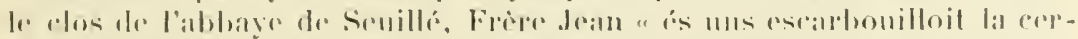

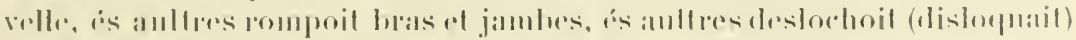

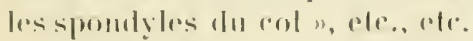

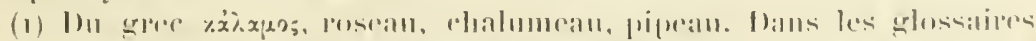

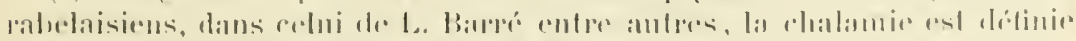
justement: Hoite rhampube ou cormemuse. 
cornemuse, ywe les fredonnements des luts, rebees at violons auliques (1). ") (L. III, ch. Xuvi.)

La colonne vertélnale était appelée conduit on tuyau sacré par les Grees, parce qu'elle contient une partie noble, la moelle.

La chalamie dessinée ci-dessus est la reproduction exacte de celle qui a liguré, en 1892 , à l'Exposition nationale de Tours (section de l'Art rétrospectil), dans lacollection d'anciens instruments de musique de II. Tolbecque, de Niort.

La seconde vertibre du cou est la plus curieuse : elle est surmontée d'une apophyse ressemblant à une dent. Elle est décrite sous le nom de dent par Ilippocrate, de vertèbre dentale, d'axis, d'epistrophens par d'autres, el de vertèbre dentiforme par Rabelais.

Dans le royaume de la Quinte. Pantagruel vit un jeune pérazin (2) guérir lessyphilitiques "seulement leur touchant

(1) De la cour, du latin aulicus.

(2) Parazon, péraron, pérason : pour certains commentateurs. Ce mot, tui herpive do loébren perusin, veut dire chevalier. Le perusim est 111 des soixante-douze anges yui, d’après les talmudistes, marchent sous la conduite des dix ordres l'esprits qui président à tout ce qui existe et exécutent sur lout ètre cróé les volontés de Dieu. Les noms de la plupart de ces anges et de ces esprits sont cités dans le fameux ourrage : De occulta Philosophia, seu de Magia, de Comélius Agrippa (trois éditions rers 1520,1526 et 1530 ), et e'est par moquerie que maitre François en a baptisé les serviteurs de la reine de la Quinte.

Vers 1526 ou 1527, Cornélius Agrippa, étant à Lyon, a protesté violenment contre les Romans yaulois, est allé mème jusqu'ì mander, clans me lettre à Jean Chapelain, médecin royal: "Parmi les Docleurs (il ne dit pas les sarants), il s’en lrouve qui écrivent de lonteuses facéties, livres empestés qui sont lus non seulement par les princesses, mais encore avec avidité par les damoiselles, ef par lesquels les femmes s'habituent à la dépravation. "(Epil., I. IV, ch. In.)

Rabelais, pígué an vil, sest vengé en llagellant lauteur de la Philosophie occulle dans les trois chapities consacrés à la Quinte-Essence. Jajouterai tontelois que ces chapitres sonl considérés comme apocryphes par divers pantagruélistes, auraient été interealés, ansi que celui des Apedeftes, par Jean Turquet dans le Ve lirre qui est hien, quoi qu'en dise P. Lacroix, l'wenve dn maître, mais qui a été publić en 1562-156', c'està-dire apris la mort de celui-ci. (Voy. Decrot et F. Audger, Soc. des Amis el Admiraleurs de Riabelais, Tours, 1887, p. 13, et 1892, p. 16.) 
la rertible dentiforme d'un morecan de sabot par trois fois $n(1)$.

\section{L'alkatim, comme un billart.}

L'allatim, not dépió de l'arabe et qui sept à désigner le sacrum (2). Le sacrum, vulgo le croupion, est compose dre cinf redebles soudées entre elles de maniere à former un seul os appeló par Hippocrate "la grande vertèbre n. Il esl enclavé entue les denx os des hanches an-dessous de la colonne reptébrale qu'il continue. Il est diriggé obliquenent d'avant on arriere el de haut pn bas et recourbé sur luimène.

Tous les anatomistes du moven àge se servaient volonliers des termes d'Avicenne, d'Averthoes ot d'Abulcasis pour classer les diverses parties de lorganisme lmumain. Comstantin l'Africain, né is Carthage et mort a laubaye du mont Cassin rn 1087; Roger de Parme, éleve de l’ÉEole de Salerne, chancelier de l'Unirersite de Montpellier an eommeneement du xure siede: Guillanme de Salieeti, né à Plai-

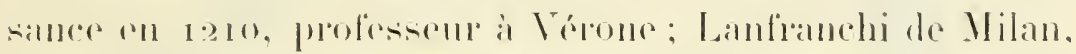

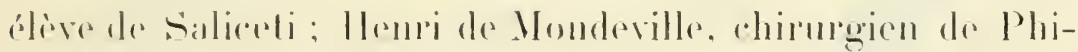
lippe le Bel; Jean Dathen Ferrari de Gradi, Denis del

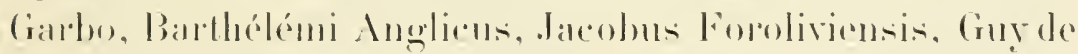

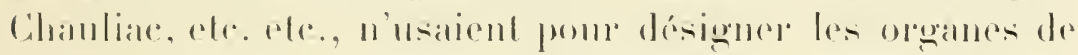

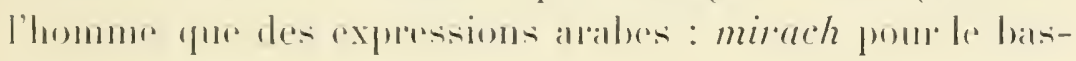

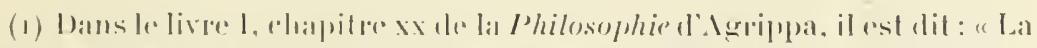

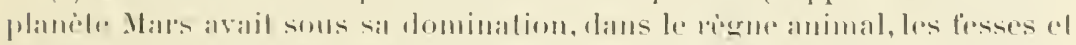

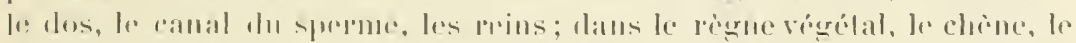

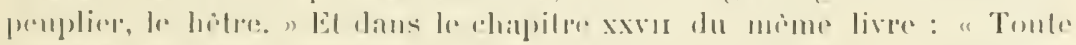

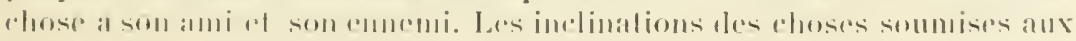

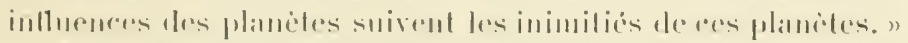

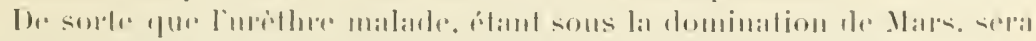

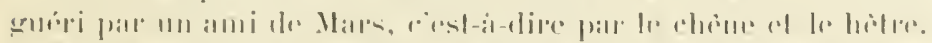

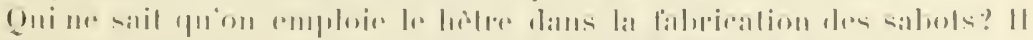

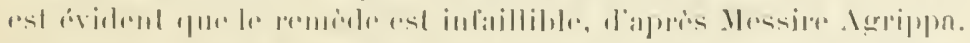

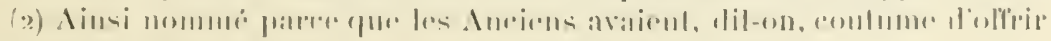

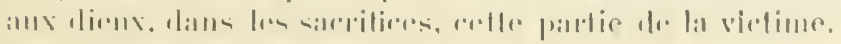


ventre, siphac ponr le péritoine, zirbus pour l'ápiploon. canna pour la trachée-artère, mery pour l'aesophage, ete. Indpeas Bellumensis (1) dit posilivement que l'alkatim renferme les einq vertebres qui sont immédiatement andessous de la douziome vertibre dorsale : Alchalim esl pars continens spondyles quinque qui sunt immerliale infra spondylem 12. Vieux eneore Rabelais l'a dit hui-même. Dans le chapitre $\mathrm{xx}$ du live III, oì, selon Johammean, Maîtıe Fran-
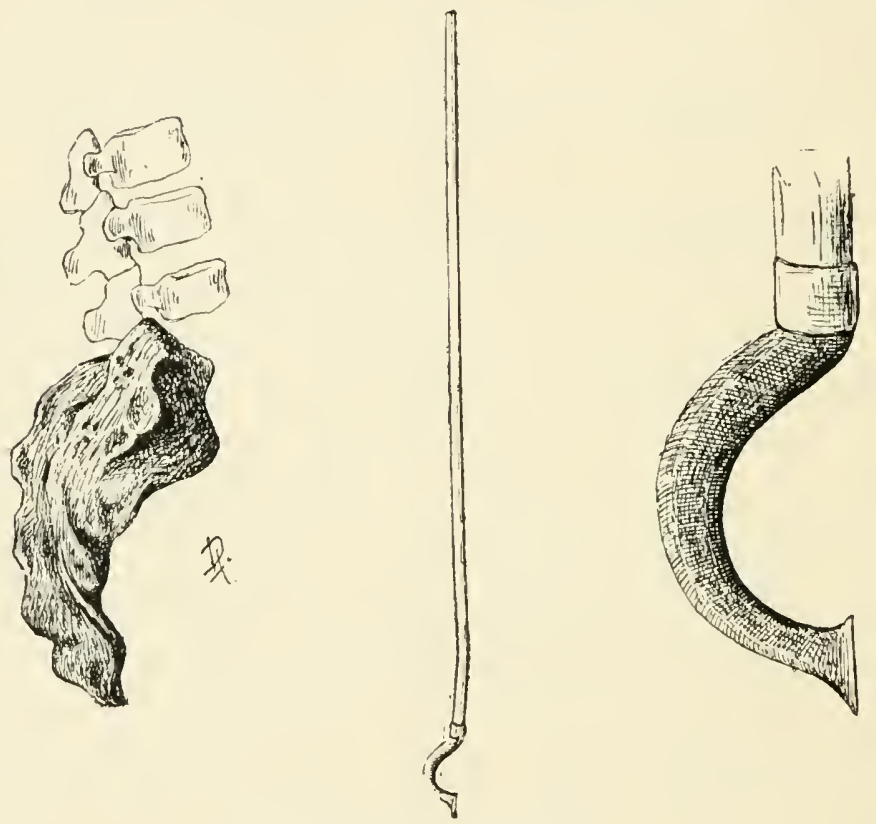

L'alkalim. comme un billart.

cois a voulu faire voir quil n'ignorait pas le langage par gestes des sourds-muets, il est mentionné que Panurge (2) "assist au-dessus des fesses, au lieu que les Arabes appellent Alkatim ", le pouce de la main droite, puis celui de la main gatuche.

(1) Interprète des mots arabes yui se tourent dans Aricemue.

(2) Celui qui lait tout, du grec räv, tout, et Ëprov, ouvage. Daucuns pensent que Panurge, esst Rabelais; d'antres, que c'est le cardinal d $\mathrm{Mm}$ boise; quelques-mus, que cest une persomuification du peuple, ote. Antant d'assertions, antant d’hypothèses. 
Fait eurieux el qui proure bien que la plupart des liveres se font avee les liveres des autres, fous les commentateurs de Rabelais que j’ai lus on traduit alkatim par péritoine.

Billart. - Mail ou maillet à pousser les billes. "Crosse ¿t crosser, " dit Ménage (Dictionnaire étymologique). Il faut donc entendre ici par billart un gros bàton muni d'une crosse dont on se servait antrefois comme d'un maillet.

Et un billarl de quoi on crosse.

(Vitlox, Ancien Teslament.)

Le sacrum est bien, en effet, me cossic adaptée à la colonne vertébrale.

\section{Le crane, comme une gibessière.}

La tète est composée de deux parties: le creine of la like. Le cràne est une boite ossense qui loge le cerveall. Eille a la forme d'un oroüde.

Gibessière, gibeciome. On a domme juspulù la lin du XV1 sicele le nom de gribecière a l'aumoniè et a l'escarcelle de grande taille a fermoirsou a recourrement puion portait, la première devant l'abdomen, an moyen de denx cordons lixís ala ceinture, la seconde sur le llance droit on le lane ganche. au moyend dune conrove passée en sautoir sul line on l'antre des denx ípanles. L'anmonnière et l'escareelle de grande taille ont la mème orighe et, par suite, à pen prós la mème forme. Quand elles sont distendues, elles ressimblent au eràne. Eu égand ì ses dimensions, le cràne a cependant plus

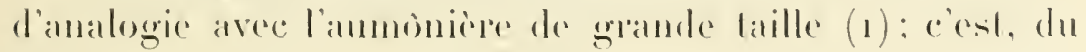

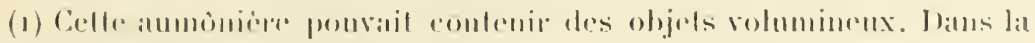
chimson de Ifuon de Bordeamx, on lil:

\section{1 prent le cor le blanc poire eler,}

Qu'en s'anmosniere anoil enselopé.

Je donne a linpuni de la comparaison de Rabelais le dessin diune.

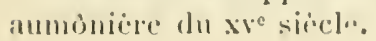


reste, cette dernière que Rabelais a, dans tout le cours de son ceurre, appeléc gibessière.

" L. Neratus, gentilhomme romain, faisoit emplir les gibessières de ses rarlets d'or et d'argent monnoyé, et reneontrant par les rues quelques mignons baguars (1) leur domnoit grands coups de poing en face. Soubdain après,
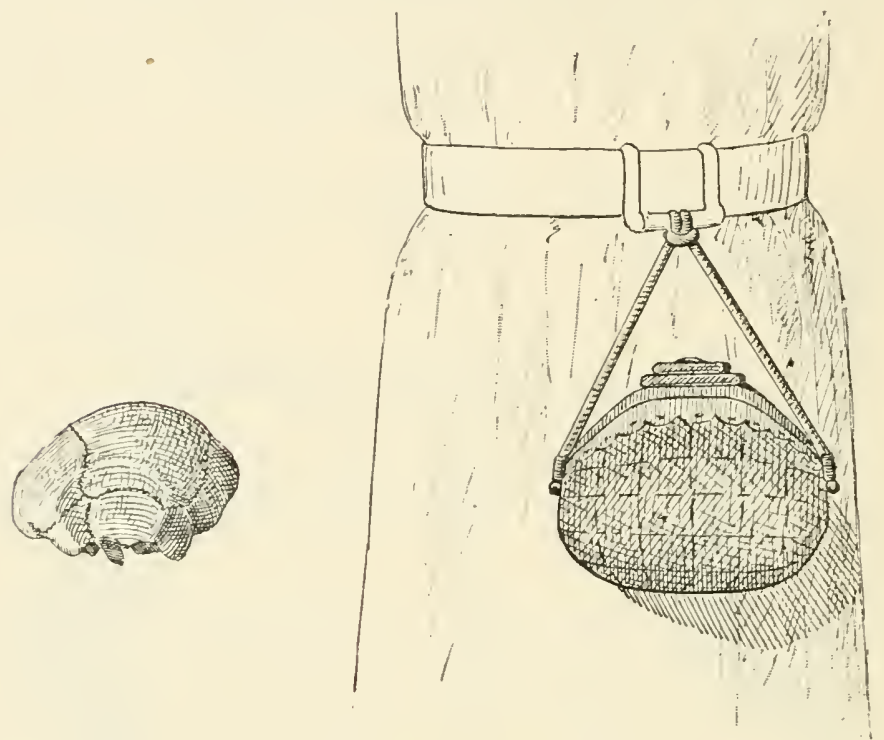

Le rrane, comme une gibessiere.

pour les appaiser leur despartoit (2) de son argent. " (L. IV, (ch. Xvi.)

"Gibessière de velour's n'est reliquaire de testons (3) ni menue monnoye; cirst un réceptacle d'eseuts au soleil, " dit Panurge à fì̀re Jean. (L. V, eh. Xr.)

Dodin, receveur du Coudray, répond à frire Couscoil qui hui demande s’il n’a pas d’argent sur lui: qu’il en a "pleine gibessiere ". (L. IH, ch. xxm.)

(1) Pimpants, bien ajustís. Cie not tire, dit-on, son origrine des bragues, calecon de toile fine.

(2) Donnait.

(3) Ionnaie d'argent, l'appée en France sous Louis XI, sur larpuclle était gravée la tite du roi. Le trston valait quinze sous et sis diniers. 


\section{Les coustures, comme un anneau de pescheur.}

Les roustures sont les sutures ou arliculations des us du cràne entre rux. Les sutures de la route du cràne ressemblent aux coutures mal faites (doù leur nom primitif) des fillettes qui commencent à manier l'aignille. Elles forment des cercles plus on moins réguliers, rerticaux et transversaux (sulures fionto-pariétale ou coronale (1), frontosphénö̈dale, fronto-ethmoïdale, ete.), el verticaux et antéropostérieurs (sutures médio-frontale, sagittale (2), inter-orcipitale, etc.).

Plusients d'entre olles sont indiquées dans Crargantua et dans I'antaypruel.

Marquet est frappé d'un coup de baiton " par la joincLure comonale de la teste sur l'artèe colonphique (:3) du costé dextre (4) $n$.

An sac de l'abbaye de Seuillí "si anleun saulver se vouloit en furant, a icelluy (.) Frie Jean faisoit roler la leste en pièes par la commissme lambdö̈de " (6). Le moine bataillenr" se "deffeit d'un de ses gardes. hui coupant la teste sur les os pétreux, et enlevant les deux os bregrmatis $(\boldsymbol{z})$, et la commissure sagillate avere grande partie de l'os coronal (8) ". ete.

Les commentalemes volent avec laison, je pense, dans les mots annean de peschenr nure allusion a la formule

(1) Paree quelle presimble à une rompomine.

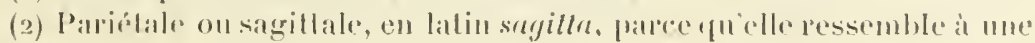
Meche.

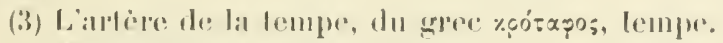

(1) Du colé droil, du latiu dererter.

(5) $\mathrm{A}$ icelıi-ci.

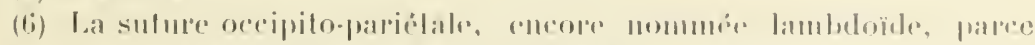

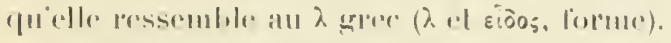

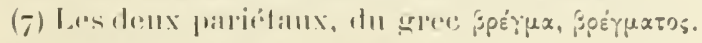

(8) Jios dil firout, le trontal. 
usitée en cours de Rome: "Sub annulo piscatoris, sous le sceaul de l'anneau du pècheur, " de saint Pierre, qui fut successivement pècheur, apòtre et pape.

Le frontal, comme une retumbe.

Le fronlal, l'os du fiont.

Dans le live $V$, chapitre xxir, on lit: "Beuvants, en belles et amples retumbes. vins de quatre sortes."

Parmi los rases d'artillerie bacehique seupptés sur l'aré antique sous lepuel on devait passer pour arriver a l'oracle
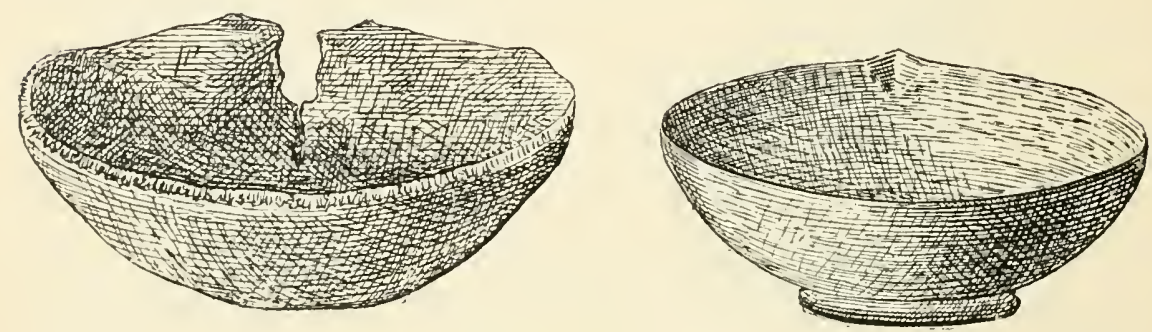

Le fronlai. comme une relumbe.

de la Bouteille figuraient: " cent formes de verres à pied, relumbes, hanaps, etc. "( 1 ).

Le Duchat pense que le not retumbe vient peut-ètre " de rotunda, en sous-entendant cupa. (Voyez.J. Bouchet, Annales d'Aquitaine, au feuillet 99 , de l'édition de Poitiers, 1557.) Lis parlant de certain waissean de verre rond, plein de vin, qu'anciemement, dit-il, on jetait pendant les rogations contre la maitresse châsse de l'église abhatiale de SaintCyprien de Poitiers, on marge de cet endroit du livere, ce vaissean rond est apjelé relumbe. "Cette signification est certaine. On lit dans du Cange : De rotumbis el cyfis vitreio, mais l'étymologie de Le Duchat est inadmissible (Esmangart et Johanneau). Voici la délinition que Cotgrave

(1) L. V.eh. хxмк 
donne de cet objet: "A false cup wherein drink falling into and odd corner seems to be drunk up; also a flat vanlt or a room that's made vault wise."

Lal relumbe est un rase rond ou lasse à boire. On compare maintenant le frontal à une coquille de pelerin. La corguille étant le premier vase qui ait servi à puiser de l'eau, il n’y a, par conséquent, qu’une diflérence de mot entre la compraraison de Rabelais et eelle des anatomistes modernes.

\section{Les os pétreux, comme un plumail.}

Les os pétreuc on poeher's, ainsi dénommés à cause de lem dureté, de lems inégalités of de leurs aspérités. logent l'appareil de l'andition. Ils forment la partie inférieure et interne de chacun des os de la tempe.
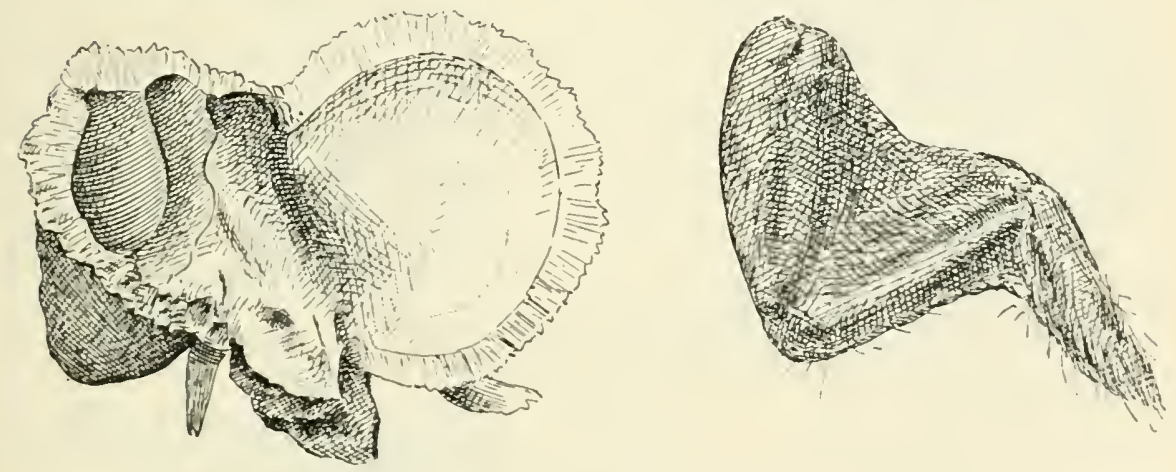

L.ess os pilreus, romme un plumuil.

I'lumail, aileron de volaille garni de ses plumes. - Ce not est encore usití en Saintonge el en P'oiton pour désigrner un aileron divie ou de dindon.

Le dessin ri-dessus lixe le degoé de lessemblance qui existe anter los pétrous et 110 phomail.

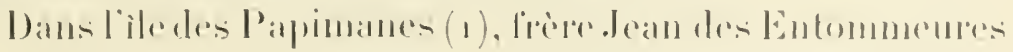

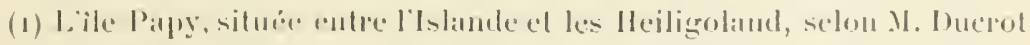
(loc. cil. sulpri, l, J9). 
"regardoit de costé les bachelettes (1), comme un chien qui emporte un plumail ".

Les soldats du capilaine Tripet, ébahis des exercices équestres de Gýmnaste (2), fuyaient "regardants derrière soi, comme un chien qui emporte un plumail".

\section{Les costes, comme un rouet.}

La poitrine on thorax est une cavité limitée par vingtquatre os longs, courbés en cerceaux, les côtes, unies en arric̀ aux vertebres du dos, en avant au sternum.
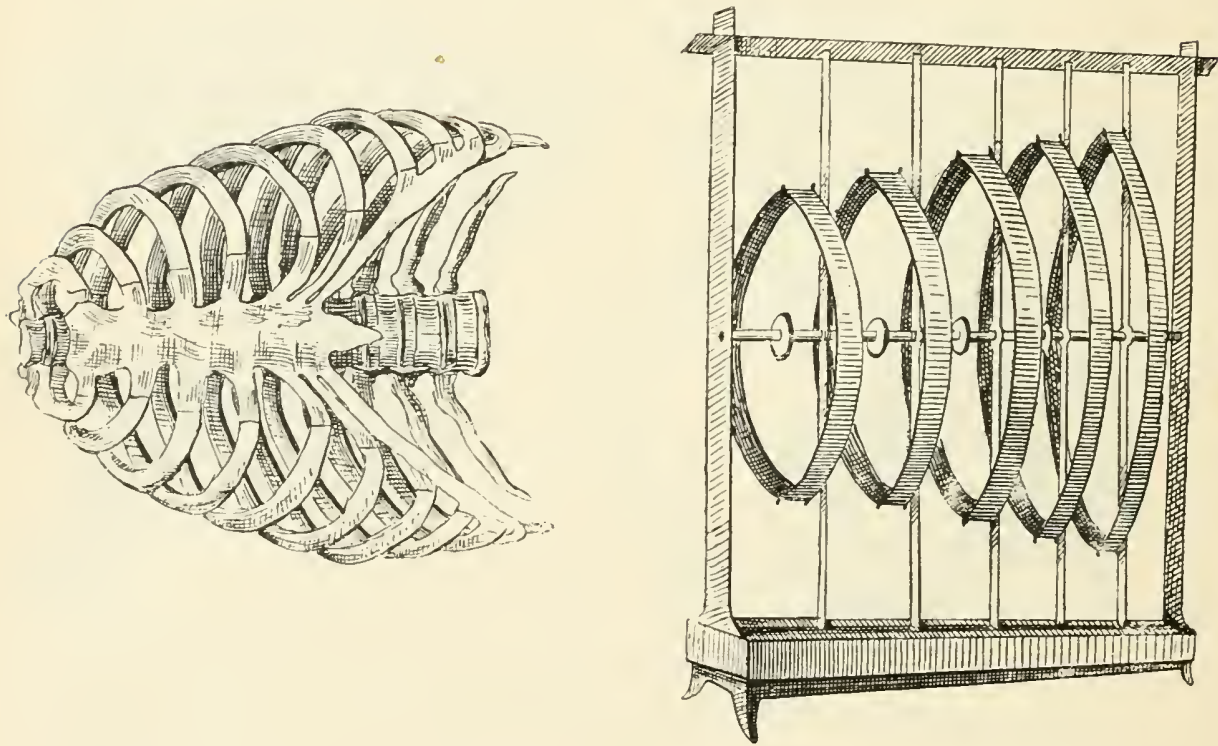

Les costes, comme un rouet.

On ne peut regarder le thorax sans penser à un ou plusieurs ronels. Le rouet ancien donton a le dessin sous les yeux appartient ì la grandimère de M. Danty, mon dessinateur.

(1) Bacheliers, jeunes hommes à marier, bachelelles, jeunes filles à marier; d'où bachelerie, bachelage, pour célibat.

(2) Du gree rupvastris, maitre des athlites. 
Le breschet, comme un baldachin.

Le breschet, le sternum.

Un des chicanous "daulbé (1) en la maison de Basché a huyet costes froissées, le breschel effondré (2), ete n.
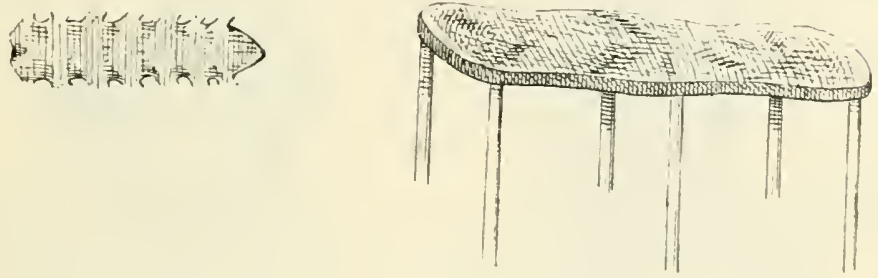

Le breschet, comme un baldachin.

Baldachin, baldayuin, mot italien (baldacchino) francisé qui veut dire dais. Baldacchino, suivant Ménage, est un diminutif de Baldacho, nom diune ville de la Babylonie dans laquelle on fabriquail des draps de diverses couleurs. Le qualificatif de baldacchino appliqué ì ces draps aurait été appliqué, plus tard, palr extension, au dais qu'on porte ant-dessus du saint Sacrement dans les processions, all ciel d'un lit, ete.

Pantagruel est reçu dans l'ìle des Papimanes parl'évèrue Homenaz el ses gens "portants banières, gonfalons, baldachins, torehes, benoistiers ") (3).

Le sternum est, effectivement, un baldaquin ossens protégeant le cour et la partie antérieure des poumons.

Les omoplates, comme un mortier:

Liomoplate on palleron. qui, avee la elavienle, lorme ha

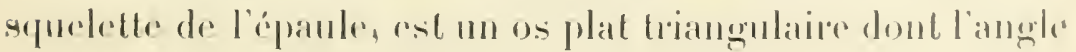

(1) Ballin.

(2) Bristi, diblenter.

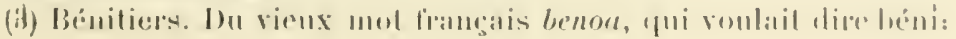


externe offre une caviti, bordée d'un bouredet carlilagineux et surmontée diun liganent (liganent acromio-coracö̈dien), dans laquelle la tète de l'os du bras (humérus) s'emboîte eomme la tète d'un pilon dans nu morlier.
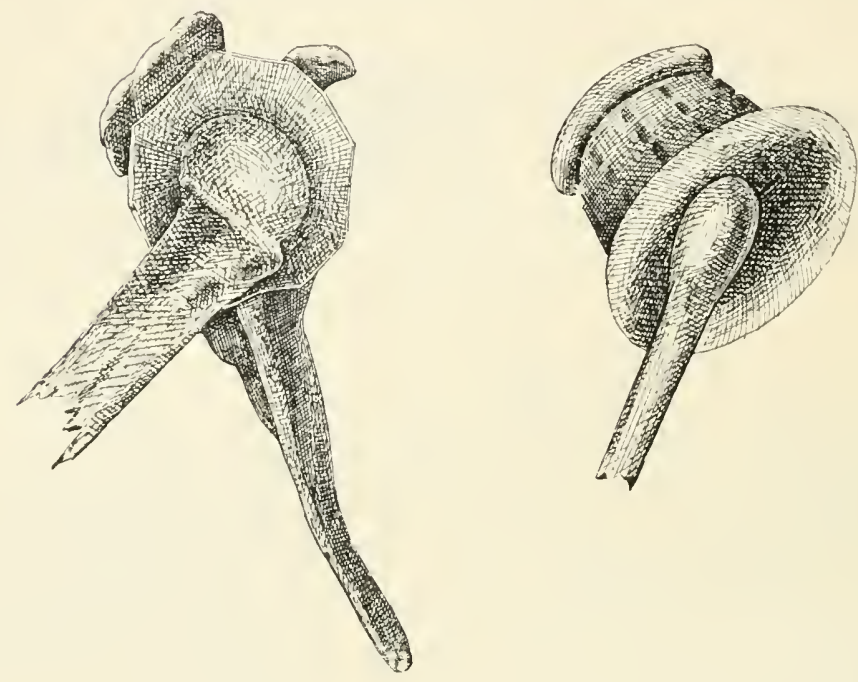

Les omoplates, comme un mortier.

Le mortier en bronze dessiné ci-dessus esl la reproduction d'un mortier du xis siecle qui a figuré, en 1892 , a l'Exposition nationale de Tours.

La face postélieure de l'omoplate est divisée an deux parties par une erète osseuse presque horizontale, terminée en dehors par une sallie aplatie nomméc aromion.

A la tin de l'escammonche de seuillé, frepe Jean " avee son baston de croix donna entre col et collet sur l'os acromion (1) du capitaine Tirarant ".

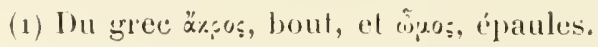


Dans l'île des Ferrements ( 1 ), les arbres semblent " animaulx terrestres, non en ce différentes des bestes qu'elles n'enssent cuir, graisse, chair, vènes, artères, ligaments, nerfs, cartilages, adènes (2), os, mouelle, lumeurs, matrices, cerveau et articulations cognues (:3); car elles en ont.... mais en ce qu'elles ont la teste, e'est le trone, en bas ; les cheveulx, ce sont les racines, en terre; et les pieds, ce sont les rameaulx, contremont (4); comme si un homme laisoit le chesne fourchu. Et ainsi comme vous.... de loing ¿ ros jambes ischiatiques (5) et a ros omoplates sentez la renue des pluies, des rents, du serein (6), tout changement de temps; aussi, à leurs racines, caudices (7), gommes, médulles (8), elles préssentent quelle sorte de baston dessoubs elles croist, et leur préparent fers et allumelles conrenentes."

\section{Les genoils, comme un escabeau.}

Les geniols, les genoux et sprécialement l'os situé à la partie antérieure de l'articulation de la cuisse et de la jambe, la rotule.

(1) Les îles Féroë, selon M. Ducrot. (Ducrot, loc. cil. supri, p. 22.) Ces iles, au nombre de quinze, ćtaient appelées, du temps de Rabelais, isles de Forrô, îles de fer.

(2) Glandes du cou, en lalin adenes.

(3) Contulues.

(4) En l'air.

(5) Atteintes de névralgie sciatique, du gree is/ı, les os des hanches. La nérralgie sciatique, maladie très difficile ì combaltre, est guérie quelquefois par laction du feu (pointes de feu, moxas). C'est ce qui est arrive ¿ Panurge. a Notez, raconte-til à Pantagruel, que cestui rostissement me guérit d'une ischiatique eutièrement, i laquelle j'estois subject plus de sept ans avoit, du costé auquel mon rostisseur s'endormant me laissa brusler."

Les doulenrs de la sciatique sont réveillées on exagérées par les chanerements de temps.

(6) Dn bean temps, du temps calme, du latin serenus.

(7) Tiges, du lalin caudex.

(8) Moelles, du latin medulla. 
La rotule est triangulaire comme le siège de la plupart des escabeanx du moyen àge (1). A Quaresmeprenant, émacié par les jeùnes, "lioisonnant en pardons. indulgences et stations, bon catholic, de grande dévotion, "fré-

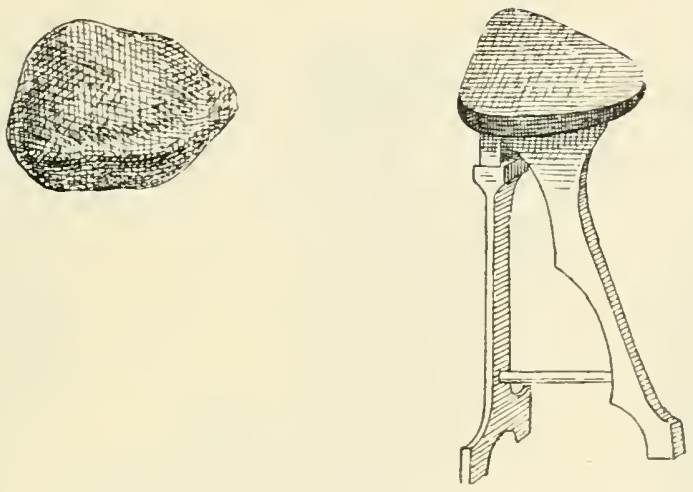

Les genoils, cromme un escubenu.

quemment à genoux, par conséfuent, reet os tenail vaiment lien diescaldeant.

\section{Les fociles, comme faucilles.}

L'arant-bras est lormé par la réunion de demx os longes. le cubitus en dedans. Je radius en dehors: la jambe pal' la rémnion de deux autres as longs, le tibia en dedans, le péroné en dehors.

Dans les auteur's du moyen àge, les os de l'avant-bras al de la jambe sont appelés fociles ou fancilles, le tibia ol le cubitus focilia majora, le péroné et le radius focilia minora.

Tous ces os sont incurves, triangulaires et tranchants comme une faucille. Dans le Berry on nomme encole les arant-bras faucilles.

II somble que liabelats se soit complu a joute sur les

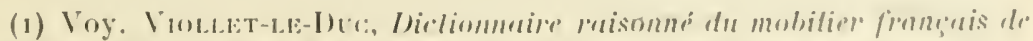

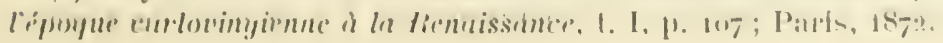


mots fociles ef faucilles. Maître François a écril aussi, en effet, dans l'ancien prologue du quart live: "Nous sommes parabolains (1) au long laucile et au grand code (2). " Et dans le chapitre xvir du livre Ier "Cenx-ei (3) s'en ront en
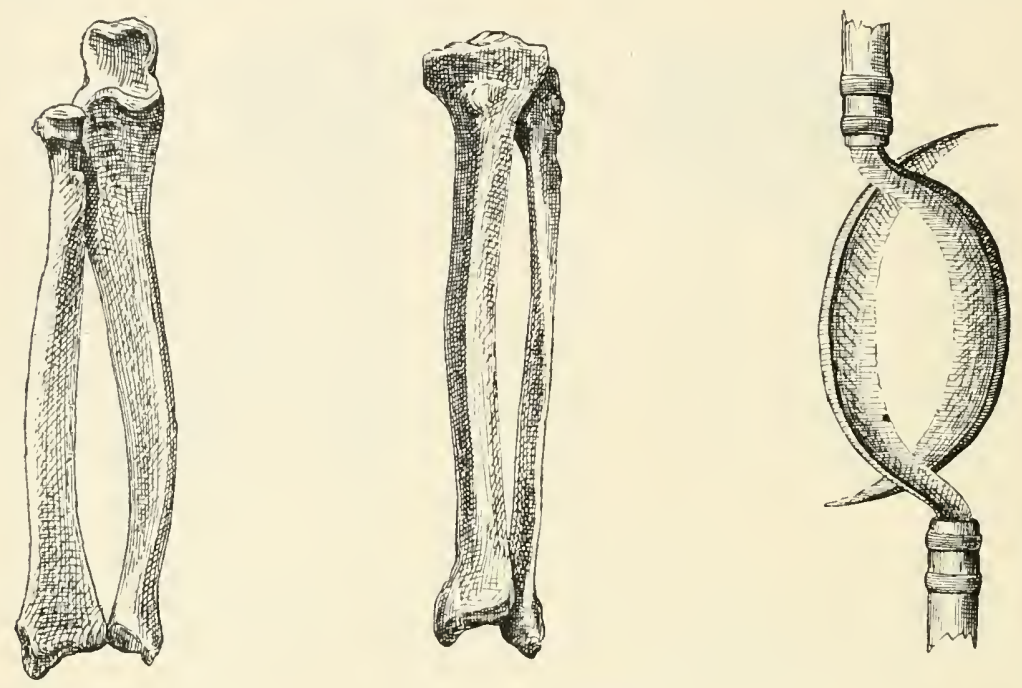

Les foriles, commc faucilles.

paradis aussi droict comme une laucille el comme est le chemin de Faye (4)."

Les rassettes, comme des échasses.

Les rasseltes, rascheles, rachettes, rasquettes, les os du poignet, c'est-id-dire du carpe et ceux aussi du cou-depied (5) ou du tarse.

(1) Hommes consacrés an service des malades dans les hoppitanx, frires convers, hommes de corvée, lu gree $\pi$ apásonos, méprisé.

(2) "Jenx de mots, dit L. Barré, d'abord sur fancille (petite faulx) et focile (os du bras); puis sur rode (livre) et coubte (conde). "

(3) Les pillards qui saccageaient le bourg et labbaye de Senillé.

(4) Aujonrdhui cheore, le chemin de Chinon à Faye-la-Vineuse décrit une conrbe assez prononcée.

(5) Lianteur a signalé un des pelits os du cou-de-pied, l'astragale: 
"Les os de la rachette de la main qui sont huit." (H. DE Mondeville, f" 1 .)

"La lasquette du pié est composte de quatre os lyés ensemble, avenamment. "(LANFrinc, l" iz, verso.)
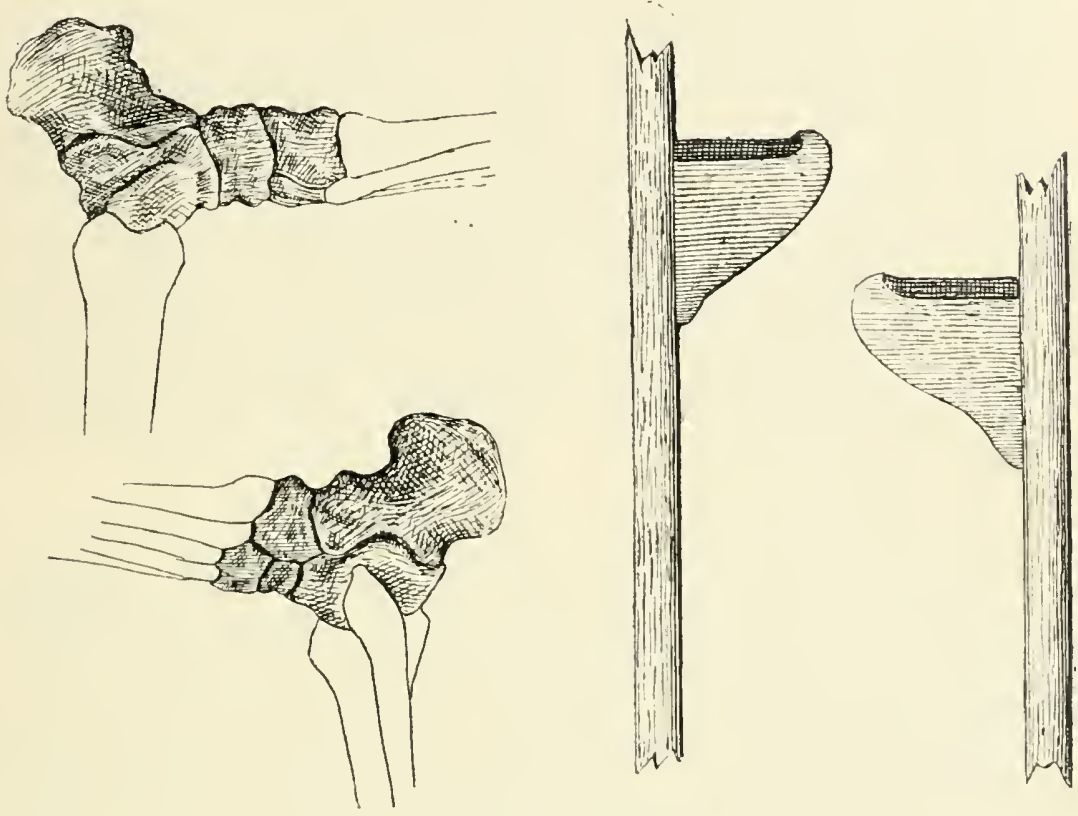

Les rasselles, comme des echasses.

Les échasses datent dre trés loin. Une paire d'échasses analogues ì eclle dont on a le dessin sous les yeux est représcrutere dans l'Misloire du saint Graal jusquà l'empire de Néron, manuserit (tin du xur" siecte) de la Bibliothèque nationale.

Pantagruel "voubit tenir fuelques propos all capitaine

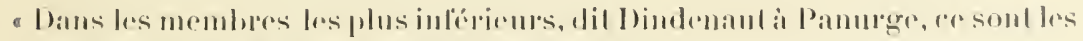

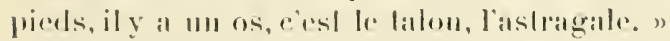

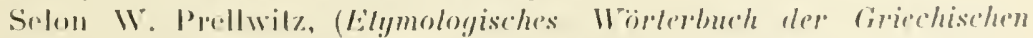

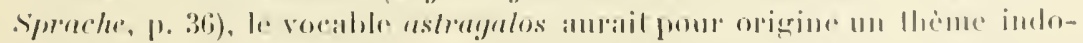

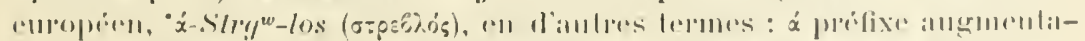

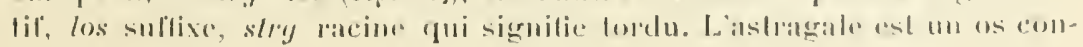
tourne, tordu. 
du palais de la reine de la Quinte-Essence : mais ne pouvant monter si hault qu'il estoit soubhaitoit une échelle ou des échasses bien grandes." (L. V, ch. xix.)

La comparaison exacte pour les rassettes dupied, dont la plante regarde en haul (1), est inexacte pour celles de la main quelle que soit la situation dans laquelle on la place. Pourquoi? Peut-être paree que le malicieux satirique a lail abstraction de la main hors nature du roi de l'île de Tapinois (2). Quaresmeprenant, il ne faut pas l'oublier, était un arrière-descendant des lils d'Antiphysic qui avaient "les bras et les mains tournez en arrière rers les espaules. Et cheminoient sus leur leste sphérique et ronde entièrement comme un ballon, continuellement faisants la roue, les pieds contremont (3)."

Physiologie. - Les os sont creusés de cavités remplies de moelle. Ia moelle abonde surtout dans le eanal des os longs. C'est une matiòre pulpeuse, d'un janne grisatre, qui, en raison de la grandr quantité de graisse qu'elle contient (4), compose un aliment très nourrissant. Elle sécréterait, d'après Bizzozero, les globules blanes du sang qui, pour eertains auleurs, ne sont que des globules rouges en voie de lormation. C'était un mets très estimé des hommes des àges de la pierre, ainsi qu’il appert de la quantité d’os d'animaux fendus an long, ramassés dans les stations préhistoriques des Eyzies, de Cro-Magnon, de Solutré, ete.

(1) Les roies échasses, les échasses anciennes et relle's de's berger's landais actuels, ne remontent gucre au-delì des mollets, sur lespuels on les fixe ainsi que sur les articulations du cou-de-pied, an moyen de courloies.

(2) Traisimblablement l'islande. (Ducrot, loc. cil. suprit, p. ,6.) Tapinois, hypocrite, homme yui se déguise; en tapinois, en eachette; regarder en tapinois, regarder sommoisement. Ile de Tapinois rent dire exactement île des gens mortifiés (Iln giec tarsevóv, humilité chrétienne).

(3) Lés pieds en l'air (I. IV, ch. xxìni).

(') 96 prarties sur 100 (Berzélius). 
Rabelais na done rien avané de trop lorspu’il a écrit pour exposer sans trop de danger sa doctrine absconse (1).

"Vistes-vous oncques chien runcontrant quelque os médullaire (2). C'est, comme diet l'Jaton, lib. II, Le Rep. (3), la beste du monde la plus philosophe. Si veu l'avez, vous avez pu noter de quelle dévotion il le guette, de quel soing il le garde, de quelle ferveur il le tient, de quelte prudener il J'entomme (4), de quelle affection il le brise, de quelle diligence il le sugee. Qui l’induict à ce faire? Quel est l'espoir de son estude (5)? Quel bien prétend-il? Rien qu'un peu de mouelle. Vray que ce peu est phus délicieux que le beaucoup de toutes aultres, pour ee que la monelle est aliment ćlabourc à perfection de nature, comme diet Galen. III, Facult. nat., et XI, Ie Usu parlium (i)."

(1) Cachée, mystripense, imprótrable, du latio abseondilus.

(2) Un Eerivain ordinatre anrat dit "os it moelle ". Rabelais, qui est anatomiste, sest servi du terme technirpue.

(3) "Le elhien aboie combe cenx qüil ne commait pats, ef thatte cenx quil connaît, quóqưils ne lui aient lait ancm bien... Par lì il manifeste un maturel hemenx et vaiment philosophe, en ce qüil ne dislingue limmi

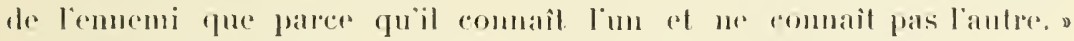
(Platox, OEumes. Trad. Comsin. - Paris, 1833. T. IX, p. 163.)

(1) L'entane, le coupe, du gree żvopxy, incision, entaille.

(5) Allention, du littin sludium fait du gree orovorn, allention, soin par-

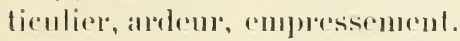

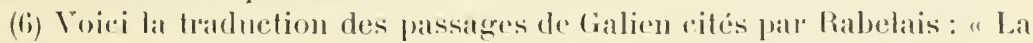
malure a déposé dans certains os une provision daliments propres à leur mulrilion... Lat moelle est l'aliment propme des os... Co que le salng ast pour les chairs, la moelle l'est pour les as..." 


\section{ARTHROLOGIE OU ÉTUDE DES ARTICULATIONS}

\section{Quaresmeprenant aroit :}

Les ligaments, comme une escarcelle.

Les cartilages, comme une tortue de garrigues.

\section{Les ligaments, comme une escarcelle.}

Les ligaments, les ressorts des artieulations, les liens fibreux, solides et tlexibles, qui unissent et maintiennent dans leurs rapports naturels les surfaces artieulaires des os. La souplesse des liganents diminue dans les derniers temps de la vie.

Escarcelle: "Grande bourse de cuir à l'antique qui se fermait ì ressort avec du fer, " dit Furetière.

Les ligaments aussi rigides que des lames de fer ou d'acier.

Les cartilages, comme une tortue de gárrigues.

Si les surfaces articulaires des os, soumises à des frottements durs et fréquemment répétés, ne s'usent pas, c'est paree qu'elles ne sont pas en contact immédiat. Dans la machine animale il y a, en effet, comme dans les machines industrielles, des coussinets protecteurs qui tempèrent les choes et résistent aux pressions. Ces coussinets protec- 
teurs sont les cartilages. Ils sont constitués par un tissu trìs résistant et en mème temps très élastique. qui recourre d'une eroùte plus ou moins épaisse (cartilayes articulaires ou d'encroutement) les parties osseuses des jointures.
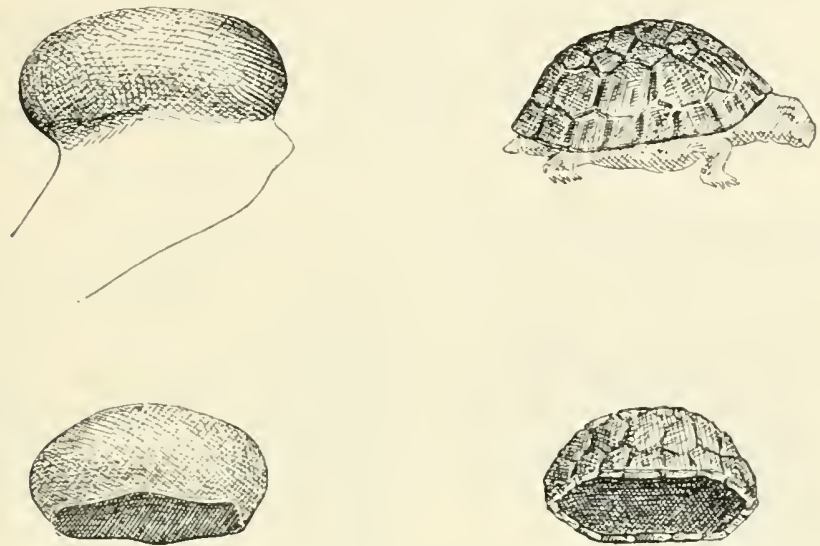

Les rartiluges, comme une lorlue de garrigues.

Tortue de garrignes. "On en roit beancoup en Languedoc, oì on appelle garrigues les landes et les brossailles. " (Le Duchal.)

"Prenez une tortue de garrigues, fest-it-dire de celles qui vivent en terre en liens sees ef qui nentrent point dans l'ealu. "Fonill. F'anc. 333.)

De butes les tortues (tortues terrestress tortues de mel on d'ean douce). la toplue terrestre est celle dont lal caratpare (1), fortement bumbée, rappelle le micus la clonte cartilagineuse qui revêt la tète de l’os do bras, la carité de l'articulation de la hanche, ete.

(1) Jentemds la portion superientre ou dossiese de la carapace. 


\section{MOLOGLE OL ÉTLDE DES MUSCLES}

\section{Quaresmeprenant aroit :}

Les muscles, comme un soufflet.

Les tendons, comme un gand d'oiseau.

Le diaphragme, comme un bonnet à la cocarde.

Les crémastères, comme une raquette.

Les muscles, comme un soufflet (1).

Les muscles se composent de deux parties bien dislinctes:

$1^{\circ}$ D'une partie centrale, rouge, peu consistantr, réductible en fibrilles contractiles (fibrilles musculaires);

$2^{\circ}$ D'une partie terminale, d'un blanc nacré, très résistante, constituant les cordes souples, appelées tendons, qui s'attachent aux os.

Les fibrilles musculaires sont contenues dans des loges membraneuses (aponévroses) qui se perdent sur les tendons dont elles ont la texture et la couleur.

Par le qualificatil général "les muscles ", Rabelais entend surtout la partic contractile de ces organes, celle qui, comme un sonfflet, est relativement relàchée à l'état de repos, gonflée à l'état d'action.

(1) Le soufllet dessiné dans la planche ammexe est un fac-similé du soufflet sculpté sur un des chapiteaux de l'église abbatiale de Vézelay, qui date des premières anmées ،lu xne siècle. 
En plus du ceur, du diaphragme, du crémastère, du sphincter, de l'anus, étudiés dans ce chapitre, Maitre Francois a signalé les muscles des parois de l'abdomen. Voy. Anatomie des formes, Le mirach, comme un chapean albanois, et " le muscle de la vole qui est au dessoubs du pouce. " (L. II, ch. xx.) Les anciens, Pline, Varron, appelaient vola la paume de la main. Par muscle de la vole, il faut donc comprendre l'ensemble de la masse musculaire,
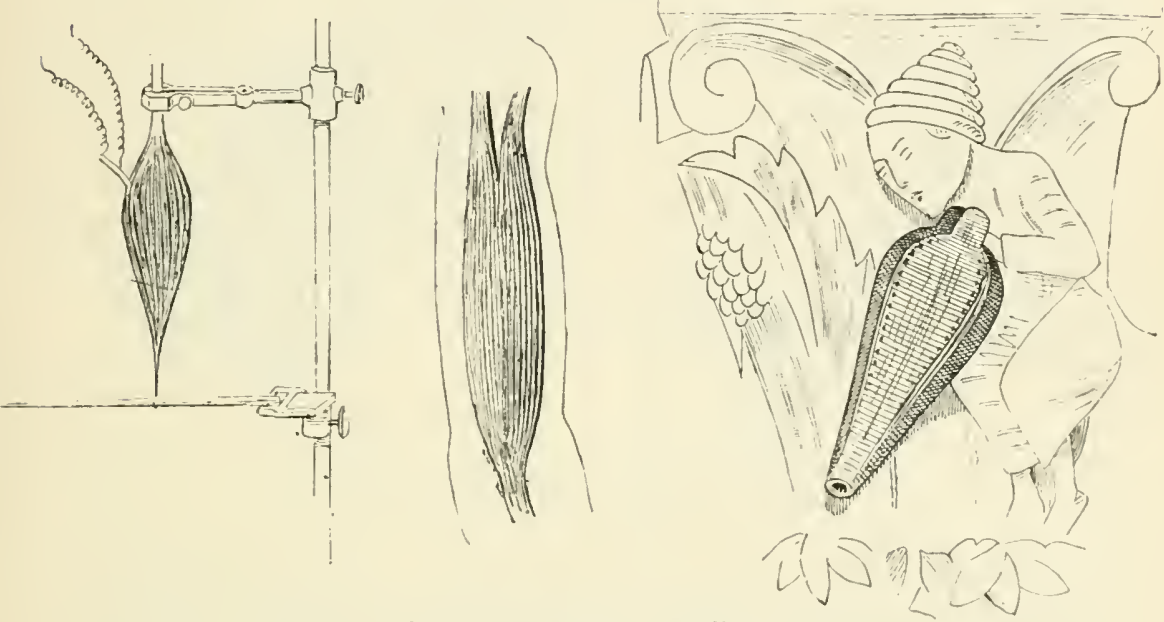

Les muscles, comme un soufflet.

(court abducteur, opposant, court fléchisseur at adducteur du ponce). qu'on troure is la base du pouce of gui constitue l'óminence thénar.

Ce sont surtout les muscles superficiels des membres (jumeanx de la jambe, biceps brachial, long smpinateur, cte.) qui ont la forme indiquéce par l'illustre écrivain. Cetle lorme est celle qu'on donne anx faisceanx musculaires représontés dans les ouvrages de physiologie. (Voy. Manes, la Machine animale, p. 30, 5e édit., Paris, 1801.)

Liexercice forlitic les muscles. Ils sont grobles dhe\% lat lemme el anssi chae\% Whomme dont la vie rest sédentaire. Ils

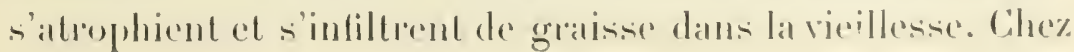


les peuples quise nourrissent exchusivement de viande, l'énergir musculaire est plus prononcée que chez les peuples frugivores. (Haller, Des rapports du moral el du physique.)

Chacun des habitants de l'ìle de Ruach "à sa ceincture portoit un beau petit soulthet. Si par cas vent leur failloit (1), arecpues ces jolis soufflets ils en forgeoient de tout frars, par attraction et expulsion réciproque."

Avec ses os fragiles, ses articulations rouillées, ses hanches saillantes, Quaresmeprenant n'était plus jeune. 11 menait une existence contemplative. "Confalonnier (2) des icthyophages ( 3$)$, grand avaleur de pois gris et de salades salées, rien ne mangeoit jeùnant, jeùnoit rien ne mangeant, grignotoit par soupcon, buroit par imagination, jannais ne se trouvoit aux nopees. "Ses muscles devaient ètre et étaient réduits à un degré inouï de mollesse et de flaceidité. Cée n'était plus de la chair... c'élait de l'air'.

\section{Les tendons, comme un gand d'oiseau.}

Cónd d'oisean, gant de fanconnier. Il était fait de peau de cerl ou de bulfle et avait tous les doigts séparés (4) et une garde assez grande courant le poignet.

"Pour un nouveau faucon il faut gand neuf de cuir de cerl bien blane, laisse neuf de bon cuir, laquelle doit estre allachés au gand, " lit-on dans le Live du roy Modus (manuscr. Biblioth. nat.) écrit au commencement du xive sièch, mais sur des documents d'une date antérieure (j).

(1) Leur laisait délaut.

(s) Gontalonicer, celui qui portait le gonfalon.

(3) Cenx qui ne mangent que du poisson, du gree iygós, posson, et

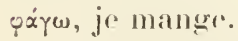

(1) 11 y avait aussi, ì cette époque, des gants sans doigts séparris, ou avec $n$ do doigt séparé pour le pouce. (Vog. Appareil digestir, Le pralul, ('omme une moufle).

(5) Le plus ancien des lives écrits en frangais sur la lanconnerie, 1328. Imprimé en caractères gothiques avec 50 gravures, en 1839 , par Elzear 
Dans une des verrières de l'église Sainte-Savine de Troyes en Champagne, saint Thibault, à cheral et en costume de chasse, a la main droite enferméc dans un gant de ce gemre, sur lequel est perché un faucon.

Au nombre des curieux renus au-derant de Pantagruel desecendu daus l'île des Papimanes tigurait " un fauleonnier avecrues un leurre et gand d'oiseau".
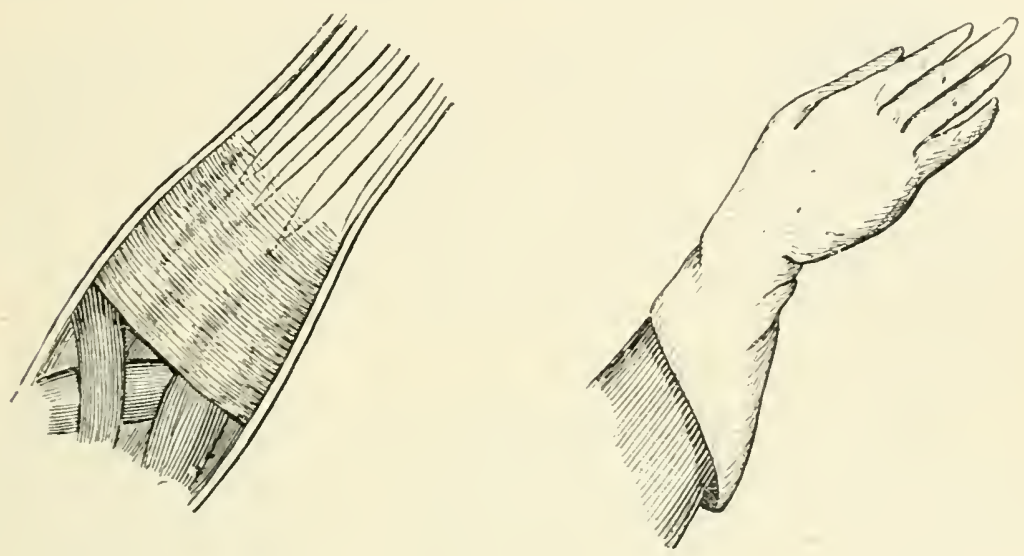

Les lendons. comme un grand doiseau.

Les digilations lendineuses blanches of la gaine alponévolique qui les prolonge à la surface de la plupart des muscles fait involontairement songer au gant blanc digité a longue gaine dans lequel étaient logés la main et le poignet d'un fauconnier.

Le diaphragme, comme un bonnet à la cocarde.

Le diaphragme (1) est une eloison musenlo-aponérorotique qui divise le trone en deux cavités: une supréleme, la

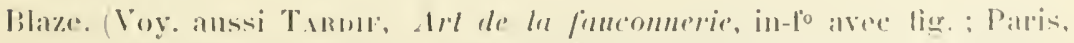

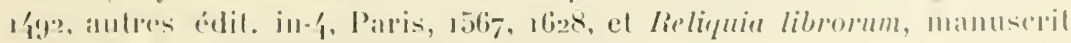

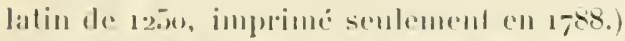

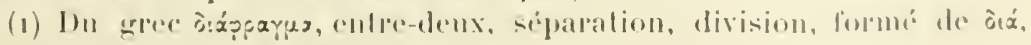

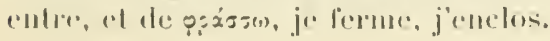


poitrinc, el une inférieure, le ventre. Il est formé d'une portion convexe en haut, concave en bas, fibreuse, c'est-ìdire d'un blanc nacré, à son centre, et musculeuse, cest-it-dire pouge, à son pourtour (corps du diaphragme), el de deux prolongements charnus, verticaux, insérés sur la colonne vertébrale (piliers du diaphragme).

"Entr'aultres despouilles et butins de ses conquestes, Ptolémée, fils de Lagus (1), présenta aux Egyptiens en plein théatre un esclave bigarré, tellement que de son corps l'une part estoit noire, l'aultre blanche (non en compartiment de latitude (2) par le diaphragme, comme fut celle femmo sacrée (3) à Vénus indique (4), laquelle ful recognue (5) du philosophe tyanéan (6) entre le fleure IIydaspes (7) et le mont Caucase), mais en dimension perpendiculare." (Prologue du livre III.)

"Toutes mes phrènes (8). métaphrènes (9) et diaphragmes sont suspendus et tendus pour encornifistibuler (10) en la gibessière de mon entendement (11), ce que dictes, "répond Panurge au philosophe éphectique (12) et pyrrhonien (13) Tronillogan.

(1) L'n des capitaines d'Alexandre, chef de la dynastie des Lagides, rois d'Égrple.

(2) Du latin latitudo, employé par les astronomes daus le mème sens, et qui signifie largeur.

(3) Consacrée, du latin sacralus.

(1) lndienne, du latin indicus.

(5) Recommue.

(6) Apollonius de Thyane, philosophe pythagoricien.

(7) Grand lleuve de l'lnde.

(8) Phrinc, opry, primitivement te diaphragme que les poetes grees confondaient arec le péricarde; par extension, surtout au pluriel, les viscères, les eutrailles.

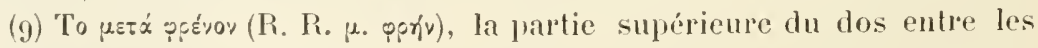
épaules.

(10) Mot lorgé, introduire, faire entrer.

(11) Voy. Ostéologie, Le crane, comme une gibessiere.

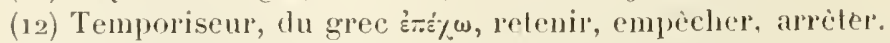

(13) De l'école de Pyrrhon, disciple d'Anaxarque et chef des philosophes sceptiques. 
Bonnet à la cocarde, bonnet d'homme s'attachant sous le menton. "Bonnet à la mode ancienne, bonnet des gens du commun, " dit Oudin.

Le premier des habitants de l'ìle des Apedeftes (1) rencontré par Pantagruel " estoit vestu d'une robe gocourte (2), de couleur de roi, avoit le pourpoinct de demi-
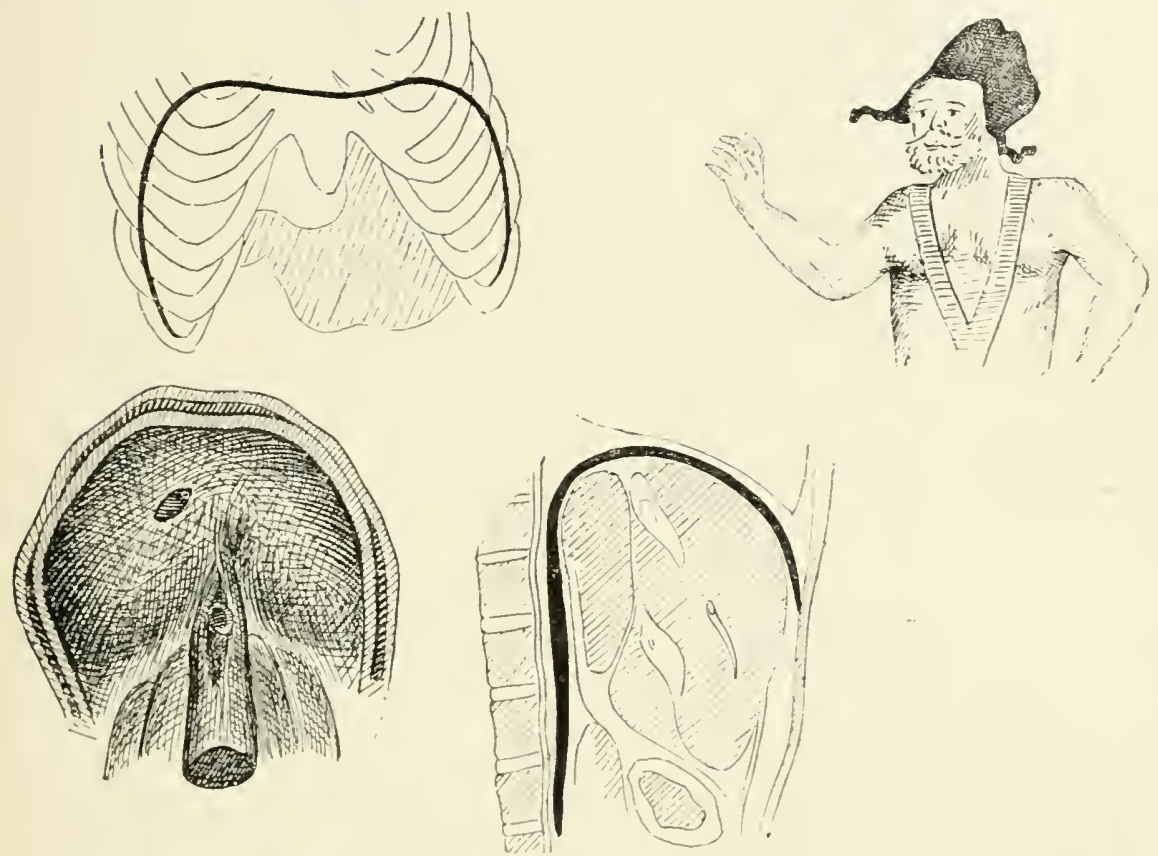

Le diaphiragme, comme un bonnel is la cacarde.

ostade (:3) i bas de manches de satin, et le latult estoit de chamois, le bommet il la cocarde ".

Cie bonnet est tresis ample, très fourd ot doublé en

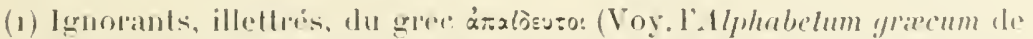

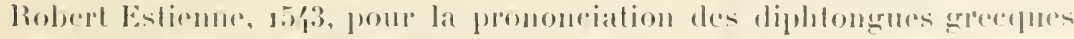

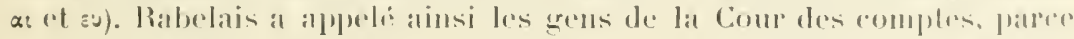

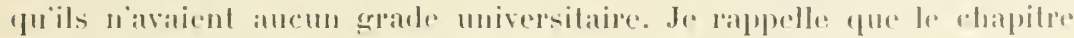

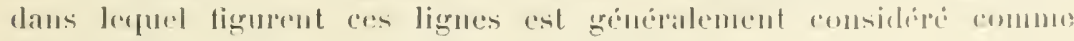
nporyphe.

(2) De inegenue Jonguent.

(3) Sortr lictolle. 
arrière de frise rouge. Louis Guyon alfirme quil en a vu un a Paris qui pesait 4 lives 10 onces. (L. Guron, Diverses leçons, I. II, ch. VI.) Dans les lariétés historiques publices par Fournier (t. IlI, p. 36), il est question également de ce bonnel.

"A la cocarde "vicul, sans doute, du vieux mot français coquenard qui signiliait niais, borné.

Le dessin du bonnet à la cocarde que nous a conservé Ambroise Paré - cest celui qu'on a sous les yeux témoigne de l'analogie évidente qu'il y a entre celte coilfure bombée, rouge en arrière et dont les deux brides, très larges à leur origine, se réduisent inférieurement chacune ¿̀ un cordonnet, et la roùte et les deux piliers ou appendices du diaphragme qui déeroissent progrressivement de volume à mesure quils descendent à droite et à gauche, le long de la colonne vertébrale.

\section{Les crémastères, comme une raquette.}

Les crémastères sont les muscles suspenseurs des glandes génitales, les agents du mourement d'ascension brustue de ces glandes (du gree xpsprox, je suspends). Les faisceaux musculaires qui composent chacun des deux crémastères naissent, à droite et à gauche, de la partie interne du pli de l'aine el se terminent en formant autour du testicule du mème coté une série d'anses dont la concavité regarde en haut.

En marge du chapitre xxvin du live V du manuscrit de la Bibliotheque nationale se trouve une liste de quinze phrases arec ce titre: Servato in-4 ${ }^{\circ}$ lib. Panoryium ad muplias, et parmi elles:

Les crémastires du taureau tant aimé de Pasiphaé (1).

(1) Pasiphaí, fille du Soleil, femme de Minos, roi de Crèle, et mère du Ifinotaure, monstre moitié homme et moitié taureau. 
"De bled en herbe, alprend Panurge à Pantagruel (l. III, ch. II), rous faictes belle saulse verde (1) qui dilate les rases spermatiques, abbrévic (2) les crémastires, cte. "
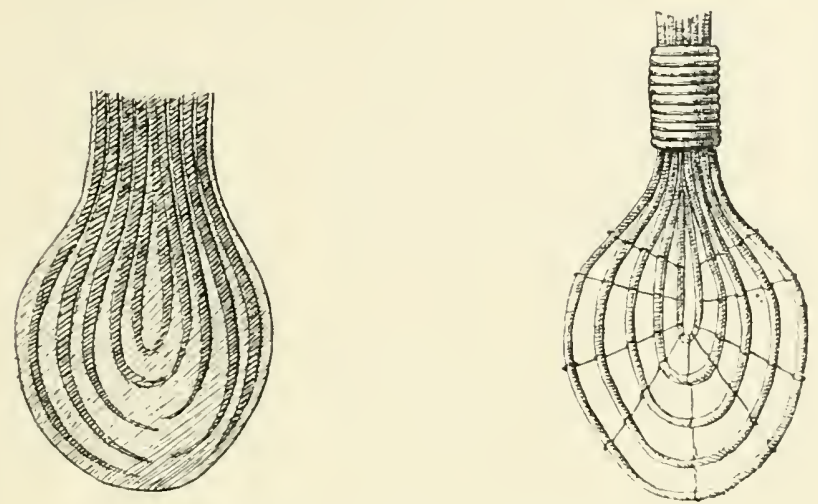

Les crémastères, comme une raquelle.

La raquelle (par corruption du latin reliculum, diminutif de rete, rets, réseau [Cazencuve]) n’a pas (hamgé de forme depuis longtemps. Elle dome non seulement une idée des contours et de lat lexture, mais encore des fonctions du muscle en question. Comme la balle, le volant, ete., s'élève et s'abaisse brusquement par le jeu de la raquette, ehaque glande spermatique s’élive et s'abaisse rapidement par le jeu de son muscle suspenseur.

Pantagruel a lait (I. II, ch. v) "le blason et divise (3) des licentiés d'Aurelians (4), disant:

Ln esteuf (j) en la braguelte (i),

En la main une raquette,

Une loi en la cornette,

(1) Verte, du latin viridis.

(2) Racenteit, du latin abbrevare, forme de bretis, bref, court.

(3) Devise.

(i) Orléins.

(5) Balle de panme, de bourre; du latin slupa.

(6) La bragnette s'entend anjourd'hui de louverture qui se trouve audevant du pantalen. Jatis cétat une piece de fee du harmais militaire, 
Lne basse danse au talon,

Vous voilà passé coquillon "(1).

Pirsiologie. - Chez un être rivant, les muscles, même à l'étal de repos, ne sonl pas complétement relithés. Cette tension permanente des museles, dite tonicilé musculaire, est sous la dépendance du șstème nerveux. Quand on coupe les nerf's du muscle qui lerme l'orifice inférieur de l゙intestin (m. sphincter de l'anus), il se distend tout à fait et laisse échapper tous les résidus de la digestion. Une émotion morale vive, surtout la peur, produit le même effet.

"Panurge esmeu (2), transit, tremblant, hors de propos, égratigné des gryphes du célebre chat Rodilardus, " s'échappe de la soute du navire où il s'était "musé (:3) entre les croustes, micttes et chaplis (4) de pain " pendant que les bombardiers (5) saluaient a coups de canon les muses de l'ìle de Ganabịn (6).

"Frère Jean à l'approcher, se sentoit je ne seay quel

située entre les denx cuissards et destince à protéger les organes génitaux ou une pièce cl'ćtotfe du vètement eivil, plus on moins large et plus on moins longur, adaptée aux hautes-chausses. (Toy. les personnages des Songes drolatiques de Panlagruel, imprimés en 1563.)

"Les chansses-hantes estoient si joinetes qu'il n'y aroit moyen de faire des poehettes. Yais, au lieu, ils portoyent une ample et grosse braguette yui avoit deux aisles aux deux costez, qu'ils attachoient aree des esguillettes, me de chaque costez: el en ce grand espace qui estoit entre les dittes denx esguiliettes, la chemise et la bragette, ils y mettoient leurs monchoirs, une pomme, une orange, on aultres fruictz. "(Louis Guyox, loc. cit. suprà.) La braguette a été appeléc aussi brayne, brayelle, gaudipisse, ete.

(1) Docteur' ; aiusi lénommé à cause du capuchon, cucullio. Les artistes donnent toujours le nom de capuchon, de fichu du dos, de muscle cucullaire, au trapize, le plus superficiel des muscles de la muque et te la partie supérieure du dos.

(2) Ėmu.

(3) Caché, retiré.

(4) Ce rue l'on ote de la croùte du pain en le chapelaut.

(5) Les gens qui tiraient les bontbardes.

(6) Ganabin, en hébreu signifie larons, voleurs. Au dire de mon sarant ami, II. Ducrot, lìle de Ganabin, c'est l'Angleterre, pays des Irafiquants dont le Dieu est Mereure, patron des volenrs. (Ducrot, loc.cil. supri, j. 22.) 
odeur aultre que de poudre à eanon. La vertu retentrice du nerf qui restraincl (1) le muscle nommésphincter - c'est le muscle de l'anus, - estoit dissolue ( 2 ) par la réhémence (:3) de la paour (4) que Panurge aroit eu en ses phantastiques risions. Adjoinct (5) le tomnoire (6) de telles canomnades, lequel est plus horrifique $(\bar{\gamma})$ par les chambres basses que niest sus (S) le tillac. Ciar un des symptomes el aceidents de paour est que par luy ordinairement soure le guischet du serrail onquel (g) est à temps la matière fécale retenue.,

Autres exemples:

"Messer (10) Pantolfe de la Cassine Senois" (11), dont les fonctions digestives s'accomplissaient mal, alla à la garde- robe, après s'ètre fait donner. pour épargner la speza d'un servitiale, la dépense d'un clỵstire. un grand coup de fourche " entre col et collet qui le jecta par terre a jambes rebidaines " (12).

"Edouard le quint (13), roy d'Angletere, aroit en si grande privaulté (1 /) reçen maistre Villon, banny de France, que rien ne luy celoit des menus négoces (15) de sil maison. Un jour, le roy susdicl, estant a ses alfaires (16), montra it

(1) Qui resserre, du latin restringere.

(2) Affaibli, du latin dissolulus.

(3) Lintensité, le haut degré, dn halin vehementir.

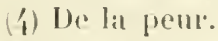

5) Joint, ajouter ì cela, du latiu auljunclus.

(6) Le tomberre.

(7) Effrityant, du latin horrificus.

8) Sur.

(9) Par lequel.

(10) Viemx not qui s'est dil pour Messire. La fonlaine a appelí l'estomat: messer Giasler.

(11) Le Duchat al décourent un Pambolfus Seneusis dans les Lethes de Louis .YII, 1. 111, 11. 267. Ouant an nonu de la Cassine, equivalant it

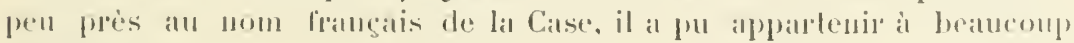
d'lliliens.

(12) Les jambes en lair.

(13) Le cinquieme, du lalin quinlus.

(19) Fantiliarité extrome.

(15) Mffiners, détaits, du latiu neyolium.

(16) I sallisfirre ses besolus malurels. 
Villon les armes de France en paincture et lui dist: Voids-lu quelle révérence (1) je porte à tes roỵs françois? Ailleurs n'ai-je leur's armoiries qu'en ce retraict icy près de ma selle perée. - Vous estes, respondit Villon, sage, prudent, entendu et curieux (2) de vostre santé! Et tant bien estes serry de vostre docte médicin Thomas Linacer (:3). II (4), royant que naturellement sus vos vieulx jours vous estiez constipé du ventre, of que journellement rous falloit un apothécaire, je dis un clistère, aultrement ne poviez vous esmeutir (5), vous a faict ici aptement (6), non ailleurs, paindre les armes de France... Et croy que si d'abondant (7) rous aviez ici en paincture la grande oriflambe $(S)$ de France, it la vue d'icelle (9) vous rendriez les boyaulx du ventre par le fondement " (10).

Le Martial des bords de la Vienne avait trop de bon sens pour approuver les excès studieux qui nuisent à l'action. Et, comme l'esprit ne saurait se développer et s'accroître que dans un corps sain, mens sana in corpore sano, c'est dans un heureux équilibre des fiacultés morales et des facultés physiques

(1) Respect, du latin reverentin.

(2) Soiguenx, du latin curiosus.

(3) Linacer, mort en 152', n'ayant pu itre médecin d'Édonard $\mathrm{V}$, el celui-ci nélant pas roi d'Angleteréa léporquedu bannissenent de Villon, il est rertain qüil y a ici confusion dans les dates el dans les personnages. In tel entretien a bien eu lien, mais antérienrement, entre Jean, roi d'Anglelerre, ef Hugues le Noir, dont les plaisanteries sont demenrées longtemps proverbiales. M. Léopolel Delisle l'a rehouvé daus mu manuswit du xur sicele de la bibliothicque de Tours : Exempla clericorum (Léopold Densse, Noles sur quelques manuscrits de la bibliothèque de Tour's, 1868, in- $8^{\circ}, 1$ ). 13).

(4) Celui-ci.

(5) Aller ì la garde-robe. Smat en anglais signifie saleté, ordure. Ainsi que le remarque Rabelais, la constipation est un des apanages de la vicillesse.

(6) Justement, en latin apte.

(7) En outre.

(8) Oriflamme.

(9) De celle-ci.

(10) L. IV, ch. Lxir. 
qu’il a cherché lidéal de l'éducation. Après l'étude, l’élère de Ponocrates s'exerçait le corps comme "il aroil son ane auparavant exeré ", course à pied, sauts de haies et de fossés, équitation, voltige, escrime, chasse, natation, canolage en Seine (1), chant, tire ì la butte et au papegai, etc., il n'élait rien que l'écolier ne fìt pour augmenter sa vigueur' physique. Le jeu des muscles, les mourements du corps et des membres ont été pour l'immortel écrivain une véritable mine à description. Il les a notés avee une de ees débauches de style qui lui sont familieres, et où il est vaiment prodigieux par l'abondance des mots et les tours du langage.

Les leçons du matin terminées, Ponocrales et Gargantua (2) " issoient hor's (3), toujours conlérants (4) des propos de la lecture el se desportoient (5) en Bracepue (6) 011 és (7) près, et jouoient a la balle, at la paulue, à la pile trigone (S), galantement (g) s'exereants le corps comme ils avoient les ames auparavant exereé. 'Tout leur jeu n'estoit qu'en liberté; car ils laissoient la partie quand leur

(1) Un sport doit itre un exercice de la somplesse, de la dextérité el de la foree des muscles de l'homme. Le canolage n'est en réalite un sport que sil y a mancure it la voile et à l'ariron. Rabelais l'a énoucé avint moi.

(2) Le ehapitre dont jextrais ees lignes (ch. xxul, l. I) est un te cenx qui ont filt dire it Guizol : "On ne mentendra pas sans étonnement nommer d'abopd Rabelais comme mu te cenx qui ont le mienx pensé ef le mienx parte en fint d'éducation, avaut Lorke el Roussesun. " La Bruyipe, Nisard, E. Clevalier, Geruzaz, M. Compayré, ote., ont exprimé sons me aulre lopme la mème opinion. (Geruzez, le Plulurque

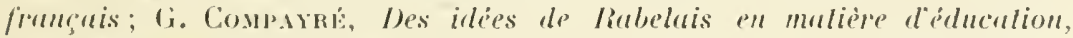
dans Mémoiress de lacudémie des sciences, inscriplions el belles-lellres de Toulouse, $7^{\circ}$ sírie; 1. Vill, Toulouse, 1866, p. 63 el suiv.).

(3) Allatient dehor's, sortitiont, du lation ire.

(1) Tratant, sentretenant, du latin conferre.

(5) Alliticul, se trimspurtaient.

(6) Jen de paume du fimbourg Saint-Matlean, à Paris, ayant pour cuseigne 11 chicn brapue.

(7) Ditus les.

(8) * Ce nom vient de ce que les joneurs étaient langés tringonenlemenl. " (Biblioplite Jacors.)

(9) Adroitement. 
plaisoit, et cessoient ordinairement lorsque suoient parmi le corps ou estoient auttrement (1) las. Adonc estoient tris bien essués (2) el frottés, changeoient de chemise, et doulcement se pourmenants (3), alloient voir si le disner estoit prest. " Après le repas ils se reposaient un instant, puis ils se remettaient à l'étude "pendant trois heures ou d'advantage", et de nouveau "issoient hors leur hostel, avec eux un jeune gentilhomme de Touraine nommé l'eseuyer Gymnaste (4), lequel lui montroit l'art de la chevalerie. Changeant doneques de restements, montoit sus (5) un coursier (6), sus un roussin (7), sus un genet (8), sus un cheval barbe (9), cheval léger, et lui donnoit cent quarrières, le faisoil voltiger en l'aer, lranchir le fossé, sauter le palis (10), court-tourner en un cercle, tant à dextre (1 I) comme à senestre (12)."

(1) Conlormément à celle recommandation d'lippocrate : "Un signe fuion s'est suffisamment exeré an gymuase, c'est la suemp " (Epid., I. V1), el it celle de Celse : "La tin de l'exercice doit ètre la snem", ou du moins une lassitude qui naille point jusqu'à la fatigue "(Trailé de méd., I. I, sect. 11). On devrait se sonvenir de ces recommandations dans nos gymmases.

(2) Essuyés.

(3) Se promenant.

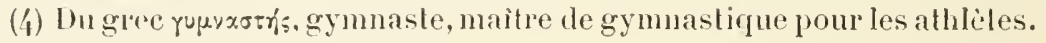

(5) Sirr.

(6) Cheval de hante taille.

(7) Cheral ćpais ef entier, propre aux royages et à la guere, de l'allemand, ross, cheval.

(8) Cheval entier l'Espagne de petite taille, lrès prompt à la comrse.

Talonne le genet et le dresse aux passades.

(Mathurin liéGNer, satire V.)

(9) Cheval de Barbarie, cheval léger. Le cheval arabe est encore préléré pour la remonte de la cavalerie légère.

(so) Le pien. C'est dn mot palus, pien - (des trois pieus qui marquèrent les limites du terrain sur lequel il a été bâti) - que le chàteau qui a ru naitre Henri $1 \mathrm{~V}$ a recu d'abord le nom de Pal el, par corruption, eelui de Pan cu'il a donné à la eapitale des Basses-Pyrénées. Les armoiries de la ville de Pau sont d'azur à trois pals. Dans les chroniques béarnaises, le chateau en question est appelé suecessivement Caslellum de Palo, Castrum de Palo, chàteau du Pieu, du Pal et tinalement chàteau de Pau.

(11) A droite, du latin dexler.

(12) A ganche, du latin sinister. 
Ensuite :

"De sa lance acérée verde (1) et roide rompoit un huis, enfoncoit un harnois, aculoit un arbre, enclavoit un anneau, cnlevoit une selle d'armes, un haubert, un gantelet. Le tout faisoil armé de pied en cap).... Estoit apprint ( 2 ) ì saulter hastivement d'un cheval sus l'aultre sans prendre tere; ;.... monter sans estrivieres; et sans bride guider le cheval à son plaisir.... Un aultre jour s'exeregoit ì la hasche.... Puis branloit la pique, sayuoit (3) de l'espée à deux mants, de l'espée bastarde (1), de l'hespagnole, de la dague et du poignand.... Couroit le eerf, le ehevreuil, l'ours, le daim, le sanglier, le liève, la perdrix, le lasisan, lotarde (5). Jonoit à la grosse balle, et la faisoit bondir en l'ater aultant du pied que du poing...

"Luctoil... D’un sault persoit (i) un fossé, voloit sus une haie, montoit six pas encontre $(7)$ une muraille, et rampoit en ceste façon i une fenestre.... Nageoit en profunde cau. ¿a l'endroied, à l'envers, de costé, de tout le corps, des seuls pieds, une main en l'aer, en laquelle tenant un livre transpassoit (8) toute la riviere de Seine sans icelluy (g) moniller, el tirant jar ses dents son manteau.... Puis d'une main entroit par grande force en un basteau d'icelluy se jectoit derechef' en l'eau, la teste la première; plongoit és (10) abysmes at goulphres. Puis icelluy bastean tommoit, gomvernoit, menoit hastivement, lentement, à fil d'ean, contre cours, le retenoit en pleine excluse (11), d'une main le guidoit, de

(1) Verte, du latin viridis.

(2) Appris.

(3) S'escrimail.

(4) Eque quon maniail a denx mains on it me seule matu.

(i) Lioutariale.

(6) Trarrersilil.

(z) Comlir.

(8) Trimmait.

(g) Coluti-ci.

(10) D):IIIs lins.

(11) linlusis. 
l'aultre s'eserimoit arec un grand aviron, tendoit la voile... "Jeetoit le dard, la barre, la pierre, la javeline, l'espien, la hallebarde...., bandoit ís reins (1) les fortes arbalestes de passe, affustoit le canon (2), visoit de l'arquébuse, tiroit à la butle, an papegai (:3) du bas en mont, d'amont en val, de costé, en arrière....

"On lui attachoit un cable en quelque haute tour pendent en (4) terre, par icelluy (5) arecques deux mains montoit, puis devalloit ( 6 ) si roidement et si asseurément, que plus ne pourriez parmi un pré bien égalé (7). On lui mettoit une grosse perehe appuyée à deux arbres, à ieclle (8) se pendoit par les mains, et d'icelle (y) alloit et renoit sans des pieds à rien toucher, qǜ grande course on ne l'eust pu aconceproir (10).

"Et pour s'exercer" le thorax et poulmon (11) crioit comme tous les diables.

"Et pour galentir (12) les nerfs, on lui avoit faict deux grosses saulmones de plomb (1:i). lesquelles il nommoit

(1) Tendait en contractant les muscles du bas du dos. (Pour arbaleste de passe, roy. Anatomie des formes: Le dors, comme nne arbaleste de passe.)

(2) Plaçait un canon sur son affùt.

(3) Oiseau de carton ou de bois peint plante an bout d'une perche pour servir de but.

(4) $\mathrm{A}$.

(5) Celui-ci.

(6) Descendait.

(7) Uni.

(8) A celle-ci.

(g) An moyen de celle-ci.

(10) Atteindre, attraper, du latin adconcipere, de capere, prendre.

(11) Poumon. Des recherches entreprises en 1878-1881, à l'École de gymmastique de Joinville-le-Pont, par Chassagne et Dally, il résulte que le thorax acquiert une amplitude consilerable quand on habitue les muscles préposés aux mouvements d'inspiration ì fonctionner avec énergie. Après plusieurs générations, le développement thoracique obtenu par un exercice continu du chant deviendrait mème, d’après M. Schmid-Monnard, un caractère de race.

(12) Fortifier.

(13) Sammons, du latin salmo; masses de plomb telles qu'elles sont sorties de la fonte. 
altires (1). Icelles prenoit de terre (2) en chascune main et les eslevoit en l'aer an-dessus de la teste, les tenoit ainsi sans soi remuer trois yuarts d'heure ou d'adrantage.

"Jouoit aux barres avec les plus forts. Et quand le poinct adrenoit (:2), se tenoit sur ses pieds tant roidement (4) qu'il s'abandonnoit és plus adventureux (5) en cas qu’ils le leissent mouroir de sal place, comme jadis faisoit Milon (6). A l'imitation duquel aussi tenoit une pomme de grenade en sa main, et la donnoit à qui lui pourroit oster...

"S'il adrenoit ( 7 ) que l'aer ( 8 ) fust pluvieux et intempéré (9)..... ils demeuroient à la maison et par manière d'apothérapie (10) après disner, en lieu (11) des exercitations (12), s'esbatoient à boteler du foin, à fendre et scier du bois et a battre les gerbes en la grange..."

Apress eette orgie de gymmastique où l'autemr de Crarganlua el de Panlagrael semble, non sans exces, avoil voulu domner au rorps une revanche sur l'ascétisme du moyen âge, on est étonné de lire encore dans le chapitre XIY du live V: "Les bons gentilshommes par raison de leur estat s'exerceoient a la volerie (1:3) et à la chasse pour plus estre en

(1) Alteres ou mieux hallipes flu latin halter. balancier de danseur de corde).

(2) Il prenait chacune de celles-ci.

(3) Artivitit, du latin advenire.

(i) Solidement.

(5) Aux plus forts, aux plus audacieux.

(6) Célibe alloble de Corolone qui lut sept fois vaingueur aux joux prlhigues el six fois amx jeux olympiques.

(z) Sil arrivit.

(8) L:air.

(9) Mauvais, froid.

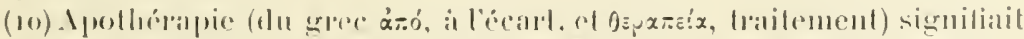

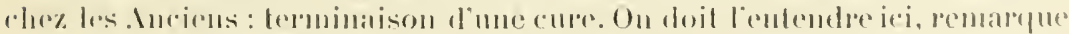

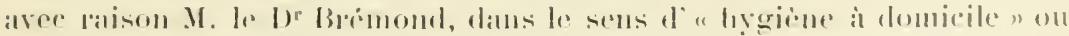

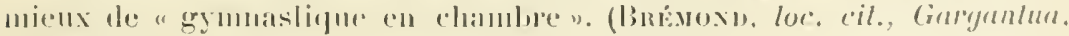
molo. 99.$)$

(11) A11 lien, "и remplateemont.

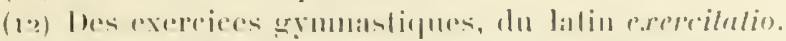

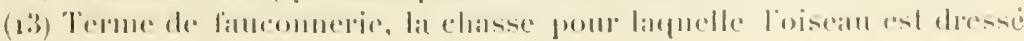


temps de guerre escorts (1) et ja (2) endureis au travail. Car renatio (3) est comme un simulachre de bataille, et oneques n’en mentit Xenophon, escripvant estre de la vénerie comme du cheral de Troie, issus touts bons et excellents chefs de guerre."

Rabelais ne s'est pas borné à montrer tous les avantages qu'on peut retirer de la gymnastique; il a fait pressentir aussi les inconvénients d'une trop grande sédentarité. Bridoye avone que "Fen M. Othoman Vadère, grand méticin, lui a dict que faulte d'excitation corporelle est cause unique du peu de santé et de brièveté de vie de touts ofliciers de juslice. " et les médecins de Pantagruel, immobilisé par des liens dans son berceau, préviennent son père "que si on le tenoit ainsi il seroit toute sa vie subject a la gravelle ».

¿ voler d'antres oiseaux ou quelque autre sorte de gibier : il a hanle el basse unlerie. - On appelait anciennement haule volerie la volerie du laucon sur le héron, sur les grues el sur les cautards; eelle du gerlaut sur le sacre et sur le milan, etc.; basse volerie, celle du laneret et du tiercelet du fancon qui volent la pie, la perdrix, etc.

(1) Avisis, prudents, de litalien scorto.

(2) Déjù.

(3) Vénerie, en latin venatio. 


\section{ANGÉOLOGIE OU ÉTUDE DES VASSEAUX}

Quaresmeprenant aroil:

Le cœur, comme une chasuble.

Le médiastin, comme un guodet.

Le rets admirable, comme un chanfrein.

Les vènes émulgentes, comme deux glyphonères.

Les artères, comme une cape de Biart.

Les vènes, comme un chassis.

Les adẻnes, comme une serpe.

Le sang bouillant, comme nazardes multipliées.

Le cœur, comme une chasuble.

Le cour, l'organe central de la circulation. C'est un muscle creux et d'un rouge foncé.

Lat chasuble est un ornement sacerdotal dont la forme s'est modiliée depuis le moyen àge. Jadis c'était mo especee de long sac brodé d'or, rouge ì l'extérieur, blanc ì l’inté-

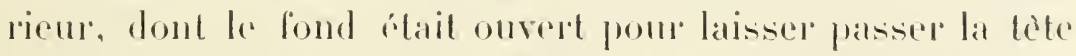

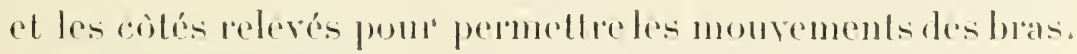
Elle se retommait et se portait le rouge on dehor's, le jour des feles des Mantyers. Les pans antérient et postérieur de colte chasuble, sontenus par les arant-bras fléchis, lappellent la forme du cour (1), el l'entre-croisement - obligaloire a

(1) La statue donl le dessiu occupe un des comprarlinemle de la planche explicative dale du $\mathrm{xrr}^{\mathrm{e}}$ sicele. 
un moment donné des cérémonies religieuses - des avantbras demi-fléchis, en avant de la poitrine, l'entre-croisement en $X$ des vaisscaux de la base du cour (aorte et artère pulmonaire).

Est-il besoin de dire que le dévotieux Quaresmeprenant devait aroir souvent les avant-bras demi-fléchis et entrecroisés en avant de la poitrine?
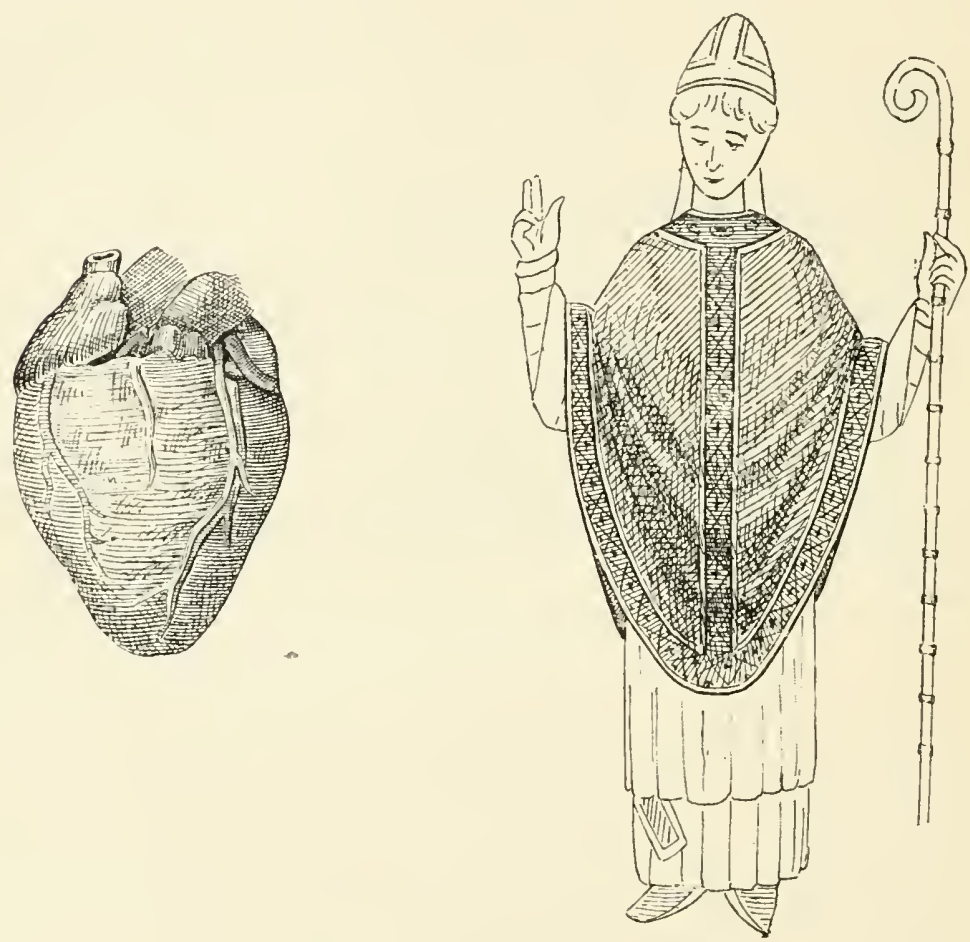

Le cour, comme une chasuble.

Le comr est renfermé dans une cnveloppe membraneuse appléée péricarde (1), fourreau, capsule du creur, xú̀sov (Ilippocrate), dans larpuelle il se meut librement el à laquelle il n'est raltaché que par l'aorte et l'artiere pulmonaire. Rabelạis en a parlé à deux reprises différentes.

(1) Du grec ris?, autour, el $\% x_{\varepsilon} \bar{z}: z$, cerur. 
Le coup de broche auquel succomba le rotisseur de Panmege pénétra " par à travers la capsule du cour ".

Toutému de la perte dı chevalier de Langey. Epistemon (1) murmure en sanghotant : "II m'en souvient et encore me frissonne et me tremble le ceur dedans sa capsule quand je pense és (2) prodiges tant divers et horrifiques (3) lespuels vismes eing ou six jours avant la mort du cheralier de Langey (4)."

Maitre Francois a eu également emre -- on le verra un peu plus loin - de la valvule "qu'est en la vène cave (j) on (i) lieu quelle entre le dextre ventricule (7) du coeur ".

\section{Le médiastin, comme un guodet.}

Le médiastin (S), la loge du cour. Ses parois sont constituées par les leuillets de la membrane, mince, transparente (la plevre) fui revèt la lace interne et la racine de chacun des deux poumons.

Dans le clos de l'abbaye de Seuillé "si personne tant

(1) Savant, du greec ériosuxı, je sais, je commais.

(2) Aux.

(3) Effrayants, remarduables, du latin horrificus.

(4) Lami et le protecteur de Rabelais, "lepuel an mont de Tarale ente Roanne el Lyon, - momml, le dixiesme de janvier, lan de son aige

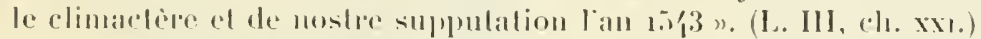

Le elimachere ou liante elimactepipue par excellence, dans les vieilles doctrines lalalistes madicales, est la neul fois seplieme on $63^{\circ}$ ammé do la

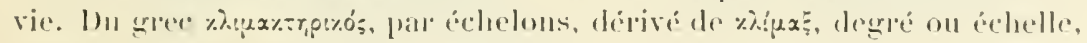
parece quion monte par degres ou échelons de sept an sepl pour arriver à lanmécelimatériqure.

(5) La veine cave inlériente.

(6) 111 .

(7) Le ventricule deoil.

(s) Ea latin mediustinus, linil de medium, milien. Il y a denx medialius:

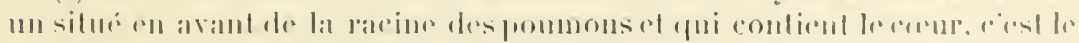

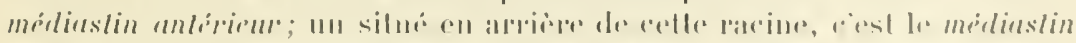

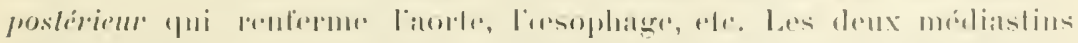

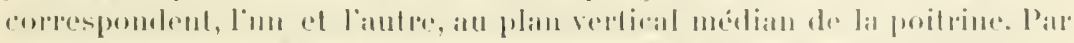

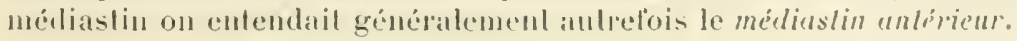


fut esprins (1) de témérité qu'il voulust résister de lace à Frère Jean, la montroit il la foree de ses muscles, car il leur transpercoit la poitrine par le médiastin et par le cœur"s.

Gruodel, "petit vaisseau rond, dit Furetière, qui n'avait ni pied ni anse et dont on usait autrefois pour boire; c'est la même chose que gobelet ".

"Enfants. buvez à pleins guodets, " lit-on dans le prologue du livre III.

La ressemblance du médiastin et d'un guodet apparait nettement sur la coupe transversale du thorax dessinée plus loin. (Toy. Splanchnologie, appareil respiratoire. La plève, comme un bec-de-corbin.)

\section{Le rets admirable, comme un chanfrein.}

Le rels admirable ou merveilleux est un réseau formé ¿ la base du cràne par l'anastomose des vaisseaux à sang
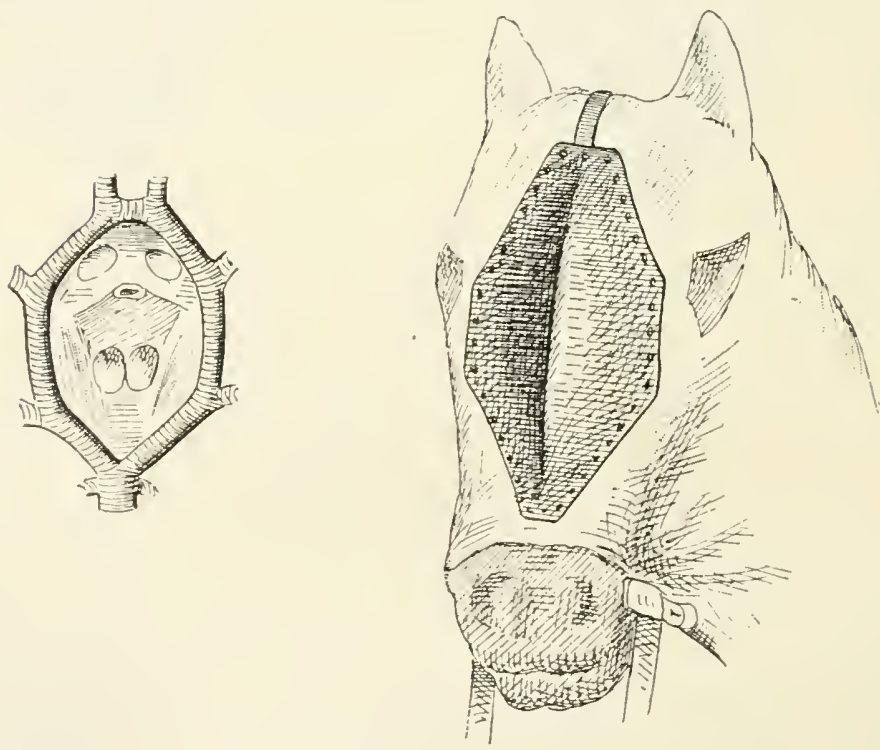

Le rels admirable, comme un chanfrein.

rouge qui se rendent au cerveau. C'est dans ce réseau que, (1) Pris. 
pendant quinze siècles, "les philosophes et les médicins ont affirmé les esperits animaulx sourdre, naistre et practiquer par le sang artérial puritié et afliné à perfection ". (L. III, ch. XIII) (1). D'où les épithìtes d'admirable, de merveilleux, dont il a été qualitié si longtemps. On l'appelle maintenant l'hexagone artéricl de Willis.

Chanfrein. Le chanfrein est une piece de fer qui garantissait le front, l'entre-deux des yeux et les narines du cheral de guerre.

A l'are triomphal dressé par Pantagruel, en mémoire de ses prouesses et de celles de ses officiers, étaient suspendus " une selle d'armes, un chanfrein de cheval, des esperons, ete." .

La comparaison de Rabelais raut celle de Willis (2).

Les vènes émulgentes, comme deux glyphouères.

Les vènes émulyentes, les veines des reins: du latin emulgere, épuiser à force de tires.

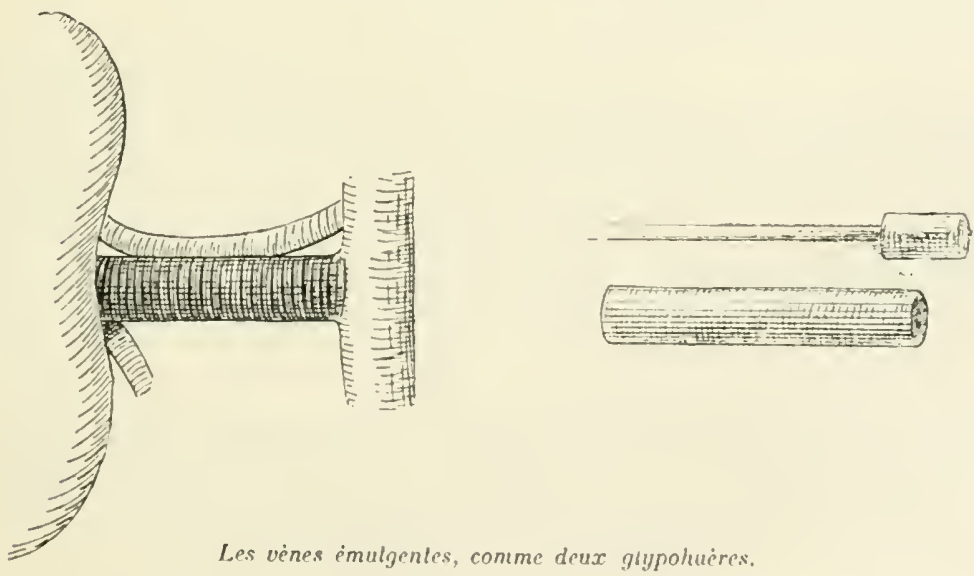

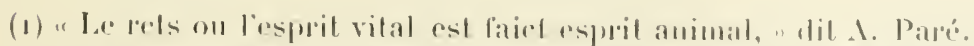

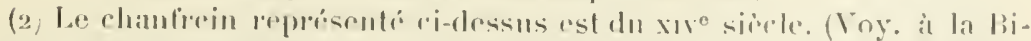

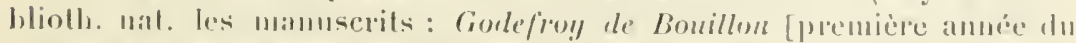

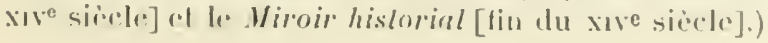


Glyphoneres, glyphoires. Dans la Touraine et dans le Berry on nomme encore glyfoire, glifoire, clifoire, et aussi fic-foire et flictoire, el, dans le bas Poitou et la Saintonge, flictocre une petite seringue liabriquée par les enfants avec une branche de sureau (1).

Les reines rénales ou émulgentes ont à peu près le calibre, la longueur et la forme eylindrique des glyphouères. Elles recoivent généralement les reines capsulaires moyennes. Dans la veine rénale gauche se jette normalement la veine spermatique chez l'homme et la reine utéro-ovarienne chez la femme.

\section{Les artères, comme une cape de Biart.}

Les artères sont les vaisseaux qui charrient le sang rouge du cour à tous les organes.

"Panurge dist à Pantagruel : le corur me bat dedans le corps comme une milaine (2). Touchez un peu mon pouls, en cesle artire du bras gausche $(3)$ : a sa fréquence et élévation (4), rous diriez qu'on me pelaude (5) en tentalive (6i) de Sorbonne ". (L. III, ch. Xi.)

(1) Glyphoneres, "Doculi feriu. On appelle, dit Le Duchat, clifoire en Anjou et à Bourges ce quon appelle à Paris une calonuiere et en Normandie me salpuebute, ce qui est un petit canon de surean avec lequel les pelits enfants ef les hadins jettent de l'ean an nez des passants. "(Voy. Mévage au mot Clifoire.) - "Létymologie que domne Le Duchat de ce mot, observent d'autre part, avec raison, Esmangart et Johanneau, est ridicule; glyphouere ou glifoire vient the eliquer en foirant; calomière est pour canomière, et saguebute vient te sayuer, tires, ef de but, tirer au but."

(2) Dans les anciemnes noees poitevines, les convives, arant de se. séparer, se frappaient à coups de poing avee les mains garnies de gros gants fourrés. Voy. les Vocés de Basché, 1. 1V, ch. xn. Dans le I'rinlemps de Jaeques-Hirer Pontevix, 11.380, Lyon, 1580, et dans le Grand Teslament de Villox, il est également lait mention de eet usage :

\section{Nitaines à ces nopees telles}

Bienheureux que rien ny a.

(3) Lartere radiale oì on palpe le pouts.

(Villow.)

(4) Toutes les inotions morales modilient le pouls.

(5) Houspille, dispute, contredit.

(6) Le premier acte (thèse) pour les grades de théologie. Allusion ì 
Cape de Biart, cape de Béarn, cape ì capuchon. Celte cape est presque toujours de conleur rouge. "Celle de la mère de ma bonne qui est née dans le village béarnais de Maumour étail rouge, ma écrit. le 28 mai 1898 , mon savant ami M. le Dr Dureau, bibliothécaire de l'Académie de médecine; celle de sa grand'mère et celle de son aïeul élaient également rouges. Maintenant le tissu de celle cape étant sourent à còtes, c'rst bien un système artériel." Un réeent royage que je viens de faire i Pau me permet de confirmer ces dires. Les Basquaises portent le foulard on le mouchoir, les Béarnaises la cape à côtes qui, de rouge qu'elle était primitivement, tend à devenir brune on noire.

La eape de Béarn a été injortée à la Cour de France par Henri IV.

\section{Les vènes, comme un chassis.}

Les reines sont les vaisseaux qui ramènent au cour le sang noir de tous les organes.

"Puisque de eestui endroict ne peulx sang de rous tirer, je vous saignerai d'aultre viene, "répond Panurge aux philosophe Troullogan. (L. HI, ch. xxxri.)

Chassis, "se dit d'un mélier"sur lequel a été tendue de la toile on de l'étoffe pour broder, ou des réseaux pour y faire des dentelles on antres ourrages. "(Furetiene.)

"Sans le pantagruélion (le chanre), de quoi feroit-on chassis? Comment somneroit-on les cloches? ete. "(L. Ill. ch. LI.)

Les vaisseanx sanguins et lymphatipues sanastomosent en formanl des réseaux à mailles plus on moins haches et plus ou moins larges. En anatomie on dit : un résean artéricl, veinens, capillaire, lymphatique, les mailles du lissll vasculatire, ete.

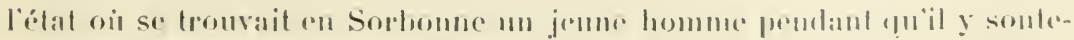
nail son premire acte de thrologir. 
Le réseau reineux apparaît seul a létat phỵsologique, sous la peau. On le voit nettement se dessiner sous forme de cordons bleuâtres plus on moins saillants, an pli du coude où on le saigne, sur la gorge des lemmes dont il rehausse la blanchemr de marbre. etc. Les varices sont
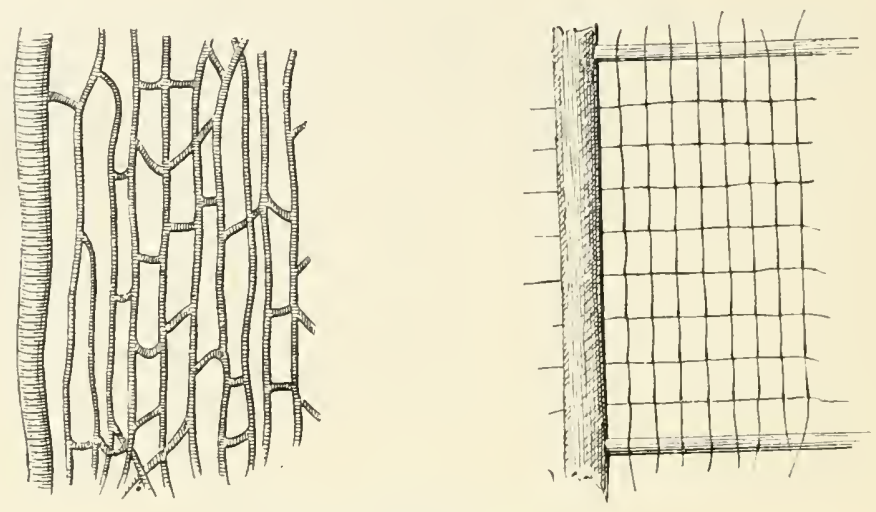

Les vènes, comme un chassis.

constituées par sa dilatation. A près la mort il est rempli de sang alors que les autres réseaux vaseulaires sont vides et qu’il laut les injecter pour les disséquer. Il est done plus facile ì voir que les autres réseaux et a été vu plus tôt.

\section{Les adènes, comme une serpe.}

Les adènes, les glandes du cou : adenes en latin et adenus en langue romane signitient glande du cou. En gree

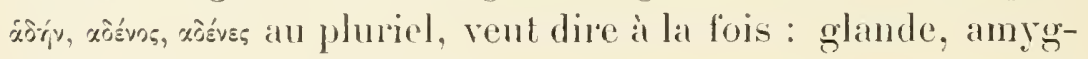
dale, tumeur glanduleuse.

Serpe, serpent et non serpe de vigneron, comme traduit Le Duchat. Serpent dérive du latin serpens, fait de serpere

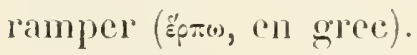

Du temps de Rabelais, la serpe pour tailler la vigne état appelíe sarpe (du latin sarpere, tailler la vigne, dont on a fait en basse latinité sarpa, outil qui sert ì couper des branches el de petits arbrisseaux). 
"Vous rous damnez comme une serpe (1) el estes larron et sacrilige." (L. Il, ch. xvir.)

Aussi seras-tu, beste immonde,

Damné comme une male (2) serpe.

Et je serai comme une herpe (3)

Situlvé en paradis gaillard.

(L. V, eh, XLvi.)

Un des quatre personnages envoyés par les Papimanes au-devant de Pantagruel était habilló comme un "vigneron d'Aurelians (4), aveeques belles guestres de foile, une panoire (5) et une sarpe à la ceincture (6)".

Les glandes du cou sont les amygdales, les glandes salivaires. le corps thyroïde et les glantes on ganglions lymphatiques. Il est question plus loin des anygdales. des glandes salivaires, du corps thyroïde et de son hypertrophic ou goitre et des délormations de la trachée qu'entraine celte hỵpertrophie. (Voy. Appareil digestil., Les amygdales, comme lunelles à un ceil; La salive, comme nne navelle, et Apparcil respiratoire, Le nou, comme un baril; Liaspre arlère, comme un gonel.) Il faut donc ententhe ici par adènes les ganglions lymphatiques cervicaux, mal dilférenciés, quand vivail Maitre Francois, des antres glandes ducou $(7)$.

(1) Le serpent qui a été l’agenut du péchó originel est un animal maulit dent la lenume ecrase la tete.

(2) Mauvais, malfaisiun, du balin malus.

(3) Harpe. "Lna ange me prendra entre ses bras, comme on tient une harpe, el en eet elat me porterat daus le paradis." (Le Dechot.)

(i) Orliaus.

(5) Holle ou corbeille de vendange.

(b) L. IV, ch, Ximir.

(7) Les trones de terminaison des vaissean lympladidues (canal tho-

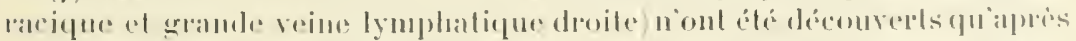

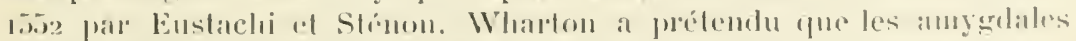

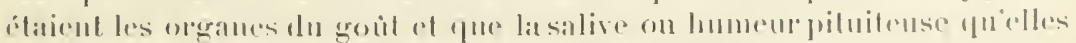

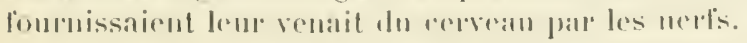

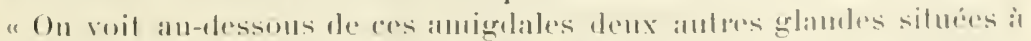

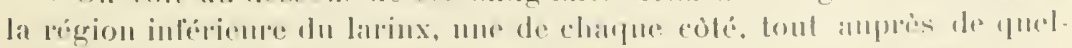

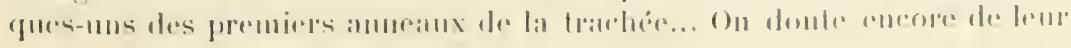


Ces ganglions engorgís forment une chaîne ou chapelet (chaine on chapelel ganglionnaire) dont les sinuosités et les bossclures rappellent celles du corpes d'un reptile en mouvement. La maladie connue sous le nom d'écronelles, d'humeurs froides, d'adénile cervicale chronique, que les rois de France avaient le don de guérir, prétendait-on jadis, par l'apposition des mains, est due à l'engorgement des ganglions susdits sous l'influence de la scrolule.
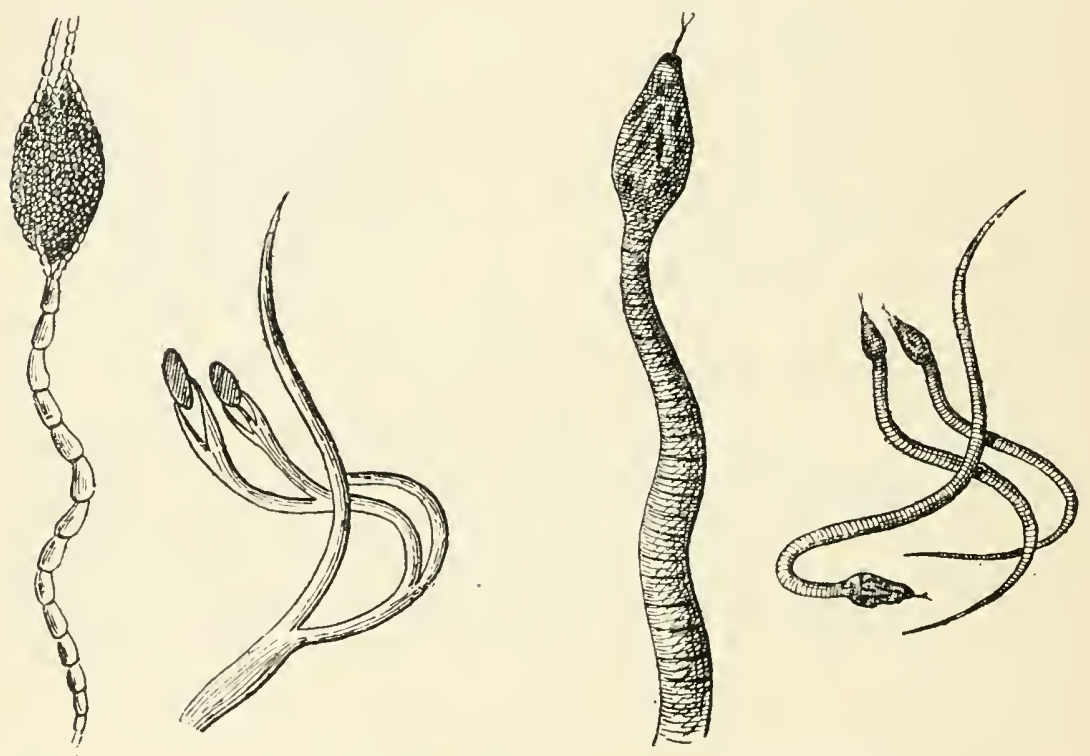

Les adines, comme une serpe.

"Vous en rostres royaulmes, dit à Pantagruel le capilaine des gardes du palais de la reine de la Quinte, avez

usage. Quelques-uns croirnt quielles sout destinćes pour aroser extérieurement le lariux d'une lumeur visqueuse et grasse, el rendre par ce moyen les cartilages plus disposés au mourement... Je crois qu'il laut plutol observel s'il u'n sort point quelques vaisseaux salivaires.

"Aupres de ces glandes sont les parotides, les glandes jugulaires et aussi les glaudes de la mâchoire situées sous la langue. " (Diemerbroeck, IAnatomie du corps hnmain. 1. II, p. 185 ; Lyon, 1729.)

Deusingius a avancé que la salive était versée des vaisseamx lymplıatiutues dans les glandes salivaires et de celles-ci dans la bouche. 
quelques rois, lesquels phantastiquement guarissent d'auculnes (1) maladies, (omme scrophule, mal-sacré (2), dicbres quartes $(\mathbf{3})$, par seule apposition des mains. Ceste (4) nostre reine de toutes les maladies guarit sans y toucher, seulement leur sonnant une chanson selon la compótence $(5)$ du mal.

"Puis monstra les orgues, destpuelles sonnant, faisoit ses admirables guarisons. Icelles (6) estoient de facon bien estrange. Car les tuyaux estoient de casse en canon (7), le

(1) Datus le sems de eentaines.

(2) De fout temps, plusicurs maladies, notamment les comvulsions, l'ŕpilepsie, l'hystipie, lo délire, la lolie ont efréconsidépées, les nues commo sacrées, les autres comme indiquant ha prise de possession du colps ef

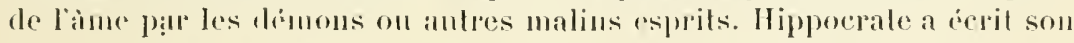
lean Traité de la maladic saerée pour combattre ce préjugé. On ne l'a pas

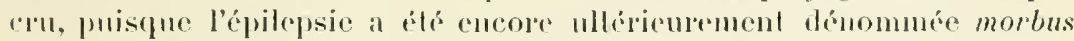
Herculeus (Aristole), morbus major (Celse), morbus divinus, morbus sacer. morbus de'moniacus, mal d'en hanl, haml mal, etc. Les Romains l'appelaicut morbus comitialis, parec qu'il lallait fermer les comices lorspue l’un des assistants tombait on comvulsions; cólait un sigme de la colère

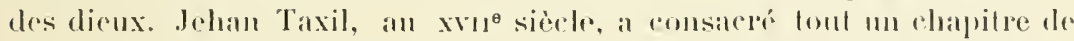
son live il promrer que les démoniaques sont des épilepliqunes. (Jemax Taxis, Trailé de lépilepsie, mahdie vulgairement appeló la gontefte anx

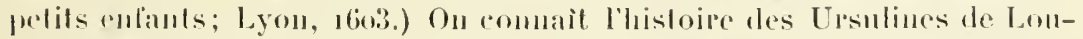

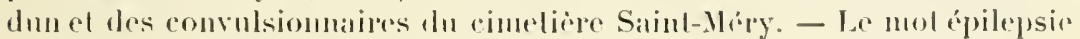
signitie "saisi d'on han ".

(3) Fievere indermitlentes, revenand tous les quatre jours ef tres dilficiles il gurririr.

\section{Quartunu te teneut. (Horack.)}

Que la fiblowe quartaine lesponse! (Main Comatror.)

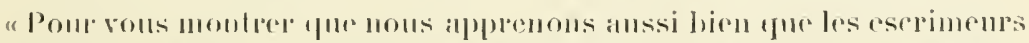

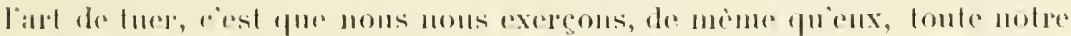

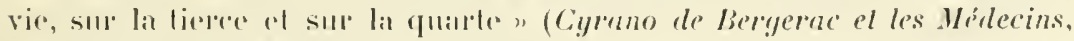
dans Chronique médlicale, juin 1898, p. 3\%2.)

(i) Cielle-ci.

(5) Nilure, comvenance, llu laliu compelere, comwnir.

(6) Celles-ci.

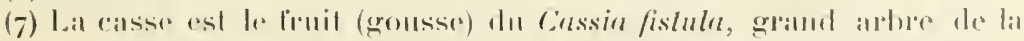

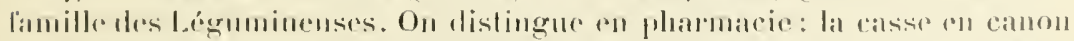

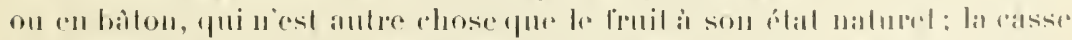

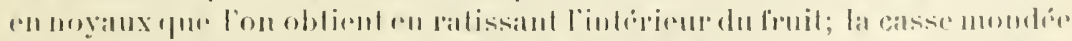

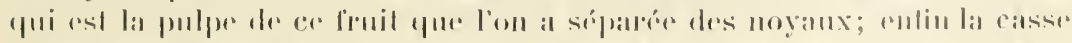

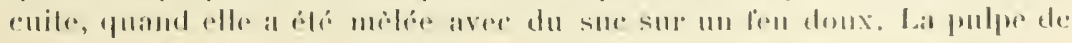
casse est legèment laxative. 
sommier de garac (1), les marchetles (2) de rheubarbe (:3), le suppied (4) de turbith, le clavier de scammonie (5).

"Furent les lépreux introduicts; elle leur sonna une ehanson: furent soubdain et parfaictement guaris. Puis les empoisennés; elle leur sonna une aultre chanson, et gents debout. Puis les aveugles, les sourds, les muts (6) et les apoplectiques de mesme. "

Quaresmeprenant était-il serofuleux? On l'admettrait d'aulant phus volontiers qu'avee son chapelet cervical ganglionnaire, son corps étique, ses boyaux rétrécis, il avait le ventre proéminent des enfants qui ont le carreau el les yeux chassieux. Ce qui est certain, c'est qu’il était syphililique. (Toy. Anatomie des formes: Il avait le ventre à

(1) Le gäac, Gruyacum officinale, arbre tle la famille des Rutacies dont le bois, léeorec et la racine sont employés comme sudoriliques et dépuratils.

(2) Les touclues.

(3) Plante de la lamille des Polygonées dont la racine a, selon la dose, un effel tonicue on purgatit.

(4) La prilale, du latin sub pede.

(5) La scammonée est me gomme-résine extraite du Convoleulus scammonia. Elle appartient ì la famille des Convolvulacées ef renferme un principe purgatil trés énergique.

(6) Muts ou mutes, muets, du latin mulus.

Remaryuons la composition de ces orgues:

Les hyanx estoient de casse en canon.

La casse était sous la domination de Jupiter ainsi que les còtes,lestomac, les intestins, les bras et le sang. (Voy. C. Agrupa, Philosophic occulle, 1. 1, ch. xxil.)

Le sommier de gä̈ac.

Le santal, l'ébène, le gayac étaient sons la domination de Mars ainsi que les veines, les reins, les fesses et le dos. Les vertus antisyphilitiques dr. l'hnile de gaĩac ont été décourertes en 1502 par les Espagnols, et le cribère gurrier Van-IIutten, guéri par cette huile, l’a recommandée dans un ouvage publié en 1519 qui a lait grand bruit en Europe. Le grä̈ac a élé appelé lignum vilie.

Les marchettes le rheubarbe.

la rhubarbe était sous la domination de la lune, aunsi que le cervean, le poumon, la moelle épiniere, les menstrues et tous les excréments.

Le suppieal de turbith.

Sagit-il ici dn turbith végétal, racine du Convolunlus turpethum, appar- 
poulaines; le mirach, comme un chapean albanois; les opils. comme un estui de peignes; le c..., comme un miroir crystallin.)

Quoi qu'il en soit, si on place - comme je le lais - le dessin diun reptile à cobé de celui d’un ganglion lymphatique cervical arec ses vasseaux afférents et efférents, tel quil est représenté dans un traité d’anatomie moderne, puis le dessin de plusieurs reptiles à còté de celui des " conduits lymphatiques et des glandes du col n, tels qüils sont représentés dams l'omvage de Jacpues Ilemri Pauli, e'est-àdire peu de temps apres la découverte du ranal llowacique. on sera surpris de roir yue, mème chez nn individu sain, la comparaison de Maîne Francois est exarte.

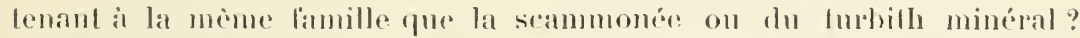
Cetle summération, qui ne eomprend que des phantes, domo lien do

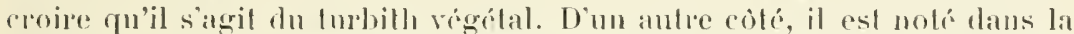
Jhilosopher oceulle d'Agriplas : que le tublh, composition alehimique de

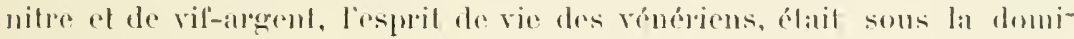

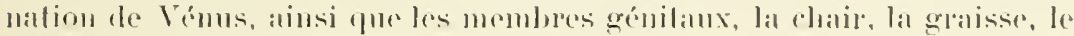
rentre, le nomblit, los sacrum et les lonules.

\section{Le clavier de scammonice}

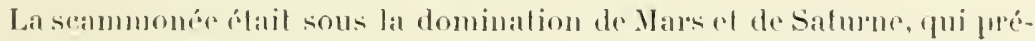
siclaient an foice el a la partie charmelle de la poitrine.

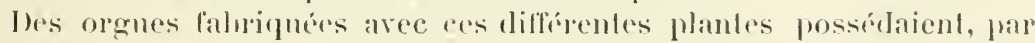

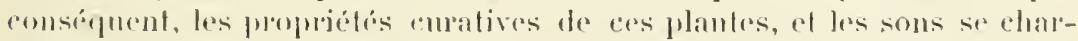

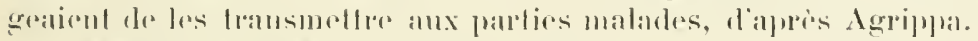

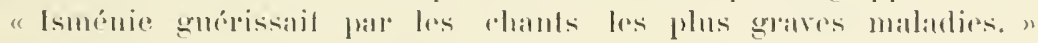

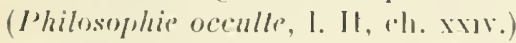

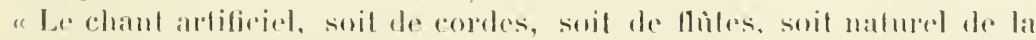

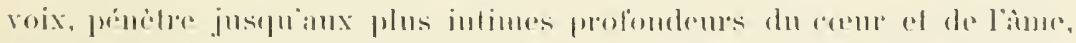

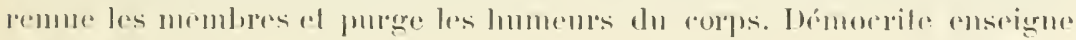

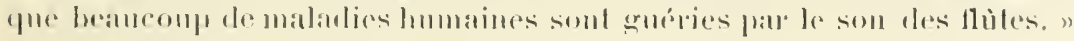
(Eorlem locos.)

Des flutes, dit Rabelatis, mais plus il y all a, mienx cela vanl : El ke

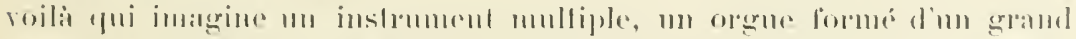

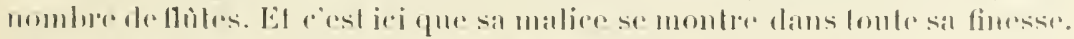

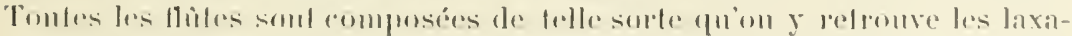

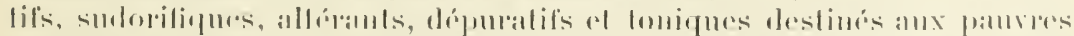

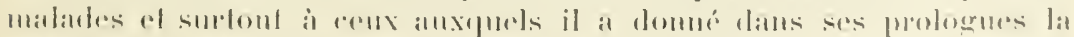

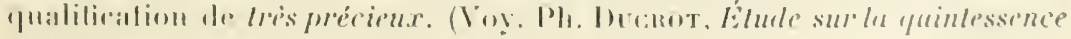
el lu mayir, lore ril. supri, 1, 16.) 


\section{Le sang bouillant, comme nazardes multipliées.}

Le sang, la chair coulante de Bordeu.

Vazardes, chiquenaudes sur le nez. C'est un homme à nasardes. qui mérite des nasardes, dit-on familièrement. Nasarder, donner des nasardes.

Dans les Enfers. "Tous les cheraliers de la table ronde estoient paures gagne-deniers, tirants la rame pour passer les rivières de Cocyte, Phlegeton, Styx, Acheron et Lethe (1). Mais pour chascune passade, ils n'en ont que une nazarde, et sur le soir quelque morceau de pain chaumeni (2)."

Que le ciel aftronlant, je nasarde la lune

(M. Régneit, Salire XI.)

"Les esprits animaux, selon la différence de leur monvement ou influence, dilatent, a noté Diemerbroeck, ou resserrent plus ou moins les orifices du ceur, e'est-à-dire de ses ventricules: d'où il s'ensuit que, daus les passions de l'àme, le sang entre plus ou moins facilement dans le ceur et en sort de mème, al e'est de lí que procèdent pour lors les différents changements des pouls; et que, dans les grandes terreurs, on sent des palpitations de ceur; dans la tristessè des constrictions avec un pouls petit; dans la joge une agréable chaleur aux environs du cour avec un pouls gai et vigoureux. " (Diemerbroeck, loc. cit. suprà, t. II, p. 62.)

Quaresmeprenant avait le pouls battant à petits coups

(1) Rivières ou plutôt fleuves des Enfers. Le Cocyle (du grec \%u»rós, pleurs, larmes, dérivé de roxúw, je pleure, je me lamente) étail formé par

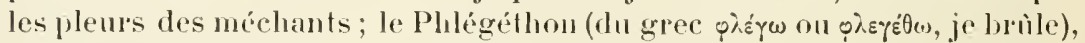
roulait des torrenls de llammes; le Styx faisail neul fois le tour des Enfers; l'Aehéron (du grec àxos, douleur, et fóos, tleuve) était le résultat du clangement en lleure d'Achéron, fils dn Soleil et de la Terre, qui avait fourni de l'eau aux Titans; le Lethé (du grec $\lambda r_{1}^{\prime} \theta r_{1}$, oubli) donnait l'oubli lu passé à cenx qui buraient de ses ondes.

(2) Pain dur et grossier, plein de chaume ou paille; du latin calamus. On disait aussi chaumoisi. 
d'un homme jeǹant depuis longtemps et "plourant les trois parts du jour" ".

Prissologie. - Dans le chapitre iv du live lli, qui est, on le sait, un résumé suceinct de la première thèse de lieence de Rabelais, on lit:

"La vie consiste en sang( 1 ) : sang est le siège de l'ame (:); pourtant (3) un seul labeur poine (1) en ce monde, cest lon'ger sang continuellement. En ceste lorge sont touts membres en office propre (.) ... Lia malière, et métal (b) convenable pour estre en sing transmuc ( 7$)$, est haillé (8) par nature: pain et vin. En ces denx sont comprinses (g) loutes espèces de alinents. Pour icelles (10) trouver, préparer et cuire, travaillent les mains, cheminent les pieds....

"Lappetil admoneste (1 1 ) d'enfourner viande. La langue en fay l'essay (12); les dents la maschent; l'estomaleh la recoit, digère et chỵlitie. Les vènes mésarärgues (1:3) en suceenteequi est bon et idoine (19), délaissent les excréments, lesquels pan

(1) Olez le sang, lis vie cesse.

(2) Onin anima in sanguine est. L'ime de la chair est daus le sange. (Lébitique, xvi, 2.) Empédocle a place le siege de lime daus le sang at Pline (Ilist. nut., l. 11, 1'h. 19) dins le cerme.

\section{Sanguinem vomil ille animam,}

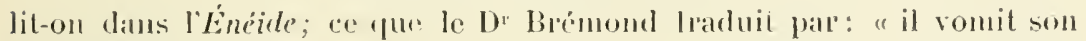
ìne lle sill1s. ")

(3) Pour cela, pour cetle latison.

(i) Prine.

(5) En ce labeur cliapue membre a son oftice propte.

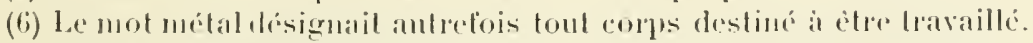

(z) Cinangé, du latin trensmuture.

(8) Dommé.

(9) Comprises.

(10) Cilles-ci.

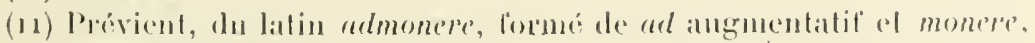
avertir; arertir lontement.

(12) La langure asl le principal organe du gonil.

(13) Les reines inlestinales conlenues dans lo mésention, du gree

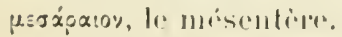

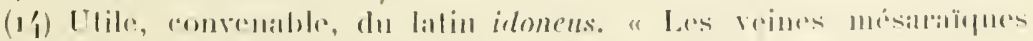

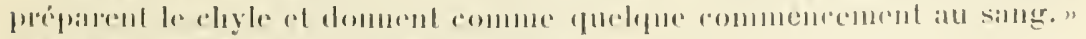
(Socragsos, Des parties naluelles, 16 , 
vertus expulsive sont ruidés hors par exprès conduicts (1); puis la portent au foye; il la transmue derechef $(2)$, el en faict sang (3)... Puis est transporté dans une aultre ofticine (9), pour mieulx estre aftinc (j) : cest le cour, lequel, par ses mourements diastoliques (6) et systoliques $(7)$, le subtilise of enflambe (8), tellement (g) que par le ventricule dextre (10) le met à perfection, et par les rènes lenvoge à touts les membres. Chascun membre l'atlire à soy, et s'en alimente à sa guise : pieds, mains, geuls, tout. Par le ventricule gausche il le faict tant subtile, qu'on le diet spirituel, et l'envoye a touts les membres par ses artères, pour l'aultre sang des vìnes eschauffer et esrenter (11). Le poulmon ne cesse

(1) Je laisse momentanément de cỏté tout ce qui a trait aux fonctions des autres appareils organiques qui seront étudiés plus loin.

(2) La transiorme, la modifie de nowveau.

(3) Pour Hipporate (1. IV, des Muludies), Platon (le Timée) et Aristole (ch. 11 de IIIsl. des anim.; l. II, ch. I, el 1. II, ch. 11, Des parlies des animanx), le sang blait engendré par le corm, et pour Galien (1. V, ch. xu et xris, et I. I, ch. Xvi de l'L's. des part.; 1. VI, ch. w et r des Sent. dHippocr. el de Plal.), Vésale, Columbus, Picolhominus, Carpus, Bauhin, Joubertus, et une infinité d'autres, tantôt par le foye, tantòt par les reines, tantòt par les deux. "L'action du foye est, dit Ambroise Paré, de tourner le chylus en sang: qui est la seconde coction. Car, bien que le chylus commence à prendre couleur de sang dès quil est tombé dans les veines misarairgues : toutefois il n'acpuiert point la vaye forme et hante couleu de sang tant quil ait esté élabouró an foye. "(Les OEures d'Ambroise Pare; Paris, 1658 , p. 11/.)

(4) Retraite, lieu, dı latin officina.

(5) Puritié.

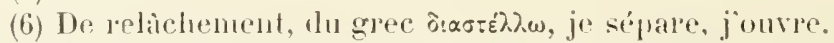

(7) De contraction, du grec oustè $\lambda$ io, je contracte.

(8) Lienllamme. Le ceenr était cousidéró jadis comme la source de la chaleur et de la vie. "Le cour est une carité sinueuse, a dit Pline (IIist. nal., 1. XI, ch. Lxix); en lui se trouve le premier foyer de la chateur et du sang; l’àme y réside. " - "Il est ridicule, a objecté Riolan à Guill. Harvey, de dire que le corur recoit du sang la chaleur et la vie, puisqu'il est luj-mime le foyer de la chaleur et de la vie, et que c'est de lui que tonte rhaten du sang résulte. " - " Le sang tombant dans les rentricules du corur y est enflammé et raréfié par le feu qui est naturel a ce viscère, "a écrit Franc. de Boë Sylvius. (Dispulal. med. Thesaur., 15-16.)

(9) Si bien, de telle sorle yut.

(10) Le ventricule droit.

(11) Suivant Galien, l'esprit du sanğ spriritueux (artériel) était formé 
avecques ses lobes et soulflets le refraischir (1). En recognoissance (2) de ec bien, le ceur lui en départ (3) le meilleur, par la vìne artériale (4). Enfin, tant est altiné dans le rets merveilleux, que par après (5), en sont faicts les esperits animaulx (6), moyennant lesquels elle imagine, discourt, jugge, résoult, délibère, ratiocine ( 7 ), et remémore (8)."

Sauf une omission fort importante, les lignes ci-dessus sont une sỵthèse parfaite de la théorie galóniste du cour's dı sang dans les vaisseaux. L'auteur n’a pas parlé des pertuis de la cloison interventriculaire au moyen desquels s'opérait, croyait-on antrefois, le passage du sang reineux du ventricule droit dans le rentricule gauche. Cette omission est-elle roulue ou involontaire? Elle est au moins singulière.

Comparons aux passagges de Rabelais que nous venons de eiter ceux du Christianismi restitutio (g), dans lequel Vichel Servet a fait la première fois mention de sa déeonverte de la circulation pulmonaire.

Michel Servet affirme positivement que: "L'esprit vital tire son origine du rentricule gauche du reour et que les poumons contribuent à sal perfection.... que les poumons au moyen de l'air inspiré donnent au sangr plus d'élaboration et d'allinement. "Il ajoute de plus que " le sang est porté

dans le renlricule gauche, el ce sang chtat seul propre "à la conservalion de la chalenr naturelle lluente ". - "Dans le ventrienle ganche, dit Dirmerluock, le sang se fermente de nouveau, se dilate, se reud spirituenx of

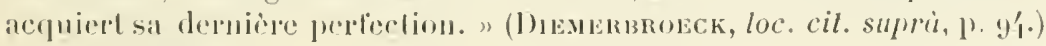

(1) Ratraichlil.

(2) Recommaissance.

(3) Lni en fournit, dn lalin purtiri, diviser, distribner.

(1) Artere pulnonaire.

(5) Quicusuile.

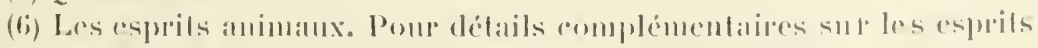
animanx ot vilatux, voy. plus loin Nérologyie.

(7) Raisonue, du latin moliocinari.

(8) Se rappelle, du litin rememoruri.

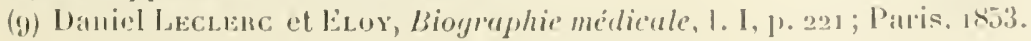


par la veinc artérieuse (1) du ventricule droit du coeur dans les poumons.... que les rameaux de la reine artérieuse le versent dans ceux de lartire reineuse (2) arec lesquels ils communiquent:..... que le sang est attiré de l'artère reineuse dans le ventricule gauche du cour dans le temps de la diastole ". Enfin " que l'esprit rital ou le sang affiné daus les poumons est distribué du ventricule gauche dans les artères de tout le corps, et que la portion la plus ténue passe vers les parties supérieures oì eet esprit de vital qu’il était commence à devenir animal."

Il y a certes loin de la physiologie de Rabelais a celle de Nichel Servet: "cependant on ne peut moins faire, observe M. le Dr Parquelin (3), que d'être frappé de l'air de parenté quielles ont entre elles tant au point de vue du fond que de l'expression mème.

" Michel Servet étudia d’abord le droit à Toulouse puis la médecine à Paris en 1 fäb et à Lyon en 153.5. époque où il publia une édition trés estimée de la géographie de Ptolémée. Quand il se rendit à Paris, il habitait Lỵon depuis plusieur's années, et par conséquent s'y trouvait en même temps que Rabelais y enseignait l'anatomie sur le cadare.

"Entin lo Christianismi restitutio a paru plusieurs années après Pantagruel. "

De ees domnées. M. Parpuelin roit avoir le droit de conclure sans trop s'avances que "Michel servet a été le disciple de Rabelais et que c'est à son enseignement rerbal ou écrit qu'il a puisé les notions qui lui ont permis d’apporter. son contingent de faits à la solution de la question qui péoccupait alors si vivement les esprits".

Parmi les raisseaux à sang rouge eilés dans Garyantua et Pantagruel, jai indirué l'artère pulmonaire, l’arlère

(1) Artipe pulmonaire.

(2) Veine pulmonaire.

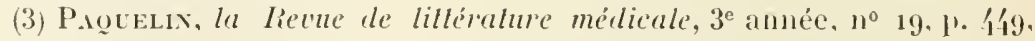
octobre 18,8 . 
radiale, l'hexagone artérel de Willis, et, parmi les vaisseaux à sang noir, les veines mésaraïques et les veines émulgentes.

Ce ne sont pas les seuls.

Dans la bataille de Lerné, "Fol'gier" alteinct Marquet de son libard (1) par la joincture coronale (2) de la teste, sur l'artere cootaphique (3) du costé dextre (1) n.

Fiòe Jean des Entommenres prisonnier "férul (5) de son bracquemart (b) l'areher qui le tenoit à dextre (7) lui coupant entièrement les vines jugulaires et artères sphagitides (S) aver le garbaráon (9) jusques és (10) deux adines n.

"Liestrange nativité "de Gargantua a fommi à Rabelais l'oceasion d'une description des veines cave supéricure el inliriener qui ramenent an ceur droit le sang impropre à la mutrition. "Des cotylédons de la matrice. par lestjuels sursaulta l'enfant, il cutra dans la vione crense (11), et glat rant (12) par le diaphragnie jusques au dessus des espantes ou la dicte vine se part ( $1: 3$ ) en deux, print (1 1 ) son chemin à gausche et surtil par laureille senestre (1.5). "

Les veines des oroganes de la génélation émanent des reines rénales ef eelles-ei de la reine cave inférieure qui se

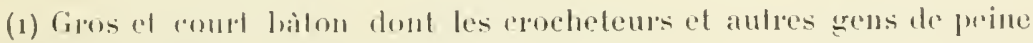
se servent ancore poul se reposer.

(2) Suture lionto-parićtale.

(3) Artine de la tempe, l'artire temporale, du gree «ótxogs, lempe.

(') Du còté diroit.

(5) Frappa, du latin ferire.

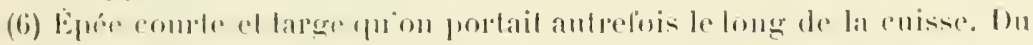

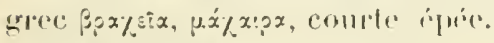

(7) 1 dinilie.

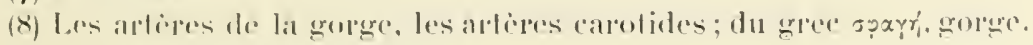

(9) Lal luelle, du greec raprapecior.

(II) A115:

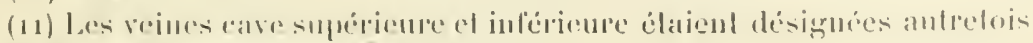
seus le mond do velue crease.

(s:) .loulanl, grasissaul.

(13) Sir diviser.

(1) Prit.

(1.i) Cialuelue, du latin sinisler. 
dégage dans le cour droit. La veine cave supérieure se dıvise en deux lones, dits trones veineux brachio-céphaliques, auxquels aboutissent les jugulaires internes et externes qui recoivent les veinules des oreilles.

Un corps étranger charrié par le sang de la veine cave inférieure ne peut parvenir à l'organe de l'ouïe sans passer par les poumons, le caur ganche et les artires du cou. Au xve siecle, avant la découverte de la circulation pulmonaire, on erovait le contraire. Gargantua, sorti du sein de sa mère, a donc cheminé d'abord, selon Maître François, dans une des veines utéro-ovariennes, puis dans une des reines rénales, la veine cave inférieure, l'oreillette droite, la veine cave supérieure, le tronc veineux brachio-céphalique gauche et l'une on l'autre des veines jugulaires qui en émane. Remarquons incidemment que le docte romancier a fait judicieusement s'engager l'énorme foetus dans le tronc veineux brachio-céphalique gauche, qui est plus large que son homologue du côté opposé.

Le savantécrivain a omis, il est rrai, les reines jugulaires, mais il en a parlé el précisé les rapports, je le répéte, dans le elıapitre XLIV du mème livee. Quant aux veines caves, il a connu non seulement leur's connexions, mais encor" leur structure, puisquil a signalé, on ne l'ignore pas (roy. le cour, comme une chasuble), la présence, à l'embouchure de l'une d'entre elles dans le coeur, de la valvule en croissant a laquelle Eustachi doit sa célébrité. Dans les tubes de la lontaine fantastique " il y a, dit Bacbue à Pantagruel, une quintuple infoliature mobile à chascune rencontre intérieure, telle quiest en la veine cave on (1) lieu qu'elle entre le dextre (2) ventricule du coenr" $"(3)$.

(1) Au.

(2) Ventricule droit, du latin deder.

(3) L. V. ch. xul1. 


\section{SPLANGHNOLOGHE OU ETUDE DES VISGERES}

\section{APPAREIL DIGESTIF}

TULE DIGESTIF

\section{Quaresmeprenant aroit:}

Les maschoires, comme un goubelet.

Les dents, comme un vouge. De ses telles dents de laitct vous trouverez une à Colonges-les-royaulx, en Poictou, et deux à la Brosse en Xaintonge, sus la porte de la cave.

Le palat, comme une moufle.

Le isthme, comme une portoire.

La luette, comme une sarbataine.

Le gaviet, comme un pelotoll d'estouppes.

Liestomach, comme un bauldrier.

Le pylore, comme une fourche-fière.

Les boyaulx, comme un tramail.

L'intestin jeun, comme un daviet.

L'intestin borgne, comme un plastron.

Le colon, comme une brinde.

Le boyau c..., comme un bourrabaquin monachal.

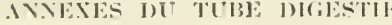

La salive, comme une navette.

Les amygdales, comme lunettes á un œil.

Le foye, comme une besaguë.

Le fiel, comme une doloire.

La ratelle, comme un courcaillet.

Le siphach, comme un brassal.

Le mésentère, comme une mitre abbatiale. 
Dans eelte énumération ne figurent pas l'oesophage ni le pancréas. Mais Rabelais a parlé incidemment ailleurs de l'osophage. Quant au pancréas, l'auteur de Pantagrenel n'a pu atlacher une grande imporlance à cette glande dont les conduits excréteurs ont íté découverts, chez l'homme, en 1622 par Wirsung, et les fonctions déterminées, seulement en 18 , s, par Cl. Bermard (1).

TLBE DIGESTIF

Les maschoires, comme un goubelet.

La cavité buecale limitée en haut par le voile du palais, en bas par la langue, en arrière par l'ouverture du gosier, peut ìtre comparée, quand les machoires sont rapprochées, au petit vase sans support et sans anses dont on se sert pour boire ou peur escamoter, faire des tours de passepasse.

"Pour rappareiller un gobelet d'or pour monseigneur d'Anjou, lequel gobelet estoit faict en manière d'un lonnel, etc..., 8 1. 1." Comptes d'Étienne de la Fontaine, 1.53.)

Panurge avait " lout plein de petits goubelets, dont il jonoit fort artiliciellement : car il avoit les doights faicts ì la main comme Vinerve (2) et Arachne (3), el avoit autrefois cric le thériacle (4)." (L. II, ch. xvi.)

(1) Ambroise Paré, qui en fail mention, avance quelle est siluéc " à lentonr de la reine porte pour lui êfe commo coussinet et consenvaleur deses divisions, en remplissant les varuiles qui sont entre icelles, el pour défondre que par violents momvements ou cheutes telles divisions ne soicul rompmes n.

(2) Minere, fille de Jupiter, déesse des beanx-arls el de la sagesse.

(3) Arachué. Très habile brodeuse qui fut changée en araiguce (en

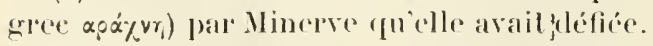

(1) Lil theriaque, solte lopiat composio de donze substances : le vin d'Espigne, la valíliane, les pribles de rose, lopium, le suc de reglisse, la chair de vipère, elc. La thériaque a élé doméc comme un spécilique 
Les dents, comme un vouge. De ses telles dents de laict vous trouverez une à Colonges-les-royaulx, en Poictou, et deux à la Brosse, en Xaintonge, sus la porte de la cave.

Vouge signific dard, pique, épien de chasse. Ce terme s'applique à la fois aux dents incisives et canines, pointues et lanchantes comme un dard et mue lance, el aux molaries massives, hérissées de cuspides (1) eomme un épieu.

La pirfue appelée vonge, qui est mne des phus anciennes armes suisses, a éle fort en usage autrelois. An xve siecle, il y a eu en liance tout un corps d’infanterie nommé voulgiers. Une vouge autrichiemne, datant de la .Jacpuerie (1620-16i.s) et fabriquée avec $u n$ soc de charrue, mesure to centimètres de longueur. (Collect. Az, à Lintz.)

Sus la porte de la cave. Rabelais entend probablement parler de dents d'animax fossiles qui, à son éporpue, servaient d'enseignes à des cabarets dans les deux localités qu'il désigne.

si les dents de lait de Quaresmeprenant ítaient si grosses, quelles dimensions devaient donc avoir celles qui les ont remplacécs? Prodigieuses! Apres lout, pourcjuoi pas?... Les jeǹneurs ont lesdents longues, dit un vieil adauge.

"Pour ceste hemre j’ai nécessitó bien urgente de repaistre, dit Panmoge : dents aigüs, ventre vide, gorge seiche, appétit strident, tont y est délibéré." (L. Il, ch. Ix.)

L'homme a plusieurs espiees de dents. L’illustre pomancier les nomme: Dans la lutle enlre Oudart el les ehicanons, un des recorts a " la mandibule smpérienre (:2) démanthée

contre tons les ventis. On la preparail jatlis solenuellenent. An the de Maitre Albertus (dont lat place Maubert, à Paris, porte encole le nom),

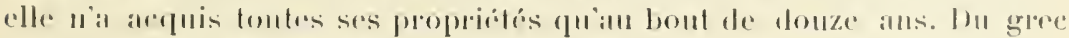

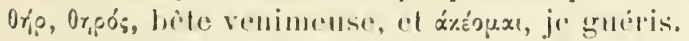

(1) I) latin resplis, pointe.

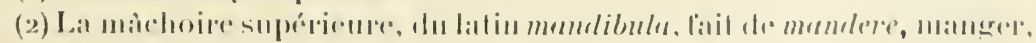
mikl|lere. 
de mote qu'elle lui courroit le menton is demi, aserepues dénudation de la hette ef perte insigne des deuts molares (1), masticatoires et canines. "

Les dents sout coustituées par une substance ossiforme, l'ivoire ou dentine recouverte d'émail. Lövoire est erensé d'une eavité qui eontient une matière pulpense dont les rannusenles vasculaires of les filets nerveux émanent des vaisseaux el des nerfs des màchoires.

"Entre leurs dents les ćléphants, dit Rabelais, ont deux grandes comes, ainsi les appelloit Juba (2); Pansanias (:3) dist estre cornes, non dents; Philostrate (4) tient que soient dents, non cornes : ce m'est tout un, pourru quentendiez que c'est le varai iroire (5)."

C'est de l'iroire; les dífenses des proboscidiens ue sont, en eflet, que des dents modifiées.

La matière pulpeuse des dents est très sensible et. dans la carie. son irritation par l'air on un corps étranger cause une doulenr insupportable. En nous racontant conment Gargantua mangea en sakade six pèlerins " et les dénigea (b) des moubles de ses dents " arec un cure-dent fait "d'un unyer grollier (7) ). Rabelais nous instruit également de cette particularité. "Par mallseur, remarque-t-il, l'un d'eulx, tastant areeques son bourdon le pars, ì scavoir s'ils estoient en seureté, lrappa rudement on la fautte d'une dent creuse, et lérut (\$) le nerf de la mandibule; dont feit triès

(1) Molailes.

(2) Nom de deux rois de Mauritanie, dont le secont, vaincu par les Romains, a cerit it Rome des ourrages sur lhistoire, la géographie, etc. Voy. Pline, I. VIII, ch. III.

(3) Puusaxis, dans ses Éliquues.

(i) Phllostrate, Fie didpollon, II, I3.

(5) L. V, ch, xxx.

(6) Dénicha.

(7) Noyer qui produit des noix ì coques dures quientament les corbeaux ou grolles.

(8) Blessa, du latin ferire. 
forte douleur à Gargantua, et commença à cricr de rage quil enduroit. "

Les dents apparaissent généralement du quatrième au dixieme mois apres la naissance. On observe poutant des cas dans lesquels elles se montrent ì une époque phus rapprochée (1). L'enfant dont la dentition est précoce est disldinaire plus robuste que les autres. Tel élait Pantagruel auquel encore au berceau "les dents estoient desja tant crenes et fortifiées, quil en rompit un morceau du grand tymbre de métal dans lequel on lui bailloit (2) sa bouillie ".

\section{Le palat, comme une moufle.}

Le palais on palal (palatus) forme la partie supérieme de la cavité buecale. Ciest moe sorte de vonte parabolipur limilér en avant ef de chaque coité par les arcades dentaires et continuée en arrière par le voile du palais.

"De l'eau fraische pour me gargariser le palat" (:3). demande Thammaste (4) an concierge de lhotel de Chum.

Moufle. Ciant d'hiver sans doigts séparés oul avec 111 doight séparé pour le pouce.

Cancier sil moutle

$$
\text { Prèl. alunt 1300, IV, İ. 136io.) }
$$

Blaies el chemises

Et moutles conltro la bise.

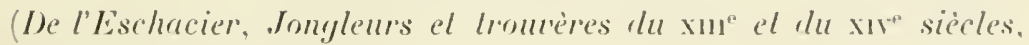
jublic par $\Lambda$. Jubinal, 1835.

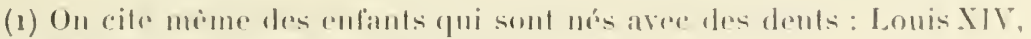

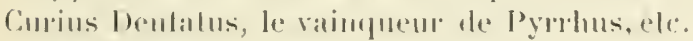

(2) Dommait.

(3) I. III, rh. XVIII.

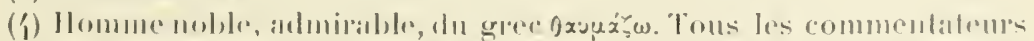

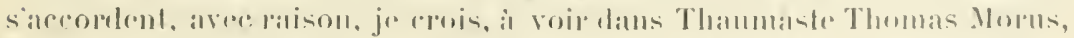

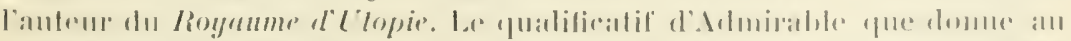

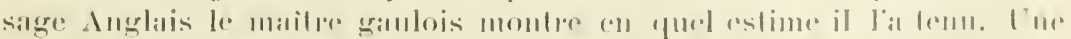

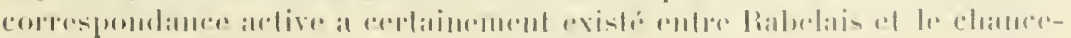


Pantagruel royant Panurge "igraligné des gryphes du cólibre chat Rodilardus (1), ne se put contenir de rire et lui dist : que rouliez-vons faire de ce chat? - De ce chat, respondit Panurge : Je me donne au diable, si je ne pensois fue fust un diableteau à poil follet, lequel nagaires j’avais capiettement (2) happé en tapinois a belles moulles."
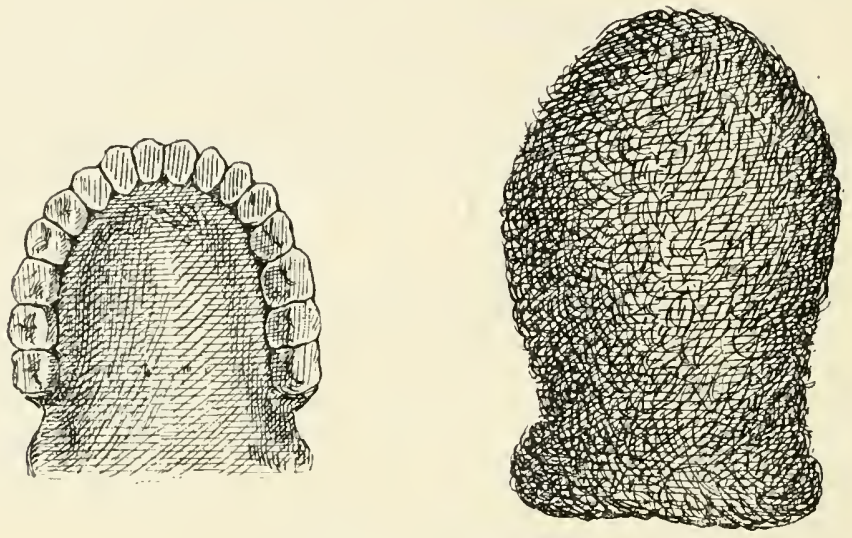

Le pulul. comme une moufle.

An xve siecle, on donnait igalement le nom de monlle ou miton (fausthandschuh, en allemand, mitlen ou inarliculed guantlet, en anglais) an gantelet sans doigts séparés. L'armure de Jeanne d'Are du catalogue de Dezest, la statuette en bronze de Guillaume IV (140/-1/17) à Amsterdam, et l'armure de Frédéric I ${ }^{\mathrm{er}}$, palatin du Rhin, conservée à la collection d'Ambras à Vienne, démontrent que partout le miton étail en usage dans la première moitié du $\mathrm{xv}^{\mathrm{e}}$ siècle. Ainsi que le gant d'hiver, il a la forme du palais.

lier d'Angleterre. Le livre de T. Morus, De optimo reipublica slalu, deque nova insula Llopia, a été publió à Lomvain en 1516. Maitre François n'a pas emprumbe à ce livre te nom seul du pays sur lequel a régné Gargantua. Il lui a emprunté aussi cette généreuse humanité de Grandgousier à l'égard de Picrochole et surlont le hean discours de Gargantua aux vaincus. (L. I, clı. L.)

(1) Ronge-lard, du latin rodere, ronger, et lardum, lard. Ce mot, que La Fonlaine a emprunté à Rabelais, paraît aroir été forgé par Élisius Calentius. (Voy. P. Jove, les Illusl.)

(2) Furtivement. 
Le isthme, comme une portoire.

Le isthme, "l'embouchure des chasse-trappes gutturates (1) ", l'entrée du gosier, du pharynx. Le mot isthme (isquós en greec) signitie une pétite langue de terre situéce entre deux mers.

"L’isthme du gosier", dit Thérenin, est situé entre la bouche et le pharynx comme entre denx mers (2)."

C'est un orilice limiti en haut par le voile du palais. latéralement par les piliers antérien's de ce voile: cu bas par la base de la langue.
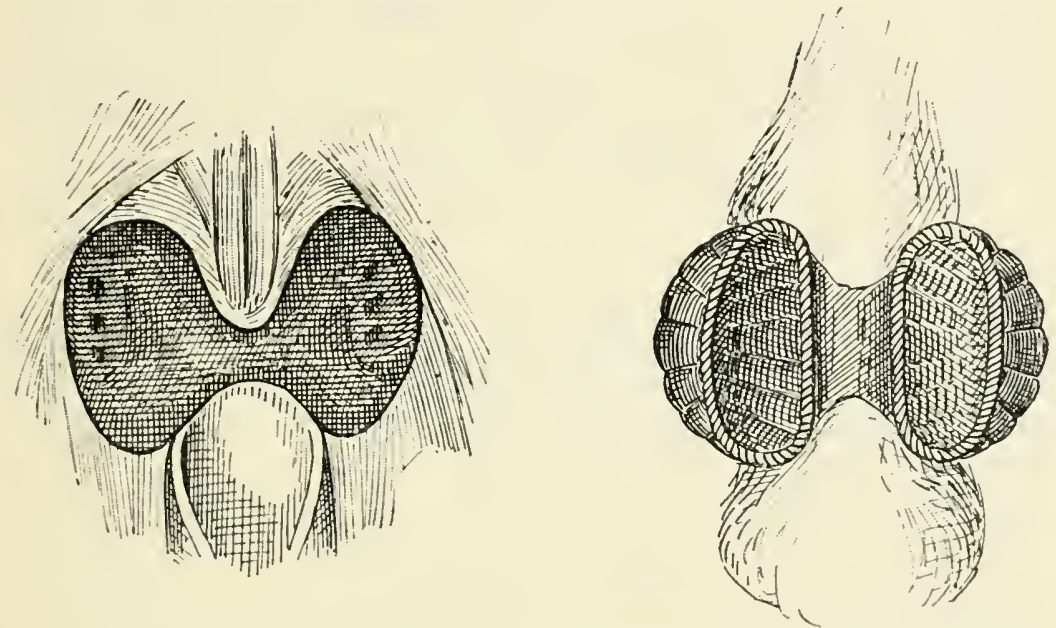

Le islhme, romme une portwire.

I'ortoire, portonoire, portoëre. Lal portoire est une holte de vendangents, un panier cintré à dossier plat. Dans les pays montagnemx, on se sert de panier's on de barpuets de

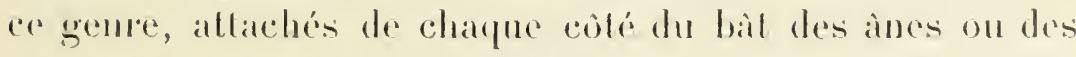
mulets pour porter des fardeaux.

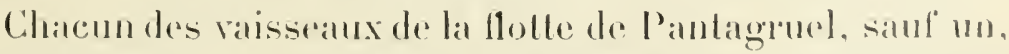
- le second, - qui avait me lanterne pour indiquel que

(1) L. I1, eh. хиा.

(2) Thivisin, bicl. des mols grees en médecine. 
cette flotte devait passer par le pays de Lanternois (1), avait pour divise (2) un objet cher à Bacchus : le premier une bouteille, le troisième $\mathrm{m}$ hanap, le quatrième un potet à deux anses, le cinquième un broc. le sixième un bourrabaquin monachal (:3), le septième un entonnoir, le huitième un gobelet. le neuvième une brinde (4), le dixieme une breusse (5), le onzième " une portoire d'or faicte à la mosaïque ", le douzième un barrault (6). "De mode que persomne... royant ce noble convoi de navires en leur's divises: ne dist que les voyagier's ( 7 ) estoient touts bureurs. "

"La vis du pressoir montré par Gagne-beaucoup a Pantagruel et a ses serviteurs (8), s'appeloit recepte (9); la met (10), despense: la croue (11), estat; le tesson (12), deniers comptés et non receus; les fusts (1:3), souffrance; les béliers (1/1), radietur; les jumelles, recuperetur (15); les cuves, plus valeur: les ansées (16), roles; les foul-

(1) Ciest La Rochelle, la patrie de Xénomanes, Jean Alphonse le Saintongeois; cest le pays de Maillezais, du savant éveque d'Estissac. C'est là que se troure le château de Légugé oi Rabelais a lu il longues gorgées a la dive bonteille de la science, en compagnie de Pierre Lamy, de Jean Bouchet, de Tiraqueau, de Barthélemy de Sałignac.

(2) Derise, embleme.

(3) Voy: plus loin: Le boyan c..., comme un bonrabaynin monachal.

(4) Voy. plus loin : Le colon, comme une brinde.

(5) Grande tasse.

(6) Mesure de liquide du Langnedoc contenant vingt-sept pintes.

(7) Les royageur's.

(8) L. I, eh. xy.

(9) Recette (du latin recepla, sous-entendu formula: formule reçne du médecin), ce qui est reçu en argent on autrement.

(10) Le conduit par où s'écoule le vin, dı latin meatus. En anatomie, on donue encore le nom de méat urinaire à l'orifice externe du canal de l'urèthre.

(11) Léerou, de lallemand schraube, vis; fait de schranben, fordre, tourner. Les Anglais disent screw (Le Duchat).

(12) Liarlure.

(13) Les fìts, du latin fustis, qui signitiait proprement bâton à frapper les criminels.

(14) Les dewx arbres qui en forment le fint.

(15) Terme latin de droit ainsi que le précédent.

(16) Vajsseaux à anse, du latin ansa, sorte de deni-couvercle atlaché à un pot, à 1111 sean. à $11 n$ panier, elc. 
loires (1), acquits: les hottes, validation: les portoires, ordonnance valable; les seilles, le pouvoir'; l'entonnoir', le quitus."

Chez les gens dont la luette est rudimentaire ou n'existe pas, - ce qui est l'exception, - l’isthme du gosier pessemble a lourerture d'une portoire, chez ceux dont la luette est bien développée. ì une couple de portoires vue dien haut.

\section{La luette, comme une sarbataine.}

La luette doit son nom a la ressemblance qu'elle a arec 111 grain de raisin allongé (du latin uea, d'on l'on a fait d'abord urette, ensuite, en préposant l'article, l'uvette, puis luette). C'est un petit corps charnu, cylindrigue ou conoüde, suspendu a la partie moyemne du bord postéro-inférieur du voile du palais.

"Pantagruel bailla (2) au roi des Dipsodes (3) et des Géants une boite pleine de euplorbe (4) et de grains de coecognide (j). confiets en ean andente (b) en forme de composte (7).... Mais lout soubdain qu’il en ent avalé une

(1) Instrunents pour louler, ol ansisi grands cuviers.

(2) Dotili1.

(3) Altílecs, dit gree ół $\alpha$, soil.

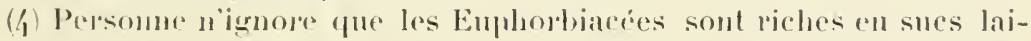
teux dont les proprictés soit purgatives, soil cansliques, soit à la fois

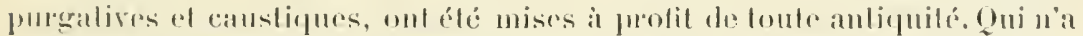

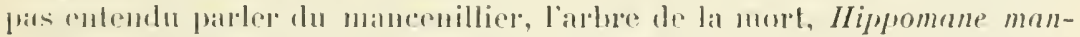

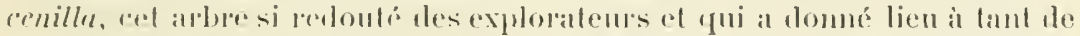

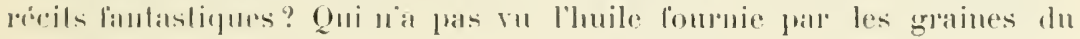
ricill?

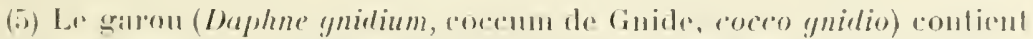

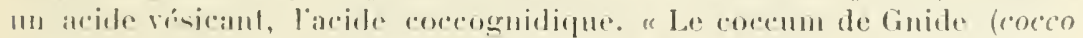

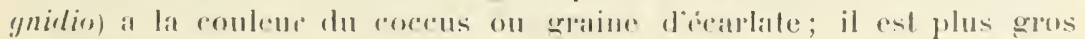

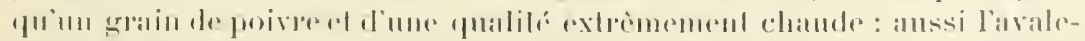

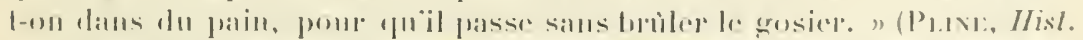

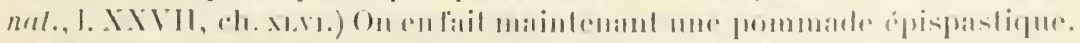

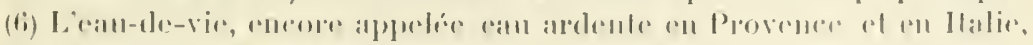

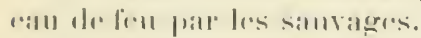

(7) Complote, contilure, du latin composilu. 
cueillerée, lui vint tel eschauffement de gorge avecques ulcération de la luette que la langue lui pela."

La sarbataine, encore appelée sarbarean, sarbatane, sarbacane (1) (de l'italien cerboltana, mot lait de Carpi, lieu où l'instrument était labriqué, et du latin canna, roseau [A. Demmin]), est constituée par un tube aree lecprel on lance de petites balles en terre en soufflant par un des bouts. Elle est encore employée aujourd'hui pour chasser les petits oiseaux (2). Comme arme de guerre, elle a servi à lancer des fliches empoisonnées, le feu grégeois qui s'en behappait en traits de fusées, et de petites balles appelées dragées.

Comme la sarbacane n'est qu'un simple tube de verre, de bois ou de métal, yui varie seulement par la longueur et par l'épaissemr, je crois inutile d'en fournir un dessin.

\section{Le gaviet, comme un peloton d'estouppes.}

Le gaviel, le gavion, le gosier, l'arrière-bouche, le pharynx.

Littré s'exprime ainsi à propos de ee mot: "Origine inconnue, la forme la plus ancienne est gosilier, primitif gosil. En patois lorrain on dit gosse pour gosier, d'où le verbe gosser, gosser un dindon. "- "Gosse, ajonte le même auteur, pourrait bien ètre le primitil de gosier, mais d'ou vient gosse?"

Diaz le fait venir du latin canus, creux. Dans Du Cange, on trouve gaviette pour gosier ou jabot. Craf en wallon et gave en picard signifient jabot, gosier. Dans le Roman du Renard, qui est très vraisemblablement du xur ${ }^{e}$ ou du xrI ${ }^{e}$ siècle, on lit aussi gave pour gosier.

(1) Le mot correct est sarbatanne. "Le changement du $t$ en $c$ s'est accompli en raison de la ressemblance quon a remarquée entre cet instrument et une camne. "(Lıtтré, Dict. élymol. de la langue frunç.)

(2) La sarbacane moderne est sourent formée par des roseanx vissés bout is bout. 
Un de mes amis, agrégé de l'Université, philologue très érudit, élève de M. Gaston Pàris, a ru successivement employer gave, gaviot, gaviete, gaviette, gavion, gosil, gosilier. gouzier pour gosier.

Les lignes ci-dessons justitient cette assertion :

"Telles ulcires souvent commencent par les gencives et. cheminent jusqua an palais et entin gaignent juspues a la luette ef gavion." (A. Parć, XI, 17.)

\section{..... Damoiselle Ade}

La fille le Roy est malade,

Il a passé huit jour's entiers

Que ne pot boirre ne mangiers,

Quar une aresle de poisson

Lui aresla an gavion

Or est li Roy si corociez.

Sill la pert ne sera pas liez (1).

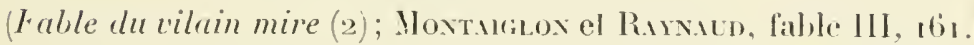

Les mules (3) an talon,

Le pelit eancre (1) au menlon,

La male (j) toux an poulmon (b).

Le catarhe au gavion,

Le gros hroncle $(z)$ an eroupion.

(RinzFa.tss, Prologue du 1. IV.)

"Du stomach vient el n'est mu panicle (s) qui monte

(1) (iali.

(2) Mire, mỵe, chirurgien plutòt que medecin; celui-ci se nommail

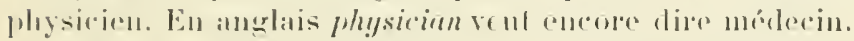

(3) Des imploules, des gemores, des angelums. Suivant le Durbal.

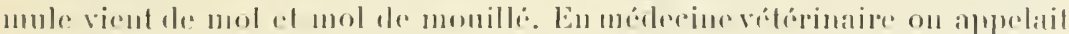

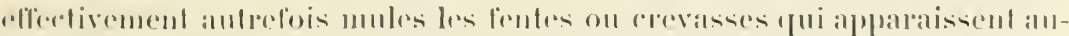

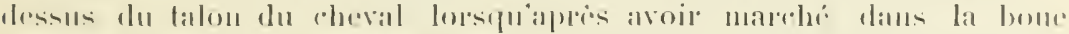

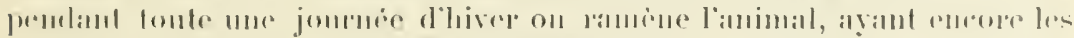

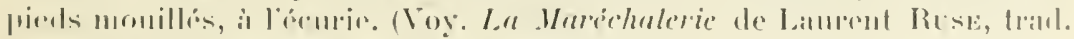

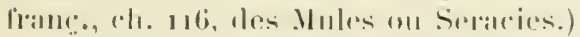

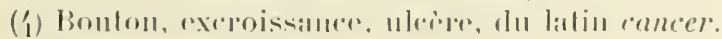

(5) Nouration, du litliu malus.

(6) Poll III0).

(7) Finnuele.

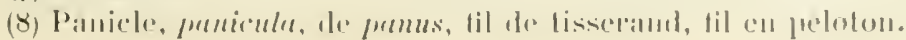


par le gosilier, lequel gosilier est dirt ysophage. " (H. DE Mondeville.)

Qu'on n’aille pas induire de ces dernieres lignes à une erreur anatoinique de ma part. Le pharynx a été longtemps confondu avec l'aesophage sous le terme générique de gula.

En résumé, le pharynx (cn grec qúporš, arrière-bouche) est une espèce de vestibule membraneux commun aux voies digestives et aux voies respiratoires, situé entre la cavité buceale et la eavité nasale, d'une part, et l'oesophage et le larynx, d'autre part. Il a la forme d'une demi-gouttière ouverte en avant. Il est constitué par une membrane muqueuse, une membrane tibreuse. des muscles intriqués, - prodigieusement multiphés par Sautorini, rayomnant dans divers sens, et par un tissu cellulaire filamenteux, très làche, qui u'est jamais graisseux, jamais intiltré de sérosité.

C'est ì sa structure si compliquée que le pharynx a dù, sans doute, d'itre comparé prar les anatomistes du moyen àge à un panicle, un peloton d'estouppes, etc.

De ce que l'auteur de Garganlua s'esl servi dans sa litanie anatomique du mot gavict pour désigner les parties situées immédiatement en arrière des piliers du voile du palais, il ne s'ensuit pas qu’il ait ignoré les noms de ees parties.

La deseription lanlastique de la bouche et de la gorge de Pantagruel et une remarpue de Bacbuc (1) (I. V, ch. xhir) aux royageurs qui lui rendent visite sont tries instructives à cet égard.

"Je cheminois dans la bouche de Pantagruel - raconte le spirituel écrivain, - comme l'on faict en Sophie $(2)$ à Constantinople, et y vid de grands rochers, comme les monts des Dannois, je croi que e'estoient ses dents.... de fortes

(1) Mot hébrenx qui signitie bouteille, on y troure une onomatopéc.

(2) Sainte-Sophie. 
et grosises villes, $n o n$ moins grands que Lyon ou Poicticrs, Aspharage (1), entre autres. Je délibérai d'y aller et la tronvai belle, bien forte, et en bel aer', mais à l'entrée les portiers me demandarent mon bulletin (2), de quoy je fus fort esbahi, et leur demandai : "Messieurs, y ha il ici dangier" de peste? - O Seigneur, dirent-ils, l'on se meurt ici auprès (3) tant (9) que le charriot (5) court par les rues. Vray Dieu, dis-je, el où?" A quoi ils me dire que éestoient en Laringues et Plaringues (6).

" Ha, dist Bacbuc, voilí que c’est non considérer en soy, ne (7) entendre les mouvements que faict la langue musculeuse (8), lorique le boire dessus coule pour descendre non ès (9) poulnons par l'artère inéguale $(10)$ comme a esté l'opinion du hon Platon, Plutarque, Macrobe of aultres. mais en l'estomarlh par l'oesophage."

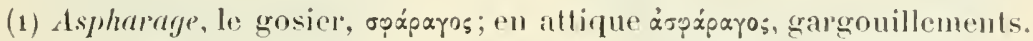

(2) Ce bullodin s'appelle anjomidluni patente : palente brute, patente suspecte, patente nelle, suirant que les mérlecins denos lazarets aflirment, soupromuent on nient l'existenes diune maladie contagicuse chez les gens "qüils sont charges de visiler. "Falloit que les soldats fussent visités pal" les médecius pour voir sils estoient malades et quils cussent toujoms sur cux leur patenle pour laire foy, signé de son capilaine af de son modecin. " (Bnastome, Rodomonlades espaynoles.)

(3) lei jurs.

(i) Tellement, daus de lelles proporlions.

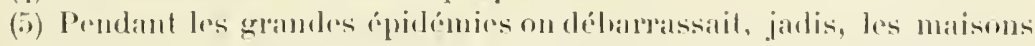

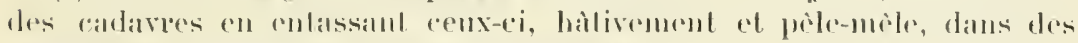
voilues pui circulairnt i travers les pues.

(6) Dans le phatryx et le lanymx.

(7) Ni.

(8) Gallien (Liv. des alim. de bon.el méch. suce, ch. w), liolan (Anthropo-

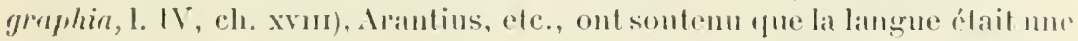
glande. Jul. Casserius Placent. au Liv. de lorgane du goul, ch. r, a alpelé la langue " non pas a la rérité un musele, mais me fandio musculense ". Ce nest done pas sills raison que Rabelais a parlé incidemmenl iei des mouvenents de la langue et de sal musculalure.

(a) Dans les poumons.

(10) La trachese-artiere. (Voy. Aprareil mespiratoiro, Lisspre arteren comme un youel.) Ilippoerate la llomme: la vectrice des boissons, 


\section{L'estomach, comme un bauldrier.}

L'estomac est la portion du lube digestil' qun lait suite $\therefore$ l'esophage. C'est une raste poche membraneuse, logée dans la partie supérieure dı ventre, au-dessous du diaphragme et du foie. "Laxe ou le grand diamètre de l'estomac est, observe Sappey (1). oblique de haut en bas, de gauche i droite et d'avant en arricre. Mais cette obliquité est peu prononcée, et l'on peut dire d'une manière générale que la direction prédominante de cet organe est à la lois transversale et horizontale. "
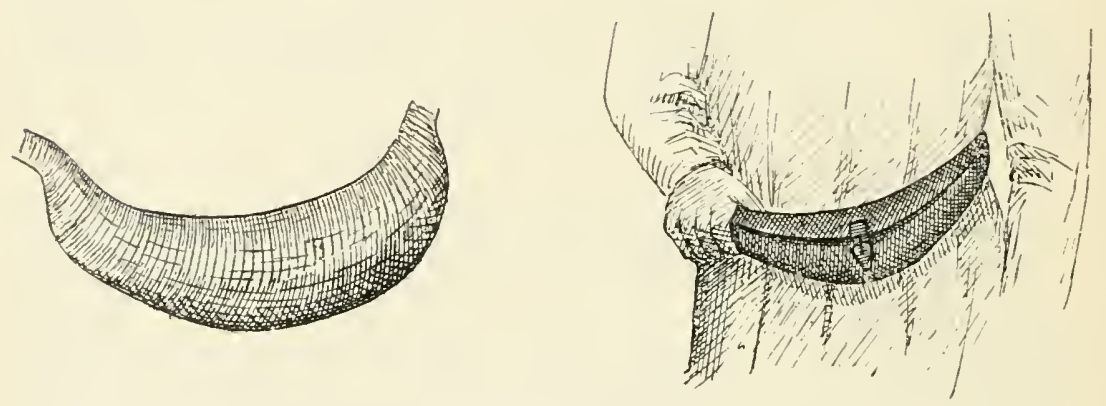

L'estomach, romme un bualdrier.

Bauldrier, bourse de cuir plate. en forme d'écharpe, qui se portait enroulée autour de la taille. Les habitants de nos campagnes usent encore d'une bourse analogue.

Bien faschés d’avoir si mal employés l'argent de leur bauldricr. (Braxtóne, ch. I, t. IV, p. 31.5.)

Pendant le débat entre les fonariers de Lerné et ceux dupays de Gargantua, Marpuet appela Forgier en lui promettant des fouaces.

"Lor's Forgier en toute smplesse (2) approcha, tirant

1) Sapper, Traité deanatomie descriplive, I. III, p. 95; Paris, 1857-186\%. Ciest aussi lopinion de Muf. Reynirer, Souligoux, ete. (Voy. Bull. de la Soc. anat. de Paris, 1891 , 1. 7og.)

(2) En toute simplicité, en toute contiance. 
un unzein (1) de son bauldrier, pensant que Marquot lui deut dépescher (2) de ses fonaces: mais il lui bailla de son fouct si rudement à travers les jambes, que les nods (?) y apparaissoient. "

"Frère, dit un des chicanous à Trudon, je te donnerai unes belles, grandes, vieilles lettres royaulx que jai ici en mon bauldrier. " (L. IT, eh. XV.)

I iestomac occupe la mème situation, a la mème direction que le bauldrier. Il en a presifue la configuration el les dimensions chez wn homme comme Quaresmeprenant, cmacir par des jeùnes prolongés et répétés. Sur sa face antérieure, on distingue une bande museulaire tres aceusion, dite cravate de Suisse: qui rappelle le bol'd inférieur saillant de la valve qui forme le hauldrier en avant.

Dans le chapitre xum du live IV, Rabelais a comparó aussi, comme on le lait aujum dhui. l'estomac it me cornentuse.

\section{Le pyIore, comme une fourche-fière.}

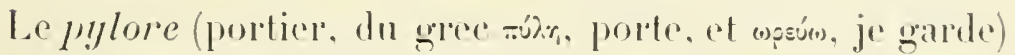
est l'orilice quil l'ait communiquer l'estomac avee l’intestin. Cet orilice est garni dime valrule qui ressemble tantòt au diapluagme diun instrument d'optique ( 1 ), tantot. mais plus rarement, ¿̀ un croissant à concarité supérieure (.).

(1) Le errand biune, onze deniers, du balin undecim, dix plus un.

(2) Dits sempresser de lni dommes.

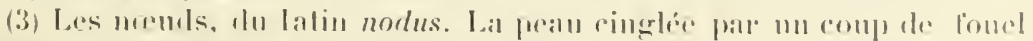

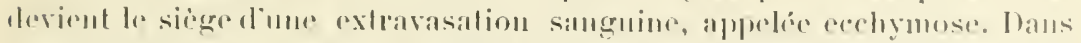

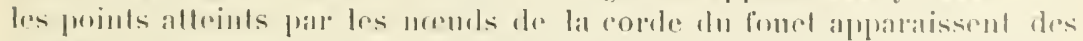

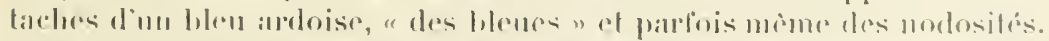

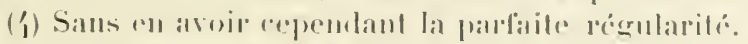

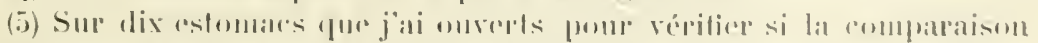

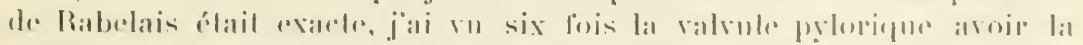

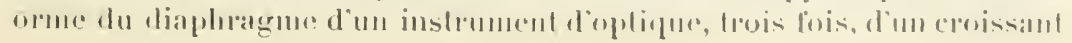


La valvule pylorique parait avoir pour usage d'apprécier le moment où les aliments sont assez modiliés dans leur consistance ef leur composition chimique pour pouvon passer de lestomac dans l'intestin.

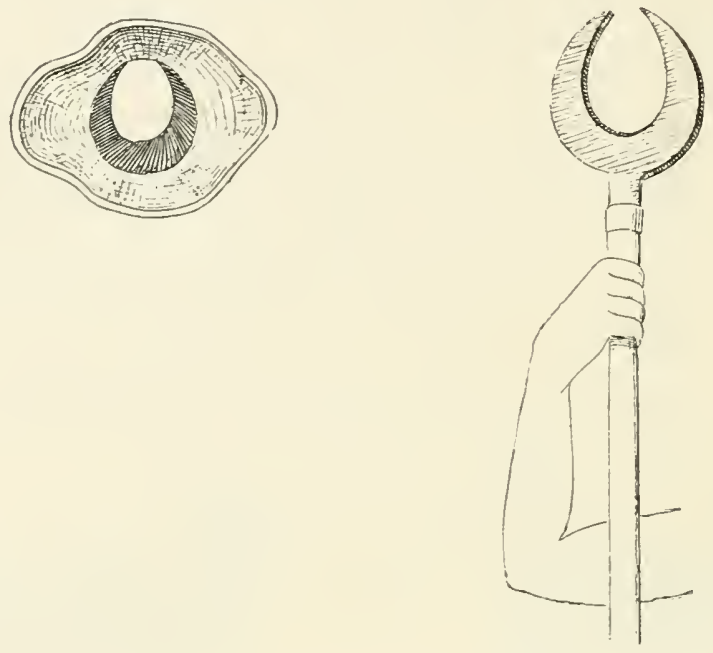

Le nylore, comme une fourhe-fière.

Fonrche-fière: fourche-forréc - on tiérée, eomme on disait aulrefois, - a deux ou trois dents. Le mot fier vient par corruption du mot ferré. Les poètes burlesques appellent to trident de Neptune une fourehe-fière. Dans les anciennes gravures, Neptune et Pluton sont représentés tenant a la main, le premier, une fourche-liere a trois dents, le second, tune fourche-fière ì deux dents.

La fourehe, qui n'est plus qu'un outil d'agriculture, a clé une arme de guere (military fork en anglais, sturmgabel

dont la partir moyenne était plus ou moins échancréc et regardait en haut; une fois. diune cloison semi-londe dont le bord supérienr liorizontal correspondait au diametre transverse de lintestin. La comparaison de Rabelais ne sapplique donc pas a tous les cas. N'en soyons pas surpris. L'auteur de Garyantua n’a pas eu à sa disposition assez de cadaves pour se rendre compte des rariations quoffrent les divers systèmes organiques. 
en allemand) qui a commencé à apparaitre vers la tin du $\mathrm{Xv}^{\text {e }}$ sièce. On trouve à l'arsenal de Genève des fourches d'échelles d'escalades prises anx Savoisiens en rboo. La fourche de guerre est aussi mentionnée dans les récits du siège de Mons (16gi), ou les grenadiers de l'ancien rrigiment Dauphin, commandés par Vauban, emportirent d'assaut un ourrage fortitié et saisirent les fourches des Autrichiens. Ciest mème depuis cet acte de bravoure que les sergents de ces grenarliers ont en le droit de porter mo fourche a la place de la hallebarde. Dans la collection Az. ¿ Lintz, figure une fourche de guerre trident du xry siè

Une aquarelle de Cilockenthon, exécutie en 15oj diapris mature (Arsenanx de Maximilien ler), domne me idée exarte de ce quélait à eette date la fourehe d'éehelle allemande. Lonele d’un de mes ramarades d"internat is Tours of a Paris, 1l. Viollet. pharmacien, a cu en sa possession unre vicilla ealu-forte oi l'arme en puestion a la forme d'un crobssint très échaneré. Une fourehe de guerre analogue. matis plus étroite, est dessinéc dans un incunable du cabinet des estampes de Mumich (1).

Sur le point d'etre assiégés par Philippe de Viacódoime. les Corinthiens "aigulsolent vouges, piques. pancouss (2). hallebandes, hanicroches (:3)... fourehes-tiones, ete. "(Thologur du I. III.)

\section{Les boyaulx, comme un tramail.}

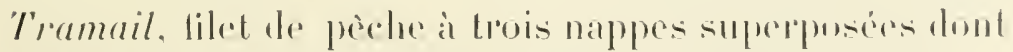
la ronde du pourlour, plus volumineuse que les autres, est granie de flotteurs and de pords de fond.

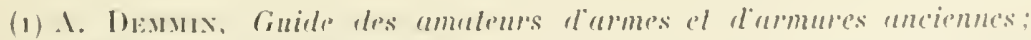

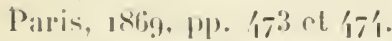

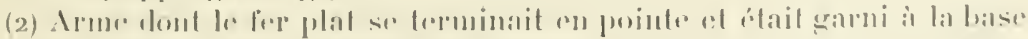

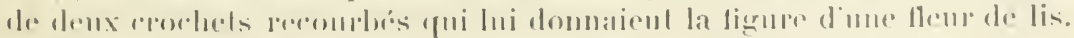

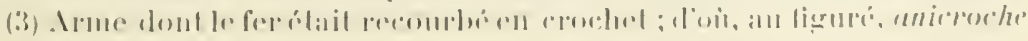

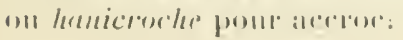


Les boyaulx, les intestins qui s'étendent du pylore à l'anus, ont été divisés, en raison de leur calibre différent, en intestin grềle ou pelit intestin et en gros intestin. Le gros intestin est pourvo d'appendices graisseux et décrit dans l'abdomen un cerele presque complet qui circonscrit la masse de lintestin grêle (1).
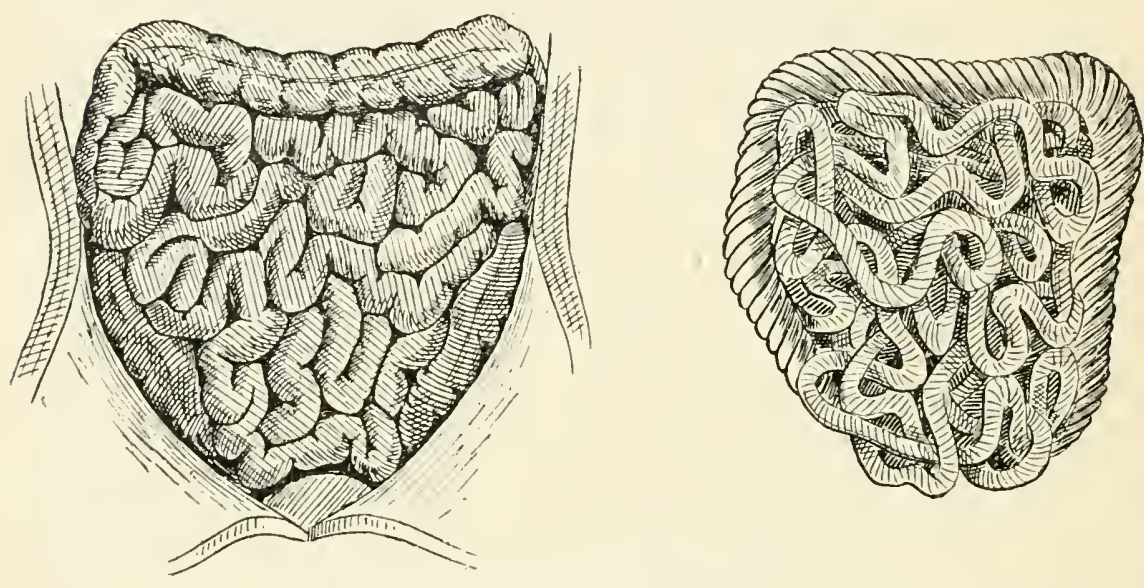

Les luyanls, romme un lramuil.

Les boyaux d'un homme monrant de faim, étant revenus sur eux-mèmes, réduits parfois même ì un cylindre plein de la grosseur du pouce ou du petit doigt (Cruveilhier), il y a une différence moins sensible chez lui que chez un aule entre le paquet intestinal ef un parquet de cordes.

Tels devaient etre les intestins de Quaresmeprenant qui vivait de privations.

La rétraction du lube digestif sur lui-mème chez les gens qui ont été soumis à un long jeùne, et sa dilatation chez les gros mangeurs étaient, qu'on n’en doute pas, parfai-

(1) Les anses du petit intestin correspondent aux cordeleltes superposées altachées à la corde périphérique plus grosse du tramail massé, monillé et reposant sur le sol, ot le gros intestin el ses appendices graisseux (franges épiplö̈ques), il celte corde priphérique munie de ses flotteurs ou de ses poids de fond. 
tement connues de Maître François. Panurge, qui, en abordant pour la première fois Pantagruel l'a imploré en ces termes : "Excellent maitre, pourquoi ne me donnez-rous pas de pain? car vous me royez périr misérablement de faim (1) ", s'écrie plus tard ne manquant de rien: "Il m'est advis que le boyau m'eslargit. Je l'avois nagaires bien seré et constipé (2)."

\section{L'intestin jeun, comme un daviet.}

Le petit inteslin se compose de trois parties:

Le duodénum, ainsi appelé paree qu’il a douze travers

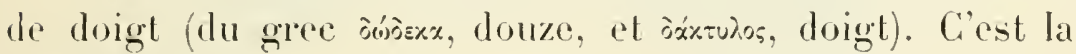
premiere.

Le jéjunnm, l'intestin jeun, ainsi appelé parce qu'on le tronve ordinarement vide sur le cadave. C'est la seconde.

L'iléon, ainsi appelé à cause de sa disposition entortillée (ìs:v, tommer, entortiller), ou paree (pưil occupe le voisinage des os iliarques. C"est la troisieme.

L’intestin jeun on jéjunmm se continue sans ligne de démarcation précise avec l’iléon, de sorte que le plus grand nombre des anatomistes contemporains les décrivent ansemble. Cela est d'autant phus logique que ces deux parties de l’intestin grèle ont la mème structure, le mème ròle physiologigue el sont aussi llexueuses l'une que l'autre.

Les replis que forment le jéjunum et l'ilóon ont recon le nom de cireonvolutions: chacune de ces cireonvolutions pent être eomparée à me anse concare an dedins, convere

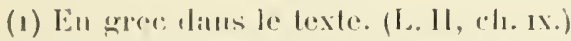

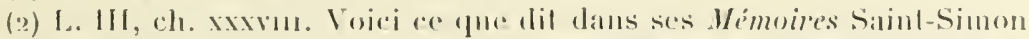

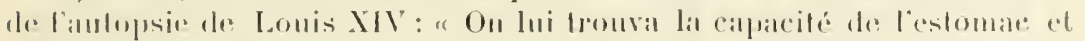
des inlestins double an moins des lommones de sal taille; ce quil esl fort

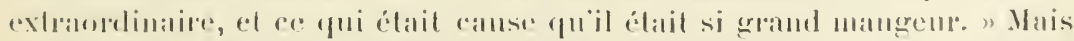

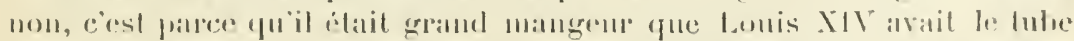

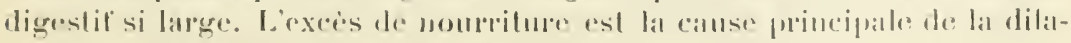

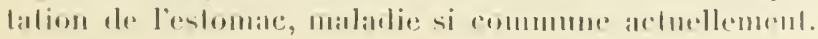


dn coté des parois abdominales, représentant un cercle a peu près complet, ou plus exactement une moitié de huit de chiffies.

Dariel, instrument dont on se sert pour arracher les dents. D’après Le Duchat, le mot davier dérive du mot allemand tanbe, pigeon, paree que la pince de eet instrument ast laite comme le bee d'un pigeon. Il y a des daviors de différentes formes, et parmi eux il en est quelques-mus dont la courbure de la pince égale celle des anses intestinales (1).

\section{L'intestin borgne, comme un plastron.}

En raison des différences de calibre, de rapports, de structure, ete., qu’il présente dans son long trajet, le gros intestin a élé divisé en crecum, en côlon, suldivisé luimème en plusieurs portions, et en rectum. Depuis la fin de

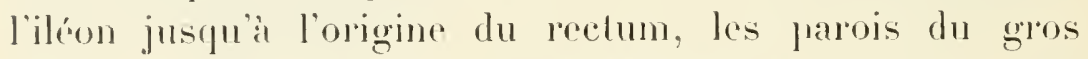
intestin offrent une sérje de bosselures et de sillons qui lui donnent quelque ressemblance arec l'appareil ehimique consistant en une longue série d'aludelles.

Le crecum ou intestin borgne (2), qui fait suite à l'iléon. est un vaste cul-de-sac, - d'où les noms sous lesquels il est désigné, - situé inmédiatement au-dessus de l'os de la hanche ducoté droit. Il est pourvu à sa parlie postéro-inlérienre d’un appendice, l'appendice recal, appelé anssi vermiculaire parce qu'on l'al comparé à un ver lombric.

On lit dans Ambroise Paré (:3) : " 11 semble admis que par l'intestin coecum Galien ait entendu ceste apophyse

(1) Ena admotlant que Mâ̂tro François ait entendu désignon ici le duvier qui sert is crocheter les serures, la compraison serait encore exacte, puisque le davier des serruriers ressemble au davier des dentistes. Panurge avait " un daviet, nu pélican, m crochet ef quel(jues authes forrements, dont it n'y avoit porte, ni colfre qu'il ne crochetast ». (L. It, ch. xv.)

(2) Du latin caens, aveugle.

(3) Ambroise Paré, loc. cil. suprò, 1. 110. 
longue et estroite (1), et de faict le commun des anatomistes lentend ainsi ; mais Vesalius a bon droit aurait en cela reprins (2) Galien : pourquoi sylvius l'exeusant reut que par le ceeum nous entendions le commencement du colon." Maitre François - sa comparaison le prouve - a été justement de l'avis de Vésale.
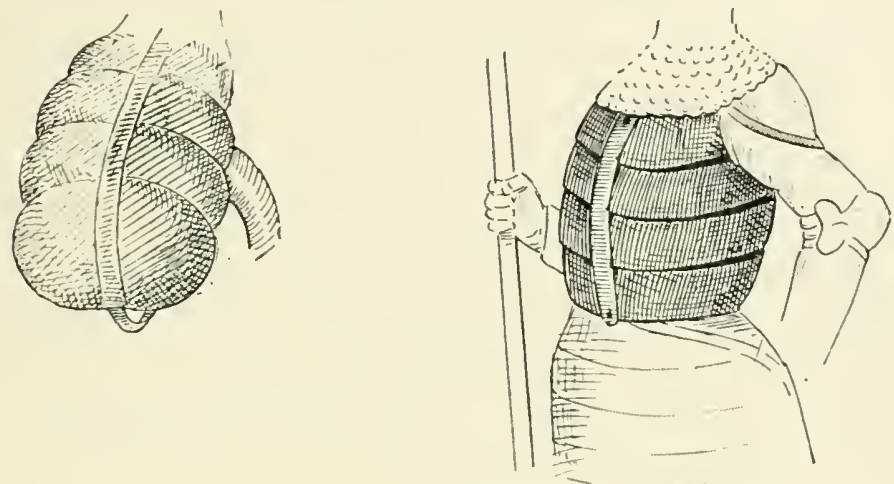

L'inlestin borgne, comme un plastron.

Plashon, pansiere. Habillement d'acier de la partie du corps comprise cutre les mamelles et la ceinture. Cuest le devant de ce que nous appelons aujourd'hui tres improprement la cuirasse.

"Les Corinthiens, par les espions advertis que contre culx Philippe, roy de Macédoine, venoit en grand arroi (:3), touts furent non ì tort espourentés, et ne furent négligents soi soignement mette chasem en oflice (4) et debroir. Les uns polissoient corselets, vernissoient hallecrets (5)), nettoyoient bardes (6), chanfreins... hognines (7), plastrons, ele. "(Prologue du livere III.)

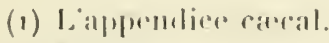

(2) Repris.

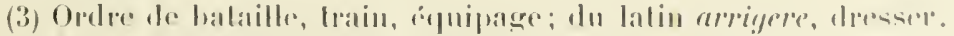

(1) Vime soms que dewor.

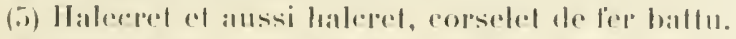

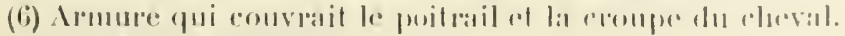

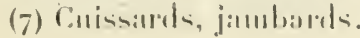


Un des archers d' Mlexandre avait des fleches dont le lel' etait " tant grand et poisant (1) qu’il en persoit branes d'acier (2), boucliers espais, plastrons " (3).

L'ampoule cacale, brillante, d'un blanc bleuatre avec des reflets métalliques, fixéc dans la fosse iliarque, et dont on ne distingue pas généralement la face postérieure ni lappendice vermiculaire, a d'autant plus d'analogie avec la pansière que celle-ci a été constituée pendant longtemps par des lames d'acier bombées, superposées, pouvant se mouvoir les unes sur les autres suivant les inflexions du torse. Telle était la pansière que portaient en 1515 les arquebusiers des bandes suisses au service de la France (4), celle du chevalier Adam Gall, mort en 1574 , et qui est conservée à l'Arsenal Impérial de Vienne, celle qui a appartenu au duc dAlbe (1508-1582), le bourreau des Pays-Bas (collection d'Ambras, à Vienne), ete.

\section{Le côlon, comme une brinde.}

Le colon (xii) ov, de xusúven, je retarde), ainsi dénommé paree que les matières exerémentitielles y cheminent lentement, forme presque la totalité du gros intestin. Il est bosselé comme le cacum qu’il continue, mais il est beaucoup moins volumineux.

C'est le côlon qui est le siège de cette maladie si douloureuse, aceompagnée d'un développement considérable de gaz, qu'on appelle entéralgie ou colique nerveuse.

"Tonte maladie naist et procède de ventosité, comme

(1) Piquant, perçant, du latin pungere.

(2) Villon, dans son testament, a légué son épée branc d'acier ou braquemart, selon la note de Marot, à un ceptain Jehan le Cornu. Dans l. grlossaire de L. Barré, on lit: "Branc d'acier, lourde épée it un seul tranchant. " De l'allemand brand, feu.

(3) L. IV, ch. xxxy.

(1) Voy. E. FuEfÉE, Histoire des troupes étrangères au service de la France; Pallis, 1854 , p. 50. 
déduiet IIippoerates (Lib. de Flatibus) (1). Mais la plus épidémiale est la colique venteuse. Pour y remédier les habitants de lisle de Ruach (2) usent de rentoses (:3) amples, et y rendent foree rentosités. "(L. IV, eh. xLIII.)

Brinde, rase à boire dont on se servait autrefois pour porter des toasts. On dit encore "ètre dans les brindes ", pour ètre ive; "porter une brinde ", pour boire à la santé de quelqu'un. Selon Ménage el Darmesteter, ce mot vient du flamand Ik breng't $u$.

La poupe du neuviène navire de la flotte de Pantagruel " pour divise (4) avoit une brinde de fin or obrysé (5) ". J'ignore quelle était la forme de la brinde. Ce que je sais, e'est que parmi les trois coupes que Viollet-Le-Due aflirme, dans son Dictionnaire raisonné du mobilier français, avoir été principalement employées au moyen àge, il en est une qui était eylindrique et bossclée comme le còlon.

\section{Le boyau c..., comme un bourrabaquin monachal.}

Le boyan c..., le rectum, la dernière partie du gros intestin. Ses parois sont lisses, et son orilice inférieur ferme par un anneau musculaire. le sphineter de l'anus, dont Rabelais a indiqué le mode de fonctionnement (Voy. Plysiologie des Muscles) - présente à :3 eentimetres au-dessus de l'anus une dilatation considérable dite anpoule rectale. Il a une direction ì peu pres rectiligne, dou le nom de rectum sous lequel il est désigné.

(1) Hurochate, Lilre de's Venls.

(2) Ilot hébreu qui signifie rent, sonllfe. Les iles Lofloden, suivant I. Bucrot. En vieux cellique, Loffoden est emuposé de deux mots : lo/f, qui vent dire rent, Hatuosité du ventre; et oden, ronte, ensemble, loute des vents. En bas breton actued, loft ef oden signitient encope bu mène chose.

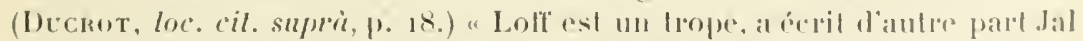

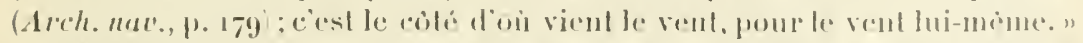

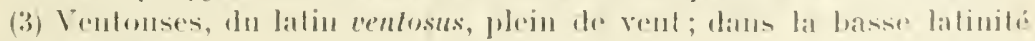
(111 dil eentosir.

(1) Jerise.

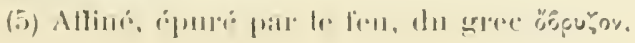


Bonmerabain monachal, llacon de moine, flacon de cuir tris allongé. Bourrabaquin est un dimimutif de bourrac, outre. On disail anssi bomraquin (1). (Lacombe.)

Panurge souhaite aux frères mendiants "d'avoir sempiternellement double pitance et que le grand bourrabaquin, plein du milieu, trotte de ranco (.) par leurs tables".
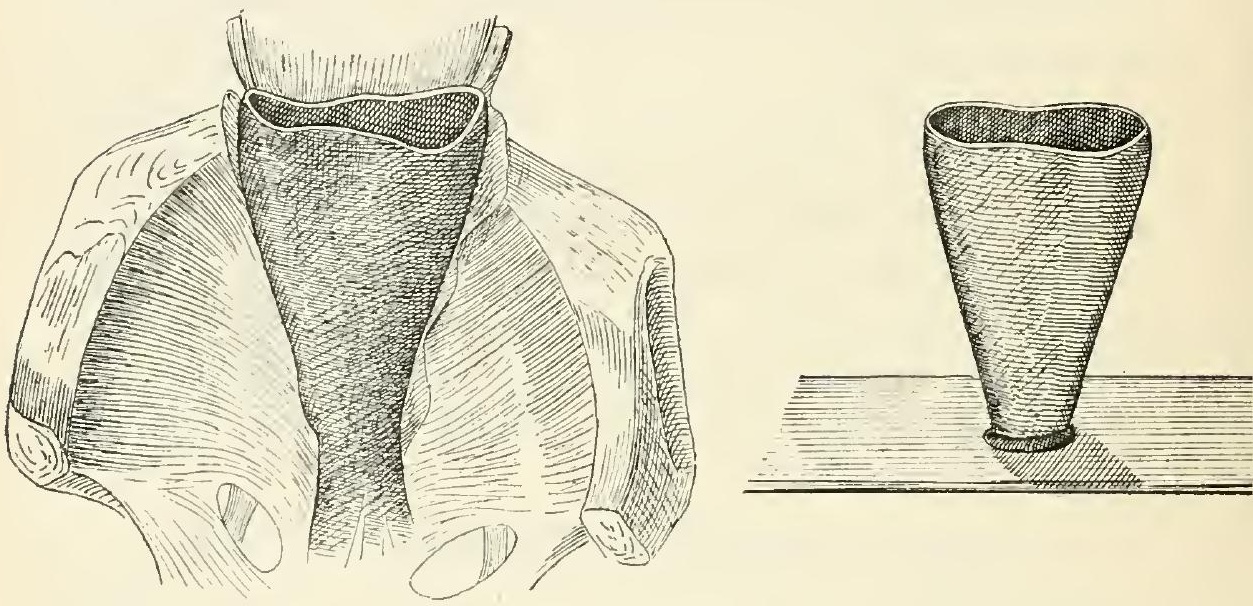

Le boyau c..., comme un bourrabaquin monachal.

The des trois coupes que Viollet-Le-Due assure qu'on labripuat principalement au moyen àge ressemble ì mn long cornet. Les vases à boire du Xvie et duxvie siècle, d'origine flançaise, représentés dans l'important ouvrage de Garnier (IIsistoire de la verrerie el de l'émaillerie; Tours, unxxry) sont eylindro-coniques. Parmi eux, il en estmème un qu'on croirait raiment aroir servi de modele à l'artiste qui a dessiné le rectum figurant dans la section transversale du bassin, dont on voit la reproduclion dans le Traité d'ana-

(1) Dipres Le Inchat, Esmangart et Johamean, bouraquin vient de l'espagnol borracha, qui signifie thacon de curr. (Voy. MÉxare an mot bourrique.)

(g) A lit ponde. (L. III, ah. xxm1.) 
tomie descriptive, de Crureilhier et de Mare Sée (qe édit., I. II, I, 169 : Рaris, 18(6.,).

Le rectum, de même que les autres portions de l'intestin, se compose d'un certain nombre de membranes dont la plus interne, la muqueuse, se décolle lacilement (1). C'est ce qui est arrivé ì Gargamelle, sur le point d'aceoucher, ì "larpuelle le fondenent escapoit (2) une après-dinée, le troisiesme jour de febvrier, par hop avoir mangé de gaudebillaux (3). Gaudebillaux sont grasses tripes de coiraux. Coi-

(1) Le décollement de la muquense rectale eonstitue la maladic appelée en chirurgir: chute du pectum. Il peut ible eausé, comme chez Gargamelle, par destforts répétés el violents de défécation, aprés l'absorption "xagéré l'me nourrilure londe on raluaichissante. On se purge encore en Touraine aver du boullon dans lefuel on a fail enire des issues ftetes, pieds, tripes, ete.) de bites it rolnes.

"En traversant le gur dr Verle, le cheval d'Eudemon enfonga le pied

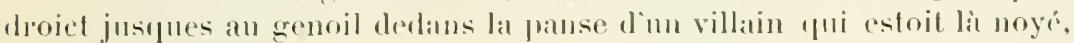

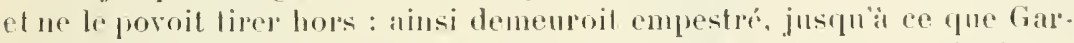
grantua, du bont de son haston, enfondra le reste des tripes du rillan en

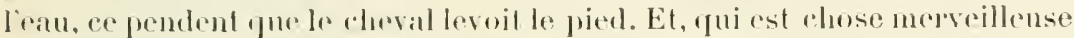

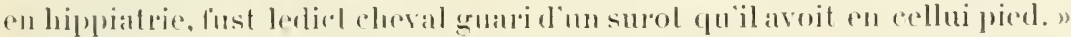
(L. I, ch. xaxvo) Le surol est une fmment dure siluese sur la partie

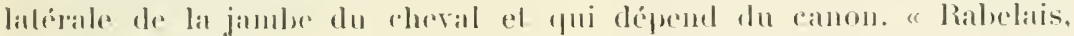

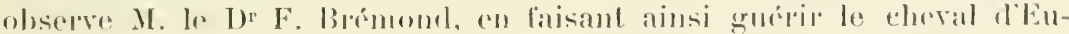
demon a songés sans doute anx bains de tripes tris comployés de son

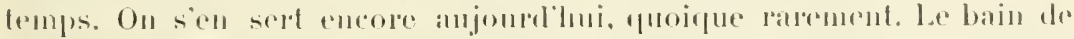

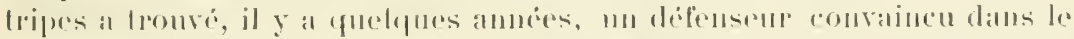

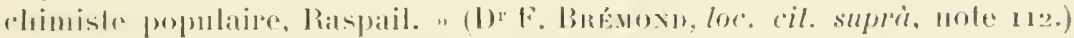

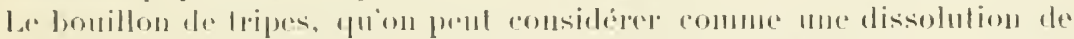

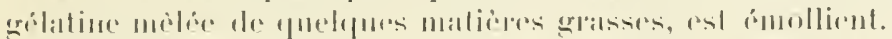

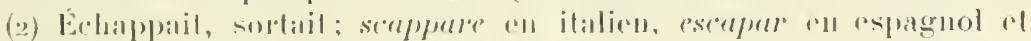

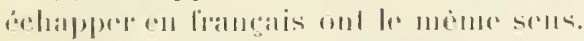

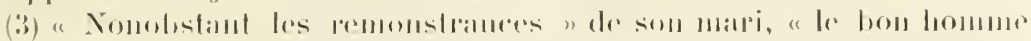

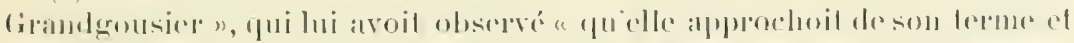

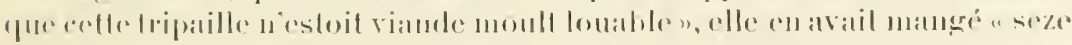

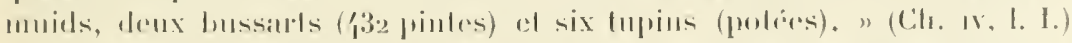

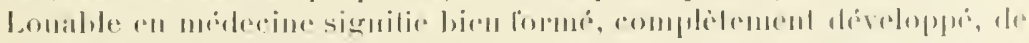

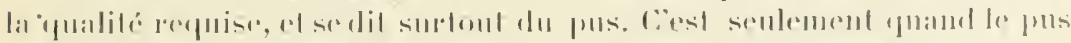

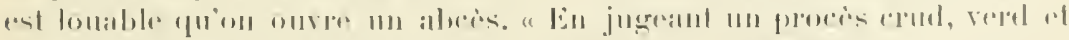

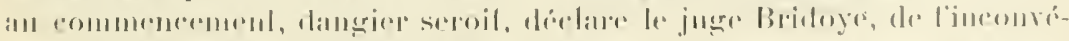

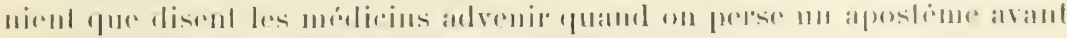

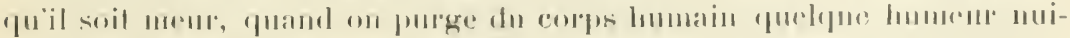

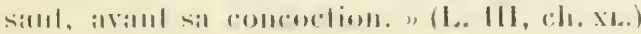


raux sont boufs engraissés à la erèche et prés guimaml. Prés guimandx sont qui portent herbe deux fois l'an. "

Dans le chapilde vo du livre I, Rabelais est revenu sur le mème sujel et en a prolité pour indiquer la direction rectiligne de la dernière partic du gros intestin. "Peu de temps apres, elle commenca à souspirer, lamenter el crier. Soubdain vinrent ¿̀ tas sages femmes de touts costés. Et la tastants, par le bas, trourarent quelques pellauderies (1), assez de mauvais goust, et pensoient que ce fustl'enfant (2); mais e'estoit le fondement qui huy escapoit, à la mollitication du droict instestin (lequel vous appelez le boyau c...), par trop avoir mangé des tripes. comme avons déclairé cydessus."

ANNECES DU TUBE DIGESTIF

La salive, comme une navette.

La salive, les glandes salivaires. Rabelais a écrit la salive pour les glandes salivaires comme il a écrit le fiel pour la vésicule biliaire. (Voy. plus loin: Le fiel, comme une doloire.)

Les glandes salivaires, au nombre de six, trois ì droite et trois a gauche, sont platées dans les parois de la bouche. Chacune d'elles ressemble ì un ellipsö̈de plein, bosselé, pourvu d'un ou de plusieurs conduits excréteurs.

Dans cette comparaison, est-il question de la nanelle d'église ou de la navette du lisserand? Peu importe, puisque ces deux objets ont - cela ressort mème de leur étymologie commune - la mène forme, la forme d'un petit navire (navis).

Les dessius ci-joints :

$1^{\circ}$ Des glandes salivaires (sons-maxillaire ef parotide)

(1) Lamelles de peau, rognures de peau.

(2) Allusion à l'ignorance des accoucheuses du temps. 
débarrassées de la peau, du peaucier of des aponévoses qui les recouvent du coté du cou (1):

20 D'une navette d'église faisant partie de la collection du musié de Cluny";

3" D'une narette copiée sur celle que tient un tissemr représentí dans une vignette du Roman d Alixandre (2);

Montrent re que raut, dans le cas présent, l'asserdion de Maître François.
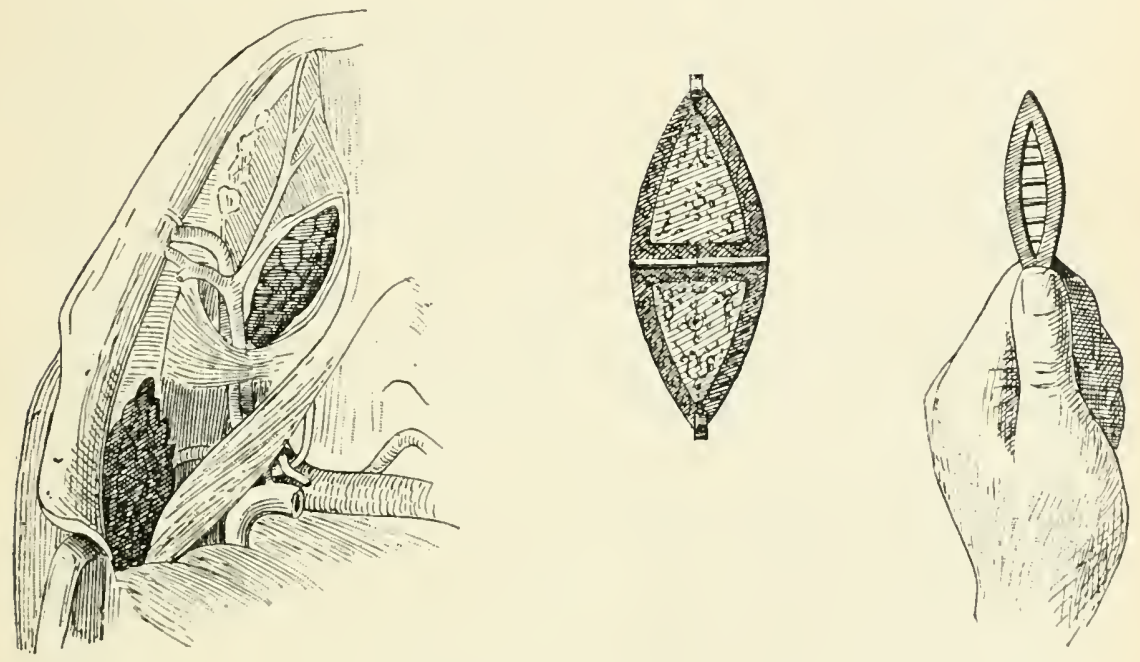

La sulite, somme une natelle.

I a salive de l'homme a céćl'objet d'ume superstition fort singuliere domt on trouve un reflet dans l'épopée pantagrmálique:

"Pourequoy, demande Eusthemes (:3) aflimó a Panta-

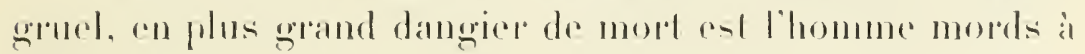

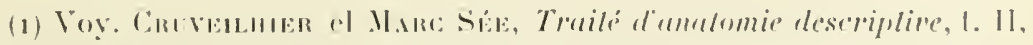
1. 71, figr. 5y); Partis, 18fic.

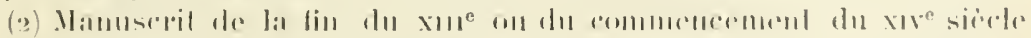
(Biblinllı. Mal.. fouds latvilliome, $1^{\circ}$ 们.

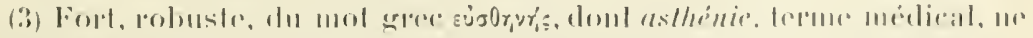

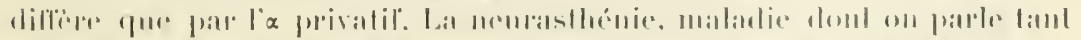

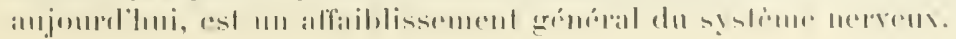


jeun d'un serpent jeun, quaprès avoir repu tant l'homme que le serpent? Pourquoy est la salive de l"homme jeun vénéneuse ¿̀ louts serpents et animanx vénéneux?"

Pour toute réponse, Pantagruel invite Eusthenes i se mettre a table et "apres le fruict ", celui-ci, bien rassasié, reprend :

"Je ne suis phus à jenn. Pour tout ce jourd'hui sont en seureté de ma salive ( 1 ):

Aspins (2).

Amphisbènes (:⿱艹) $)$.

Anémidules.

Abedissimons ( 4 ).

Alluartals (5).
Apimas.

Allatrabans.

Aractes ou Araces.

Astérions (b).

Alcharates ( 7$)$.

(1) "Cette liste des animanx vemimeux, dit le hibliophile Jacol, a clé deresce surtout daprés Pline et Aristole. J Ja retromvé prespue loms los reptiles cités par Eusthenes daus Aristote, Pline, Nicander, Pausanias, Actins, Galien, Albert le Grand, Barllélemy l'Augloys, Allovan, Lucien, Panl d'Egine, Redi, Rondellet, Ambmoise Paré, R. Linocier, P. Lacroix, olc. Losdre alphabelique l'onmmeralion des reptiles dont il sagrit est imilé de Pline, l. XXXVI, elı. x.

(2) La roulenr essentiellement rarialoledr la Vijèro aspic (I'ipera aspis merrem) cu a lait décrire m certain nonture d'espoces (Coluber aspis, Colnber cherser, Vipere Rherlii, ele.). Ces espices sont pmrement nominales. Dans une IIstoire nalurelle des plantes el des animande el principalemenl des serpents do Geolfroy Linocier, naturaliste et médecin de Toumon

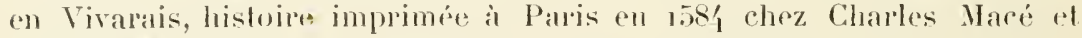
dédié a Monseignem de Toumon, il est lait mention de "trois sortes d'aspics: des terrestres, des hirodiniers et des rracheurs ".

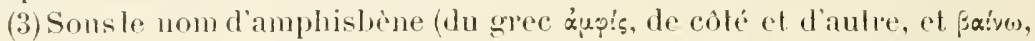
allor) on de donble-marcheur, les Anciens ont désigné un serpent qui rampait daus les deux sens el itait pourvo de deux tètes, l'uncen avaul, lautre en arrière. Cest to Typhlops lermiculaire, dont la quene ressemble a la lète, et qui chemine lantot dans mu sens, tanlot dans l'autre. Le préjugro du serpent a denx tètes a juis vraisemblablement naissance dams lobservation de quelques cas de monstruosite hicipilale, monstruosité qui nest pas tres rame chez les sopents et fui s'explifue par l'agglomération des anls et les greffes fróguentes qui en résultent.

(1) Espiees de dragons on serpents menlionnés par Pline.

(5) Dragons (Bibliophile Jacob). Ce not doit dériver de I'arahe.

(6) Araigués venimenses rayées de blanc. (Plxe, l. XXIX, ch. Iv.)

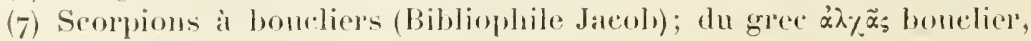
amme téfensive. 


$\begin{array}{ll}\text { Arges (1). } & \text { Ascalaboles (5). } \\ \text { Araines }(\cdot) . & \text { Emorohoüles (i). } \\ \text { Ascalabes }(: 3) . & \text { Basilics }(7) . \\ \text { Attelabes }(4) . & \text { Beleltesictides (8). }\end{array}$

(1) Serpents d'un blane hrillant; du grer ápós, blanc, éclalant de blanchen.

(2) Araines, arrynes, araiynes, araigures.

(3) Tarentules, selon Pline; lezards, selon d'autres.

(1) "Siluterelles de la plus petite esprece ef qui nonl pas d'ailes. " (GotREAc, Recherches sur les Insectes mentionmés dans la Bihle, in Bullet. de lu Soc. des se. hist.el nat. del Yonne, Anxerre, 1861, 1. XV, 1) 19.) Voy.écal. Pline.

(5) L'tsculubote d'Aristote, le stellion de Gezner, le yaléole de Theophraste ot d'Aristophane est un sampien du groupe des fieckos. Ciest mo bète déshéritic de la nature el soltement calomuicée.

(6) Sclon Avienne : L'xmorrhoüde, Hemorrhus ou conle-sang, d" grec

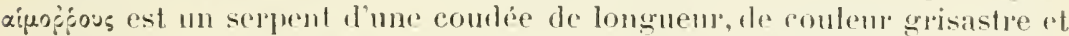
reluisante, marqueté de taches noires. Sa demene est dans les cavernes piereruses anpros du Nil. Conx qui en sont mordus jettent le sang par tous les pertuis dn corjs, les gencives lem entlent aver mu grincenent ou chente de bents, le sing lenr sort par les ongles et par le aning des

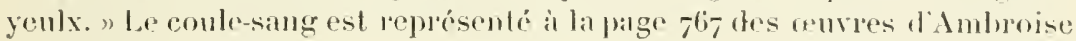
Pinei. (Panis, 1628.)

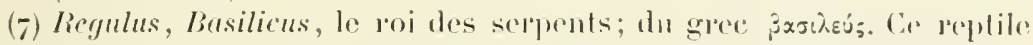
ćtail appelé le roi des serpents paree que son renin passait pour lo plus terrible de tous. Il était dénommé aussi cocedrix, parce quil élait censé

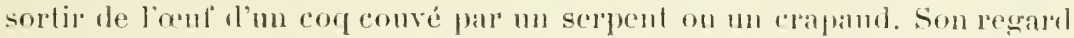
seul farsait mourir: les pierpes so brisabent, les plantes sonllammaient it son contact, ete. Il est diffeite de savoir an juste à quel ophidirn lamli-

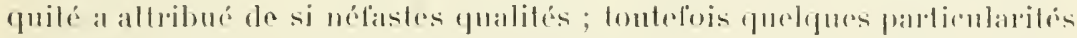
signalés par Pline, notamment que cet animal " releve ordinaloment la

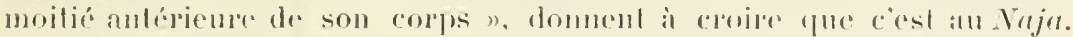

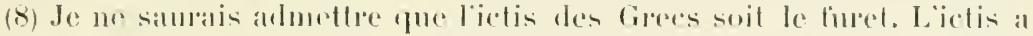

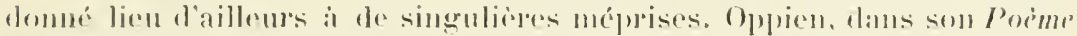

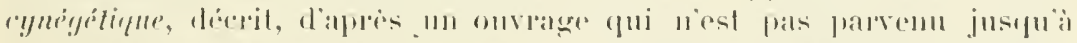

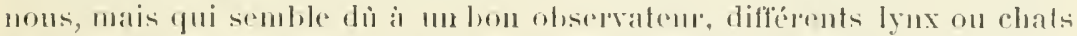

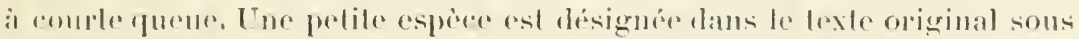

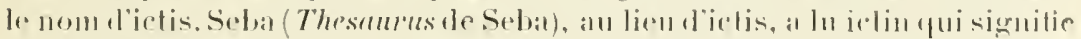

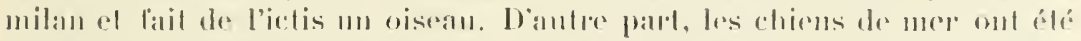

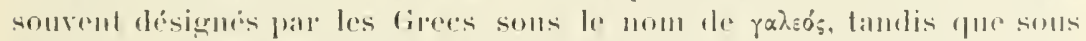

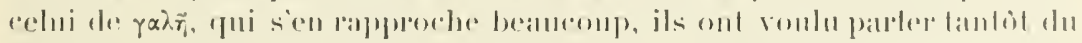

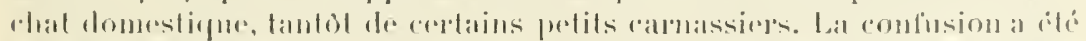

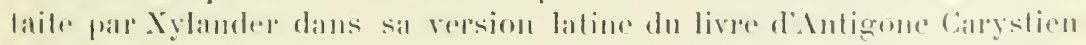

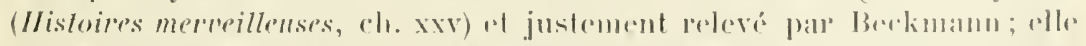

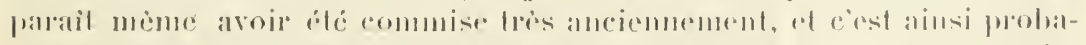

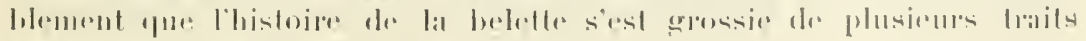
ipluatrolant il celle des sipuales. 


\author{
Boies (1). \\ Buprestes (2). \\ Cantharides (:3). \\ Catoplebes (4). \\ Cirrastes (j).
}

Chenilles (i).

Crocodiles (7).

Crapaux (8).

Campuemares (g))

Chiens enragés.

(1) Boas (Ophidiens ptéropodes) serpents non renimenx qui, au dire de Pline, étaient communs en Italie du temps de Clande et dans le ventre de l'un desquels, tué au Vatiean, on trowra un enfant entier. (Pline, I. V'III, ch. 1 .) Sclon Vetaxa, le reptile appeté boa par Pline est l'Elaphe-guatreraies. "Les phus grands seppents d'ltalie, a obsepró d'antre part Cuvier dans ses annotations de Pline, sont la couleure d'Esculape ef la coulenre unatre-raies, yui ne dépassent pas 2 mitres. Il laut donc supposer que le serpent tué dans lo Vatican était véritablement un hoa on un python. Mais comment un semblable ophidien se tromait-il la? "Le nom rulgaire du boa ronstricteur est giboya, giboüa.

(2) "Le bétail enfle après aroir mangí cet insecte, " dit Nicander. Lenfle-brent, enere employé en médecine rétérinare, est l'insecte coléptère appelé melos on triongulin.

(3) Les cantharides sont aussi des insectes coléoptiores. Elles contiennent un principe résicant et aphpodisiaque fuissant, la cantharidine. La trop célibre Aqua Tolana n’était, d’apres Ozanari, qu'un extrait alcoolique de cantharides décomposir par l'ean.

(f) "Bestes santrages, pelites de corps : mais elles ont les testes grandes sans proportion, a peine les peuvent lever de terre; elles ont les yeuls tant rénéneux, que quiconque les voit, memt soubdainement, comme qui

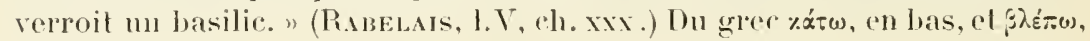
je rois.

(5) Vipores cormues, viperes d'Égypte (Vipera cerastes, Cerasles ay!lplincus). Ce reptile porte au-dessus de chaque sourcil me eorne écailleuse, bien dérelopprée. Du grec \%ếę̧. corme; c’est le serpent à cornes de Pline et de Plutarfuce. (Voy. Plixe, l. VII, ch. xini, et Plutaroue, en la Vie de Calon.)

(6) "Les chenilles pousses et velnes appelées an latin mullipedes engendrent grande démangeaison, rougenr et tumeur an lieu qu'elles mordent. " (Ambroise Pirḱ.)

(7) Le Crocodile terrestre des Anciens est un varan.

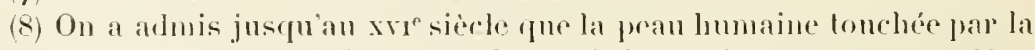
bave, la sueur on lourine du crapaud entrait immédiatement en putrélacelion. Les glandes cutanes de ce batracien sécretenl, en effet, un venin, mais un renin pen puissant. (Voy. Pusalax, Recherches sur la toxiritedu venin du crapand, Hém. de la Soc. de Biologie, mai 1893.) Boccare a alfirmé sépieusement fu'un homme stait "sonbdanement mort par sescurer les dents diun brin de saulge "sur lequel un crapatrd arait répandu sou veniu (Rabecals, l. IV, ch. xrm.)

(9) Reptiles fabulenx dont Rabelais a parlé en ces termes dans 


$\begin{array}{ll}\text { Colotes (1). } & \text { Chellydres }(5) . \\ \text { Cychriodes. } & \text { Cronicolaptes }(6) . \\ \text { Cafezades }(2) . & \text { Chersydres }(7) . \\ \text { Cauhares }(3) . & \text { Cenchrynes }(8) . \\ \text { Coulatbres }(4) . & \text { Coquatris }(9) . \\ \text { Cesharces. } & \end{array}$

lancien prologue du live IV : Je ferai tant avec le petit comte George de la basse Egypte, qüi chascun de vous il tera présent d'un hean crocodile du Nil et d'm caufuemare dEuphrates."

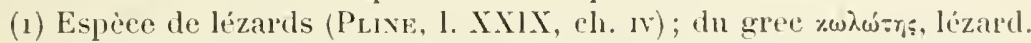

(2) Cafezates, petits serpents rougeatres tris renimeux (Biblioph.J.сов).

(3) Serpents renimenx (Biblioph. Jaco в).

(f) Couleurres (Le Ducurat). La couleurre possede des glantes renimeuses, mais la matière toxique qu'elles seerètent, an lieu de se localiser pour ètre inoculée par la morsure à un autre organisme, se répand, réhiculée par le sang, dans loorganine de lanimal. Voila pourquoi la conlenre mortue par une ripere ne succombe pas. Elle se raceine ellemème contre le venin des reptiles dangerenx. (Toy. Mém. de litcadémie des sciences, 8 nor. 189.5 .)

(5) "Le chellydre on chesncan est, dit Linocier, serpent hoste perpétnel des chesnes, long de denx condés, le colps assez charnu et garni d'écailles fort rudes doi vient puion lappelle chellydre on rude peau. Il est de conlenr suye et si puants yue si on ne voits, on le sent. "Linocier (loc. cit. suprò, 1) goo) en a donné anssi le dessin.

(6) Esmangart et Johamean pensent qu'on cloit lire ici cronacolaptes,

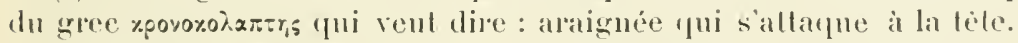

(7) Serpents arpuatiques qui ressemblent beancoup ì cerlains serpents te mer renimenx. Curier ne comprend dans le genre chersydre que de chersydre a bandes (Chersyelrus fuciculus). Dans son glossaire, L. Barré traduit ce mot par "serpents amphibies".

(8) Serpents dont la peau est pronsemée de petites laches semblables a

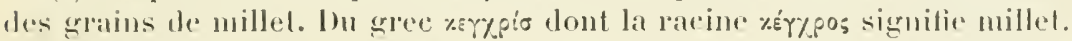

(9) Serpent fabulenx nt diun eof. On roit rucore, daus certames rógroms de la Touraine, du Berry et du Poilou, tue les poules tont loviaire

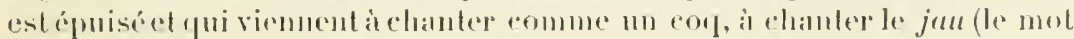
jau en potois peiterin est synonyme de copp), pemelent en dernier lien mu

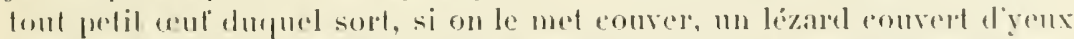

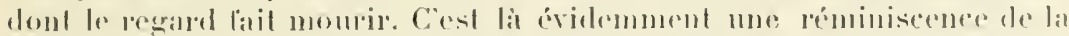

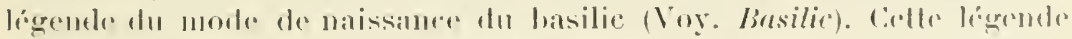

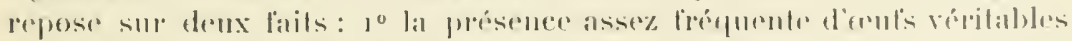

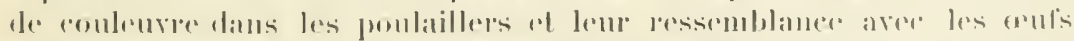

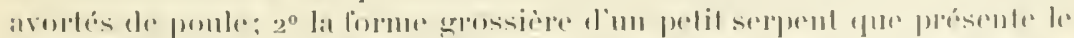

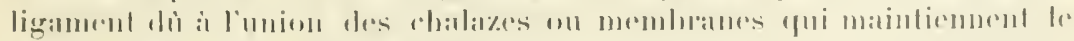

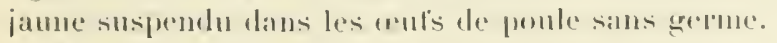

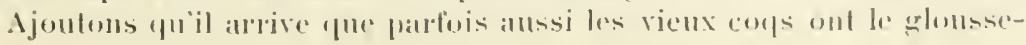


Dipsades (1).
Domèses (2).
Dryinades (3).
Dracons (4).

Elopes (5).
Enhydres (6).
Fanuises $(7)$.
Galéotes (8).

menl de la poule et rendent des amas mous, comme membraneux, formés de glaire coagulée et ayant l'apparence d'ceufs, d'où l'on a conclu, en voyant sortir des petits l'un fumier où une couleuvre avait pondu, que les coqs hardés protuisent des orufs quils ne couvent pas et d'où naissent des reptiles.

(1) On élait persuadé jadis que la morsure des reptiles de l'ortre des

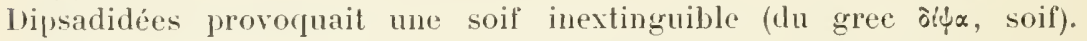
L'altéré ou Dipsas décrit et représenté dans les ouvrages anciens correspond au Dipsas type des traités récents d'erpétologie. (Voy. Lrxocier, loc. cil. suprà, 1. 375; Galien, II, Liv. simpl.; Lucien, les Dipsades.)

(2) Serpents logeant dans les murailles; du gree ooprots, construction.

(3) Serpents vivint au sein tes arbres et principalement des chènes. Du gree ofútivos, dont la racine ôpüs veut dire chène.

(4) Dragons, draco en latin, op $\alpha$ \%wv en grec. Dans une IIisloire des Indes, très appréciée, publiée en 174́ par l'abbé Guyou, on lit encore : Le dragon n'est dans sa figure qu'un serpent extraordinaire, etil yen a de trois especes. Les uns habitent sur le haut des montagnes, d'autres dans les cavernes, dautres dans les marais. Les premiers sont les plus grands de tous:ilsont les écailles dorées, du poil ou nue espèce de barbe assez longue sur le front et sur la mâchoire, les sourcils sont ouverts, le regard affreux et cruel, le eri enticrement aigre et perçant, une crète rouge semblable à un charbon allumé. Ceux du plat pays ne diffèrent que par la conleur de leurs écaittes, qui sont argentées, et par l'usage qu'ils ont de lréquenter les rivières. Les autres, qui vivent daus les narais, sont prespue noirs, plus lents à la course; ils nont point de crète. C'est à lort qu'on les a privés de leurs ailes. Ils ont aussi dans la tète une pierre précieuse qui donne autant de feu que le diamant et qui est naturellement taillée à différentes facetles par où elle domne toutes sortes de couleur. "Les anciens naturalistes ont évidenment décrit sous le nom de Dragons les grands serpents appartenant au groupe des Ptéropodes. Les ergots quofrent à la marge de l'anus ces reptites d'une force considérable et d'une taille énorme sont devenus, gràce à l'imagination des poètes, des pattes et des ailes.

(5) Ou Ellops; "serpents ", dans le Dictionnaire de Novitius; " serpents non venimeux ", dans le glossaire tle L. Barré.

(6) Couleures aquatiques (Plwe); du gree śv, dans, et šôs, eau. On dit aussi Enhydrides.

(7) Serpents tachetés (Bibliophile $J_{A C O B}$ ).

(8) Voy. Ascalabotes. Quelques commentateurs font des Galéotes 11 genre d'Arachnides de la lamille des laux Scorpions. Pour Cotgrave ce sont des lézards ennemis des serpents. 
Ilarmènes (1).

Handons $(2)$.

Icles (3).

Jarraries.

llicines (4).

lchneumons (5).
Kesudures (6).

Lievres marins $(\bar{t})$.

Lizards chalcidiques ( $\$$ ).

Myopes (9).

Manticores (10).

Molures (11).

(1) Pelits basilies (Bibliophile $\mathrm{J}_{\mathrm{A}} \mathrm{COB}$ ).

(2) Handons on Handions, dragons venimeux (Bibliophile Jacos).

(3) Le Duchat, Esmangart ef Johanneau présument quon doit lire ici lacles, "car lacles pourrat bien che formé de jaculus, nom dune espèce de serpent qui sélance conme un trait. Pline le nomme jaculum "; ne serait-e pas l'Eryx jaculus de Linné ?

(4) "Serpents d'eau. Ce nom, disent Esmangart et Johamean, doit dériver du mot latin illex, illicis, qui charme, qui attire."

(5) Rats de Pharaon (Betox); Chercheurs (Lixocier); Ilerpesles ichnenmon (Geoffroy); Viverer ichneumon (Lixié), ete. C'est l'ennemi né du erocodile ef d'une lonte d'animaux muisibles. Les Egyptiens lui rendaient, en raison de son utilité, les homneurs divins. (Voy. Oppian en sa chảsse.)

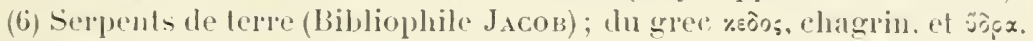

(7) Aplysies, mollusques galstéropodes dont les deux tentarules antirieurs lessemblent aux oreilles d'un lievre. Les Aplysies onl blé lobjet des lables les plus alsuldes. Daprès Pline, non seulenent la clan du lieve marin el l'eau dans laupulle on l’a lait infusel seraient véníneuses, mais encore une femme en alal de gestation ne pourrait suporter la rue diune Aplysie sans dere prise de nansés, de romissements, ele. (Toy.

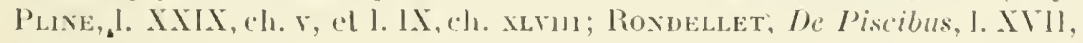
De Lepore marino.)

(8) Le Sepis chalciule (Laeerla chalcida). qui passe ruente en Sardatigne pour faire mourir les berul's qui lavalent en mangeanl, esl abso. lunent inoltersile.

(9) Insectes dipléres qui ont la rue rourte, du grec powsós, myopre. Dims le chapitre va du live IXIX de Pline, il est question de mouches myoüdes.

(10) "Brstes bien estranges: elles ont le corps comme un lion, he poil mouge, la lace el les atureilles comme un homme, trois rangs de dents, entranls les unes dedans les aultres, comme si vous entrelacioz les doigh des mains les mus dedans les aulleses : en la queue elles out un aguillon, duquel elles poignent (piyturnt, du litin pungere), comme font les scop-

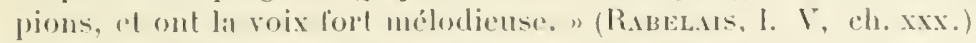

(it) Le Pylhon molure (I'ylhon molurus. ophidien plérepode). Tite-Live

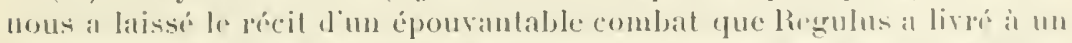
serpent diune taille grigantespue qui ne peut ilre que lo Python de Sedalo

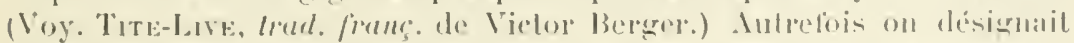
sous le terme gémerigue de moulures lous les serpents dui matrehnt sme leur quene; du grrec pö̀ovess. 
Myagres (1).

Musaraignes (2).

Miliares (3).

Megalaunes.
Ptyades (4).

Porphyres (5).

Paréades (6).

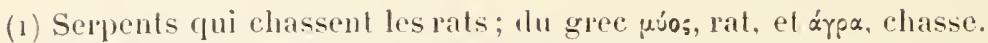

(2) La Musette ou Musaraigne commune (Sorex araneus) est encore, dans les campagnes, victime d'un préjugé; on croit que par sa morsme elle cause aux chevaux me maladie souvent mortelle. Cefte imputation est d'autant plus fausse que la Iusaraigne n'est pus venimeuse, mais encore qu'elle ne peut mortre en raison de la petitesse de sa bouche.

(3) Mille-pieds (Bibliophile JАсов), Mille pedx. Ovoi, Cloportes. (Voy. Galien, l. II, de Compend. méd. sec.l.).

(1) Aspics craclienrs (Voy. Aspies); llu gree rove, je crache. "Les serpents aspics sout, arec la vipere arictans, très communs en Alrique, sur la cote dOr. Si quelequn passe pres deux, ils se redressent et lancent à près dinn mètre, ef surfout dans la direction des yeux, un liquide principalement composé de salive. Cette bave produit la creité si elle arrive jusquau globe oculaire. "(Reıchexow.)

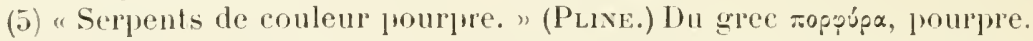

(6) Seruents inolfensifs dont les jones sont très saillantes; du grec זxpsíx, jolle.

Le Paréas, ainsi qu'un cerlain nombre l'autres reptiles de la liste ei-dessus, sont indirués dans la Pharsale de Lucain. Aprés avoir rappelé comment ces animanx sont nés des gouttes de sang qui tombèrent de la tète de Méduse, Lucain ajoula: "Le reptile qui le premier sonleva la tète, éclos de cette lange putride, ce lut l'aspic; le Nil l'enferme daus les sables du désert. Aussitót l'xemorroüs, ce reptile qui ne doit laisser aux mallieureux aucune goutte de leur saug, surgit tout couvert d'écailles et déployaul ses anueaux immeuses. A sou tour se lève le chershydre, que son instinct envoic aux rives incertaines des seythes, ef le chellydre, qui répant la tumere sur ses traces; puis le cenchris, qui glisse toujours droit devant lui; sur son dos se gravent des milliers et plus de petiles taches qu'ou n'en voit peintes sur lophite, ce bloc sorti des mines de Thèbes; el l'hummodyle, dont l'écailure, au redlet ardeut, se confoml avec les sables qui lentourent; et le cépteste, qui va incessamment se repliant sur son dos; et le seylale, fui seul, avant tous les autres, s'apprète à dépouiller sa parure dhiver; et lo britant dipsas; of le redoutable amphishene qui court dressant ses deux tèles; of le natrix, qui souille les ondes; of l'ailé jaculus; ef le paréas qui se borme a sillommer la ferre de sa quene; et lavide prester qui entroure sa guenle cumante; et le seps. dont le poison corruptem lait dissourle le corps et les os; et le monstre dont le cri ćpourante tous les autres, le basilie, qui tue avant mème l'emploi de son venin: écartant loin de lui la foule des reptiles, il règne daus la solitude des sables.

"Et rous qui recerez nos pieux hommages, qui n’ètes nulle part dans 


\author{
Phalanges (1). \\ Pemphredones (2). \\ Petrocampes (:3). \\ Ruteles (名).
}

Rimores (5).

Rhagions (6).

Rhaganes.

Salamandres $(\bar{\gamma})$.

l'Univers, dragons, brillanls d'écailles d'or, seule la Lybie rous pend renimenx sous son ciel ardent." (Lucars, la Pharsale, trad. Courtand-Devernélesse, t. II, I, IX.)

(1) L'une ou l'aulre des deux espèces de Galéodes (Galeodes græcus et Galeodes areaneoüdes, Arachniles articulées) encore nommées Phalanga dans tonte la Russie septentrionale, et dont la morsure détermine une inflammalion violente suivie d'une paralysie passagère. (Voy. Aristote, Patl d'Égine, Aetil's et Pline, I. AXXix, ch. iv.)

(2) Pemphredons, insecles hyménoptères: du grec rx́upprôo, bourdons.

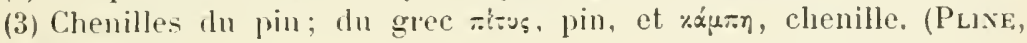
1. XXIX, ch. w.)

(4) Rutélides, insectes colioplères de la tribu des Scarabées. "Vers "qui rongent les arbres ", assurent Esmangart et Johanneau.

(5) Vraisemblablement Remores. L.Echneis remora,le sucet, le nancrate, est un poisson dont la lite porte me plaque armée de crochets aumoyen desquels il se fixe aux rochers, à la carène des vaisseaux, au corps des grands Squales. Ovide et Lucain onl prétendn que le remora fixé à la carène d’un vaissean en suspendail la marehe. Pline, plus crédule encole. a écril: "Il sert il composep les poisons rebigéranls; il apete laction de la justire et le cours des lribmuax, mais, en verlu de la mème puissance, il compense les manx qu il pent produire: il délive les femmes flum aecruclement prémaluré, et, si un le eonserve dans du sel, son approeler serte suffil pour relirer du fond tes puits les plus profonds l'or qui pent y

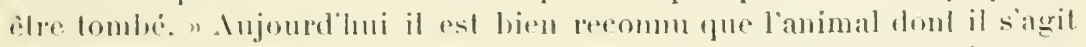

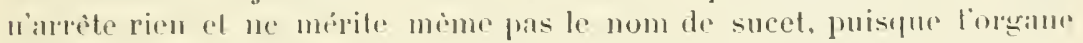
dont il se sert comme d'un crampon est dépourver dorganes de suceion. (Pour diblails complémentaises, roy. Anat. ('omp.)

(6) "Araigues rondes et de couleur noire comme nu grain de raisin dont elles portent le nom. " (Ambroise Paré.)

(7) En dépit de Mallhiole, de Pierins, d'Amalus el de Gallen, l'ineombuslibiliti de lasalamandre (Sulumandra maculosa) a blé acecplín comme un artiele de foi pendant le mogen àge. On a mime altribue à ret animal le

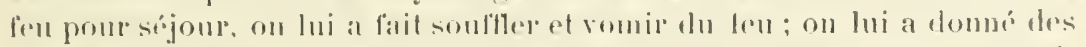

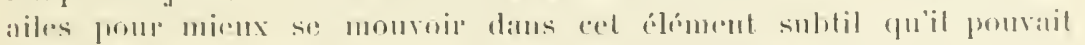

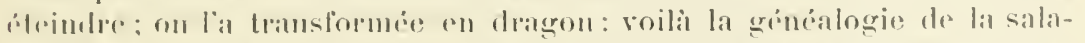

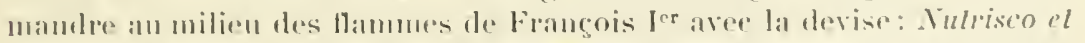

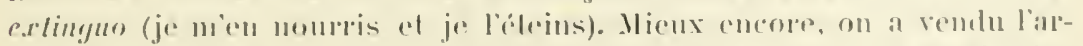

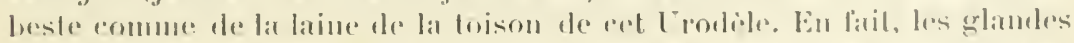

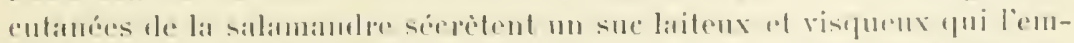

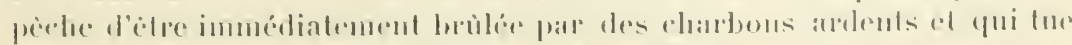

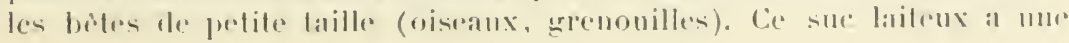




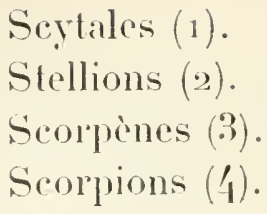

Sclsirs.

Scalarotins (5).

Solofuydars (i).

Sourds $(7)$.

odem (uni rappelle beancoup celle de l'insecte connu sous le nom de Cerambyx moschalus; son évacuation est loujours subordonnée a une exeitation musculaire volontaire (Albixi). Rabelais s'est parfaitement rendu compte que la salamandre ne résistait pas a laction d'un feu tries vif. "Je eonfesse hien, dit-il, dans le chapitre Li du live III, que petit leu de paille la végite (la fortitie, Ini donne de la viguemr, dn latin vegelare) et resjonit. Mais je vous asseure que en grande fournaise clle est, comme tont anttre animant (animal), suffoquée et consumée. Nous en arons vu l'expérience. Gaten l'avoit long-temps confermé et démonstré, lib. 3, de Temperamentis."

(1) "Ce serpent, dit Linocier, est d'une venue comme le Donble-marcheur, excepté qu'il est plus gros : car l'antre est comme un ver; celui-ci esl de la grosseur d'un manche de dolonère de laquelle il relient son nom et ne va que d’un côté. 11 est tout marıuetlé sur la peau. Ce serpent of le Double-marehenr sortent les premiers te la tannière; mais combien que tous les antres aient ceste propriéte, qu'estant sortis ils compent au fenoil pour recourrer la vene, toutes fois celuj-cj ny va poinct, d'oì vient qu'on l'appelle cecilie en latin ou areugle en français. Sa morsure est comme celle de la ripire. "Un dessin de Linocier complete celle deseription. (Livocrer, loc. cil.suprà, p. 893.) L'espèce de ce serpent renimenx dont ont parlé Elien, Dioseoride et Nicander nous est inconnue. C'est ce reptile ani a donné son nom à la seytale, bâton de eorrespondance secrète des Lacédémoniens. En erpélologie moderne, le scytale est un ophidien opistoglyphe.

(2) Le stellion (Stellio vulyaris), on Étoile, est nul lézard portant des taches en forme llétoiles. Sa chair, saulf celle de la tète ef tes pattes, a été employée contre la piquire du scorpion of l'ípilepsie; ses excréments, appelés slercus lacerli ct erocolilea, ont servi te fard.

(3) Poissons de mer (Pline, l. XXXIl, ch. rx) ; poissons lhoraciques; "Scorpions jamnes ", d'après L. Barré.

(4) Dans nos pays on cite quelques cas oir la piquire de celte arachnide a amenó un état adynamique assez graps arec fìre, romissements, tremblement et gonllement du membre hlessé. Dans la zone Ioride, elle pent canser la morl. (Voy. Joreux-Lafreve, Sur lappareil venimente el le venin du scorpion, th. Paris, 1886.)

(5) Animanx de la famille des lézarts (Bibliophile JАсов); du grec

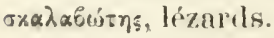

(6) Fompuis venimenses (Dibliophile Jacon).

(7) Lorvet (Anguis fragilis), encore appeli Seppent de reme, jaref que sa quere se rompl facilement. 


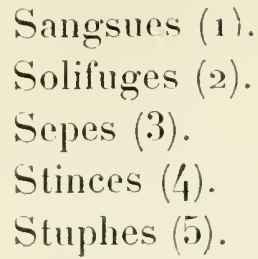

\author{
Stabins. \\ Sangles (6). \\ Sepédons (7). \\ Scolopendres (8). \\ Tarentoles (9).
}

(1) Hirudinées dont Savjgny a fait un genre. Parmi les Hirulinées, les Bdelles et prineipalement la Bdelle du Nil, qui mesure jusqu'i so centimètres, peuvent ètre nuisibles à l'homme. On se sert en médecine de la sangsue verte et de la sangsue grjise.

(2) Fommis venimeuses qui fuient le soleil. (PLine, I. XXIX, ch. 1v.)

(3) "Le Seps ou Serpent pourrisseur est semblable an Conle-sang, excepté qu'il va droit et de l'autre costé ef n'a aucune conco. Il est de conleur pasle el blafarde ou de plusieurs couleurs, comme dit Nicanler. Les aceidents après sa morsure sont une grande douleur, à cause du renin pourrissant, puis me cheule universelle de tout le poil du corps quil

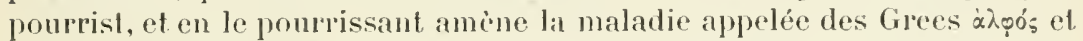

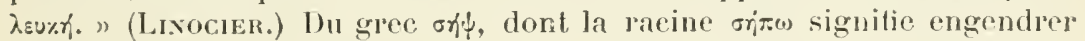
la pourriture. Ambroise Parí nous a laissé un dessin du pourrisseur. (A. Paré, loc. cil. supril, 1. 768.)

(4) "Crocodiles trepestres ", d’apres Pline (1. VIII, ch, xxy). Herodote a réalement fait mention de a Crocodiles terrestres, semblables aux Lézards ef vivanl dans la région pareourue par les pàtres de la Lybie ». Ces préfrudus Crocodiles sont - leur description ne permet aucun loute à cet égard - les Varans ( Iarani arenarii). Quant aux animanx appoles maintonant Seinques (Slinees), ils nont, hen qu'appartenant aussi ì l'opdre des Saluriens, rien de eommun aree les Varans.

(5) Serpents du genre des Singles; ; grec oź́ọ, resserrer.

(6) On donne toujours le nom de Sangle a la Lisse de grande faille (Coronella auslriaca), qui b́loutfe sil proie en śentortillaul aulomp d'elle.

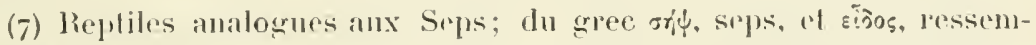
blance.

(8) Gands serpents de mer. Le physétere tue par Pantigrmel "se renversa ventes sus dor's (dos, du latin dor'sum), conmme font fouts poissons morls; ot ainsi, lenversant les fonthes contre bas en mer, ressembloit an scolopendeserpent ayant cent pieds, comme l'ha deseripht le sage

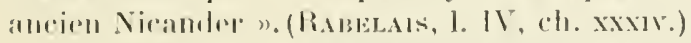

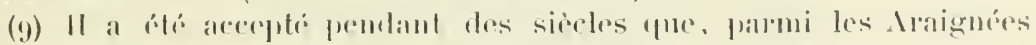

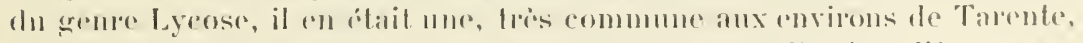
la Lyeose larentule, dout la piquire anenait une maladie singuliope carac-

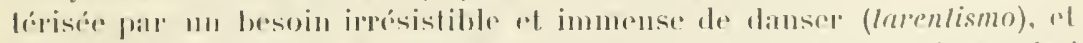

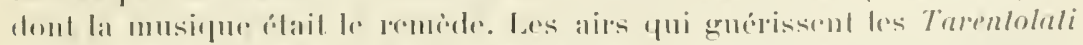

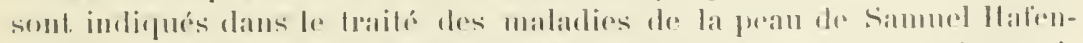

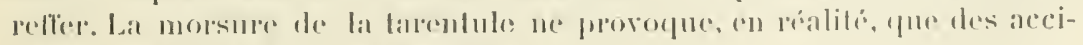
dents focans te pen d'impurlance. 
$\begin{array}{ll}\text { Typholopes (1). } & \text { Téristales. } \\ \text { Tetragnalies (2). } & \text { Vipères }(3) .\end{array}$

Aristote (4), Nicander, Galien, Pline, Paul d'Égine, Sérapion et divers médecins du moỵen âge et même du siècle dernier ont écrit maintes lignes pour soutenir que

(1) Serpents dont le regard provoque la stupeur on qui ont des yeux

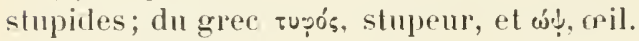

(2) Tétragnathes, araignées dipulmonées, du grec sєтр $\alpha$, quatre, et ryx́fos, màchoire.

(3) La partie active et délétère du venin de vipère est une toxalbumine désignée sous le nom de vipérine ou d'échinidine. Elle est très dangerense puisque M. Viand Grand-Marais a vu la mort survenir elıez un septième des individus mordus par des Vipères (ehez 53 sur 37o).

La durée de la gestation des Vipères est d'environ huit mois. Bien que les petits éclosent d'un aeuf, ils sortent eependant vivants du sein de leur mère. Celle-ei se débarrasse à la fois de ses petits et des eoquilles qu'ils ont brisées pen de temps avant de naitre. Il est possible que ce soit dans cette particularité qüil laille chercher l'étymologie du mot latin vipera dont nous arous fait vipère (de vivi, phr. de vivus, vivants, et parere, engentrer : qui engendre des petits vivants). Mais suivant lsidore, que nous serions plus disposé à croire, le terme vipera, an lien de tóriver de vinipara, dériverait de vipara, formé de vi (ablat. de vis) par violence, et parere engendrer : 'pui engendre par violence. Et cette étymologie tronverait son origine dans un préjugé ancien qui voulait que la fenelte coupàt, avant d'enfanter, la tète du male avee les deuts et que les petits, pour venger la mort de teur père, déchirassent en naissant le sein de leur mère. (Voy. Héronote, Pline, Elenen, Lacuna, Imperat, Amatus, Vincext, CAuÉRIN, ete.)

Il résulte des rers ci-dessons rue Rabelais a cru aussi i cette sortie contre nature des vipereaux du ventre maternel:

"En ceste vie, dit Panurge i Gripleminaud, rons rongez et mangez tout; en laultre rous rongerez
Et mangerez comme vipères
Les costés propres de vos mères.
Une bien jeune et toute blondelette
Conceut un fils éthiopien sans père;
Puis l'enfanta sans douleur la tendrette,
Quoiqu il sortist comme faict la vipère,
L'ayant rongé, en moult grand vitupère,
Tout l'un des flancs..."

\section{(L. V, ch. xir et xirr.)}

Je n'ai pu reeueillir de renseignements précis sur les Anérudutes, les Apimaos, les Alhatrabans, les Aractes, les Cychriodes, les Cesharces, tes Jarraries, les Rhaganes, les Selsir's, les Stabins, les Téristales.

(4) Aristote, Des Animaux, 1. VII, ch. xxix. 
la salive de l'homme à jeun est un poison mortel pour les animaux renimeux. En roici quelques-unes :

Est uli ut serpentes hominis contacta salivis

Disperil ac sese mandato conficil ipsa.

Crachez sur un serpent, sa l'oree l'abandonne;

Il se mange lui-mème, il se dérore, il meurt.

(Lucrèce, Trad. de Voltaire.)

La salive fait mourir les scolopendres marines, ainsi que les rubètes (I) et les grenonilles. (Plive, l. VII, ch. Iı. Trad. de du Pinet.)

Salive d'homme,

Tout serpent domme (2).

(Leroux de Lixcr.)

"La salive d'un jeune lomme bien sain à jeun est bonne pour les morsures des serpents et chien enragé. " (LéMerr, art. Homo du Diclionnaire des; drogues simples, 1. II ; Paris, I 783.$)$

Dans le Ijictionnaire philosophique, Voltaire dit que deux personnes "lui ont attesté aroir vu un chirurgien tuer des serpents en les frappant légèrement aree une baguette humectéc de salive " (:3).

Si Lémery et Voltaire se fussent renseignés sérieusement, ils enssent su qu’au xvme siècle Redi, médecin de la cour du grand-duc de Toscane, a fait boire, pendant quinze jours de suite, de la salive humaine a des vipères sans que celles-ci en aient élé aucunement incommodées (4).

(1) Especes de Grenouilles regardées il tort pendant longtemps comme renimellses.

(2) Domple.

(3) Pour de plus amples dibails, voy. "le Cuchat ef la Salive dans lus superstitions at les croyances populates ", par P. Sébillot, in journ. l'llomme, no 10 , Paris, 1884 .

(4) Si les serpents ne redrutent pas la salive humaine, ils alfortionnent

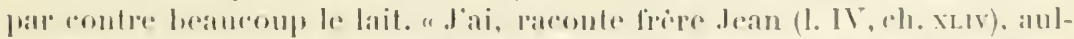

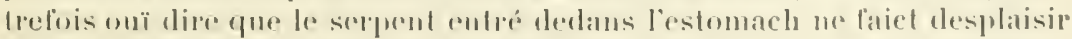

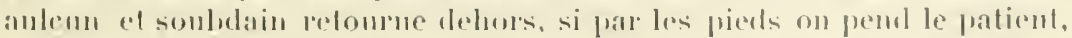
lui présentant près de la bouche un poeston plein de laicl chanlul. - Vous, 
Il y a cependant quelques rérités générales dans la question d'Eusthenes. La glande renimeuse regorge de venin lorsque le serpent n'a pas mordu depuis longtemps, et le venin est plus actif que dans le cas contraire. Un serpent lue plus vite un ètre à jeun qu'un être qui vient de manger. Pour faire périr un animal en digestion, il faut une dose de strychnine double de colle qu'il faut pour le farre mourir quand il est ì jeun (CI. Bernard). Au dire de Brehm, de Sallé, ete., les individus qui sont sous l’influence de l'alcool ne ressentiraient même presque pas les terribles effets de la morsure des serpents. Si la salive de l'homme n'est pas toxique pou' les animaux, elle l'est pou' les plantes, en raison du sulfo-cyanure de potassium qu'elle contient (1).

Les amygdales, comme lunettes à un œil.

Les amygdales (du gree żuyróxin, amande) sont deux glandes en forme d'amande logées, l'une à droite, l'autre a gauche de l'entrée de la gorge, dans une excavalion limitée en haut, en avant et en arriere par les piliers du voile du palais of inlérieurement par la base de la langue. Elles sécretent un liquide onctueux qui favorise le passage des aliments i travers l'isthme du gosier. Chez certains sujets, elles existent ì peine; chez d'autres, au contraire, elles sont très prononcées.

dist Pantagruel, lavez oü lire : anssi avoient eenly qui vous l'onl racomplé. Mais tel remede ne lut onques vu ne leu. Hippocrates, lib. 5, Epirl., escript le eas estre de son temps advenu : et le patient subit estre mort par spasme el convulsion. "Si prouoncé yue soit le goùt des Ophidiens pour te lait, il est, en effet, dilficile, sinon impossilıle, fu’un de cenx-ci, renfermé dans l'estomac, puisse forcer le sphincter musculaire qui en lerme l'entrée.

(1) Consultez: Chouppe, De l'action de la salive humaine sum la vie et la germination des plantes, Revue scienlifiyue, $n^{\circ} 21$, p. 58 Florase, Sur la Salive et les propriétes du sulfo-cyanure de polassium, Gazelle médicale de Paris, 188 4, et Bull. de Ia Soc. des sc. méd. de Gannat, 1890. 
D'apress Le Duchat, " ce passage (1) et celui du lirre $Y$. chapilre xxris, où il est dit que les Frères Fredons (2), dormants aroient bezicles au nez, ou lunettes pour le pire, fait voir dans Ménage que ce quion appeloit lunettes du temps
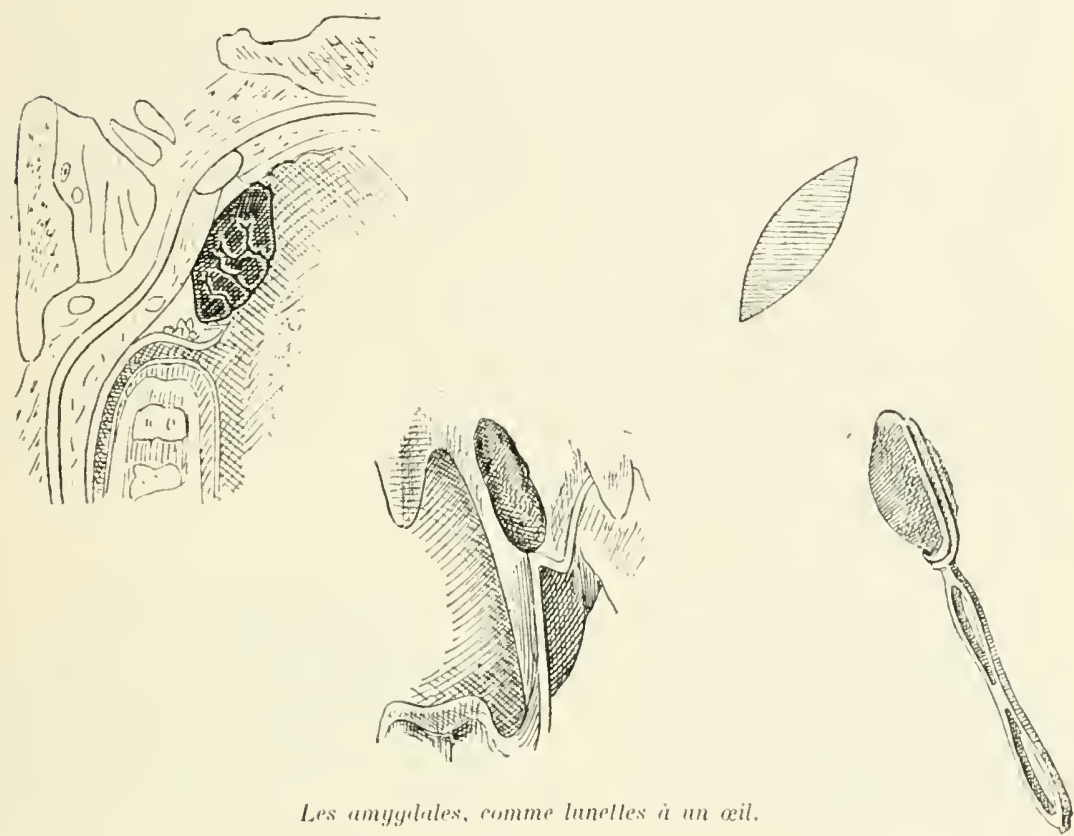

Les amygliales, somme lunalles is un wil.

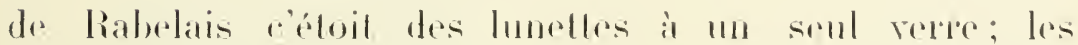

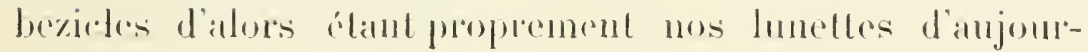

(1) Les amyegralos, commo hmelles a un aril.

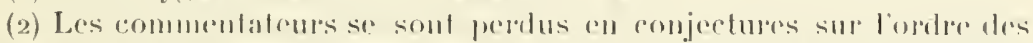

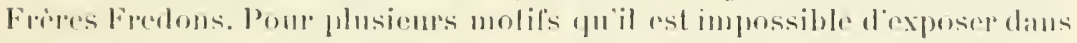

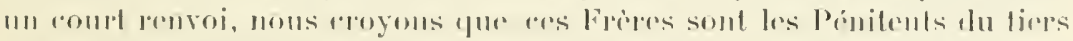

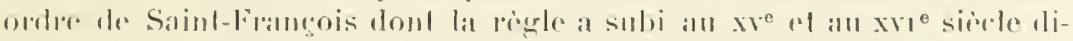

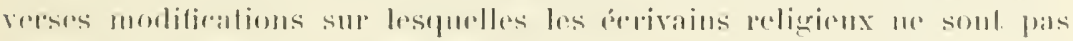
1) aceord.

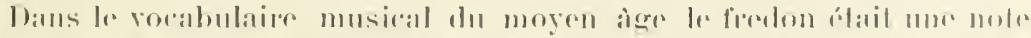

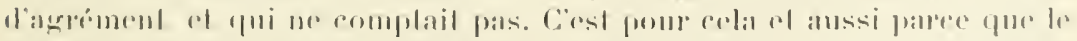

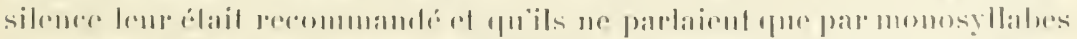

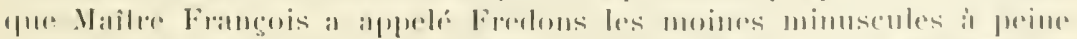

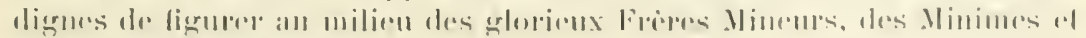
mine des Cilpuroins. 
d'hui " (roy. Étienne Pasouier, les Recherches de la France, I. VIII, ch. xxx) (1).

Le Duchat a raison, et un des tableaux - le portrait de Léon $\mathrm{X}$ - peints au Vatican par Raphä̈l en fait foi. Dans ce tableau, le pape, assis devant un missel richement enluminé, tient dans la main droite une lunette (2) à un ail ressemblant absolument ì une loupe emmanchée, au simple oculaire bienvexe ou lentille convergente, qui se place au-devant de l'oil pour donner des images ampliliées des petits objets dont les détails échappent à la vue. Le mot besicle ne vient pas, comme on le croit communément, du latin bis oculi (deux yeux), mais bien de l'ancien mot français béricle (écril quelquefois béril ct aussi bézicle), qui désignait le cristal dont on faisait autrefois les verres de lunettes; plus tard on donna ce nom an vere artificiel qui remplaça le cristal, et enfin, par extension, aux lunettes à deux oculaires assemblés, l'un à coté de l'autre, dans la même enchàssure. On appelle cncore béryl une sorte d'émeraude (ne Laborde, Notice sur les émanx du Loure. Glossiire) (3).

Bacon, aprìs l'Arabe Alhazen-Ben-Alhezen, a parlé des lentilles à verres convexes comme moyens d'aider les gens

(1) "Les bezicles sont pour les deux yeux ensemble ef les lumelles pour un seul ceil, " a dit encore aillemrs Le Duchat (t. Il de son Rabelais, p. 256 en note).

(2) "Lunelle, verre laillé ressemblant à une petite lume, " dit Ménage. "Un verre sphérique convexe, composé de segments d'une petite sphère, grossit les objets qu'on regarde ì travers, de sorle quion pent remarquer distinctement leurs petites parties; e'est pour cela qu'on dome à ce verre le nom de lonpes, "lit-on, d'aulre part, dans l'Essai de physique de Pierre de van Musschenbroeck (1. II, p. 594, trad. de Pierre Massuet; Paris, 1739). Les mots lunelle et loupe niudiquent donc que la forme domnée ì la matière employée pour les instruments d'optique en question, de mème que le mot besicle n'indique que la matière dont ils onl éte primilivement formés.

(3) Il y a en latin mu substantil beryllus qui veut dire il la fois cristal et lunetles. Doin le verbe beryllare, briller.

Beryllus a formé le diminutif beryculus, beryc'lus, d'où est sorti le mot beryeles, bericles et enfin besicles par le changement si fréquent de ren $s$. 
¿̀ vue faible ou àgés dans la lecture des manuscrits. C'est " ¿̀ grand renfort de besicles practiquant l'art dont on peult lire lettres non apparentes "que Rabelais est parvenu a déchiffrer la généalogie de Gargantua.

Conclusion : l'amygdale, encastrée dans les piliers du roile du palais, comme la lentille biconvexe, autrement dit en lorme d'amande, sertie dans la monture métallique de la lunelte à un wil. (Pour de plus amples détails, voy. Appareil génital : La géniture, comme un cent de clous à latte.)

\section{Le foye, comme une besaguë.}

Le foic est un organe glanduleux, silué dans la partie droile du ventre, au-dessus de l'estomac, et qui sécrète la bile el le sucre (1). Il représente un segment d'ovoüde, obli-
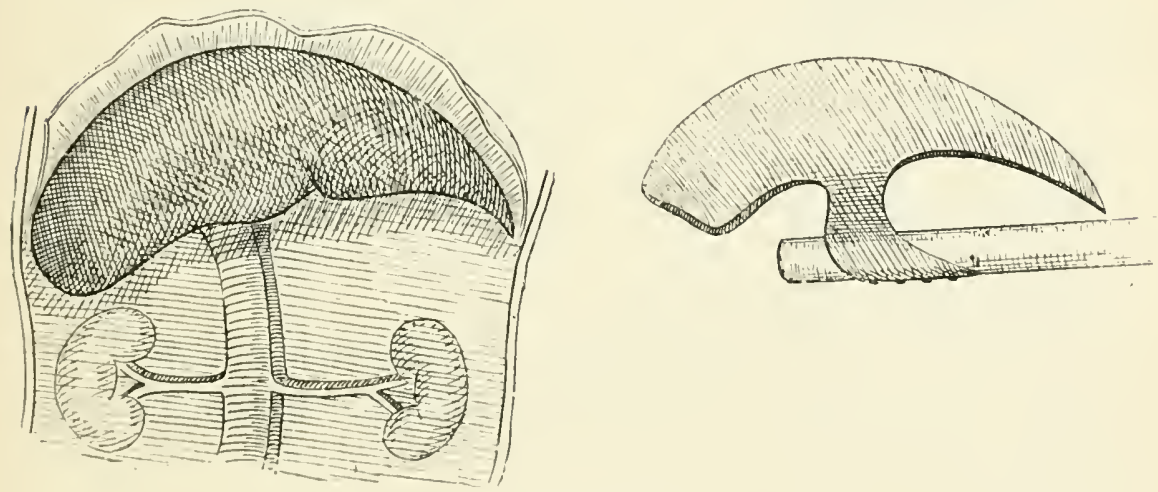

Le foye. comme une lies ugue.

quement coupé snivant la longueur el plus épais à som extrémite droite qu'ì son extrémité ganche recourbée et terminér par une languetle lamehante. Du milien de sa lince inférieure, légèrement enncare, émerege un gros trone vasculo-nerveux appelé pédieule du foie, formé par l'acenlement de nombrens vaisseamx ef nerl's el des camaux

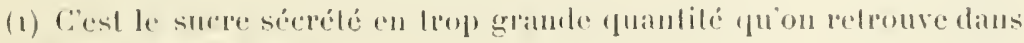
loriue des diabélingres. 
biliaires. Le foie est composé de trois lobes, dont le plus petit est dénommé "tierce lobe " par Maitre François.

Un des Tures qui martyrisaient Panurge succomba à une blessure eausée par une broche qui " lui perça le tierce lobe du foye, le diaphragme et, par à traver's la eapsule du cœur, lui sortit par le haut des espaules, entre les spondyles et l'omoplate senestre (1) ".

Resayuë, Jisaiguë, variélé de fauchard, hache ì deux tranchants (du latin bis, deux fois, et acutus, aigu; aigu ses deux extrémités). Le petit fauchard à manche coúrt des piétons (2), ainsi quon peut en juger', ressemble au loie représenté dans les OEnores d'Ambroise Paré.

\section{Le fiel, comme une doloire.}

Le fiel, la vésicule biliaire. Les bouchers et les ménagères disent encore le tiel du boul, le tiel du poulet pour désigner la vésicule qui renlerme la bile. Le " tant docle et gentil médecin chinonois " a appelé dans sa première thèse de licence (Voy. Physiologie de l'appareil digestif) ce réservoir qui est enclavé dans une lossette de la face inférieure du foie, la bouteille du fiel.

Doloire, sorte de hachereau emmanché à angle droit dont les tonneliers se servent pour dresser les douelles ou douves des tomneaux. An xire siècle, la doloire est devenue plus recourlée du còté du tranchant et plus légère par suite de la suppression du renfort court postérieur pouvant servir de marteau qu'elle a cu d'abord.

La comparaison de Rabelais est préférable à celle indi-

(1) Gauche.

(2) Il existe an musér de Munich (collection du roi de Suède; Charles $\mathrm{ST}^{\mathrm{T}}$ ) une hache d'anmes allemande du xve siècle, à longue hampe, pour homme de pied, et au musée d'arlillerie de Paris (K. 9.̈) une hache l'armes russe également à longue hampe pour homme de pied, dite bardiche, dont le fer ressemble à celui du petit lauchard a manche court. (A. Denun, loc. cil. suprà, pp. 460 et 461. ) 
quée dans les traités classiques. On en sera convaincu si l'on regarde les deux dessins mis ici en parallèle et dont l'un est extrait d'un travail sur la vésicule biliaire qu'a publié en juillet 1891 , dans les Bulletins de la Société anatomique, M. Hartmann, prosecteur ì la Faculté de médecine de Paris,
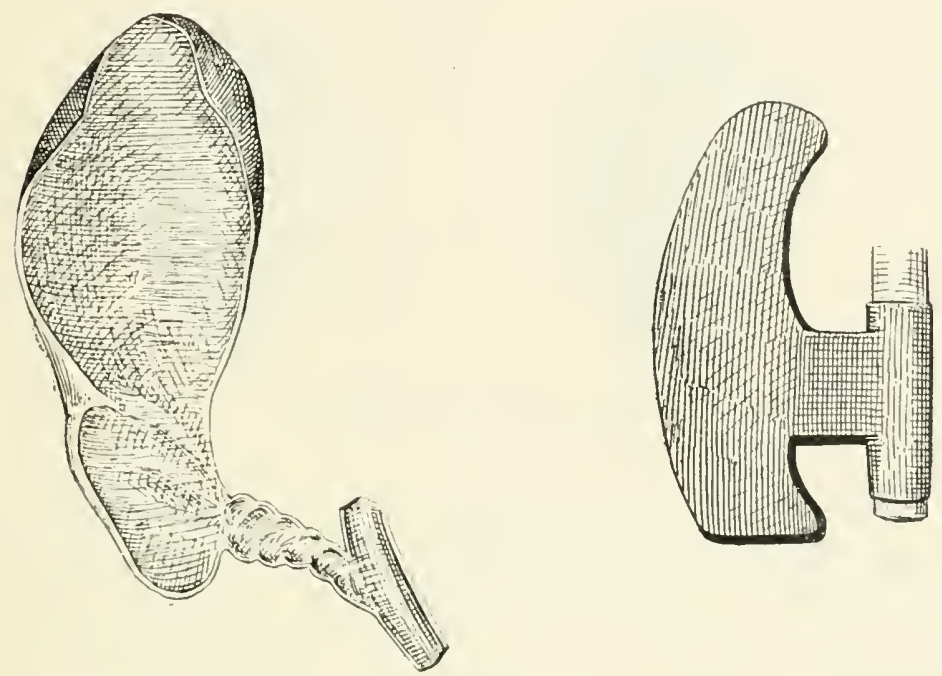

Le fiel, comme une dolvire.

et dont l'autre est la copic d'une doloire que porte suspendue à sal ecinture un ouvier chapentier ligurant dans un vitrail du xure siecle de la cathédrale de Bourges.

\section{La ratelle, comme un courcaillet.}

La ratelle, la rate, est une glande vasculo-sanguine, irrégulièrenent arondie, noiràtre, sur certains points, blenatre ou violacée sur d'autres, située à gauche de l'estomac. Elle crie sous le doight qui la presse en laisant éprouver une sensation de eranguement semblable a celle qui est connue en minéralogie sous le nom de "cri de l'élarion".

En vorant un grand rétacé inonder d'ean le navire de ller 'Trippa, "Panurge entra en joye tant excessive, et tant 
exercea sa ratelle qu'il en eut la colique plus de deux heures " (1).

Courcaillet (2), appeau pour attirer les cailles. C'est une poche de euir munic d'un sifflet, rui imite le cri des cailles quand on la serre entre les doigts. On fait aujourd'hui des
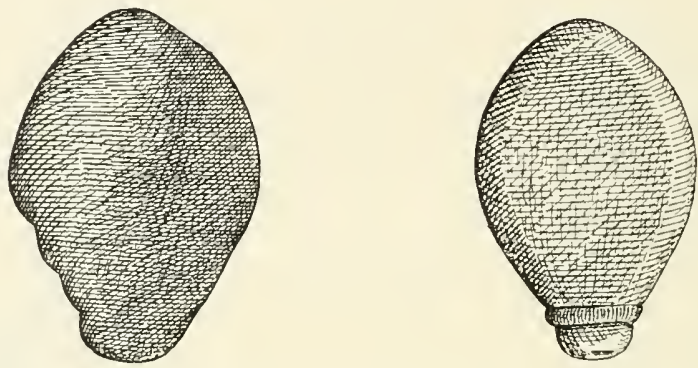

La ralelle, comme un courcaillel.

courcaillets de diverses formes. Un chasseur de mes amis en possède un en cuir noir, rond, un peu allongé, qui a par conséquent l'aspect de la rate. Un courcaillet analogue existait-il au $\mathrm{xvI}^{\mathrm{e}}$ siècle? Cela n'est pas absolument impossible (3).

Je prends la simple caille, entrimitant son chant.

(Philippe Despontes, 15/1-1606.)

(1) Corneille Agrippa, qui avait prédit a Panurge le malheur de son mariage avec une persislance outrageusement lésobligeante. Descarles a dit: "que la rate sécrétail denx espèces de sang: un fluide ténu qui était la canse de la joie, un antre plus tenace qui était la cause de la lristesse; el selon que la rate cnvoyait an coen. une quantilé plus grande te l'mon de l'autre de ces deux sangs, on étail gai ou triste. C'était sur Ie prélendu dégrorgement de la rate ch sang grossier qui la remplit dans la tristesse qu'était tondée celle locution vulgaire: s'épanouir, se désopiler la rate. " (Avelox.) L'opéralion inverse a donné lien à cette autre locution: s'échauffer la rate. Les fonctions de la rate ne sont pas encore connues.

(2) Mot fait par onomatopéc : kourkitié, cri des cailles.

(3) Cerlains objets usuels nont subi depuis cetle époque que des moditications insignifiantes, par exemple : la cognée, le compas d'épaissenr, la truelle, etc. 


\section{Le siphac, comme un brassal.}

Le siphae, le péritoine (1). C'est une membrane transparente qui revèt la liare interne das parois de l'abdomen et les viscires qui y sont contenus. Dans son traité De Medendis morbis, Leoneflus liaventinus a défini le a siphac pannicalus nervosus continens inter se zirbum (2), stomachum et hepar. Le siphac est un pannicule nerveux cnveloppant l'épiploon, l'estomac et le loie."

Maitre Francois ent pu aussi bien dire próloine. On lit, en effet, dans le chapitac xvil du live V: "L'hoste de Roullac finoit (3) ses jours en erevant. phus ne povant le péritoine el pran clope et relenir ses hriples. qu'elles n'enfondrassent (9) pal dehors, comme d’un tonnean déloncé."

Brassal, brassard. I. Instrument de bois, solte de manchon, dans lequel le jouenr de ballon enfone le bras justgu'au conde et qu'il tient en saisissant une forte cheville qui en traverse obliquement l’intérieur.

II. Garniture en euir dont on se couve le bras pour jouer an ballon.

III. Corbeille d'osier fort allongée que las jonemes de ballon altachent a leme hats droit pour donner plus d'impulsion an projectile. Dans le live IlI de l'Ilistore macaronique de Folengo, je relive les dens phratses suivantes: "Balde assom par foree se met de la partie. On lui domme un brassint, il latecommode a son brats droit et sur sit matu; il se présente a jourer."

IV. Parties de l'armume qui protégeatent le bras el souvent aussi lavant-loras.

V. Pièce de mótal ou d’ivoire qui servait à marantio

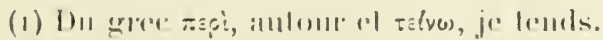

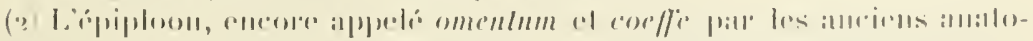

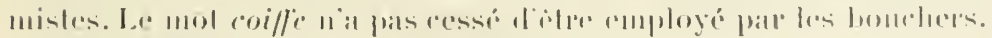

(3) Finisinil.

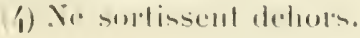


le bras de l'archer contre les choes de la corde de l'are.

De tous ees objets portant le mème nom il en est un, la corbeille d'osier ou chistera du jeu national de pelote des Basques qui, si elle était plus large, ressemblerait absolument à la portion du péritoine dite grand épiploon, qui apparait des qu'on ourre l'abdomen (1).

\section{Le mésentère, comme une mitre abbatiale.}

Le mésentère est un repli triangulaire du péritoine, dirigé obliquement de haut en bas et de gauche à droite (du côté gauche de la deuxième vertèbre lumbaire au côté droit de
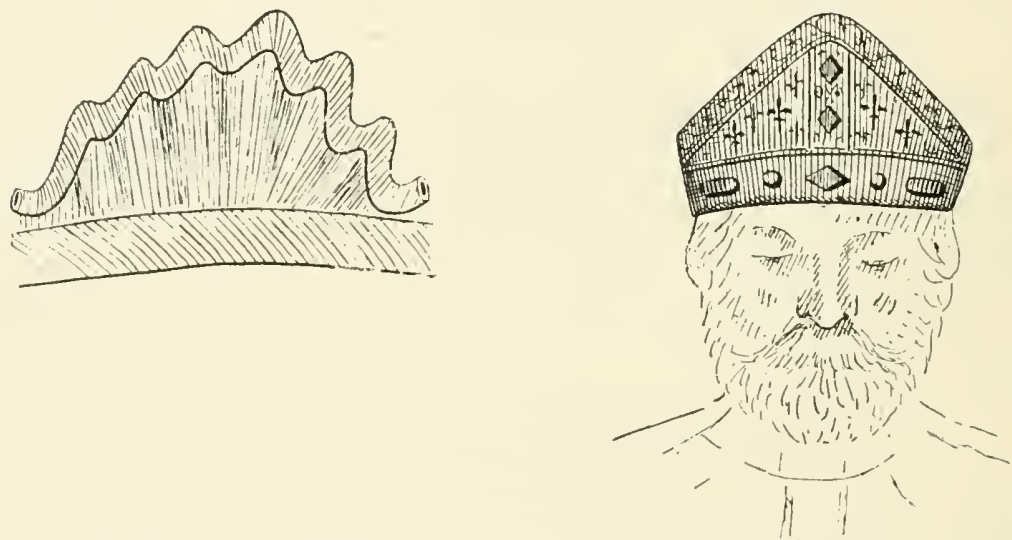

Le mésentere, comme une milre abbaliale.

la cinquième) el composé de deux féuillets entre lesquels sont placés les anses, les vaisseaux et les nerfs des deux dernières portions du petit intestin (jejunum et iléon); du gree présos, qui est au milieu, el ëvrspov, intestin (2). On l'appelle fraise dans le veau.

Milre abbatiale, initre d'abbé (:3). "Les abbés, dit Fure-

(1) Il m'a été donné de connaître trop tard cette corbeille pour pouvoir en faire prendre un dessin.

(2) Le dessin schématique du mésentère de la planche explicative est extrait du Traité d'analomie de 11 . Fort.

(3) La mitre était autrefois moins haute qu'aujourd'hui. 
tière, doivent porter la mitre tournée de protil pour montrer qu'ils riont juridiction spirituelle que dans leur cloìtre. ")

Un des chicanous qui alla assigner Basché " estoit personne publique, serviteur de la mille abbatiale ".

Qui ne serait frappé ici de la comparaison de Rabelais?

La mitre abbatiale

est lriangulaire,

formée de deux valves entre les-

quelles est logé le haut de la tète,

placée de protil sur la tète.

\section{Le mésentère}

est triangulaire, conslitué par deux lames contenant les anses, les vaisseaux et les nerfs des deux dernieres portions du petit inteslin, dirigé obliquenent par rapjort à la colonne vertélraale.

Pinsiologie. - Manger est la fonction la plus importante de l'homme, puisque e'est par elle quil répare principalement ses forees et conserve sa vie. Rabelais médecin n’a eu garde de l'oublier. Après avoir "portraictouré (1) Messer Gaster (2), ce roy inflectible (3) ", dont "le mandement est nommé (4) Faire le lault sans délai, ou mourir" n, et raconté comment "à l'exemple des membres conspirants contre le ventre, ainsy que descript Esope, tout le royaulne des Somales (5) contre luy conspira et conjura soy

(1) Peint.

(2) Lisfomile, en gree $\gamma \times s+r_{i}$.

(3) Lutlexible. Le poète Guinlus Seranus a appelé lisslomate le roi du corps.

Qui slomachum Reyem totius corporis esse

Conlendunt, veru nili ralione videntur,

Ilujus enim validus firmal lenor omniu membra

El contrè, ejusdem frungunlur cunctu dolore.

Ce quon peut résumer aingi : Ceux qui soutiennent que lentomate est le roi du corps ont bien l'aison, catl de sil bonne constitulion dépend lit

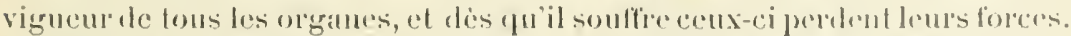

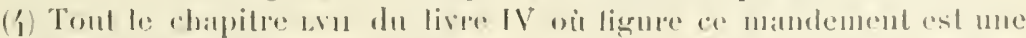

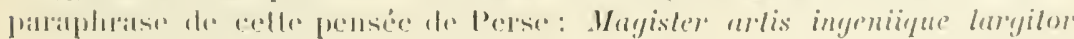
venterr.

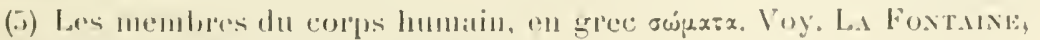

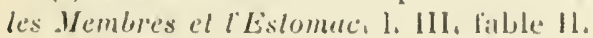


soubstraire à son obéissance; mais bien tost s'en sentit, s'en repentit, et retomrna en son service en toute humilité; aultrement touts de male (1). famine périssoicnt ", Rabelais a exposé gè et là dans son oeurre le mécanisme de la digestion.

"Liorifice de l'estomach, commun ambassadenr pou" l'avitaillement de touts membres, tant inférieurs que supérieurs, nous importune (2), lit-on dans le chapitre xxu du livre $T$, leur restaurer par apposition (3) d'idoines (4) aliments, ee que leur est dochu par action continue de la naïve chaleur en l'humidité radicale (j)) :

(1) Mauvaise, terrible.

(2) Nous avertit.

(3) Par apport.

(4) Conrenables, appropriés, du latin idone'us.

(5) Au dire d'Hippocrate ef de Galien, il y avait qualre humeurs dans le corps humain : le sang, le phlegme ou pituite, la cholere ou bile et lhumeur mélancholique ou atrabile. Amhroise Paré a indique d'une lacon procise, dans le tahlean suivant, la nature ef les caraction physignes de chacuue de ces humeur's :

Distinction des Humeurs

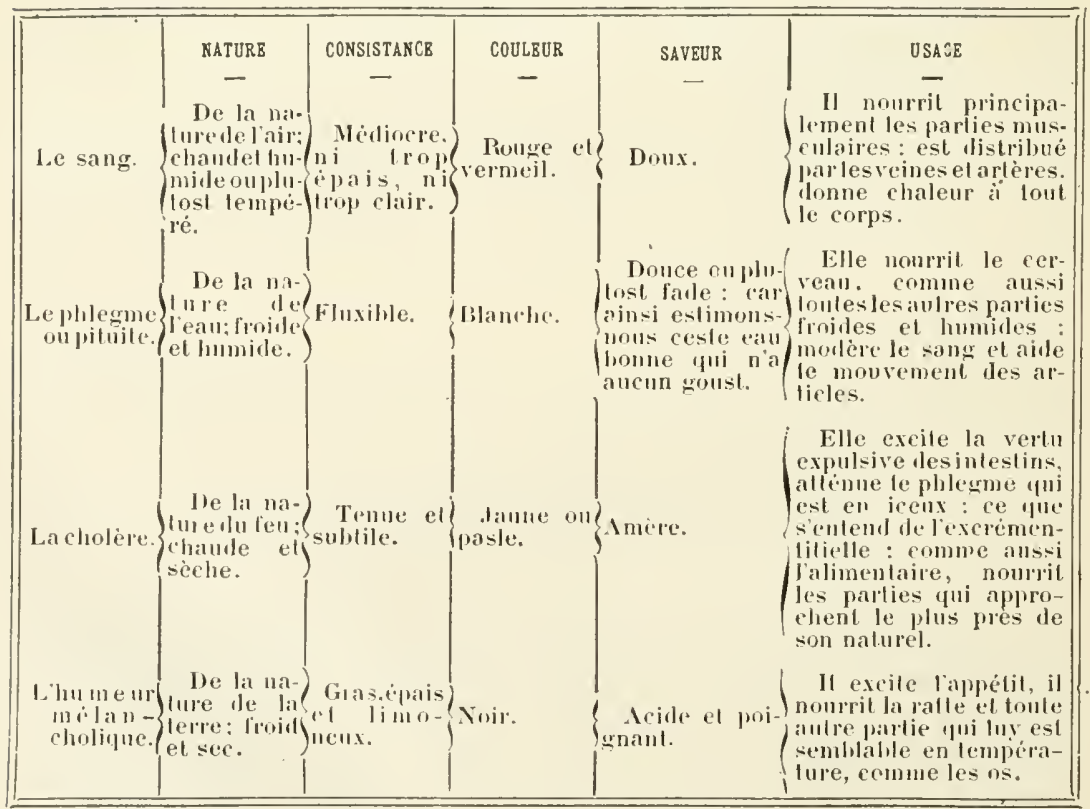

Il y avait imminence on état de malatic confirmé lorsfue liune ou 
poine (1) est par Nature adjoincte (2), et si ne obtempérons, résolution (:3) des esperits."

A quelle cause lorilice stomareal doit-il d'etre ainsi transformé en un serviteur aussi prévenant qu’indispensable? Dans le discours de Panurge ì la louange des presteurs et des debteurs que j’ai déjà eu et aurai encore l'oceasion de citer, mon illustre confrère a renseigné ses lecteurs sur ce sujet ainsi que sur la transtormation dans l'estomac des aliments en mo liquide assimilable d'un blane laitenx, l'absorption de ee liquide par les veines de l'intestin et sur les fonctions de la rate et de la bouteille du fiel.

"L'appétit, en l'orilice de l'estomach, moyennant un peu de mélancholie aigrette, que (4) luy est transmis de la ratelle, admoneste (5), dit Panurge, d'enfoumer viande. La langue

phsients de crs humeurs venait á problominer sur les antres ou à s'altérer yualitativement. Pour guérir les malates, il fallat donc, par des saignées, des purgatils répétés ef la diete, ramener ces lumeurs it leurs rapports normanx, ¿̀ leur composition chinique accoutuméc. L'énumération, dans la première sciene du Valude imaginaire, des remedes fournis par M. Purgon n’a rien d'imaginaire, et le lamenx :

\section{Clysterium donure, \\ Postea seignare, \\ Ensuita puryare,}

dome ume idre exacte de la llérapeutique médicale, telle quelle était encore an lemps de Moliene.

(1) Peine, soruffrance.

(2) Ajoulie, du litlin adjungere.

(3) Disparition, du latin resolnlio. En médecine on dit encore diune maladie ou d'une tumeur yui diminne yublle se résont, quelle est en voic de risolution.

(4) Qui.

(5) Arentit fortement. Les Anciens ayant remarpur que les acides, le

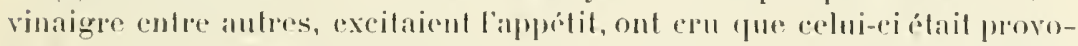

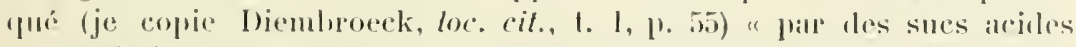
portés de la late au ventricule par le vasiseau veineux court. Mats celle ophinion a été entiemenent détrute par les recherehes des analomistes de re tems, qui fout voir, dans les anmanx vivans, fue viribuldement it

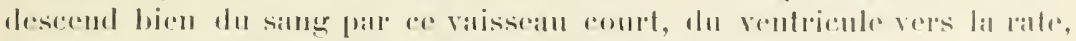

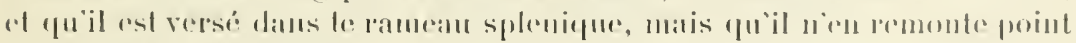
de lis rate au ventrieule. "

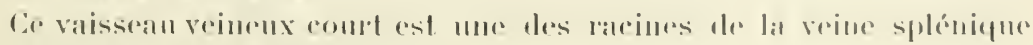
qui se jefte dans la veine porte.

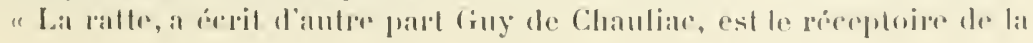


en faict l'essay (1); les dents la maschent: l'estomach la reçoit, digère (2) et chỵlifie (3). Les vènes mésarä̈ques en

superfluite mélancholique engendré an foye... La ratte a denx conduicts : par l'un elle attire du toye la dite superfluite, par lautre l'enyoye à l'estomach. "(Guy de Colalliac, Anat., ch. vi.)

On a altribue le faim à libritation de la mutuense stomacale par le suc gastrique, au frottement donloureux el it la contraction latigante des parois de lestomac, anx liraillements que le foie et la rate, qui ne penvent plus s'appuyer sur l'estomac, exercent sur le diaphragme, ete.

Xenomanes affamé demande ì Pantagruel (1. IV, ch. Lxin): "Manicre déequilibrer et halancer la cornemuse de l'estomach, de mode qu'clle ue penche poinct plus d'un costé que d'aultre?"

On clil encore avoir des tiraillements d'estomac pour aroir faim. 11 est plus que probable que la faim, qui est un sentiment instinctif de conservation, a, comme le besoin de respirer, son siege dans le système nervenx central.

(1) Distingue ce qui est bon de ce qui est maurais, ce ru’il fant prendre on rejeter.

(2) A l'éporpue de Rahelais, on professait cue l'estomac limil des aliments, par une coetion particuliere, un sue laiteux semblable a de la creme ef que l'on appelail chyle (du gree \%ùos. humeur épaisse). Pour Paracelse, l'Arehie aree ses esprits méeanifues était la cause de la chỵfieation des aliments dans le ventricule. Or, par ee mot Archée Paracelse a entendu la chaleur nalurelle. Riolan (Not. sur les Epl de Wallows) a déclaré: "Jen altribue la eause à la différeuce de la chaleur naturelle, qui varie selon l'état ele la substauce, cest-ídire à la propriétó de la chaleur imme. "Les lignes ci-jointes de Copnelins 1 grippa rósument assez bien, an surplus, les opinions ruont enes les Anciens sur la digestion et sur la Paçon tont elle songerait : Les philosophes et les médecins ne sont pas d'aceord, dit-il, sur la conversion on digestion du boire on du manger. Hiplocrate, Galien et Aviceme attribment ì la chalenr de lestomacla coclion des aliments. Erasistrate assure ru'elle se fait dans le ventre. Asclépiade, niant la concoction stomacale, vent que la nonrriture soit partagée dans le corps toute "rue comme elle y est entrée. " Cornelius Agrippa, the Vanit. sciene., I. L.XXXII.)

Le terme plyssologique enneotion (en latin concoctio, dérivé, dans la mème acception, de coruere, cuire) n’a pas servi seulement à désigner les fransformations qu'éprouvent les aliments dans le tube digestif, mais anssi les transformations que subissent les humeurs peerantes aranl d'arriver à maturité. (Voy. Le boyau r..., comme un bourpabaquin monachal, p. 12.3, note 3.)

(3) Il ne faudrait pas induire de eette phrase de Rabelais que celui-ci a cru que les phénomenes digestifs étaient limilés a lestomac. Le commentateur de Galien lia pas dù ignorer yue le médecin de Pergame a erit : "Quoique les intestins ne soient pas faits pour euire le chyle, mais senlement pour le continuer et le distribuer, néonmoins, comme la nature ne demenre jamais oisive et sans agir, le chyle reģoit dans les intestins, 
succent ce qui est bon et idoine (1), doblaissent les excrúments, lesquels par vertu expulsive sont ruidés hor's par expres conduicts: puis la portent au foye : il la transmue derechef, et en faict sang.... Les rognons, par les vènes ćmulgentes, en tirent laiguosité (2), que vous nommez urine, et par les meteres la découllent en bas. Au bas se trouve réceptacle propere : éest la vessie, laquelle en temps opportun la ruide liors. La ratelle $(: 3)$ en tire le terrestre et la lie, que vous nommez mélancholie (1/). La bouteille du fiel en soubstraict (j) la choliepe superfluc (b). Puis est transporte dans une aultre offeine, pour mieulx estre affiné : èest le corur."

a mesure qüil y passe, sa depmirpe enction." (Galtex, I. IV, De I'su parl.) Il a d'autant moins di l"ignorep rue Spigelius, Regius, Pemplins (en son 1. Il des Fond. de méd., ch. vin). Aretorns et Aetius, ete., ont dit la mome clinse.

Pour distinguer la digestion stomacale de la digestion intestinale, on appelle aujourel'hui la premiere ehymifieation (du grec yupós, lumillie grisitte et homogene), et la seronde, eliylitication.

( ا) Convenable, du latin idoneus.

(2) La partic aquense, l'ean, du latin aqua.

(3) La rate.

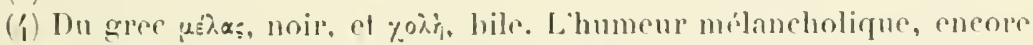
appelée lie, terestre, cholère noire, stait avec la cholire ou par addition la cholére jaune, entsidérése comme ume humenr exerementiticlle dont le sang derait itre lóbarrassé avant d'olre porté par les arteres el les reines il fontes les parties du corps.

"Le fiel n'est qu’une exerétion de la piaptie la plus vicieuse du sang et cest pour cela quil est amer." (Puxe, Hisl. nal. I. XI, ch, Lxir.)

Le mot francais molipe vienl du mot gree \%olì. parer que les Anciens altribuaient la colere a lagitation de la bile. lictyunlogie exigerait quion scrivit rholere.

(.) En souslrait.

(6) "La cholive janne (bilis flava) est altirée par le follieule du fiel, dit Ambroise Pare, oì elle demenre lant quielle ne piohe en quantití ou qualite : el alors elle passe par les intestins, pour les purger et neftoyer pilr son amertume el acrimonie, el pour irpiter la vertu expulsive dienter. anssi jour tuer les ver's qui y somt quelquefois engemdre\%,"

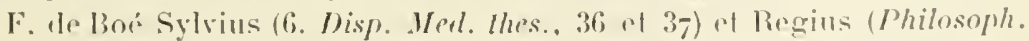

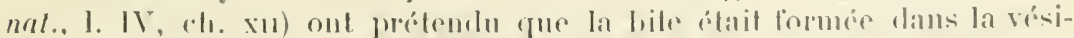

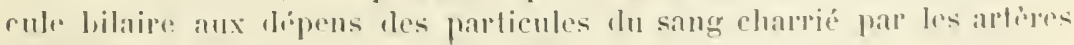
rystipulus. 
Les vaisseaux de lintestin absorbent les sucs des substanees mutritives comme les racines des plantes pompent reux de la terre. Ce qui a fait dire à Ilippocrate: "Qnemadmodum terra arboribus, ità animalibus "entriculus; " ct i Boerhaave: "Les animanx ont leurs racines en dedans d'euxmêmes ". Les vaisseaux absorbants de l'intestin sont les veines mésaraïques ef les chyliferes. Les chylifères (1), cncore appelés vaisseanx lactés, ont été découverts en 1622 par Gaspard Aselli, professeur à l'Ĺniversité de Pavie. Quelques physiologistes prétendent, il est rai, qu'ils araient été apercus arant lui par Aristote, Erasistrate et Hérophile. Cela est douteux. Dans tous les cas, Aristote, Erasistrate et Hérophile n’ont pas soupconné l'usage des ehylifères, puisque Galien lui-même a prétendu que toutes les substances alimentaires étaient absorbées par les reines mésaraïques (2). Les théories galénistes touchant l'absorption exclusive par les reines mésaraïfues des sues nutritils ont régné dans les Écoles jusqu'an xvi siècle. Eustachi, influencé par elles, a regardé comme une reine le canal auquel aboutissent tous les chylifères, le canal thoracique qu'il a découvert chez le cheval. Rabelais a accepté ces théories.

Avec tous ses contemporains, il a admis également que le chỵle, transporté en tolalité par les veines mésaraïques dans le foice, y élait converti en sang impur composé du sang proprement dit, principe essentiel de la vie, du phlegme, liquide séreux excrété sous forme d'urine par les uretères et la ressie, de la cholère (bile jaune), expulsé par l'intestin après un court séjour dans la résicule biliaire, et de I'humeur mélancholique (bile noire) dont une partie était destinée à nourrir la rate et une autre partie portée par une veine de cet organe à l'orilice de l'estomac pour exciter l'appétit.

(1) Du gree \%ùòs, rhỵle, et ọ́ges, je porte.

(2) Les veines absorbent tous les produits le la digestion, sauf les graisses qui sont absorluées par les vaisseaux chylifères. 
De tous les actes de la digestion, l'acte de la digestion stomacale est un des plus importants, sinon le plus important (1). C'est celui sur lequel Rabelais a le plus insisté.

"Le pantagruélion (2), dit Pantagruel, éteincten l'homme la semence génératrice (:3). qui en mangeroit beaucoup et souvent. Et quoi que jadis entre les Grees d'icelle l'on feist (4) certaines especes de fricassées, tartes et bignets, lesrfuels ils mangeoient apres souper par friandise, et pour lrouver le vin meilleur (5); si est-ce qu'clle (6) est de difficile coneoction, offense l'estomach, engendre le maulvais sang, et, par son excessive chaleur, férit (7) le cerveau et remplit la teste de fascheuses et doloreuses rapeurs (8). "

"Mangez, dit Panurge an docteur Rondibilis, un peu de ce pasté de coings (g) : ils ferment proprement l'orifice du ventricule à cause de quelque stypticité joyeulse qui est en eux, et aident à la concoction première (10). "n

(1) Les phénomines de digestion prodominent dans l'estomac, cenx dissimilation dans le pelit intestin, renx dexcrition dans le gros intestin.

(2) Le chanve.

(3) Voy. Plixe, 1. V111, ch. xH1.

(4) On fit de celle-ci.

(5) Toy. Jeax de la Baurake, De lie cibaria.

(6) Elle est pourtant.

(7) Blesse, disorganise, du latin ferire.

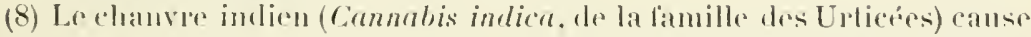
des latlueinations qui rappellent des idees horribles on allatyantes. Les anciemes chronigues rapportent que le Vienx de ba Joutagne en domait aux hommes dent il taisait les instruments de son anbition et de son lana-

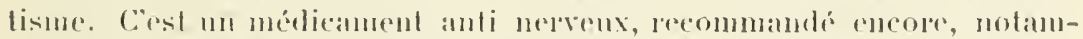
ment ronlre los recetions dontoureuses.

(9) Ce paté, dont on mangeail auldefois atu commencement du repas

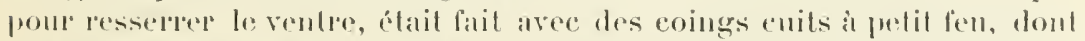
on avait culere le comp, pour les remplir de moelle assaisomende sucre of d'un peol de sel. (PLataxe, De Obsoniis, lib. V'lll.)

Les eoings sont slypliques, cest-it-flie jomissont de la propriété de

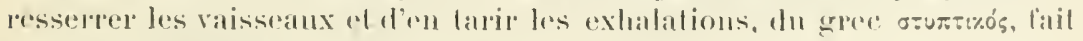

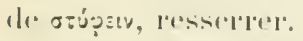

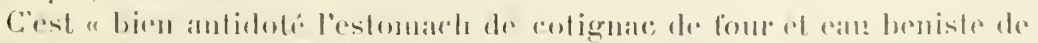

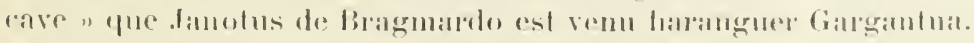

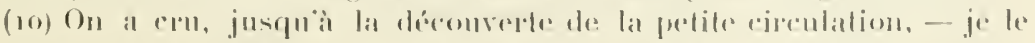

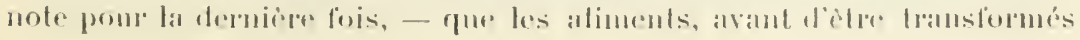


" Debled en herbe vous faictes, professe le chatelain de Salmigondin, belle saulse rerde (1), de lígère concoction, de facile digestion, laquelle vous espanouit le cerveau, esbaudit (2) les esperits animaulx, resjouit la vue, ouvre l'appétit, délecte le goust, asseure (3) le cour, chatouille la langue, faict le tainct clair (4). fortifie les muscles, tempère (5) le sang, allige (6) le diaphragme, refraischit le foye, desoppile la ratelle, soulage les rognons, assouplit les reins, desgourdit les spondyles (7), vide les uretieres, dilate les vases spermatiques (8), abbrévie (9) les crémastìres, expurge (10) la ressie, enfle les génitoires (11), corrige (12) le prépuce, incruste (1.3) le balane (14), rectifie (1.5) le membre, etc. ")

en un sang subtil dans le efeur, btaient transformés en chỵle dans l'estomar par une première coction, en sang impur dans le foie par mne seconde coction, en sang pur par l'absorption de la bile et de latrabile par la résicule biliaire et la rate.

"Les móflecins des princes doivent avoir égard aux excréments naturels, qui sont les restes des eoctions qui se font dans nos corps. " (Corraro, larl de conserver la santé.)

(1) Il nentrait pas que du blé en luerbe dans cette sauce verte dont a parlé Platine (loc. cit. sujpra).

(2) Rend plus vifs.

(3) Rend plus dur, fortifie.

(4) Le régime végétarien rend la peau phus blanche et plus brillante. les Parsis, qui ne mangent jamais de viande, ont un teint bhlonissant. On défend le poisson, le gibier. la viande de boucherie sous toutes ses formes et les boissons alcooliques aux gens qui sont alleints d'une malalies cutanée.

(5) Diminue la chaleur, l'ardeur du sang, du latin lemperare.

(6) Rend plus líger, ote me partie de la charge, du latin alleviare.

(7) Les verlibres. "Les firecs appelaient ces os spondyles, à cause de la ressemblance quils ont arec les petites pirouettes dentelées qui sont au bout des fuseaux à filer, " (De Laurexs, Des Os.)

(8) Les gtandes gínitales.

(9) Raccourcit, du tatin abbreviare.

(10) Nettoie, du batin expurgare.

(11) Les résicntes séminales.

(12) Relive, porte en arriere, th latin corrigere.

(13) Net un revitement de marbre, hu latin incruslare.

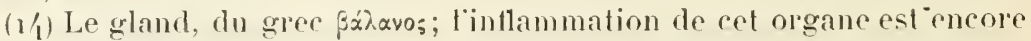
appelér balanite.

(15) Redresse, du latin rectus, droit, et facere, faire. 
"En attendant la concoction et la digestion de leur past (1), Ponocrates (2) et Gargantua laisoient mille joyeulx instruments. " (L. I, ch. xxitr.)

"Le sommeil tousjours renforee la vertus concoctrice, selon les théorìmes de médieine (3). " (L. III, ch. xIr.)

A l'exemple de Socrate, "tousjours riant, tousjours dissimulant son divin sçaroir ", Rabelais a mis " en silenes ", ،'est-itdire en petites boites d'apothicaires comvertes "de painctures contrefaretes à plaisir, pour exciter le monde i rire, ses fines drogues, pierreries et aultres choses prócieuses. C"est pour quoi fault ouvrir le live, et soigneusement peser ee que y est déduict. Lors eognoistrez (4) que la drogue dedans contenue est bien d'aulte valeur que ne promettoit la boite, c'est-à-dire que les matières iey traictées ne sont tant lolastres comme le tiltre au dessus pretendoit."

Qu'on se conforme à eet avis, quion mette à nu dans Córgantua et dans Pantagruel les pensées affublées d'un costume comique, et on trourera, comme nous, des préceptes précienx, mème dans les chapitres les plus osés.

Celui qu'on a aceusc d'une intempérance immorale el malsaine s'est moqué des gens qui font un dieu de leur rentre, des "Gastrolatres (.), poids el charge inutile de la terre " et les a renvogés a leur "selle persie, voir, considérer, philosopher, of contempler quelle divinite ils frouroient en leur matière fécale ".

(1) Pature, nourrilure, el anssi pepas.

(2) Homme lalonpiens, du gree rivos, travail, el \%pózog, fopee.

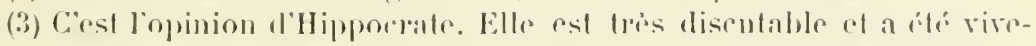
ment et it juste tilme combilfur par liroussais. Chez les amimanx hibermanls foules les fourdions de la vie de mutrition sont ralenlies.

Si lo sommeil engraisse, ce nest pas parece quil angmente l'assimila-

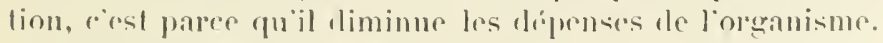

(i) Commatrez, du latiu cognoseeree.

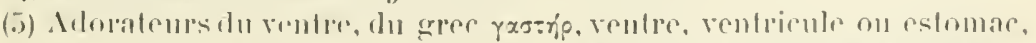

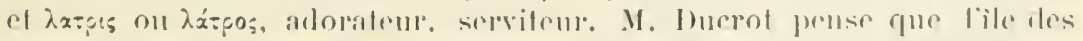

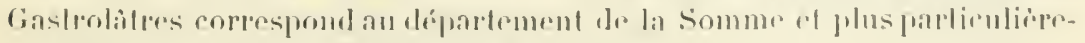
ment ì Amiens. (Toy. I) ecrot, loc. cit., p. 22.) 
"Le disner de Gargantua estoit sobre et frugal : car tant seulement mangeoit pour refiéner les abois de l'estomach: mais le disner estoit eopicux et large; car tant en prenoit que lui estoit de besoing à soy entretenir et nourrir. Cie que est la vaic dicte ( 1 j prescripte par l'art de bonne et seure médieine, quoi qu'un tas de badaulx médicins, herselés (2) en l'oflicine (3) des sophistes, conseillent le contraire. "

Une conversation de Pantagruel et d'Epistemon (4) complite cette asscrtion: "- Quantes heures sont? (5) demande Pantagruel à Epistemon. - Neul, et d'advantage, respond Epistemon. - C'est, dist Pantagruel, juste heure de disner; car la sacre ligne (6) tant célébréc de par Aristophanes en sa comédie intitulée les Prédicantes (7), approche, laquelle lors escheoit (8) quand l'umbre est décempédale (9). Jadis entre les Perses l'heure de prendre réfection estoit és ( Io) rois

(1) Diète est ié synonyme de régime. En médecine, on dit d'un malade auquel il est défendu de prendre autre chose que du lait : qu'il est soumis à la dicte laclée.

(2) Elevés, instruits.

(3) A l'École. Avicenne ot ses disciples ont reconmanté, et des hygiénistes recommandent encore, de se lever de lable avant d'ètre complètement rassasić. Si la cessation de la laim suffil a la conserration de la vie, la plénitucle de la jouissance qui ne va pas jusqu à la satiété donne plus de jeu a l'exepeice des organes. A l'exemple de Gargantua, on pourra done manger pen le matin pour avoir l'esprit plus libre pendant le jour et largenent le soir. Quon noulsie pas, toutefois, qu’il est dangerenx te substiluer à un plaisir nalurel, physiologique, un plaisir artificiel qui est toujours payé par l’iritation on par l'insensibilité prématurée des organes, par leur destruction ou par leur impuissance.

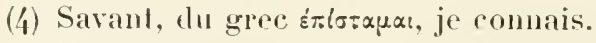

(5) Quelle hemre est-il ?

(6) La ligne sacrée.

(7) Les Prédicuntes, les harangueuses. "Dans cette comb́die, nous apprennent Burgatud des Jarels et Rathery, Praxorus, expliquant i son mari Blepyrus son plan de république communiste, lui dit (к. 652, 653) : " Tu " n’auras antre chose à faire que d’aller manger lorsque l'heure du cadran "sera de dix pieds. "C'était l'henre des repas; celle du bain était quand lombre marquait six pieds."

(8) Tombe, arrive.

(9) Dix pieds, de decem, dix, el pes, pedis. pied.

(10) Aux. 
seulement prescripte: à un chascun aultre estoit l'appélit el le ventre pour horloge. De faict, en Plaute, certain parasite soy complainct, el déleste furieusement les inventeur's d'holloges et quadrants, estant chose notore qu'il n'est horloge plus juste que le ventre (1). Diogenes, interrogé à quelle heure l'homme doibt repaistre, respondit: "Le riche, yuand il aura faim: le paure, quand il aura de quoy (2). "Plus proprement, disent les médicins l'heure canonique (3) estre:

Lever à cinq, disner à neuf,

Soupper is cing, coucher is neuf (4).

La magie du célible roy Petosiris estoit aultre (5). "

One le somper soit, eontrairement is la régle adnise maintenant, plus abondant que lo repas du matin: l'esprit n'on sera que plus lueide dans la journée, et on ne sen trouvera certainement pas plus mal pendant la nuit, si, comme Gargantua, on a soin de ne se coucher que longtemps appis s'ètre leré de table (6), de ne pas prendre pour un besoin réel le désir qui nait de l'apprèt de cerlains aliments, de converser entre chaque bonchéc et quelques instants

(1) Sam, me puero, ulerus hie eral solarium

Jullo omnium islorum optimum el verissimum.

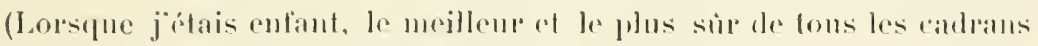
Etait mon ventw. [Plaute. Fragmenls].)

(2) Voy. Dogdia be Lanere, lie de Diogine le Cynique.

(3) Sclon dis liegrace.

(i) Le proverbe ajonte : Fait vire d'ans, nomante-nente.

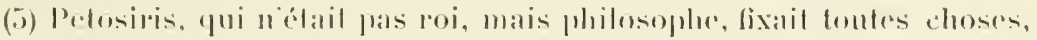

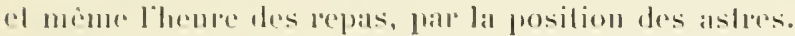

. Fypra licet jureal. erupiendo nulla videtur

Iplior hora rilo, nisi ylum dederit Pelosiris.

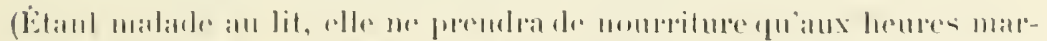
pures pall Pelosiris. [Juverill, sal. V1, vers 5i3].)

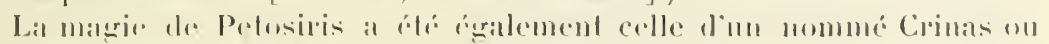

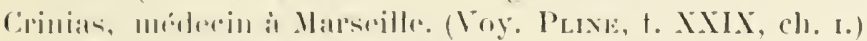

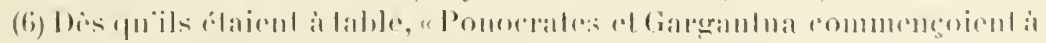

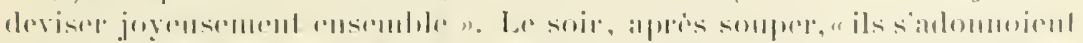

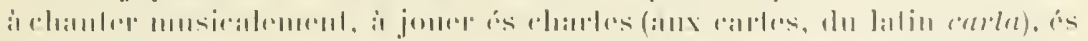

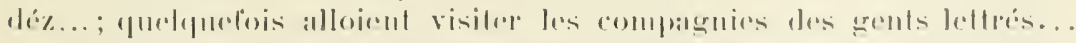

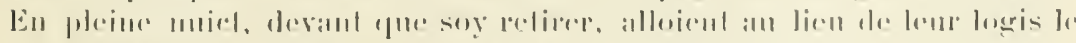

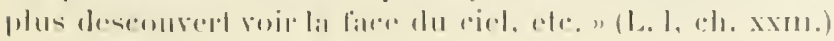


après aroir nangé (1), et de se présenter, autant que possible, aux mèmes heures, "és lieux secrets pour laire. excrétion des digestions nalurelles" (2).

Il conviendra aussi, une fois rassasié, de ne pas travailler avant de se mettre au lit. "Nature ha faict le jour pour soy exercer, pour travailler et vaquer chascun en sa négociation (:3) : et, pour ce plus aptement (4) laire, elle nous foumil de chandelle, c'est la chane el joyeulse lumière du soleil. On (5) soir, elle comnence nous la tollir (6), et nous dict tacitement: Enlants, rous estes gents de bien : e'est assez travailler, la nuict vient : il convient cesser du labeur, et soy restaurer..., puis soy quelque peu esbaudir $(7)$, coucher et reposer, pour, on (8) lendemain, estre lrays et alaigres au labeur, comme devant. Ainsy lont les laulconniers, quand ils ont peu (9) leur's oiseaulx. Ils ne les font voler sus leurs grorges, et les laissent enduire (10) sus la perehe (11)."

L'enfant, en raison de sa eroissance, de sa cireulation

(1) Un habile médecin de Vichy, 11 . le Dr Grelelly, a publić, en 1888, une brochure fort intéressante pour nontrer les dangers quiofre le silence imposé pendant les repas dans les pensiomnats et les courents.

La digestion est meilleure,

Lorsque l'on conteste un quart d'heure,

Un moment après le repas,

a dil, d'autre part, Scaron.

La sćcrélion de la salive qui contient un ferment digestif des phus puissants, la ptyaline, est en effet active et persiste quand on cause cn mangeant of immédiatement après aroir mangé.

(2) A trois siècles de distance, le frotesseur Troussean, le compatriote do Rabelais, a insisté, dans un chapitre d'une de ses cliniques de l'IoblelDieu de Paris, sur l’importance d'une exonération réguliere el quotidienue des résidus de la digestion.

(3) A ses allaires, du latin negolium.

(4) Conrenablement, du latin apte.

(5) An.

(6) Nous la ravir, nous lòter, du latin tollere.

(7) Réjouir.

(8) Le.

(9) Pu ou peu, repu, lait nanger.

(10) Digérer, du latin inducere.

(II) L. III, ch. xy. 
plus active, de sa vivacité plus grande qui lui fait brùler plus vite le carbone des aliments qu'il absorbe, ne salurait toutefois ètre soumis à ces règles. Il doit manger anssi souvent que sal laim, plus impérieuse que celle de l'adulte. l'exige.

"Donnez ì repaistre aux jeunes, prescril Panurge (notez jeunes). Carr, selon la sentence d'llippocrates (1), jeunesse est impatiente de faim, mesmement (2) si elle est vivace, alaigre, bruscfue, nouvante (?), voltigeante (4), galoise (J)."

Rabelais ne s'est pas préoceupé seulement de la quantilé d'aliments que l'homme doit ingéerer aux différents àges de la vie et des heures auxquelles il doit les ingérer, il s'est préoceupé aussi de leur préparation et de leurs propriétés physiologinues $(\mathbf{6})$.

Citons alu hasard :

Le bouillon s'obtient en faisant bonillir un morecan de beul dans de l'eau légèrement salée à laquelle on ajoute des légumes pour en rehausser le gont. L'eau dissout d'abord l'albumine dont une partic forme l'écume qu'on enlève, puis la créatine, la créalinine, l’acide inosique, cte., puis, entin. quelques portions des fibres musculaires qui sont détachées par la continuité de l'ábullition. Pour avoin de bon bouillon et de bon bouilli, il faut que l'eau s'echaufle lentement, alin que l'alloumine ne se coagule pas dans l’intérieur de la

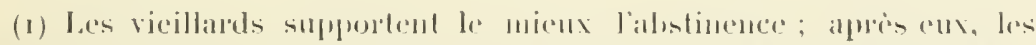

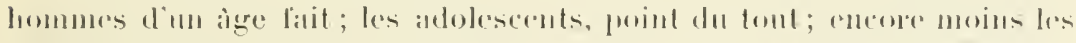

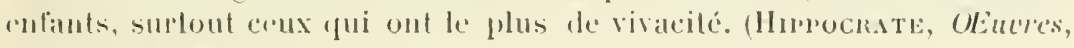
trid. de Pariset.)

(2) Surtout.

(3) Remuante, do latin movere.

(4) Mene sens que ci-dessus.

(5) Joyeuse nlerte. (I. 111, ch. 11.)

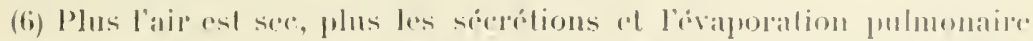

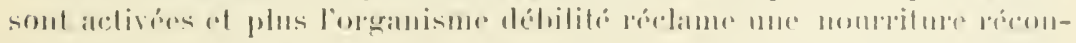

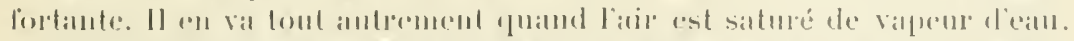
"Par les tempes humides, Ponocrates et Garerantua mangeoient plus sobrement qu’és aultes jours el viandes plus désiccatives et extémantes." 
viande: il faut que l'ábullition s'aperengive à peine, afin que les autres composés chimiques qui sont successivement dissons puissent simir intimement et sans trouble. L̈incorrigible railleur fait déclarer gravement par le fondatenr de l'abbaye de Thélìme que e'était surtout pour methe plus tôt "la marmite elaustrale au feu ", que les moines se levaient jadis de bonne heure. "Plus matin se levants, plustot estoit le beuf an feu;

Plus y estant, plus cuicl restoit;

Plus cuict restant, phus tendre estoit,

moins usoit les dents, plus délectoit le palat (1), moins gravoit (2) l'estomach, plus nourrissoit les bons religieux (3). "

La chair du chapon, de la perdrix, de la géline, du pigeon, est appétissante et très digestible. Et si "feu Amer, médiein d'eau doulee à Angiel's, deffendoit aux malades l'aiske du chappon gras on celle de la perdrix, le croupion de la géline et le col du pigeon, disant: Ala mala, cropium dubinm, collum bonum, pelle remota (4) ", c'estoit aflin que tout fust réservé pour sa bouche. - "La rougeur des viandes est indice qu'elles ne sont assez cuictes. Exceptés les gammares (5) et escreviers que l'on cardinalise (6) a la cuicte $(7)$. " - La charculerie sous toutes ses formes (8), les

(2) Le palais, du latin palalus.

(I) Chargeait, pesait sur, du latin graeure.

(3) L. IIl, ch. xт.

(1) "Laile est manraise, le crompion passable, le con bon ruand on en a oté la peau. "Jean do la Bruyipe Champier (l. XV, ch. vur de son De Re cibaria) a cerpit : Inlyas jactat collum acium, sed priesertim gallinacei generis, bonum cule debracti. Alii clarilati oculorum officere crediderunt. Par "médicin d'ean douler", Le Duchat croit que Rabelais a voulu dire: "médecin dont les remèdes ne font pas plus de bien ou de mal que si ce n'itait de l'eau douce ".

(i) Les homards, du grec xx́uxpos.

(6) Jules Janin, qui lisail assilliment Gargantua, sest souremu sans doule le cette expression quand il a appele le lomard le cardinal des mers.

(7) L. I, ch. xхxix.

(8) Le xrre siecle s'est gorgé de chareulerie et de salaisons. Lemr áloge revient sans cesse dans Rabelais. Ici, cest frère Jean apportanl pour 
salaisons, "les langues de bouf fumées, boutargues 1) et tels aultres sont avant-coureurs, aguillons de vin, compulsoires de beuvettes ". - "La laitue tempère la soil (2). " " Nature nous instruit cueillir el manger les fruicts

entrel en vin " quatre horrificques (énormes) pastés de jambon \%. Lia, ee sont les cuisiniers poyan tuant "beuls pour eslor at Marily-gras salés, affin quin la primevère (au printemps) ils eussent bunlside saison a tas pour au commeneement des repas faire commomoration des sitlures". An nombre des "beauls livers n, conselvés préciousement dans la bibliotherpue Saint-Victor it Parris, ligment: Des Pois an lard. cum commento; lAyuillon de rin; le Tripier de bon pensement; Majoris, de morlo faciendi boudinos: Berla, de oplimilale lriparum; Rererendi palris fralris Lubini, provincialis Burardix, de Croquendis lardonibus libri lies, ete.

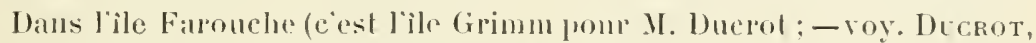
loc. eil. supri, 1. 17: - envieille langue gothique, Grimm reul dire: furieux, féroce, farouche, toujours en lage), oi lon adore Mardigras, quanantedeux mille Andonilles, altilées comme dans les fréries popmlaires ef commandés par les eapilaines Riflandonille of Tailleboulin, attapuent "alenlour du chasteau de Saloir ol de la forteresse de Catues " laumie de Pantagruel. Frope Jean, dont la momoire ast rexcllenle, assiste par bouheur a ce combat. Il songe au cheral de Troie el fiat eonstruire " une grande truye en bois " capadile de loger daus ses flanes deux cents cuisiniers, apperés: "Simpiefuel (sance piguante), Grasboyau, Pillemortier, Crenpelardon, Tirelardon, Frizelardon, Grattelardon, Guaillarelon (par syneope, Guallartardon), anquel se joint Bondinandiere, etc. " En

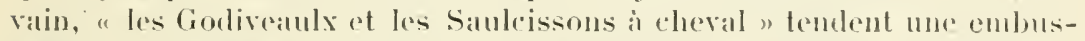

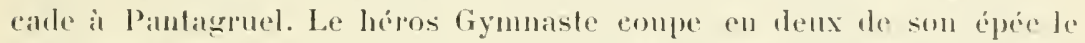
labuleux général Cervelat. Enfin l’infinte Niphleseth (phallus en hébreu) et soixanle-dix-huit mille de ses sujetles "Andonilles royales " sont envoyes a Gargantua qui en lait présent au "grand roy de Paris ". Mais, hélas! "par laulfe de moustarde (baulme naturel et restaurat d'andonilies) mommentent presigue foutes ".

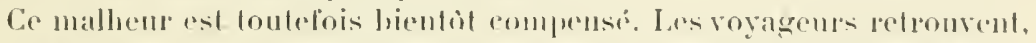

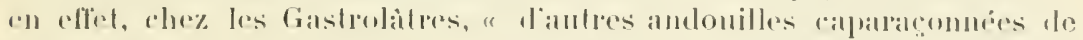

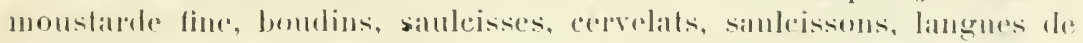
bunl finmés, jambons, lumes de sanglier, sammales (cretons, menues litures, de litalien sommala).

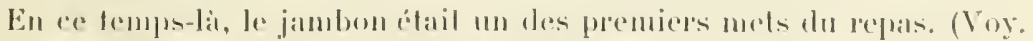

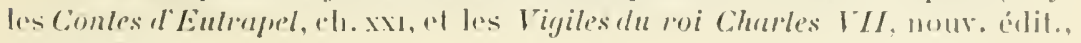
t. I, $1,80$.

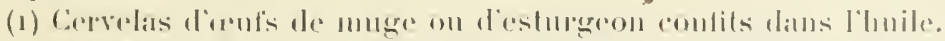

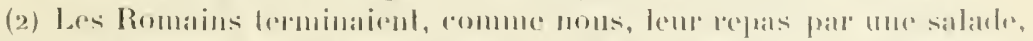

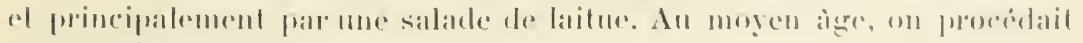
(1) serls inverse.

Gamganlua mangeait de la salade an debul de ses menas, mais las 
quand ils sontmeurs (1). " - Les poires de bons chrétiens cuites " en casscrons (2) par quarticrs arecques un peu de vin "sont très salubres, "tant is malades comme és sains " (:3). - "Ciest viande (4) cóleste manger à déjeusner raisins arec fouaces fraisches mesmement $(5)$, des pineaulx, des fiers (6), des muscadeaulx $(\boldsymbol{7})$, de la bicane (8), des foirars (g) pour ceux qui sont constipés du ventre."

Il est de vieilles coutumes qui araient du bon. La cure de raisins est de ce nombre. Voulez-rous débarrasser ros viscires de l'enduit qui les engorge? Faites une cure de raisins. Mangez-en autant de grains que vous voudrez, mais en évitant d'araler les pépins et les pellicules, qui sont des corps indigestes et sans utilité. Ce qui agit dans le grain, e'est le jus qui contient tous les principes d'un excellent savon: des tartrates, des malates de potasse, neutralisants bien supérieurs au sel de Vichy (bicarbonate de soude) et un acide

lrères fredons à la fin du leur : "lls commençoient leur repas par lormage, el l'achevoient par moustarle et laictue, comme tesmoigrue Martial avoil esté l'usage des anciens. "Dans l'épigramme 1'f du lirre XllI de Antial, on trouve en eflet les deux ver's suivants :

\section{Claudere qux conas lacluca solebat avorum}

Dir mihi, cur nostras inchoat ille dapes.

A Rome, la salade de laitue élait jadis servie de prélérence le snir. l'après le conseil de Dioseoride, qui arait reconum les propriétés tempéranles et hypmoliques de la plante en ruestion. L'emperen Auguste fit élever une statue à son médecin Iusa qui lavait guéri an moyen de la laitue. A l'henre actuelle, le suc de laitue, on lachucarium, entre daus la composition de la plupart des potions calmantes et antispasmodiques.

(1) Quand ils sont trop rerts, ils contiemnent mu principe àcre rui irrite la muruense digestive el provoque la diarhée.

(2) En cassiloles.

(3) Pline dit (1. XVIII, ch, vin) que toutes les poires sont pesantes et indigesles, sauf quand elles sont cuites.

(1) Dans lo sens de mets, laliments; vieanda en basse lalinite. lait de vivere, signifie tout ce qui fait vivere.

(5) Principalement.

(6) Raisins appelés anssi fumés.

(z) Raisins museats.

(8) Raisins ì faire le rerjus.

(9) En Guyente on appelle ainsi les raisins appelés pincaux en Touraine. 
susceptible de se dédoubler comme l'acide du vinaigre en alcool el en acide carbonipue. Sous l'influence de ce jus " divin ", les selles se multiplient entrainant l'acide urique, les engorgements du loie disparaissent, l'hypochondrie senrole colorant l'avenir des fons les plus posés, les affections cutanées s'éteignent laissant le calme et la donce chaleur dans les régions où régnait la veille un prurit dévorant. N'en déplatise à Brillal-savarin, il est tres bon de prendre quelquelois son vin en pilules.

Le roi des condiments, le vinaigre, qui excite la sécrétion des glandes salivaires et des follieules gastriques dont les snes sont indispensables à la digestion des viandes noires, est prôné par Maìtre François :

... Manger levrault, c'est malheur

Sans de vinaigre avoir mémoire (1):

Vinaigre est son ame et valeur.

Relenez-le en poinel péremploire (2).

Les chevaliers de Pantagruel " feirent rostir leur venai-

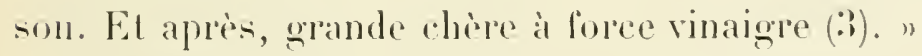

Les ragoits sont en général mal supportés par les estomacs délabrés. Il en est de mème des sancess sauf de quelques-unes, la sauce Robert ou sauce au paure homme.

(1) I. II, ch. xxris.

Comuilz rostis, anssi poulaille

siont bons pour estre bien repuz

Arec la sallec du verjus.

Guillaume Buxis, Conseils pour ke préserver de la pesle.)

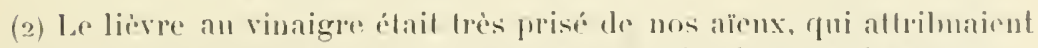
a la chair, aux visceres et mème au sang de cet animal me foule de vertus. La chair conservilt on domail la beantó; les grlandes génitales gucéris-

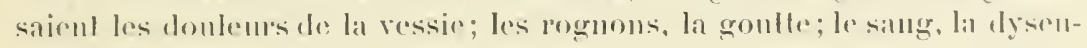
torie, ale.

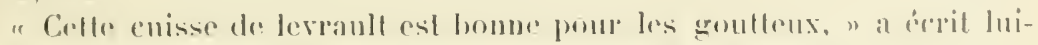

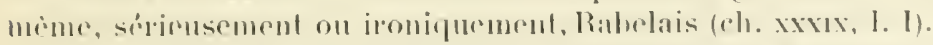

Lin rela, nos a

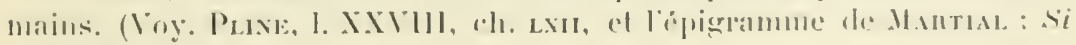
yuculolo lingurem...)

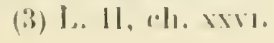


entre autres (1): "Lans salubre et nécessaire aulx comnils (:2) rostis, canars, pore frait, uul's pochés, merlus salés".

En aidant son maître Rondellet dans ses recherches sur les poissons, Maitre François a retrouvé le garum, cette saumure célébréc par Horace, Martial et Ausone (3), et en a enrové à E. Dolet, arec ces rer's :

Guod medici quondam tanti facere priores Iynolum nostris en tili millo Garum.

Vini addes acidi quantum vis, quantum olei vis.

Sunt quibus est oleo plus sapidum lintyrum.

Dejectam, assicluus libris dum incumbis, orexim

Nulla tibi melius pharmaca restiluent,

Vulla et aliquaculi mage deteryent pituitam,

Nulla aldum poterunt solvere commodius.

Mirere id potius, quantum ris clulcia, sumpto.

Salsamenta, Garo, nulla placere tibi (4).

"Ce Garum, que nos médecins ne eonnaissent plus, et que leurs prédécesseurs estimerent tant, je te l'envoie. Tu ajouteras, à ton gré, du vinaigre et de l'huile; il en est cependant qui préfèrent le goùt du beurre. Pour toi qui passes ta vie courbé sur les livres, il n est point de meilleur remède pour te rendre l'appétit, te balayer les humeurs at te relicher plus commodément le ventre. Surtout, et cela ne sera point sans t'étonner. quelle que soit la finesse des condiments

(1) L. IV, ch. xh. La sauce Ponbert, eneore indinuée dans les livers de cuisine, est une sance dans la comprosition de laynelle entrent du vinaigre et de la moularde.

(2) Mienx conils, hapins, du latin cuniculus; on disait anssi comnin.

(3) Pline cot Dioseoride en ont donné la recetfe. Mais cette pecette stait completenent tombée dans lonbli. (Voy. S. Rovenelet, Histoire des Poissons, lad. frans. de Lanrent Jonbert; Lyon, MCLuH, l. V, ch. xiv. - Du Picarel, pl) 126-127, 1. VH, ch. x. - De la Sardine, 1. 181 etl. V11, ch. I11. - Des Anchoies, p. 177.)

(1) Florelum philosophicum seu ludus Meudonianus in terminos lolius philosophia autore Antonio Le Roy prestylero Cenomanensi IV. Licent opus elucubralum .Meurloninij in Musieo clariss. Fr. Labelesi, elc. Parisiis, 16 19. (Proprixfintione, $I$, iij.) 
dont tu te sers, nul pour toi ne vaudra le Garmm quand tu l'auras gorité. "

Treut-on savoir ce que le prètre-médecin pensait du régime quadragésimal? Il n'y a pas d'aliments plus excitants que ceux qui sont prescrits par l'Église pendant le Garème (1): "febres, pois, phascols (2), chiches (:3), oignnons, noix (4), huistres, harens, salures (j)), garon (i), salades toutes composées d'herbes rénéréiques $(7)$, comme éruce, nasitord (8), targon (9), cresson, berle (10), lesponse (11), pavol cornu, houbelon (12), ligues, riz, raisins (1:3) ")

Le pain, qui est la base de notre nourriture, doil. comme l'indique Pantagruel (14), Stre salé ot fermenté pour itre lower et sapide. "Chose on (15) monde plus les hmmains ne

(1) I. V, сh. ххм.

(2) Hirricols, du latin phuseolus.

(3) Les lèves, les pois, les harieols, les chiches, le riz sont les aliments végétanx qui contienuent le plus de matieres azotéen, principes estenliels de lat mutrition.

(1) Les hygienistes apont fur laction stimulante expere par less

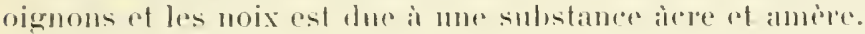

(j) Les salaisons et la chair de poisson sent tres mutritives. La chail

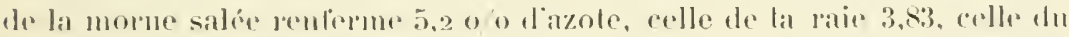

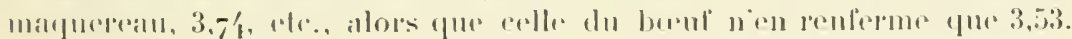

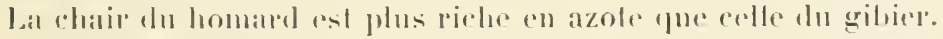

(6) Poisson appelé intrefois en Langruedoe picarel. Il doit son nom moderne il haludais yui s'on ast servi pour recomposer le gallum.

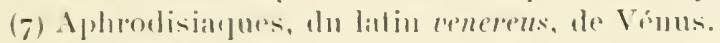

(8) Cresson alénois.

(9) Estrigon.

(10) Plante de la lamille des Ombellitéres.

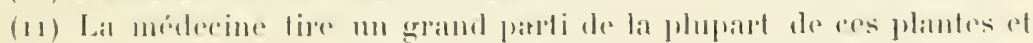

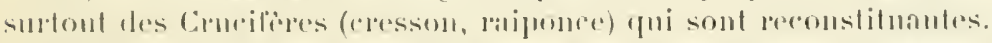

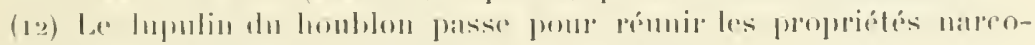

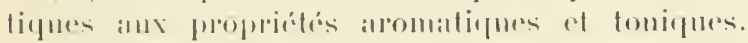

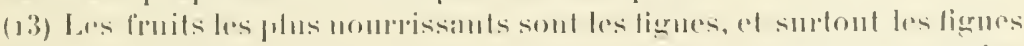

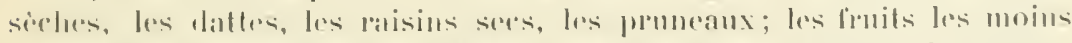

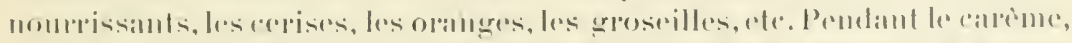

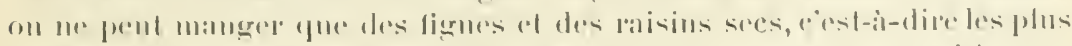

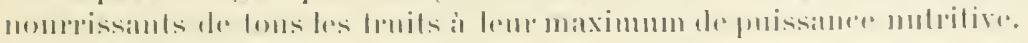

(1) 1.. IV, rh. L.x.

(15) A11. 
lend à maladic subjects, que de pain non formente, non sale H-el (1). »

Poursuivons. Après les aliments solides, les aliments liquides, les boissons.

La menthe, qui entre dans la composition d'unc excellente liqueur, rend le sang plus fluide. "En tesmoignage, sont les champs de lisle de Samos (2), dicts Panema (:3), c'est-didire tout sanglant, auxquels Bacchus les Amazones (1) acconecut(.)), furantes de la contrée des Ephésians (6), ef les mit toutes à mort par phlébotomie (7), de mode gue (S) le dict champ cestoit de sang tout embu (g) et couvert. D'ond (10) vous ponrez doresenavant entendre mieuls que n'ha deseript Aristoteles, en ses problemes (11), pourquoy jadis on disoit

(1) Le pain sans levain ef sans sel est fade, incligeste et moins nourissant. Le levain ou la levure trausforme une portion cle la léeule de la larine en dextrine et en glyeose. Ainsi est commencé le travail de translormation de la fécule de la farine en dextrine ef en glyeose, que complète laction de la salive.

Le sel entre dans la composition de divers tissus de l'organisme, du tissu musculaire entre autres. Il active la sécrétion des liquides de l'estomac indispensables à la digestion des aliments azotés. Les animaux ont, de mème que l'homme, un gout prononé pour le sel et le mangent arec aviclité.

(2) Ile de la nier Égéc.

(3) Du gree $\pi \tilde{x}_{j}, \pi \alpha y o_{5}$, tout, et $\alpha \hat{j} \mu \alpha$, sang. (Voy. Plutaroue, dans ses Demandes des choses grecrutes, eh. xcru.)

(4) Fenmes guerrières habitant la Cappaloce, sur les bords du fleuve Thermodon, et qui brûlaient le sein droit de leurs filles pour les rendre

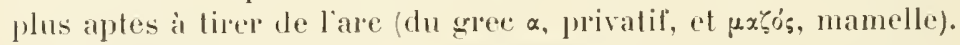

(5) Atteignit, rejoignit, du latiu adconcipere, de ad, augmentatif, ot capere, prendre.

(6) Linnie.

(7) Par ouverture des reines; du grec pidus, reine, et ropì lait de ?úve, je coupe.

(8) De sorte que.

(9) Inprengé, imbibé, du latin in, dans, declans, et bibere boire.

(10) Doir.

(11) Aristote a arancé (Sect. 20, Probl. 2) que la menthe étant froide par elle-nème ne convient pas aux soldats. Le père de la botanique, Dioscoride, a, d’autre part, prétendu que les fenilles de menthe jelées dans le lait l'empèchent de se cailler et de se mettre en fromage. Selon Lerwis, 
en proverbe commun: "En temps de guerre, ne mange et ne plante menthe." La raison est, car en temps de gutrore sont ordinairement despartis (1) coups salns respect (2), or que l'homme blessé, šil ha celluy (:3) jour manié ou mangé menthe, inpossible est, ou bien difficile, lui restreindre (4) le sang (5).

Le vin, pris avec modération, donne des lorees: "les acadómies l'afferment (b), rendants l'étỹnologie de Vin, lerpuel ils disent en grec orvos, estre comme vis, foree, puissance. (7)" - Le vin rouge est " l'esperon du fromage ". - Le vin banc "soulage les rognons " (8). - "L'hỵpocras clairet est salubre et stomachal (9)."

Trousseau ef Pidoux, la menthe nempricle pas la coagulation du lait, mais la retarte. An dire de Limé, les raches qui mangent de cette labiér

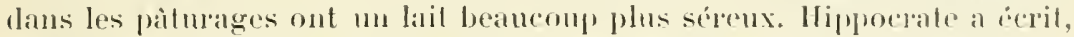
enlin, que "le lail est le frère du sang of Galien (I. IV, De l"Ĺsuge des parlies, ch. vir, et De ren. sect. contre Errusistrale, ch. v), yue le lait est engendre du sang menstruel. Les Anciens ont conclu frat analogie.

(1) Distrilucé, dı latin despartiri.

(2) Sans igard, an hasurd, du latin respechs, linit de respicere, regander, aroir égard.

(3) Ce jour-lii.

(4) Arreter, du lalin reslringere.

(5) L. V, ch, тххт.

(6) Lialfiment.

(7) L. V, ch. xLr.

(8) Est diuretipue, lait urined. Le vin blane est la base des rins médienmentenx diurétiques de Tronssern, de Delbrenes, de Tessier, de Corvisart, ete.

(9) Vin (rouge on blane) alromatise. Voici la recette quen domm Taillerent : Ponr une pinle, frois tréseanle (trois gros) de cynamone line el paré, mu drésean de mesche on demx qui veult; denx tréseauls de: girolle; ot de sue fin six onces, el mettez en poudre; ef le lintt toul mettre en un contonoir (entomoir) avee le vin, et le peot desionbs, ef le passer sans qu'il soit roulé, et lant plus est passé et micux raull; mais "fuil me soit esweré."

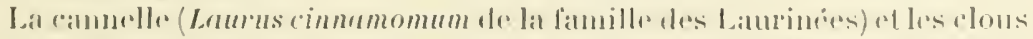

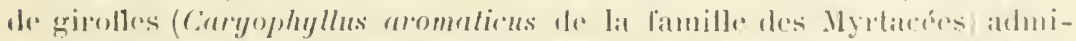

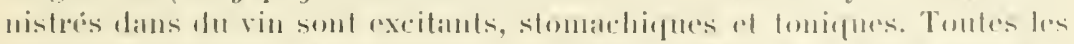

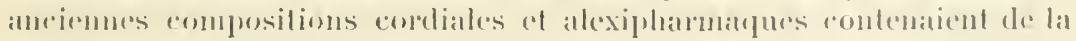
cambelle.

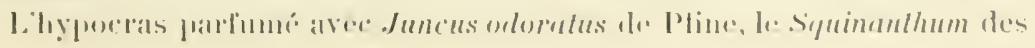


Pris avee excis, le vin blane, comme le vin rouge, amène la goulte, rongit el délorme le nez, desquame la langue, irrite la muqueuse gastro-intestinale, ete.

Parmi les ancetres de Pantagruel (1), il y en avail dont le nez " sembloit la flente d'un alambic (2), tont dia-

apothicaires, était moins prisé que celui qui n’élait pas parlumé, paree quon supposait, sans donte ì cause de l'analogie verbale, qüil pouvait donner lesquinancie. (Voy. Pline, I. XII, ch. xxil, et I. XIV, ch. xve, el la $1^{\text {re }}$ des Sérées de Bouchet.)

"Voulez-rous eneore un traiel dhypoeras blane? demande Panurge it Rondihilis. Nayez paour de l'esfuiuance, uon. Il u'y a dedans ne squinanthi, ur zinzembre (gingembre), ne graine de Paradis (eardamome). II n'y laa que la belle cinamome friée ef le bean suere fun, avecques le bon viu blance du cren (eru) de la Devinière." (L. III, ch, xxxu.)

Ménage et d'autres attribuent i tort l'invention de l'hypocras a Hippocrate. Le mot hypocras vient du gree irò, sous et «pãsıs, mélange, lérivé de жśávvipu, je mèle.

(1) Prol. du 1. II.

(2) La llùte de l'alambic est le tuyan allongr cylindro-conique qui lait communiquer le chapitean avec le serpentin.

Dapris .I. Bepthelot, les appareils distillaloires proprement dits ont

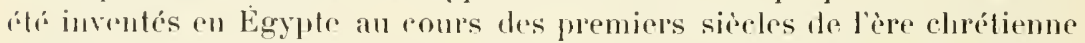
el décrits daus les traités de deux femmes alchimistes appelées Cléopàtre et Marie. Ce sont ces appitreils qui ont conduit, par leur's transformations, it la déconverte de lalambic décrit dis la tin du $x^{\mathrm{e}}$ sieccle de notre ère par Synesins. (Bertuelot, la Chimie al moyen ige.)

C'est Amaud de Villeneuve qui parait, le premier, avoir employé de terme d'ran-de-rie, pour désigner le produit de la distillation du vin. Encore l'a-t-il employé, non comme terme spécitique, mais pour marquer l'assimilation de ce produit aree l'ólixir de longue vie. En réalité, c'est sous la dénomination d'ean ardente, c'est-à-dire iuflammable, que l'aleool Ij) araît d'abort.

Dans le Live des feux de Mareus Gracus, live dont les manuscrits ne remontent pas au-delà de l'an 1300 , la préparation de l'eau ardente est aussi indiquée:

"Préparation de l'ean ardente. - Prenez un vin noir, épais, vieux. Pour un quart de live, ajoutez deux scrupules de sonfre vif, en pondre fres fime, une on denx livres de tartre exfrait d'm bon vin blanc, et denx serupules de sel commun en gros fragments. Placez le tout dans un bon alambic de plomb, mettez le ehapitean an-dessus et rous distillerez l'ean ardente, rous la conserverez dans un vase de terme bien fermé. "

Les origines de la physique et de la chimie sont encore obscures et cenx quils préoccupent ne seront pas fàchés de trouver daus Prulagruel non seulement l'indication de l'eau ardente (Voy. la Luelle, comme une sar- 
pré (1), tout estincelé de bubelettes (2): pullulant (3), purpuré, à pompettes (4), tout esmaillé, tout boutonné, et brodé de gueules (j). Et tel arez vu le chanoine Panzoult, el Piedebois, médicin d'Angiers : de laquelle race peu furent qui aimassent la ptisane (6)."

"Les bourgeois d'Aurelians ( 7 ) avoient tant bu de vins poulsés (8) qu'ils ne faisoient que cracher aussy blane comme coton de Malthe. (9)"

"Du blanc verse, la laugue me pelle (10), " s'écrie un des invités de la noce de Gargamelle.

Gargantua avait les intestins relàchés " tant de sa complexion naturelle que de la disposition accidentale qui lui estoit advenue par trop humer de purée septembrale (11)".

L'alcool sous toutes ses formes (rin, liqueurs, etc.) pris le matin a jeun irrite la muqueuse stomacale, en provoque l'inflammation et détermine plus rapidement des accidents d'intoxication. "Boire si tost après le dormir, ce n'est rescu en diète de médicine (12)."

Le vin n'est pas seulement un aliment, e'est aussi, intus

bala ine), mais encore des deux partirs essentielles de labanbic morloruc, la thite ef le ballon. (Voy. Anat. des formes : la leste contourne comme un alambic.)

(1) Temte de plusieurs couleurs et surtout de violet. Le diaprum est un b́lectuaipe de prunes violelles.

(2) De petites bubes, du gree Goveciv, grosseme, tumeur.

(3) Croissant it vue d'oril.

(1) Chargé de verpues de toutes formes of de foutes dimensions.

(5) Brodé de dessins rouges. Terme de blasou.

(6) Tisane.

(7) Orlians, Aureliu. embellie par l'empereur Aurólien.

(8) La pousse on fomroe est me fepmentation smplémentaire du vin au contact de l'ail'. Le vin poussé n’a ancun effet muisible sur l'économie.

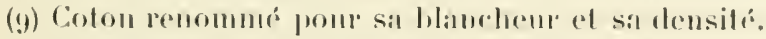

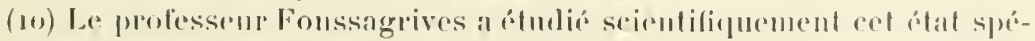
cial de la langue des buveurs.

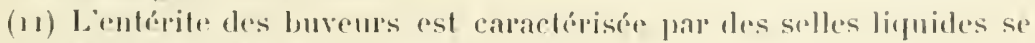
produisant gincralement le matin.

(12) Dans le sens de légime (I. I, ch, xu). 
et extra, un agent thérapeutique prócicux. Au dire de Lorhas, ancien inspecteur génćral du corps de santé de la marine, c'est mème le remède le plus eflicace contre le mal de ner (1). C'était celui des Thalassiens (:2). Avant de prendre congé de Pantagruel el de ses compagnons sur le point de s'embarquer, ils "ferirent de leurs maisons force vivres et vinage apporter. Touts burent ì eulx : ils burent ì touts. Ce lut la cause pourquoy personne de l'assemblée onques par la marine (3) ne rendit sa gorge (4), et n'eut perturbation d'estomach ne (.)) de teste. Anquel inconvénient n'eussent tant commodement obvié, buvants par quelques jours paravant (6) de l'eau marine (7), ou pure, ou mistionnée (8) avecques le vin, usants de chairs de coings, de l'escorce de citron, de jus de grenade aigres et doulees, ou tenants longue diele: ou se couvrants l'estomach de papier, au aultrement laisants ce que les fols médieins ordonnent à ceulx qui montent sus mer (9)."

Arant l'emploi de l'acide phénique, de l'iodoforme, des sels de mercure, du salol, ete., le pansement à l’alcool était d'un usage courant en chirurgie. L'action bienl'aisante des composés alcooliques, vin, jus de raisin, ele. sur les plaies et les contusions, était connue du professeur Sehyron (10)

(1) Rochas, art. Mal de mer du Dict. encycl. des sc. méd.

(2) Les habitauts de Thalasse, du grec $0 \dot{\alpha} \lambda \alpha \sigma o x$, la mer.

(3) En mer.

(4) Nent de romissements.

(5) $\mathrm{Ni}$.

(6) Auparavant, avant.

(7) Eall salée.

(8) Mélangée, du latin miscere.

(9) Tous les remides signalés ici (I. IV, clı. r) par Maitre Francois ont bié, en effot, employés inlructueusement contre le nal de mer.

(10) "Vous derriez bien nous envoyer, a cicrit ailleurs Rabelais, de cet excellent vin que le célebre docteur Scuron vaute pour la guérison et la dessication des playes. "

Lorthographe exacte du nom du maitre de Rabelais est Sehyron. (Voy. Nérrologie : Le conare, comme une vièze)

Guy de Chauliac, le chirurgien des papes Clément VI, Innocent VI el 
ol de Maître Francois, son élive. Parmi les divors servitrums de Gargantua of de Panlagruel qui ont dì ì un pansement i l'alcool "d'estre tantost guaris " je me contenterai d’indirpuer :

Forgier, aupuel " les bovirs, bergers ol métayers de Senillé et de Sinais, arec gros raisins chenins (1) estuvarent (2) les jambes contusionnós. "

El Epistemon (3), décapite, auquel Panmoge " nettoya tres-bien de beau vin blanc le col el puis la teste; apros les oignil de je ne seay quel oignement (4). el les afusta (j) justencent vione contre vine, nerf contre nerf, spondyle contre spondyle, affin qu'il ne lust torti-colli. Ce fatict, luy feit a l'entour quinze ou seze points d'aguille (li), aflin qu'elle ne tombast derechef. "

Élancher la soif aree des boissons froides lint de tout - Lempis un plaisir recherehé. Le sensuel Horace enveloppait de neige lamplose contenant son falerne.

Par le chaud qu il faisail, nous n’avions point de grlace.

Point de glace, bon Dicu! dans le fort de l'éti!

An mois rle juin !...

s'écrie nu des convires du Festin ridicule.

"Lorspuentrastes en Lybie, demande al Prepochole (7)

Trbain V, qui a preconiso le pansement a lanleonl, llon ast pats, fomme

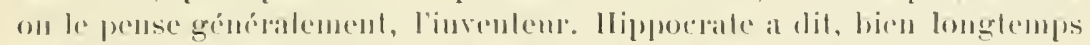
arant lui : "Liver les plaies aver du vin est loujours ulile."

Comme pour justilieg le vers d'Horace:

\section{Mullu renuscentur quie jum reridere,}

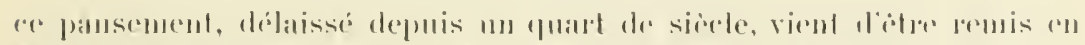

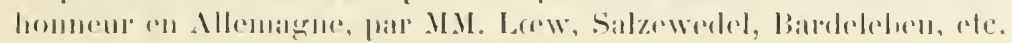

(1) Raisin doul on fint le gros vin.

(2) Pansirent, laverent.

(3) Silvall, du gree ćtols:xuxt, je commais.

(1) Ongurent, du latin unguere, wisuler.

(j) La ajuslal.

(6) Siguillr.

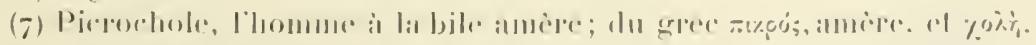
bile. (Noy. Anat, rlitrteg. 
un de ses officiers, la camarane de la Mécha (1) ne vous fournit-elle de vin à suffisance?

"- Voile : mais, dist-il, nous ne busmes poinct flais."

"Buvez liais, si faire se peult (2)... Burrz bon et frais assez (3), conme vous diriez sus le eommencement du second degré (1), "recommande Maître François à ses clicents $(\overline{)})$.

Boire frais, si faire se peut, est un conseil d'hygiène qui a besoin d'explication.

La fraîcheur des boissons n'est pas un lux², c'est une nécessité. A la température de 4". les boissons exercent une action stimulante sur l'estomac at l'intestin: elles farorisent la digestion; plus froides elles font crisper les

(1) Mecque.

(2) L. I, ch. I.

(3) Prol. du l. III.

(4) Tempéré. Le froid, ainsi que le chand, le ser et l'humide, comprend, daprès Galien, quatre degrés. A peine marquée an premier degré, son action est appréciable an second, dangerense an troisième, destructive au quatrième (Voy. Galiex, I. V des simples et 1. I des Aliments.)

(5) La mème pensée est encope exprimée dans le chapitre xu du dernier livre. "Ainsi maintenons que non rire, ains (mais) boire est le propre de lhomme. Je ne di boire simplement et absolmment, car aussi bien boivent les bestes; je di boire vin bon et frais ", et dans le chapitre xuI du mème livre: a Ce vin n'ha que ce mal quil est frais, mais je dis froid plus que glace, que l'eau de Nonacris et Dircé, plus que la fontane de Contoporie en Coriuthe, laquelle glaçoit l'estomach et parties nutritives de ceulx qui en buvoient."

L'ean que foumissait la fontaine de la montagne de Nonacris en Grèce était, disait-on, si àcre quelle pergait tous les vases, hormis ceux faits de la corne du pied d'un mulet. Cest elle qui, portée de Grèce ì Babylone et verscé à Alexandre, aurait causé sa mort. (Voy. Vitruve, VIII, 3; Plitarole, dans la Vie d'Alexandre; Strabox, Vill, p. 309, et Pausanias ell ses Arcadiques, cit., par Pridenu dans son IIstoire des .Juifs, édit. Amsterdam, 1722, t. II, pp. 476 et 477 .)

La Direé ou Dircenna de Martial itait froite comme de la glace.

Avidam rigens Dircenna placabis.

(Martial, Ep. 51, III l. I.)

Pour des délails circonstancies sur la fontaine de Contoporie, voy. Athenée, I. II. 
vaisseaux du tube digestif et provoquent des congestions réflexes du poumon, de la plère, ete. C'est une pleurésic et non un empoisonnement qui a causé la mort du grand Dauphin auquel le comte de Montecuculli arait offert un verre d'eau glacée.

Harpagon roulait quion gravat au-dessus de la cheminée de sa salle à manger": "qu'il faut manger pour virre et non virre pour manger"; nous ajouterons " et ne pas boine trop lirais ".

Rabelais n’a pas dit autre chose. 


\section{APPAREIL RESPIRATOIRE}

Quaresmeprenant aroil:

Le nou, comme un baril, auquel pendoient deux goitrous de bronze bien beaulx et harmonieux, en forme d'une horloge de sable.

L'aspre artère, comme un gouet.

Le poulmon, comme une aumusse.

La plèvre, comme un bec de corbin.

Le nou, comme un baril, auquel pendoient deux goitrous de bronze bien beaulx et harmonieux, en forme d'une horloge de sable.

Le non, le larynx (1) ou noud de la gorge, l'organe de la voix, la portion supérieure renflée du canal aérifére de l'appareil respiratoire. "Sa figure, dit Diemerbroeck, est i peu près cireulaire, s'arançant sur le devant et étant aplatic sur le derrière pour laisser l'espace libre à l'oesophage (2)." II est fermé en haut par une membrane fibreuse mobile, l'épiglotte (:3), et constitué par une série de cartilages dont la partie mogenne du plus important, du cartilage thỵö̈de (4), forme, à la lace antérieure du cou, une saillie appelée pomme d'Adam (5). C'est à cette saillie que le larynx est rederable

(1) En greec $\lambda \dot{\alpha} \rho u y \xi$

(2) Diemerbroeck, Inc. cit. suprà, t. I1, p. 179 .

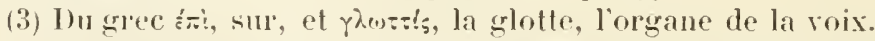

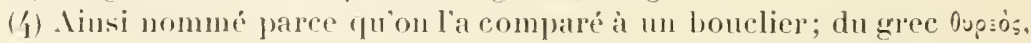
rondelle. honclier, et siòos, ressemblance.

(5) D’après Diemerbroeck, "cet avancement, d’autant quil est plus visilule dans les bommes que dans les femmes, est appelé en enx pomme thdam, parce que le rulgaire s'est imaginé que le morceau de la jomme 
du nom de noud ou phutót de nou, sous lequel il a éló désigné autrefois par les anatomistes et soms lequel il est désigné eneore dans les campagnes.

Les barils (barris) anciens étaient des tonnelets s'ouvant par l'un des bouts ou munis d'un mobinet, faits labituellement, les uns d’un bois précieux, voire mème d’ivoire on d'argent, et que l'on plaçait sur les buffets et dressoirs pendant les repas. ef qui contenaient des sauces froides. des liqueurs, de la moutarde (1), etc.; les autres d'un bois
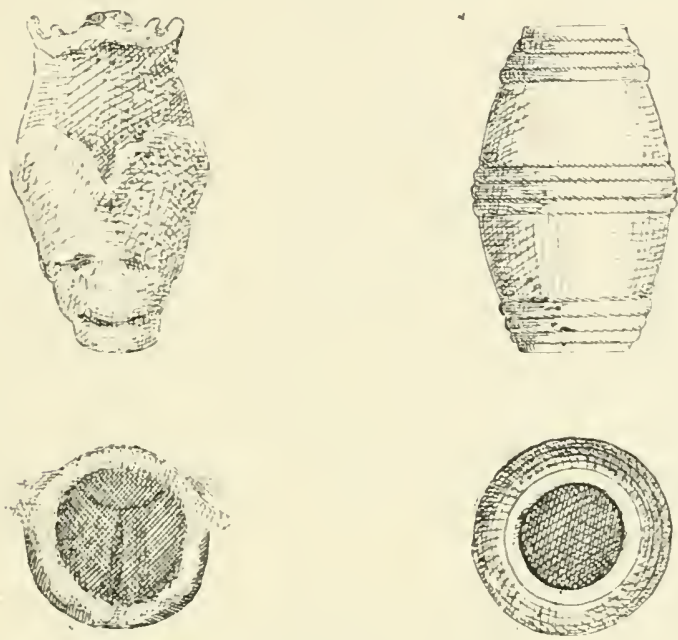

Le nun. comme un baril.

grossiar. el que l'on lamsportait sur les épaules ou sous le bras au moyen d'une controie el avee lesquels les religieux queteur's (2) s'en allaient demander du vin ef de

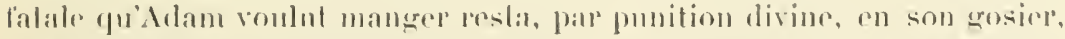

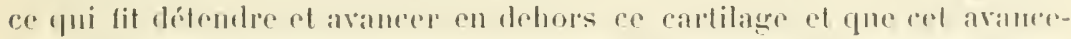
ment on profubérance est passé an ses descendante comme par lápi-

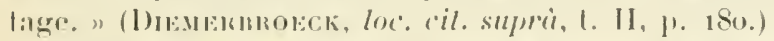

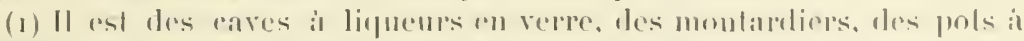

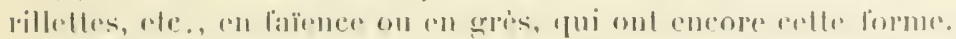

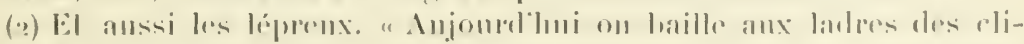

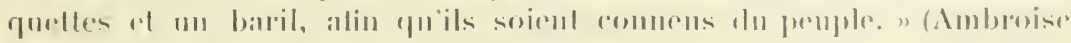

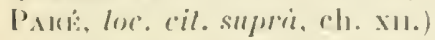

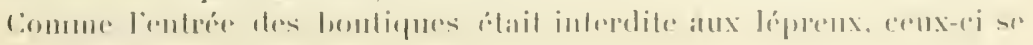


l'huile. Il est évident que, dans la comparaison en cause, il s'agit des petits barils de salle à manger. Un dessin de l'Inventaire de Charles I permet de constater que ces barils n’étaient que des réductions enjolivées de nos barils actuels.

A la naissance de la trachéc el sur les parties latérales du larynx, ou, pour parler plus exactement, sur les parties latérales de son principal cartilage, on trouve un corps glanduleux, le corps thyroïde, composé de deux lobes réunis par une portion rétrécie dite isthme du corps thyroïde. L'augmentation de volume du corps thyroïde constitue la maladie connue sous le nom de goître, goètre, gouètre (du latin guttur, gorge). Celte augmentation de volume du corps thyroïde peut ètre totale ou partielle. Quand clle porte seulement sur les deux lobes, ceux-ci, transformés en deux tumeurs plus ou moins symétriques, aussi dures que du bronze el tròs rapprochées par suite de l'aplatissement du conduit aérien el de la disparition presque complète de l'isthme, représentent assez bien " une horloge de sable (I) " couchée sur l'un ou l'autre de ses cotés.

Le groître accompagne souvent le crétinisme et est très commun dans les pays de montagnes, principalement dans les Alpes et dans les Pyrénées. Le mot de Cagots s'applique, d'autre part, aussi bien aux moines mendiants revètus de la cagoule qu'aux habitants du Béarn atteints d'une hypertrophie de la glande thyroïde. On appelle mème liagot, dans les Pyrénées l'hypertrophie de cetle glande (2). Le "père

servaient de lenes elipuetles pour prico les mapehands de leur apporter dans la rue le pain et la boisson dout ils avaicnt besoin.

(1) L' "horloge de sable " était formée de deux ampoules de verre superposées ou le sable, tombant de l'me dans lautre, mesurait un certain espace de temps. Le sabliep dont se servent encore les cuisinieres pour se rendre compte du degré de euisson des ant's quelles déposent dans leau bouillante en est une rédnction.

(2) Pour de plus amples détails sur l'étymologie du mot Cagot, roy.: 
et nourrisson des médicins " était donc eagot d'esprit et de corps.

A la suite d'une angine, le larynx et son couverele l'épiglotte sont parfois le siège d'une fluxion oedémateuse qui, en empèchant l'entrée de l'air dans les poumons. peut amener la mort par suffocation. C'est cette maladie, appelée adime de la glotte, que les habitants de la Quintessence soulaitent en ces termes aux ennemis de leur reine :

"Leur male-angine (1), qui leur sulloquast le gorgeron (2) arecques l'épiglottide."

\section{L'aspre artère, comme un gouet.}

L'aspre arlère, la trachée-artère, est le tronc commun des canaux aérifères des poumons. Elle est verticale et a la forme d'un eylindre dont le tiers ou le ruart postérieur aurait été enlevé. Situéce en partie dans le cou, en partic dans la poitrine, elle est formée par seize à vingt cerceaux cartilagineux superposés que séparent autant d'anneaux fibreux (3).

Dans le chapitre xix du livre II, Maître François a domné is ce conduit le nom qu'il porte anjourd'hui. Panmege, con-

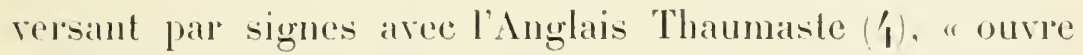
quelque peu de la bouche, et arecques le plat de la main

le Monde primilif de Court de Gebelin, les Observalions de Ramoma, le Voyage ant Alpes de Salussure, ele.

(1) L'angine maligne.

(2) Le morul de la golege, lo laryox.

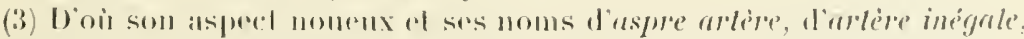

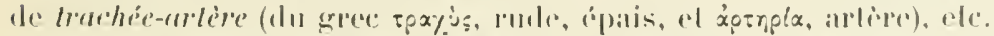

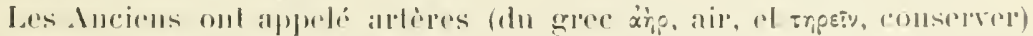

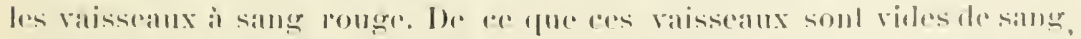

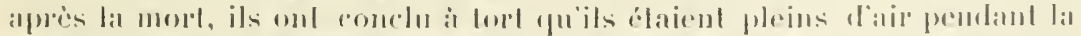

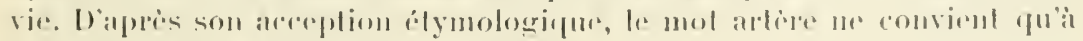

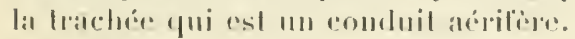

(1) Homme noble, admirable. 
dextre (1) frappoit dessus, faisant en ce (2) un grand son et profund, comme s'il venoit de la superficie du diaphragme (3) par la trachée artìre ". On sait que Rabelais a appelé encore l'organe dont il s'agit " artère inéguale ". (Voy. Appareil digestil": Le gaviet, comme un peloton d'estouppes.)
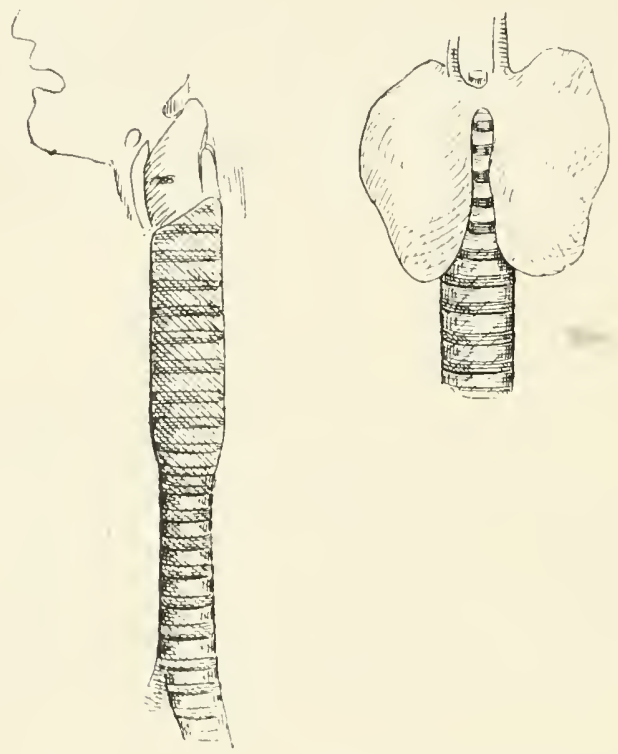

Laspre artere, comme un gouel.

Gonets, "petits demy-cousteaulx, dont les petits enfants de nostre pays cernent les noix, " dit Rabelais (4). Par " demycousteaulx $)$ il faut comprendre les couteaux de travail ou de table qui avaient, au moyen àge, des dimensions moindres que les couteaux de combat ou de chasse. Le gouet est

(1) Droite.

(2) Par ce moyen.

(3) En appliquant vivement et fortemest la main sur la houche, on fait rentrer une certaine quantilé d'air dans les voies aériennes, mais le son ainsi produit ne samrait avoir le timbre ni l'intensité de celui qui suit l'inspiration brusque provoquée par une convulsion du diaphragme (hoquet, sanglot).

(台) L. I, cli, xivil。 
toujours une petite serpe ou couteau sans ressort at manche rond et à lame droite ou recoubce.

"Un goé ou sarpe que le suppliant tenoit en sa main de quoy il tailloit les vignes. "(Lettres de rémission de 1 qog.).)

Dans son article Goitre du Dictionnaire encyclopédique des sciences médicales, M. Krishaber avance que ce mot a été employé pour la première lois, pour désigner les tumeurs du corps thyroüde, par Fabrice de Hilden (Observat. et anat. chirurg. cent., III, 1614). S'il eùt lu Pantagruel, M. Krishaber ent vu que Rabelais a usé non seulement du mot goître pour désigner les tumeurs du corps thyroïde, mais encore signalé la valriété de déformation de la trachée que cause l'hypertrophie des deux lobes latéraux de ce corps et qui a élé décrite suceessivement sous le nom d'aplatissement bilatéral de la trachée par Bonnet, en 185.5 (Comptes rendus de l'Acad. des sc., 1 jo aùt 185.5); de trachée en fourrean desabre, par Demme, en 1 stin (Medicin Zeitschrift; Wurzburg, 1861, t. I1); de trachée en ruban, par Rose, en 1877 (Corresp. IBl. für Schweiz. derzte, 1877). En comparant la trachée, comprimée par les deux lobes augmentés de volume du corps throoüde, à un gouet, le romancier-médecin a mème été mieux inspiré que Bonnel, Demme et Rose. On croirait, en eflet. d'apres les companaisons de Bonnet, de bemme el de Rose. que, daus ce cas, la laachée est déformée dans toute sa longueur. Or, il n'en ast rien. Le goilue thyroüdien double ne descend pas d'ordinare dans la pois trine (Crureilhier). Il s'ensuil pu'il ne peut aplatir el u'aplatil, en la comprimant a droite et à gatuche, que la portion du conduit aérien incluse dans le cou, laissant indemne la portion incluse dans la poitrine. Avee sa portion cervicale aplatie Lanstersalement et sa portion thoracique restéc ronde, la trachée ressemble entiòrement is un coutean is lame droile sans ressort.

En somme, la comparaison en question est doublement hemreuse : elle est tros exacte al lémoigne que Rabelais 
s'est autant soucié de l'anatomie pathologique que de l'anatomie descriptive, de l'anatomie chirurgicale, de l'anatomie comparée, de l'anatomie des formes.

Le poulmon, comme une aumusse.

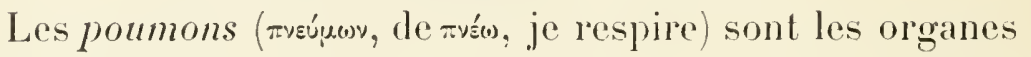
de la respiration. Ils sont au nombre de deux, renfermés dans la cage thoracique et constilués par un amas de vésicules élastiques qui se distendent pendant l'inspiration et reviennent sur elles-mêmes pendant l'expiration. Le poumon gauche est divisé en deux portions ou lobes, distingués en supérieur et en inféricur, et le poumon droit en trois lobes, distingués en supérieur, moyen et inférieur.
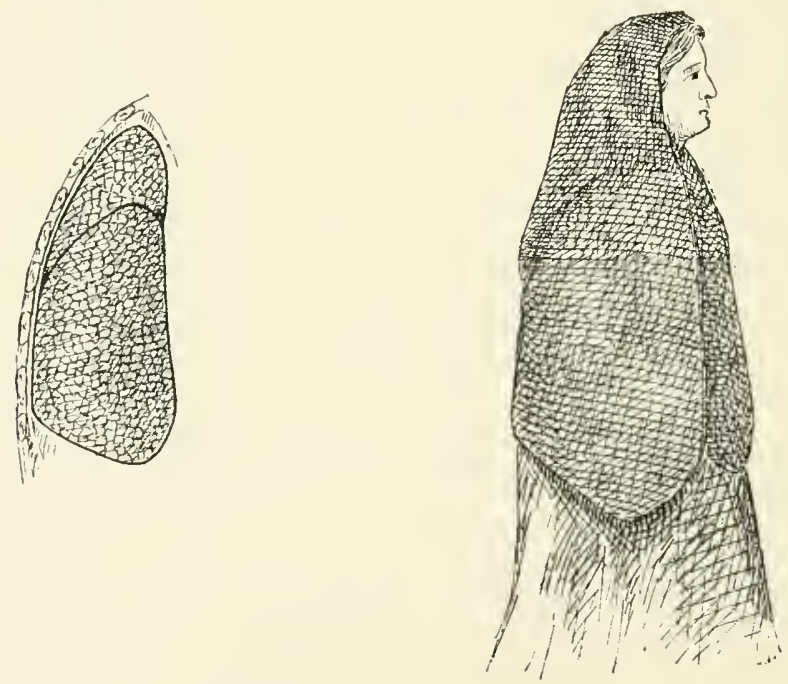

Le poulmon, comme ane aumusse.

L'anmusse ou aumuce - (du batin barbare almucia, qui vient, selon Wachter, de l'allemant mälze, sorte de coiffure ou d'habillement de tète), - dont la bande d'hermine que portent aujourd'hui sur le bras les chanoines, et sur l'épaule les magistrats et les prolesseur's, est un reliquat, était un man- 
telet en fourrures on doublé de fourrures, pourvu d'un capuchon rond ou pointu. L'aumusse des femmes du moven àge ressemblait au capulet actuel des paysannes du Midi de la France.

"A Paris, dist Garpalim (1), Groingnet, cousturier", sus la lorme d'un casaquin tailloit par mégarde une aumusse." "Je les ai ru non aumusse, ains (2) armet en test porter." ( L. IV, ch. L.)

L'aumusse, recourrant la tète et la partie supéricure du trone d'une personne en prière, e'est-à-dire dont les avantbras sont à demi fléchis ct les mains accolées l'une à l'autre, perpendiculairement à la poitrine, a beaucoup de similitude avec un poumon et son pédicule. On peut mème présumer que Rabelais a vu l'équivalent du lobe supérieur du poumon dans le capuchon de l'aumusse, et du lobe inférieur du poumon dans le reste de ce vètement. Cette lypothese est d'autant plus admissible que, pendant fort longtemps, les anatomistes ont eru que, ehez l'homme, le poumon droit n'avait normalement, comme le poumon gauche, que deux lobes. Dans l'A natomie de Diemerbroeck (1727), que j’ai déjà en l'occasion de citep plusieurs fois, on lit (t. II, P. 150) : "Chacun des poumons se divise en lobe supérien", qui est le plus petil, et en inférieur, qui est le plus grand, rarement le poumon se divise-t-il an trois lobes. Il y a neanmoins plusienrs lobes dans les chiens, surtout dans les chiens de chasse."

La plèvre, comme un bec de corbin.

La plevere est un sac membranenx qui contient les ponmons. Elle est rósistante et néamoins si mince et si fransparente quelle laisse voir, avee la limpidité du coristal, les moindres détails el toutes les muances de coloration du

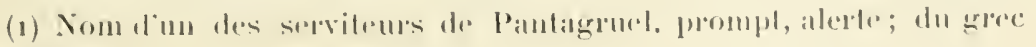

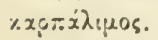

(2) Milis. 
parenchyme pulmonaire. Il y a deux plèves comme il y a deux poumons.

Bec de corbin. "Instrument de chirurgie, dit Furetière, fait en forme de pincettes ou tenailles et qui sert à tirer des plaies les corps étrangers et nuisibles: son nom lui vient de sa ressemblance avec le bec d'un corbeau. "

Sous Louis XIT, il y avait encore à la Gour un corps de hallebardiers commandés par Lauzun el appelés les Becs-de-corbin, en raison de la courbure en bec de corbeau du fer de leur hallebarde.
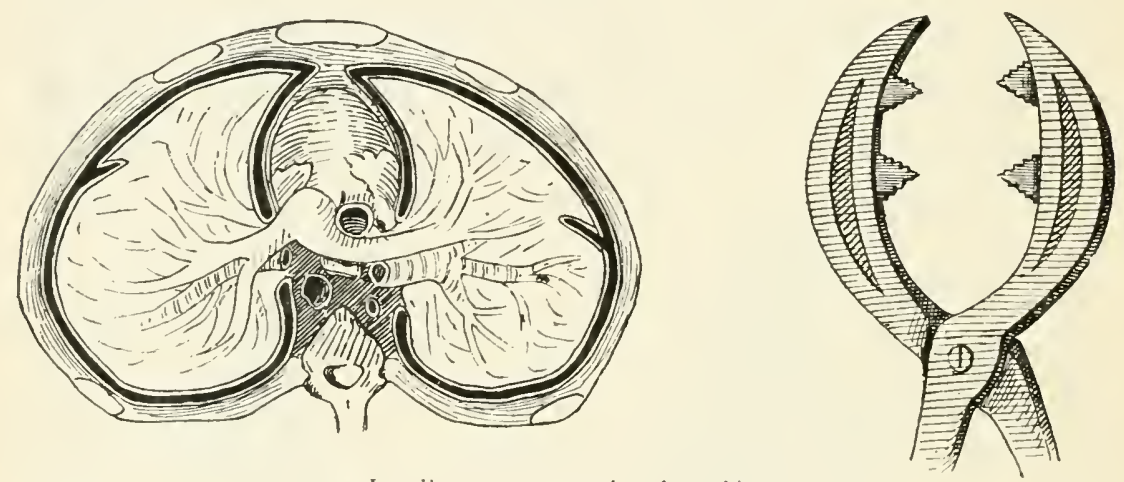

La pleve, comme un hes de corbin.

Ainsi que chaque poumonsur lequel elle se moule, chaque plivre présente une base concave, une lace externe convexe, une face interne concare, deux bords et un sommet plus ou moins pointu. Une coupe horizontale des deux plères a les contours d'un des becs de corbin d'Ambroise Paré (1).

Phisiologie. - Rabelais a écrit: "Le poulmon ne cesse avec ses lobes et soufflets refreschir le sang. "Ce refroidissement du sang dans le poumon, dont Helvétius a fait la base de sa théorie mécanique de la respiration, longtemps nié, est aujourd'hui incontestable. Cl. Bernard a démontré expérimentalement que le sang contenu dans le ventricule

(1) Ambroise P.ré, loc. cil. suprì, p. 633. 
gauche, c'est-ì-dire le sang qui a traversé le poumon, a une température moins élevée que celui qui est contenu dans le ventricule droit. Le sang se rafraîchit en traversant le poumon, parce qu'il y est en contact plus immédiat avec l'air extérieur, dont la température est inférieure à la sienne, et qu'il y perd par éraporation une certaine quantité d'eau. On sait que, dans les cas où la mort est douteuse, il est recommandé de placer une glace ¿̀ l'entrée des voies aériennes pour voir si cette glace se ternit ou non. 
APPAREIL URINAIRE

Quaresmeprenant aroit :

Les rognons, comme une truelle.

Les pores uretères, comme une crémailliẻre.

La vessie, comme un arc à jallet.

Le col d'icelle, comme un batail.

L'urine, comme un papefigue.

Les rognons, comme une truelle.

Les rognons, les reins, les glandes au nombre de deux, qui séerètent l'urine. Ils sont logés, de chaque côté de la colonne vertébrale, dans la région qui porte leur nom, au fond d'une large excavation remplie de graisse que Rabelais a comparée au pot de grès ventru dans lequel on conserve le beurre (1). Chacun d'eux a la forme de la truelle dont on se sert pour retirer le poisson d'un vivier ou d'un baquet.

Les Anciens ont-ils connu ce genre de truelle? Il serait aussi imprudent de le nier que de l'aftirmer. On retrouve

(1) Les reins, comme un pol beurrier. Maitre François, qui a parlé des reins ef de leur loge, a parlé également de la porlion de la colonne vertébrale, dite colonne lombaire, à droite et à ganche de laquelle ils sont placés. Il l'a comparée à un cathenat, "cadenas, quon a écril arssi cadenat et qui se dit catenaccio en italien, du latin catena, chaîne. Passerat remarque, sur Properce 654, que les serrures n'étaient anciennement attachées aux portes qu'avec des chaînes. "(Esmaxgart el Jomanneau.) Chez un individu élique les vertèbres se dessinent, en effet, sous la peau, à la laçon d'une chaîne.

La maigreur squelettique de Quaresmeprenant attestée par : ses hanches, comme un vibrequin; ses genoils, comme un escabeai; ses lumbes. 
chaque jour, je me plais à le répéter, des objets, et principalement des objets usuels, qu'on croyait d'invention récente. Ce qui n'est pas douteux, cest que le mot truelle, diminutif de trua (euiller), signitie une chose creuse et appartient à la mème famille que le verbe gree qúues (trouer, creuser). Quant à la truelle des maçons, qui n'a pas ehangé de forme depuis la période romaine (Viollet-Le-Duc), elle ne
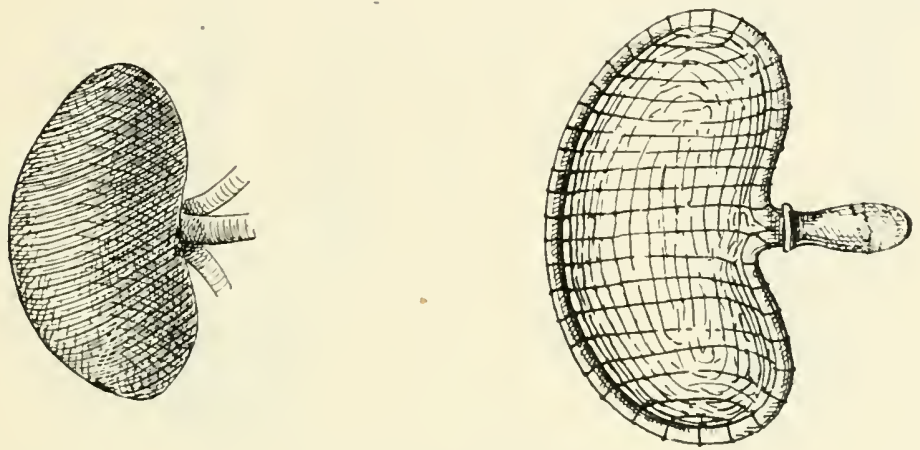

Less rognons, comme une truelle.

ressemble pas au rein, et la truelle d'argent pour découper el servir le poisson n'est ordinairement pas emmanchée de coté.

\section{Les pores uretères, comme une crémaillière.}

Les pores urelères, les uretères. Cie sont denx canaux qui portent l'urine des reins à la vessic. Ils s'étendent obliquenent de la région rénale à la région pelviemne.

Crémaillière, appareil de enisine que tout le monde connâ̂t. La crémaillère ancicme se composait d'une tige ver-

comme un eathenal, l'est encore par : sa poilrine, comme un jea de reynalles, w1.

Le jen de regualles est le jun de lorgme, fus comm soms le nom de joul de vois humatines.

lal poilrine amaigrie, avee ses sallies et ses romx sucersits, a rvidemment quelyue ressemblance ave un jend dorgues. 
ticale supportant une barre horizontale mobile garnie de chaînettes ou de tiges auxquelles on accrochait les mar-
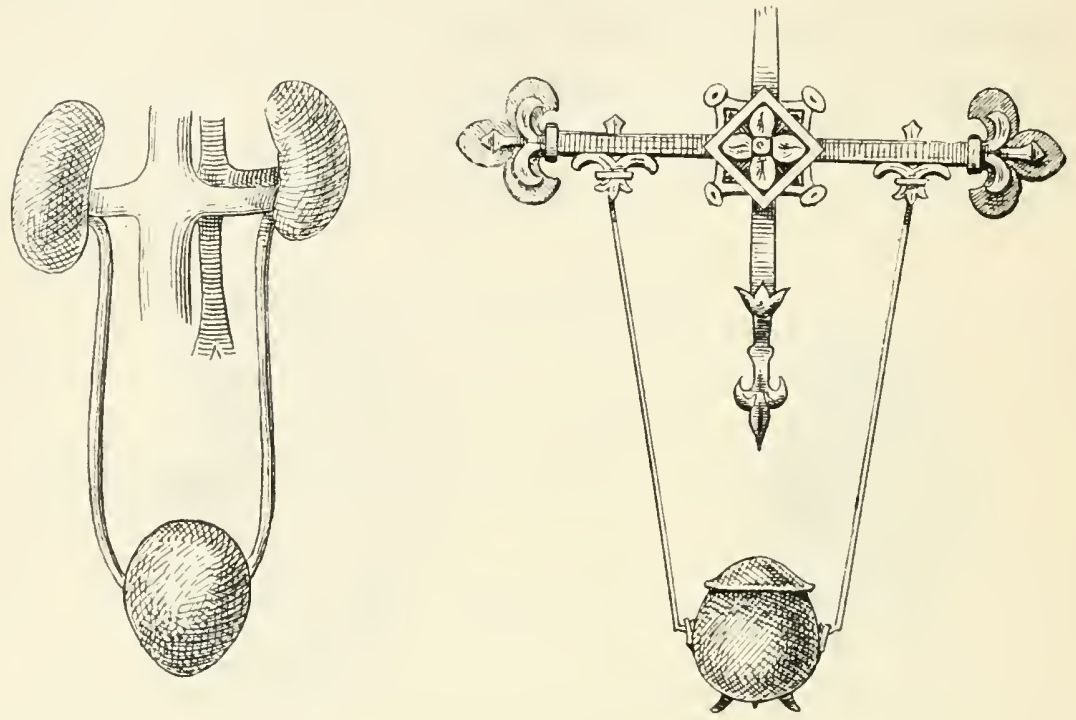

Les pores ureteres, comme une cremailliere.

mites. Cielle du modèle ci-dessus a liguré à l'Exposition nationale de Tours, de $18_{92}^{2}$.

La vessie, comme un arc à jallet.

La vessie est un réservoir musculo-membraneux dans lequel l'urine, verséc goutte à goutte, s'acemmule et séjourne jusqu'au moment de son expulsion.

Pleine, elle a l'aspect d'un ouf énorme, à grand diamètre dirigé obliquement de haut en bas et d'arrière en avant. Vide, elle présente une forme arrondie, presque sphéroïdale. Quelquefois elle est aplatie d'avant en arrière, de sorte que son diamètre transversal s'allonge au point d'égaler ou mème de surpasser son diamètre longitudinal. C'est ce qui s'observe surtout che\% la femme.

Arc à jallet on à jalet. Arbalète de chasse plus légère 
et plus petite que les arbalites de guerre et qui lançait, au lieu des carreaux-fliches, de petites balles de plomb el mème de terre glaise, el avee laquelle on tirait sur les oiseaux.

C'est une arbaliele de ce genre que, sans doute, Grandgousier" feit laire ì Pantagruel comme il estoit petit, pour s'esbattre après les oisillons".
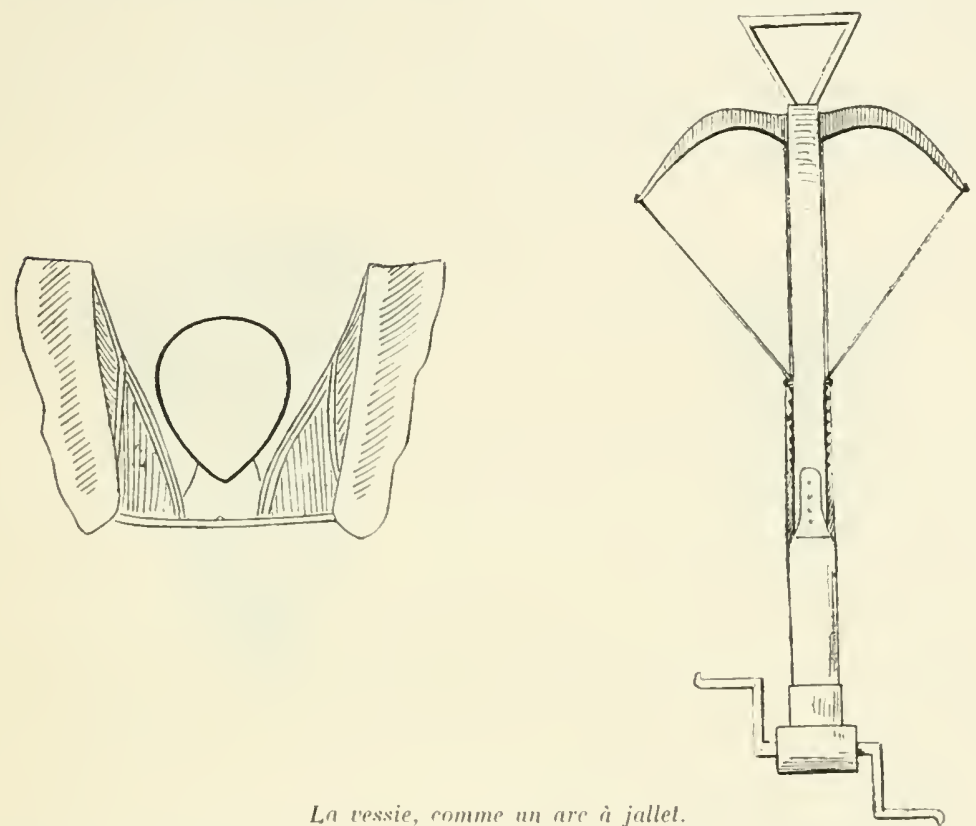

La tessie, momme un are ì jallet.

Les Allemands appelaient cette arbalete balestre, die quielle était un pen grande. Jallet ou jalet parail dériver dn gree iánise, mitlere, anvover, lancer. L'are ì jallet, dont on voit le desing, est reprósenté dans Raleinet (le Costume hislorique, pl. 218; Paris. 1886').

La ressie, on revenant sur elle-meme, chatsise l'urine dans le canal de l'urethre comme la rorde de l'are à jallet lanee les balles.

Ouand la ressie se remplit. elle pemonte du hasin dans le ventere el le temd. Lefret inverse se produit quand elle se désemplit, d'oil les rexpressions : arolr la ressie

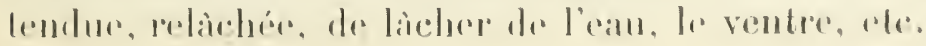


Le col d'icelle, comme un batail.

Le col d'icelle, le col de celle-ci; le col de la ressie est l'orifice interne du canal de l'urethre. 11 est rond, évasé, plus large que l'orifice externe et offre à sa partie médiane une saillie longitudinale, dite crête uréthrale on verlt-montanum, dont l'extrémité postérieure est renflée. Par suite de l'augmentation de volume de la prostate, cette saillie est très prononcée chez les vicillards.
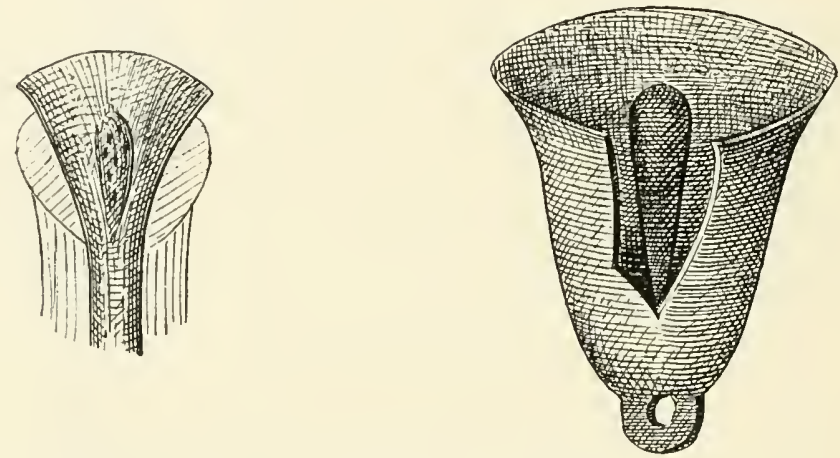

Le col dicelle, comme un batail.

Balail, battant de cloche.

Il est fait mention, dans le chapitre xix du livre I, qu'un latiniste, demeurant près de l'Hotel-Dieu, désirait que les cloches de Notre-Dame "fussent de plume, et le batail fust d'une queue de regnard (1) : pource (2) qu'elles lui engendroient la chronique (3) aux tripes du cerveau (4) ". (Voy. Névrologie, Physiologie.)

Entre l'orifice évasé du col de l'urèthre et le ver'u-montanum et une clochette dont le battant touche la paroi, c'est-

(I) Renard.

(2) Parce qu'elles.

(3) Une maladie chronique, laquelle ? La migraine, répondent quelques commentateurs. Est-ce hien sùr?

(4) Aux circonvolutions cérébrales dont les flexuosités rappcllent en petit celles de l'intestin. 
a-dire une clochette renrersée dans le sens de son grand axe, il y a une eertaine analogie.

\section{L'urine, comme un papefigue.}

Papefigue, hérétique, homme qui fait la figue au pape. Rabelais nous apprend lui-mème l'origine de ce mot (I). Autrefois, les Papefigues étaient appelés Gaillardets (2). Un jour, ils insulterent le portrait papal, et les Papimanes (:3), pour se venger, leur dicharirent la guerre, "taillarent (4) à fil d'espée tout hommr portant barbe. Aulx femmes et jouvenceaulx pardonnarent areeques condition semblable à celle dont l'empereur Federie (.)) Barberousse jadis usa envers les Milanois.

"Les Milanois s'estoient contre luy absent rebellés (6), et avoient l'impératrice sa femme ( 7 ) chassée hors la ville, ignominieusement montée sus une vieille mule nommée Thacor (8) à chevauchons de rebour's (9). Federic a son retour, les aỵant subjugués et resserrés (10), feit telle diligence (11) qu'il r'ecouvra la célèbre mule Thacor. Adoncques (12), au milicu du grand Brouet (1:3), par son ordonnance, le bourreau

(1) I. IV, ch. хн.

(2) Hommes qui noml pas peur, hardis graillards.

(3) Les gens qui ament le pape, qui sonl dévonés au pape. On dit aujourdluni les ultrimontains.

(i) Tuirenl.

(5) Frécléric.

(6) Rivoltis, dn latin rebellare.

(z) Binalris.

(8) Thacor ou 'Thecor en hébren signitie anus, ulecre ou fic ì l'anus. Cest lo nom des lies dont furent alhigés les Philistins. (Voy. Le Liver des liois, ch. ve, vers 5.)

(9) En chevaluchant it rebouts. On disail aulpelois a devatuchons, romme nous disons concole it hilons, it reculons.

Celle peine, considéro comme inlamante, elait jadis appliquée puncipalemenl anx prostiluers of anx lemmes alultipes.

(10) Rerufermess, fatils prisommiers.

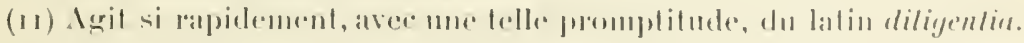

(12) Mlors.

(13) " C"est la grand- halle de Milan " (Brichive Déclaration). Lat place ou 
mist és membre honteux de Thacor une ligue, présents et royants les citadins captif's: puis cria de par l'empereur, à son de trompe, que quiconques d'iceulx rouldroit la mort évader (1) arrachast publiquement la figue avecques les dents, puis la remist on propre lieu ( 2 ) sans ayde des mains. Quiconques en l'eroit relus, seroit sus l'instant pendu et estranglé. Aulcuns d'iceulx (3) eurent honte et horreur de telle tant abominable amende (4), la postposarent (5) à la craincte de mort, et furent pendus. És aultres la craincte de mort domina sus telle honte. lceulx, avoir à bellesdents tiré la figue, la monstroient au boye (6) apertement $(7)$ disants : Ecco lo fico (8).

"En pareille ignominie, le reste de ces paurres et désolés Gaillardets furent de mort garantis et saukés. Furent faicts esclaves et tributaires, et leur fut imposé nom de Papefigues, parce qu'au portraict papal avoient faict la ligue (9)."

était située cette halle porte dr nos jours le nom de place de Broglio, de Breuil en lrançais, c'est-à-dire place du Petit Bois ou du Jardin.

(1) Fuir.

(2) Au mème lieu.

(3) Quelfues-uns d'entre eux.

(4) Chatiment, punition; du latin emende, pour emendatio, dérivé d'emendare, corrige's.

(5) La mirent après, luipréférirent; du latin post, après, et ponere, poser.

(6) Au bourreau; de litalien boju.

(7) Très visiblement; du latin aperle, ouvertement, nettement.

(8) "Voici la figue ", cn italien.

(9) Cette périphrase se trouve dans mainty écrits anciens.

\section{Puisque par l'aide de Dieu \\ Sommes mis en nostre lieu, \\ El 'jue nous faisony la figue \\ Aux tyrans de la ligue....}

(Leroux DE Luxcy, Recueil des chanls hisloriques, t. II, p. 487.)

"C'est icy la rraye et souveraine liberté, qui dome de quoi l'aire la figue à la force. "(Moxtajgie, Essais, l. I, ch. xim.)

Plusieurs se sont trouvés rui, d'écharpes changeants, Au danger, ainsi qu'elle, ont souvent fait la figue.

(La Fontane, la Chauve Souris et les Delix Belettes, 1. II, fable 5.)

Faire la figue, cétait montrer le pouce passé entre l'index et le 
Ce premier point fixé, il me reste à établir en quoi l'urine de Quaresmeprenant ressemblait ì un ennemi du pape, à un liérésiarque. J'y arrive.

En 1546, l'année qui suivit la concession d'un privilège donné it Rabelais pour imprimer le tiers live de Pantagruel, Francois Ier permettait d'employer les armes pour punir les Vaudois de Cabrières et de Mérindole. Grippeninaud d'Oppède fit revire un areèt rendu eing ans auparavant par " les Chats-fourrés " du Parlement d'Aix, et les soldats se mirent en campagne. "Tout était horrible el eruel dans la sentence qui fiut prononcée contre les hérétiques, nous apprend l'historien De Thou, et fut plus horrible et plus eruel encore dans l'exécution. Vingt-deux bourgs ou villages furent brùlés ou saccagés avec une inhumanité dont l'histoire des peuples les plus barbares présente à peine des exemples. Les matheureux habitants surpris pendant la nuit et poursuivis de rocher's en rocher's, a la lueur des feux qui consumaient leurs demeures, n'évitaient souvent une embùche que pour tomber dans une autre; les cris pitoyables des vieillards, des femmes el des enfants, loin d'amollir le cour des soldats loreenés de rage, comme leurs chet's, ne faisaient que les mellre sur la trace des fugilifs et marquer les endroits où ils devaient porter leur fureur., "

"Quiconque élail soupcommé d'hérésie, aflirme de son cóté l'historien Macaulay, quel que fùt son l'ang, son saroir, sat réputation, devait se disculper a la satisfaction d'un lribunal sévère et vigilant ou mourir par le leu. "

mélins, comme pour figurer une figue. En Italie, et principalensent it Milan, ce geste a élé considéré pendant loot longremps comme execysivement injurieux.

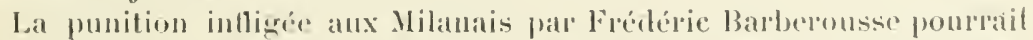

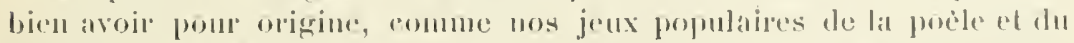

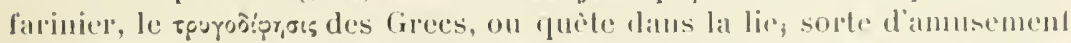
qui rousistait a mettre les manus derriere le dos el a saisir avec la bouche un whjet place an lond d'un plat the lie. 
L'urine de Quaresmeprenant élait brùlante, corrosive. avail la température d'un papeligue sur le bùcher (1). Elle élait en rapport avec la nourriture échauffante que prenait le lidèle observateur des lois du carème: (Voy. Physiologie de l'appareil digestif', aliments du carème.)

Pinsiologie. - Après aroir analỵsé les phénomènes de la digestion et de la respiration, Rabelais a rendu compte de la façon dont s'opèrent les sécrétions de l'urine el du liquide spermatique.

"Les rognons, par les vènes émulgentes (2), tirent du sang, dit-il, l'aiguosité (3), que rous nommez urine, el par les uretères la découllent en bas. Au bas trouve réceptacle propre: c'est la vessie, laquelle en temps opportun la vuide hors."

Soumettons cette théorie à la eritique de la science contemporaine. Les Poissons ont une veine rénale afférente ou, si l'on veut, une veine porte rénale. Celte veine porte rénale existe chez les Batraciens, les Reptiles et mème aussi chez les Oiscaux, s'il faut en croire les travaux de Jacobson.

(1) En admeltant que par Papefigues Rabelais ait entendu désigner, comme le pense M. Ducrot, les habitants des iles Heiligoland, la conchusion serait la mème. "En 1519, dil M. Ducrot, Christian II, surmommé le Cruet, roi de Danemark, emahit la Norvege el ses iles, massacra les évèques, les pròtres et les moines, détruisit le culte catholique, et força les habitants ì faire la figue au pape en embrassant le luthéranisme, après aioir lavagé, brùlé, saccagé tout le pays.

"Irrités de ces cruautés inouĩes, les quatre étals du royaume, le clergé, les nobles, les bourgeois et les paysans, s'insurgent, prennent les armes, massacrent les Danois, ef foreent Christian Il à s'enfuir en son pays. Le culte catholipue est partout rétabli : mais on ue put relerep aussi vite les ruines dont ce pays désolé était courert. "(Ducror, loc. cil. supri, 1. 18.)

(2) Les reines des reins, du lalin emulgere, épuiser à force de tirer.

(3) La partic argueuse, l'cau, du latiu aqur. C'est i leur situation aupres de laes limpides ou dótangs mareagenx que les villes didiguebelle (ayua, ean, el bella, belle, (n hasse latinité), Aigueperse (aqua sparsa, eau éparse), Aignes-Mortes (unnx morlux, caux morles, eaux croupissantes), Aigues-Vives (ayux vivæ, eaux courantes), ctc., doirent d’ètre ainsi dénommées. On dit encore aigue pour eau, dans tout le Midi de la France. 
La veine porte rénale de tous ces Vertébrés concourt puissamment à la sécrétion urinaire.

Les Mammifères n'ont pas de reine porte rénale, mais Cl. Bernard a découvert que, ehez eux, la veine cave a deux usages: celui de porter le sang au cœur et de le rapporter par reflux au rein; joue, par conséquent, le rôle de veine porte rénale indirecte. Des expériences ultérieures de Béraud ont établi enfin que, chez ceux-ci, "l'artère rénale et par moments la veine rénale concourent à la séerétion urinaire " (1).

En écrivant: " les rognons par les vènes émulgentes, tirent du sang l'aiguosité, que vous nommezurine, " Rabelais a donc, après Galien, exprimé une vérité relative, du moins en ce qui concerne les Mammifères, y compris l'homme.

La sécrétion urinaire est augmentée par l'ingestion de diverses substances médicamenteuses. Rabelais en cite plusieur's à propos du déluge urinal qui noya les Dipsodes et les Géauts assiégés dans leur camp (2). "Panurge donna à manger à Pantagruel quelque diable de drogues composées de lithontripon (3), néphrocatarticon (4), coudignac cantharidisé (5) et aultres espèces diurétiques (6). "

(1) BÉraun, Éléments de physiologie de rhomme, t. II, J. 152 ; Paris, 1857 .

(2) L. II, ch. xrvir. Pour II. Ducrot, les Dipsortes, engrec altéré (de oblu, soif), ce sont les Scythes. "Dans le mot "Seythii ", Rabelais lit, dit-il (loc. rit. supri, p. 6), silis, eu latin la soif, et jone sur ce ntot avee d'antant plus de raison que cette contrée, très fertile en quelipues parties, est remplie de déserts de sable; lhiver, les habitants ne penvent se désaltérer : les lleuves, les lacs, les rivières, tout est gelé pendant neuf mois de l'année.. "

(3) Le lithontripon (de $\lambda(605$, pierre, et refpho, broientent) est l'essence des lithontriptiques. Les lithontriptiques sont des substances quon croyait proples il dissoudre les pierres dans la ressie, le jaspe rert, le sang de bouc mèlé ì du vin blanc, par exemple.

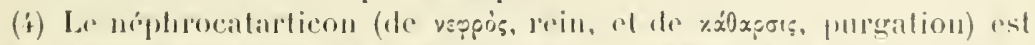
une substance qui servat it videre les rognons. Mais landuelle?

(5) La confiture de coings, it laquelle an a ajoute de la poudre de canthavides dont l'action sur l'appareil gionito-urinaire est tonte-puissante.

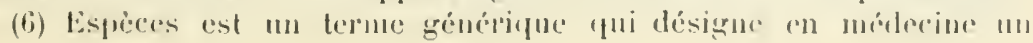


Jusqu'au xvile siècle, l'examen des urines a joué un ròle capital en médecine. Dans le tableau la Femme hydropique qui est universellement regardé comme le chef-d'ourre de G. Dow, un médecin contemple attentivement les urines de la malade, qui sont contenues dans un ballon de verre i long col. Parmi les nombreux ourrages ayant trait à l'examen des urines, qui ont été publiés par les savants du moṿen âge, je me bornerai à indiquer le Tractatus de urinis de Rondellet, le De Lrinis de Mon tagnana, le De Lrinis d'Actuarius, les Carmina de urinarum judiciis d'Egidius, et le Ite Cautelis urinarum de Bernard Gordon. Dans le dernier, il est fait mention de différents tours de passe-passe et d'un choir de réponses équivoques propres à tirer d'embarras les uropathes de cette époque, auxquels le liquide sécrété par les reins d'une personne souffrante n'indiquait rien. Cette rogue de l'uroseopie aux xive, $\mathrm{XV}^{\mathrm{e}}$ el XVI $\mathrm{I}^{\mathrm{e}}$ siecles est altestée par tous les vieux conteurs(1) et par divers passages de Cargantua et de Pantagruel.

"Prinse (a) Italie, remarque un des gouver'neur's présomptueux de Picrochole (3), voila Naples, Calabre, Apoule (4)

ensemble de racines, de fleurs ou autres parties végétales tlouées de propriétis analogues. fl y a des espèces astringentes, laxatives, narcotiques, ete. Les especes thurétiques ou qui lont miner (en grec ososerstrós, fait de o:ougéco, jurine) sont le chiendent, l'asperge, la guimaure, etc.

(1) Merlin Coecaie dit :

"Le módicin trottant par la ville va contempler les urines. " (L. II.)

Jean Bouchet :

"Elle fust contraincte ele demeurer an lict malade.... son espoux y list renir plusieurs médicins, mais ils n'eussent peu cognoistre son mal au poux, ne a furine. " (Le Panegyric de Loys de la Trimoille, ch. rin.)

Marguerite de Navare:

"Quand elles pereeurent qu'elle ne se disposoit à garison, elles ordonnèrent que line d'etle yroit à Rouen porter son urine à ung médecin de grande renommée. "(Cent Vouvelles nouvelles, xx.)

De dirorses phrases de Caton et de Cicciron, on pent inférer que l'examon des urines ŕtait également considéré comme un moyen précioux de diaguostic chez les Grees ef los Romains.

(2) L'Italie prise.

(3) L. I, ch. xxxil.

(1) L'Apulie, aujourd'hui la Pouille. 
et Sicile toutes à sac, et Malthe avec. Je roudrois bien que les plaisants chevaliers, jadis Rhodiens (1) vous résistassent, pour voir de leur urine (2). "

Bringuenarilles (3), avaleur de moulins à vent, "sus l'heure de sa digestion, estoit en griève maladie tombé, par' certaine crudité d'estomach, causée de ce (comme disoient les médicins) que la vertus coneoctrice de son estomach, apte naturellement à moulins à vent touts brandifs (4) digérer, n'avoit pu à perfection consommer les paelles (5) et coquasses (6): les chauldrons et marmites avoit assez bien digéré. Comme disoient cognoistre (7) aulx hypostases (8) et énéorèmes (9) de quatre bussarts (10) d'urine qu'il aroit a ce matin en deux fois rendu. Pour le secouril usarent de divers remèdes selon l'art. Mais le mal fut plus fort que les remèdes. "

" Comme graudement est par Herophilus blasmé Callianax, médicin, qui, à un patientlinterroguant et demandant: "El mon mine, rous diet-elle poinct que je menre? " il (1 1) follement respondit: "Non, si t'eust Latona (1.2) mère des beaulx enlants Phobus et Diane engendré (1:3). n

(1) Les ehevalions de Malle, mimitivement les chevalier's de Rhodes.

(2) Tant elle serait curieuse à voir, modifie piu les émotions du combat out de la perur.

(3) Fenden de naseanx. De bringer, frotter, fonelter, et mailles, les marines. (L. IV , ch. xrir.)

(1) Tout enliess.

(5) Pelles.

(6) Coquasses, de eoquere, cuire; eopuemars.

(7) Commaitre.

(8) IIypostases oul hypostallemes, sédiments de l'urine.

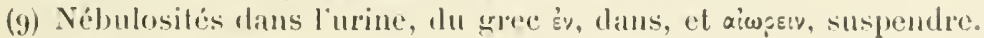

(10) 864 pinles.

(11) Celni-ci, Callianax.

(12) Jalone, fille de Cios el de Pherbé, a en de Jupiter deux entants, Plumbus-1 jollon el liame.

(23) Letlere an cardinal de Chatillon, I. IV Rabedais a rommis ici mon

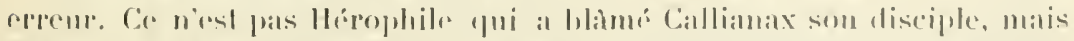

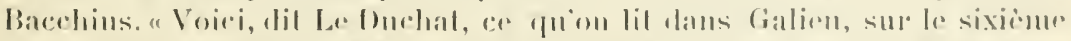

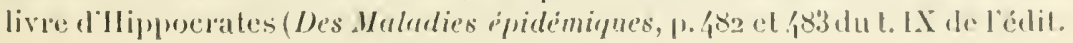


Stercus et urina medici sunt prandia prima. Ex aliis paleas, ex istis collige grana (1)...

déclare Panurge au docteur Rondibilis.

"- Vous prenez mal, dist Rondibilis : le rers subséquent est tel :

Nobis sunt signa, vobis sunt prandia digna (2).

"Si ma femme se porte mal : j'en rouldrois voir" l'urine (3), toucher le pouls et roir la disposition du bas ventre, et des parties umbilicaires (4), comme nous commande Ilippocrates, 2 , Aphoris. 35 , avant oultre procéder. Non, non, dist Panurge, cela ne faict à propos. C'est pour

de Chartier): Car quelques-uns d'entre les médecins tiennent des discours thue fatuité incroyable, semblables à ceux que cite Zeuxis du livre de Bacchius, ou cet anteur a rapporté les paroles et les actions d'Hérophile et de ses sectateurs. Il raconte de Callianax l'Hérophilien que, royant un malade qui lui disoit: - Mourrai-je? - Oui, lui répondit-il par un rers grec : oui, sans doute à moins que vous ne soyez le fils de Latone. A um autre malade qui lui demandoit la mème chose, il répondit: Patrocle est bien mort, qui valoit infiniment mieux que vous. "

(1) Les matières fécales et l'urine sont les mets prélérés du médecin ; des autres recueille la paille et de ceux-ci la graine.

Le premier de ces deux rers est une allusion à un rìglement de Henri II, dont voici le texte : Sur les déclarations des personnes décédées par la faute des médecins, il en sera informé et rendu justice comme de tout autre homicide, et seront les médecins mercenaires tenus de goùter les excréments de leurs patients et de leur impartir tout autre sollicitude, autrement seront réputés avoir été cause de leur mort et décès. "(Voy. Mercier, Tableau de Paris, vi, p. 227.)

"Le second rers que Panurge accole plaisamment au premier est emprunté à un brocard de droit qui n’a aucun rapport arec le sujet." (Burgaud des Marets el Rathery.)

Dans la Briefve Déclaration, attribuée à Rabelais, on lit : "Maschm..., virant dexcremcnt. Ainsi est par Aristophanes, in Pluto, nommé Esculapius, en mocpuerie commune à tous les médicins. "

(2) Nous trouvons dans ces matières des éléments pour nos diagnoslics, mais ce sont des mots digues de vous. "Réponse, remarque judiciensement M. L. Sardon, que tevait naturellement faire te médecin Rondibilis."

(3) Dans son traité De Urinis, Rondellet a recommandé que le nédecin " voye l'urine des malades ".

(i) Ombrlicales, du latin umbilicus, ombilic, nombril. 
nous aultres légistes, qui avons la rubrique (1) De ventre inspiciendo (2). Je luy appreste un clystère barbarin (3). Ne laissez ros affaires d'ailleur's plus urgents (4). Je rous envoyerai du rillé (5) en rostre maison; et serez toujours nostre amy.

"Puys s'approcha de luy, et luy mist en main sans mot dire quatre nobles à la rose (6). Rondibilis les print $(\boldsymbol{7})$ tris bien, puis lụ dist en effroy, comme indigné : - Hé, hé, hé, monsieur, il ne falloit rien. Grand mercy toutesfois. De méchantes gents jamais je ne prends rien (8). Rien jamais

(1) Titre, du latin ruber, rouge. Dans les liveres aneiens, les tilres et certaines remarques étaient imprimés à l'encre rouge.

(2) De linspeelion du ventre, Digesles, 1. XXV, t. IV.

(3) "On comprend, olservent Burgand des Marets et Rathery, quelest le clystere que Panurge apporte is sa femme; mais pourquoi l'appelleI-il harbarin? Nons pensons que ceest là une lacétie italientie dont l'origine nous cehajple."

Cetfe explession se reneontre dans direrses pièces de théâtre du moyeu ìge :

LA FEMME

(Elle reproche à son mari de la négliger)

Enda j'ay le cueur si fasché

Que je vouldrois estre en purgatoire.

L'HOMME

Vous faut-il un suppositoire

Ou (ung) clistiere barbarin?

LA FEMME

V'ous m’avez abusée, marin,

Avee vous je vis en langueur.

(Ancien Théatre français, 1. I, 1. 31, Furce du frère Guillebert.)

Je suis drogueur appoticquaire,

Je fais elistives barbarins.

(Le Vurlel ì louer, Recueils de poésies francoises, I. I, 1. 83.)

(1) Rabelais, comme bon nombre d'écrivains de son éporjue, met au masculin te mot atfaire.

(5) Des rillons on des rilletles.

(6) Pieces dor lris fin ralant vingl-ing lranes, frappées en 1334 par

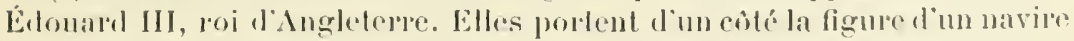
1. de liulde celle d'une rose, armes des maisons d'York el de Lancastre. Lat consultation élait royalement payéc.

(z) P'ril.

(8) Traduction du rel's latin de Calulle:

Namque eyo ab indignis pramia mulla pelo.

(Catelle, De comel Berennis, Y. 1,is.) 
de gents de bien je ne refuse. Je suis tousjours à rostre commandement. - En payant, dist Panurge. - Cela s'entend. respondit Rondibilis (1)."

Maitre Francois est, avec Lisset Benancio (2), un des lares médecins de la Renaissance qui n'ait pas eu une foi aveugle dans l'examen des urines. Je n'en veux pour preuves que les lignes dans lesquelles il a flagellé si cruellement (3) Picrre Gilles (4), "lequel dans le pays de Satin. "au milieu

(1) "Quelques auteurs, entre autres de Thou, ont lail, dit le professeur Planchon, ancien doyen de la Faculté de médecine de Montpellier, un reproche à Rabelais d'aroir trailé légèrement et presque ridieulisé, sous le nom de Rondibilis, son aneien maître et ami Rondellet; mais Cuvier, moins sévère, plaide l'indulgence pour l'autrur de Pantagruel, parce que, d'une part, dans Ja comique consultation médieale de Pammge, Rondibilis, sous une forme batine, dit au fond des ehoses sensées, et que, d'autre part, la conclusion du chapitre, bien quayant l'air te taxer le professeur d'avidité pour l'argent, n'est, à vrai dire, qu’un batinage à l'égard du salaire des médecins en génílat. "(Prancnox, Rondellet et ses disciples.)

Selon M. Dubouchel, les motif's de l'animosité de thaître François enver's Rondellet seraient tout autres. Durant l'année 1536 , les droits de matricule et de bacealauréat fiurent, à la Faculté de médecine de Iontpellier, élerés te deux livres à un écu d’or, unum aureum. "Rabelais, n'ayant pas de quoi payer de suite et intégralement l'ácu d'on en question, se contenla, écrit M. Dubonchet, de dommer un arompte de trois lirres, dont le versement lut intiqué en marge, sous forme de quittance.

"Mais, le soir mème de ce jour, il emprunta sans doute de l'argent on rn reçut d'un ami, car nous trourons consigné dans le meme registre (liber Procuratoris) l'acquittement de cette dette; Rondellet en accuse reception: Franciscus Rabelasus diocesis Turonensis solvit, die 17 septembris 1530, unum aureum.

"Ce zèle dut paraitre extrème a Rabelais, et nous ne serions point éloigné d'y tronver l'origine de la raneune sournoise qu’il garda foujours un peu envers Rontlibilis, ce rapace qui osa consigner dans un registre public une defle quil roulait faire ignorer, puisqu'il ne l'inserivait pas lui-mème, ainsi que cela se faisail habituellement." (A. Dưouснет, loc. cil. suprà, p. 33.)

J'estime, comme de Thou, que Rabelais a ridieulisé Rontellet, altaché au cardinal dr Tournon, parce que son ancien maître l'a aceusé, auprès du chancelier Dubourg, d'aroir révélé des secrets d'État.

(2) An moment où le cliagnostie par les urines avait le plus de rogue, Lisset Benancio a écril dans les Abus des apolhicaires : "Plusieurs maladies adviennent au corps, desquelles les urines ne justifient rien."

(3) L. V, eh. xxx.

(4) Pierre Giltes, naturaliste français, né ì Albi en 1490, voyagea en 
de philosophes et de géographes hàbleurs, parlant de tout par ouï-dire (1), "tenoit un urinal en main, considérant en profunde contemplation l'urine des poissons... " pour s'assurer de l'état de leur santé!

Imitons notre grand Ancètre, croyons ì l'uroscopie (2). Usons-en. mais ne lui demandons pas plus qu'elle ne peut domner. Si elle permet de reconnaître d'une façon irrécusable le diabète, l’albuminurie, la dégénérescence des reins, ete., elle ne foumit encore que des indieations insuffisantes dans beaucoup d'autres maladies.

Asie et en Arique, par orde de Frangois lor, pour recueillir des manuscrits. Ne recevant aucun secours, il lut obligé de s'enrỏler dans les troupes de Solinau II, fut lait prisonnier par des corsines of ne dut sa libertí quä la générosité du eardinal d'Armagnac. Gilles est mort ì Rome cu 1553. Il a puhlic chez Gryphius, sous le litre de Piscium Massiliensium gallicis el lalinis nominibus, un catalogue tris superficiel des poissons de la Méditerranée.

(1) Pour II. Ducrot, " le pays de Sitin c'est le pays des draps de Frize dont parle Thibault de Pleini en sa description de la Touraine. C'est Tours oit se fabriquaient ces riches étoftes, toutes bordés de fleurs, de fruils, d'animatux, de blasons, en toutes belles couleurs". (Dtcrot, loc. cil. sulpri, p. 31.)

(2) "Linine n’est que la lessive du corps" (Fourcroy); et "il est aussi naturel de juger les phénomones nutrilils par lurine que de juger ce qui se passe daus un fourneau par la naluredes produits ejue laisse échalper sa cheminée. "(Cl. Bersand). 
()uaresmeprenant avoit:

Le perinæum, comme un flageolet.

Le membre, comme une pantophle.

Les c..., comme une guedoufle.

La penillière, comme une dariole.

Les vases spermatiques, comme un gasteau feuilleté.

Les parastates, comme un pot à plume.

Les génitoires, comme un rabbot.

La géniture, comme un cent de clous à latte. Et me contoit sa nourrice, qu'il, estant mariè avec la Miquaresme, engendra seulement nombre de adverbes locaulx, et certains jeusnes doubles.

Le perinæum, comme un flageolet.

Le perinæum, le périnée. On définissait autrefois le périnée la région comprise entre la racine du pénis et l’anus; on la nomme aujourd'hui région périnéale antérieure.

"Les gryphes d'un chat de mar's (1) exulcérarent (2) tout le périnée (3) " de Gargantua.

Comme un flageolet, e'est-à-dire comme un instrument à rent, comme une flùte de Pan (syrinx). On sait que cette flùte est composée d'un certain nombre de tuyaux (roseaux) de différentes longueurs, assemblés les uns à côté des autres, et sur l'ouverture de chacun desquels la bouche se

(1) "Une martre ", disent tous les commentateurs. Une chatte, selon moi. (Toy. Anat. comparée.)

(2) Ulcérèrent, déchirèrent.

(3) I. I, ch, xilI, 
promène successivement pour obtenir des sons. Au moyen àge, le syrinx (1) antique appelé fretel, frestel, fresteal, fretiau, sistre, a été employé dans les concerts (2). Au $\mathrm{XI}^{\mathrm{e}}$ siècle. on le voit représenté dans l'antiphonaire provenant de l'abbaye de Saint-Martial de Limoges (Biblioth. nat, latin, $\left.11^{\prime \prime} 1118\right)$. Une chape masque les saillies et les dépressions que forment les sept tuyaux juxtaposés, tout en laissant libre, pour receroir le souffle de l'exécutant,
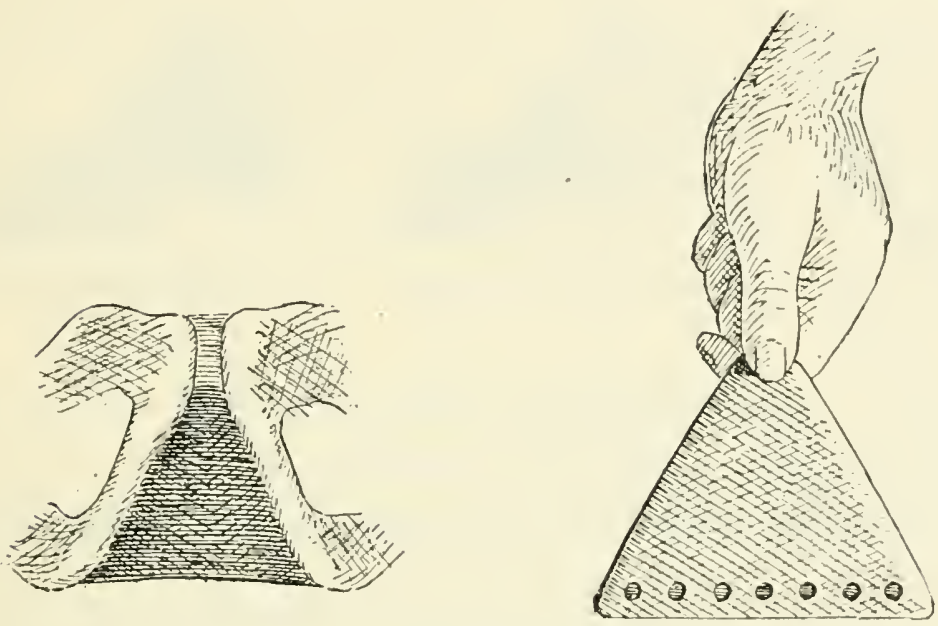

Le perinxum, comme un flageolel.

l'orifice de chacun d'entre eux. C'est choz l'homme surtont sur une préparation à l'aponérrose périnéale moyenne. vore de face, que la ressemblance du fretel de l'abbaye de SaintMartial de Limoges et du périnée saute aux reux. - Se reporter aux deux dessins ci-dessus.)

(1) Syrinx, tille du heure Ladon, élait me des nymphes de Diane. Pan l'aima inutilement. Syrinx, fuyant sa poutsule, arriva sur les berets du Laton et implora le secoms de son père. Celui-ci la changrar en loserau.

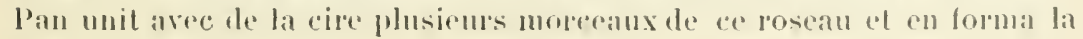
tlùte.

(2) "Somnent tlenstes ef fretel, "lit-on (v. 20/9) dims le Roman de lu riolelle (ville sivele). 


\section{Le membre, comme une pantophle.}

Le membre, "le membre nerveux, caverneux (1), " la verge.

Pantophle, pentophle (2), pantoufle (3).

Gargantua, soumis à la discipline des précepteurs sophistes, "disoit (4) que les mites (5) et bournes de boire

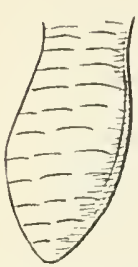

Soleret ou pédieux du milieu du $\mathrm{x}$ ve siécle.

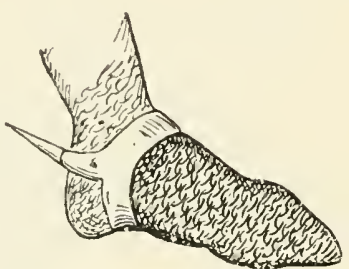

Chaussure milituire en mailles de fer, des xis et xvo siecles.

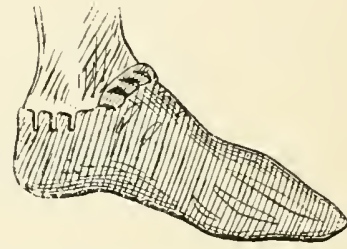

Soulier francais de la première moilié du $\mathrm{xvr}^{\circ}$ siécle.

estoient, quand la personne buvant, le liège de ses pantophles enfloit en hault d'un demi pied ".

Constitué comme une pantophle, l'organe de Quarespre-

(1) L. III, ch, xron. Le membre viril est constitué en majeure partice par deux corps juxtaposés, érectiles, à pen pros eylindriques, communiquant l'un arec l'aulre, appelés corps carepneux, parce qu'ils sont remplis par des travées et des lamelles fibreuses, limitant des espaces irréguliers. En anatomie, le mot carerneux signifie: qui a de pelites cavilés, de pelites cellules.

(2) Ce mot est orthographié de la sorte dans l'éumméralion des chaussures faites par Jehan Salle, .cordouonnier, pour le duc d'Orléans, Thierry, II. de Clives, ete. (Calalogue des archives du baron de Joursaucault.)

(3) Spigelius (Anat., ch. x) a jugé, par la grandeur de la verge, du plus ou moins de penchant d'un individu pour lacte vénérien. Selon Alex. Petronius (1. Il res Malad. ilal., ch. xvin), la verge grande est 11 témoignage d'esprit pesant et grossier, semblable ì celui d'un âne. D'ilprès Dirmerbroeck (loc. cit. suprà, t. I, 1) 171), "les gens de peu de sens et les stupides ont la rerge grosse; ces règles néanmoins ne sonl pas perpétuelles, el elles souffrent plusieurs esceptions".

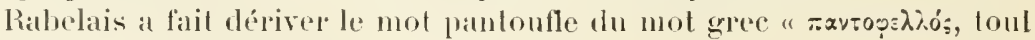
fail de liège, o s $\lambda \lambda 0_{5}$, escorce de liège, suber".

(4) L. 1, ch. xx1.

(5) Mesures, du litiu mela. 
nant dont il s’agit était nécessairement susceptible, comme elle, "l'enfler en hault ( 1 )".

Il n'est guere question de la pantoutle avant le $\mathrm{xv}^{\mathrm{e}}$ siecle, et il me serait difficile de donner sur cette pantoufle primitive des renseignements quelque peu précis. Tout ce qur je puis dire, e'est que les dessins du soleret ou pédieux, du milieu du xve siccle (2), de la chaussure militaire en mailles de fer des xive et xve siecles et du soulier français de la première moitiédu xv1 siècle $(3)$, qu'on trouve dans le Guide des amateurs diarmes et d'armares anciennes de Demmin (Paris, 186 g. p. :36o, fig. 9) el dans l'Ilistoire de la chanssure de Paul Lacroix, Duehesne et Seré (Paris, 1862 , p). (jó et 72), et que je reproduis, ont l'aspect général de la veroge, el pu'il est présumable qued dutros chaussumes avaient alor's la même lorme.

\section{Les c..., comme une guedoufle}

Les c..., le " pallotoc des vases spermatiques ", les bourses. Elles forment une poche à cavilé double, situéc en avant du périnée dans l'intervalle des cuisses.

Dans le Norvan on appelle encore e... un asise longen élui de bois, rempli d'eatr, suspendu en arant, entre les deux cuisses, et daus lequel les laucheurs phacent la pierres a aiguisere le dared.

La bourse de Galgantua "fut faicte de la e... d'un oriflant (1) n.

(1) Quaresmeprenant rbat laible, débile el dejà d'un cerlain âge, mais

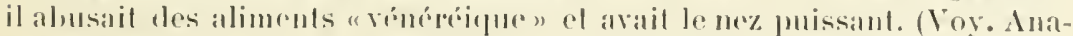
fumie des formes: Le nez, comme un broderguin anle én esensson.)

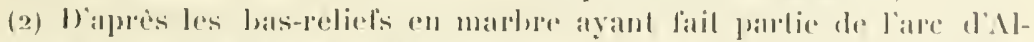

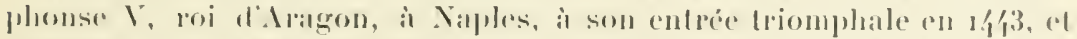

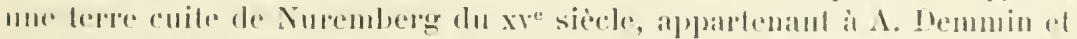
représentant Chatrumagne.

(3) N'apròs Horlué.

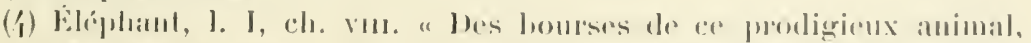

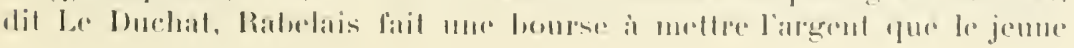


Si le terme anatomique qui sert à désigner ici le scrolum appartient aujourdhui au langage libre et plus que familier, il a appartenu au langage scientifique, voire au langage poétique (1).

Dans la Brie-Champenoise on donne toujours, sans y entendre malice, le nom de c... aux habitants du petit village de Coilly ou Couilly.

Le professeur Malgaigne, qui a élé, avec Littré, un des médecins les plus érudits de ce siècle, a toujours préféré ce terme à celui de bourses.

Guedoufle, coutoufle, contofle, gothelfe, guédolfe, guiédoufle, guedousle, guesdoule. A la page 483 du tome I du Gilossaire archéologique du moyen age de Gay (Paris, 1887), on lit :

Gargantua portoit ordinairement sur soi ; et ce qui le porte ì cela, c'est que comme anciennement les Particuliers laisoient leurs bourses de la pean qui enveloppe les testicules de bélier, il faloit qu'un Géant et un grand Prinee comme Gargantua eût une bourse incomparablement plus grosse, puisqu'dle devait itre proportiomne aux richesses et à la taille de cet lomme extraordinaire. "

Cette interprétation de Le Duchat est confirméc par la phrase suivante que je lelève dans le ehapitre svir du livre IIf.

"Panurge presenta ¿̀ la sybille de Panzoust un bourrabaquin garni de breuvage, une $c . .$. te bélier pleine de Karolus nouvellement lorgés (lrappés) : enfin, avec une profunde révérence, lui mist an doigt médical une verge d'or."

Panzonlt est un petit bourg du Clinonais. La Sibylle en question a labtité, près de ce bonrg, me grotte que l'on voit encore.

Le karolus est une momnaie de billon qui valait quatre deniers tomrnois (il peu près quatre centimes) et qui remonte a Charles VIIl. Elle est marquée d'un $K$, première lettre du mot Karolus, Charles.

Le doight médical des Anciens est l'annulaire. "On s'est généralement accordé à porter les ammeaux principalement à la main gauche, et an doigt qui est í côté du plus petit et qu'on appelle doigt médical." (Macrobe, Salumales, Vil, 13.)

(1) Voy. leniltet 43 b du Roman de la Rose; Clément Marot, Dialogue de deux Amoureux; Dopoexs, IIisl. des planles, trad. de Charles de l'Eschise, Anvers, 1557 , P. 152 ; Ambr. Paré, passim ; Antoine du Pinet, Commenlaires de M. Pierre-André Mallhiolus, Lyon, 1572, p. 473; Gui-Patix, Correspondance, lettres du 6 janvier 165/ et du 24 avril 1647; Supplément du Calholicon ou Nonvelles des régions de lu lune, ch. vi; Satire Ménippée, luarangue de Rose; etc, etc. 
"Coutoufle, vase à double récipient et à deux bees opposés l'un à l'autre, dont la courbure est disposée en sens inverse ; il est plus connu sous le nom de guédoufle.

Une contofle d'argent pesant un marc et demy

La m. 745. Valent III, 6.

(Inventaire de Raoul de Clemont.)"

Et à la page Sor du mème tome:

"Coutoufle ou Gothelphe au XIve siècle élail peu diflérent d'une sorte d'huilier ì deux bees fabriqué, au $\mathrm{x}{ }^{\mathrm{e}}{ }^{\mathrm{s}}$ siècle, dans les verreries de la Lorraine. "
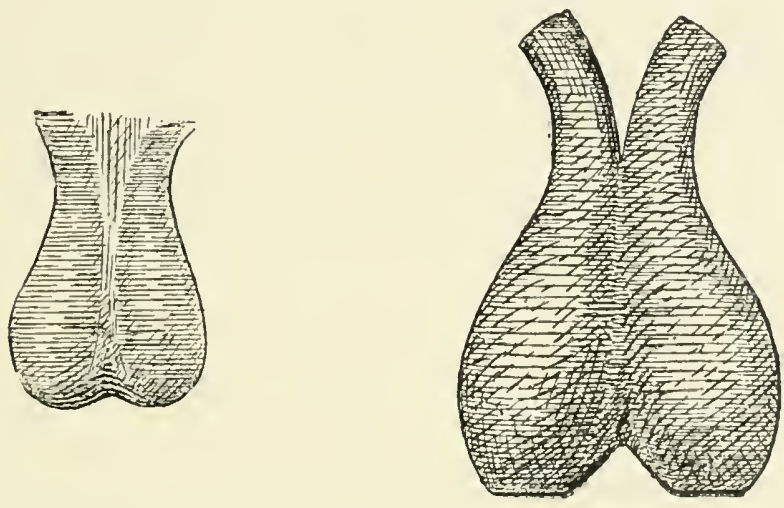

Les c..., comme une guedouple.

D'après Le Durhat: "La figure de la Guedoufle, qui est celle d'un trètle dont on a oté la feuille d'en bas, convient très-bien à ee qu’ici Rabelais dit lui ressembler. "

Maître liançois nous apprend, entin, qu il y avail deux ustensiles de ce genre : un dins lequel on ne mettait que de l'huile, l'autre dans lequel on ne meltait que du vinaigre.

Panurge "aroit une petite guedonfle pleine de vieille huile, ef quand il trompit on lemme, on homme qui eust quelyue belle robe, il lem en graissoil el gastoil loms les plus beaulx endroicts (1)."

(1) L. II, ch. Xir. 
"Une guedoufle de vinaigre, une salière de terre, un goubelet de Beaurois, etc. ", entraient dans la composition du trophée élevé en mémoire des levrauts par l’incorrigible vaurien $(1)$.

Le Musée de Cluny possède une guédoufle dont on ignore la provenance. mais que $\mathrm{M}$. Saglio, l'éminent direceteur de ce Musée, eroit dater du xvi ${ }^{e}$ ou du xvir ${ }^{e}$ siècle. Gràce à M. Le Dr Dureau, dont la complaisance égale le savoir, jai pu en ubtenir un dessin pour l’édification de mes lecteurs.

On trouve diverses expressions médicales dans la longue énumération des qualités des organes génitaux externes de frère Jean, - jeune, débordant de santé et capable de renouveler le plus fameux des exploits d'Hercule, - par Panurge (2), grisonnant et mal guéri par Mercure des blessures contractées dans les bras de Vénus (3) ; jen vite quelques-unes (位):

(1) L. II, ch. xivir.

(2) L. III, ch. Xxis.

(3) "Tu me reproches mon poil grisonnant, répond-il an fondateur de l'ordre des Thélémites... Vray est quen moi je recognois quelque signe indicatif de vicillesse: je dy rerde vieillesse, ne le dict a personne; il demourera seret entre nons deux. C'est que je trouve le bon vin meilleur et plus à mon goust saroureux que ne soulois (que je n’arais coutume, du latin solere); plus que ne le soulois je crains le rencontre du maulvais vin. Note que eela arguë je ne scay quoy du ponent (conchant), et signifie que midy est passé." (L III, ch. xхтй.)

En entendant raconter par Epistemon, de retour des Enfers, que ceux qui n'ont pas eu la maladie de Fracastor dans ce monde l'auront dans lantre, Panurge s'écrie : "J'en suis donerques quitte. Car je y ai esté jusques au trou de Gilbathar, et remply les bondes de Hereules, et ai abattu des plus meures. " (L. II, ch. xrx.)

Les bondes d'Hereule sont les colonnes qu'Hercule a élevées près du détroit de Gibraltar.

(4) Les adjectifs de l'énumération qui suit, ainsi que ceux de l'énumération dont il sera question plus loin (Voy. Anat. chirurgicale), sont plus ou moins nombreux et rangés dans un ordre différent dans les diverses éditions. 
C...(1) Dispermutisivt, riche en sperme, liquicle.

laicté, laiteux (2).

goildronné, épais, visqueux.

aromatisant, exhalant une odeur lorte comme les aromates.

gréné, contenant des graines, des
germes ou spermatozoïdes.

C... visg.sus.s, propre au mariage. Du mot arabe algam, qui reut dire mélange d'or el de mereure, el du mot gree ráusos, mariage.

C... leutné, gami de poils, comme le feutre.

C... Génent, double, géminé. C'est l'élat normal. On a signalé, par exception, l'absence d'une ou des deux grlandes grénitales (anorchidie simple on double; ‘n gree $\dot{x}$, privatif, el ǒšs, testicule); la fusion des deux glandes en une seule (synorchidie, du grec és, ensemble, et óy glandes génitales triorchidie et pentorchidic, du grec zeššs, trois, réses, einq, et ơs\%s.)

C... oris, ayant la forme ronde et oblongue d'un ceuf.

C... mesculecx, bien musclé.

C... maxur, de quoi remplir la main, volumineux. Latrophie du teslicule ou microrehidie (du gree pusós, petil, et öp»s) est une cause l'impuissance. La microrehidie constitue la maladie appelée féminisme, maladie féminine (3).

C... P.sllatogéé, ele, entouré, revitu d’un palleloc. C̈est ce palleloc mouké sur son contenu que Maître Frangois a comparé à une guedoulle. Il est composé de plusieurs couches qui sont, en procédant de dehor's en dedaus: $1^{\circ}$ la peau ou scrolum (du latin scrolum, sac ou bourse de cuir) ; $2^{\circ}$ une couche musculo-

(1) Certains eommentatenrs voint dans celte ónuméralion une parodic

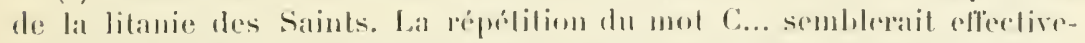
menl lindiquer. Observons ceprendant que ces longs dénombements de

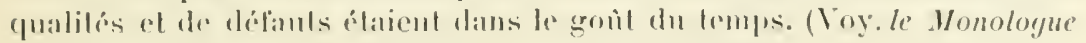

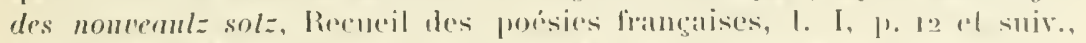
ainsi que le Monoloyge des solz joypuld, dams la meme collarlion, I. I. [1. 15 el suiv.)

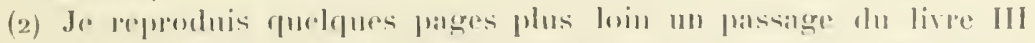

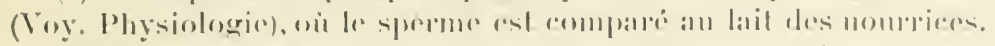

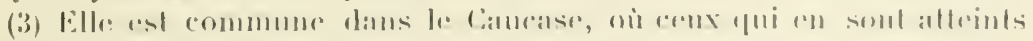

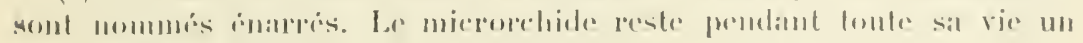
gramel enfant. 
élastique, le dartos (du grec òstós, écorché) ; $3^{\circ}$ une tunique entièrement musculeuse, la tunique érythroüde (du gree

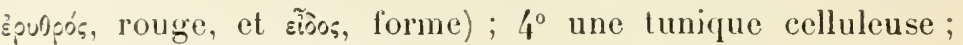
$5^{\circ}$ une tunique séreuse.

Le paletot actuel est le palletoc, le justaucorps modifié de nos aïeux.

\section{La penillière, comme une dariole.}

La penillière, le pénil, la région couverte de poils située au-dessus des organes sexuels.

"Le feu que j’arois jecté au giron de mon paillard rostisseur lui brusla tout le penil, " déclare Panurge à Pantagruel.

Dariole, gâteau à la crême.

"Les porphyres, les marbres du palais du seigneu" Stozzi sont beaulx, observe le moine Pierre Lardon; je n'en dict poinct de mal: mais les darioles d'Amiens sont meilleures a mon goust. ") (L. IV, ch. xr.)

La toison annelée du bas-ventre perdu dans le pus crémeux d'un écoulement uréthral ou cachée sous une carapace de conerétions melliformes engendrées par le délaut de soins ou la vermine.

De ces deux opinions, la première me paraît la plus vraisemblable. Ouaresmeprenant était atteint en effet, quelquefois, d'une blennorrhée, par suite de la nourriture échaulfante qu’il prenait : "aubers salés (1), casquets (2), morions salés (:3) et salades salées "(4).

(1) Aubers salés, jeu de mot arec salade (casque). Liarmure apluelée aubert couvre avec le torse une partie de la lète, du cou et la nurue, ef peut, par conséquent, ètre considérée comme une espèce de salade ou easque.

(2) Autre jeu de mot arec salade (casque). Le casquet est une armure de tite, une sorte de salade.

(3) Noureau jeu de not. - Voy. an paragraphe suivant la définition du terme morion.

(1) Mème jeu de mot. La salado est une sorte de casque sans crète. Ce mot vient sans donte de l'espagnol celadu (petit casque).

"Aubers salés, ete., toutes viandes de Carème indigestes et de lanut 


\section{Les vases spermatiques, comme un gasteau feuilleté.}

Les vases spermatiques, les grandes qui sécritent le sperme, les testicules (1). Ils ont la lorme d'un ovoüde aplati Jatéralement.

Dans l'exclamalion de Panmoge en quète d'une prude femme : "Dien gard" de mal les pelotons! (2) " on thonve, disent judicieusement Esmangart, Johamnean et le DrF. Brémond. une indication succincte de la structure de res glandes.

Le parenchyme testiculanire est composé, en effet, de tubes tris étroits, emroulés sur eux-mèmes et groupés au nombre de trois a six pour eonstituer des pelotons on lobules quion peut séparer les uns des autres ainsi que les différentes couchesd dun gastean fenilleté. Les tubessprermatipues constituant ces lobules aboutissent, à droite comme à gauche, ¿a un organe collecteur appelé épididyme (paraslate), ancuel

goul, dit Le Duchal, doul les nous sont eommuns a aulant de différentes formes de anspues aceompagnés de leur coille de maille guon appeloit

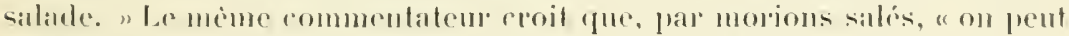
anssi entendre dre pelites morilles salees pour l'hyver"

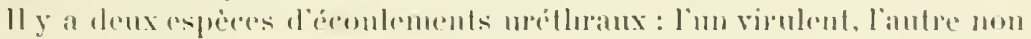
virulent povorjuc:

soit pardes relations intimes avee ane lemme lymphatique, en dehors

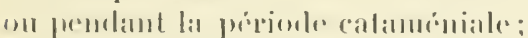

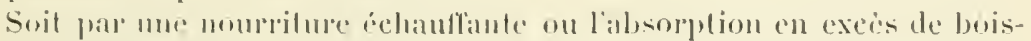
soms lepmonties (biere);

Soit pal linjertion de substances impitantes dans le ranal exeroleur de

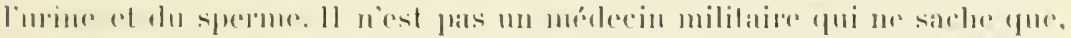

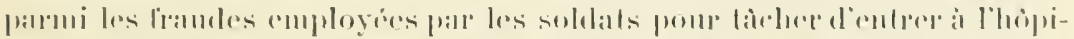

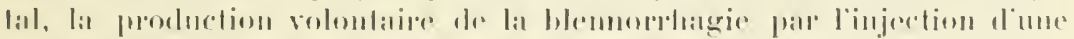

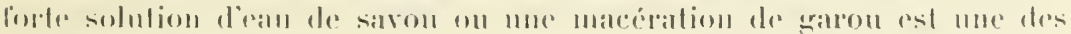
plus remommunes.

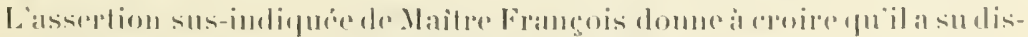

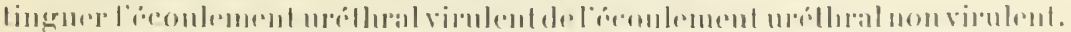

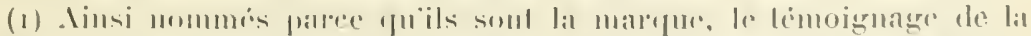

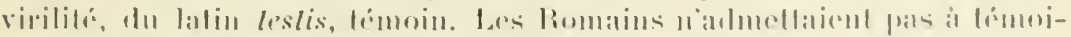

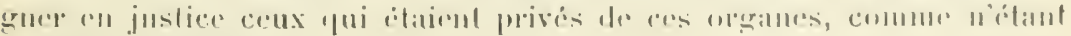
pas des hermmers.

(2) I., III, ih, i11. 
lait suite un conduit recteurqui " col longs ambages et thexuosités." (Voy. plus loin Physiologic), aboutit ì un réservoir dit vésicule séminale (génitoire).

"Ayants (1) vidé et espuisé en ce jour précédent touts ros vases spermatiques, au jour subséquent (2) y en peutil tant aroir"." demande Panurge au frère Fredon.

"Fr. - Plus.

"Pan. - Ils ont, on je resse l'herbe de l'Indie célébrée par Théophraste $(3)$. "
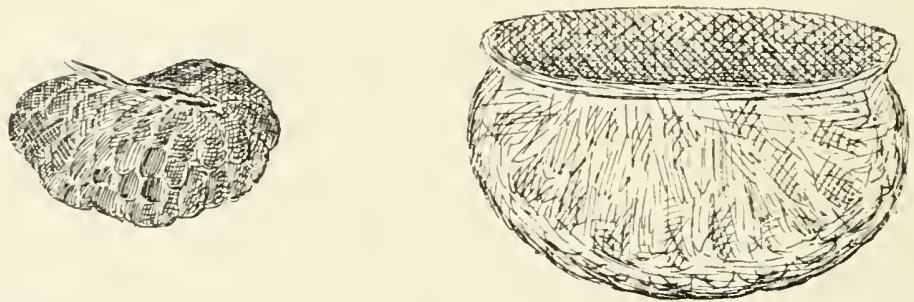

Les voses spermaliques, comme un gasteau feuilleté.

Maître Francois ne sest servi qu'une fois du mot testicule, c'est quand il a mis dans la bouche du chatelain prodigue de Salmigondin (4) ees paroles qui sont une allusion a la légende de la papesse deanne (.j) : "Il ne sera jamais pape, cal": testiculos non habet."

(1) Les auten's d'alor's, encore sous l'empire des règles latines, écrivaicht tous les participes présents rules faisant varier, et alor's mème ipue ces puticipes araient des rigimes ou complements.

(2) Suivant, du latin sub, aphis el sepui, qui suit, qui vient apuès.

(3) Thíophluste, l. IIl, ch, r.

(i) L. IIl, ch. xir.

(5) El lat reproduction mi-française, mi-latine de ce dieton rimé, très répandı atı moyen âge :

\section{Testiculos qui non habet}

Esse papa non polest.

Colui qui na pas de testicules re peut pas itre pape.

Lne légende datant du vun siecle prétend qu'me femme due pape sons le nom de Jean VIII, sans qu'on se liit préalablenent assuré de son sexe, antil, an grand scandale rle la chrétienté, aceonché pendant une procession.

Jann Bonchet et le Pere Jabillon ont contribue à domer quelene 
Les parastates, comme un pot à plume.

Les parastates (1), les épididrmes. L'épididyme du grec s-ri, sur, et óônos, testicule) est la première partic du canal qui conduit le sperme du lesticule à la vésicule séminale du mème còté.

Pot à plume, morion, casque on salade di cinnicr des hommes d'armes à pied. Le morion du xrye siecle était rond, allongé el comronné d'un cimicr coloré fait d'une matière
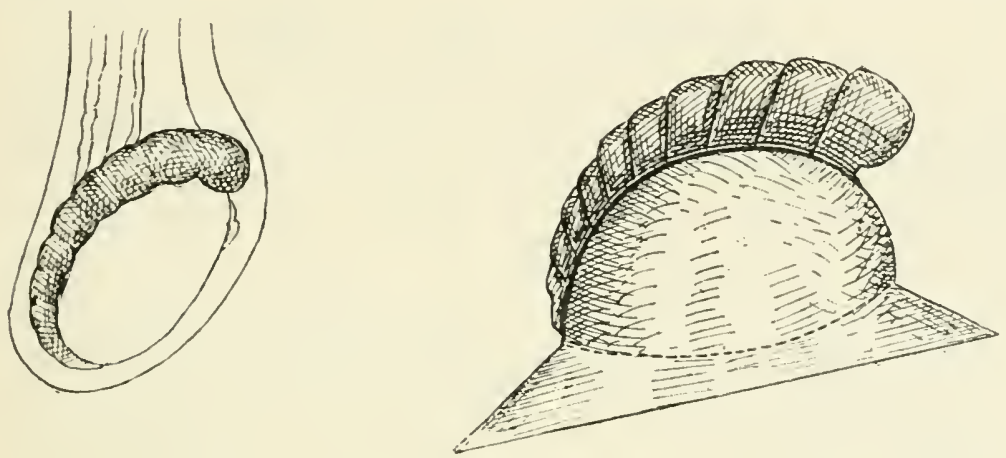

Les purastules, comme un port it plume.

somple. Sit visière, relevere an triangle par devant et aldaissée latéralement pour protéger less oreilles, élail réunie au convie-muque.

Quelquelois, cependant, il navail pas de labal proterteur. Dams la neflatérale gantehe de l'église romano-gothipue de l'abhaye de Laxenil. anjourd'hui église paroissiale, on voit une série de vitranx représentant diverses seènes de lar Passion et dont lous les persommages sont, sant le Christ. la Vierge et mone des saintes lemmes. costmmés conmme du

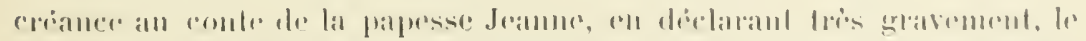

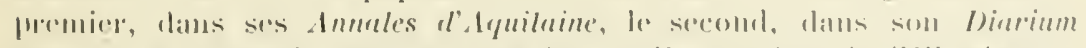

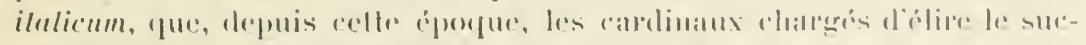

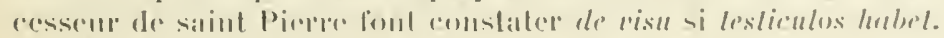

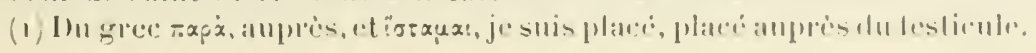


temps de Frangois Ier (1). Au nombre de ees personnages ligure ( $7^{e}$ vitrail) un soldat dont le pot i plume, dépourvu de rabat protectemr, rapjelle, encore phus exartement que celui dont je doune le dessin, une coupe antéro-postérjerre horizontale du testicule, à quelque distance de l'épididyme (z).

"L'épididyne, disent MM. Cruveilhier el Mare Sée, est conché à la manière d'un cimier de casque, le long du bord supérieur du testicule (:3). "

Rabelais l'avait dit bien longtemps avant eux.

\section{Les génitoires, comme un rabbot.}

Les génitoires, les vésicules séminales, sont deux poches membraneuses siluéesdans le ventre, au voisinage de l'anus, el dans lesquelles séjourne, justu’à son expulsion au dehors, le liquide spermatique.

"Elle's ont la forme, dit Sappery, d'un cone dont la base serait arrondie et la surface un peu comprimée de haut en bas."

"La teste perdue, ne périt que la personne, dit Panurge $(4)^{\prime}$; les c... perdues, périroit foutr humaine nature. C'est ce qui meut le galant (j) Cl. Galen, lib. 1, de spermate, a bravenent conelure, que mienls fést-it-dire

(1) Qu'on ne soit pas trop surpris de cet anahronisne. Les arlistes dn moyen âge en ont eommis bien d'autres. Jésus de la sainte Famille de. Rubens (Anvers) apprend it lire dans le Nonvean Testancol; daus unr des vieilles tapisseries de l'église de Notre-Jame-de-Nantilly, ì Saumul, un des soldats de Tilus assiégeant Jermsilem lient une arpuebuse; un des saints do Solesnes (ehapelle ret sépulerede Nolde-Seignemer), Joseph d'Arimalhie, est habillé comme du temps de Lonis XI cl décoré du collier de fuelque order de chevalerie; les Romains de Ia légion Thébaine qui ornent la laçale de la callédrate Saint-Manrice, d'Anger's, sont revelus, chacun, d'une armure complète, cle.

(2) Ces vilmax sont modernes, mais coptix sur des anciens.

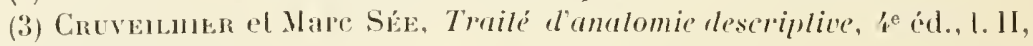
367 ; Paris, 186.5.

(4) L. III, ch. vilt.

(5) Estimable, méritant; du latin t'ulente, ablatit de valens, participe de ualere, valoir, avoir du prix, du mérite. "Allusion à $\gamma \alpha \lambda \gamma_{i} v^{\circ}$, nom grec de Galien, "dıt Le Duchat. 
moindre mal) seroil proinet de cour n'avoir, que poinct navoir de génitoires. Car là consiste, comme en un sacré repositoire (1), le germe conservatil de l'hmmain lignage $(2)$."

"Les Utopiens aroient les génitoiles tant léeonds, ef les Ulopiconos portoient malriers tant amples. gloutes (:0), tenaces (f) ot cellulese (j) par bonne architecture, yur,

(1) Réplacte sacri, tabernacle, du latin reposilum.

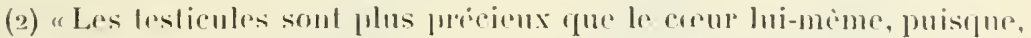
indéfundamment de la chaleme ot de la vie qu"ils impriment aux animaux, ils leur fournissenl le germe conservatil de l'humain lignage.n (Cl. Cintex, I. I, de la simence.)

(3) Goulues, avides, du latin gluto. Nristote of Platon ont pregande la matrice romme un animal avisle de sperme.

Riolau, qui u’ignorail fas la nature musculeuse de cet organe, a berit (Anthropogruphie, Paris, 1629) : J'athour lianchement pue je ne suis pas

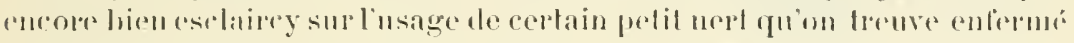

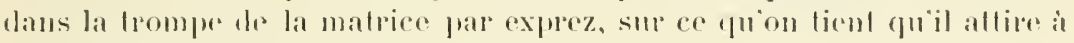
soy la semence of la carlue.

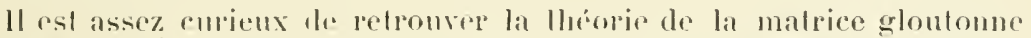

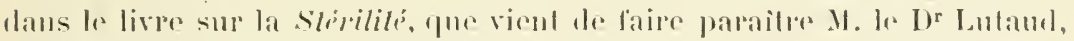
módecin de Saint-Lazare. "Pendant la copulation, dit M. Lutaud, l'uldrus entre lui-meme en jeu. Soms lönlluence de lexeitalion gémésique, sa

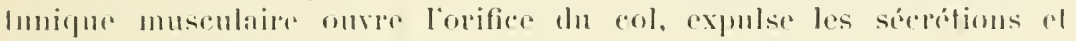

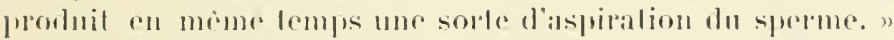

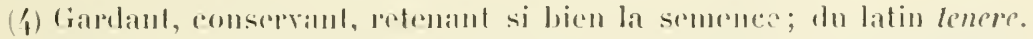

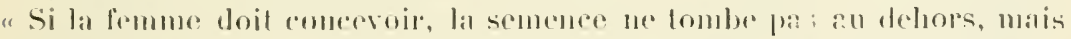

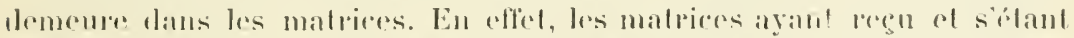

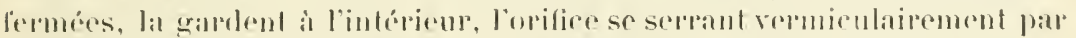

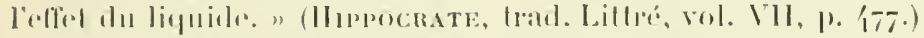

(5) Divisee rn eollules, en loges, an compartimenls. Pour Hali-

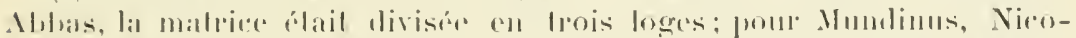

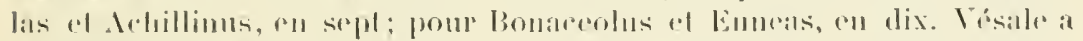

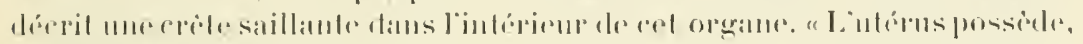

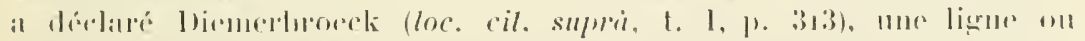

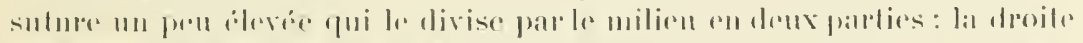

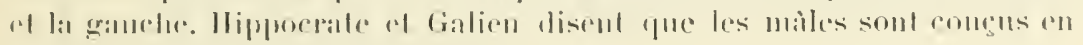

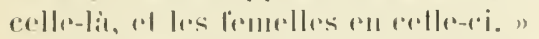

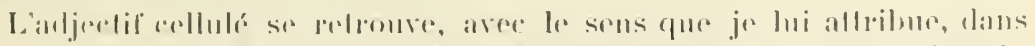

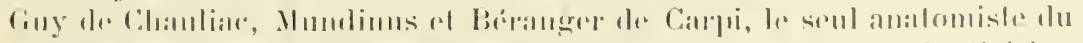

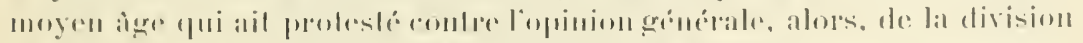

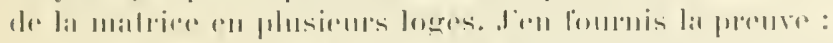

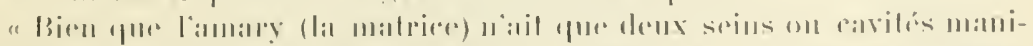

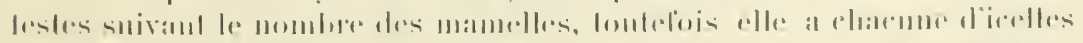

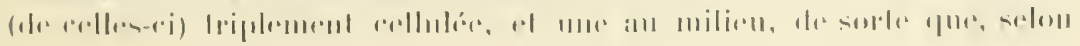


on (1) bout de chaseun neuviesme mois, sepl enfants pour le moins, que masles, que femelles (2), naissoient chascun mariage. "

Rabbe, rabbot, navel, grosse rave; du latin rapa ou rapum, fait dans la même signification du grec páşus ои ра́тus (3).
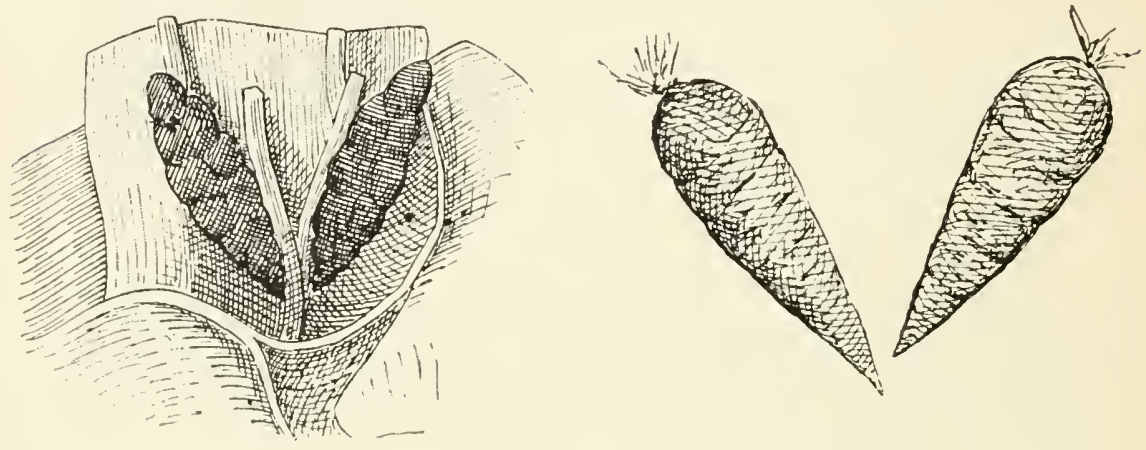

Les geniloires, rommo un rabbol

A trois sièdes de distance, Sappey s'rest reneontré, sans le savoir, arec Rabelais.

Mumlinus, on y lroure sept réceptacles, "(GuY be Cunutuc, Grande Chirurgie, 1. 77, idlit. Jomberl, Ronen, 1632.)

"Concavilas trero ejus hubet seplem cellulas, tres in parle dextra el thes in parle sinistra el unum in summilute vel medio ejus. La cavite de l'utarus a sept rellules, trois it droite, trois à gamehe of mue, an milien, à la

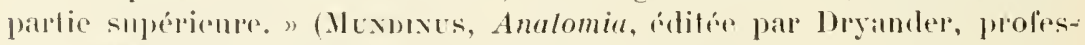
seur it Marpug, imprimerie de Clusthial Egenolphus.)

" Est furum mentacium direre quad malrix habeal seplem cellulas. Ciest un mensonge absolu que de dipe que la matrice a seph cellules." (Carpi Commentaria cum amplissimis adelitionibus super analomiam Wun dini unu cum lextu ejustem in pristimum niloremi redaclo, 1. 184.)

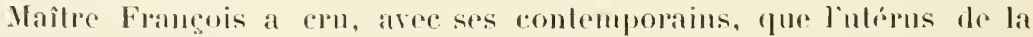
felume étail cloisonné, commo il a cru que celui-ci étail pourso de colylódons, dont dume mobilite extrome el ro rapport avec les principales parties du corps. (Voy. Physiologie de lappareil grinital de la femme.)

(1) Aur

(2) Taut màles que lemelles. (L. IH ch. 1.)

(3) En Aurergne on nomme rabiole une sorte de grosse rave on de limpeps. 
La géniture, comme un cent de clous à latte. Et me contoit sa nourrice, qu'il, estant marié avec la Miquaresme, engendra seulement nombre de adverbes locaulx, et certains jeusnes doubles (1).

Le mot génilure signifie aujourd hui descendance, progéniture. Jadis il servait à désigner à la fois:

$1^{\circ}$ Les parties génitales de l'homme et eelles de la femme;

$2^{\circ}$ Lionuf lécondé dans le sein de la mire lorsquil n'est eneore qu'une masse informe dans son organisation (2). llippocrate étend ce temps jusquan sixième jour, apres lequel la géniture prend le nom dembryon et edui de

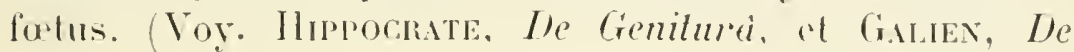
s'emine, (alp. q.)

3" La semenee de thomme et celle de la femme. (Voy. Hippocrate, Le Nalurâ pueri: Amb. Paré, OEneres XXII; J. Cimestan, Cénéralion de lhomme, p. 10\%, 15.9.).

Quel sens a-t-il ici ? Rabelais na certanement pas entendu désigner par ce terme l'appareil génilal, puisqu'il en a ébdie siparoment chacume des parties, ni le produit de la conception. puistu’il s'agil d'un homme. Il a entendu

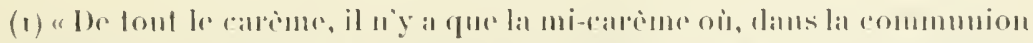

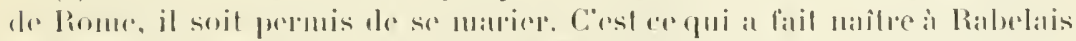

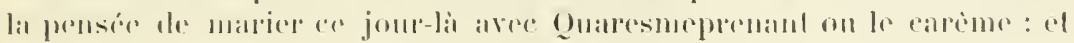

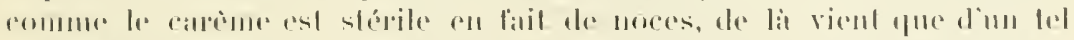

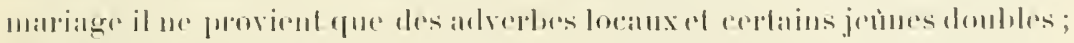

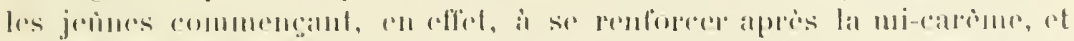

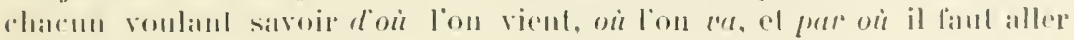

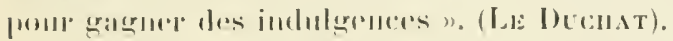

(口) Na voix ure vous soit poinl andire;

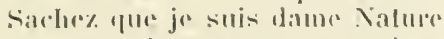

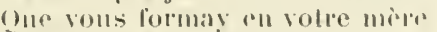

Tantiol apris lat géuiture:

le mos rove forme el ligure

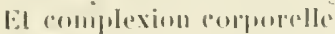

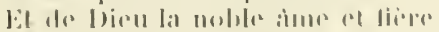

lal lat vertu -piriturlle. 
désigner la semence humainr (1), et on se demande arec un suprême étonnement... s'il n'aurait pas c.u notion des spermatozoüdes.

La semence bumaine (en grec, orésur.x) tient en suspension des corps dits animalemles spermatiques, spermatozoïdes, spermatozoaires, visibles seulement au mieroseope. Les spermatozoüdes sont pourvus d'un renflement antériem (tête ou disque) terminé par une pointe onduleuse très tine (quene). Ce ne sont point, comme on l'a cru, des animalcules ou des êtres reproduisant en petitle corps de l'homme, mais de simples éléments collulaires. Le sperme qui n'en posside pas n'est pas de la semence, lant au point de vur anatomique quau point de vue physsiologique. Pas de spermatozö̈des dans le liquide sécrété par les testicules. pas de fécondation.

Cést dans une lettre datée du mois de novembere abitiz, mais publiée seulement en $1(6-8(2)$, sous le litre: Observelions sur les animalcules de la semence humaine, que Leeuwenhoeck a lait conuaître qu’il renait de décourrir des animaleules dans le sperme (:3).

(1) "La semence, dit Diemerbroeck (loc. cil. suprè, t. 1, p. 350), est appelóe tantôt sperme, lantôt génilure: et fuoique Aristote, l, De Ort. animul, c. 18 , semble mettre quelque distinction entre la génilure ef le sperme, comme si celle-ci dait la semence des animanx qui sacemplent, et celleri de ce qui ne s'accouple pas, comme les plantes; néanmoins, parer ques le philosophe lui-meme eontond par tout ailleurs ces noms, ainsi que lait Galien et plusieurs autres, nous aussi, nous nous servirous indiferemment le ce nom pour une seule ot mème cliose."

Uno dernicre preuve qu'en atluiluant ici au mot gŕnilure la significalion de sperme je ne me trompe pas, e'est pue, dans le chapitre xxw du live 111 on lit encore qu" "Hippocrates maintient grande portion de la gíniture sourdre du cerveau et de l'espine du dos".

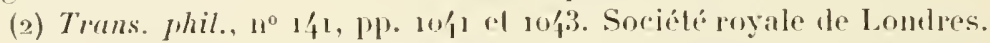

(3) La decouverte des spermatozö̈des a dé contestée ì Leeuwenhoeck pall llartsoeker (Essais de dioptrique). "Si Leenwenhoeck, dil Buffon, liest pas le fremier qui ait fait celle décomverte, il est celni qui l'a surve le plus loin et le plus aceríditée." (BuFfox, Mist. natur., De la Génération des animaux.) Leeuwenhoeck a été olıligé de reconnaître luj-mème que les spermatozoüdes avaient eté rus arant lui par un étudiant de Leyden, L. IIanm. 
si limrention du microseope n nitail pas. - du moins on lo prétend (1), - posterieure diune qualantaine d'années is Rabelais, on pomrait croire quil a ru les spermatozö̈des: d'autanl (2) micux :

1" Ou'en raison de l'abermalion de sphéricité des lentilles primitives les éléments fécondants du liquide spermatique examines aver ces lentilles ont une tibe tris aleondie. mon queue droite, courtr, rectiligne, resemblent élrangement, en un mot. ¿̀ "des clous à latte ". Ainsi les a dérits et leprosentés lserumenhoecli hi-mème:

(1) Cost vers 1 jogu que furent, dit-on. lithliqués par Hans Janssens of som dils Zarcharias les premiers microsenpes. Ce qui niest pas dontemx.

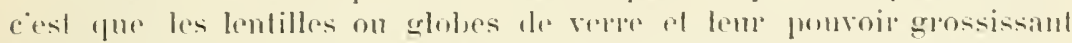

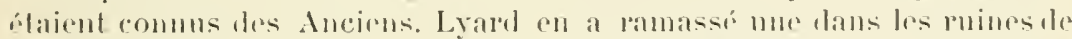
Ninive. Noron, dont la vere élait manvaise, regardait les combits des

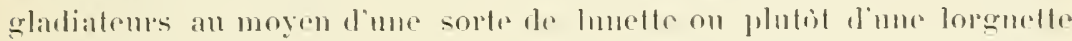

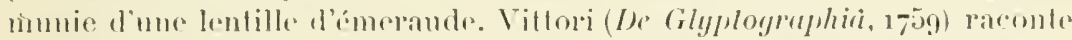

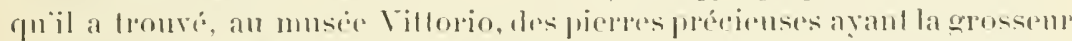

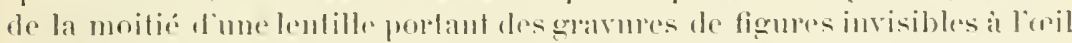
mu. Dans ldoistoire de la l'deademie des Inscriplions (ch. 1, 1. 276), on

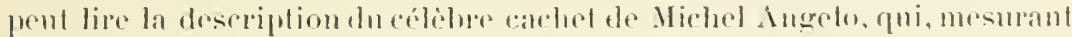
15 millincetres de long sur 12 millinitres de large, presente 17 figures

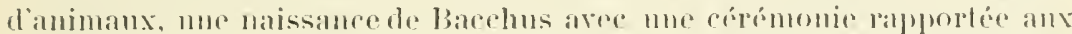

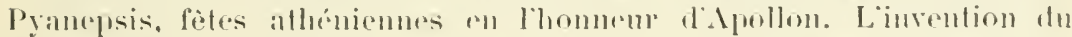

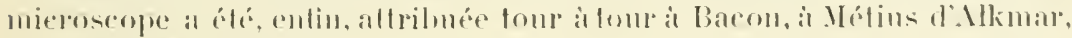
a Porlat, it Rialilise, ete.

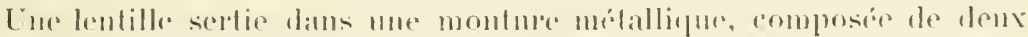

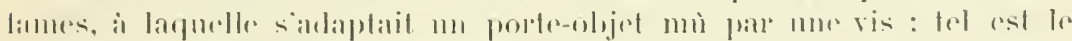

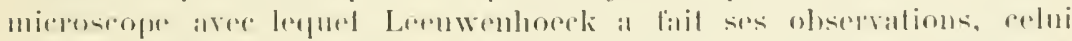

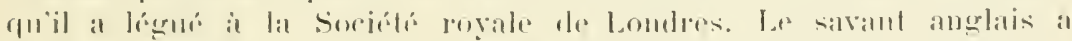

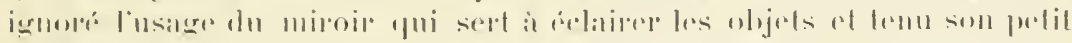

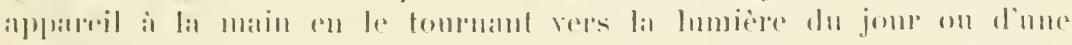
chinulelte.

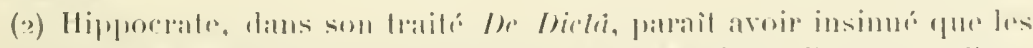

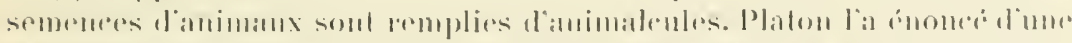

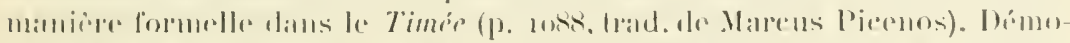

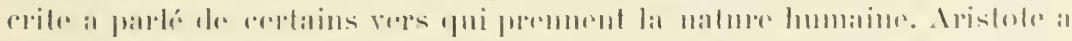
-

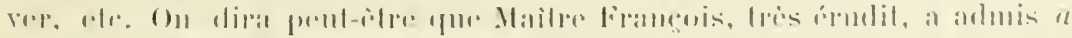

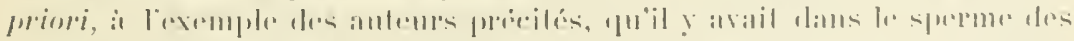

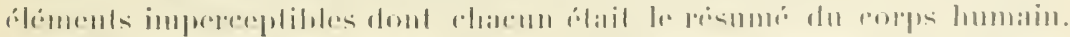

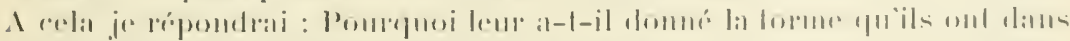

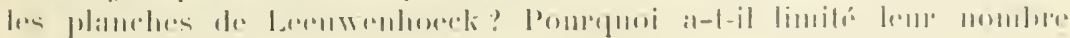
it eroll? 
$2^{n}$ Que Ie chiffre cent concorde arec la diminution du nombre des spermatozö̈des chez un homme d'un certain àge, émacié et rivant de privations (1):

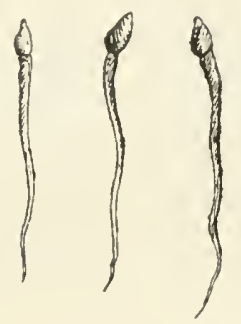

Suermalozö̈des, usu auec nos mieroserpies.

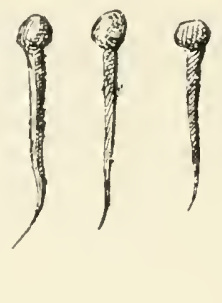

Spermalozoüles, vus aver les mirrosernpes de Leeumenhoerk.

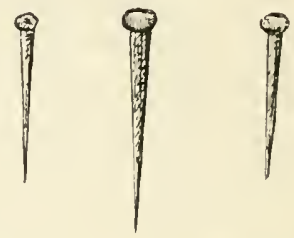

Clous à lalte.

30 Qu'il n'est pas besoin d'un très fort grossissement pour voir les spermatozoïdes (2), que Leeuwenhoeck luimème les a vus arec des doublets et des triplets (3):

$4^{\circ}$ Quau moyen àge les Arabes élaient réputés les premiers lunettiers du monde et araient des rapports constants avec la Faculté de Montpellier où a étudié Rabelais (4):

Jo n'insiste pas. Pour terminer, je ferai seulement obserrer que c'est folie de croire qu'une invention quelconque ait élé l'ouvre d'un seul jour et l'aurre d'un soul homme (i).

(1) 11 y a des milliers de spermatozoüdes daus une goutte de sperme grosse conme une tète d'épingle.

(2) A un grossissement de 300 is quo fois, on voit pue leur longueur totale est, chez l'homme, de $120^{\circ}$ de millimitre, et le grand diamidre de leur tite de $1300^{\circ}$ it $1200^{\circ}$ de millimitre.

(3) Arec tes mirroseopes, différant sensiblement, par conséquent, du microscope comprosé actuel.

(1) Rabelatis a parlé couramment larabe. Un paragraphe entier du chapitre $1 x$ du livre II est écrit en arabe, et, en plus des termes auatominues Allatim, Wirach, siphac, DAlymala, etc., que jai cités, on troure encore dans l'épopéc pantagrnólique les termes astronomiques arabes Azimulh, Almicanturah, ete.

(5) A lipoque oì parut Newton, Descartes avait change la face des sciences mathématiques par l'applieation fieconde de lalgible à la théorie des courbes et des fonctions variables. La gémétrie del linfini, dont cette théorie renfromait le germe, commeneait d percer le toutes parts. Wallis, Tren, Huyghens renaient de lourer les lois du mourement. La dícouverte de Galilée sur la chute des graves, ef dHuyghens sur les developpées ot la 
Quel immense laps de temps śestécouléentre la découverte de la rapeur et son application à la traction des wagons! On commence seulement à emmagasiner l’électricité. qui est connue depuis Ampere.

Il ỹ a quelques siècles. il était plus prudent de garder le secret dune invention scientifique que de la divulguer. Chassé de son monastire, emprisonné. Roger Bacon est mort en murmurant : " que les hommes ne valaient pas la

force centrifuge condusaient it la theorie du mourement daus les courbes. Répler arail détrmini lemlipse que décrivent les planètes. Enfin Hook arait tries bien ru que les mourements de ces planetes sont les résultats l'ume force de projection combinse avec la forec allractive du soleil. La mécanique cóleste niallendait quinn homme de plus jour

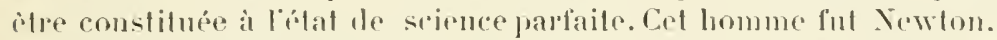

Combien de sibeles aratit falln pour laire éclore lesentes. Wallis.

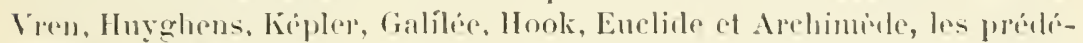
cessemps de Newton?

Cest a limprimerie gue lo siode de Rabelatis doil som inclat. Elle arul-

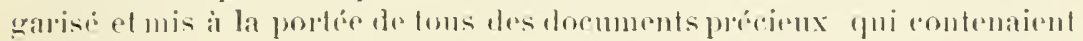
en gepme foute lit sejence moderne. Que d'inventions pogardeses comume récentes, dont loorigine se perd dans la moil des temps. Nat-nn pas

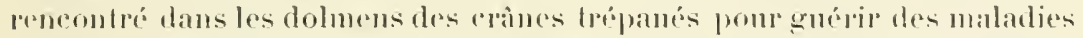

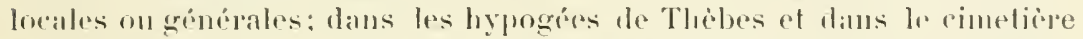

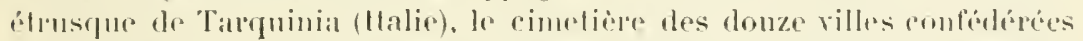
du Latiom, des dents caries auritieres daus la maison diun mélecin

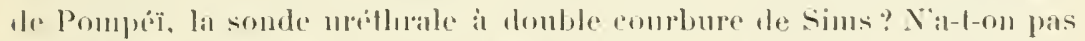

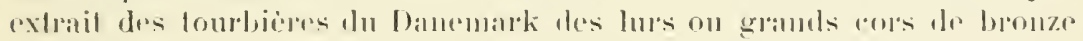

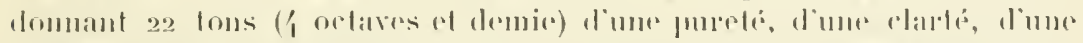

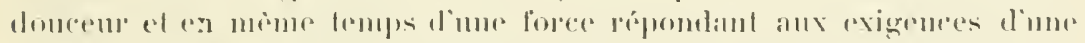

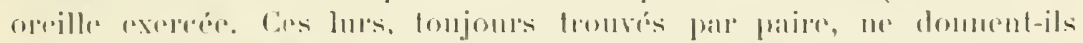

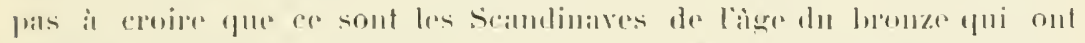

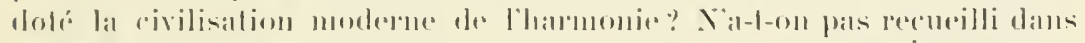

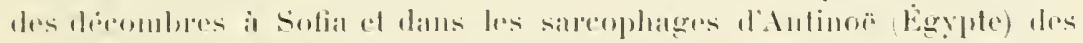

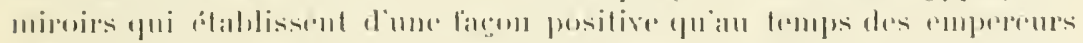

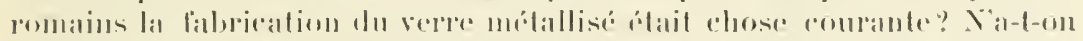

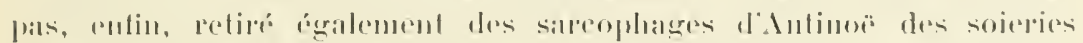

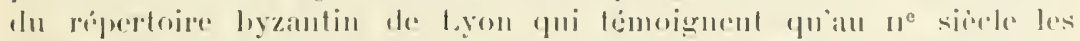

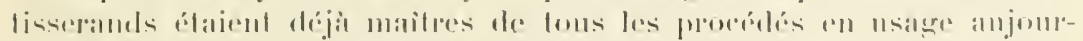

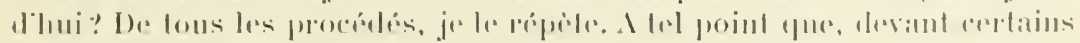

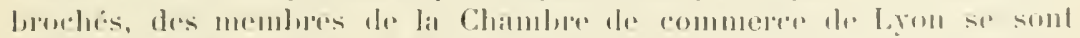

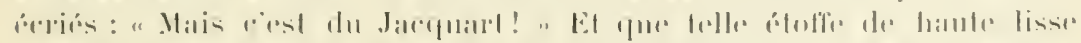

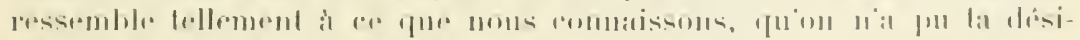

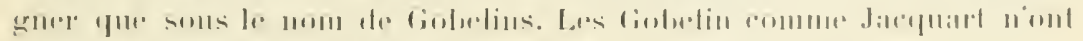

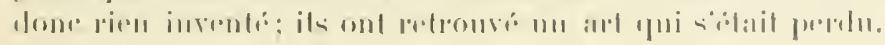


peine qu'on s'ocempat de leur avaneement. "Dans sa Magia nniversalis naturix el arlis, Scholt raconte que Scheiner, un des plus grands savants de son lemps, a ché considéé comme magieien el privé de sépulture, pasce qu'on avait tronvé chez lui, après son décès, un vilram pulicarium (1) duquel te diable s'était échappé transformé en puce.

Les jeusnes doubles. Les jennes doubles, les abstinenees doubles commandées par l'Église el aussi les jeùnes doubles, les monstres doubles ou Pygopages (2). On devine le jeu de mols qu'a voulu faire Rabelais. Comme Velpeau, son compatrote el son conflìre, Maître Francois en a liat beaucoup d'aulres.

Panurge entraine Anarche, roi des Amaurotes (3), vìu d'une livrée "pers ef rest (4)", en observant que cette livrie " luy adrenoit (5), veu quil aroit élé pervers ". - "Clerice (6), dist Homenaz, clerice, esclaire icy a double lanternes."

Au coms de la fete qui précede la délivance de Gargamelle, un buveur s'érie : "Le grand Dieu leil (7) les planites, et nous faisons les plats-nels."

Dans les Enlers, "Nicolas Pape lier's (8) estoil papelier".

(1) Employés parliculirement pour observerdes pucesel des mouches, les phus anciens microscopes simples élaient qualifies de tombeanx ou cimelières de petils animanx, te vilra pulicaria, de vilma muscaria.

(2) Les Pygopages sont des monstres composés de deux individus à ombilies distinets, soudrs a la région fessiere. Ils se divisent en trois tribus : les monstres m X. les pages, les monshes en Y remrersé, les adelphes, les momsles en Y, les dymes. Celle momstruosité rare est produite par la soudure de deux germes dans le mème ornle. IlélèneJudith, Millic-Crristine, Rosa-Josepha en sont des spérimens.

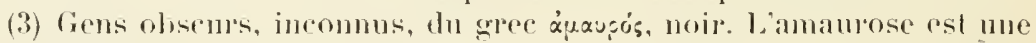
maladie des yeux caractérisé par la perte de la vision.

(1) Vieux mol presque imusité qui servail á désigner une étofle dime couleur intermécliatre entre be vert et le bleu.

(5) Convonait, du latin alvenire.

(6) Clere, en latin clericus.

(7) Fit.

(3) Troisieme du $\mathrm{mom}$. 
Arant de manger, la reine du pays de Lanternois (1) prenait " en guise de pilules qui sentent si bon (je dis ante cibum) (2) pour soi desgraisser l'estomate, une cuillerée de pétasunnen. "Nasardons rien, s'exclame le poltron Paumge, à ce (3) que ne soyons nazardés." Triboulet est fol a lalere (1), altéré; le eapilane Tripet ment estripé; le général Cervelat, esecrvelé. Frère Jean interrompt le service divin pour le service du vin. De Lyra (o), délire, ete.

Adverbes locanlat. "Les adverbes latins ande, qua, quo, les stations d'où on vient, où on va, et par où il liant allere pour magner les indulgences. (Mphabet de l'auleur.)

Pinsiobogie. - "Chascun membre du plus précieux de son nomrissement (6) décide (7) et rogne, dit liabe-

(1) La Rochelle, foyer de la Rélorme, pays des lumieres, de la science.

(2) Lialocis est un des mólicaments purgalits bo plus anciemement employés. Les pilules anle cibum, emone ordomées aujourdlut, el quion prent avant de manger, comprement:

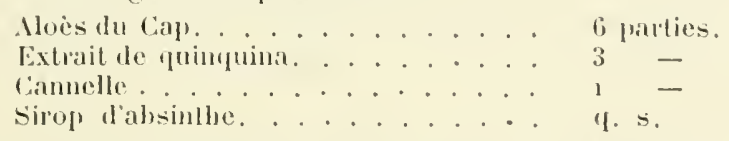

(3) Pour yne, alin que nons ne soyous pas. (L. IV, w. LV.)

(i) Latere, a latere. Légal a latere, candinal covoyé extraordinater-

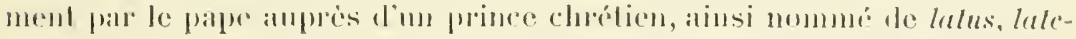

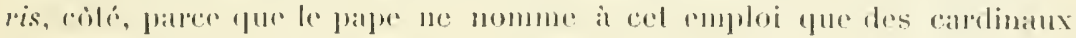

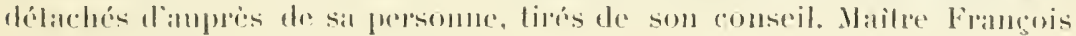

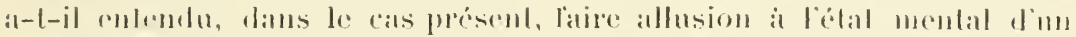

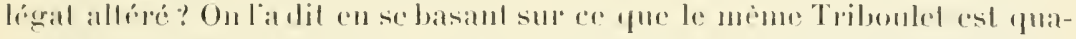

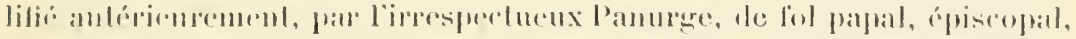

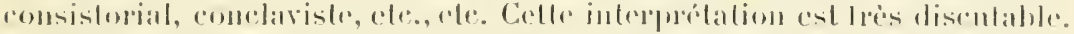

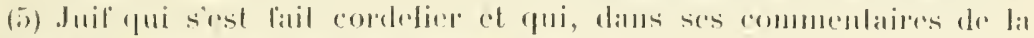

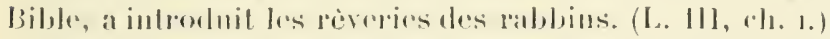

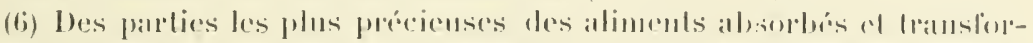

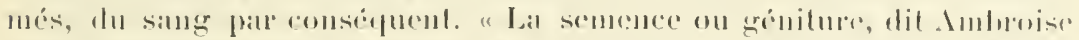

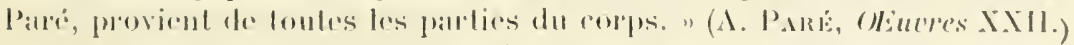

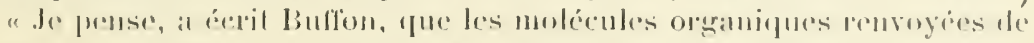

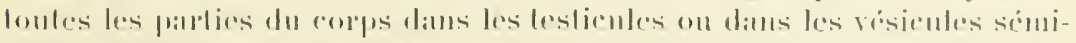

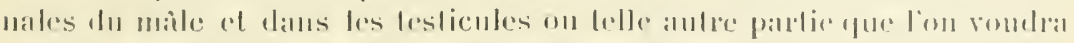

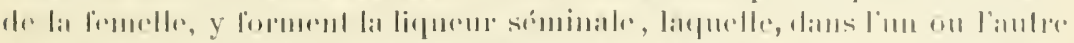

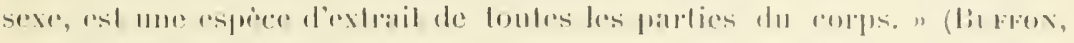
IIstorire molurelle des animanx.)

(7) Clhoisil. 
lais (1), une portion, el la renvoye en bas. Vature y ha préparé vases el réceptacles opportuns, par lesquels descendant és gínitoires, en longs ambages et tlexuosités, regoipt forme compétente 2 ) et trouve lieux idoines (3), tant en l'homme comme en la femme, pour conserver et perpétuer le genre humain."

La sécrétion spermatique. qui a pour objet la conservation de l'espece, et la digestion, qui a pour objet la conservation de lindividu, sont les deux fonctions physiologiques les plus importantes. "Entre les dons, graces et prérogatives, desquelles le souverain plasmateur (4) Dieu lout puissant ha endouaire (5) et aorné (i) l'humaine nature it son commencement, celle 7 ) me semble singulière (8) et excellente, par laquelle elle peult en estat mortel acquérir espèce d'immortalité, et en décours (y) de vie transitoire perpétuer soll $n 0 m$ et sa semence. Cie que est faict par lignée issue de nous en mariage légitime (10)."

C'est pour ces motifs que Maitre Francois s'est cerlainement étendu aussi longuement sur la sécrétion spermatique que sur la digestion. Dans les réponses du médecin Rondibilis à Panurge, qui lui demande sil doit se marier, on trouve une énmméralion à peu près complete des causes qui influent sur eette sécrétion.

(1) L. III, ch, w.

(2) Convenable, du latin competens.

(3) Propres, du litin idoneus.

(1) Le souverain Créatem de l'homme. Il $\dot{x} \sigma \alpha x$, la créature, l'lomme formé du limon de la terre. On nomme aujourdhui plasma la partie liquicle des sues nutritils, et notamment le sang. Rabelais médecin s'est servi à diverses reprises du mot plasmature pour désigner l'ensemble de l'organisme. - "Dieu notr" plasmateur " (Nef eles dames vertuenses, par Symphorien Chanpier; Lyon, 1503).

(5) Doué, doté.

(6) Orné, du latin ardornalis.

(7) Celle-ci.

(8) Unique, particulière, du lalin singuluris.

(9) Cours ripide, du latin decursus.

(10) L. II, eh. vill. 
"Vous dictes, observe le doeteur Rondibilis a P'anurge, que sentez en vous les poignants aguillons de sensualité. Je troure en nostre faculté de médicine, et l'avons prins de la résolution (1) des anciens platoniques (2). que la concupiscence charnelle est réfrénée par ciny moỵens:

"Par le vin prins intempéramment; car par l'intempélance du vin advient au corps humain refroidissement de sang, résolution (3) des nert's, dissipation de semence générative, hébétation des sens, perrersion des mouvements, qui sont toules impertinences (4) à l'acte de génélation. De faict, rous royez preinct Bacehus, dien des ivrognes, sans barbe el en habit de femme, lout efféminé. comme ennuche (.) ... Aultrenent est du vin prins tempéramment (6). Limtique proverbe nous le désigne 7). alupuel (s) est diel : que Venus se morfond sans lat eompatganie de Cerès et Bacehus (9). El estoit l'opinion des anciens, selon le récit de Diodore sicilien (10), mesmenent des Lanpsaciens (11), comme atteste le grand Pausianiats (12). que nessed Priapus ful lils de Bacelus et Venus."

Les effets généraux de l'aleowl sum le systime nerverux sont bien lels. Quant a ses eflect particulicers sll les fontelions de la génération, il est reconnu par tous les hỵgiénistes

(1) Pris, appris, de Ja décision.

(2) Jisciples de Platoln.

(i) Dejuression des nerl's.

(i) Disposilions impropures, du litlin imperlinens.

(i) Eunurute.

(6) Arece modération.

(7) Nous lo moulde, nous l'indigue.

(8) Dims lexpuel.

(a) Silns pilin si vile

Verbum, Herde, hic verum est : sine Cerere el bucito

Fintyel Venus...

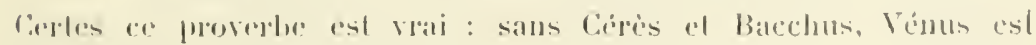

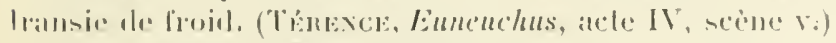

(10) Diendore ke Sicile, I. V, V.

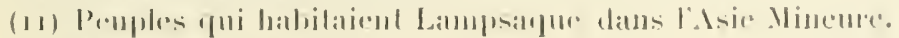

(12) Pacsivis, lib. IX, 31. 
que l'alcool pris passagerement en exces excite les désirs vénénins, mais qur pris habituellement en exces il affaiblit les fonctions génélatrices. Examinons les antres moyens proposés par Rondibilis a son client:

"Scocondement, par certaines drogues et plantes, lesfuclles rendent l'homme refroidy, maléficié et impotent i génération. L'expérience y est en nỵmphea heraclia (1), amerine saule (2), chenevé (3), periclimenos (4), tamalix (5), vitex (6), mandragore (7), ciguë, orchis le pelit (8), la peau d'un hippopotame (9), et aultes, lesquelles dedans les corps humains, lant par leurs vertus ćlémentaires, que par leurs propriétés spéciliques, glacent et mortitient le germe prolitique; ou dissipent les esperits qui le debvoient conduire aux lieux destinés par nature; ou opilent (10) les voies et conduicts par lesquels poroil (11) estre expulsé.

(1) Le némuphas, ou volet d'ean donce, de la lamille des Nymphéacées.

(2) Sclon Manty, fui a rason en cette circomstance, il laut écrire ces deux mots sans les séparer par une rirgule. L'Amerina salix est, en effet, nne sorte d'osier d'Amérie, en Ombric, qui nest rien autre chose que lamerino des Provenesau.

(3) Clieneris.

(1) Ie chèreleuille. (Voy. Plixe, 1. XXVlI, ch. xil.)

(5) Le lamaris ou Lamarin.

(6) "Le nom de vilex, disenl Burgaud des Marets et Rathery, servail a désigner les Verlénacées, lelles pue l'Aynus castus ou gatlilier, arbrisseall aromatique. ,

(7) Lempereme Julien a cependant mentionmé, daus son épitre à Callixène, qu'il buvail du jus de mandragore pour s'exeiter au jeu de lanour.

(8) D'appos Théophraste (1. IX, ch. xix), " le phus grand des deux lubercules de louchis ou salyrion, pris daus du latil de chien, lavorise l'acte vóncrien, tandis quan contrate le plus petit l'empeche n.

Le Salyrion a dù sa répulalion ì som odeur spermatipue ef à la ressemblance de son hube arec la grlande simmale, d'où son autre nom d'Orelis.

(9) 11 etait également admis an temps de Rabelais que les goulteux étaient soulagés en portant, au-dessus du genou, une jarrelière faite aree un morecau de la pean du meme animal.

(10) Bouchent; du latin oppilare. An live I, chapitre n, des Causes des symplomes, de Gialien, il est dit que "l'inllnence de la laculté animale est emperhée lorsque le neef qui a en soi des ourertures est ou bouché ou comprimén.

(11) Pouvail. 
Comme au contraire nous en avons qui eschanfent, excitent et habilitent à l'acte vénérien (1). ")

Je ne veux pas discuter la propriété anaphrodisiaque de toutes les herbes indiquées par Rondibilis. On attribue cependant encore cette propriété an nénuphar, au gattilier (vitex), à la ciguë. Quant au tamarin, à l'amérino, au chèvrefenille (periclimenos), au chènevis (cheneré), il est douteux ru’ils la possèdent.

"Tiercement (2), dist Rondibilis, par labeur assidu. Can' en icelluy est laicle si grande dissolution (3) du corps, que le sang, yui est par icelluy (4) espars pour l'alimentation d'un chaseun membre, n’ha temps, ne (5) loisir, ne laculté de

(1) Rabelais en a rilé furelynes-mos : les alimenls du carcime (Voy.

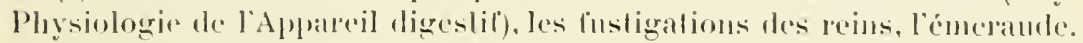

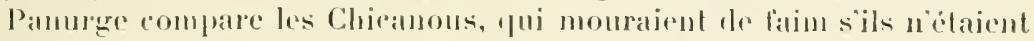
pas haltus, "anx gens qui ne pourent le cerele cavernemx vel's lo cerele

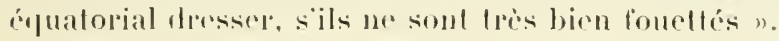

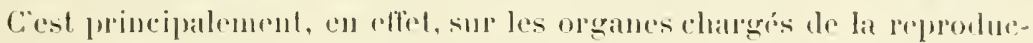
lion quagit la flagellation. Les persommes qui ont lu les Confessions de

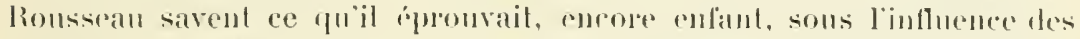

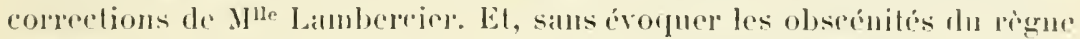
de Niron, ni les flagellations de llenri 111 et de ses mignons, sills lent-

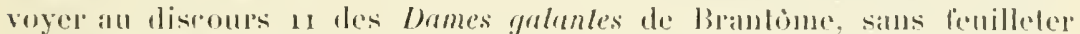

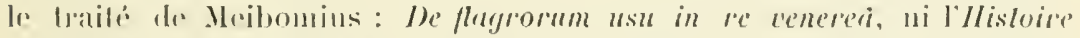

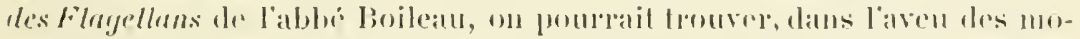

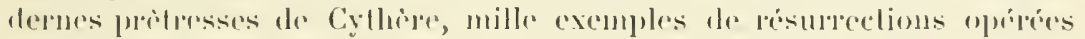
sous leurs reraes ensiunglautés.

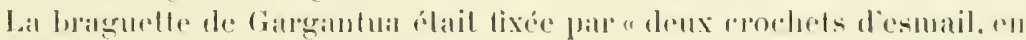

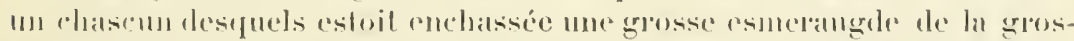

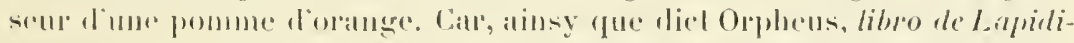
bus, w Pline, libro ullimo, elle ha vertu érective et contortative du nember natuineln $n$.

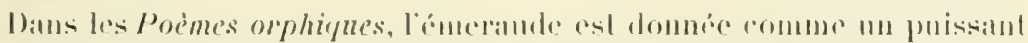

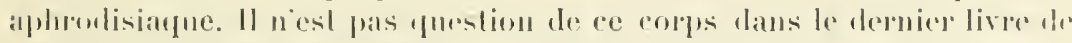

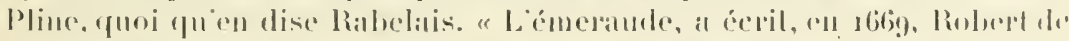

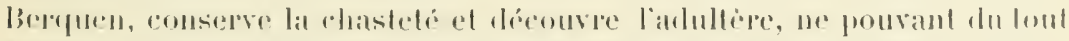

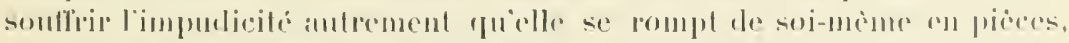

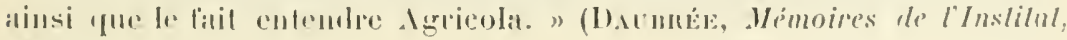
$18(9) 1$.
(2) Troisiontemenl, du lalin lertius.
(3) Dlfibhlisionent, ancianlissonent, du lalin dissolulio.
(i) Dalls celui-ci.
(i) $\mathrm{Ni}$. 
rendre celle (1) résudation séminale (3) el superlluité de la tieree concoction (3). Nalure particulierement se la réserve, comme trop (4) plus nécessaire à la conservation de son individu, qu'à la multiplication de l'espèce el genre humain. Ainsy est dicte Dianc chaste, laquelle continuellement travaille a la chasse. Ainsy jadis estoient diels les castres, comme castes (5) esquels continuellement travailloient les athlietes et souldars (6). Ainsy escript IIippoe. lib. de Aëre, Aqua et Locis $(7)$, de quelques peuples en Seythic, lesquels, de son temps, plus estoient impotents (8) que eunuches (9) à l'exbatement (10) vénérien, parce que continuellement ils estoient a cheval et au travail (11). Comme au contraire disent les phylosophes, oisiveté estre mère de luxure. Quand l'on demandoit à Ovide, quelle cause fut pourquoy Egistus devint adultire? rien plus ne respondoil, sinon qu'il estoit otieux (12).

(1) Dans le seus de cette.

(2) Sécrétion de la semence spermatique, du latin resulatio, lait de resulere, rendie un liquide, le rejeter.

(3) Voy. Appareil digestil.

(1) Beaucoup.

(5) Les camps reastra, m litin), comme chastes (cusla, en liatin). Jon de mots emprunté a Isidore qui dit, all live IX de ses Élymologies: "Dicla aulem castra, quasi colsla, ĕ quöd ibi castrabelur libido. On les appelle castres, comme yui dirait castes - chastes, - parce que toul lésir vénérien en élait banni."

(b) Les soldats.

(7) Au live de l'Air, de l'Ean ef des Liems.

(8) Impuissints, du datin impolens.

(9) Eunuques.

(10) Au jell, il lamusemenl.

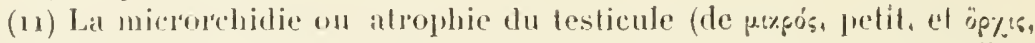
testicule) élait en quelque sorte endémique chez les Scythes, aussi l'impuissance chat-elle fréquente parmi eux. La microrchidie est la maladie liominine d'Aristote. (Voy. Les c..., comme nue ynedoufle.)

(12) Oisif, du latin oliosus. Jans lonvarge dOOvide intitule De Remedio amoris (1. I, Y, I61), on lit :

Oueretur. Eyystus quare sil factus aduller, In promplu caltse esl, desidiosus erat.

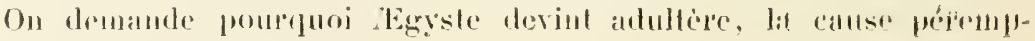
toire est puil élait paresseux. 
Et qui usteroit oisireté du monde, bien lost périroient les arts de Cupido (1): son are, sa trousse et ses thiches lụ seroient en charge inutile. jamais nen fóriroit (2) personne. Call il n'est mie si bon arehier (3), qu'il puisse férir les grues volants par l'aer, et les cerfs relancés par les boeages (comme bien faisoient les Parthes), c'est i dire les humains tracassants (4) et travaillants : il les demande cois (5), assis, couchés el à séjour (16). De faict, Théophraste, quelque fois interrogué quelle beste ou quelle chose il pensoit estre amourettes, respondit que c'estoient passions d'esperits otieux. Diogenes pareillement disoit paillardise estre l'oceupation des gents non aultrement occupes (7). Pourtant (8). Canachus (9) Sicyonien, sculpteur, roulant donner entendre quobisiveté, paresse. nonchaloir (10), estoient les gouvernantes de ruffiennelie (11), feit (12) la stalue de Venus assise, non debout, comme arolent laict ses prédécesseurs."

11 nest pas besoin de longs commentaires pour démontree que len travalux maturels, el encore plus le surmenage physique, chatsent les idées érotiques. Les ourriers et les paysans sont moins portés rer's les plainir's de la chair que les citadins et les oisifis. Eatles raisons que donne de ce lail

(1) Traduelion de ere reos d'Ovide:

ollu si lolles, periere Cuphidinis arles.

(1) Remedio unoris, 1. 1, 1. 139.)

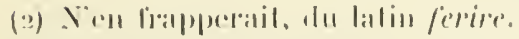

(3) 11 11

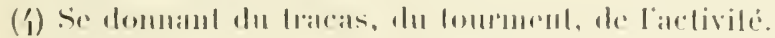

(i) Trancuilles, du linlin quielus.

(bi) Lil lepus.

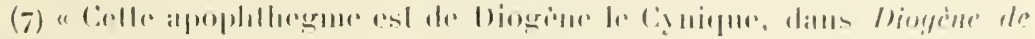

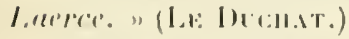

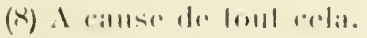

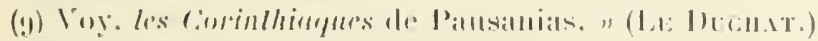

(10) Nollchiliture.

(1) l) aldinuche.

(12) I.it. 
le médecin du moyen àge sont encore admises par les physiologistes d'atujourd'hui.

"Quartement (1), par ferrente estude. Car en icelle est faicle incrédible (2) résolution des esperits, tellement quil n'en reste de quoy porter aux lieux destinés ceste résudalion générative (3), el enfler le nerf caverneux (4), duruel l'oflice est hors la projecter, pour la propagation d'humaine nature. Qu'ainsy soit (5), contemplez la forme (6) d'un homme attentil a quelque estude, rous voirrez en luy toutes les arteres du cerveau bandées, comme la chorde d'une arbaleste, pour lui lommir dextrement $(\boldsymbol{z})$ esperits sulfisants à emplir les ventricules du sens commun, de l'imagination et appréhension (\$), de la ratiocination (g) et résolution, de la mémoire el récordation (10); et agilement courrir de l'un à l'aultre par les conduicts manifestes ( 11 ) en anabonie, sus (1:2) la lin du rets admirable (13), onquel (14) se terminent les

(1) Quatriemement, du batin quarlus.

(2) Incroyable, du latin incredibilis.

(3) Voy. 1). 226, note 2.

(4) Les nerl's eavernenx sont cenx ymi se distribuent anx denx copps caverneux qui, aree te prépuce of liurthe, constituent la repge. (Voy. Le membre, comme une panlophle, p. 202, note 1.) - Par nert caremenx, on doit, je crois, entendre ici les corps cavernenx dont l'érection est nécessaire pour "projecter hors la résudation générative". Je le crois d'iutant plus : $1^{\circ}$ qu'Aristote ef Galien ont dit que la semence du màle, essenticllement chaude, contenait un southe qui dilatait les corps eaverneux ed en provoquait lérection; $2^{0}$ 'que Rabelais a appelé (l. III, ch. xrmu) la verge " le membre nervon, caverncux".

(5) Pour en juger.

(6) Lapparence, lattitude.

(7) Aree dextérité, rapielité, du latin derler, formé du gree ôšttêpós on

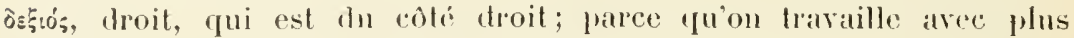
d'adresse de la main droite que de la gauche.

(8) Appréhension, du latin "pprehéntio.

(9) Raisonnement, du latin raliocinalio.

(ro) Sourenance, du latin recordulio.

(11) Apparents, du lalin manifestus.

(12) Sur.

(13) Voy. Angéiologie: Lé rels admirable, comme an chanfrein; et Névrologie, Physiologie.

(1) Dans lequel. 
artères, lesquelles de la senestre armoire (1) du coeur prenoient leur origine, et les esperits vitaulx aftinoient ( 2 ) en longs ambages (:3), pour estre laiets animaulx. De mode qu'en (4) tel personnage studieux vous voirrez suspendues toutes les facultés naturelles, cesser touts sens extérieurs: brief (5) vous le jugerez n estre en soy vivant, estre hors soy abstraict par ecslase (6), et direz que Socrates n'abusoit du terme quand il disoit: Phylosophic n'estre aultre chose que méditation de mort. Par adventure est er pour quoy Democritus s'areugla $(7)$, moins estimant la perte de la vue, que diminution de ses contemplations (8), lesquelles il sentoit interrompues par l'esgarement des yeuls (9). Ainsy est vierge diete Pallas, déesse de sapience (10), tutrice (11) des gens studieux. Ainsy sont les Muses vierges; ainsy drmeurent les Charites (12) en pulicité éternelle. Et me soubrient aroir leu (13) que Cupido quelfuesfois interrogué de sa mòre Venus, pour quoy il n’assailloit (1/) les. Muses, res-

(1) In ventrienle ganche.

(2) Puritiaient, rendaient plus sublils, du latin affingere, formé de ad, augmenlatil, et fingere, laconner.

(3) En longs dáloms. Les artios vertabrales el les carolides intornes,

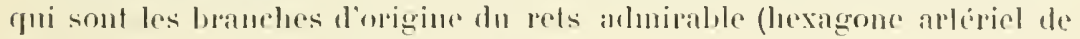
Willis), onl un trajel lrès compliqué.

(1) De manière que.

(5) IBret.

(6) Exhise.

(7) "La gramde passion que Démocrile avail pour l'budr fil qu'il

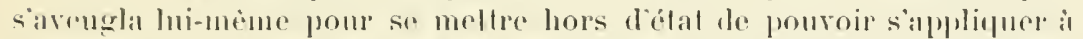

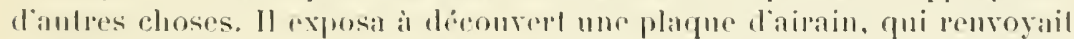

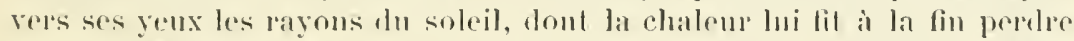

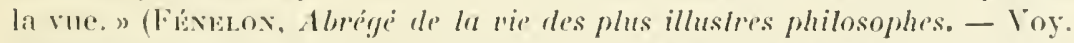

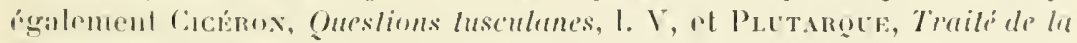
(iuriosili.)

(8) Mélitalions, du latin contemplatio.

(a) Lal distraclion due produit la rue du monde exterieur.

(ai) I) la sigersie, du lalin sapienliu.

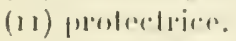

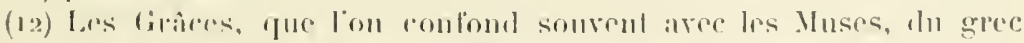

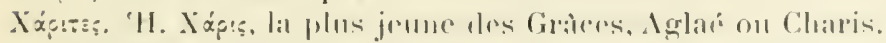

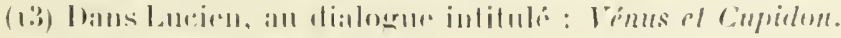

(1) Il nallampail pas. 
pondit qüil les tromoit tant belles, tant nettes (1), tant honestes. tant pudiques et continuellement occupées, l'une a contemplation des astres, l'aultre à supputation des nombres. l'aultre à dimension des corps géométriques, l'aultre à invention rhétorique, l'aultre à composition poćlique, l'aultre à disposition de musique, que, approchant d'elles, il desbandoit son are, lermoit sa trousse (2), esteignoit son flambeau, de bonte et craincte de leur nuire. Puis ostoit le bandeau de ses yeulx pour plus apertement $(: 3)$ les voir en face, et ouir leurs plaisants chants et odes poétiques. Lá prenoit le plus grand plaisir du monde. Tellement fure somventil se sentoit tout rary en leurs heautés ef bonnes graces, ot s'endormoit à l'harmonir. Tant s'en fault qüilles ronlsist /4 assaillir, ou de leurs estudes distraire. En cestuy arlicle (5), je comprend ce quescript Hippocrates au !ire sus dicl, parlant des seythes, et au live intilule (i) De genilura, disant touts hmmains estre à génération impotents $(7)$ esquels (8) l'on ha une fois coupé les artires parotides (g) qui sont à costé des amreilles, par la raison cy-derant expusée quand je vous parlois de la résolution des esperits el du sang spiribel, duruel les artires sont réceptacles $(10)$ :

(1) Pures.

(2) Sou callermois.

(3) Distinctement, dn latin aperle.

(i) Voulut, partjeipe passe de lancien reple rouloir.

(5) En ce qui touche cettr arliculalion, cette assertion.

(6) De la grésiture, de la semence.

(7) Impuissumts, llu lalin impolens.

(8) Allxipuels.

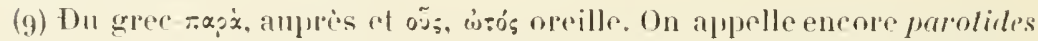
les glandes salivaires siluées pres des oreilles. Chacune de ces glames est traversép par lantère camotide cextrome.

(10) "Les artires sont destinies pour porter le sang spiritueux. Non pas que le sang artíriel soit tout spuriturnx, mais c'est que sa plus grante partie chant telle, il lire d'elle, comme étanl sa plus noble partie. sa dínomination. Car il faut remarquer que des parties du sang, les umes sont plus, les autres moins spirituenses. En éfet, il ne faut pas rooire tue le cluyle, yni après s’ètre melé arec le sang dans la veine cave, entre pour la première lois dams le corur, y acquiére dabord et sur le champ 
aussy qüil maintient (1) grande portion de la géniture 2 sourdre du cerreau et de l'espine du dos (3). "

Que le sperme soit sécrété directement par les testicules au lien d’y ètre, comme on le erorait autrefois. porté de la moclle et du cerreau, il ne s'ensuit pas moins que l'exces des travaux intellectuels, appliqués aux lettres, aux seiences ou aux arts, est reconnu comme une cause d'affablissement de la virilité, de l’áloignement des désirs rénésiens et. onfin. de l’impuistinane.

a rette mime entrie, autant de spirituositi. quen ont deja aequis lis antes particules du sang qui aroient ampararant fite mbles avee fo

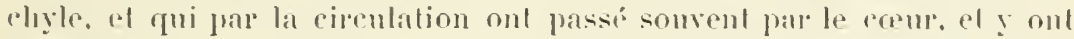

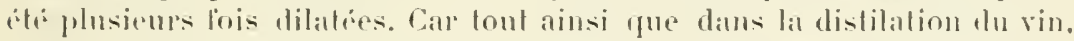
plus le vin est distile de fois. plus lesprit quiou on tire est subtil, pur of

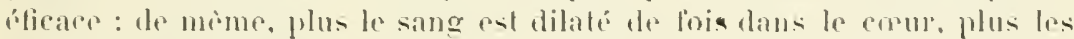

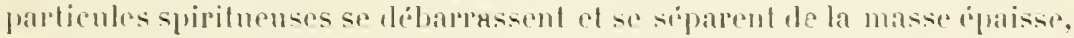
rt plus elles sattement. Celles qui sont moins spirituenses, of mon sutli-

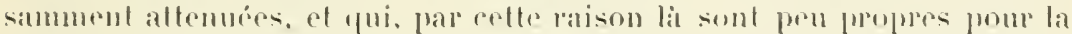

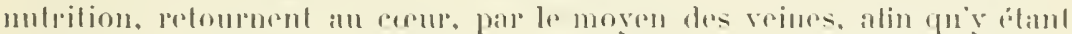

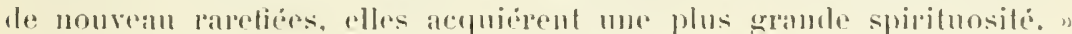

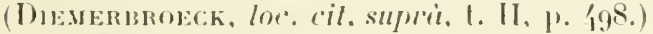

(1) Ainsi rüHippocrale assure.

(2) De lil semenee.

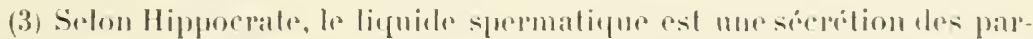

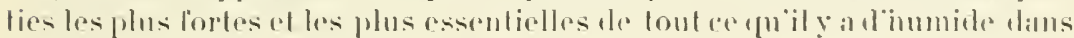

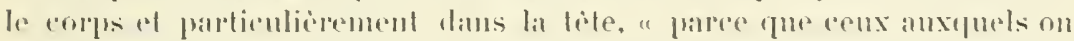

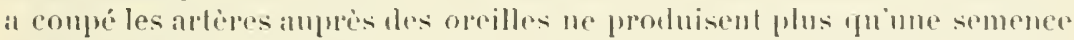

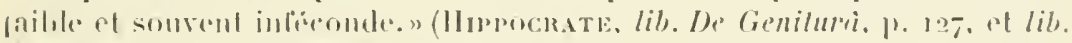

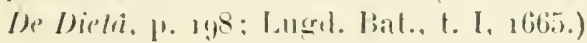

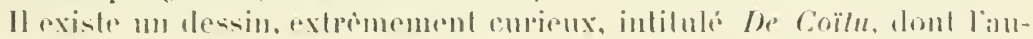

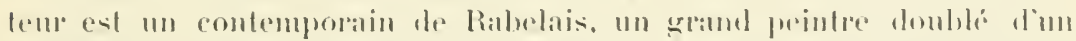

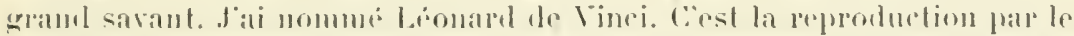

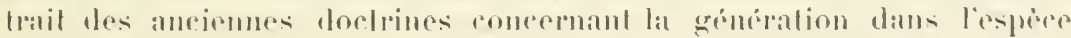

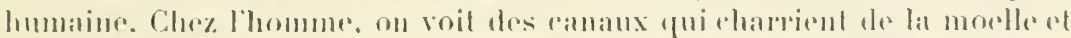

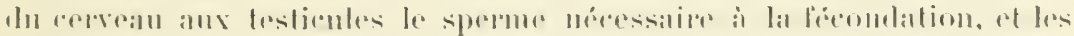

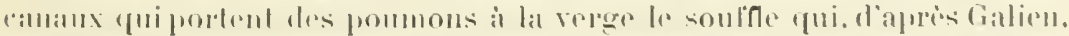

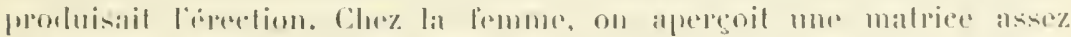

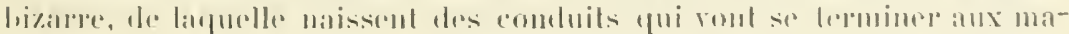

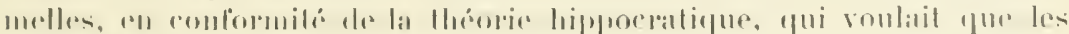

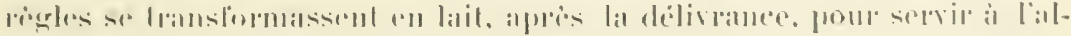
linitemarnl.

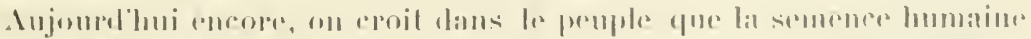

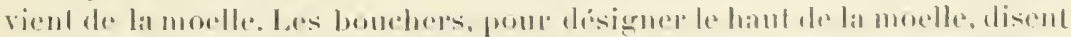

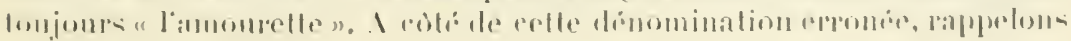


"Quintement, par l'acte vénérien " fréquemment répété.

L'abus des rapports sexuels entraine non seulement l’impuissance, mais encore la spermatorrhée, qui débilite lorganisme.

A ces causes de la diminution de la sécrétion spermalique, il faut généralement ajouter, enfin, le défant de fonctionnement régulier des glandes génitales et la vieillesse.

"Panurge, mon ami doulx, remarque (1) le londateur de l'abbaye de Thél’me (2), je ne te conseille chose que je ne fisse, si jestois en ton lieu. Seulement aye égard considération de tousjours bien lier et continuer tes comps. Si tu $\mathrm{y}$ fais intermission (3)..., t'adviendra ce qu'advient aux nourrices. Si elles désistent (4) allaicter enfants, elles perdent leur laict. Si continuellement n'exeree ta menInle (j), elle perdra son laict... Par non usage sont perdus touts priviliges (6)... Pourlant $(7) \ldots$, maintien tout ce bas et menu populaire, tooglodyte (8), braguetodyte (9), en estat de labourage sempiternel. Donne ordre qu'ils ne vivent en gentilshommes, de leurs rentes, sans rien faire.

"Le temps matte tontes choses. II n'est le marbre ne (10) le porphyre, qui n’ait sa vieillesse el décadence. Desja voi-je ton poil grisonner en teste. Ta barbe, par les distinctions du gris, du blane. du tanné et du noir, me semble une mappe-monde. Regarde icy. Voila Asie; icỵ sont Tiggris ot

quils nomment très exactement la matrice la " portière " (de porter), et le fortus enveloppé de ses membranes, "lonfant de chemr".

(1) L. I11, eh, xxin ef xxrm.

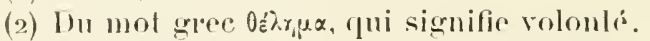

(3) Si tu espraces d'une manière régulière. Conserrí dans re sens.

(1) Si elles renoncent, si efles cessent, du latin desistere.

(5) La verge. En latin menlula.

(6) Ancienne maxime de droit canonique.

(7) Pour en motil, à cause de rela.

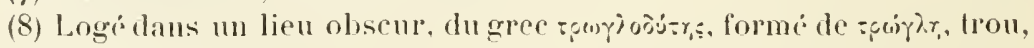
ef de óve ou ớm, jentre.

(9) Mol forgí, cachí dans la braguetle.

(10) Ni. 
Euphrates (1). Voila Arrique; icy est la montagne de la Lune (a) ; voids-tu les palus (:3) du Nil? Deça est Europe: roids-tu Theleme? Ce toupet iey tout blanc, sont les monts Hyperborées (4)... mon ami, quand les neiges sont és (o) montagnes, je di la teste et le menton, il n'y ha pas grande chaleur dans les vallées de la braguette."

"Ce qu'il y a de vil et de moëlle est élouffí. par ses longueries, " a dit Montaigne, ennuyé par un diseoureur prolixe. Pour ne pas encourib ee reproche, je passerai sans transition de la description des organes génitaux de l'homme it celle des organes génitaux de la lemme. La naissance de Gatrgantua a fourni a Maitre Francois - je le mpelle (Voye. Angéiologie) - l'oceasion de parlep des organes génitaux de la lemme, dès le $\mathrm{VI}^{\mathrm{e}}$ chapitre du live $I$.

"Gargamelle (ii) eommenca à se porter mal du bas... Peu de temps aprés, elle commenca à souspirer, lamenter et crier. soubdain rindrent 7 i las sages-lemmes de touts costés (S).

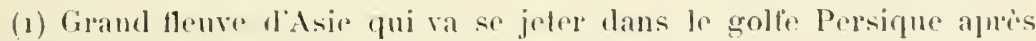
avoip reç un anlere lenve, le Tigre.

(2) Les montagnes de la Lune (en arabe El-Komar) limilent au sud l’ancienno Nigrilic ou Somdan.

(3) Les manais, du lalin prolus.

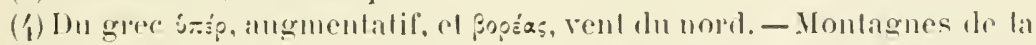

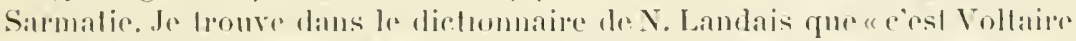
qui, le premier, a daus lorphelin de Chine, francise lanljeelit lallin hyper-

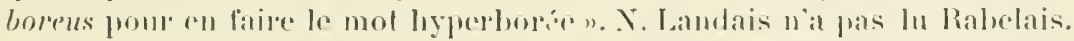

(5) Aux sommets des montagnes. Pammen naval erpendant que " trentw

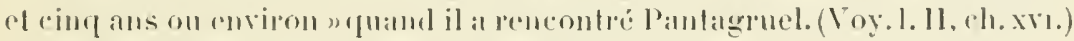

(6) Giande gorge, en palois langurdocien.

(7) Vinrent.

(8) "Pendant fort longlemps, les lemmes an eourhes, mime les reines,

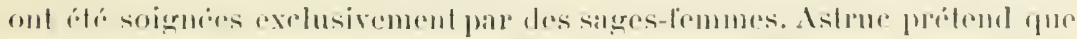

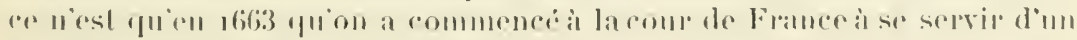

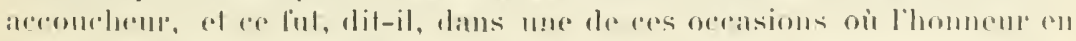

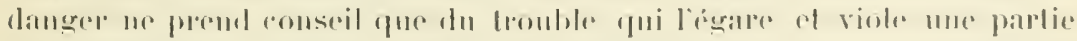

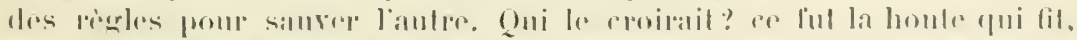

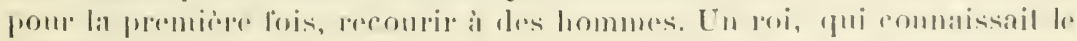

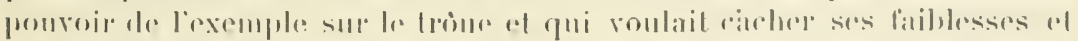

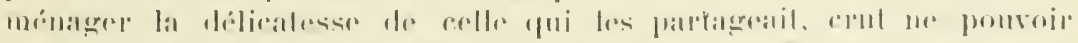

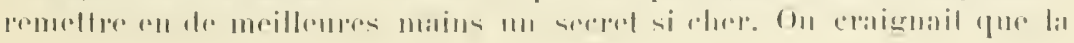


"Et la tastant par le bas, trourarent 1) quelques pellauderies 2, assez de maulvais goust, et pensoient que ce fust l'enfant (3); mais c'estoit le fondement qui lui escapoit (4), a la mollification du droict intestin (lequel vous appelez le boyau c...) (5), par aroir (6) trop mangé de Lripes, comme avons déclairé cy-dessus $(7)$.

"D'ond (8) une... vieille de la eompagnie (9), laquello aroit réputation d'estre grande médicine... lui feit (10) un restrictif (11) si horrible (12), que touts les larris (1:3) tant (1/) furent oppilés (1.i) et reserrés, que à grand'-peino areceques les dents vous les eussiez eslargis...

présence d'unc sage-femme dans le palais, où les soupcons régnaient déjì, ne foumit un nouvel aliment ì la maligne euriosite des eourtisaus. On se servit pour leur domer le change d'm elimurgien, que son minis-

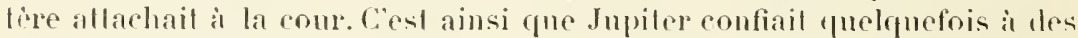
dienx subaltermes, plutot quä des diesses, son embarras ef le soin dro

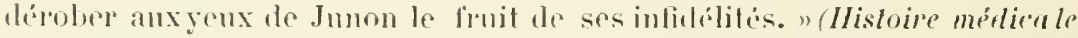
el philosophique de la femme, par le Dr Mexinule de Possax, $2^{\text {e }}$ idlit., t. I. J. fog.)

(1) Tremivenl.

(2) Lamelles de pean, pogmures de peatr. En Normandie, on nomme les mégissier's : paultiers.

(3) Allusion ì l'ignorance des accourhenses du lemps.

(1) Echappait, sortait, lombat: scappare on italien, eseeturar en espa-

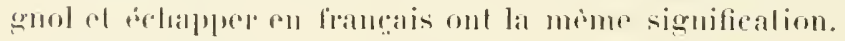

(5) Je rectimll.

6) Portr aroir.

(7) Voy. Aplareil digrestif: Le bo!gan e.... enmme un bourrabayuin mona('hall.

(8) Par suite, pour ce motit.

(9) De la corporation des sages-femmes.

(10) Lui til.

(11) Restrajuctil, en laugue pomane, un remede astringent, du latin restringere. Un restrainctif, en vieux langage médical, est un remide qui resserte le veutre. Dans cortains eas de chute du fondement, on couseille rneore aujourd lu des topiques astringents (iujection, liniment, pommade).

(12) Energique, exeesidf, violeut, dn latiu horribilis.

(13) Le col de la matrice el les parois raginales, du cette larma, qui veul dire pean, cuir, membrane. Ce sens est attribur igalement au frrme larris daus un passage des Cent Souvelles nourelles, qüil est impossilule te reprouluire.

(19) Furenl si licu.

(1.5) Bonchés, du lation ofpilure. Le remedr, dont la dose ahait evees- 
"Par cest inconvonicnt 1 furent au-dessus rolaschés 2 i les cotylédons 13 de la matrice par lesquels (4 sursaulta .j) lenfant, et entra en la vène creuse 6 ). et gravant $(7)$. par le diaphragme jusques au dessus des espaules, on ( 8 ) la

sive, avait agi a la fois sur le pectum ef sur les organes crenx avec lesquels celni-ci est immédiatement en rapport en bas ef en avant.

(1) Dans le sens du mot latin inconveniens, qui ne s'aceorde pas aree les vues, les projets, les espéranees, ete.; formé de in négatit, ef de conrenire, eonvenir, stacenterer.

(2) En vertu de la vieille théorie du strichum et du laxum d'Aselepiade ef de Coplius Aureliams, qui prétend que, dans deux parties organifues roisines, lorsque liune asl pessemée. liuntre est relichére. En laisant preserire pour ciargamelle un "restrictif si borrible " par whe des sages-fenmes, Maitre Fumegois a done ell ses masons. It a remblu imposible. dime part, la sortie de linfant par les rojes

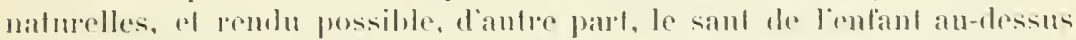

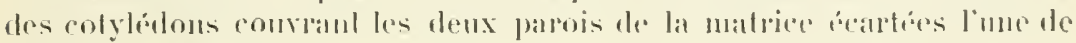
liatile.

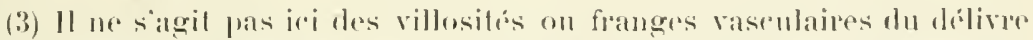

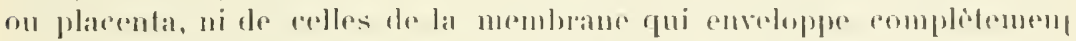

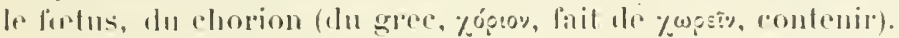

"Las cotylidons sont, dit Diocles de Caryste, des bras de poulpes on des rolues, exeroissances en forme de mamelles larges a la hase,

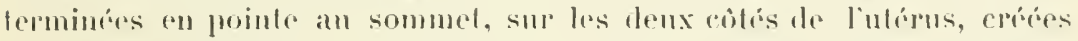
par prevoganed par la nature pour exereer le fiefus a altirep le mameIon du sein. "Aristole en a fait mention (l. V'll, els. r). Dans le Trailé

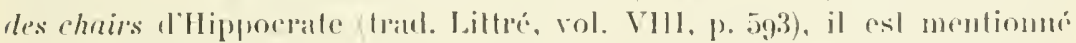
yue "lentint dans lo vonter maternel ayant les liveres continuellement

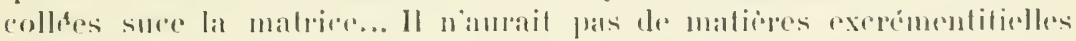

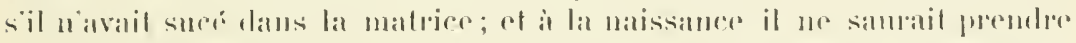

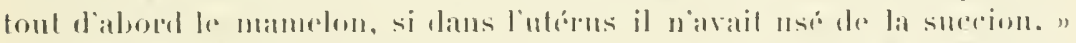

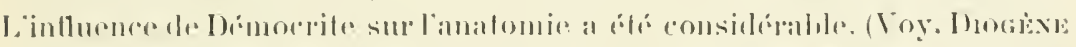

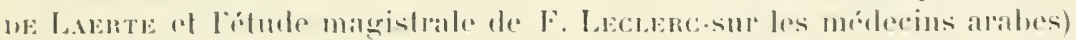

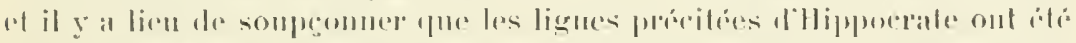

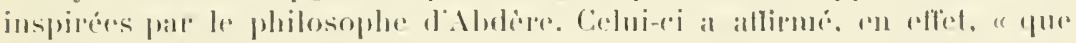

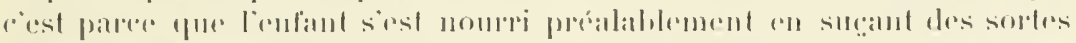

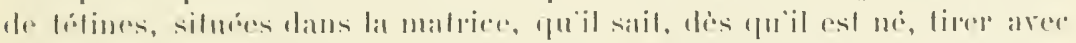

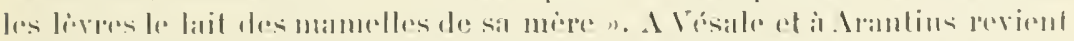

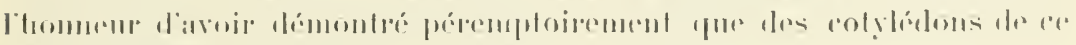

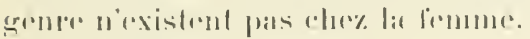

(1) du-desists despluels.

(i) Sillllil.

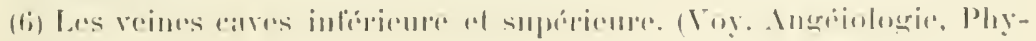
sirologrie.)

(7) . Monlints.

(8) Oii. 
dicte rime se part 11 en deux, print (2) son ehemin à gausche, et sortit par laumeille senestre (3). ")

Il appert de ce passage et de ce que jai dit antérieurement (Voy. Les génitoires, comme un rabbot) que Rabelais a admis non senlement la division de la matrice de la lemme en plusieur's compartiments, mais eneore la présence dans ce riscire d'excroissances mamelomnées, "cotỵlédons," créées par la nature pour permettre au foetus de s'exereer ¿ la succion. Ye placons pas pour cela Maître François bien au-dessous de Vésale. Ce dernier n’a pas dépassé luimème de beaucoup Achillinus, Béranger de Ciapi, Gabriel

(1) Se divise, se partage, du latin prerliri.

En traitant de lapprobil circulatoire, jai chal,i que l'illustre prolesseur dont la Facultí de numberine de Montpedlier garde si piensement le sourenir, a lail mention gín et lì, dans Gargantum et dans Panlayruel, des

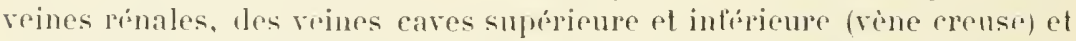
de la valrule quoltie la veine care inférieure à son rutrés dans le eorur, des reiges jugulaires et qüil a fait justement ehemines l'onorme low dans le trone reineux brachin-céphalique gauche, qui est plus large que le tronc reineux brachio-céphalique droit. Le moment est venu dobserver que Maître François na pas dit un mot des veines utéro-ovariennes. qui relient la matrice ì la veine rínale ganche el à la veine cave inférieure, ef par l'une ou l'autre desquelles veines utéro-ovariennes Gargantua a dù aussi lorément passer. Le commentateur de Galien les a ávidemment commues. Elles ont ibé, en effet, décrites en ees termes par le savant médecin de Pergame: "De la veine cave et de laorte partent également deux raisseaux, deux reines et deux artipes. Elles se divisent en deux eroupes, eomprenant chacmn me artire et me veine. Le groupe droit se porte sur les parties latérales droites de lutérus, le groupe gauche sur les parties latérales gauches. Avaut latteinule la matrice, res vaisseaux donnent quelques branches aux testicules (oralies), puis elles viemnent se ramifier et se perdre dans les tissus uterins. Ces vaisseaux naissent un peu au-dessous de ceux qui se rendent dans les reins. Les veines sont beancoup plus grosses que les artires. Chez certaines femmes, ces raisseaux pourraient provenir, ì ce qu'assure Hérophile, des vaisseanx rénaux. Je nai rencontré que tris rarement refle disposition chez les animaux, sauf chez les singes. Je ne dis done pas qu'Héroplite nait pas raison pom la femme. Cétait en effet, it ce quil me semble d'alpès mon expépience personnelle, un excellent anatomiste qui a travallé beaueoup plus souvent sur les cadarres humains que sur les catarpes des animaux." (Lir. de la dissect. de lulírus, trad. Haremberer.)

(2) Prit.

(3) Ganche, du latin sinisler. 
de Zerbis, ete. (1). dans sa description de l'appareil génital féminin (2).

Lat longue tirade de Rondibilis sur le mode de genése de l'hystérie chez la femme fourmille également d'assertions erronces. C'est une compilation pleine de rerve, d'élégance et d'érudition, mais très diffuse et que je négligerais, si je ne tenais, avant tout, i être impartial et complet.

"La nature laa dedans le corps des l'emmes, posé con lieu secret et intestin (3), professe Rondibilis, un animal, un membre (4), lequel n’est (5) és homme; onquel quelquestionis sont engendrées certaines humeurs salses (6), nitreuses (7), bauracineuses ( 8 ), acres, mordicantes, lancinantes, chatoil-

(1) Achillimus, Béranger de Carpli, Gabriel de Zerbis vivaient an $\mathbb{1}^{-0}$ sicele. Achillinus et Beranger de Carpi, probesserurs à Bologne, ont découvert, le premier la membrane hymen, le second liunite de l'utépus; Gabriel de Zerbis de Vérone a isolé tous les ligaments de l'utérus, silut le ligament rond.

(9) Il a prétendu que la matrice étail divisée en deux par une erète saillanle ef oublie la plupart des liganents de ce viscere.

(3) Intérim, du latin inlestinus.

(1) La matrice a che considéée par Platun comme un animal; puis par Guy de Chauliac, Mundinus, Mathien de Giralihus, etce, comme un membre vilil petoupre et interne. "Ello est, dit Guy de Chanliac, eomme la verge renversere on mise an dedans, an quatorzieme de lusige des parties. Car elle a au-dessous deux bras rellulandes aver les testicules, comme la boutse des testicules. Elle a ausi un ventre commun an milien comme les farties du pénil. Elle a son col en bus camuli comme la verere. Elle a allsis la volve comme une balatuce ot la mithe. Elle a allsid

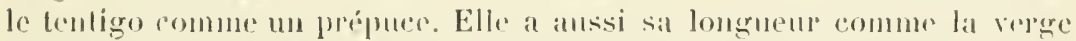
de huit on neul' doigts. Et, bien quelle n'ait que denx seins ou cavites maniliestes suivant le nombere des mamelles, foutetois elle a chatcune

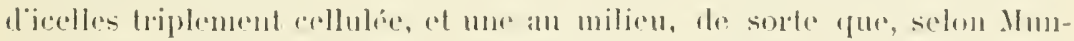
dinus, on y troure sept péceptareles. Elle a colligenee on alliance alvec

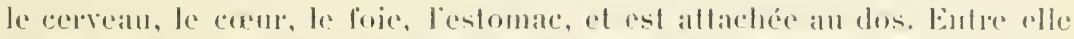

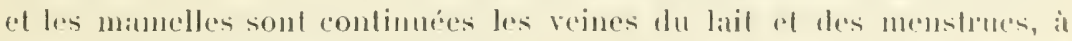

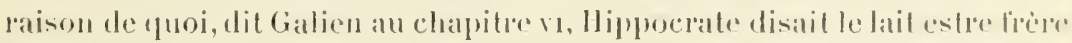

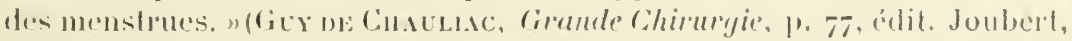
Romen, 163\%.)

(i) Olli 11 existe pas alie\% les lommmes.

(ii) Sillées.

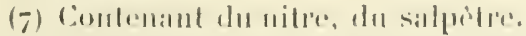

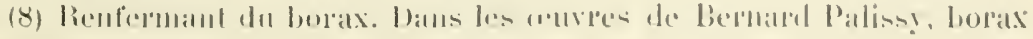
est écrit bourrete. 
lantes (1) anèrement: par la poincture (2) et fretillement doloreux (3) desquelles (car ce membre est tout nerveux et de vif sentiment) tout te corps est en elles esbranlé, touts les sens ravis, toutes affections intérimées (4), touts pansements (5) confondus. De maniere que, si Nature ne leur eust arrosé le front d'un peu de honte, rous les voirriez comme forsenćes, courrir l'aguillette (b), plus espouvenblement, que ne feirent $(\boldsymbol{7})$ onques (8) les Protides (9), les Mimallonides (10), ne (11) les Thyades (12) bacchiques au

(1) Chatouillantes.

(2) La picjure, du lalin punyere.

(3) Douloureux.

(1) Éteintes, du latin interimere.

(5) Pensies.

(6) On disait jadis des lemmes de mauvaise vie qui sollicilaicut les passants dans les rues quelles conraient liaguillette.

Ciest pourduoi je recherche une jeune tillette,

Experte des longtemps à courir l'aiguillette.

(M. RéGsieli. Épitre II.

Sulvant quelques élymologisles, celte locution aurait pris naissance it Tonlouse, nit, au moyen àge, les proslitueses btaient obligies de perter, comme une marque d'infamie, une aignillette sur l'épaule.

Suivant dautres, elle serail née à beancaire, où, la veille de Ja lóre. le's femmes de moeurs laciles cólébraient la sainte Madeleiur, en olganisant entre elles une course dont le prix bilail m parpuet diaguillelles, cest-iddire un parpuet de tresses on cordons ferrés par les deux bouls.

Cetle dernière explicalion est évidenmenl la plus platusible.

(7) Firenl.

(8) Jamais.

(9) Les Proélides, tilles de Proćlus, poi d'Argos, étaienl au $110 \mathrm{mbre}$ de lrois, savoir : Lysippe, Yphinoé el Yphianasse. Avanl néglige lo enlte le Bacchus, an dire des uns, ayant osé comparer leur beauté à celle de Junon, an dire des antres, elles furent puries par un accis de dénence

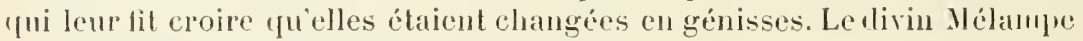
les guritit én épousant l'une d'entre ellós.

preclides implerunt falsis mugitibus ayjos.

VIrithe, Egl. VI, v. As.)

(10) Mimallonides, Mimallones (STrut.). Mimallonides (Oride). Les bateHantes, les fredresses de Bacelnus. Les Minallonides wul liré leur nom th mont Mimas, en Isie Mincure, ou clles célibraienl leurs orgies.

(1i) $\mathrm{Ni}$.

(12) Thyades, du gree gós, etre en furie. Autre nom donnc aux hac-

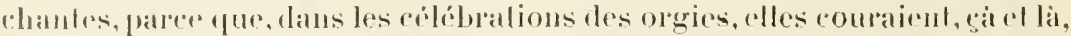
lout échevelées, vèlues de peatux de tigre, arec me viracite qui res- 
jour de leurs bacchanales (1); paree que cestuy terrible animal a colliguance $(2)$ i toutes les parties principales du corjes, comme est évident en l'anatomic.

"Je le nomme animal, suivant la doctrine, tant des acildémiques (:3) que des péripatétiques (4). Cial', si mourement propre est indice certain de chose animée, comme escript Aristoteles (5), et tout ee qui de soy se meut est dict animal, a bon droict Platon le nomme animal (6), recognoissant (7) en luy mourements propres de suffocation, de précipitation, de corrugation (\$), de indignation : voire si violents, que bien sourent par culx est tollu (g) ì la femme tout aultre sens et mourement, comme si fust lipothymic (10), syucope, épilepsie, apoplexie, et raic ressemblanee de mort. Oultre plus, nous royons en icelluy discrétion (11) des odeurs manifeste (12). et le sentent les femmes finir les

semblait in de la foreur, en tenant des thyoses, des toldeles, des flambeams el en poussant des hurlements effroyables.

(1) Fèles de bitchus.

(2) Alliance, mion, relition.

(3) Les disciples de Plalon. On les appelatit ainsi faree fue Plalon

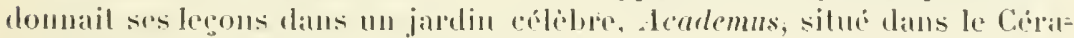
mique, limbourg important dillènes.

(i) Les philosophes de l'école d'Aristote. On les qualitiat de lat sorte

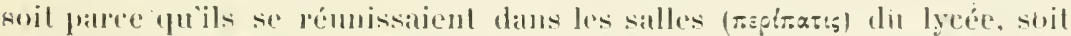

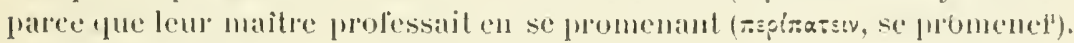

(j) Aristole.

(6) "Lil matrice, dit Platom, est un animal qui desire atrelemment

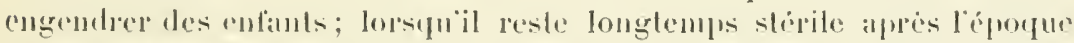
de la puberte, il a peine at le supporter; it sündigne, il pareonet lout he corpes, obstruant lesissues de l'atr, arretant la mespiralion, jetant le corpen

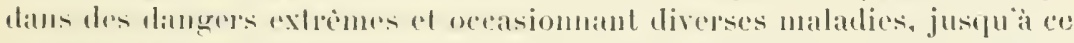

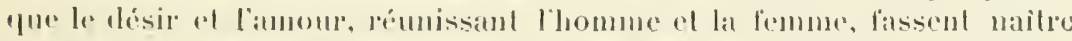

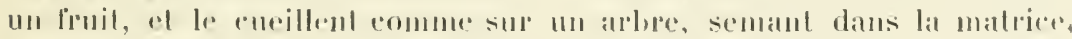
"omme dans mu champ, des animam invisibles far leur petitesse el

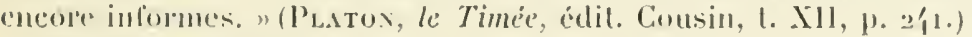

(7) Reconnalisimlnt.

(8) De plissement, de froissement, de contration, du lalin corrugares

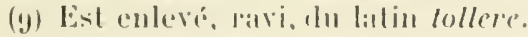

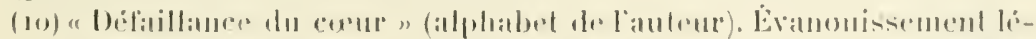

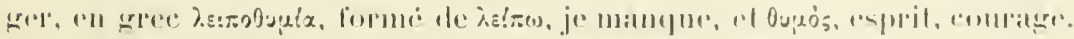

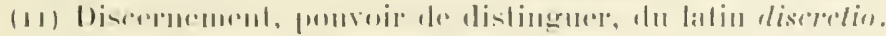

(12) Evident, cortain, du datin manifeslus. 
puantes, suivre les aromatipues (1). Je seay que Cl. Cialen (2) s'efforee prourer que ne sont mourements propres et de soy, mais par accident; et qu'aultres de sa secte travaillent à démonstrer que ce ne soil en luy discrétion (:3) sensitive des odeurs, mais efficace (4) diverse (5), procédente de la diversité des substances odorées. Mais, si vous exaninez studiensement et pesez en la balance de Ciritolaüs (b)

(1) Ciest la codiliealion de la lhéorie de lıutérus mobile qui a doniné pendant de longs siècles l'tistoire de l'hystérie.

"Cette névose, dit Hippocrate, sobserve surtout chez les femmes fui nout pas de rapports sexuels, et chez les femmes d'un ceptain àge plutot que chez les jemes, paree que les vaisseaux sont plus vides, et la matrice, lesséchée par la fatigue, est vide aussi et légere et se déplace; elle se jelte sur le foic, y adhire et se porte aux hypocondres; clle court, va en hant rers le thuide. Or, le foie est plein de fluide. Quand elle s'est jetéc sur le loie, clle cause une suffocation subite, interceptant la voie respiratoire fui est dans le ventre. Partois, en mème temps, du phlegme descend de la tète anx hypochondres; alors la matrice quitte le foie, refourne it sa place, et la sulfocation cesse; ayant pompé du huide et étant devenue pesante, la matrice retourne; diantres lois, elle se porte vers les lombes ou ver's les hanches el canse des soufrances. " (Hupocuste, édit. Littré, t. VII, p. 33.)

Le traitement hippocratique de l'lystérie est le rellet et le corollaire de la thérie ci-dessus énoncée. "Comme les accidents convulsifis, ajoute le pière de la médecine, surviennent surtout chez les vieiltes filles ef chez les reures qui, étant jeunes el ayant en des enfants, restent daus la viduité, le mienx est de les engager ì se marier. "(T. VII, 1) 315.)

"Quant aux médieaments antispasmodiques, les fétiles font fonir lutérus en haut, les aromatiques lattirent en bas. On placera done des substances fétides sous les narines : asphalte, soufor, corme, miche de lampe, huile de vean marin, et on lera des fumigations aromatiques aux parlies gémilales. " (T. V11, 1, 343.)

(2) Galien a maintenu loorigine utérine de lhystérie, mais reponssé conme absurde l’ielée d'une matrice mobile se cléplaţant comme un animal. "Ceux qui ont acerédité, remarque-t-il, ces erreurs n’avaient ancme conmaissance en anatomie, car les persomes exerées dans cefle seience sarent que les monrements de la matrice sont impossibles. n (Galex, De Locis effectis, lib. V.1, plp. 3-38.) C'est la rélention dius la matrice des huments, et surtout du liquide seminal, yni est pour Gatien la rérilable canse de la névrose.

(3) Discernement, dn latin discrelio, lait de discernere, discerner, distinguer.

(i) Vertu, du latin efficereiu.

(5) Contraire, opposé, du latin dicersus's

(6) Philosophe péripatéticien que les Athéniens cuvoyérent en anbas- 
leurs propos et raisons, vous trouverez qu'en ceste matière, et beaucoup d'aultres, ils ont parlé par gayeté de corur et affection (1) de reprendre leurs majeur's (2), plus que par recherehement (3) de rérité. En cette disputation (4) je n'entreray plus avant. Seulement vous diray que petite n'est la' louange des preudes femmes, lesquelles ont rescu pudiquement et sans blasme, et ont eu la vertus de ranger cestluy (5) effrenć animal a l'obéissance de raison."

En anatomie et en physiologie humaines, c'est l'anatomie et la physiologie des organes génitaux de la femme que Rabelais a le plus mal connu. Lui, l'anatomiste habile, qui a fait une coupe des rentricules du cerreau identique ì celle qui est reproduite dans le Traité d'anatomie de Beaunis et Bouchard (Voy.phus loin, Névrologie : Les ventricules, comme un livefond) et des comparaisons anatomigues que CruveiIhier, Mare sée, Sappey, ete, eroient aroir faites les premiers; lui, l'humaniste par excellence, a ignoré on n'a pas mentionné les ourrages d'Aetius (6) et de Paul d'Égine, on se trouve une explication des aceidents hystériques qui se rapproche de la notre, n’a tenu aucun compte des sages róserves de Galien, cru avee Platon, Hippocrate, Fernel.

salde il Rome avec Cancade el Diogène, lam 15is avanl Jésns-Chrisl. Crifolaüs appartenait i la troisieme dealémic qui enseignait pue la probabilite est le dernier degré de la sejemee. On pent admeltre que les expressions " peser en la halanee de Critolaüs" venlent dire : en tenant compte du pour el du contre.

(1) Lambilion, le dósir, du latin affeclio.

(2) Cenx rui les ont précides, du latin majores, les ancètres, les aïenx.

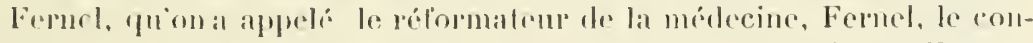
lemporain de Rabelais, a aldessé le mème reproche a Galien: "En pró

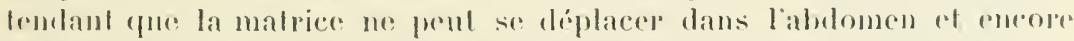
moins dans la proitrine, Galien, dit-il, śest tompé ; jai senti, dams juln-

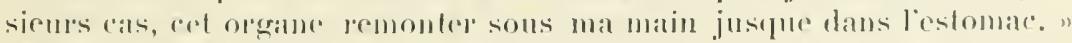

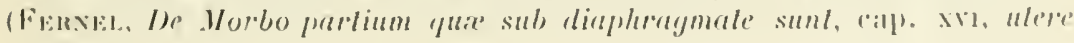
s $(y m p l$.

(3) Recherehe.

(i) Débal, controverse, du lation dispulatio.

(i) Cir.

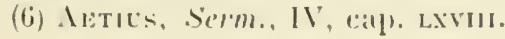


Mundinus el Guy de Chauliae, que la matrice cellulée, garnie de cotylédons, mobile à l'extrème, avait colligence ou alliance avec toutes les parties principales du corps. Pourquoi? Paree quil n’a disséqué et ne pourait guère disséquer, comme ses contemporains, que des cadaves d'hommes. des cadavres de criminels (1).

Qu'on me pardonne cette digression; je reviens à la naissance de Gargantua.

Vta-t-on se récrier sur la facon dont il est venu au monde ?

"Pourfuoy ne le croiriez-vous? Pour ce, dictes-vous. qu'il n’y a nulle apparence. Je vous di que, pour ceste seule cause, rous le debrez croire en foy parfaicte; car les sorbomnistes disent que foy est argument des choses de nulle apparence.

"Est-ce contre nostre loy, nostre foy, contre raison, contre la saincte escripture? De ma part, je ne trouve rien escript és (2) Bibles sainctes, qui soil contre cela. Mais si le vouloir de Dieu tel eust esté, diriez-rous qu'il ne l'eust pu faire? Ha! pour grace (3), n'emburelueoruez (4) jamais ros esperils de ces vaines pensées. Car je vous di, que à Dieu rien n'est impossible. Et s'il rouloit, les femmes auroient doresenavant ainsy leur's enfints par l'aureille. Bacehus (5)

(1) El aussi, comme je laai indiqué quelques lignes plus haut, paree une les femmes en couches on atteintes de maladies dı bas-rentre étaient nlors soignées principalement, sinon exclusivement, par les sagesfemmes.

(2) Dans les.

(3) Palr grâce.

(4) Ne torturez, ne tourmentez. Le verbe emburelucoquer se relroure au chapitre von du live 11 et an chapitre xxu du live Ill. Suivant Le Duchat, il signifie : "Ne vous remplissez pas la lite de chimeres semblabley à celles que les moines ont accoutumécs de loger sous leur capuchon de bure."

(5) Bacehus, fils de Jupiter et de Sémélé. Sémélé étant morte en ítat de grossesse, Jupiter enferma Bacchus dans sa cuisse, ou celui-ci resla lout le temps yu'il aumil dì demenere dans le sein maternel. 
ne fut-il pas engendré par la cuisse de Jupiter? Roquetaillade (1) nasquit-il pas du talon de sa mère? Croquemouche, de la pantoufle de sa nourrice? Minerve (2) nasquit-elle pas du cerveau par l'aureille de Jupiter? Adonis (3) par l'escorece d'un arbre de myrrhe? Castor et Pollux, de la corque d'un ouf, pont (4) et esclos par Leda (j)? Mais vous seriez bien d'advantage esbahis et estomés, si je vous exposuis présentement tout le chapitre de Pline, onquel (6) parle des enfantements estranges ef contre nature. Et loutestois je ne suis poinct menteur tant asseuré $(\mathbf{7})$ comme il ha esté. Lisez le septiesme de sa Naturelle Histoire, chap. :3 (S), et ne men Labustez (g) plus l'entendement."

(1) Rahelais fail rentainement allusion à une légende de la famille de la Roupetaillade. 11 existe encore, dans l'Aude, pros de Carcassonne, wi "habité lauteur de lépropée pantagroélique, un hameau de la Rounclaillade.

(2) Déesse de lat sigresse ef de la graerere, qui sortil lout armée du cerveaul de Jupiter.

(3) Prince célebre par sa beanté, né du commerer incestuenu de Cynérar,

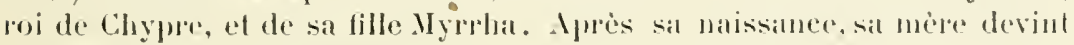
l'arbe puiporte la myrdic.

(i) Pondu.

(5) Léda, femme de Tyndare, roi de Sparto, fut aimes de Jupiter

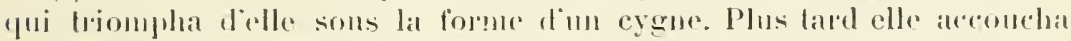

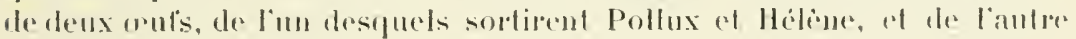
Cinstor at Cilytemmestre.

(6) Daus lepuel il.

(7) Effronte.

(8) C"est all rhapitre of el non all chappitre 111 du live VII fuion troure le texte de Pline amenel remvole Rabelatis. Le voiri :

" 11 est aréré yüil pent natre trois entants il lat fois, temoins les

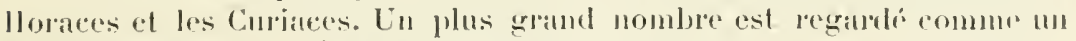

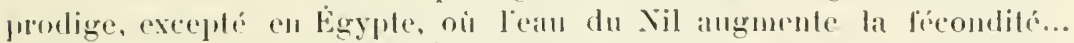
Trogne nons appreml quen Egypte les fenumes metlent all monde jus-

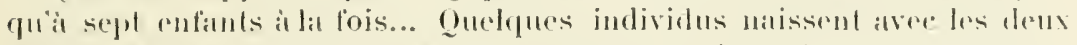

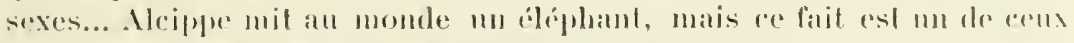
futon regarde comme des présilges sinistres. Co fut all rommenrement

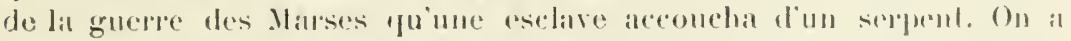

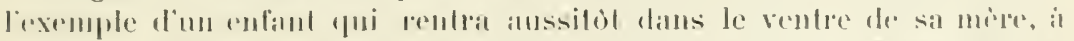

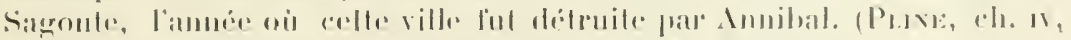

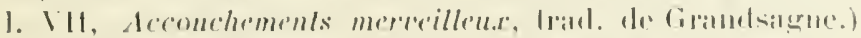

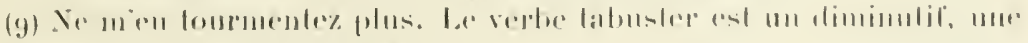
rontraction du verbe baribuster. 
En faisant accoucher la lemme de Grandgousier par l'oreille, le prêtre-médecin a été inspiré par d'autres molifs que ceux qu'il accuse. Ces motifs, quels sont-ils? Ceux-ci, je présume :

In principio erat verbam, et verbum erat apud Deam ct Deus erat verbum.... et verbum caro factum est, lit-on dans l'Évangile selon saint Jean. Nos bons aïeux ont paraphrasé (Voy. la dissertation de Grimaldi) à la Musset cet article de foi (1). Un noël de la Monnoye abonde en détails d'une naïveté charmante sur la conception et l'enfantement par l'oreille du divin enfant. Dans l'Histoire de la peinture sur verre, de Lenoir (t. II), figure le dessin d'un vitrail qui pendant la tourmente révolutionnare, a été, grâce à l'intervention de l'évêque constitulionnel Grégoire et de Lenoir, transporté de l'église/Saint-leu au couvent des Petits-Augustins (alor's le muséc des monuments franģais, maintenant l'École des Beaux-Arts). Ce vilrail, aujourd'hui

Où le père a passé, passera bien l'enfant.

(IIUsset, te Rhin allemand.)

"Je suis entré en elle par le sommet de la tète, " dit Jeshu au sujet de la conception de la Vierge Marie. "Le Verbe du Père est entró par l'oreille de la femme bénie, " lit-on dans le bréviaire des Maronites. Selon saint Angustin et le pape Félix, la Vierge est devenue enceinte par loreille. Dans une hymne de saint Éphrem, dont l'inspirateur serait, d'après Voisin, saint Grégoire Néocésaréc ou le Thammaturge, on troure cette alfirmation : "Virgo, qu: per" aurem concepisti; Vierge, qui as concu par l'oreille. "(Voy. Voltane, Dict.philosoph., au mol Généalogie.)

On chante maintenant dans les églises catholiques :

Gaude, Virgo, mater Christi,

Quæ per aurem concepisti.

Du temps d'Agobart, on y chanlait : "Le Verbe est entré par l'orcille de la Vierge Marie, et il en est sorti par la porte doréc."

"Un sujet de sermon sur lequel, an moyen ige, les moines des différents ordres revenaient sans cesse élait si la Vierge, pendant l'opération dn Saint-Esprit, avait éprouré du plaisir. Lorsque denx ordres b́taient d'accord pour le plaisir, il lallait agiter les questions : ubi et quomolo?" (NoEl, loc. cil. supri, p. 701.)

Rabelais s'en est temu sans doute à cet axiome physiologique : cest toujours par la voie par laquelle s’est opérée la fécondation que sort le produit de la conception. 

VITRAIL DE L'ÉGLISE SAINT-LEL

Colombe (st-E-prit fimlont w ravon lumineus sur lt coité gauche de la tète de la Vierge

Ji-11s:

aucentre dis

rayou luminetix.
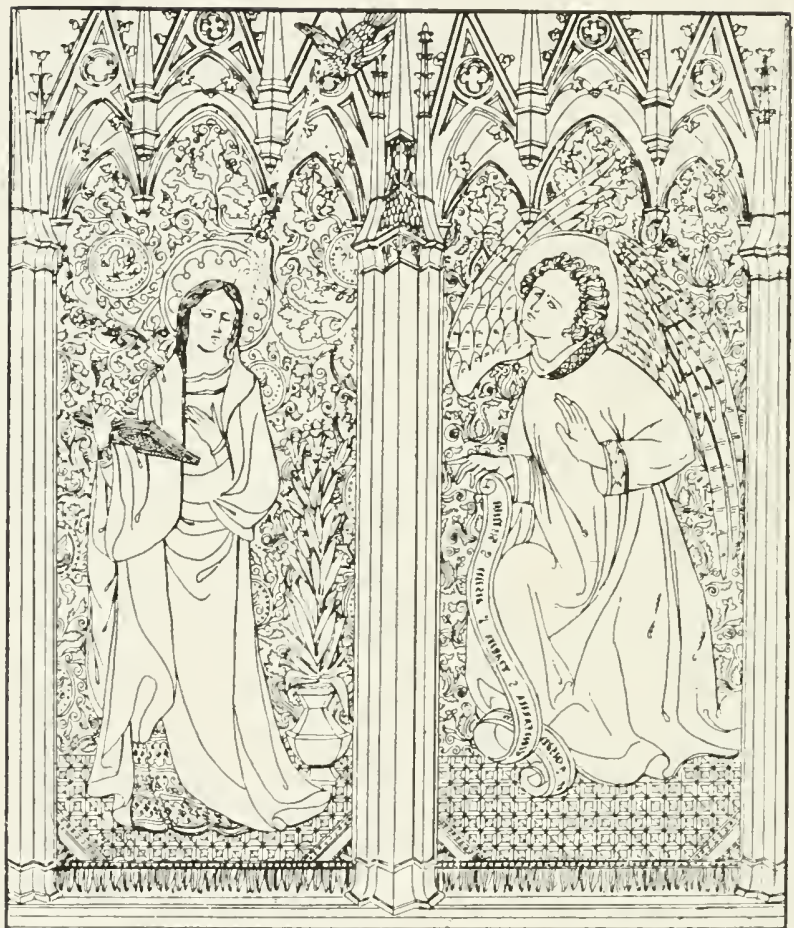

Vierge Marie

Archange Gabried

CONGEPTIOX DE LA VIEIRGE 
disparu, représente (Voy. la planche ci-jointe) une colombe (1. Saint-Esprit) planant au-dessus de la Vierge, sur l'une des oreilles de laquelle il envoie un rayon lumineux, au centre duquel se trouve un petit fotus avec une croix (Jésus) (1). A quelque distance de la Vierge se tient l'archange Gabriel, qui vient de lui parler.

Le grand railleur s'est-il associé, avee une désinvolture toute gauloise, aux innocentes plaisanteries de ses contemporains? Il me parait difficile de soutenir le contraire.

Ce qui est certain, c'est qu'en prolongeant la durée de la grossesse de Gargamelle au-delì du terme accoutumé Maître François a voulu protester contre l'opinion des médecins, des légistes et des philosophes grees et romains qui ont déclaré légritime "l'enfant né de l'emme l'unziesme mois apres la mort de son mary" (2).

A savoir :

" Ilippocrates, lib. de Alimenlo (:3);

"Pline, lib. VII, cap. V (4);

(1) II. le Dr A. Dureau, bibliothécaire de l'Acarlémie de médecine, m’a cerit quil a trouve l'indication d'un vitrail analogue dans un des eatalogues de la tibrairie Tross, a Paris.

(2) L. I, ch. 111.

(3) " Le fretus est formé le 35 jour" il se remue le $70^{\mathrm{e}}$ et il sort le $210^{\mathrm{e}}$; d'antres disent quil nest formé que le $j^{\mathrm{e}}$ jour, qu'il ne remue que le $76^{\circ}$ et qüil sort le $210^{\circ}$; il y en a qui pensent qu il a besoin de 50 jours pour étre lormé, de soo jour's pour se renuncer, quil sort le $300^{9}$ jour. Celar est et cela nest point, suivant les cas. Les enlants restent daus le sein de lenr mere pendant fout leur temps, ou ny restent que partie de ce temps. Il y en a davantage de cenx qui restent moins que de ceux qui restent plus " (H11pockats, had. Giardeil.)

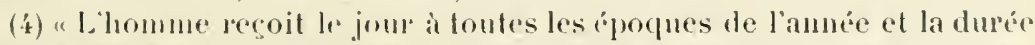
de la grossesse n’a pas de lerme tixe. Il naît des enfants au $7^{0}$ mois, an 8e et jusqu'an commenerment du $10^{\mathrm{e}} \mathrm{et}$ du $11^{\circ}$. Ceux qui naissent avant le $7^{\circ}$ ue vivent pas; ce niest que lorsquils ont efe conçus la veille on le lenmain de la pleine lume ou pendant linterlune que des colauts naissent avanl le $F^{e}$ noris. Il est commun en Egypte de voir nailie des enlints a 8 mois.. La dure de la grossesse varie heancoup. Vestilia, suecessivement femme de C. Iterditius, de Pomponius el d'Orsilus, ciloyers tris

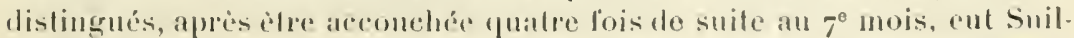

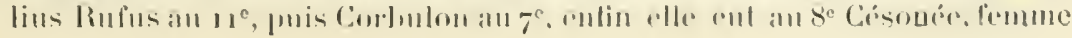


"Plaute, in Cistellaria (1):

"Marces Vario. en la satire inscripte le Testament. alléguant l'autorité d'Aristoteles (2) à ce propos (3);

"Censorinus, lib. de Die nalali (4);

"Aristot,, lib. VII, cap. IIf el $1 \mathrm{v}$, de Valura Anima$\operatorname{litum}(5)$ :

"Gellius, lib. III, cap. xir $(6)$;

de l'empereur Caligula... Le préteur Papirius, sans sarrèter aux réclamations d'un héritier collatéral, donna droit de possession à un enfant sur la déclaration de la mère qu'elle avait été enceinte pendant 13 mois, jugeant quion ne pomrait préciser la durée d'une grossesse. " (Plixe, trad. de Gransagne.)

(1) "Celle-ci mit une enfant an monde après le $10^{e}$ mois passé..... Celle-là accouche dans le courant du $10^{\mathrm{c}}$ mois. " (Plaute.)

(2) D'Aristole.

(3) Lopinion de Varron esl rapportée plus loin par Aulu-Gelle.

(4) "Que la femme puisse acconcher au bout de 7 mois, cest un poinl peconnu par la plupart des antenrs, tels que Theano, Aristote, Dioclés, Evenor, Straton, Empédocle, Epigène et beancoup d'antres encore dont les colonmes serrées n'effrayent point, cependant, Eutyphron de Gnide, qui nie intrépidement cette possibilité. Il est combattu à son tour par presque tous les philosophes qui, a l'exemple d'Epicharme, nient que l'enfantement ait lieu dans le $8^{e}$ mois. Dioclès de Caryste, néanmoins, et Aristote, de Stagire, ont pensí le contraire. Quant ì la naissance daus le $9^{\circ}$ et $0^{e}$ mois, elle est admise, et par la phupart des Chaldéens, et par Aristote dont je viens de parler. Eprigine de Byzance ne la nie point pour le $9^{e}$ mois, ni Hippocrate de l'ìle de $\operatorname{Cos}$ porr le $10^{c}$, mais le $11^{\circ}$ mois, admis par Aristote seul, est rejetí par tous les aulres. "(Cexsonixes, trad. Mangeart.)

(5) "Le lemps de la gestation des animamx est limité à mnespace fixe; le terme ou ils mettent bas n'est point sujet à variation. L'homme senl uait à différents termes; il naît à 7 mois, à 8 , i 9 , ì 10. Ce dernier terme est le plus ordinaire. Quelyucfois la duréc de la grossesse entame le u mois..... l'ignorance do la véritable époque de la grossesse est rraisemblablemenl encore ce qui fait croire anx temmes qu'elles acconchent i phus de u mois." (Aristote, lrad. Camus.)

(6) Et les médecins et les philosophes les plus célébres ont álerí des questions sur le temps de la naissance diun entant ef de la gestation de la mère. Lopinion la plus généralement reçe, et quon regarde mème comme certaine, est que, le sein de la mère ayant été fécondé, elle met an mondr son fout, rarement $\because 7^{\circ}$, jamais an $8^{\mathrm{e}}$, souvent an $9^{\mathrm{e}}$ et assez souvent an $10^{\circ}$ mois; et que non le commencement de ce $10^{e}$ mois, mais la fin, dome l'époque la plus longue et la plus reculée. Cette opinion se tronve appuyée par en endroit de la Cislellaire de Plaule, où cel ancien poète comique dit : 
Seritus (1), in ecl. exposant ce mètre (2) de Virgile:

Matri longa decem. etc... (3).

"Et mille autres fols (4). Le nombre desquels ha esté par" les légistes accreu..."

Celle arec laquelle il arait eu commerce accoucha d'une petite fille à la lin du $10^{\circ}$ mois.

Ménandre, poite plus ancien encore et très versé dans les opinions savantes, insinue la mème clıose daus sa comédie intitulée Plocius où il s'exprime ainsi :

"La femme acconche le $10^{\mathrm{c}}$ mois."

Cacilius, dans une autre comédie sur le mème sujet et ayant le mème titre, pièce qüil a presque entièrement imitée de lénandre, ne passe pas, comme son modèle, le $8^{c}$ mois sous silence, en parlant des mois destinés aux accouchements; mais il dit :

"Lne femme a-t-elle coutume d'enfanter au $10^{\circ}$ mois? Certainement elle le peut, de mime qu'au $9^{c}$, an $7^{\mathrm{c}}$ et an $8^{\mathrm{c}}$."

II. Varron nous est garant que Coccilius na point dit cela inconsideré-

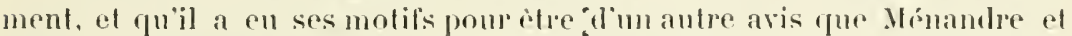
plusieurs autres écrivains; car il assure que somrent on a vu des enfints naître au $8^{e}$ mois. Il ajonte qu'un enfant pent demeurer 11 mois dans le sein de sa mìre, ef il appuie ces deux assertions de l'autoriti d'Aristote.

.... Ontre ce que je viens de rapporter des diffrents auteurs, je erois levoir citer an lecteur une particularité remarguable que jai entendur aul sujet dlume dame romaine. Une dame comme par la surete de ses

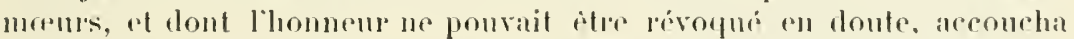
11 mois apros la mort de son mari. Cofte affine fit grand butut on lac:eusa davoir en un commere illicite apus la mort de son époux, parec que la loi portée par les décenvirs détermine l'ápoque de lenthutement all $10^{\mathrm{e}}$ of non a $111^{\mathrm{c}}$ mois. Mais l'emperem Adrien, au tribunal dupuel lat eause lut portéce décida que laecouchement était possible $: 1111^{\mathrm{e}}$.

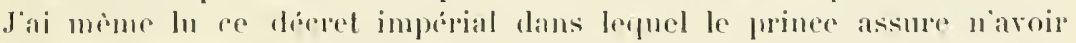
pris rette décision pue dapues lavis des anciens philosophes of módecins

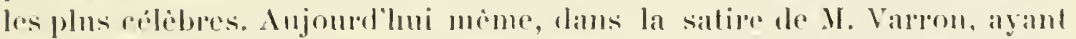
pour litre le Teslament, jai lu ces paroles : "Si un ou plusiemrs enlimts

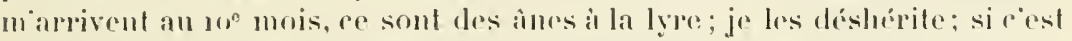

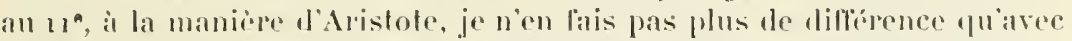
les precédents que de Titus et d'Accius. Ces dernières paroles font allusion au vieux proverhe sur les choses qui ne dilléraient guipe entre elles." (Arle-Geble, Nuils alliques, trad. V. Verger.)

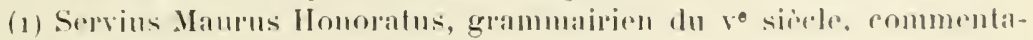

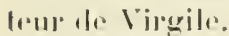

(2) Vers, du latiu melrum, mesure.

(3) Le vers romplet est :

(1) Fons.

Molri longu decem Iulerinl fuslidiu menses. 
On a reproché a Rabelais de ne pas ètre exempt d'un défaut quil a repris chez les savants de son temps : d'abuser de l'épudition, d'avoir la manie des cilations. C'est exact; mais, s’il est pédant avec les pédants, c'est un peu à la façon de Socrate, qui se latisait sophiste pour désarconner les sophistes. On n'aura aucun doute à cet égard si on lit les passages des ourrages des auteurs précités. En lraitant de " fols" ces auteurs, en n'admellant pas les naissances tardives, Rabelais n'a cependant pas été entièrenent dans le rrai. De nos jours, les accoucheurs conviennent que la grossesse peut se prolonger jusquan dixième mois et qu'il est mème fort probable que cela arrive plus souvent qu'on ne croit. Celte prolongation d'un mois ćtant admise, quelle peut être la durée maximum du séjour de l'enfant dans le sein maternel? "Sans allirmer la réalité des gestations de douze à treize mois, le lait, dit Joulin (1), ne me paraît pas absolument impossible. Les adversaires des naissances tardives invoquaient à l'appui de leur opinion l'orde immuable de la nature. Ge sont la des phrases vides de sens; ear on constate à chaque instant que la nature s'écarte de cel ordre prétendu immuable (2)."

Maître François a élé lui-mème consulté par lettre (3) sur une naissance arant terme, par Mgr l'élissier, évêque de Maguelonne, ambassadeur de Sa Majesté Francoois Jer à Venise. On ne connaît pas sa réponse, mais, d'après ce qui précède, elle est facile à deviner. Je reproduis celle lettre à titre de document :

(1) Joulix, Traité complet d'accouchements, 1) 456, Paris, 1867.

(2) Le premier, en France, j’ai établi, avec de nombreux faits à l'appui, l'exactitude de cette proposition, en ce qui concerne la texture lu corps lummain. (Voy. Le Double, De LÉpididymite blennorrhagique alans les cas de hernie inguinale, de varicocèle ou d'anomalies le l'appareilgénital, Paris, 1879, et Traité des rariations du système musculaire de l'homme et de leur signification au point de vae de l Authropologie zoologique, Paris, 1897.)

(3) Cette lettre, tirée du manuscrit 142 de la bibliothèrque d'Arles, a été communiquée au Comité des travaux historiques par M. l'abbé Verlacque et publice par II. Marty-Laveaux, dans le tome III, p. 382 de son édition de Rabelais, 
A Monsieur le doeteur Rabelais.

Venise, le 23 juillet $15 \%$.

Je ne rous escripris point dernierement tant pour la presse que jarois que aussi pour ce que ne arois receu aucune lettre de vous ne scaurois argument meritant vous faire entendre. Ce neanmoins, pour mentretenir toujour's pue puissions avoir nourelles l'un de l'autre, nay point vouleu discontinuer de vous escrire, et pour n'avoir a présant meilleure matiere vous ay bien rouleu advertir de ce que nous arons iey touchant cerlaine ronsultation qui me semble appartenir pour vostre profession et suffyence a rous. C"est tue mons. Philipus Saceus, présidant de Milan, a mandé icy et a Boulogne a consulter aux colleges des docteurs si une fille que luy est née est sienne, et est pour vuire ef si doibl estre tenue pour legitime : et ce dlantant que du 15:39, le XX6 d'oetobre a puatre heures de nuit arant la pleine lune se assembla la premiere fois avecque elle : or du 15 qo le XIII d'avril sa dicte femme luy a faict ma pieta piche. Se dispula si cest enfantement est de sept mois et suil est pour vuire el est legitime. Tous les docteurs se travaillent, mais en somme quasi la plus grande partie si incline a l'opinion qu'elle ne soit point te sept mois. Par quoy ne ponroil survuire, el adrenant l'aranture quelle survesquit ne lestimeroit point legitime ne de sept mois ains de neuf a la barbe del signor presidente a Boulogue. Sont encores ceux qui attendent la resolution du dict college, ce neanmoins certains icy treuvent, tant pour la raison d'Hipocrates comme des anciens et de Pline, que cest enfantement peut arriver au semestre et par consequent estre vital et legitime, et lous leurs fondemens sont que les anciens, non seulement Hebrieux, mais Arabes et Caldéens, content leurs mois selon le cours et peregrination de la lune el selon icelle considerent le temps de l'enfint, de sorte que toutes et puantes fois que a ung enfantement se trouroient sept lunes ils le tenoient pour sepmestre, comme se pent roir par ce que Pline en escript en son libve septiesme an chap. 5, el en lliprocrates an live de semestre parle nonobstant que le diet libre soil corrompu en ce lien la, et par ainsi mal traluit par mons. Labro de Vavena. Je aurois bien a plaisir que vous men mandissiós vostre advis, d'autant que la chose de soy mesmes ast digne d'estre examinée, et le sieur merite bien que tons les serviteurs du Roy luy disent le proficiat tout aimsi yuil a mérile el est allectionno de sal majesté.

PÉRISEIE,

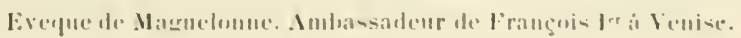


Quand il est impossible à une mère d'allaiter son enfant, elle doit le confier à une nourrice.

En racontant " comment Pantagruel transporta une colonie de Utopiens en Dipsodie, et explora par sorts virgilianes (1), quel sera le mariage de Panurge ", Rabelais a montré que le choix d'une nourrice n'est pas chose indifférente.

"Arec le laict de leurs mères nourrices, les Utopiens avoient pareillement succé la doulceur et débonnaireté.

"Jupin (2) ha esté le plus fort ruffian... (3) qui onques (4) fut (5), paillard, tousjours fumant comme un rerrat (6) : aussy fut-il nourri par une truic en Dicté (7) de Candie, si Agathocles babylonien (8) ne ment; et plus bouquin (9) que n'est un bouc : aussy disent les aultres qu'il fut allaicté d'une cherve."

Ainsi que le grand Ancêtre, les doctrinaires de l'École d'Alexandrie soutenaient que nous sucons avee le lait le germe de nos passions et de nos inclinations futures, de nos vertus et de nos vices. Caligula, ce monstre de cruanté,

(1) Les rers de Virgile.

(2) Jupiler, fils de Saturne el de Rhe le phus puissant des dienx.

(3) Díbauché.

(4) Que quiconque ne firt.

(5) Il s'est métamorphosi en cof pour síduire Junon, sa sorur ; en taureau pour enlever Europe ; pu pluie d'or pour pénélrer jusquà Danać en eygue pour tromper Léda; en pigeon pour eharmer Phthie; en satyre poul' surprendre Antiope; en aigle pour porter Ganymide an eiel. Il s'est présenté à Alemène sous la forme de son mari; il a pris la taille et la tignue d'un jeune homme pour plaire à Sémélé; il a emprunté les traits le Diane pour en imposer à la nymphe Calisto; il s'est lait berger pour vaincre la résistance de Mnémosyne

(6) Porc entier el aussi sanglier, du Jatin verres.

(7) Montagne de lïle te Candie, dans la Méditerranće, aulrefois l’ìle de Crète.

(8) Voy. Athénée, I. I, rh. r.

(9) Plus bour. Le boue a, comme le mulet, une réputation de lubriciti hien étahlie. Quant ì la truie, elle recherche les approches du male. quoiqu'en état de gestation, ce qui est un exès parmi les animaux dont la lemelle, dans presque toutes les espices, reluse le mile dès quielle est fécondée. 
et Véron, ee tỵpe d’immoralité, ce spécimen des mours corrompues de la Rome impériale, leur servaient de prineipaux exemples. Ils prétendaient que la férocité de Caligula lui venait de ce que sa nourrice frottait de sang ses mamelons avant de les lui présenter. Quant à Néron, sa nourrice était irrogne, et il passa des bras de cette mégère dans ceux d'une danseuse et d'un barbier. Mithridate, dans un langage figuré, mais emprunté aux idées que je rappelle, disait que les Romains avaient pris le gout du sang dans le lait de la louve qui avait nourri leurs premiers chefs.

D'accord aussi arec cette théorie (1), les poètes et les anteurs anciens, Vacrobe (2). Columelle (3) et Virgile lui-mène, font allaiter leurs héros par des lionnes, des tigresses, ete. Didon, abandonnée par Énée, l'apostrophe en ces termes:

Nec lili diva parens generis, nee Dardanus auctor:

Perfide, sed duris genuit le cautibus horrens,

Cancasus, Hireanaeque admorunt ubera ligres.

\section{(Énéide.)}

Non, tu n'es pas le lils d'une diesse, non, tu ne descends pas de Dardanus ; perfide, tu es sorti des roches hérissoes du Caucase, et tu as sucé le lait des ligresses de l'Hy' canie.

Sans mappesantir davantage sur ees citations que je ponrais multiplier a l'infini, je dirai que l'édueation commence dis te prenter jour de la naissance el que les passions de la persomne qui nourril n’agissent pas seulement

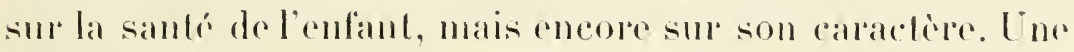
nomrice crabutive, combagense on méchante pent, jusquä

(1) Manricean, un des médecins-acconchenrs les phus eminents du xwo sièrle, croyat eneope fermement is eette inthener de l'allatement sur

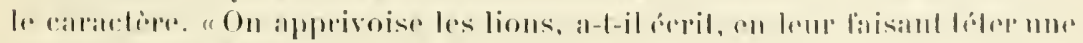

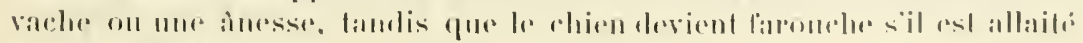
Hall me lomron."

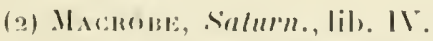

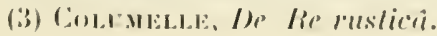


un certain point, rendre son nourrisson courageux, craintif ou méchant. Certainement, si l'on attribue au lait, comme les philosophes de l'École d'Alexandrie et Rabelais, cette inlluence exercée par la femme sur l'enfant, on avance une chose fausse; mais si l'on ne reconnaît, pour expliquer le fait en question, que la puissance de l'éducation, c'est-à-dire l'action de causes cérébrales directes et puissantes, opérant sur un cerveau infantile, modifiant l'organisation de sa masse et l'imprégnant d'idées nouvelles, l'assertion cesse d'être inexacte, il s'agit d'un phénomène physiologique, naturel, facile à concevoir.

C'est à la mère qu'il appartient de façonner le moral de son enfant à l'image du sien, d'approuver devant lui ce qui est bien, de lui faire entendre ce qui est mal, ce qu'il doit éviter. La raison, qui se forme plus tard, conserve toujours quelque chose de ce mystérieux assolement, et, de même que l'homme porte sur sa figure le signe de son siècle, la marque distinctive de sa nation, celui que sa mère a nourri de son lait, qu'elle a élevé sur ses genoux, porte toujours en lui un reflet des vertus de la famille, qualités héréditaires qui circulent arec le sang et finissent par faire partie intégrante du tempérament. Les préceptes qu'il recueille dans son adolescence s'altirent et s'effacent comme un vernis qui s'use et se détruit, mais ce qu'il aura appris, encore vêtu de langes, il le conservera comme l'essence de lui-même. 


\section{ORGANES DES SENS}

Ouaresmeprenant avoit :

Les narines, comme un bẻguin.

La langue, comme une harpe.

Les tympanes, comme un moulinet.

Les nerfs optiques, comme un fusil.

L'epidermis, comme un beluteau.

Les narines, comme un béguin.

Bégriuin, coifle d'enfant.

"Ce que (1) faict les aureilles des asnes si grandes. déclare Panurge, cest paree que leurs mères ne leur mettoient poinct de béguin en la teste, comme diet d'Alliaco (:) en ses Suppositions (:3). "

Les narines très larges, tries ouvertes.

\section{La langue, comme une harpe.}

La harpe ancienne a la forme de la langue. Telle est la forme de celle que tient Apollon dans le tablean Apollon jouanl de la harpe que posside le inusée de Tours (4). C'est eelle dont le dessin accompagne ce lexte.

On nomme frein ou filet de la langue un repli murpurux

(1) Cre qui fait.

(a) Pierre d'Ailli, doctenr en Sorbonne, areherique de Cambrai, mort ․ㅣ 1 彷5.

(3) 1.. II, clı. XY.

(1) Une harpe analogne se voit sur la compe de Casted-I)urante, de 1525 (Apollon el Marsyas), qui est la proprité du musée da Lomror. 
étendu de la face inférieure de cet organe au plancher de la bouche. C'élait jadis et c'est encore un préjugé, à peu près général, que la section de ce frein est indispensable pour assurer aux enfants une parole facile.

An xrine siècle, on disait couramment d'un grand parleur : "II n'a pas de tilet."
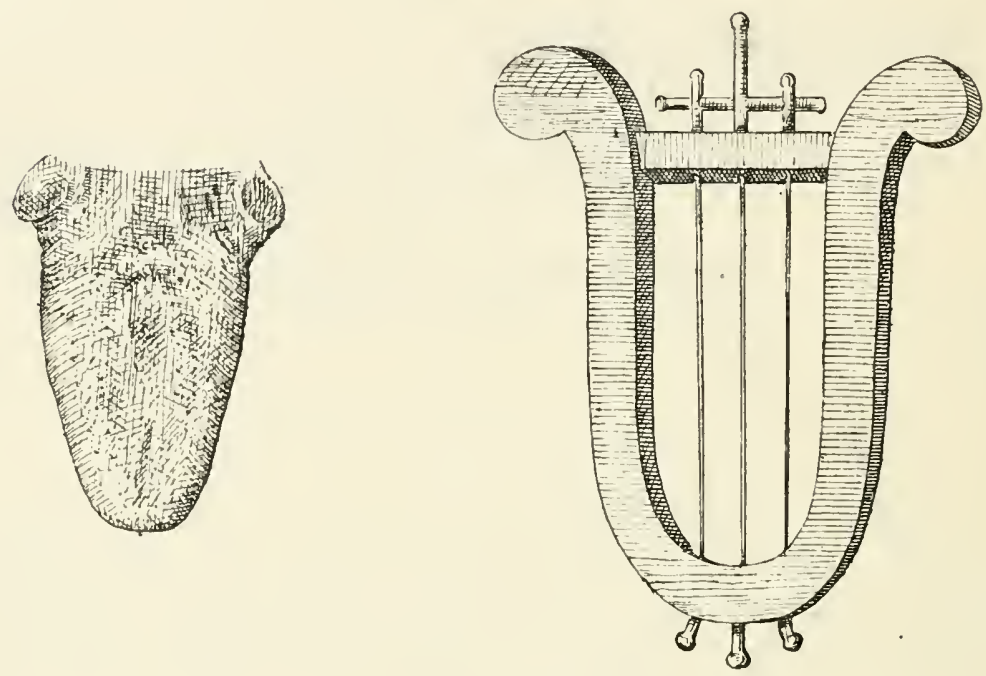

La lanyae, comme ane harpe.

Dans son épître $\pi$, Boileau s'exprime en ces termes:

Tout charme en un enfant dont la langue sans fard,

A peine du filet encore débarrassée,

Sait d'un air innocent bégayer sa pensée.

II. Sébillot aflirme que l'usage de conper le frein ou sublet est très répandu daus les campagnes de la haute Bretagne.

M. Moisset assure que, dans l'Yomne, c'est une opinion acceptée par tous que le nourcauné dont on aurait omis de comper le frein de la langue serait muet.

Dans le l'oilou, on répond à un barard: "Celui qui l'a coupé le lignoux n'a pas volé ses cinq sous."

"II laut remarquer avec soin, arance Riolan, que la 
nature n’a mis de frein qu'à la langue seulement et aux parties honteuses: parce quidle a voulu que, sur toutes choses, les hommes fussent modestes dans l'usage de ces organes."

Le frein de la langue ne rend réellement la prononciation et la succion diliciles que lorsqüil est tròs court; alor's, mais alor's seulement, il estindiqué de le sectionner. Il est question de cette petite opération dans la comédie (la Femme mute) (1), composée par Rabelais et jouée a Montpellier, en 15\% ou 15.3., par lui et ses camarades, Antoine Saporta (2), Guy Bourguier, Balthazar Noyer, Tolet (3), Jean Quentin (4), Francois Robinet (.) et Jean Perdrier (6) :

Il s’agit d'un " bon mary qui avoit espousé une femme mute. Il rouloit qu'elle parlasl. Elle parla par l'art du médicin et du chirurgien, qui luy couparent (7) un encyliglotte (8) quelle avoit soubs la langue. La parole recouverte $(9)$, elle parla tant et tant, que son mary retourna au

(1) Muette, du latiu mulus. M. Dubouchet a retrouré dans le Liber Procu-. raloris de la Faculte de $\mathrm{Dontpellier,} \mathrm{ad.} \mathrm{amn.} 1530$, lindieation de la sonme payce il lauteur : "Pro composilore moralitatis, stullice el comedie qunturor aureos. valentes VIII libras Turonensium."

(2) Antoine Saprortat, dorig̨ine espagnole, a été prolesseur en médecine el chancelier de l'Université de Montprellier.

(3) Pierre Tolet a été médecin de l'hòpital de Lyon et a laissé divers ourages importants : un Truité de la goulte; une traduction des arures de Paul d'Égine, otc.

(1) Peut-itre Jean Quinliani qui a habité Venise en 15 f6 el pui a pris i partie Galien dans un opuscule inlitule : liel. Is. Spach. Bibliolh. meel. impr. Francofurt, $15 y$ r.

(5) Francois Robinel a exercé la médecine à lines.

(6) Rahelais était le précepteur de Jean Perdrier, à l'éponte (1531

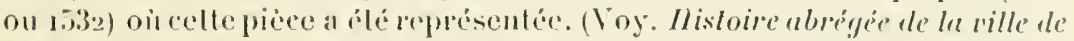
Montpellier arec un abrégri de la rie de quelyues hommes illuslres, lanl en droil civil quen médecine de le dile ville qui s'y sonl rendus recommundubles,

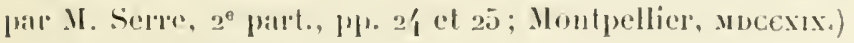

(7) Couprisent.

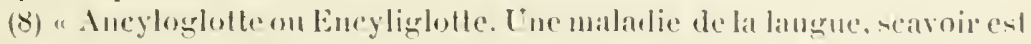

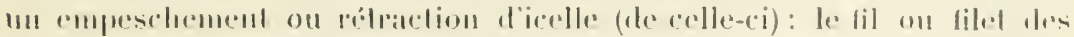

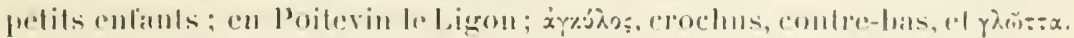

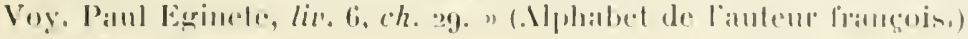

(9) Roromstron. 
médicin pour remède de la faire taire. Le médicin respondit en son art bien avoir remedes propres (1) pour faire parler les femmes; nen avoir pour les faire taire. Remède unique estre surdité du mary (2) contre cestuy (3) interminable parlement (4) de femme."

On sait que c'est dans cette comédie de Maître François que Molière a puisé les éléments de son Médecin malgré lui.

Le Dr Chervin a démontré que les sourds-muets ne parlent pas parce qu'ils n'entendent pas et leur apprend a parler en lisant sur les livres de leurs interlocuteurs les lettres qui eomposent les mots (5). Si grand que soit le mérite de M. Chervin. les lignes qui suivent n'en corruborent pas moins, jusqu'à un certain point, l'opinion émise par Esmangart et Johanneau, à propos de la conversation mimée de Nazedecabre (ij) et de Panurge (Voy. Ostéologie: L'alkatim, comme un billart), que Rabelais a eu peut-être notion du langage par gestes des sourdsmuets, perfectionné, longtemps après lui, par Ammant et les abbés de l'Épée el Sicart:

" Conscil prenez de quelque mul ( $\mathbf{7})$, recommande Pantagruel a Panurge. - J'en suis d'advis, respondit Panurge. - Mais, dist Pantagruel, il conviendroit que le mut fust sourd de sa naissance, et par conséquent mut. Car il n'est mut plus naïf (\$), que celluy qui onques n'ouït (9)) -

(1) Elficace, souverain, du latin proprius.

(2) Llinam aul hic surdus, ant hae mula facla sil, dit Davus, dius l'Adrienne de Térence.

(3) Cel.

(4) Bavardage. (L. 111, ch. xxxw.)

(5) Dapris la forme quelles premnent en les ateentuant.

(6) Naz de cabre, $110 \mathrm{z}$ de chevre, en pratois languedocien.

(7) Muet, du latin mulus, tiré du gree $\mu u ́(s)$, je ferme la bouche, d'où mystere. On dit encore rage-mue pour rage muctte.

(8) Dans le sens du not latin natious, naturel, immé, sans fard, sans artifice.

(9) Nentendit jamais. 
Comment, respondit Panuruge, l'entendez". Si vari lust que l'homme ne parlast, qui ne eust ouî parler, je vous meineroin ¿ logicalement inférer une proposition bien abhormente (1) et paradose. Mais laissons la. Vons doneyues ne croyez ce qu'escript Hérodote $(2)$ des deux enlants gardés dedans une case 3 par le vombir /) de Psammetic (o), roy des Egrpptiens, et nourris (i) en perpétuel silence : lespuels. apres certain temps, frononecarent $(7)$ reste parole, Becus, larpelle en langue Phrygienne signilie pain? - Rien moins, respondit Pantagruel. Cóest abus dire que ayoms langage naturel; les langages sont par instilulions anbitratres et convenances (S) des peuples : les roix $/ g)$, commm disent les dialecticians, ne signilient naturollement, mais a plaisir (10). lo no vous di ee propos salls ranse (1 1). Call Barble, l. I, de Verbor. obligat., lateomple fue, de son lemps, lut en Eugube (12) nn nommé messed Nello de Gabrielis, lequel par areident estoil sound devenu : ee

(1) Absurite, ridicule, du lialiu abhorens.

(2) Au commencenent du live 11.

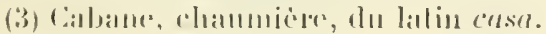

(') La volonte.

(i) Paimmóligue, qui at comslruit le lalsyoinlle.

(6) Ėlevés, du lintio mulrilus.

(7) Prononciersil.

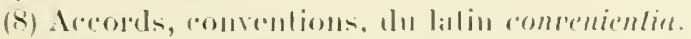

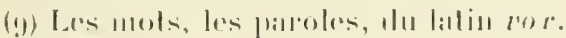

(16) Comme il plait, commure on veut.

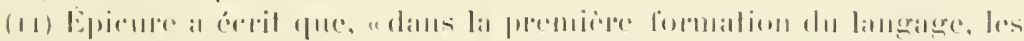

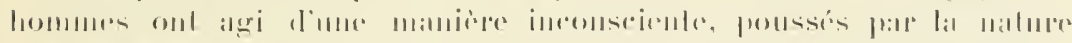

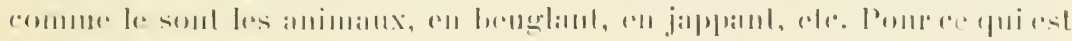

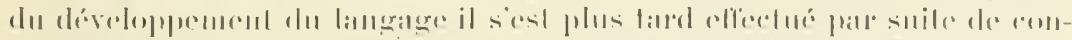

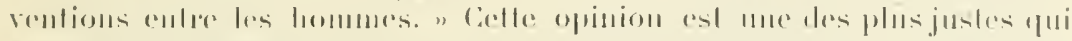

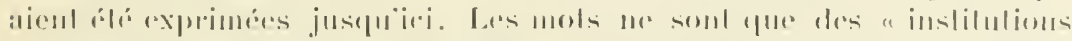

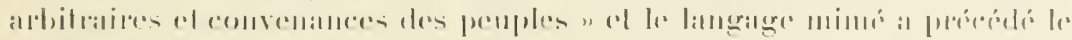

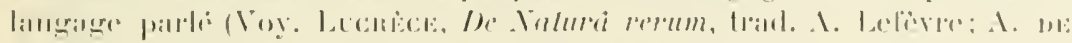

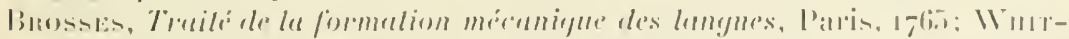

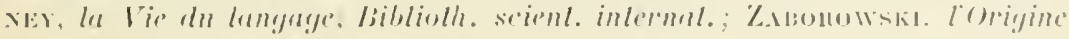

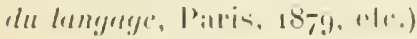

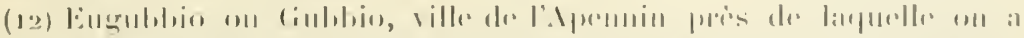

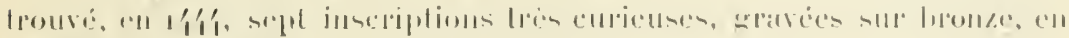
lamgue ombrienue. 
nonobstant entendoit tout homme thalian, parlant tant secribement que ee lust, seulement à la vue de ses gestes ef mourement des baulievres (1). I'ai d'advantage leu, en auteur (2) docte el élégant (3), qur Tiridates, poy d'Arménie, au temps de Néron, visita Rome, el fut receu en solennité honorable et pompes magnifipues, allin de l'enlreteniren antitié sempiternelle du sénat el peuple romain : el n’y eut chose mémorable / /) en la cité, qui ne luy lust monstrée el exposéc. A son dípartement (i), l'empremeur luy leit de gramds dons el exeessifs; oultre luy feit option (6) de choisir er que plus en Rome luy plairoit, aree promesse juréce de non l'eseonduire, quoy qu'il demandasl. Il demanda seulement un joueur de faree leguel il aroit vu an théalde, el n'entendant ee qu'il disoit, entendoil ce qu'il exprimoit par signes et gesliculations $(7)$ : alléguant que soubs sa domination astoient peuples de divers langages, pour anxquels responde et parler luy convenoit user de plusieurs truchemens (s) : il (a) soul à touts sulfiroit. Car, en matiere de signitier (10), par gestes, esloit tant rexellent, qu’il sembloil parter des doights. Pourtant vous fault choisir un

(1) Des levres. Ponr Le Durhat ce mot viont de bis, deux, ef labra. livese et pour Esmangapt of Johameau de bon et lieves; l'n de ban s'étant rhangé en $n$ romme dans courent, de con-tenlus. La depnière étymologir me parail plus plansible que la premièe. On lit en elfet bauliveres dans l'édition de 1552 .

(2) Luciex. Dialogue de la danse.

(3) Élégant, du latin elegans, signifir iri plein de goùl, de charme.

(位 De lanmenx, de bean; dn latin memordbilis.

(5) A som départ.

(6) Lui permit, lui donna le droit.

(7) L'histoire uons apprond que ceplains mimes cólibres de lancienne Rome rendaienl arec nue perfection inouie les sensations ef les sentiments des persomages do la lable quils repurisentaient. De nos jours encore, et dlme maniere assez prarlinite, on jone, a Naples, de petites pieces dont le public comprend pardaitement le sens dans fous ses dítails sans qu'aucune parole soil prononcér.

(8) Interprètes.

(9) Celui-ci seul.

(10) bans le sens du verbe latin significare, se faire entendre, comprender. 
mut sourd de nature, aflin que ses gestes (1) el signes soient non leinets, lardés ne (2) affectés. "

\section{Les tympanes, comme un moulinet.}

Les lympanes, l'oreille movemne. la caisse du lympan. ties :

Chez l'homme, l'organe de loüe comprend lrois par-

Une exlerne, formée par le pavillon de l'oreille el le conduit andilif externe :

Une moyenne, la caisse du tympan, ainsi nomméc paree

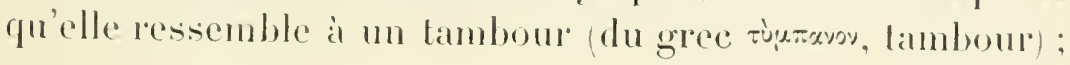
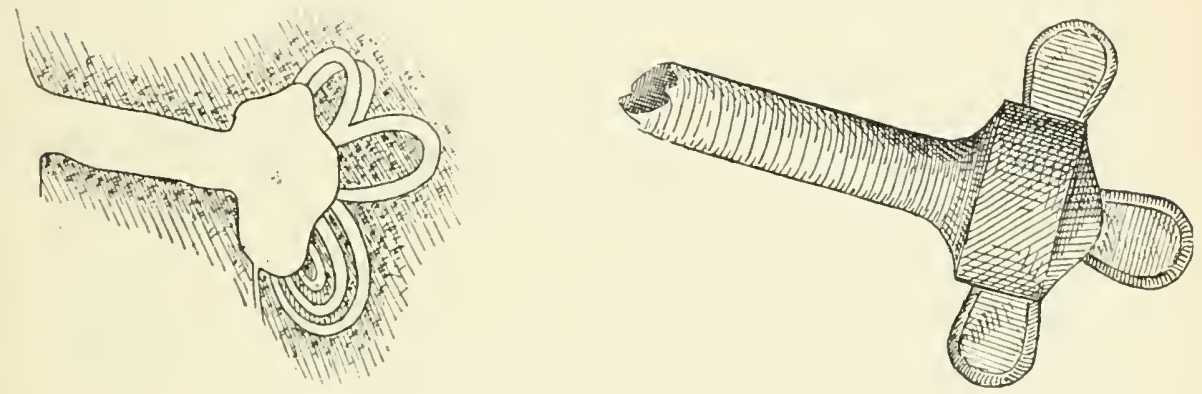

Les tympanes, comme un moulinet.

Une interne, l'oreille interne consliluce par des camanx renfermant mo liquide dans lepuel baiguent les extremiles du nerf acomsliegur.

Lal caisse du lympan est laverséc par mone chaine de

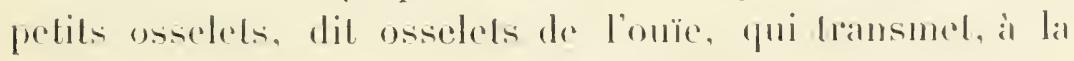
manicere d'une poutre muissant les parois opposéres d'm appatentenl, les vilualions de loneille externe a l'omeille inferne.

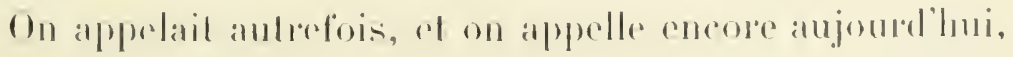

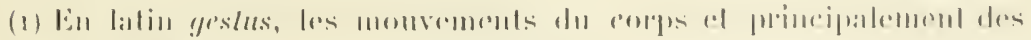
mains al dem liras.

(2) $\mathrm{Ni}$. 
monlinet un petit moulin à rent dont on fait mouroir les ailettes en soufllant dans une lige erense de surean qui hui sert de support.

P'rè de l'ìle de Caneph (1), pendant le sommeil de Panlagrucl. "Carlpalim (2) d'une conpuille de noix grollière (:3)

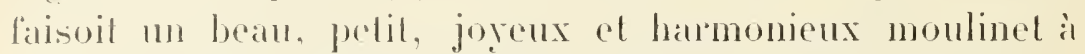
aiste de quatre belles petiles aisses d'un tranchoir de vergine $)\left(\begin{array}{l}1 \\ \text { ). }\end{array}\right.$

"Lequel culant seshatoil par soy, à ung pelit moulinet

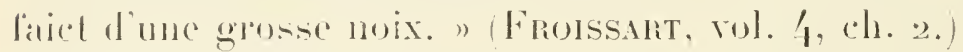

Lat tige creuse de sureau du moulinel est l'homologue du conduil auditil externe, et la caisse du moulinet, l'homolugue de la caisse du tympan.

\section{Les nerfs optiques, comme un fusil.}

Les ners optiques, les nerfs de la vision. Chacum d'eux décrit une légere courbe i concavité interne et mesure 5 eculimedres de longueur.

"Len productions mammillanes élant òtées, la prenière paire te nerl's, que lon appelle la paire optique, se présente d'abord a la vie." (Dienerbroeck.)

Parmi les objets dont l'usigge, comme celui des monchelles, a presque disparu, il laut citer le briquel, remplacé presque partout aujourd'hui par des allumettes chimiques. Le bripuet ancien, appelé fusil-. fusil ou forsil (de l'italien forile, fait, avere la mème aceeplion, du latin focus, feu), ansistait daus un morecau d'acier dont la pereussion sur

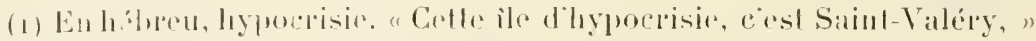

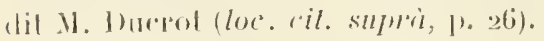

(2) Com d'un des domestipues de Pantagruel. Prompt, alerte, du gree $\% \alpha \rho-\alpha \lambda(\mu, 0)$

(3) De noix mange par les grolles. Les grolles on freux (par conlacetion du latin frugilega, formo de frugess, fruits, el de legere, cucillir, paree

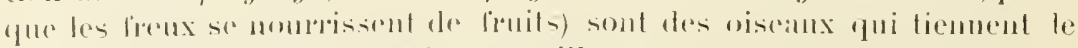
milien rolde les corberam at les commeilles.

(4) De quatre berlles pelites planches d'un rond de rergur. 
un silex faisaitjaullu des éline elles quicommuniquaient lo feu ¿t des matièes lres inllammables, telles qur lamadon, Ie bois pourri, le papier, le vienx linge brilé, ete. Colte sorte de batterie perfectionnée a été appliquée, vers 168.5 , an mousquet. yuion a. depuis, appelé fusil.
Voulez-rous ouïr chansonnelte
De tous les cris de Paris?
Lun erie: Allumette?
Liutre: Fusilz, bon Fusilz!

Chanson nouvelle de lous les cris de Paris el se chante sur la volte de Provence. (xwe siele, collecl. Macp.s. t. I, l. 2,3.)

Panurge avait " un lusil garni d'esmorehe (1) d'allumettes. de piere it fer, et tout aultre appareil it ee requis " (2).

Larme dou devise de la Maison de Bomrgngue blait un fusil en forme de B (Bourgogne), pusé sur trois piereses, avec ces mots : Irotits feril quam flamma micet. quion peut

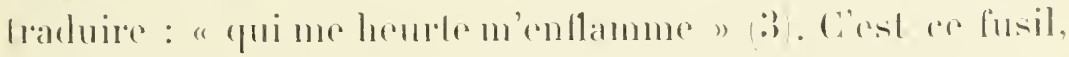
sculpté a profusion sur lestombeamx, les voutes, les slalles,

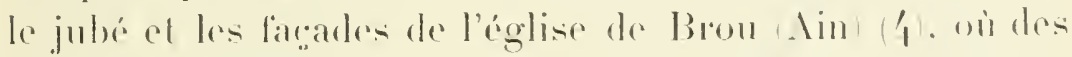
lions le presentenl wolennellement du hamb de lems colonnes. et entrant avereson caillon dans la composition du collier de la Toison dor .j) a cest er lusil, dis-je, qui me parail donner la meilleure idée de la parie oplipure des merfis

(1) Diamores.

(2) L. II, (1), NTr.

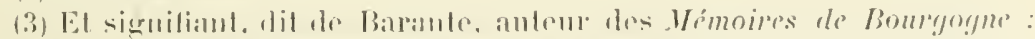

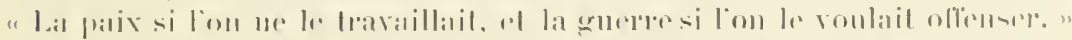

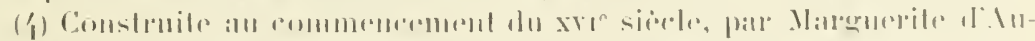

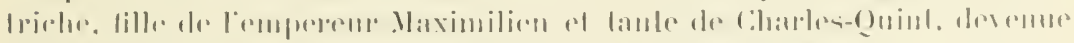

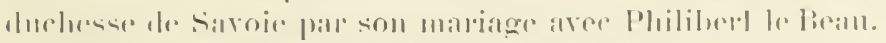

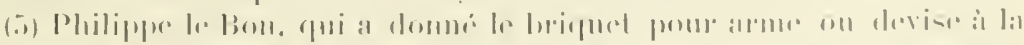

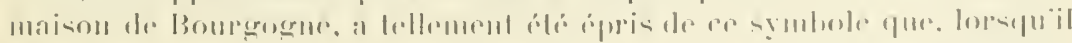

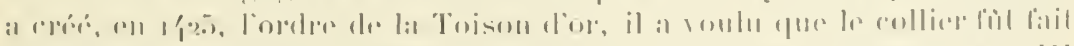

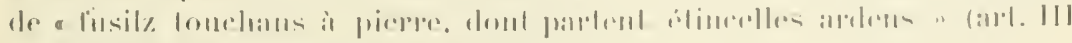

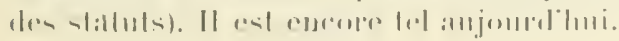


optiques (1), depuis leur chiasma (2) ou cutre-croisement au-dessous du cerreau, jusqu'au bord antérieur de la membrane appelée réline, quiles prolonge à l’intérieur de chacun des deux yeux.

Qu'il me soit permis d'ajouter yue la pereussion, l'altrition des nerf's optiques ne provoguent pas de la douleur, mais des sensalions lumineuses. In coup de poing sur l'oeil, frand il ne le creve pas, "fiat, scelon nne "xpression populaire, voir trente-six chandelles ".3); c'est un choc qui fiat jaillir également des étincelles du briquet.
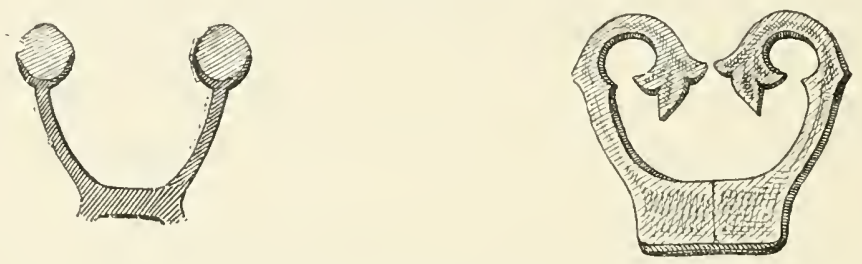

Les nerfs optiques, comme un fusil.

On lit dans Gargantua (ch. xx) "que les larmes venoient is yeulx de Ponoerates et d'Eudemon (4) esclaffís de rire (5), par la véhémente concussion de la substance du cerveau, ¿ laquelle (6) lurent exprimées $(\boldsymbol{7})$ ces humidités lachry-

(1) On trouvera ce briquet, plus on moins finement ciselé, représenté dans le Blason des armoiries de tous les chevaliers de la Toison dor, par J.-B. Maurice, La Haye, 1667 ; l'IIstoire des Ducs de Bourgogne, par DE Baraxte, 1839 , t. I, p. 230 ; le Guide de l'église de Brou, par M. l'abbé II.-P. Bourg, 1896, p. 90 , ele.

(2) Du grec, $\lambda i \alpha \sigma \mu \alpha$, entre-croisenent.

(3) La lésion d'un nerl sensoriel fait naitre des sensations en rapport avec ses lonetions: des sensalions lumineuses, sil s'agit du nerf optique: des sensations anditives, s'il s'agit du nerf acoustique, ete.

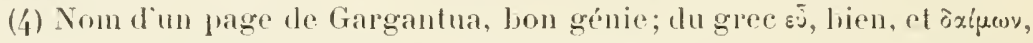
providence, dieu, génie, démon (bon on manvais).

(5) Dans le.tome XVIII du Grund Diclionnaire de médecine, le professeur Adelon s'est étendu asscz longuemenl sur le mécanisme du rire à chaudes larmes.

(6) De laquelle.

(7) Extraites, tirées, du latin exprimere. Je lis encore il la page 352 du tome It de l'Analomie de Diemerbroeck: "Dans la tristesse les mem- 
males et transcoulées (1) jouxte (2) les nerfs optiques n. La joje, la lristesse, ele. délemninent bien un écoulsment plus considérable des larmes, mais ces larmes prot-

brames du currean, conjoinctement arec le cerveau mème, se retirent et stresserrent : "lon vient que les humenrs sepeuses du sang urteriel (auxquelles re viscipe humide al visquens eommunique nu peu de riseidité) sont exprimées des glandes de l'óroree el de la substince monte du correau dans les petits vaisseanx ef daus les poles duquel il so porte beinconp de sang arlériel eomme anssi de la glande pituiluse el des

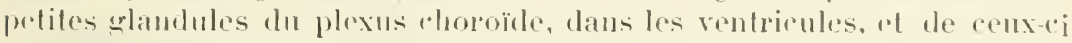
clles fombent en abondance par les productions papillaires, el par les pores de los criblenx, dans les partios longuruses des latrines intérienres;

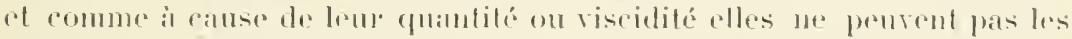

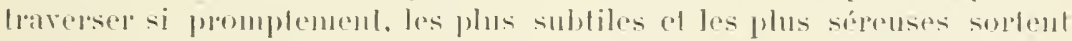

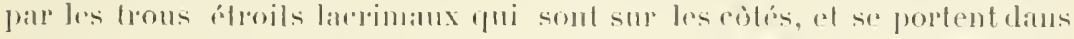
les grauds angles des yeux, oil en lis monillant entiépement, el sécoulant all débeles, colles lorment les larmes...

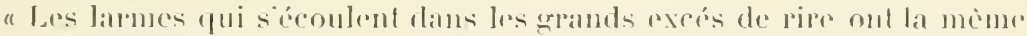

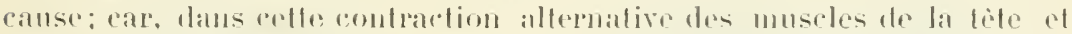
aussi du cerveatu of te ses membrames, il se lait du cepreallu el des

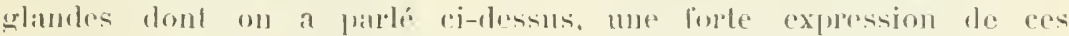

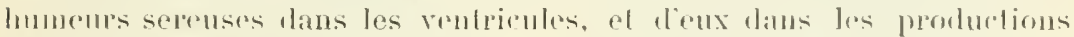

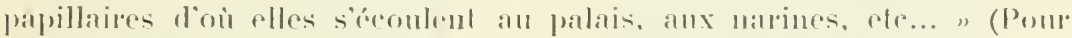
délails complémentaines, voy, plus loin Sóvologie of AnIstore, Pro-

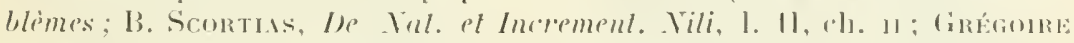

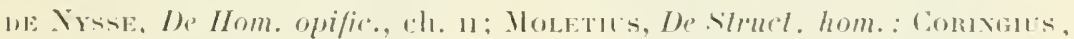

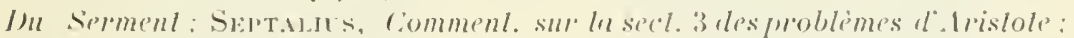

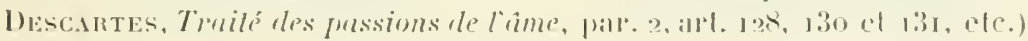

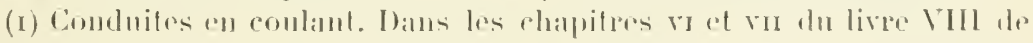

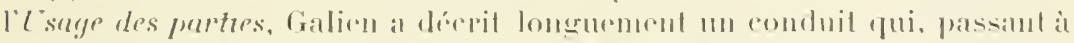

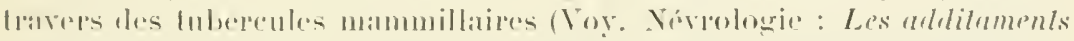

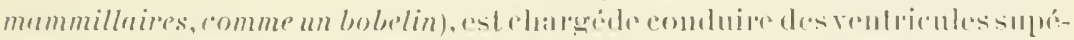

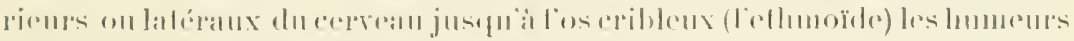

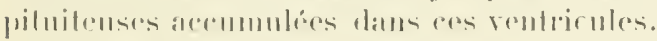

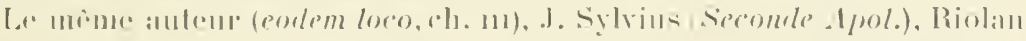

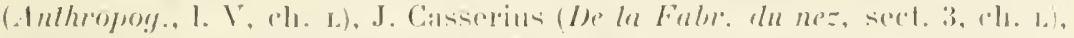

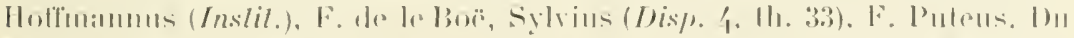

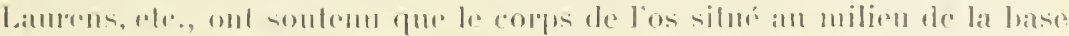

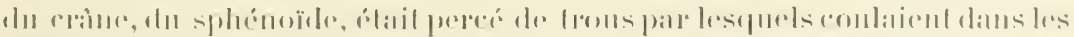

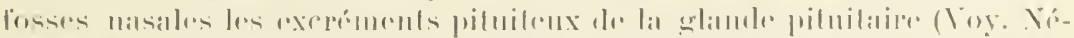

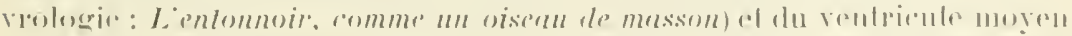

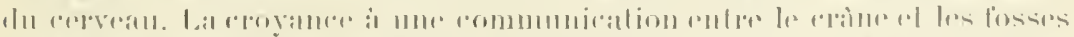

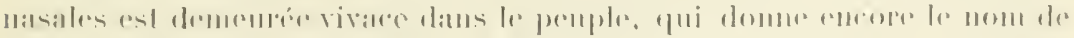

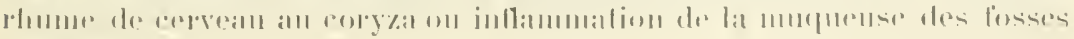
11:14ialris.

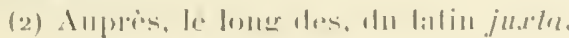


viemnent d'me glandre, dite glande lacrymale, silúe sous la paupiere, al la partic externe de l'orbite ef non du cerreau, "en transcoulant jouxte les nerfs optiques, " comme l'ont eru Galien, Riabelais, ete.

\section{L'epidermis, comme un beluteau.}

La prau est composée de deux eourhes : me couchr superficielle, l'épiderme, el une eouche profonde, le derme; L'ípiderme (du gree ṡai, sur, ed, séfux, peau) est une membrane mince, résistante, criblée de pelits trous correspondant aux poils et aux orifices des glandes qui sécrètent la sueur et l'humeur sébacéc. Ciest la pellicule grisatre que soulive la síposité du vésicatoire.
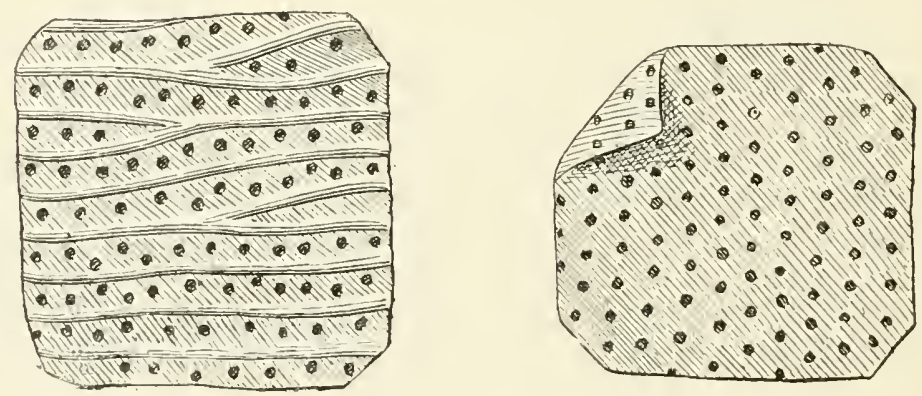

Lepuistermis, romme un belutean.

Belutean, bluteau, blutoir, crible pour bluter ou passer la farine du latin blulare, ancien mot barbare gui signifie vider, parce qu'en secouant le blutoir il se vide insensiblement).

"Loine pétrissoil sa paste; sa femme belutoil la farine (1). ")

Dans le dessin ci-desus, l'épiderme comparé au beluteau est l'épiderme de la paume de la main ru par sa face profonde ì un grossissement de s diamitres. Il représente

(1) L. IT, ch. XIr. 


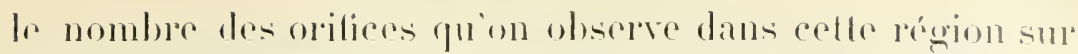
un espace de as millimetres carrós.

Rabelais a-t-il vu ces orilices (1)? A-t-il élí conduit à se prononeer d'une liacon aussi catégorigue par l'existence et la croissance des poils et par le dépót à la surface de la peau de la sueur el de l'humeur sébacée? Comme pour les spermatozoüdes, je ne pus le dire.

Constalation de visu ou induction logique, il n'est pas moins vai qae Maîte françois a émis une opinion qui a élé inoncée ences termes, mais seulementen obli, par .lalpighi :

"Quand on sommet l'ópiderme à l'action de l'eau bonillante, la partie superlicielle ou cornée, tenace, résistante, bien que plus minee de moilié en génépal, se détaclie sous forme de lame, alors que la partie profonde se présente sous forme de lambeanx criblés de bous el ligurant un risean (2)."

Opinion eneore contestée appos les délicates et patientes

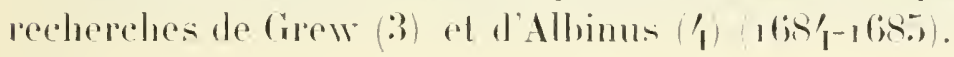

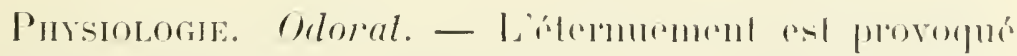

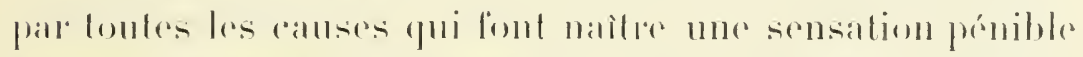
sur la mupuense qui lapisse los losses masales. Pammi les

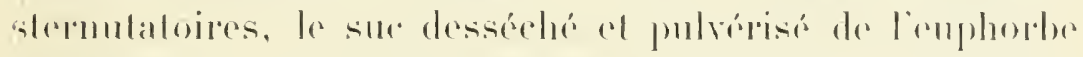

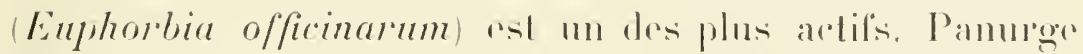

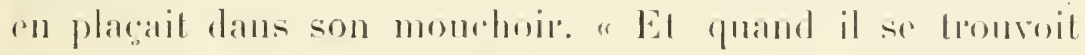
en compagnie de quelepues bonnes dames, il frs melloit sus fre propos de lingerie, demandant : "El cest ourrage, est-il de filandres, ou de llainault?" Et puys liroil son monchene\% (i) disant: "Tenez, tenez, voyez on ci (b) de

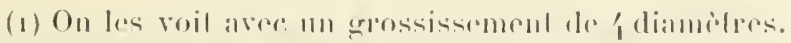

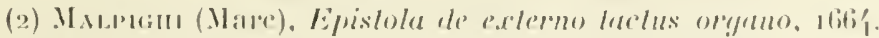

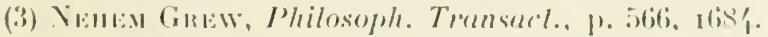

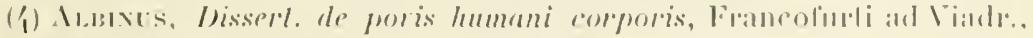

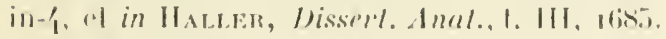

(5) Mourhoirs.

(i) Eu voici. 
l'ouvage : alle est de Foutignan ou de Foutarabie (1)." Et le secouoit bien lort ì lem nez, et les lanisoit esternuel qualle hemres sans repos."

Oüe. - L'oreille, qui distingue la hautemr, l'intensité at le timbre du son, n'en pereoit pas toujours l'origine. Les rentriloques (2) ou engastrimythes (:3) donnent i croine que les paroles quils prononcent viennent du ventre. La ventriloquie (1) a été cultive de tont temps par un certain nombre d'individus ef ceux-ci considéris lanlòt comme des ètres divins et inspirés (.), tantot comme des démoniaques dignes du bùcher (i). Dins le elapitre Lven du live IV, il est question de lenr généalogie :

"Les Engastrimythes soi disoient estre descendus de l'antique race d'Euryeles, et sur ee alléguoient le tesmoignage d'Aristophanes en la comédic intilulée les Tahons, on mousches-gnespes. D'ond (7) anciennement estoient dicts Eurycliens (8), comme escript Plato (9), et Plutarehe on (10)

(1) Fontignan et Fonlambie, villes d'Espagme, sur la Bidassoa. Pal ouvage de Fontignan " on deit entrude, dit Le Duchat, cette sorte de point que le Roman Bourgeois, p. S9, appelle le Pontigna a la dillépence de celui de Gènes".

(2) Parler du ventre, du latin venter, ventue, et loqui, parler.

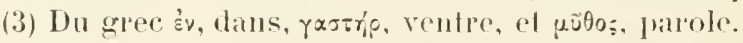

(4) a Le mécanisme de la ventrilornie réside dans une expiration lente el gradue, libée en quelque sorte, expiralion qui est toujomrs précédé dime forte inspiration au moyen de laynedle le rentrilogue introduil dans ses poumons nue masse d'air dont il ménage la sortie. "(Ricnenaxio)

(5) Par saint Chrysostome, Origene, l'areheriegue Eustathi. La célébre Pythomisse d'Endor et maintes antres sibylles envirommaient lenrs prédictions d'un prestige plus éclalanl en usant de lat ventriloquie.

(6) Par Augustimus Slenchus, dit Euguhinus, ́rènur de Ghïsaimo, en Cindie.

(7) Doù.

(8) "Devineurs Engastriens ab Enrycle Engaslrimylho, cujus meminit Scholiast. Aristoph. in Vespis, el Cólins lódig., liv. 8, ch. 10. "Alphabet do l'antenr françois.) Euryelis étail un devin faneux d'Athenes, surnommé l'Engaslrimythe, paree yu'on croyait qu'il avait daus le ventre un démon ‘ui lui rérélait l'arenir.

(9) Dans celui de ses dialognes intitule le Sophisle.

(10) Aı. 
live de la Cessation des oracles. És saincts décrets. 26, 4. 3 sont appelés Ventriloques ; el aussy les nomme en langue ionique Hippocrates, lib. 5., Epicl. (1), comme parlants du ventre. Sophocles les appelle Stemomantes (2). C'estoient divinateurs, enchanlenrs, et abuseurs de simple peuple, semblants, non de la bouche, mais du ventre parler et respondre ì cenlx qui les interrogeoient. Telle estuit, rnviron l'an de nostre benoist servaten (3) 1.51:3, dacobe Rodogine (4) ilaliane, femme de basse maison. Du rentre de laquelle nous avons souvent ouï, aussy ont aultres inthuis en ferratre (.) el ailleurs, la voix de l'esperit immunde, certanement basse. foible, et petite: foutesfois bien articulíe, distincte, et intelligible, lors que, par la curiosilis des riches seignems et prinees de la Gaulle Cisalpine (i). elle estoil appelée et mandée. Lesquels, pour

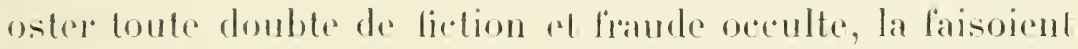
despouiller loute nue, et luy laisoient clorre la bouche el le nez."

lue. - Les lomgurs lechures, les traraux délicits réclamant une contlatelion permanente ef persistante du muscte ei-

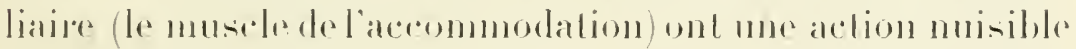

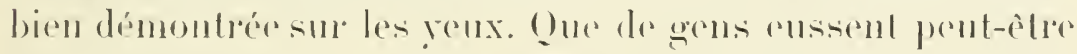
en une bonne vore qui l'onl perelue par suile d'une applicalion trop conlimue dans lent enlinee!

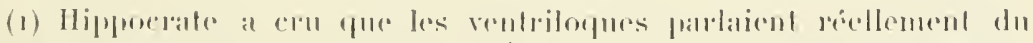

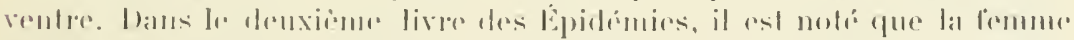

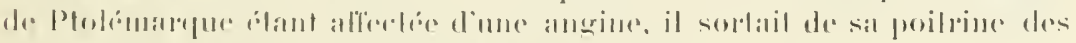

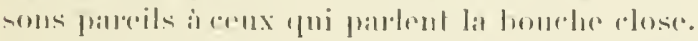

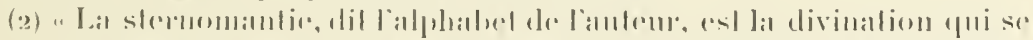

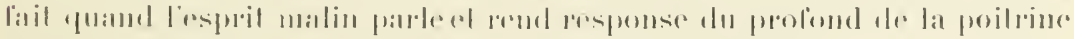

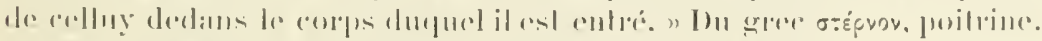

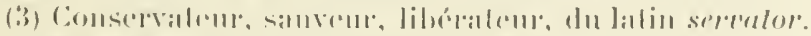

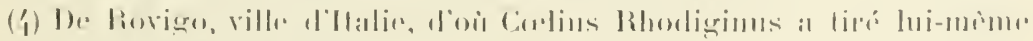
son strmom de Rlonliginus.

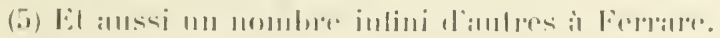

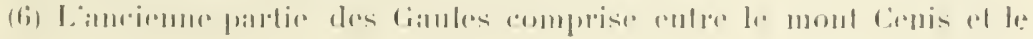
liubicon, 
Cetle verité est proclaméne dime facon plasisante an chapiter " Des faicts du moble Pantagmel en son jemne age ". "An regard de se rompre fort la teste ì estudier, il ne le laisoit mie (1), de paour (2) que la rue luy diminuast. "

Rapprochous de ce chapitre celui oil est notí l'effet désastreux quia sur la rétine, dans les pays couverts de neige, la réverbétation de la lumire. "Le blanc extériorement (:) disgrege (4) etespart (o) la rue, dissolvant manilistementles esperits visils (bi, seton l'opinion d'Aristoleles en ses problimes (7). el des perspectils: el le rogez par expérience. quand rous passez les monts converts de neige : en sorte

(1) Pas.

(2) De perm:

(3) Extérientrement.

(1) Separe, dirise, disperse.

(5) Wème sens que mot prócédent. "Éparpille, diverge "glossaire de L. Barre.

(6) Galien, snivant en rela la prosée d'Hómophile, dit (1. Volll de

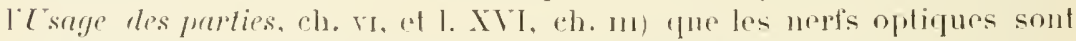
creux, ont un trou manifiste. Plempins, an liver I de son Ophlathalmographie.

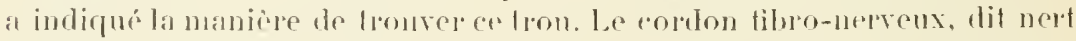

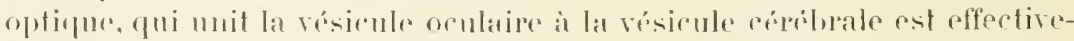
ment creux. (Voy, Virvologie: Le's nerfs, comme un robinet.)

Tous les philosoples et les médecins du moyen àge, el Descartes luimème (Voy. sa ldoplrique ot anssi sou liver lle lllomme, art. 18, 19 et 20) ont pensé due les yeux élaient podevables de la faculté do voir aux esprits animaux on risifs qui y aflluaient en plus on moins gramele quantitc par la carité ynoffre chatue nerle en question. Riolan a enseignó (Animall'. sur Bauhin) yue la jouction du nerfoptique thoit et dn nert optipue ganche axait lieu par lintermébiaire d'un petit canal ayant la forme de la lettre II. Bauhin, Nereatus. Senuede et plusienrs autres ont affirmo que rette jonetion avait lien par fe málange tolal de la substance des deux nerfs pour que les esprits risifs pussent passer aver facilite d'un wil dans l'autre pone angmenter l'ótendue ef laculé de la vision, "non seulement dans les persomes saines, mais encore chez les per-

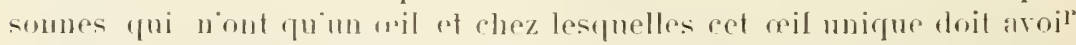
la fore te deux." Mrjstote, Galien. Alexander ont declapé que ces spprils visifs, vicies, de manvaise qualiti, temissaient les mimoirs en sortant des yeux ot communipuaient par contagion tophthalmie.

(7) "La couleur vertr médiocrement excite el esment l'organc de la rene, partant luy domne soulagement ef le conforte : ce que peut laire la coulem blanelur, attendu 'puclle excite, esment et change grandement 
que rous plaignez de ne powoir bien regarder, ainsy que Xemophon escript estre advenu a ses gents : et comme Galen expose amplement libon X de L su partium (1). "

A ces lignes relatives a l'organe de la rision quion releve dans Craryantua et I'antayruel il faut ajouter les -nivantes:

"Gialen, lib. !) de l'Lsage de nos memberes (2), diet la

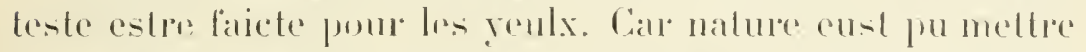
mus lestes anx genoulx ou aux coubles :3); mais ordomnant

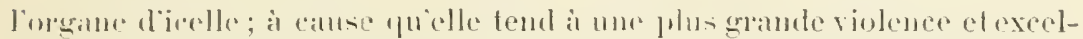

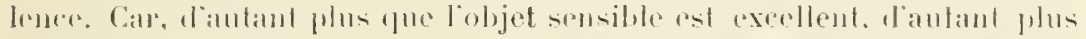

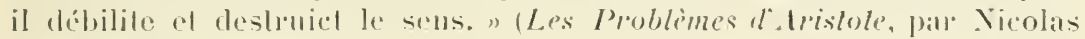
BONFox-)

(1) "Ralpelez-vols comment une lumiere vive et brillatule liatigne les

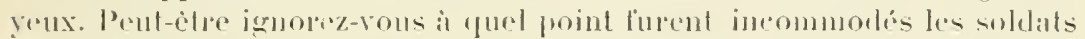

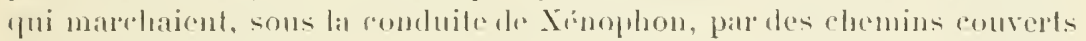

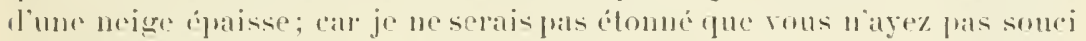

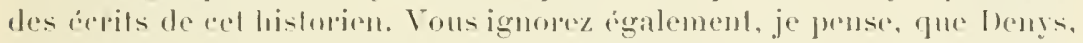

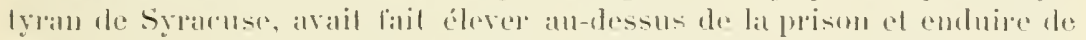

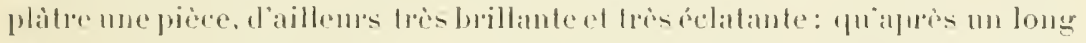

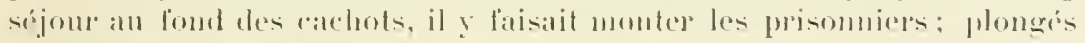

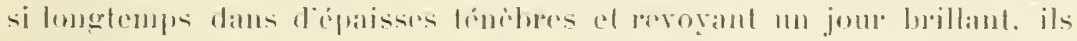

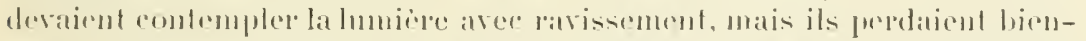

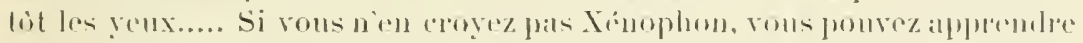

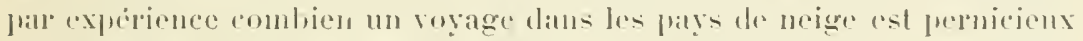

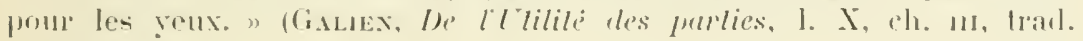

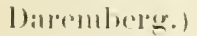

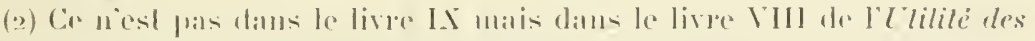

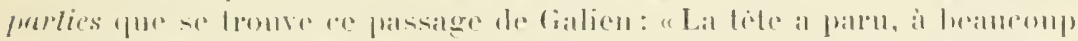

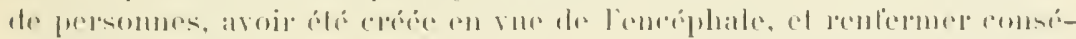

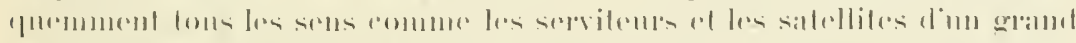

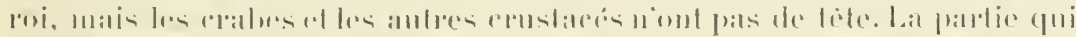

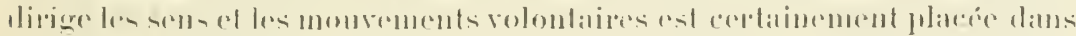

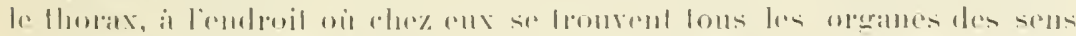

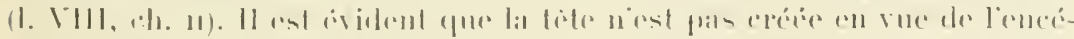

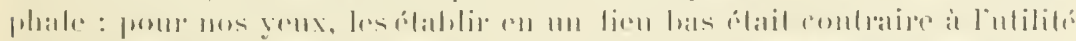

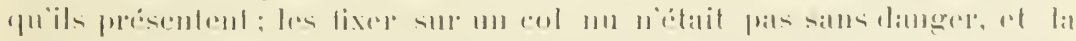

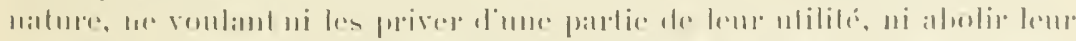

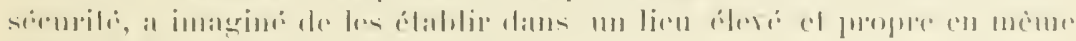

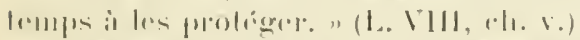

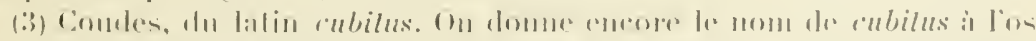

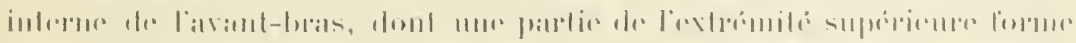

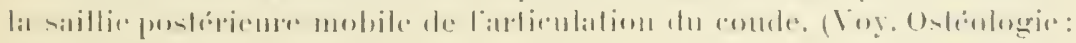
loes fociles, comme fancilles.) 
les yeulx pour descouvril au loing, ficha (1) la teste, comme rn un baston an plus hault du corps; comme nous voyons les phares et haultes tours sus les haves de mer estre érgées, pour de loing estre vue la lanterne (2). "

Toncher. - Une des caractéristiques du génie de Rabelais, c'est de passer du noble au lamilier, du sévère au plaisant, sans gêne et sans disparate. Jamais écrivain na a fait plus lestement et plus facilement volte-face. La sueur humaine est salcée. Elle est composée d'eall, des sels ordinaires du sang (le chlorure de sodium (3) domine : 22 P. 100 ). de principes gras el de plusieurs addes. Partant de là, Maître François a expliqué, avec un dévergondage inouï d'imagination, pourquoi la mer a un pont de saumure. "Xu temps que Phoebus bailla (4) le gouvernement de son charrot lucitique (5) à son lils Phacton (i), ledict Phaeton, malapprins (7) en l'art, et ne scavant (8) ensuive la ligne ecliptique entre les deux tropiques de la sphère du soleil, varia de son chemin, et tant approcha de terre, qu'il mist à sec toutes les contrées subjacentes... Adonc la terre fut lant eschaufíe, qu'il luy vint une sueur énorme, dont elle sua toute la mer qui par ee est salée : car loute suem est salée. Ce que vous direz estre vrai si vous vouler taster de la vostre. ")

Organe d'absorption, d'exhalation el de tact, la pean, pour conserver l'intégrité de ses fonctions, a besoin d'ètre débarrassée fréfuemment de la poussière et des produits qu'elle sécrète (humeur sébacée, sueur, cellules épidermiques). Quand sal puissance éliminatrice est aflaiblie, des

(1) Fixa, plaça.

(2) L. III, eh. vir.

(3) Le chlorme de sodium est le sel de cuisine.

(4) Donma accorda (1. 11, ch. n).

(5) Qui porte la lumiere, lmminenx, du lafin lucifer.

(6) Placílon, dils d'Apollon et de Clinòne, nue des Océanides.

(7) Mal appris.

(8) Sachant, dı latin scire. 
aceidents morbides apparaissent: si elle est recourerte d'un enduit impermóable, la mort survent (1).

A une éporque oì la propreté rétait loin d’ètre considérée comme mo recommandation dans les collegges ( 2 ), les cloitres et mime les palais $: 2$, l'auteur de Gargantua et de Ponlayruel a insisté sul la nócessité de la balnéation, el mème sur les avantages de la firetion. du massage et de la sulation.

Devant le manoir des Thélémitrs " estoient les nata-

(1) Lin voila mu exmple éclataut. On cólobait à Palerme me tète populaire, mélange bizare de traditions mythologiques el de pratiques chrélienues. An nomberles spectactes olferts at la curiositi des habilants ef des blamgers aceomrus de toutes parts, on admirait me brillante cavalcade composion de grompes de cavaliers splendidement costumés ot de chats olmés de trophées et d'emblemes allégoriques. Parmi ees

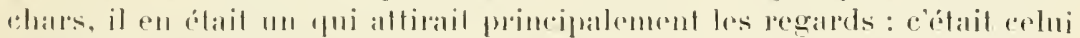

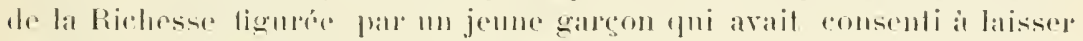

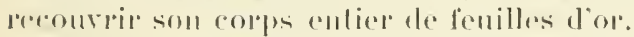

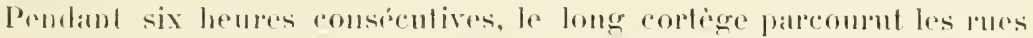
de la ville, soulevaut sur sou fassage les exclamations joyeuses de lat

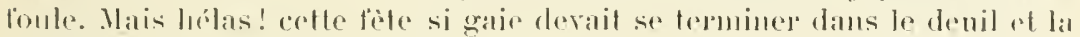
lristesse.

Quand on roulut retires le panre entant de son enveloppe dorée, il

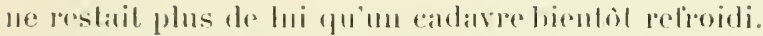

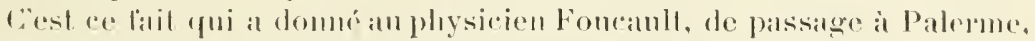

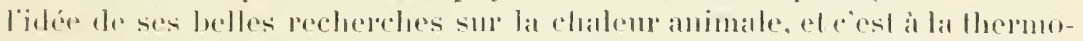

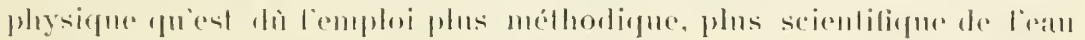

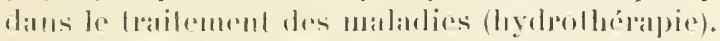

(2) "Sanl" la chaire du protesseur, les chasses navatent au xro siocle ni

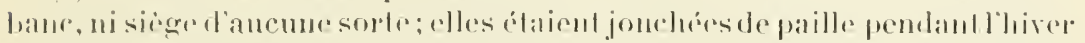

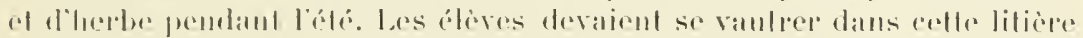

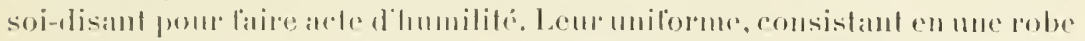

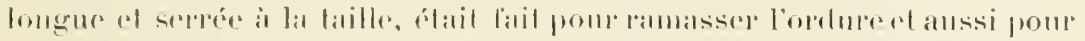

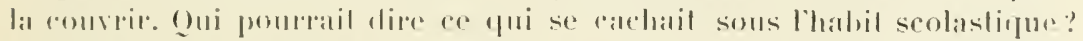

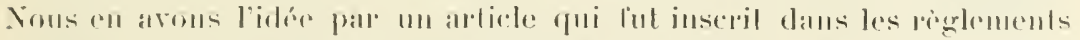

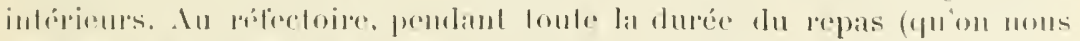

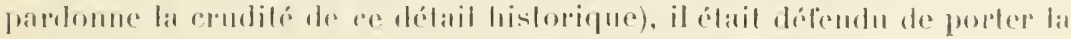

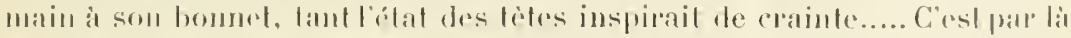

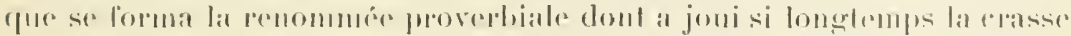

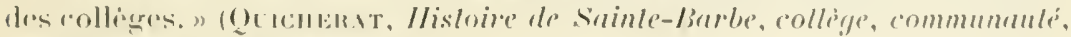
instilution: Paris, Harlurlle.)

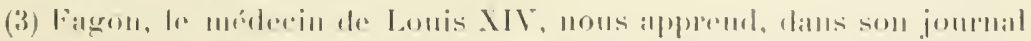

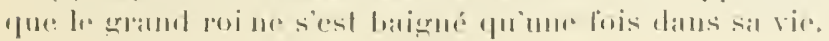


toires (1), avec les bains miriliques à triple solier (s), bien garnis de touts assortiments, el foison d'eau de myrrle " (:3). "Gargantua nageoit en profunde eau, à l'ondrojel, à l'envers, de eosté, de loul le corps, des seuls pieds, une

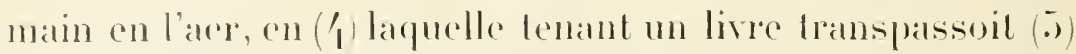
loute la riviere de secine sans icelluy (i) moniller, el lirant par ses dents son manteau... Puis d'une main entroil par grande force en un basteau : d'icelluy ( $T$ ) se jectoit derechef en l'eau, la teste la première : sondoil le parfond (8), plongeoit és alysmes el goulphres.

"Issant de l'eau (a), roidement montoil encontre la monlagne, el dévaloil (10) aussy franchement, ete."

Puis:

"Le temps ainsy employé, luy liotlé, nettoyé et refraischi d'habillements, tout doulecment retoumoit."

N'est-ce pas la le grand hain ou bain d'immersion, pris dans une riviore on dans mor piscine de natation - ainsi

(1) Lieux oì lon nage, du latin nululoritu.

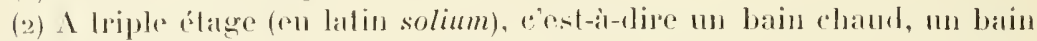
liede el un bain lipoid, dans chacun destguels l'ean blait distribuce au moyen de camaux telle quil lal lallail.

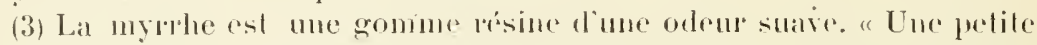
quantite dans l'ean forme un liquide exeellent pons laire des lotions stimulaules." (1) E. Brémoxb.) Chez les Hébrenx, on frotlait d'huile of de uyrohe pendant dix mois les filles destimées an roi.

(1) Aree laquelle.

(5) Travorsail. Sons la dise ipline de ses premiers préecplems sophistes, Gatrantua stait tres sale. Il se peicuail aree $n$ peigne quelque pen pri-

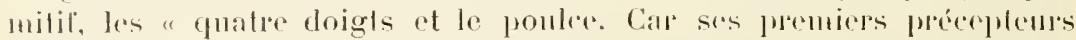

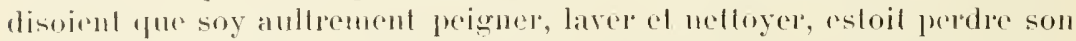

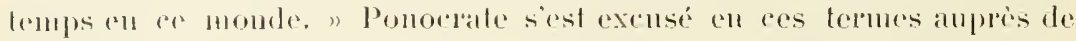

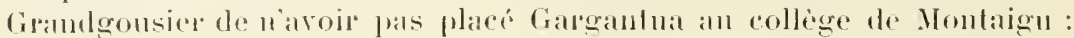

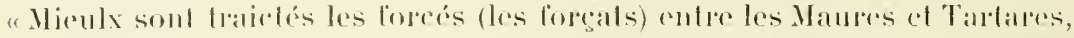

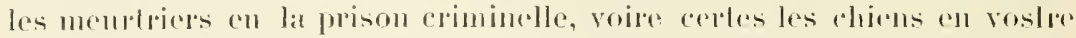
maison, que ste sont res malautrus andict collége de poutlorice"

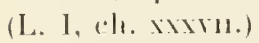

(6) Sans mouiller celui-ci, ce live.

(7) be colui-ci, de ce bateau.

(8) Le forted.

(9) Sortant de l'eatu.

(10) Descendait. 
yue le recommandait Priessnitz, le fondateme de l'hỵdrothérapie, - bain d’immersion all sortir duquel, bien essuyé, énergiguement frietionné at promptement habillé, on ra latire me promenade phus ou moins longute en marehant plus oll moins vite? 


\section{NÉVROLOGH OU ÉTLDE DES NERFS}

\section{Quaresmeprenant avoit:}

Les membranes, comme la coqueluche d'un moine.

La cervelle, en grandeur, couleur, substance et vigueur, semblable au c... gausche d'un ciron masle.

Les ventricules d'icelle, comme un tirefond.

La voulte, comme une goimphe.

Le conare, comme une veze.

L'entonnoir, comme un oiseau de masson.

Les additaments mammillaires, comme un bobelin.

L'excrescence vermiforme, comme un pilemaille.

La nuque, comme un fallot.

La mouelle, comme un bissac.

Les nerfs, comme un robinet.

Les esperits animaulx, comme grands coups de poing.

Les esperits vitaulx, comme longues chiquenauldes.

Les membranes, comme la coqueluche d'un moine.

Les membranes (du latin membrana, parchemin), les méninges, sont des gaines qui protìgent les centres nerveux. Elles sont an nombre de trois. Rabelais n'en a connu que deux. Frère Jean des Entommeures "tranchit les deux méninges "d'un des archers chargés de sa garde. La troi-

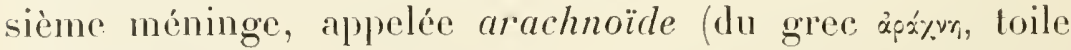
d’araignée, et zĩoso, ressemblance, qui ressemble à une toile d'araignće), fort mince, transparente, très difficile ì isoler 
entièrement, n’a été décrite que longtemps après la mort de l'auteur de Grarganlua. L'inflammation des membranes constitue la terrible maladie appelée méningite.

Coqueluche, capuchom, partie de lhabit de restains moines qui leur conve la tète. On dit familierement prendre la capuchon, pour se faire moine. Un certain nombre d'étymologistes arancent que le nom de eoqueluche, déja attribué, en 1419, du temps de Charles VI, au catarthe spasmodique el conlagieux des bronches (MEzeral), dérive
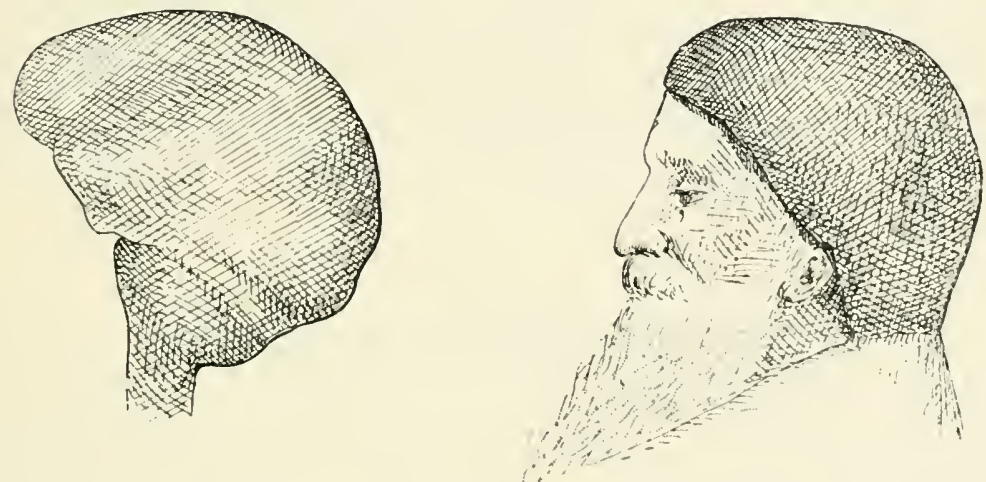

Les membranes, comme la coqueluche d'un moine.

de la conpucluche (1) qu'ont portín primitivenent les enfants atteints de cetle maladie. Comme celui des moines, a capmehon était généralement rond.

Les membranes enveloppent le cervean à la maniere

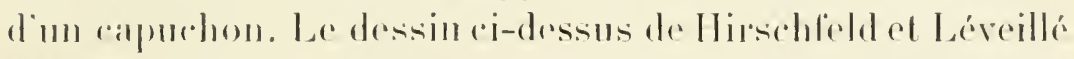

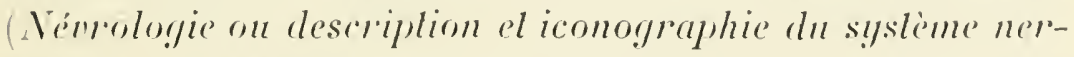

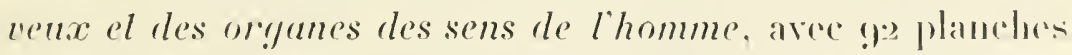

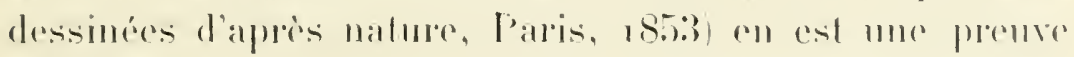
Evidente.

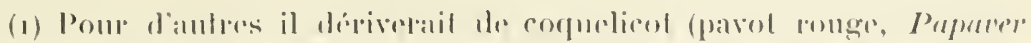

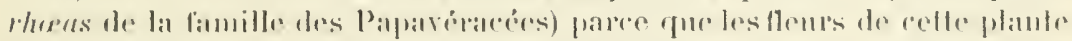

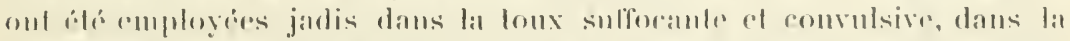

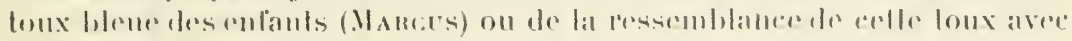

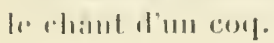


La cervelle, en grandeur, couleur, substance et vigueur, semblable au c... gausche d'un ciron masle.

Le testicule ganche est plus rolumineux que le testicule droit, mais constilué, ainsi que lui, par une substance d'un gris rougeàtre, assez peu consistante, dite pulpe testiculaire.

Le cervean des aliénós et des idiols ast revenu sur luimème, piqueté de rouge al ramolli.

En établissant un parallèle entre la cervelle de Quaresmeprenant el la glande génitale d'un ciron, un des animaux les plus intimes de la crialion. Riabelais contirme ce qu'il a domné antérienrement ì entendere de l'élat mental du prersomnage susdit. En choisissant la glande gauche, plus grosse que la glande droite (1), il tempere légèrement sa comparaison.

\section{Les ventricules d'icelle, comme un tirefond.}

Le cerveau est creuse de cavités, dites ventricules. Cies ventricules sont an nombre de trois : un moyen, rertical, plus large a sa partie infirienre quà sa partie supérieure ct yui est moins une cavité qu'une fente (fissura media, (iordon, et deux latélaux. horizontaux, communiquant entre eux par l’intermédiaire du précódent (:s).

(1) Maitu Francois s'est lros hien aperen que le testicule gauche est

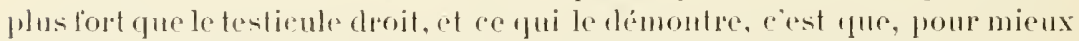
marpuer son antite a frère Jean, Panurge en lui parlant a ajouté plu-

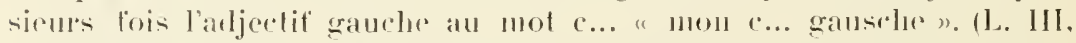
ch. xw1.) Ce mot a encore mu sens anical dans le peuple.

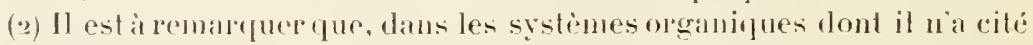
que qurlques parties, lo savant anatomiste a toujours choisi colles qui ćlaient considétés de son tempre comme les plus importantes.

En myologie: Je diaphuragme.

En angéiologie: le corur. le siège des esprits vilaux; lhexagone arterice de Willis, pall lefunel ces esprits vitam étaient transmis an cerveau pour derenir animaux; l'artire pulmonare, les carotides, les

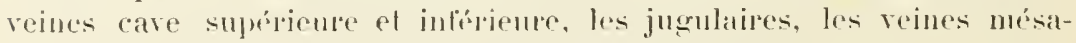

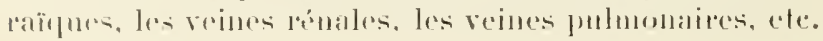

En névologie: la voute soutenant toute la masse du cerveau; les ven- 
Tire-fond, instrument d'acier aver lequel le chirureien enleve la pièce d’os qu'il a sciée avec le trépan.

Pour démontrer l'exactitude alssolue de la romparaison de Maitre François, il me suflira d'aceoler Voy. le dessin ci-dessons, une coupe transversale ef rerticale du
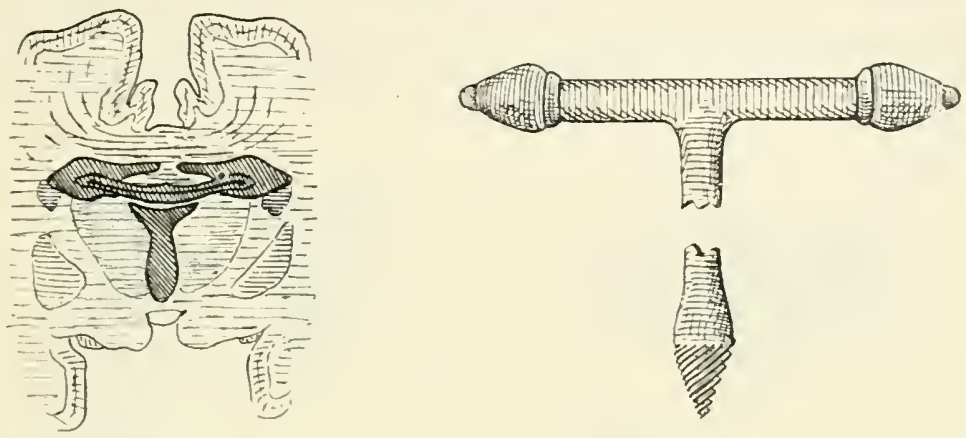

Les tentrienles tirelle. comme un tirefond.

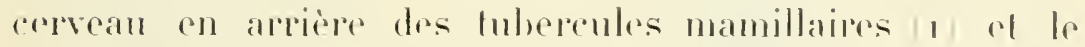
time-fond. qui esl dessiné dans le $\mathrm{X}^{\mathrm{e}}$ live des ourres

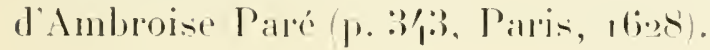

\section{La voulte, comme une goimphe.}

I a coulle, la ronte à trois piliers, le trigone céróbral. est

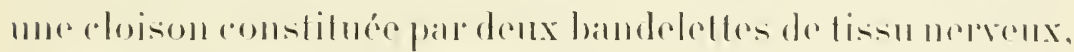

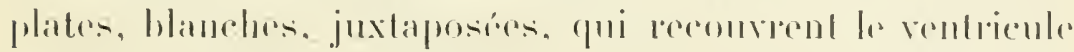

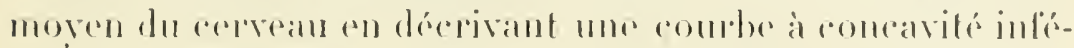

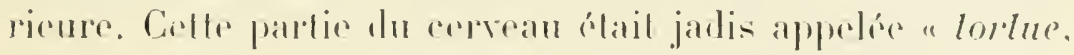
par la raison qu’il semble, dit Diemerbroesck. quim la

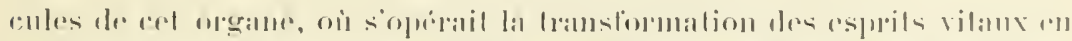

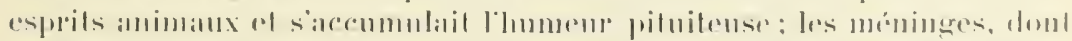

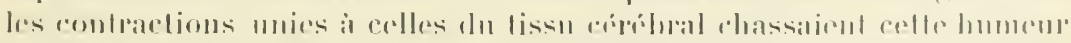

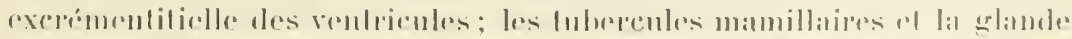

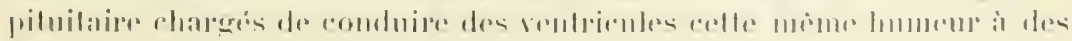

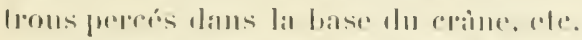

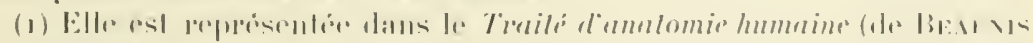
(1) 13.)('(1).1R1). 
maniére des tortuës, ou des rontes dans les bàtiments, elle soùtient toute la masse du cerveau qui est appuyée dessus, et cela alin que le troisiéme ventricule n’en soit pas comprimé » (1).

Coimphe; róksusts, ell grec, signitie assemblage, reunion de plusieurs pièces en une seule. On donnait autrefois le nom de goimphe à un bonnet de femme composé de divers morceaux. J'ai entendu, dans le Morvan, dire encore goim-
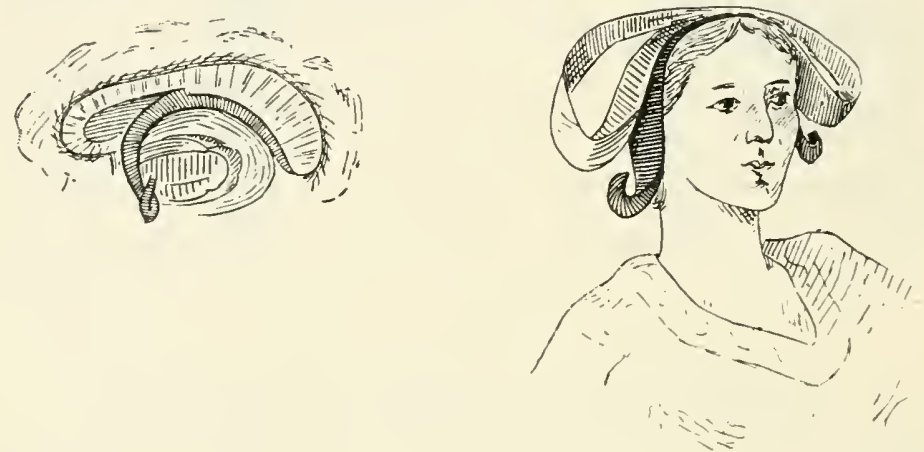

La voulle, comme une goimphe.

pher sainte Catherine, pour : coilfer sainte Catherine. Iuspue sous le rigne de François Ier, les femmes ont porté une coiffe sur laquelle était posée une bande d'étofle, dont les pans pouraient ètre et étaient généralement relevés sur le sommet de la tête, ainsi que le montre un des dessins (2) ci-dessus. Ces pans relerés donnaient plus de liberté an cou et plus de coquetterie à la coiffure.

\section{Le conare, comme une veze.}

Le conare, la glande pinéale, est une petite excroissance épithéliale avee quelques éléments nerveux, siluée sur la

(1) D) EMERBRoeck (loc. cil. supri, 1. 11, p) 2/1).

(2) Ciest la eopie de la coilfure d'une des suivantes de Marguerite de Valois, peine de Navare, serur de François I ${ }^{\mathrm{r}}$, auteur de l'Ileplaméron. 
ligne médiane du cerreau, en arrière du ventricule moỵen. Galien et Oribase l'ont comparé à un còne (d'où ses noms. divers de conare, conarium, xavrároy, còne: pinea, pomme de pin, etc.).

La glande pinéale est un restige de l'aril pariétal impair at médian des sauriens ignanides. Descartes en arait lait lr. siege de l’àme.
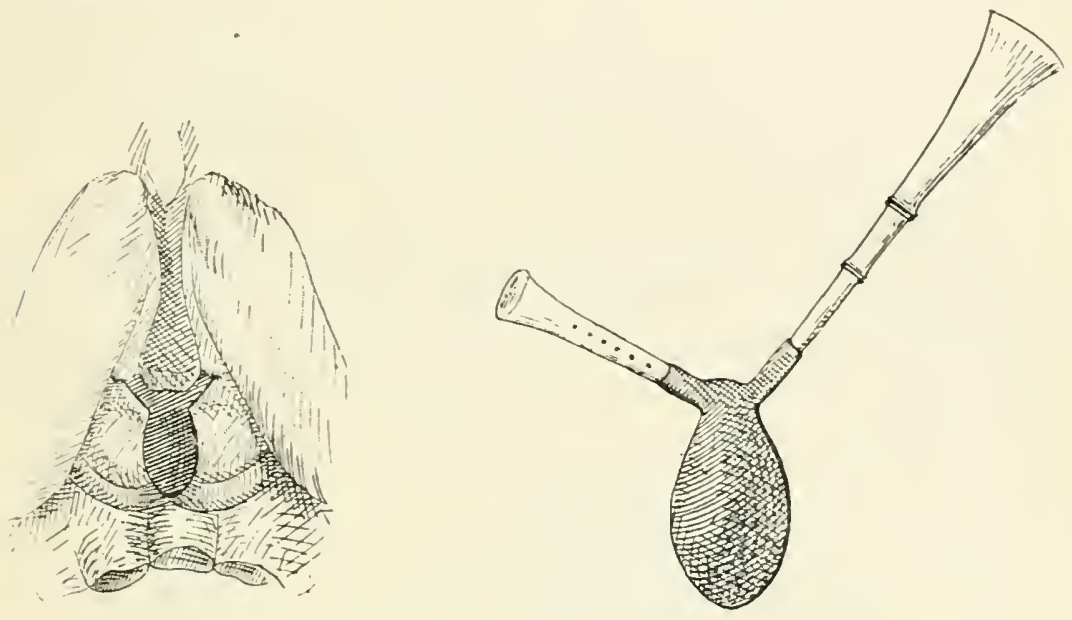

Le connre, comme une veze.

leze, cormemuse, en langage poiterin el saintongeois. livers commentatours écrivent un reze. En patois poitevin el samtongeots, ce not est féminin. Il vient, selon Esmangarlet el Johannean, de resica, vessie.

Les Andouilles fanourhes marehaient au eomhat "auson des rezes et piboles 1 .

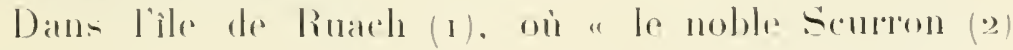

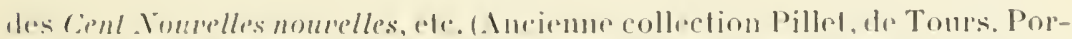

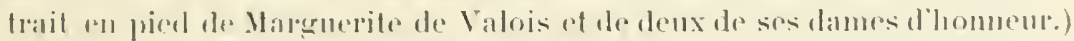

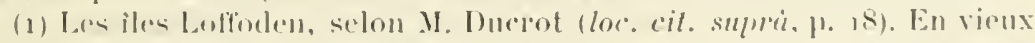

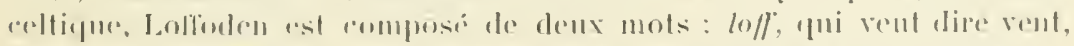

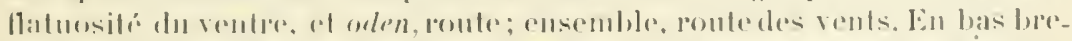

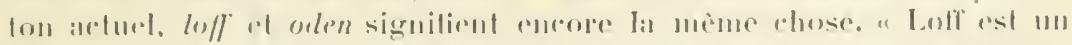

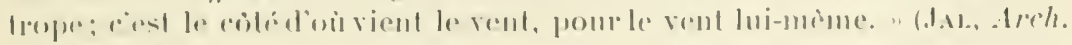
na1\%. p 1. 17\%.)

(2) Un des mathes de Rabelais. Son nom exact est Silyrent ainsi 
mádicin, passant un jour, nous comptoit que le Cierce (1) est si fort qüil renverse les eharmetles chargies... on aroit robé (2) an roy une reze pleine du vent propre que jadis à

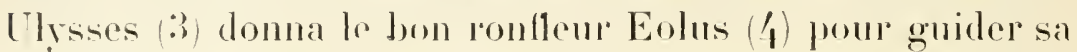
naul (.) en temps calme. Lequel il gardoit religieusement, comme un antre Sangreal (6), et en gurrissoit plusieurs énormes maladies. "

"Tellement que reste mariée ne voulut jamais bouger de là oì elle estoit, que les menours ne l'allassent prendre et que les piboleux el vezeurs n'eussent soufflé là. " (BouCHET, SERÉ, 5.)

La glande pincale est une réduction minuseule du sac: de peau de la comemuse, distendu par le soultle du musicien. Pour plus de précision scientifique et pour mieux firre ressortio l'identité de forme des deux objets comparés, jai fait reprosenter, dans les dessins qui viennent à l'appui de ces ligues, la glande pinéale telle qu'elle est figurée dans la seconde idition du Systeme nerrenx de lhomme, de Van Gehuchten (Lomvain, 1897, p. 115), et me cornemuse poitevine du xre sicele dont le tuyan d'embouchnre, rejete en arriore, est masqur par le sac. Cette vèze appar-

quen lémoigne linscription suivante, grảive sur la porte du théatre anatomique que llempi II tit construive à IIoutpellier : Cubuntibus Johanne Schyronio, Antonio Saporta, Guillielmo Rondeletio el J. Bocalio 1556. (Voy. Tessier, addit. ì l'öloge de G. Rombllet, el l'llistoire de l'I'nileresite de Monlpellier, de J.-E. Strobelger; Nuremberg, 1625, en latin.)

(1) Le vent circins (onest-nord-onest), qur désiraient les penples de la Narbonnaise pour purger lem pays des manvaises exhalaisons.

(2) Dépolié, vole.

(3) Ulysise, fils de Laërte et dinticlée, roi d'Ithaque, dont Homène a narró les aventures daus l'Odlyssée.

(1) Énle, fils dr Jupiter, dien des vents ot des tempètes. Il rignail sur l'Eolie (anjourd'hui les îles Lipari), et fit cadean à Ulyse d'outres dans lespuelles itaient renfermés les vents contraires à sa navigation.

(5) Navile, du balin navis.

(6) Sanyreal ou saint Granl, espece de calice dans lequel, suirant l'Éeriture, Joseph d'Arimathie recueillit le sang qui conlait du corps du Christ. On entend aussi par ce nom le grand plat creux dams lequel on prétend que Jésus décompa l’agnean pascal. 
tient à une famille poiterine amie de la mienne. L'n instrument analogue. mais avec trois turaux apparents, est scupté en ronde-bosse sur le chapitean en bois d'un des piliers de la pelite porte de la facade de la maison d'Alam (xve siecele), regardant la place Sainte-Ciroix, à Angers. On en voit un autre à quatle tuyaux entre les bras d'un des musiciens du lablean le Coneert de Famille de Jacques Jordaens.

\section{L'entonnoir, comme un oiseau de masson.}

L'entonnoir est un cordon rougeatre, cremx, comprimé d'arriere en avant et ivasé supépienrement (1), placé andessous du ventricule moyen. L'entomnoir, eneore appelé choana, infundibulum, lige du corps pituitaire, est terminé
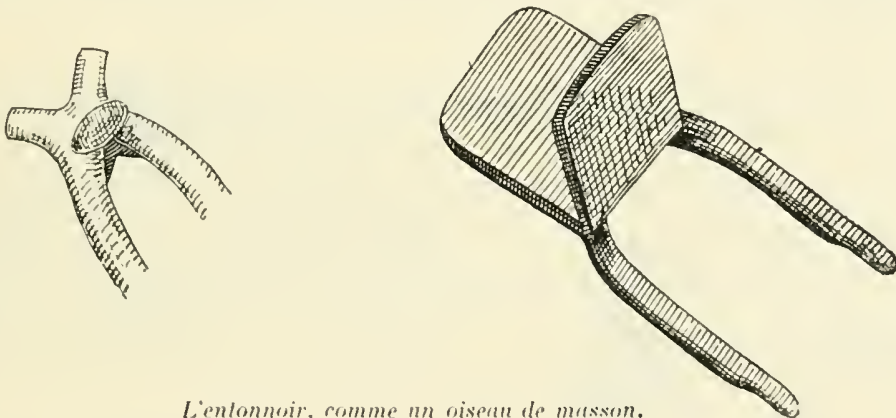

Lentonnoir, romme nn oisean de masson.

par un corps grisitre ovalaire, formé d'un lobule épithélial ef d'un lolule glandulaire intimement muis. le eorps pituilaire. Les anciens anatomistes ont donné à ces deux lobules intimement muis le nom de corpse pituitaire, pareer

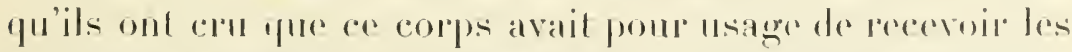
huments piluiteuses amassées dans le forsieme rentrienle on ventricule moyen du cerveau, et de las conduire a des

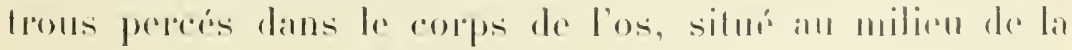


base du cràne, du sphénoïde, d'vì celles s'écoulaient dans les fosses nasales. Il est dénommé glans pituitam excipiens par Vésale.

Oisean de masson, sorte de lolte composée de deux planchetles disposées en éfuerre, ot qui sert ì porter le mortier sur les bathments en construction. On retrouve l'oisean de macon sur les bas-reliel's de la colonne Trajane el sur plusieurs de nos monuments des premiers temps du moyen àge. Dans quelques provinces de France, les macons emploient encore cette hotte, et partout les couvens en font usage pour porter les ardoises sur les toits.

L'entonnoir, la glande pituitaire, les bandelettes optiques cl le chiasma des nerf's optiques rappellent l'oiseau de macon. Jadis, quand on eroyait que la glande pituitaire était presque carrée, plus dure et plus plate (1) que les autres glandes, la comparaison en question a pu paraître bonne.

\section{Les additaments mammillaires, comme un bobelin.}

Les additaments mammillaires, les tubereules mamillaires, sont deux petits corps sphériques, très rapprochés l'un de l'autre, qu'on trouveà la lace inférieure du cerveau.
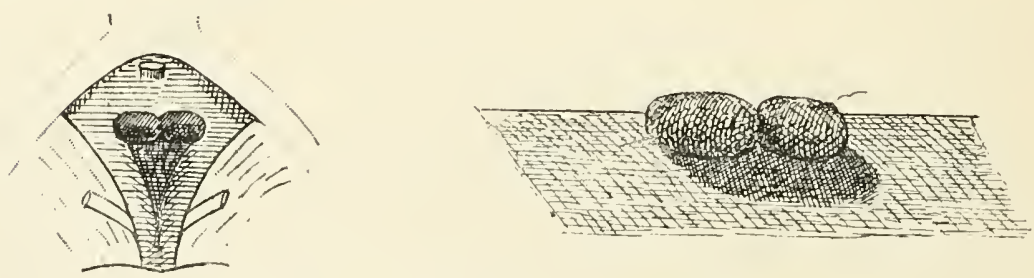

Les addituments mammilluires, comme un bobelin.

Additament vient du latin additamenlum, addition, augmentation, et mammillaire, de mammila, petite mamelle, parce que les Anciens " nont pas mis ces productions all nombre des

(1) Toy. Hemerbroeck, loc. cit. supmit, t. II, p. 270. 
nert's (1), qu'elles sont très blanches, et que l'extrémité de chacune d'entre elles est ronde en forme de mamelon ". (Dienerbroeck.)

Bobelin, peloton de laine ou de fil (2). On dit encore bobeliner ou boubeliner, pour bobiner, pelotonner.

Charpe tubercule mamillaire est semblable à un petil peloton de fil blane. L'analogie est d'autant plus évidente que chacun d'eux est formé par l'enroulement sur' elle-même de l'extrémití antérienre d'un des faisceanx nerveux qui entre dans la composition de la voùte du cerveau. (Casserius. Ciruveiliner, Luss, ele.).

\section{L'excrescence vermiforme, comme un pilemaille.}

I. exerescence vermiforme, excroissance qui a la forme d'un rer, excrescentia nermiformis en latin. On l'appell.
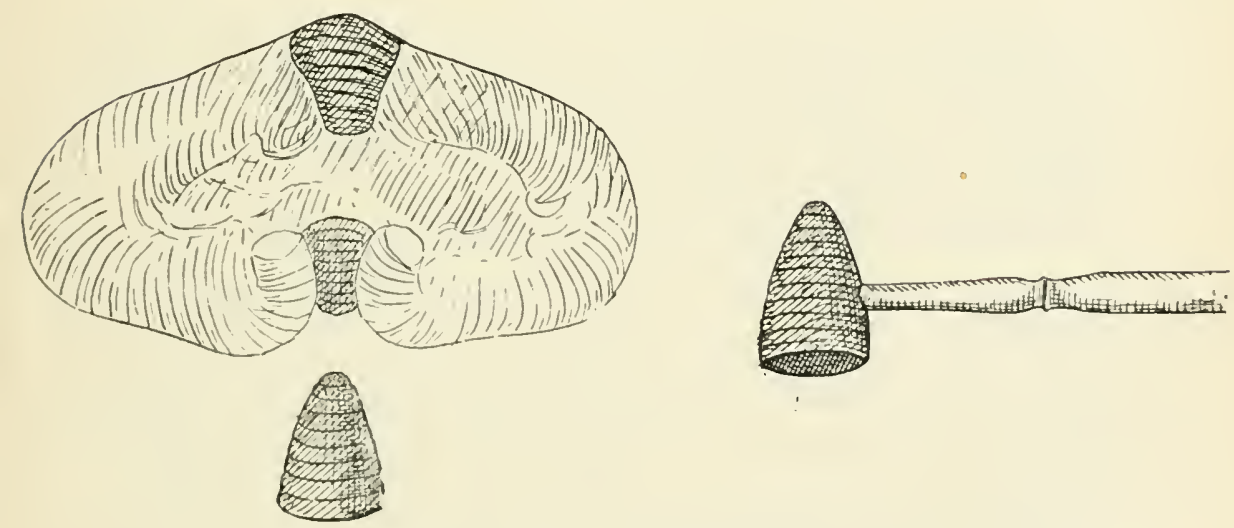

Lexcrescenes lermiforme. comme un pilemaille.

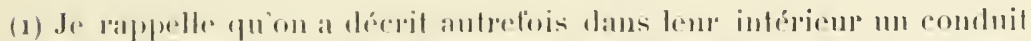

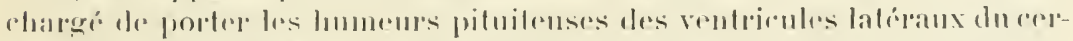

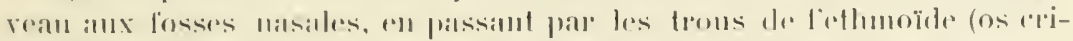

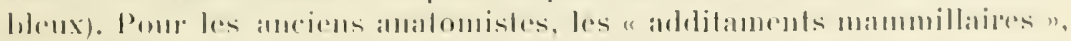

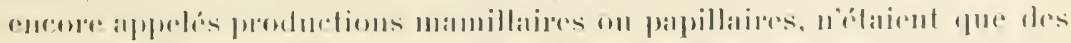

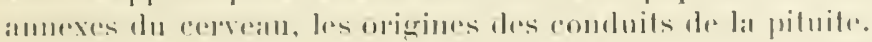

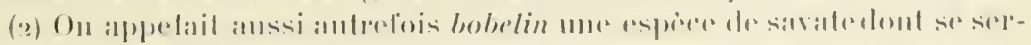

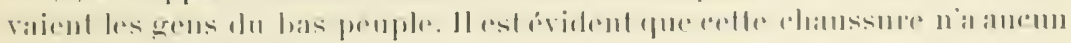

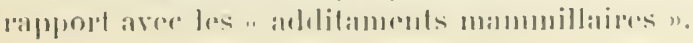


aujourd'hui éminence vermiforme. Cette íminence est constiture par le lobe médian du cervelet, dont la surface annelée rappelle celle d'un ver.

P'ilemaille, maillet dont on se servait jadis pour jouer an mail. De pila, balle à jourer, boule, et de mallens, marlean. maillet. Le jeu même s'appelait palemail ou, comme a écrit Nicot, palemaille. Sclon Burgaud des Marets ef Rathery, on disait également paille-maille.

Dans les OEurres d'Ambroise Paré (loc. cit. suprà, p. 168,1 . T), on troure déjà un bon dessin de l'exerescence vermiforme: "le vermiformis, tant antérieur que postérieur, dont l'antérieur est entièrement séparé. " C'est ce "rermiformis antérieur entiòrement séparón qui ligure, dans notre dessin, ì côté du pilemaille.

\section{La nuque, comme un fallot.}

Rabelais a donné au mot nuque le sens que lui attribuaient les módecins de son temps (Voy. Furetiere); par nuque il a entendu la moelle allongée, le bulbe rachidien. En arabe Nou Kha'a signifie moelle.

Le bulbe rachidien ou bube rànien (pars cephalica merlullie spinalis, Hasse) est un renflement polygonal, aplati d'arriere en avant, à base supérieure, qui couronne à lamanière d'un chapiteau la moelle épinière dont il constitue l'extrémité supérieure (principium medulle spinalis des Anciens).

Fallot, lanterne adaptée an bout d'un bâton. Falot, en terme de blason, designe anssi une sorte de vase avec un manche.

Dans l'ìle de Médamolhi (1), " Panurge achapta

(1) Nulle part, en hébreu. Daprès M. Ducrot, cest Arkhangel. Mais Arkliangel nesl pas une île. De nos jours, non! mais, an temps de Rabelais, cen était une, séparée de la tore forme par la mer Glaciale of par le fleure Pinegre, qui baignait la ville de Sabatea, ef qui recerait comme tri- 
un grand lableau painct et transsumpt ( 1 ) de l'ourage jadis faict a l'aiguille par Philomela (2)... Je rous jure par le manche de ce lallot, que c'estoil une paincture galante et mirifique (:3) ").

Au bal de la reine de Lantermois, "se taisoient bion valoir les gentils lallots arecrues leur's jambes de bois n(
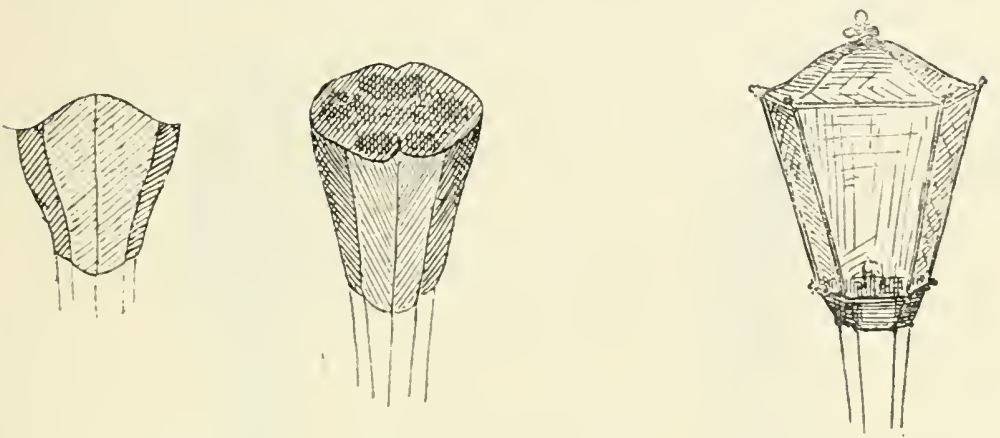

Li nuque, comme un fillol.

Oui connail l'anatomie et a rules lanternes emmanchios qu'on porte encore, dans certaines campagnes, de eharpur colé du dais pendant les processions ou derant le prèlece qui va administrer les dernierssacrements a un malade, applouvera la comparaison (j).

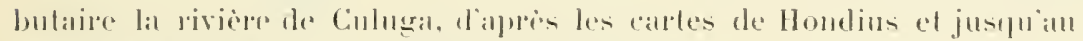

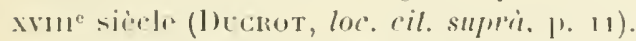

(1) Inili, copie, du latin lranssumplus.

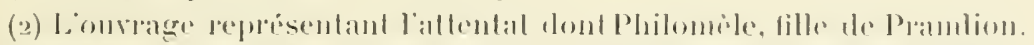

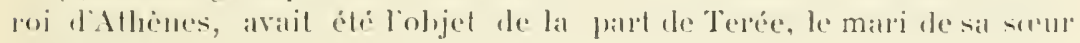
Prognex.

(3) Merveillense, du litin mirifirtus.

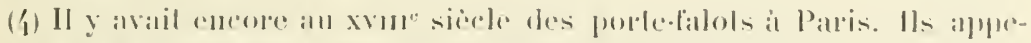

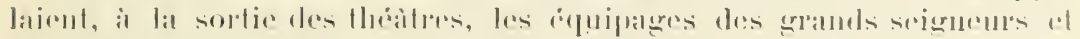

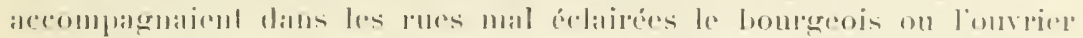

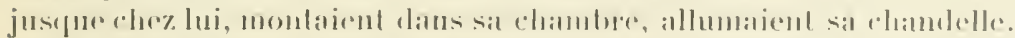

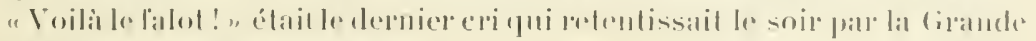
Ville, il y a rent rimfuninte ans.

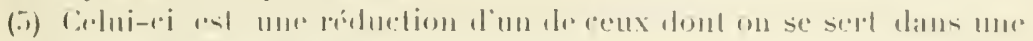
communc du Loir-cet-Clser. 
La mouelle, comme un bissac.

La monelle, la moelle épinièrere est cette lige nerreuse, blanche, qui estlogée dans la colonne vertébrale. La moellen’a pas le même calibre dans toute sa longueur: elle se renfle au nivean des premières vertibres cervicales (ren/tement cervical, intumescentia cervicalis). duminue ensuite successive-
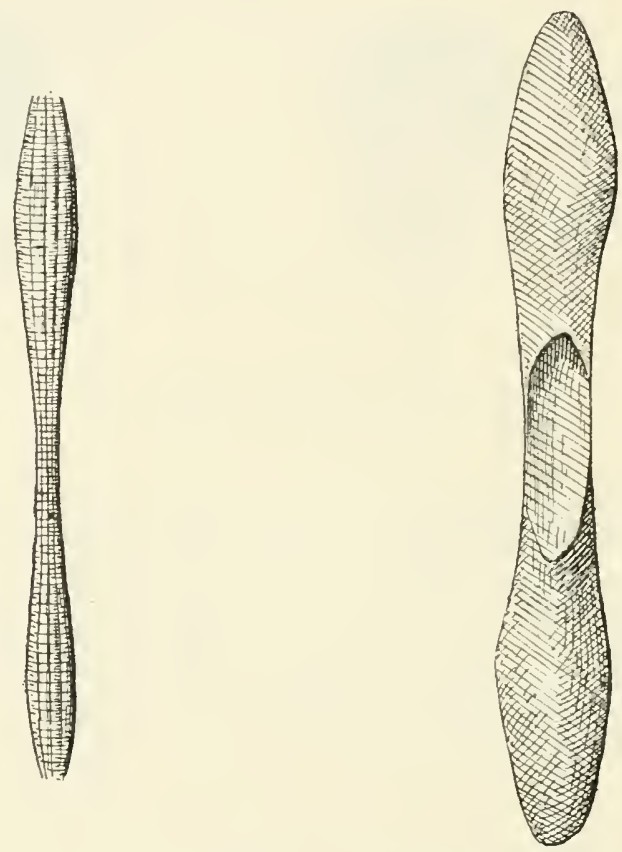

La monelle, romme un bissac.

ment jusqu'à ce qu'elle ait repris son rolume initial, se renfle une seconde fois an nivean des dernieres rertiones dorsales (renftement lombaire. intumescentia lumbalis) et se termine en pointe à la hauteur de la première lombaire.

Du premier renflement partent les nerfs destinés aux membres supéricurs, du second ceux qui se rendent aux membres inférieurs.

Le bissac (du latin bis et saccus, sac i deux poches) est un long sac de cuir ou de toile ourert par le milieu el leermé 
par les deux bouts; en sorte pu'il forme deux poches. Les moines des quatre ordres a cagoule, les moines mendiants, s'en servaient jadis pour aller queter. On dit encore étre an bissac pour : ètre réduit à la mendicité.

"Ce matin, dist Panurge, jai trouré un bon homme, qui en un bissar tel comme celuy de Esopet (1) portoit deux petites fillettes de l'age de denx ou trois ans au phus, l'une devant, l'aultre derrière. Il me demande l'aumosne (2).

"Estienne Tappecoue (:3), secretain (4) des cordeliers de Saint-Maicent, en Poictou, qui retournait (.) de queste, dist (6) en ress macaroniques (7) a Villon et à ses compaanons:

Hic est de patria, natus de gente belistra,

Qui solet antiquo bribas portare bisacen (8)."

Le bissac dont les derix poches sont remplies de provisions a la configuration générale de la moelle. On en sera persuadé fuand on aura regardé le dessin ci-contre de la moclle, d'apris Van Gehuchten (loc. cit. supra, p. 24).

(1) Voy. la lable de La Fontaine intitulée. Jupiler el le Besacier. Ésole, uri ar Membre dams la Thrace, vivail dans la premione moitio du $\mathrm{r}^{\mathrm{e}}$ siorle. Esclave dans sal jemesse, il a porté en voyagu, daus un bissac, les vives destinés à sal nomprilure et ì celle de ses compaguons. Les lables allribues anjourloui i Esope sont un recueil dapolognes recurillis el arrangés, vers le milien du vive siecle, par Planude, moine de Nieomédie.

(2) L. II, ill, XY.

(3) "Ce nom bulesque de Tappecone on Tappequenc, lorge lres pro-

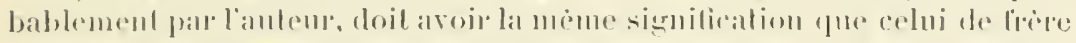

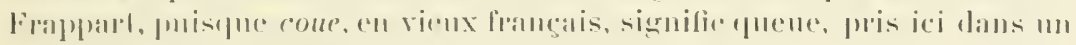

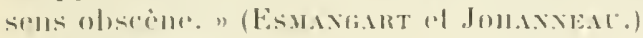

(i) Silleristall.

(5) Reremiril.

(6) I. IV, in xill.

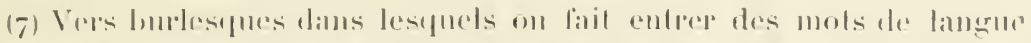

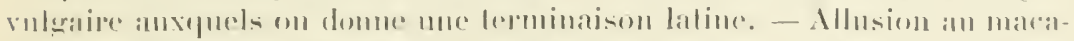

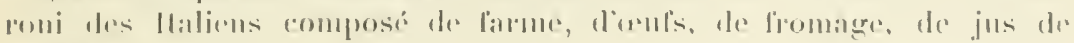
vimule, ale.

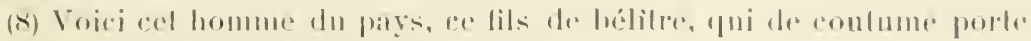
des restes de colisine dans son vienx hiside. 


\section{Les nerfs, comme un robinet.}

Les Anciens croyaient que les nerf's itaient de petits luber pourvos de valvules on soupapes, dans lespuels circolatent des corpuseules d'une ténuité et d'une subtilité extrèmes, appelés esprits animanx. Ambroise Parté a délini les nerl's: "Les voies el instruments ou organes de l'esprrit animal et des facultés portées par iceux. "Regius a enseigné (Philosophie naturelle, ch. 26, 1. IV) que les nerf's étaient munis de valvules dans toute l'étendue de leur trajet, et Descartes (Traité de l'homme), sculement dans les points ori ils se divisent en plusieurs rancaux pour pénétrer dans les muscles. L'opinion que les nerl's étaient creux a mème persisté longtemps après la découverte du microscope. Cela tient à ce que les filnes nerveuses examinées, à l'état fratis, au microscope, apparaissent comme des eylindres reguliers, clair's et transparents, dans lesquels on distingue " une partie centrale qui devient largement obscure quand on éloigne l'objectif, el de chaque eoté une bordure, qui paraît brillante dans les mèmes conditions ". (RANver) (1) Aujourdhui encore, on appelle couramment les nerfs : lubes nervenx, malgré l'erreur que consacre cette dénominalion (口).

(1) Les fibres morvenses sont romposées: $1^{\circ}$ d'un filament rentral tries trinu, chargé de comduire le lluide nerveux (cylindre-axe) : $2^{0}$ d'une gaine isolante lorméc par une matiore grasse (myéline on moelle des nerfs) entomrant ce filament; $3^{\circ}$ d'une enveloppe élastique, transparente, périphérigue. La partie obsende des tibres nervenses examince an microscope, ainsi qưil vient d'éfe dit, répond au cylinderexe, la partie claire à la gaine médullaire.

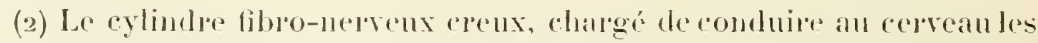
impressions visuelles, ne mérile pas (Noy. Organes des sons, Physiologie

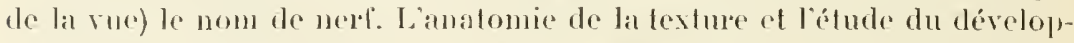
pement du corps humain démontrent péremploirement que cest un probongement tu cerveau, le pédicule, gui pémit la vésicule oculaire à la résicule cérébriale. 
Les esperits animaulx, comme grands coups de poing. Les esperits vitaulx, comme longues chiquenauldes.

En plus des esprits animant. exessivement sublils, formés dans le cerveau, circulant datns les nerl's at produisant non seulement les mouvements musculaires, mais encore l'imagination, la perception, la mémoire, ete., on a admis, pendant des siocles, des esprits vitum. plus lourds, moins lémus, "seconds en dignité, "engendrés dans le coent", at principalenent dans le rentrienle gatuche du coure, et portés par les vaisseaux daus toutes les praties du corps pour y culretenir la chaleur nécessanire à la vie (1).

Montaigne, Fónelon, Racine tils, Voltaire, Ramazzini, ele., ont lait mention des esprits animaux el des esprits vitaux.

"La rélémence el la tristesse ayant accablé ses esproils vitaux le porta roide mort par terre. "(Montargane, Essais.)

"Du cerveau qui est la souree de lous les nerl's partent les esplits. Ils sont si subtils quon ne peut les roir, et néanmoins si réels. et d'une action si forte, qu'ils font tous les monvenents de la machine el toute sa forece. Ces esporits sont en mo instant envopés jusquans extrémités des membres : tantòt ils coulent doncenent et arec uniformité; tantòt ils ont, selon les besoins, une impétuosité irréguliore: et ils rarient a l'intini les postures, les gestes ed les anteres actions du corpen.....

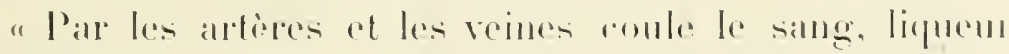

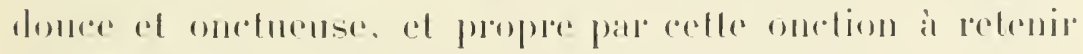

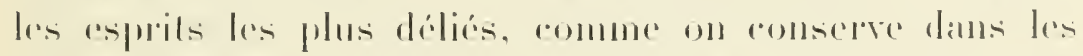

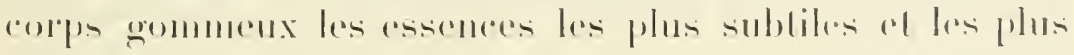

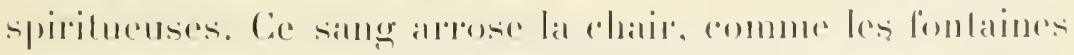

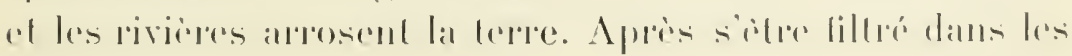

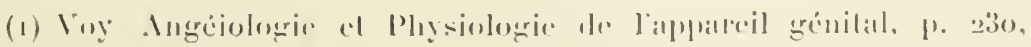
noto 111. 
chairs, il revient à sa source, plus lent et moins plein d'esprits: mais il se renouvelle et se subtilise encore de noureau dans cette source pour circuler sans fin. " (FÉNELON, Traité de l'existence el des attributs de Dien.)

.... Ces esprits subtils, toujours prêts à partir,

Attendent le signal qui les doit avertir;

Yon àme les envoie, et, ministres dociles.

Je les sens répandus dans mes membres agiles.

(Racine fils, la Religion, ch. I.)

"Je ne connais point de plus puissants remèdes pour les maladies de l'âme que l'application sérieuse el forte de l'esprit à d'autres objets. Cette application détourne le cours des esprits animanx. "(Voltane, Corresponilance.)

"Outre les mineurs, tous ceux qui demenrent ou travaillent aux environs des mines sont exposés aux mèmes maladies, puisqu'ils participent aux mêmes exhalaisons métalliques qui épaississent et altìrent les esprits vitaux et animaux dont la nature est éthérée et subtile. "(Ramazzixi, Maladies des Artisans, Irad. de Fonreroy.)

Descartes a déerit les voyages de ces corps éthérés, leur's opérations, avec la mème précision et les mèmes détails que s'il en avait été le témoin oculaire.

Les miracles de la chimie, en séparant, dans le fluide qui nous entoure, le principe respirable de celui qui ne l'est pas, en montrant, dans le gaz respirable, l'agent de la coloration dusang, et, dans la décomposition de l'airpar la respiration, la source de la chaleur animale, ont inaugurél'admirable théorie moderne de la calorilication animale et mis fin à celle des esprits.

Ceci établi, les deux comparaisons sus-indiquées sont expliquées. Quaresmeprenant était aussi lourd d'intelligence qu'il élait débile de corps. (Voy. Angéiologie : Le pouls. comme nazarles multipliées.) 
Phrsiologie. - Dans le prologue du live I, Rabelais prévient ceux qui le liront d'avoir " en rérérence (1) le cerveau caséiforme (2) qui les paist (:3) de ces belles billevesies ". Et, dans le chapitre xix dı même live, Janotus de Bragmardo (1), - "Londu à la résarine (5), restu de son liripipion à l'antique (6), et bien antidoté l'estomach de cotignac de four et ean beniste de cave $(7), n$ - pérorant in modo et in figura. arec tout latlirail de la dialectique syllogistique pour ravoir les cloches de NotreDame, emportées par Gargantua, sexprime en ces termes : "Un quidam (8) latinisateur (9), demourant pros l'hostel Dieu. dist une fois, allégnant l'autorité d'un Taponnus (je laulx (10), c'estoit Pontanus) (11), poëte séculier, qu'il désiroit qu'elles fussent de plume, et le batail (12) fust d'une queue de regnard (1:3); pouree quelles luy engendroient

(1) Respect, considiration, du latin reterentio.

(2) Ressemblant i du fromage, du latin cosens, fromage, et forma, forme.

(3) Le's instruit, les entretiont.

(1) Comme Marqnet, Picpochole, Raminagrobis, Cirippeminamb, we., Janotus de Bragnarde a cxiste. Le Duchal nons apprend que Vallamlerl diallon, médecin el poite, a lat des épigrammes contre un certain Janotus, oratour tris fatigant.

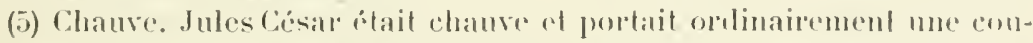

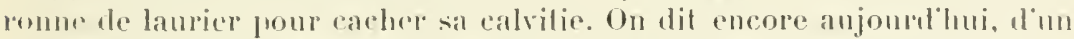
homme rui a la chrrelure courte, qüil est toudu a la Titus.

(6) Le liripipion bhait le chaperon des docteurs de Sorbonne.

$$
\begin{aligned}
& \text { Jisus! que ung liripium } \\
& \text { Aurfuel nos maistres lant soutiennent } \\
& \text { Qur le Saint-Esprit conlienurut }
\end{aligned}
$$

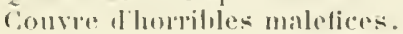

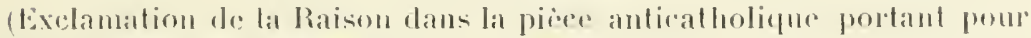
titre Farce des Theologgastes.)

(7) Lestomal hien pepu de contiture de coings ed de vin.

(8) Lu certain.

(9) Latinistr.

(10) Jo me trompe, du latiu fallere.

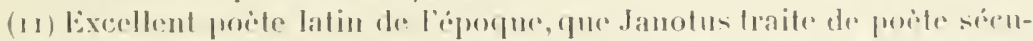
lier, épithe de dedain que les predauls appliquaient alors is Virgile et it Horace.

(1:) Le battant.

(13) Une quene de renard. 
la chronique (1) aux tripes du cerveau (2), quand il composoit ses vers carminiformes (3). "

Le ramollissement di cerveau andine la folie. On dit vulgairement d'un imbécile " qu'il est ramolli ". En prérenant sess lectemrs qu'il avait le cerveau caséiforme, e'esta-dire mou comme du fromage, Rabelais a fait à la fois preuve de saroir et de prudence. Il a avancé un fát varai, crée un néologisme imagé, entré aujourd'hui dans le langage médical (4), et s'est garé de la persécution. Les Sorbomnistes, les Chats-fourrés et Grippeminaud lui-mème ne pouvaient s'en prendre à un homme avouant à tout venant qu'il n'avait pas l'esprit lucide.

Le mol tripes, employé par Maître Francosis pour désigner les circonsolutions du cerveau, choquera pent-ètre

(1) Voy. 1) 188, note 3.

(2) Anx circonvolulions cérébrales dont les llexuosités rappellent en petit relles de lintestin.

(3) Carminiformes, en forme de vers, de poòme. Vers carminitormes, pléonasme.

Les halitants de likr de liundo o en leurs jardins ne sèmént que les trois espreces de anémone. Lit rue el aultres herbes carminatives, ils en escurent (arrachent) soigneusement. "Certaines plantes de la Pamille des Renonculacies, notamment le bouton dior (Ranunculus bulbosus), la Renoncule àcre (Ranunculus acris), la Renoncule scélérate (Ranunculus sceleralus), l'anémone (Anemone pulsatilla), elc., mangées à l'état frais par les bestiaux, déterminent dans la panse une production exagérée de gaz, à laquelle il faut remédier sourent par mne opération. Quant ì la rue, elle irrite également la muqueuse gastro-intestinale, mais celte irritation se traduit principalement par une doulenr ì l'épigastre, des éructations et de; romissements continus, ete.

Les médicaments qui ont la vertu d'expulser les gaz eontemus dans le lube digestif sont appelés camminatil's. Pour quelques linguistes, ce mot viendrait de carmen (chant). Dans le Dictionnaire universel de maliere médicale, llérat of de Lens ont écrit is ce propos : "L'étymologie qui lanit venip carminatil de carmen, paree quon employait des paroles manipues pour dissiper les flatuosilés, quoique assez généralement adoptée, nons paraît an moins ridicule. "Jinclinerais, en eflet, beancoup, plus volontiers a roire fue carminatif vient de carminare, qui signifie carder de la laine ef, far extension, lireg ce quil y a de grossior, purgers.

(1) Calnanis, pour ne citer que lui, sen est servi à plusieurs reprises datns son tratit: Inu Pluysique el du Moral. 
les lettrés délicats. Il n'en est pas moins absolument exact. lant au point de rue anatomique qu'au point de rue physiologique. Les circonvolulions cérébrales ressemblent en petit aux circonvolutions intestinales. Les unes sont les organes essentiels de la pensée quelles digìrent eommo les autres digìnent la nourriture. Que ces circonvolutions soient le siegre d'une maladir aigur on chronique, la pensée en jaillit moins brillante et moins belle aver son caractère d'immortalité (1).

Le moindre labeur intellectuel provoque un afflux de sang vers la tête. Qu'on plonge le bras dans un rase, tinement gradué, contenant de l'eau, et qu'on se donne la peine de résoudre la plus simple des équations algébriques, on verra presque aussitot le niveau de l'eau baisser dans le vase. Une partie du sang du bras immergé sest portó an cerveau pour mettre en auve les combustions cellulaires nreessailes anx fonctions de l'intelligence.

- Apprenez-moi, demandait un philosophe à Vollaire. s'il n'y a pas une égale quantité de mourement dans lo monde?

- C'est, lui répondit l'ermite de Ferney, une ancienne chimere d'Ficure renouvelée par Descartes.

Eh bien! cette chimere est devenue, wrice ì Carmol (2), ¿ Mohr, à Siguin, à Mayer, à Béchard, a Hirn, ¿ Lomhard (de Boston), à Sehiff, à Mosso, à Luys, ete., une des bases de la physique el de la physiologie. Tout travail physiologique, comme méeanique, est mesuré par la dilférence de température entre la chaleur avant le travail

(1) Montaigne a lit de meme dans ses Essuis : "Notpe espril so constipe on vieillissant."

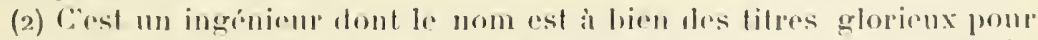

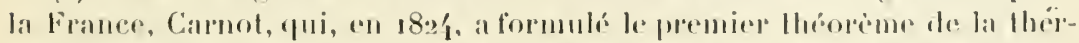

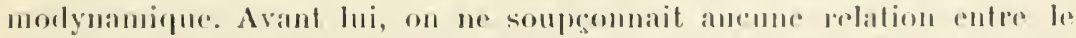

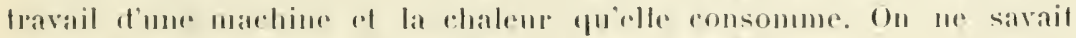

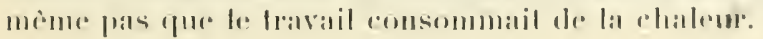


et la chaleur après le travail (1). Ainsi qu'on peut s'en rendre compte au moyen d'un thermomètre placé en dehors du cràne, la température du cerveau croît en mème temps que sa circulation, des quil fonctionne. La congestion du cerveau pendant un effort intellectuel a été notée par Rabelais :

"Contemplez, dist Rondibilis, la forme (2) d'un homme attentif à quelque estude, vous voirrez en luy toutes les artires du cerveau bandées, comme la chorde d'une arbaleste, pour lui fournir dextrement (:3) esperits suffisants à emplir les rentricules du sens commun, de l'imagination ef appréhension (4), de la ratiocination (5) et résolution, de la mémoire et récordation (6); et agilement courrir de l'un à l'aultre par les conduicts manifestes $(z)$ en anatomie, sus la fin du rets admirable (8), onquel (9) se terminent les artères, lesquelles de la sénestre armoire (10) du coenr prenoient leur origine, et les esperits vitumx alfinoient (11) en longs ambages, pour estre faicts animaulx."

Les anciens anatomistes n'étaient pas d'aceord sur la région du cerveau où sopérait la transformation des esprits vitaux, engendrés dans le cour el chargés de la conservattion de la chaleur vitale, en esprits animaux nécessaires au

(1) Qu'il sagisse d'une machine, d'une planète, d'un muscle ou du cervean, la loi qui régit lemr mise en aruve, loi de la consercution de la force, est la mème.

(2) L'apparence, l'attitude.

(3) Rapidement.

(4) Compréhension, du latin apprehensio.

(5) Raisonnement, du latin ratiocinatio.

(6) Souvenance, du latin recordatio.

(7) Apparents, du latin manifeslus.

(8) Lihexagone artériel te Willis.

(9) Daus lequel.

(10) Ventricule du creur.

(11) Purifiaicnt. Je rappelle que Rabelais a écrit ailleurs (Dédicace au cardinal de Chastillon, I. IV) : "Sans vous mestoit le corur failli (sans vigueur, qui faull) et restoit tarie la fonlaine de mes esperits animaulx." 
mourement et au sentiment. Pour P. Laurembergius et D. Sennert (Institut., I. I, ch. vir), c'était dans les sinus de la faux du cerveau; pour Descartes (Traité de l'homme, I. I), dans la glande pinćale; pour F. Sylvius (Inispulat. 4. thes. 18), dans les artires situées à la surface du erveau et du cervelet; pour Bauhin, lloffmann, Emilius, Parrisianus, ete. dans le lissu du cervean; pour And. Du laureus, Riolan, Regius, L. Mercatus, dans les cavités des ventricules du cerveau, du sang artériel le plus chand yui s'exhale du plexus choroüde : pour les Arabes, dans le ventricule moren seulement qu'ils ont appelé. pour celte raison. très principal, principalissimum; pour d'autres, contin, dans le plexus choroüde. (Guant à Galien, il a enseigné tour à tour. comme And. Du Lanrens, Riolan, ete., que la transformalion des espreits vitaux en esprits animaux s'opérail dans tous les ventrieules du cerveau et, comme les Arabes, que cette lransformation s'opérait uniquement dans le rentricule

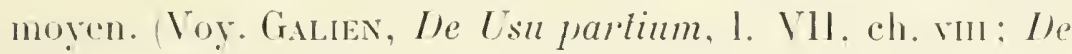
Locis a/fect., i. Ill, ch. vil, et Ile IJecret. IIippocratis et Platonis, I. VII, ch. III.) Riabelais, plus ácleclique eneore, al placé le lieu de naissance des esprits animaux dans l'hexagune artériel de Willis, les branches artírielles yui le conli nuent el les rentrientes cérébranx.

Ene alimentalion insultisante de longue durée canse dans l'organisme des désoldres profonds caratelérisés par des hallucinations de la vue et de l'onëe, la perte plus ou moins complete du sommeil, une exaltation délinante suivie d'abaltement et de stupeur (1). Ces effots dime abslincence prolongere unt éte admirablement décrits par le philosophe et phesiologisle Rabelais. "Bien, croi-je a-t-il

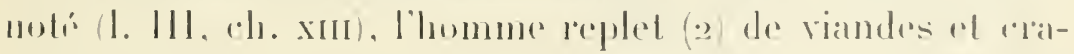

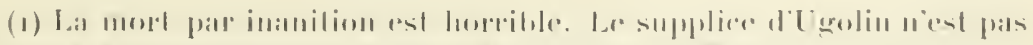

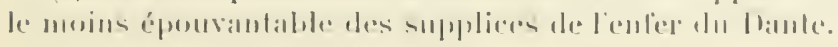

(2) Gorege, du latin replelus. 
pule (1). diflicilement concepoir notice (2) des choses spirituelles (:3) : ne suis toutesfois on l'opinion de ceulx qui, après longs et obstinés jeusnes, cuident (4) plus arant entrer en contemplation des choses célestes. Soubrenil assez vous peult comment Gargantua mon pire (tequel par honneur je nomme) nous a souvent dict les escripts de ees ermites jensnems, anltant estre fades, jejunes (5) et de manlvaise salive (6), comme estoient leurs corps, lorsquils composoient; at diflicile chose estre bons et sereins rester les esperits, estant le corps en inanition, vu que les philosophes et médicins afferment les esperits animaulx sourdre, naistre ot praticquer par le sang artérial purifié el affiné à perfection dedans le rets admirable, qui gist sous les ventricules du cerveau ( 7$)$. Nous baillant (8) exemple d'un philosophe, qui, en solitude pensant estre et hor's la lourbe (9), pour mieux commenter, discourir et composer. ce pendent toutesfois autour de luy abayent les chiens, mlent les loups, rugissent les lions, hamissent les chevaulx, barrissent (10) les éléphants, siftent les serpents, braislent les asnes, somnent les eigales, lamentent les tour-

(1) De vin. Plenus crapula (Lr.), Crapule distentur (Apur.). Dans le chapitre xхxw lu lirre $Y$ on lit encore : Les pontiles, et touts persomages, qui saddonnent et dédient (se consacrent, se wotent, du latin dedicare) a contemplation des choses divines, doibvent en tranquillité leurs esperits mantenir, hors toute pertubation de sens : laquelle plus est manilestéo en ivognerie, quen aultre passion, quelle que soit."

(2) Conceroir, du latin concipere, concevoir, et nolitia, notion, idée.

(3) De l'intelligence, du latin spirilus.

(4) Croient, du latin credere.

(5) Vides, ereux, du latin jejunus.

(6) Pour les propriétés nocives altribués a la salive de l'homme it jeun, voy. Apluareil digestit: La salive, comme une navelle.

(7) Voy. Angéiologie : Le rels admirable, comme un chanfrein.

(8) Nous domnant, nous proposant.

(9) De la foule, du latin lurba.

(10) Barri, cri de l'éléphant; barriquer, crier comme un éléphant. On appelait autrefois l'éléphant barre aux Indes orientales; et c'est raisemblablement de ce mot qu'est dérivé le nom barras, que les Latins ont domé à ce pachỵlerme. 
terelles, éest-it-dire, phus estoil troublé, que soil fust à la foire Fontenay ou Niort: car la faim estoit au corps: pour a laruelle remádier, abaye l'estomach, la vue esblouit, les vines suceent de la propre substance des membres carniformes (1). et retirent en has cestuy esperit ragabond, négligent du traictement deson nomrisson et hoste naturel. qui est le colpe : comme si l'oiscant, sus le poing estant, rouloit en laer son rol prendre, et incontinent par lis longes seroil plus bas déprimé (2). ")

Près de l'ile de Ganabin (:i), frère Jean envoie Panurge " à toutsles diables qui luy puissent anatomiser la correlle et en faire des entommeures n. Ce qui précède prouve que cette exclamation nest pas une simple bontade de Maitte Francuis, 'pu'il a dù "anatomiser " la cervelle et en faire maintes coupes pour saroir :

$1^{\circ}$ Que ceste masse d'apparance pulpense, quion a cru primitivement tenir le milien entre les liquides et les solides, est aussi merveilleuse dans la délicatesse el dans l'arlifice de sa sloucture que daus la sublimité de ses fonelions:

$2^{n}$ Qu il y a, jusfüa un certain point, me corrélation entre lintégrité et la quantité de la masse encéphalique el l'intelligence:

: Que la eireulation rérébrale est plus active pendint un travail intellectuel;

4" Qu'un travail intellectuel est rendu difticile, sinon impussible, quand lablimentation es insuffisante on trop abondante.

Les monrements du cenur sont régis par le systime nervenx. Toutes les fois yue, pour une cause quelcompue telle que la cranter la doutrum. la joie, etce l'intlux des

(1) Formes de chatir, dı lalin remis, chair.

(2) Rabaisser, du latiu deprimare.

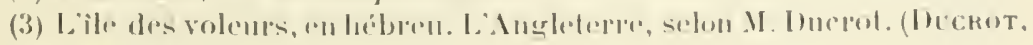
loc. cil. sitprit, 1. 22.1 
centres nerveux sur le cour cesse, diminue ou augmente, la mort peut survenir.

Dans l'épopéc pantagruélique, il est question de divers personnages qui ont fini ansi leurs jours, mais dont Rabelais a attribué, avec Galien, la mort à la "résolution des esperits vitaula n dans le coeur.

"Tout ainsy le coeur, par joye excellente, est interiorement espars, et patit manifeste résolution (1) des esperits vitaulx : laquelle tant peult estre acerue, que le cour demonreroit spolic de son entretien, et par conséquent seroit la vio rstincle par ceste péricharie (2), comme dict Galen, l. XIl Method., libro V' de Locis affectis, el libro II de Symplomaton rausis (3). Et comme estre au temps passé advenu losmoignont Mare Tulle, libro I Quastion. Tuscul. Verrous, Aristoleles, Tite Live, apris la bataille de Camnes, Pline, lib. YlI, cap. xxxu et Lin, A. Gellius, lib. $111, x v$ ot aultres; à Diagoras Rhodien (4), Chilon (5), Sophorles (i),

(1) Et sontfre de la diminution des esprots animanx. "I Te corm est m viscère noble et royal duquel se répand continnellement de foutes parts dans les parties généralement de tout le corps une liqueur vitale avee une chalen prerpetuelle qui y entretient la vie; de laquelle, lorspue ces par!ies en sont, pour si peu de lemps que ce soit, prirées, elles tombent et meurent." (Diemerbroeck, loc. cil. suprà, t. 11, p. 63.)

(2) Joie excessive, du gree ripy xosıx.

(3) Voici les textes de Galien relatils a l'action de la joie sur le curn: "Chez beancoup la joic, la colere provoquent me lipothynies subite." (Méltorle thérapeutique.) - "La mort suit toujours les dyscrasies du corme, car, si le ceur est vicié, tontes les parties du corps sont atteintes "m mème trmpls. (Des Lieux affectés.) - "La crainte, dont les alfels sur le cornl sont semblables a ceux de la joie. "(Des Maludies.)

(4) Diagolas, ćlant tlígi avancé en àge, se rendit à Olympic avec ses deux fils, Damagète et Aculisaüs. Ceux-ei, ayant étí vainquemrs aux jeux, frirent lenr pere dans leurs bras et le portirent au milien de lassemblée, qui l'aceneillit par des acelanations enthousiastes; un Spartiate qui assislait à celte scène s’écria pour exprimer le haut degré de gloire qur. Diagoras arait atteint : "Meurs, lliagoras, car tu ne peux pas espérel de mouler au ciel. " (Larousse.)

(5) Chilon, l'un des sept Sages de la Grèce, monrul de joir, dit-on, en embrassant son fils couronné aux jeux Olympieques (Boullet).

(6) Sophocle mourul de joie en remportant le prix de tragédie (PLINE). 
Dionys (1), tyran de sicile, Philippides (2), Philemon (:3) Polyerate (4), Philistion (5), M. Jurenti (6), et aultres qui moururent de joye $(\mathbf{7})$ ! ")

".... Le Supplementum supplementi chronicorum (S) dict que Garganelle mourul de joge au chastean de Grandgousice (y)."

Certains poisons anènent également la mort en agissant sur les nerfs du cour. Parmi eux, Rabelais a signaló le silfran. "Etcomme dict Avicenne, in a canone, el libro de Iriribus cordis, du zaphran, lequel tunt esjonil (10) le corur qu'il le déponille de vie si on en prend dose excessive, par résolution (11) et diatation supertlue (12). ")

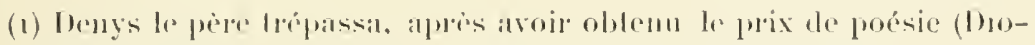
WRE DE SIGILE).

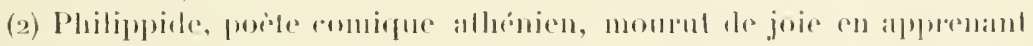

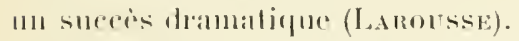

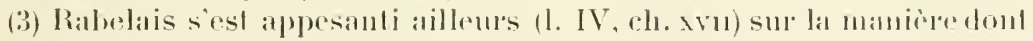

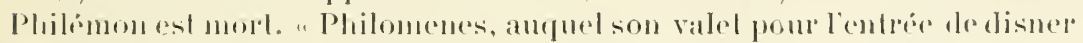
ayant appreste des lierues movelles, pendent le lemps qu’il alla an vin, un asue c... esgaré estoil entré on logis, et les figues apposérs mangeoil

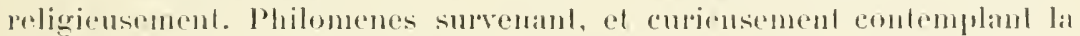
grace de lasme sycophage (mangeme de lignes), dist au valet qui esloil

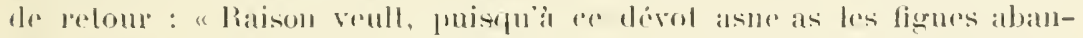
domme, que pour boine fu luy probluises de ee bon vin quas apporté. "Ces

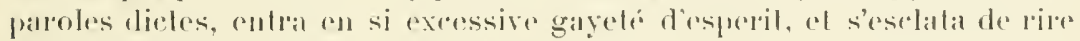

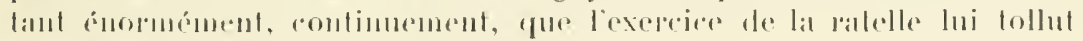
toute respipalion, el subilement mombut."

(i) Polycrate, on mienx Polyerile. est le num thute lemme que la joire

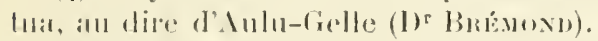

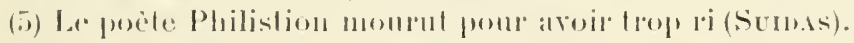

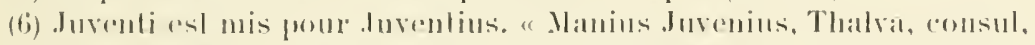

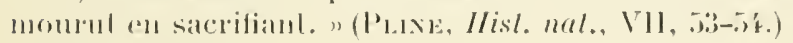

(7) I. I, i.h. x.

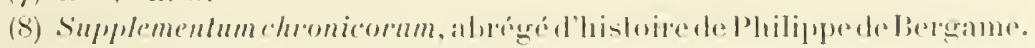

(a) I. I, ch. xxxril.

(10) Riend licuremx, réjouit.

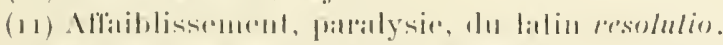

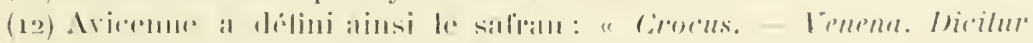

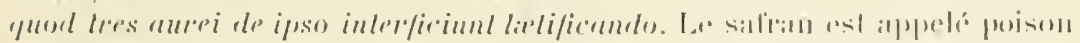

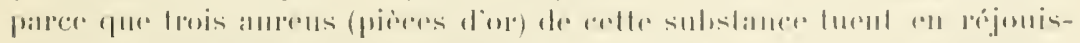

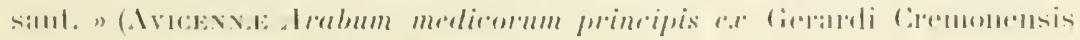

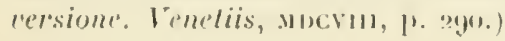


Au moyen ìge, comme aujourdhui, le safran, - Crocus suticus, plant de la famille des Iridées dont les stigmates sont seuls employés, - se trouvait dans toutes les apothicaneries.

"An Mans, dist Eudrmon, Funçois Cornu, apothécaire, avoit en cornets emploieté (employé) mes extravagantes frippées, je désavone le diable, si tout ce qui dedans fut empaqueté, ne lut sus linstaut empoisomm, pouri et gasté : encens, poive, girofle, cimmanome, zaphran, cire, espiers, casse, rheubarbe, tamains; généralement tout, drogues, guogures et senogues. ") (L. IV, ch. LiI.)

Gogues el senogues pour agogues et xinagogues, purgatits.

Extravagantes, constitution des papes ajoutée au corps du droit canoll.

Le safran est toujours d'un prix tris b́levé, et cela se conçoit puisque 11. Pereira a calculé quil ne fallait pas moms que les stigmates de 79.200 flemes pour lournir 500 grammes de safram. 
ANATOMIE CHIRURGIGALE 



\section{ANATOMIE GHIRURGIGALE}

La science pure précede foujours la science appliquée; l'mure est la source vive de l'autre. A costé de l'analomie descriptive, il ya l'anatomie topographique, chirurgicale on des régions, qui décompose le corps humain on 111 reptain nomlne de régions dont, à la facon de la géologie, elle étudie sucessivement, en procédant de la superficie à la profondeur, les rapports des conches superposées el les différents éléments qui entrent dans la constitution de chacone de ces conches; l'anatomie qui donne an chirurgien l'audace d'aller chereher, a travers des parties dont la lésion serait dangerense ou mortelle, le vaisseau yu’il laut lier, la tumeur qu’il faul extirper.

Rabelais a on des connaissances anssi étendues en analomie chirmegicale qu'en anatomie deseriptive. Pour en

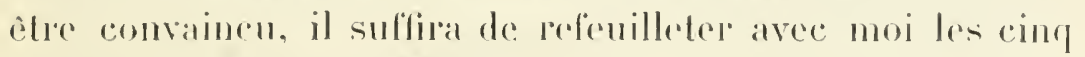
lives de l'Oruste du Mailre.

Dans lo grand débal "rotre les fonaciers de Lerné ed

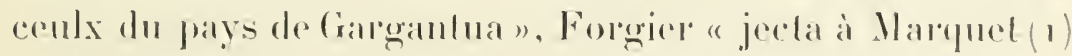
ungros tribard (:) qu'il portoil soubs son aisselle, at l'alleinel

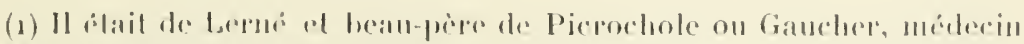
de Madame de Fontermult. (Voy. Aundien, les Héros de liabelois. 1. 8.)

(a) Biton conte al massil des gens de proine. 
par la joincture coronale (1) de la teste. sus l'artère crotaphique (2), du costi dextre (:i) : en telle sorte (4) que Marquet lombit (.j) de dessus sa jument, mieulx semblant homme mort que vif."

Lartìre temporale on crotaphique est exactement an rapport avere la jointure coronale ou sulure fronto-partictale, et les coups portés sur la tempe sont presifur fatalement mortels.

Au sac de l'abbaye de senille, lire Jean, "liappant à tors el à travers à la vieille escrime (6). És ( 7 ) uns escarbonilloit (s) la cervelle, és aultres rompoit bras el jambes, is aultres destochoil (a) les spondyles du col (10), is aultres démoloit (11) les reins, avaloit le nez, poschoit les yeulx, fendoit les mandibules (19), enfoncoit les dents, descroulloit (1:i) les omoplakes, sphacéloit les grives (19),

(1) Suture tronto-paricilale.

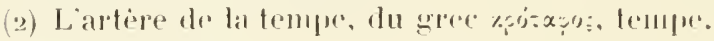

(3) Du côtó droit.

(1) De telle sorte.

(j) Tomba.

(6) "Sans tontes les laçous inventées par les maitres d'armes." (L.t Duchat.)

(7) Anx.

(8) Réduisait en bouillie.

(9) Disloquait.

(ni) Les vertibres du cou, les vertelues corvinalen.

(11) Démolissait, cassait.

12) Les nuchoires, du latin mandilualu.

1.3 Désalliculail.

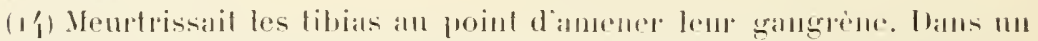

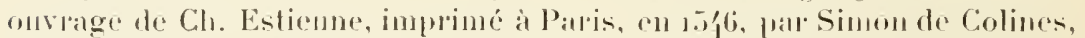
of intiluli: la Dissection des parties du corps humain, les derix os de la jambe sont représentés (p. 10), J péponé avee rette indication: le pelit focile de la jambe; le tibia, avee celle-ri : le gros focile de la jambr ou crive. A la page 13 du mence ourage on petroure 10 desin du libia aceompagné de ees mots : la grove de la jambe. On donnail également autrefois le $n o n$ de grève ál l'armure qui protégeatil la jambe. 
dergondoit les ischies (1), débécilloit les foeilles (2).

"Si auleun (3) saluber se rouloit en luyant, a icelluy faisoit rolerla teste en pièces par la commissure lambdoïde (4).

"Et si personne tant fut esprons (.) de témérité qu il luỵ roulust résister en fave, lá montroit-il la foree de ses muscles. Car il leur transpercoit la poictrine parle médiastin (i) et par le ceerr: à daultres domant sus la faulte des costes (7). leur subreptisoit (s) l'estomach. et mouroient soubdainement; és aultres tant fièrement (g) frappoil par le nombril. 'qu'il leur farisoit sortir les tripes ; és alultres parmi les e... percoit le boyall c..."

Le rectum n est, en effet, séparé des bourses. qui contiennent les ghlandes génitales, que par quelques muscles et quelques aponévoses et le bas-fond de la resside. Un eoup porté de haul en bas, et d'arant en arrière peut léser les lesticules, la régron périnciale antérieme el la partie inlérienre du leechum sans atteindre lat ressie.

Tripet voulut traitrensement fendre de son épée la cervelle de Gymmaste. mats celui-ci " estoit bien armé.

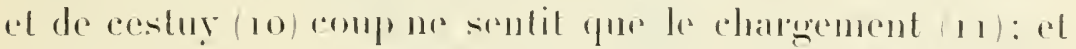

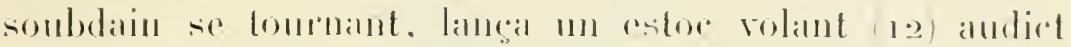
Tripet, et re prendent (1:i) qüreelluy se compoit en hamblt.

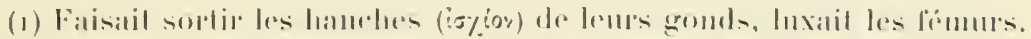

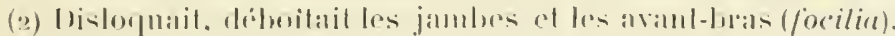

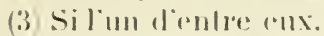

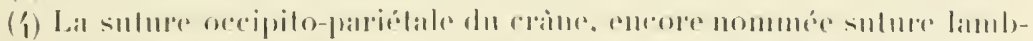

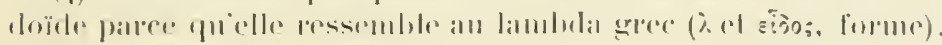

(5) Pris, rmuli.

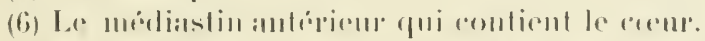

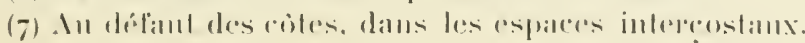

(8) I.ene dichinait.

(9) Itardiment, fortument.

(Ii) Ce.

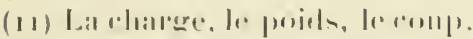

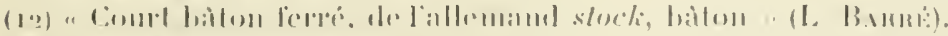

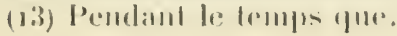


lui tailla d'm coup l'estomach, le colon et la moitić du foie." "Peut-on, dim coup, dit M. le D) G. Brémond, toucher les trois organes cités, et dans l'ordre indingú ? Parfaitement, pourvu qu'on dirige l'arme un peu de bas en haut, direction qui est indiquée par l'auteur ainsi : "icelluy se couvroil en hault (1). ")

Frère lean, gardé par deux archers, "tira son bracquemart (2), et en lerut (3) l'archicr quile tenoil is dextre (4), luy coupant entièrement les vines jugulaires et artères splaagitides (5) du col, arecques le gargaréon (6), jusques és (7) deux adines (8) : ef retirant le coup, luy entre-ouvit la mouelle spinale (9) entre la seconde et lierce vertebre (10): li tomba l'archier tout mort. "

L'areher de gatuche épowranté se rend à discrétion :

"A louts les diables, dist le moyne.

"Lors d'un comp lui tranchit la teste, luy coupant le test(11) sur les os pétreux (12), et eulcrant les deux os bregmatis (1:3), et la commissure sagittale (19), avecques grande

(1) Dr Bréxoxp, loc cil. suprà, note 120 ter.

(2) Éée conte ef large quon portait autrefois le long de la cuisse,

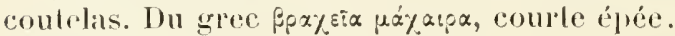

(3) En trappa, du latin ferire.

(1) 1 droite.

(5) Les artires de la gorga, les carolides, du gree spayt, grorge.

(6) La luette, encore appelée columelle et gargaréon, du gree $\gamma \alpha$ çapsois,

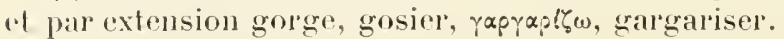

(7) Jusqu’aux.

(8) Adène n'a pas ici le sens fju’il avait précédemment (Voy. Anat. deseript., Appareil circulatoire : Les allenes, comme une serpe) et reut dire amycrlale, du grec $\alpha \dot{\delta} r_{i}^{\prime}$.

(9) La moelle allongée, le bulbe rachidien.

(10) La seconde vertèbre cervicale on axis et ta troisieme vertebre cervicale.

(11) Le couverele du erine, du latin testum.

(12) Voy. Anat. descript., Ostéologie : Les os pélreux, comme un plumail.

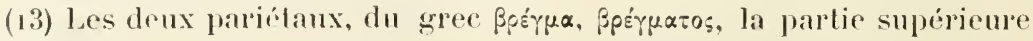
de la tète.

(1 1 ) La sulure pariétale ou sagiltale, du latin sagilla, paree qu'elles ressemble it une fliche. 
partie de l'os coronal (1), ce que faisant lui tranchit les. deux méninges (2), et ouvrit profundement les deux postérieurs ventricules du cerveau (3) : et demoura le crane pendant sus les espaules à la peau du péricrane par der-

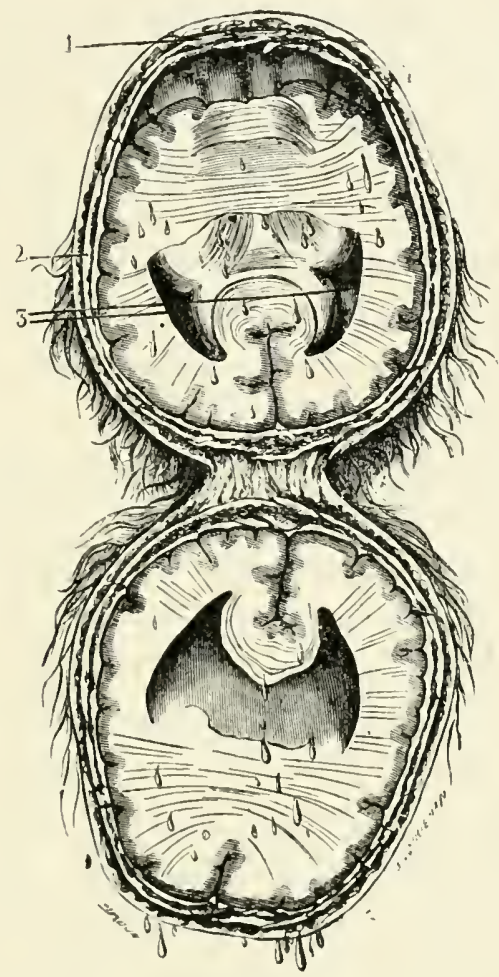

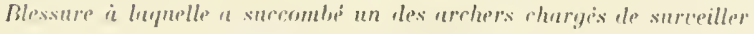
Fire dean prisomnier.

1, แ2; 2, mentuges; 3 . rentricules pusteriens Ju cervenn.

riere, en forme d'un bonnel doctoral noir par dessus, ronge par dedans. Ainsy tomba roide mort en terre (q). "

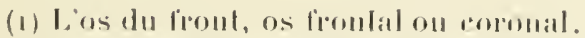

(2) Voy. Anal. Ilescriplive, Verrolonic: Le's membranes, cemme la ropueluehe diun moine.

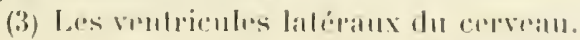

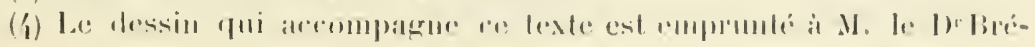


Tout est exact au point de rue anatomique dans le premier paragraphe, et dans le second il n'y a qu'une erreur concernant léchiffre des méninges, qui sont, je le rappelle, an nombre de trois et non an nombre de deux. Au point de vue physiologique, il n'y a rien à reprendre dans les deux paragraphes; de telles blessures sont instantanoment mortelles: l'une est une décollation en sens inverse de celle pratiquée par la main du bourreau; l'autre, me abrasion complete de la vonte du cràne et des parties qu'elle recourre.

Les lésions tramatiques du corur ont autant de gravité que celles du cerveau, du bulle rachidien ou des gros trones vaseulaires du cou : aueun des persomnages de l'épopée rabelaisienne n’y survit.

Ilastiveau transpereé un peu au-dessus de la mamelle gauche par l'épée de Toucquedillon "mourut incontinent".

Panurge raconte en ces termes a Pantagruel comment il a été détaché par le maitre de sa maison de la broche à laquelle il avait été attaché par les Tures. "De pleine arrivée (1), il tire la broche où j'estois embroché, et tua tout roide mon rostissenr, dont il mourut li par faulte de gouvernement (2) ou aultrement; car il luy passa la broche pen au dessus du nombril vers le llane droiet, et luy perega la tiere lobe du loye (3), et le roup haubant luy pénétra le diaphragne, et par a travers la capsule du cour luy sortit la broche par le hant des espaules entre les spondyles (4) et l'omoplate senestre (.). ."

11. le Dr F. Brémond a vierifié sur le cadarre que ce

mond. (Voy. liabelais-méderin, 1rar M. le I). Brénoso, fig. 2, à la tiu

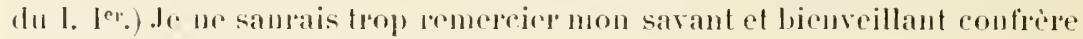

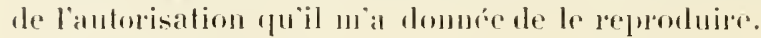

(1) Aussitot arriri.

(\%) De pansement.

(3) Le troisieme lobe du foie, dit bolule de Sirgel. On a attribue tour à tour sa décourerte ì Spigel, à Eustaldi, a Sylvius, à Vésale.

(4) Vertebres, du grec s.róvòvos.

(5) Omoplate gauche, du latin sinister. 
vigomrenx coup de broche a un trajet parlaitement en riogle avec l'anatomie lopographique (1). Une tige de fer pénélıant dans l'abdomen à droite, au-dessus de l'ombilic, peut traverser le foie, pereer le diaphragme, pénétrer dans le périearde et aller sortir entre la colonne vertébrale et l'omoplate du côté gauche, aprós avoir lésé le poumon que Rabelais a oublié d'indiquer. Quant "au lierce lobe du foye " on lobule de Spigel, il présente ì sa partie moyenne un mamelon entouré d'un cerele artériel constitué par les artìres splénique, coronaire-stomachique, hépatique, dont la blessure - abstraction faite de celle des vaisseaux et des viscères voisins - sultirail pour amener une mort presque foudroyante (2).

Nombre de symptomes ef de complications des contusions des plaies el autres traumatismes ont ité du reste signalés par le sarant romancier.

Frèe Jean " avec son baston de eroix donna entre col at collet sus l'os acromion (3) si rudement a Tiravant quil l'estomna, et leit perdere tout sens et monvement of tomba és pieds du chevaln.

P'ar estonner il faut entendre ici " rester saiss, élourdi, b Woni ". Les mots estounna et resta tont estant ont eneor. en provençal et en patois berrichon celte signitication. Sur les bords de la Méditerranée, les malelots disent de quelqu'un qui ne pent se mettere an bain que graduellement : lä̈go lestouno (1). Les éblonissements, les tintrments livreille, la perte monentanée de connaissance et de mouvement sont les symptomes de la eommotion répébrate

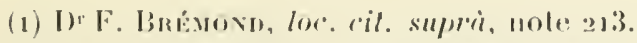

(2) On sait que Henri III ef le president Camot sont morts d'une

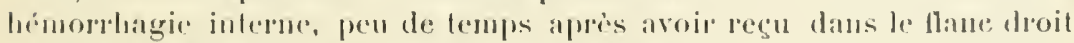
un conp le poigname qui avait alleint le lone.

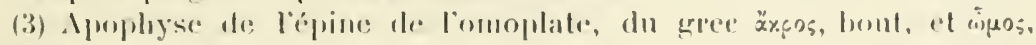
ipante.

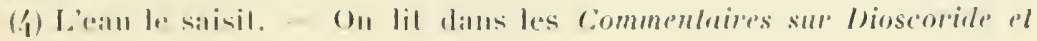


provoquéc par un coup violent porté sur la tête ou le cou.

Marquet "bailla (1) de son fouct à Forgier si rudement a travers les jambes que les nods (*) y apparaissoient". La peau cinglée par un vigoureux coup de louet devient le siege d'une extravasation sanguine appelée ecchymose. Cette rechymose, dont la coloration varie du noir foncé au jaume paille, suivant l'intensité, la période de la contusion et quelques autres conditions, est plus prononée si lit corde du fouet a des nouds. Elle est limitée d'abord amx points qui ont été touchés par les nouds de la corde.

Le seigneur Basehc (3) et Oudart (4) "festoyarent i grands coups de gantelets un chicanous, si bien quil resta tout estourdi et meurtri, un oeil poché an beurre noir, huict costes froissées, le breschet (5) enfondré (6), les omoplates en quatre quartiers, la maschoire infériemre en trois loppins .... Ainsy refoume i l'Isle Bouchard ( 7$)^{-}$chicanous accoustré à la tigresque.... et moyemnant le secours des bons chirurgiens du pays, vesquit tant que vouldrez. Depuis

Malthiole d'Antoine du Pinct: "La vipere, rencontrant wne branche de feu, demeure tout thoy comme estomnée. "

Et dans la Condamnalion de Banquel, de Nicole de la Chesnaye, essai médico-prétique du commenceurent du xra siecle :

Et moi ‘ui suis epilencie (épilensie)
Dois-je pas avoir renommée.
Par moi est la teste estonnée...

(I) Donna.

(2) Les noruds, les nodosités, du latin norlus.

(3) La terre de Basché est située sur le territoire de la commune d'Azay-le-Ridean, à 12 kilomètres de Chinon. Le seigneur de Basché dont il s’agit était, sans doute, Perrot de Basché, aucien maître thòtel du roi Charles VIl.

(4) "Le curé de sa praroisse, qni le servoit de sommeiller, comme lors estoit la coustume en France." (L. IV, ch, xit.)

(5) Le sternum.

(6) Brisé, défoncí.

(7) Petite ville dn Chinonais qui doit son nom à une ile de la Viemne dans laquelle un châtean fort fut bâti an $x^{\circ}$ ef an xie siecle ot à 11 Bonchard, qui fut un de ses premiers seigneurs. 
n'en fut parlé. La mémoire en expira (1) avecques le son des cloches, lesquelles quarillonnarent i son enterrement."

Est-il possible de trouver une phrase plus précise et en mème temps plus imagée que celle accoustré à la tigresque, pour expriner l'état moucheté; tacheté de mar ques noires, plus ou moinslarges et régulières, de la peau meurtrie de-ci de-là del'homme de toi? Celui-ci survécut-il? Mourul-il? Gràce au soin des chinmegiens de son pays, "il resquit tant que vouldrez ". Les contusions multiples de la pean et du lissu cellulaire sous-cutané, les fractures, même complinfuées, de lomoplate et de la màchoire inférienre guérissent, en génóral, assoz bien; mais la flacture du stelnum avec enfoncement des fragments peut avoir, en raison du voisinage du curur et des poumons, les conséquences les plus graves. Et le doctenr Rabelais, qui le sait, réserve sagement son pronostic.

Dans son combat contre le capitaine Leupgarou, Pantagrruel "le frappa du pied un si grand eoup contre le ventre. qu’il le jecta on arrière a jambes rebindaines (2), et vous le tratsmoit ainsy.... Et Lomperarou s'escroit, en rendant le sang par la gorge : Mahom, Mahom, Mahom! (3)"

Un violent eonp de pied dans le rentre pent fort bien, en effet, provorguer ume déchime des visceres abdominamx, suivie, quelques instants apres, d'une hémorthagie plus ou moins abondante par la bouche ou le londement.

Qu'on mo sy lompe pats, Rabedais a possiodó lontes les qualitís d'un méderin d'élite: la science, l'humanité, l'amé-

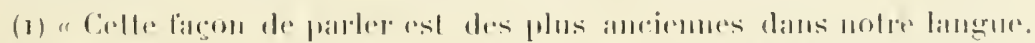

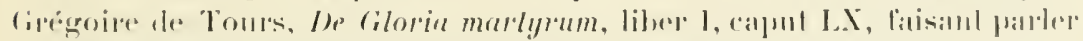

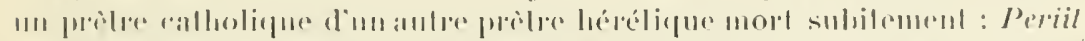

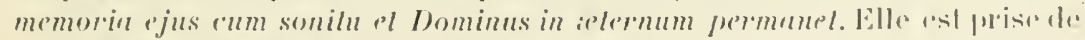

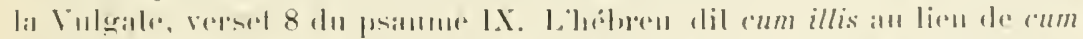

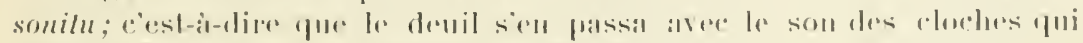

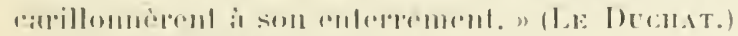

(2) Las jambos en l'air.

(3) M:1 Mormel. 
nité de caractire, de gestes et de langage, le soin de sa personne.

I. La science. Tout le démontre: les ourrages de Maître François (1), les instruments de chirurgie qu'il a inventés, les médailles frappées en son honneur, les écrits en vers et en prose que lui ont dédiés ses contemporains, les

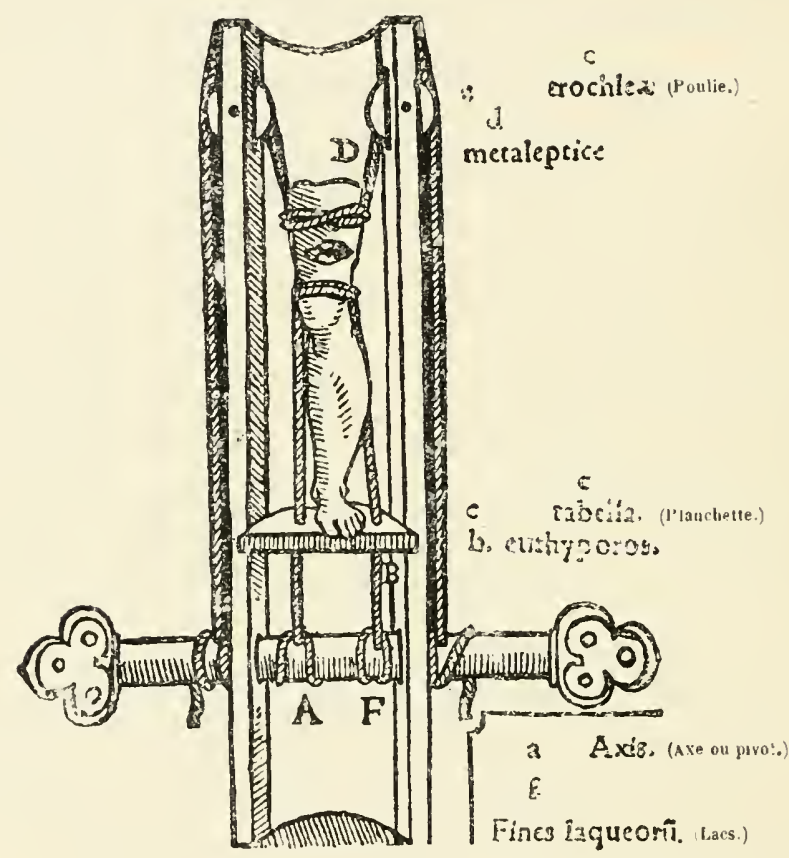

Glusoromion de Iirhelnis.

hautes positions qu’il a oecupées dans l'enseignement médieal et dans les hòpitanx des premières villes de France, la réputationqu’il a laissée partout où il s'est livré à la pratique de son art.

Au nombre des instruments de chirurgie inventés par Rabelais, ilenest deux quisont surtout très ingénieux et très per-

(1) Gargantua, Pantagrurl, une réimpression des Aphorismes dIItpo'rule, une prélace aux Épilves médicales de J. Menardi de Ferrare, une traluction du premier live d'Hérodole, etc. 
sonnels: unglossocomion, glottocomion on solène mécanique pourla réduction des fractures de l'os de la cuisse, et un sirynngolome pour débrider l'intestin hernié et étranglé. On doi a M. Heulhard Nivernoys la connaissance d'une traduction du IVe live de Galien, publiée à Lyon en 1.xij, donnant la

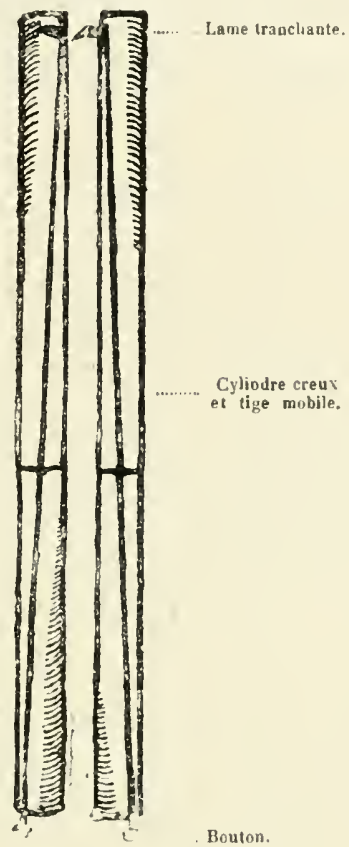

Siryngotome de Rubeluis.

description de ces deux objets et leur dessin de la main mème du grand raillente. Ainsi quion peot s'en render compte de visu (1), le ghlossocomionde Rabelais (2) ressomble absolument à celui d'Ambroine Paré, dont presque tous les

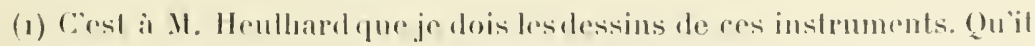
me permette de lui exprimer icei foute ma sratilurle.

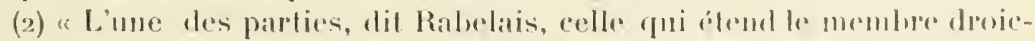

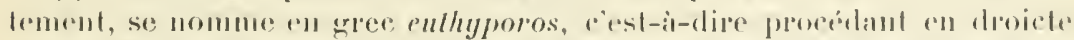

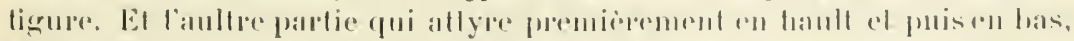

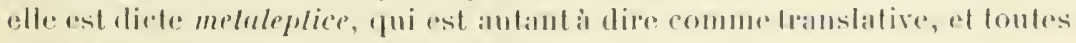

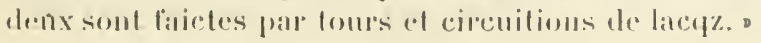


appareils à extension el à contre-extension employés mainterant dans les cas de fractures du fémur ne sont que des moditications plus ou moins heureuses.

Quant au siryngotome, il est constitué par un tube de bois ou de métal contenant une tige mobile terminée, à l'une de ses extrémités, par une lame tranchante, et à l'autrepar un petit bouton. En appuyant sur ce petit bouton, l'opératenr lait saillir, au moment voulu, la lame tranchante (1).

Sur quatremédailles frappées en l'honneur de Rabelais. deux exaltent le médecin. Une, large de 4 centimètres, offre sculement le buste de face et, en exergue, l'inscription: M. François Rabelais, Ir en méd. Surl'autre sont gratrás, d'un côté, le mème buste et une devise latine et, sur le revers, un $\operatorname{coq}(2)$ et un renard habillé en pielerin tenant une bulle d'absolution avec les mots allemands: Wer glaubl zu geschwint oft schaden emp findl (:3).

Paul Lacroix a écrit que Ilubert Sussannean, correcteur à l'imprimerie Sébastien Gryphe en mème temps pue Maitre Francois, mais broullé avee lui, " ne balança pas a s'adresser ì ce savant homme, quilui inspirait plus de confiance que tous les professeurs de la Faculté de Montpellier, ot que Rabelais répondit à cette contiance en le guérissant. Leur réconciliation data de la convalescence du poète, qui ne manqua pas, dans ses Ludi, de cólébrer cette belle cure" .

Voici la pièce de vers des Ludi de Sussanneau dont a roulu parler Paul Lacroix :

(1) Liapureil de fracture ef l'instrument it inciser les fistules appelés le premiel yinsso\%óurov ou swing, le second siryngolome par les médecins grecs, nont rien de eomnum que le nom arec le glossocomion et le siryngotome de l'illustre mélecin chinonais.

(2) Chez les Grees et les Romains, le coq était offert en holocanste i Esculape, dieu de la médecine. On sait que Socrate, avant de boire la ciguë, a recommandé à ses amis de ne pas oublier d’immoler à Esculape un corf quil lui arait promis.

(3) Gui eroit trop promptement, mal s'en ressent. 
SUSS.INELS

IU RUBEL.ESUN

CUM ESSET IN HONTE PESSLLAXO

Inbertus celsa medicorum languet in urbe:

Pharmaca languentem nulla juare queunt.

Tu potes: haud ullo, ni fallat opinio, morbo.

Est desiderio lanyuidus ille lui.

Fronle serenahis dulci, penitusque recedel

(uni tolo mixtus corpore languor eral 1 .

SUSSANYEAU

A R.ABELAIS

AloRS A MONTPELLIEl

Dans la haule cilé chicre à la Médecine,

Hubert languil ; rien ne pent le guérir;

Toi, tu le peux. Il n est pas soufliant, j’imagine:

Mais de ne plus te voir le fait languir.

liens à lui, front riant; la langueur qui lo mine

sobloignera pour ne plus revenir.

Que P. Laceoix ail plus on moins bien eompris les disliques de Sussanneau, la réputation de gomérisseme du Grand Chononaio nen souflura pas. je présume. Rabelais a-t-il en compassion te labat de son ancien ami? Oui, de l'aven mème du poète. (Voy. H. Sussiveseat, Llexandri quantitales emendala, 15:) (11-8.)

Sa muse ne fut pass semle ì cób́brel les cures de Maitre Fancois. Salmon Vacrin, poite londunais (2) anpluel ses magnilipues composilions lalimes ont valu le smomom

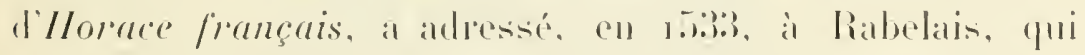
exereat la médecine à Lyon, more ode on il rhanter ses

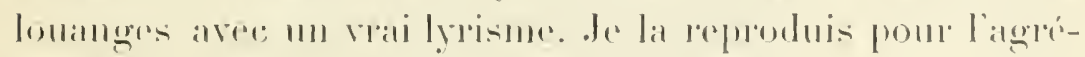
mont dul lectrits.

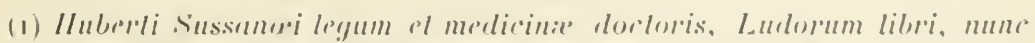

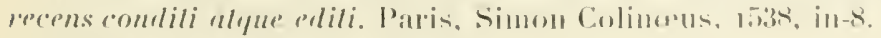

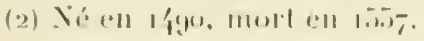




\section{SALMONIUS MAGRINUS}

II FRINCISCLY R.MBL.ESU CHINONIEN, MEDICUM PERITIS.

Idem, Rablasi, penè solum mihi est

Natale lecum : Juliodunicis

Nam Chino ricinus nucetis

Contigua regione floret:

Aërrque nostris civilus ac tuis

Hawritur ilem, parque serenitas,

Par ruris uligo beati,

Morum eadem quorque lenitudo.

Natalis agri concilians tibi

ricinitas me, jungit amabili

Tinclo, sed impense luarum

ris sociat mage litterarum.

Chinonienses inter enim tus

Lnus, Rablasi, es, cui Deus, el favens

Natura, doctrinam eleganlem

Non neget, atque sales aculos;

Unus lepores cui simul Alticos

El circularis dona perilie

Dilargiatur. florulentam et

Coynitionem utriusque lingux;

Artem ut medendi prateream, el tibi

Sudore mullo parta malhemala,

Ouid Luna, quid stella minentur,

Ouid rapidi facies planeta.

Tu non Galeno Pergamreo minor,

Mullos al, atris faucibus eximis

Lethi propinquantis, tuaque

Depositos opera focillas.

Ouil quaque radix hertave conferal,

Ungues, tenes, el non secus ac tuos,

Famamque lucraris perennem.

Arte levans genus omne morbos.

Testes tuarum Parisii artium,

Testisque Narlo Martius, alque Atax;

El dile Lugdunum, penates

Sunl tili ubi, placidie que sedes. 


\section{SALMON MAGRIN}

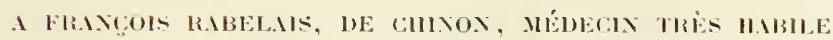

Nous avons, Rabelais, presque un herceau commun :

Car Chinon, qui la donné lìre.

Fleuril tout près de ce Loudun

font les noyers me virenl nailre:

C̈est mème air, mème cicl, mème sćrénité

Chez nous quen la cile nalale;

Aux rhamps pareille humidite

Et dans les menrs donceur égale.

D'un sympalhique norud, mon ceur est joinl au tien

Par cel intime roisinage;

Mais les écrits sont un lien

Oui mallache à bo davanlage.

seul de les Chinonais, Rabelais, In lecens

Je Dien, de la Nalure amic

La science élégante, en plus

De la fine plaisanterie;

Chez toi seul sont - largesse mique du bestin -

Rassemblés ces dons: sel altique,

Maitrise en gres comme en lalin,

El savoil encrelopédique :

Pour passer sous silence encor l'all médical,

Lastrologie, âpre conquète,

(Oni, sur l'aspecel, sail de puel mal

Ilenacent lune, astre ou plancle.

Nombrenx soul cenx que prés léja du moir lombean,

In biober dont rouve la llanume,

Pus sarves, Galien nourean.

Eigal a lianrien de Pergame.

Tu possides an boul desomgles les verlus

Thes simples, el mainle virloire

sur hos manx, par loi comballus,

Te vant more aloptelle gloire:

Trionples par Paris, par Narbonne allestís

El par l, you, la riche rille,

()i les penales lranspolles

fonissonl diun paisible asilo 1.

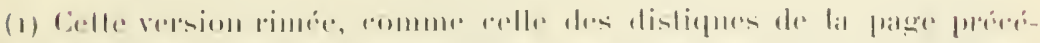

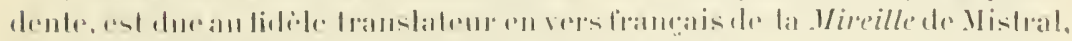

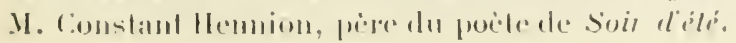


En 15:37. Étienne Dolet a lèté dans un banquet le céfiber toulangeau : "lhonneur de la médecine, qui arait te ponvoir de rappeler les morts des portes du tombeau el de les rendlor is la humière. "

Dans ses mémoines, de Thou a qualitié Rabelais " d'homme extrêmement versé dans la connaissance des lethes gneecpues et latines et de tris habile médecin. I ï lilteris gracis, latinisque instructissimns el medicina quam profitebatur peritissimus " (1).

Pierre Boulanger, de Loudun, médecin et pròte lout ensemble, a composé une épitaphe commencant par ces mots : "Francisci Rabelesi medici doctissimi facetissimique tumulus (2)."

L'auteur de Garyantua et de l'antayracel a professé la módecine à l'Université de Lyon et à celle de Montpellier. Dansi la notice de l'édition de Genive (OEnvres choisies, 16.52), il est mème dit que, "devenu célèbre prar sa science médieale, Maitre François ful appelé, à une date non précisce, à l'Université d'Angers pour y donner des lecons; mais que la peste s'étant déclarée dans cette ville, il s'éloigna, laissant les médecins se débattre contre le llóan ". Je dois laver mon illustre confrère de l'aceusation de làcheté portéc contre lui, comme je l'ai lavé de l'acensation d'avoir pris le titre de doeteur arant de l'avoir eontuis. Si son passage ì Angers est indiseutable, il n'est pas eertain qüil ait habité cette ville. La peste à laquelle il est fait allusion dans le cinquieme chapitre du second live (:3) est relle qui a éclạté

(1) Guillanme Colnetet, Nolice sur líabelais al Mémoires de la vie de J. A. de Thou, 1. VI, De vilâ sui, - a l’année 1598 ; édition de Londres, 173 \%.

(2) Tombean de Rabelais, médecin tres savant ef tres lacétieux. (BouLANGER, Mippoeratis Aphorismoram paraphrasis poelica, 1587.)

(3) Voici en quels termes: "Pantagruel s'en partit du Rhosuc, et it trois pas ef un sanlt vint à Angiers, oit il se trouvoit fort bien ef y eust demouré qualdure espace, n’eust esté que la peste bes en chassa. " 
au mois d'aoùt 1.jos et forcé François ler à quilter l'Aujou. Or, à cette époque, le futur auteur de Panlagranel étail encore au couvent de Fontenay-te-Comte (1). Au dos d'un acte de rente consenti an profit des cordeliers de Fontenayle-Comte, on trouve, à la date du 5 aril risig, la signature de Maitre François, à coté de celle de Pierre Lamy (2).

Rabelais a été, de Pârues $15 / 16$ au 2.j juin 15\%- médecin de lihopital de Metz, aux appointements de 120 livres par all (3), et pendant quinze mois médecin de l'Hotel-Dien du Pont-du-Rhòne, à Lyon, aux appointements de fo lives par an (4). Il a perdu, en 153 , sa place de médecin de l'IlotelDieu du Pont-du-Rhòne, pour s’ètre "absenté de la ville el dudict hospital sans congé prendre pour la deuxiesme loys " (.). On a beancoup reproché à Maitre Frangois ces deux manquements à ses devoirs prolessionnels. Le premier s'explique par le désir qu'il a eu de voir home et de ne pas s'aliéner son protecteur, J. Du Bellay, évêrue de P’aris, envoyé en qualité d'ambassadeur extraordinaire auprès du saint-Siege par François Ier (6); le second, par la néees-

(1) 11 est í jeen pres certain que Rabelais a passé an moins seize ans au convent de Fontenay-le-Comle, de 1507011508 i 152\%. (Voy. Aconteter, Rabelais a Fontenay-le-Comle, Bullet. de la Soe, des dmis el Admiralents de liabelais, Tours, 1892, 1) 49; et BLonuen-Laxabons, Angers et linjou. Augers, 18 15.)

(2) Voy. lutroduclion, p. 21, fexte el notes.

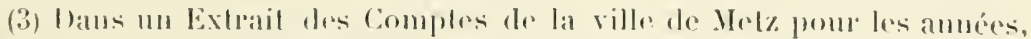

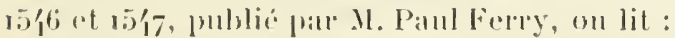

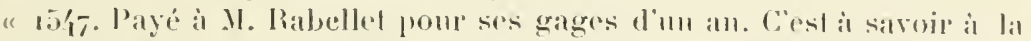

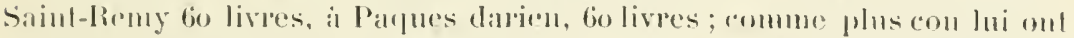

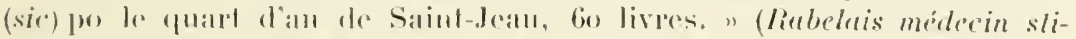

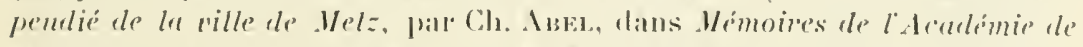

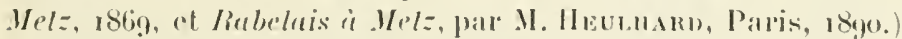

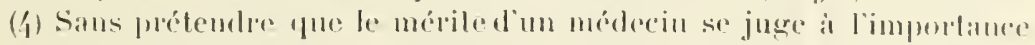

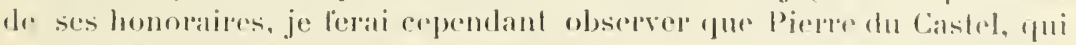

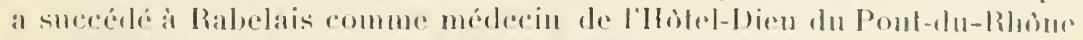
a Lyou, na louché que 3o liveres le "gages " par all.

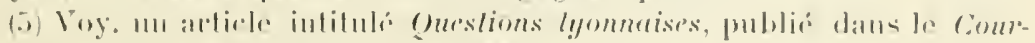

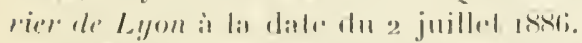

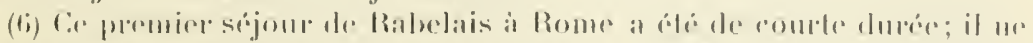

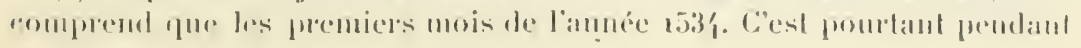


sité où il sést trouré, quand le premier livre de Pantagrael a été censuré par la Sorbonne, de se réfngier a Grenoble, chez le président de Vachon (1), som ami, pour pouvoir, en cas de danger, liranchir la frontière.

Dans le chapitre L du live IV, il est fait mention par frère Jean qu'à "Senillé comme les coquins (2) souppants un jour de bonne feste a l'hospilal, et se vantants l'un avoir eelluy jour gagné six blanes (3), laultre denx sols, l'aultre sept karolus (4), un gros gueux se rantoit aroir gagné trois testons (5). "Aussy, luy respondirent ses compagnons, tu has " une jambe de Dieu (6). "Comme si quelque divinité fust absconse (7) en une jambe tout sphacélée (8) et pourrie." Il y avait done un hopital a seuily? Oui. cet établissement déjà indiqué dans une charte de 127!), eoncernant une transaction entre l'abbé de Senilly (9) et Guillaume Marmande,

cethe bréve pérode que Maitre Francois anrait alceompli celte série te bouflomeries - flelle que eelte sur la mule du pape, qui est indiquée dans be ch. xurn du I. IV) - dont la réalité niest nullement démontrée et qui font plus dhomeur a l’imagrination des commentateurs qǜ la rérité historique.

(1) "François Rabelais, dit Chorrier, ent chez lui une sineté fu il n'ent pas trouvere ailleurs." (L'Impartial des Alpes, numéro du ti arril 1885 ; lartiele Rabelais, de Gir-Alesro, dans le Diclionnaire hislorique, public

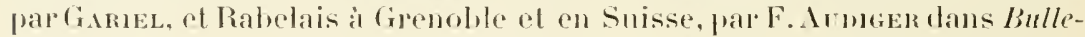
lins de la Sociélé des Amis el Admiraleurs de lirbeluis. Tours, 1889, p. 10.)

(2) Les vagalonds, les mendiants, les guenx qui haulaient les cuisines, oì ils trombaicut des restes dont ils se régalaient. Ce mot semble, commur celui de mailre-gutene, venir du latin coquus, yni signifie cuisinier. Dans lal mane on appelle cog le enisinier.

(3) Le blance est une menue monnate dont on se servail eneope an rommencement de re siocle. Il valail 5 deniers. J'ai entendu bien des lois estimer des denrées alimenlaires 6 blanes, est-it-dire 2 sols el demi.

(1) Voy. 1) 203, note 千.

(5) Le teston est une ancienne momaie dargent qui valait 15 sons et G deniers, et sur laquelle élail gravé la lete du roi. Elle a eonmencé a aroil conrs solls Lonis XI1.

(6) "Une jambe, dit Sardon, que Dien a frappe dime infirmité inenrable. - C'rst une locution hébrä̈que."

(7) Caclué, du latin abseonsus.

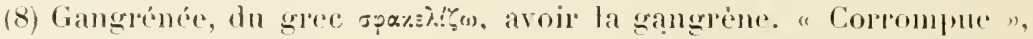
dit la Briefie Diclaration.

(9) La paroisse de Senilly. sur le terriloire de tarnelle est silué la 
seigneur du Condray-Montpensier, a été d'abord une léponserie, puis une aumonerie at, en dernier lien, un hripital. Arant d'éribe la lie inestimable du grand Ciarganlua.

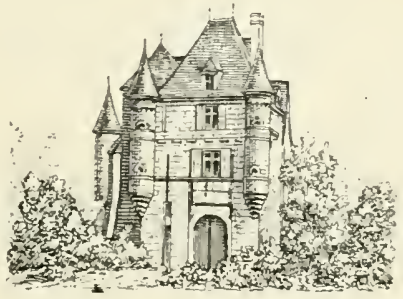

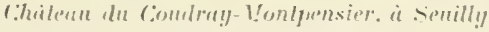

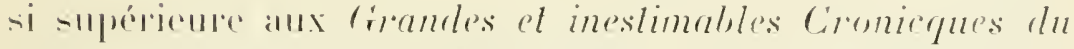

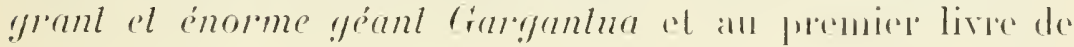

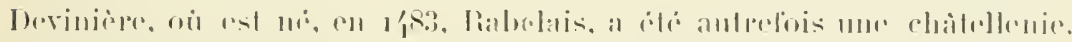

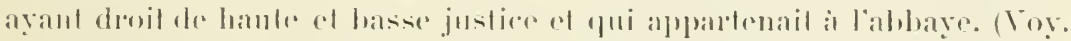

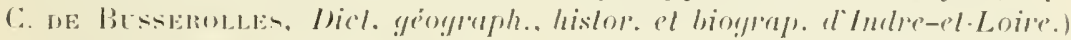

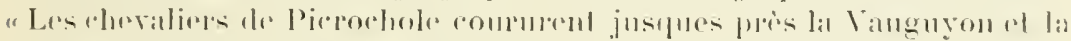

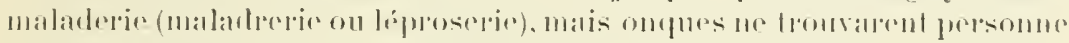

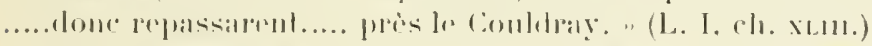

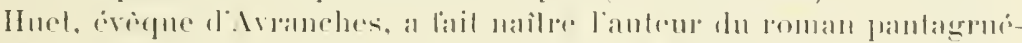

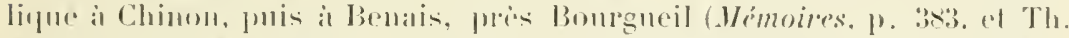

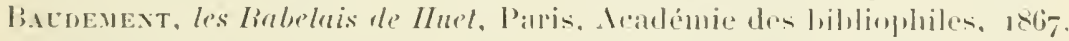

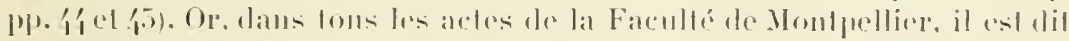

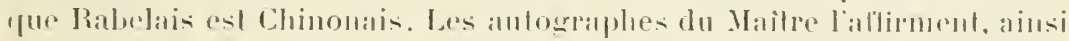

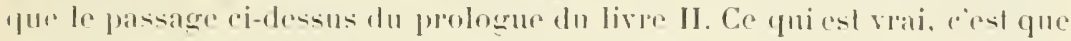
des parents do liblustre satirique out habite Benais el pue lui-mene a

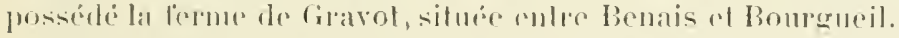

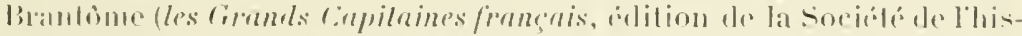

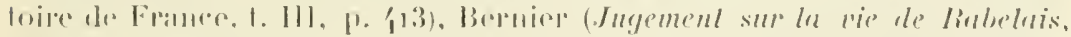

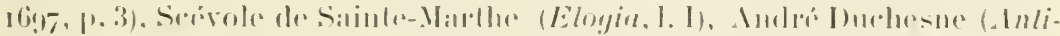

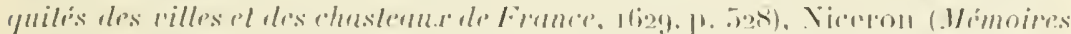

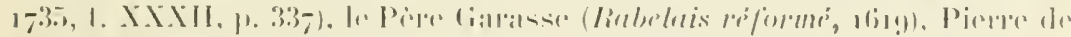

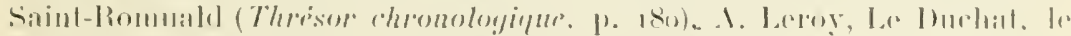

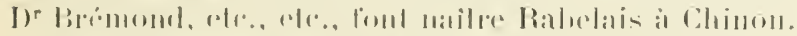

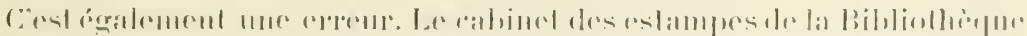

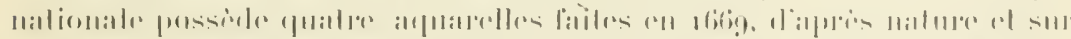

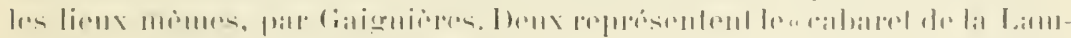

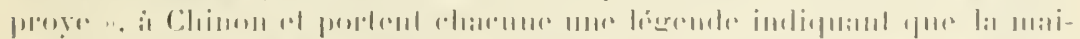

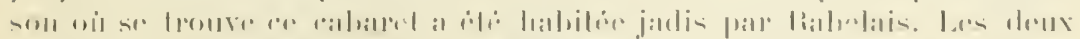

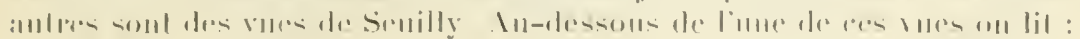


Pantagruel, roy des Dipsodes, publiés antérieurement (1), Maître Alcofribas Nasier (2) est revenu "visiter son païs de

"La Deviniere à une bonne lieue de Chinon, à deux portées de fuzil de l'abbaye de Sully et presque vis-ti-vis la Roche-Clermanlt, el le lien où est né Rabelais; de la fraroisse Saint-Pierre de Sully en Touraine ; 1699 . "

Et au-tessous de l'autre:

"Veue de l'abbaye de Nolpe-Dame de Sully, de l'optre de Clugny, en Touraine, 1699. - Saint-Pierre de Sully ou a esté baptisé Rabelais, et la paroisse du Coudray-Montpensier. "(Bibliolherpe nationale, dépratement des estampes, ${ }^{\circ 5} 5323,5324,5325$ et 5327 .)

Ce lémoignage clót tout débat. 11 s'appuie sur ee que le créateur de l'archéologic lrançaise a vu, sur ce quont pu lui dire les moines de l'abbaye de Seuilly et les gens du pays, ete. Rabelais est né a la bevinière, dont sa famille a été propriélaire pendant deux siècles (1/50-1650), el a été baptisé dans l'église paroissiale de Scuilly, placée sous le vocable de saint Pierre et non dans l'église abbatiale qui éfail placée sous le vocable te Nolre-Dame. La maissance th grand railleur at la Devinière ne lait, du reste, aucun donte pour personne en Touraine, mème à Chinon. (Voy. Dunousten, Essuis historique's sur la ville de Chinon, $2^{\mathrm{e}}$ édil., $180 y$, 1. 192; Bellaxger, la Touraine ancienne el moderne, 1845, 1). 523; Chevalar, Promenades piltoresyues en Touraine, 1869 , 1) 459; Charles de Gravimason, Guide du voyayeur de Tours anx Sables-d Olonne, 1875, 1. 99 ; Inventaire des archives déparlementales d'Indre-el-Loire, I. 11I, p. 17 de la prélace; Mémoires de la sociélé des antiquaires de l'Ouest, I. II, P. 367; Mémoiress de la Société archéologique de Touraine, t. IX, p. 323 ; t. XXVIII, p. 465, el t. XXX1, p. 248; II. Grinaud, Revue poitevine el sammuroise, $1898,11^{\circ} 7$, p. 48.)

Pour la date de la naissance de Maître François, celle de 1483 , génćralement acceptée, me paraît beaucoup plus plausible que celle de 1490, 1492, 1495, proposéc la première par Guy Patin, la seconde par H. Grimand, ta troisieme par Rathery et divers autres commentateurs.

Un dernier not : Le père do Rabelais itait-il aubergiste, comme l'alliment les uns, ou apothicaire, comme l'assurent les autres? Aubergiste? je l'ignore. Apothicaire? je le nie formellement. Les privileges et statuls de l'ancienne Université de Montpellier aceordaient aux Maîtres le droit "d'élever gratuitement a la maitrise lems fils, temes petitstils, ete. "Or, t'illustre Chinonais a payé trois livres ef un écu tror pour son inmatriculation. Il neélait lonc pas fils de Mâ̂tre.

(1) Il est incontestable pour moi, comme pour Ch. Brmel, le libliophile Jacob, cte., que Gargantua a paru après le premier live de P'antayruel.

(2) Pseudonyme dont Rabelais a signé ses deux premiers livres. Ciest, ainsi qu'on peut le vérifier ci-dessous, l'anagranme de Frangois Rabelais.

$$
\begin{aligned}
& \text { A I, G O F P I B A S N A S I E R }
\end{aligned}
$$

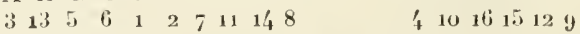

Ces deux noms viendraicnl, d'après M. Ducrot, du gree $\ddot{\alpha} \lambda \%$, du cel- 
vache (1) et sgavoil si en vie estoit parent sien aulcun." s’il faut en croire des témoignages dignes de loi, il a rempli alors, pendant un certain temps, les fonctions de médecin de l'abbaye de Senilly el de l'hòpital qui en relerait, et soighé, mème en dehors de l'abbaye, divers persomnages de qualité du Chinonais ou du Loudunais. C'est aimsi yu il a pu se rencontrer en consultation avee un irascible médecin loudunais dont il a en gravement a se plainde et quil a lait, pour se venger, figmer sous le nom de Picrochole dalls son immortel roman.

"Picrochole estoit médecin de Madame de Fonteraulx (.). Il se nommoit Scévole on Gaucher, grand père de Messients de sainte-Marthe (3). Il demenovit à Lerné, fui est mog buan village despendaut de Fontevraulx. Lequel village madame luy aroit domné sa vie durant, eomme elle aroit latet a deux précédents (ce qui fut) canse qu’il (habelais) lappela tiers du nom... Il estoit fort cholere : estant an consultation avee Riabelais, qui estoil médecin de l'abbaye de Semilly, il fiappa Rabelais, qui fut cause qu il l'appela

lique fri el bas, ret nasier, composé de nasus, nez, an latin, ef de la dési-

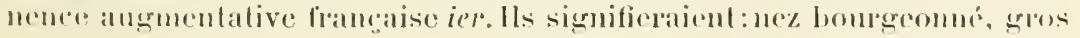

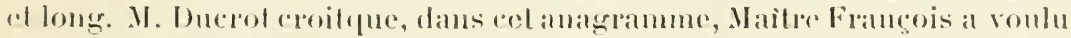
se peindre bui-meme of quil avilt un nez florissant an lien dn petit nez

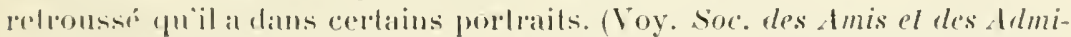

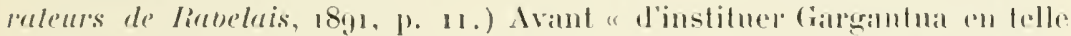
rliscipline quil ne pereloit heme du jour, Ponocrates, consideranl pue nalure ne rndure mutations sombdaines sans gramle violence..., supplia

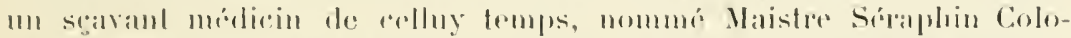

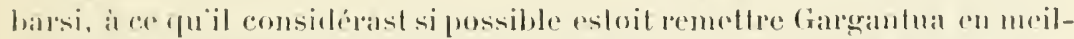

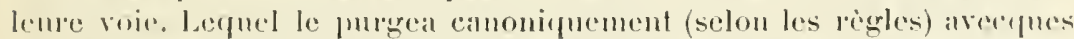

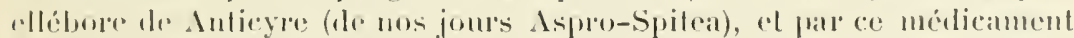

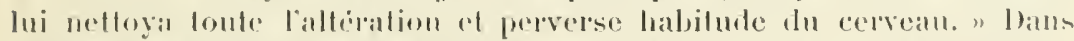

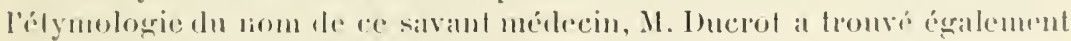

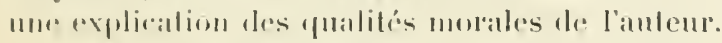

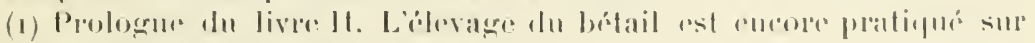
Hue vaste ichelle dins le Chinomatis.

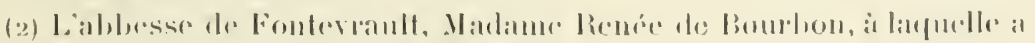

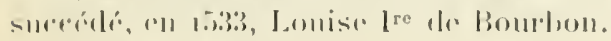

(3) Céblue lamille du lemulumais. 
Pierochole (1), le roy de Lerné, troisieme du nom. Il levoit les cons ot rentes de sa seignemie, el les loygles tailles (inde Royj). Il y eut un procès enter ankeuns de Lerné et les moines de Seuilly; lour temporel ful saisi. culde auldes le rlos de l'abbaye; qui fut baillé à ferme, peu avant les rendanges. Les lermiers s'ingérèrent de jould. ¿̀ quoi s'opposa friche Jehan des Entommenres, qui estoit leur pro(111011\% (2). ")

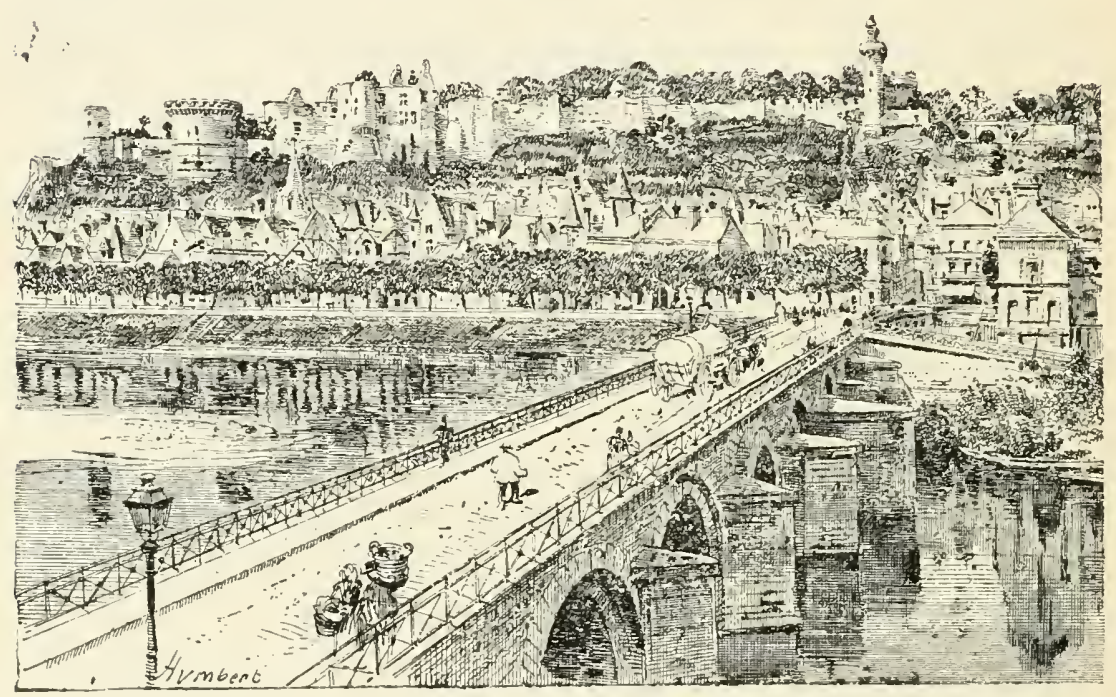

Chinoth.

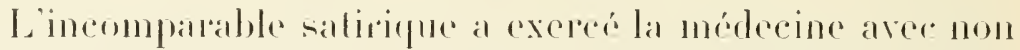
moins de distinction à Gatigny (i), à Fontenay-le-Combe.

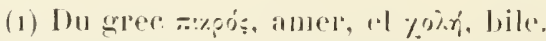

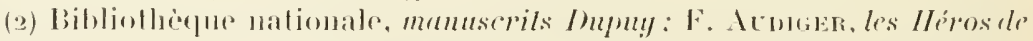

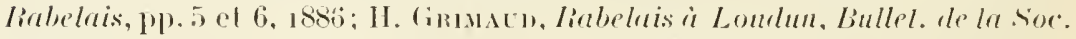

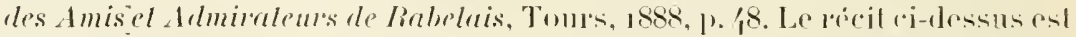

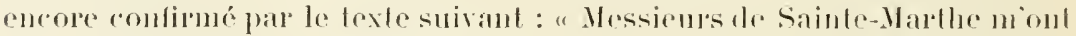
dit que le Picpochole de Rabelais estoit leur gramelope, gui estoit mó-

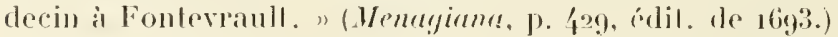

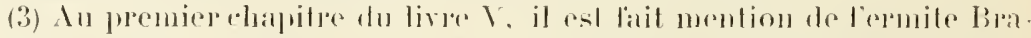

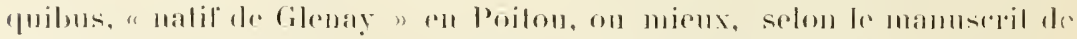

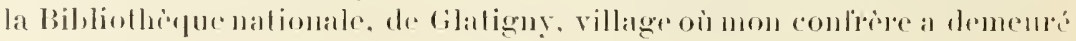
entre 1.528 et 1530. 
¿ Castres (1), a Parris, à Saint-Maur, ele., qu à Montpelliel, ¿ Lyon et a senilly. Antoine Leroy, un des arrière-suceesseurs de Rabelais dans la cure de Meudon, a dit de celui-ci: "que sa maison estoit a lout le monde, exeepté aux lemmes: qüil rassembloit somvent des scavants pour sentretenir avee rux: que les misérables trouvoicnt des socours dans sa bourse; qu il estoit d'mor si grande intégrité que jamais on

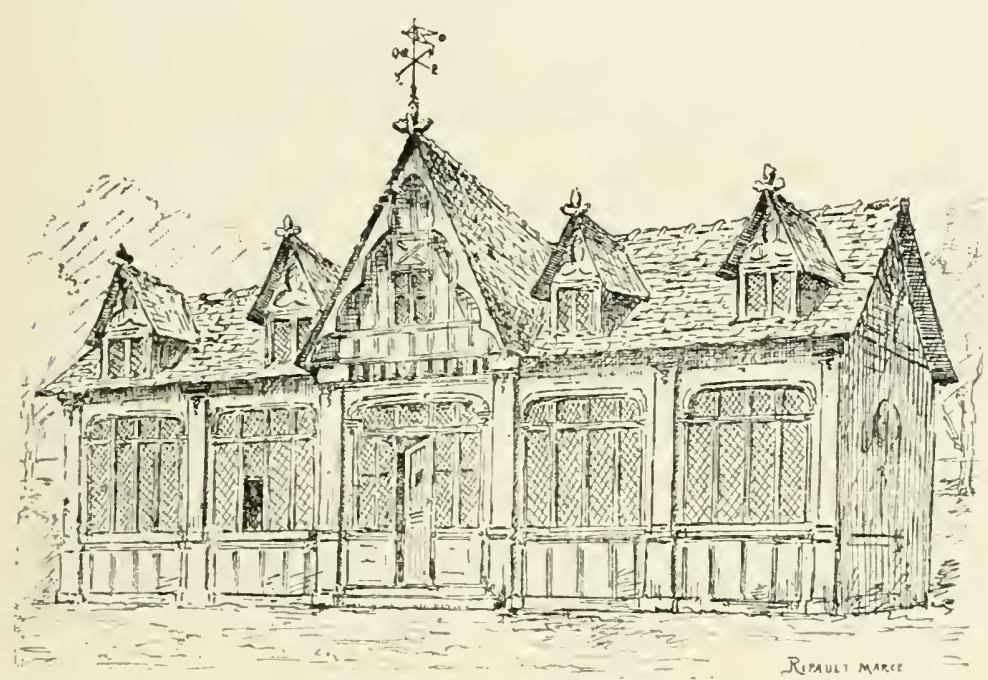

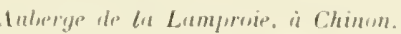

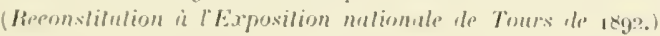

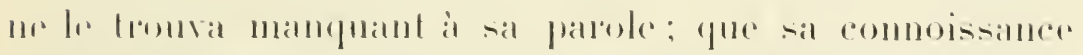

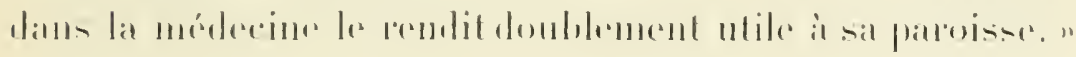

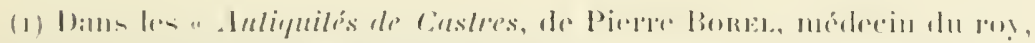

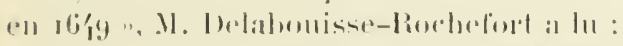

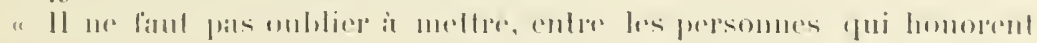

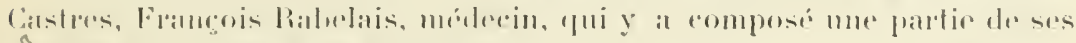

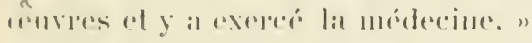

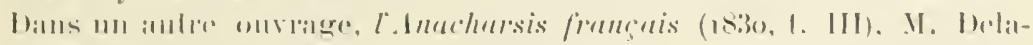

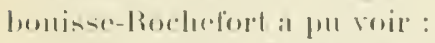

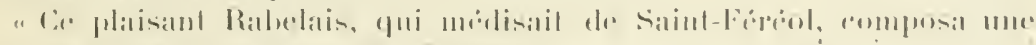

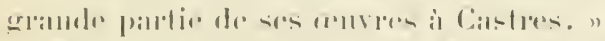

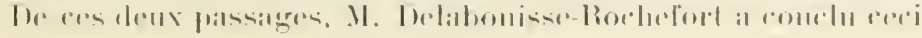


Jai lam, pour ne rien omettre, à lapporter celle déclaration élogieuse, bien que je n'y attache quime importance tries relative.

Rabelais n'a été curé de Meudon que pendant deux ans moins quelques jours et il me parait douteux qu'ily ait laissé des souvenirs aussi profonds el aussi vivaces dans les pays dont les bois charmants attirent pendant la belle saison un si grand nombre de Parisiens. Au mois de juillet 15is, lors de sal première tournée pastorale, l'érêque Eustache du Bellay a été recu à Meudon par Pierre Ruchard et quatre prêtres. La piece quile constate ne porte pas le nom de Rabelais. Mâtre François a, d'autre part, résilie la cure de Yeudon, ainsi que celle de Saint-Christophe-du-dambet. du diocèse du Mans, le g janvier iñ. pour ne pas entraver la publication de son IVe livre, qui est sorti entierement imprimé des presses de Fésendat, le 28 janvier 1.5. . Je ne dirai pas que l’illustre écrivain n’est jamais allí à Meudon. mais je suis intimement convaincu qu'il n'y a guire séjourné.

Il a passé les dernières années de sa vie à l'ablaye de Saint-Maur (1), ou plutòt dans le magnifique chàteau roisin,

"Dr. 1525 in 1531, il y a sept ans tont Rabelais a pu consacrer i Castres la phus grande partie. Borel le soutient, el persome ne le lui conteste. Objectera-t-on que, Borel disant que Rabelais exerga la mélecine à Castres, il n’aurait pu y habiter de 1525 à 1531 , puisqüil ne fut reçu tocteru à Montpellier yu à la fin de cette époque? Mais cette diffirulté tombe d'ellemème, puisque, dans son eouvent, Rabelais avait éludié la médeeine poú son plaisir et pour son instruction, ef cưil la pratiqua longtemps avant de la prolesser. Il ne se fit agréger ì la Faculté de Ifontpellier que de surérogation et pour se voir atlaché à un corps illustre. Allant habiter cette ville, ilne roulait pas aroir contre lui les membres d'une école anssi crilibre, qui anrait pu lui muire par prévention et par pivalite. Ainsi, je le répite, Borel est me autorití suffisante. Puisfuion ne trouve pas la possibiliti te lui répondre non, la question est résolue, et cest oui.n J'ai dit précédemment ce qüil fallait penser de la date fixée pour la réception de Maitre François au doctorat. (Pour détails complémentaires, consulter A. Forrots, Rabelais à Toulouse, à Castres et à Narbonne, Bullet. de la Soc. des Amis et Admirateurs de Rabelais. Tours, 1892, p. 44.)

(1) "Lieı, ou (pour mieulx el plus proprement dire) paradis de salu- 
bati, assuret-on, par Philibert Delorme pour le cardinal Jran du Bellay. Il n'esl cependant pas mort à Saint-Maur. mais à Paris (1), oì il a été inhumé dans le cimetière de l'église Saint-Paul, selon le R. P. leuillant Piere de SaintRomuald et Colletel, daus la nel de cette iglise, selon le Pipe Garasse.

Il n’a jamais ressé d'ìtre le módecin de Guillaume du Bellay, ni de .Jean du Bellay. Or le cardinal Jean du Bellay demeurait à Saint-Man en 155 et en 1.5.5. Rabelais a done exeré, quolque temps avant de mourir, la médecine à Saint-Maur et à Paris. J'ai vu, à Tours, chez mon regretté ami Audiger, un portrait sur toile du Maitre avancé (n) ige, et arec cettrinseription : Franciscus Rabelasus medirus Parisiensis (2). La mème inseription se retrome sur montrail peint sur un petit panneau dans la manière de Janet. mais adoucie, appartenant a M. le baron de Beurnonville a Paris (3), et sul un portrat grave ayant une rertaine analogie avec celui de la Chronologie collée de linonard Gamltier (n" (1) (1)

II. L humanilé. - Rabrais a élé aussi grand par lesenliment qüil a été pand par l’intelligence of le savoir.

lrike, amonite, sirnite, nommodite, déliees et touts bonestes plaisirs

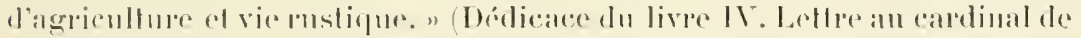
Chastillom.)

(1) Viaisemblablement en 1.53.

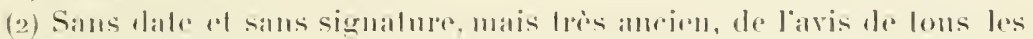

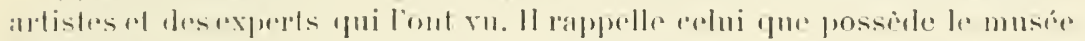

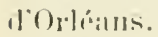

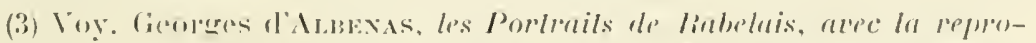

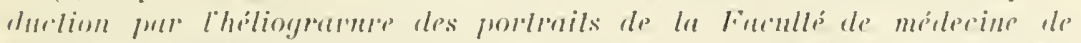

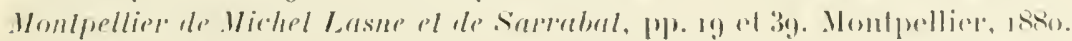

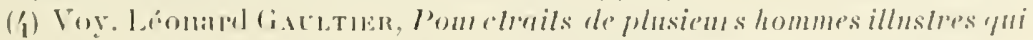

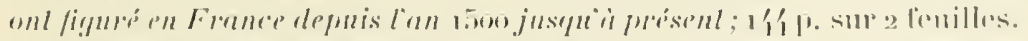

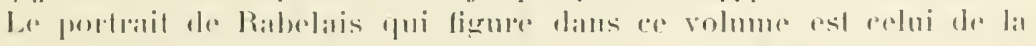

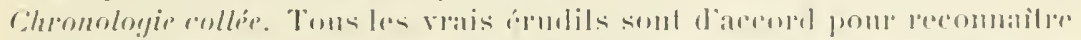

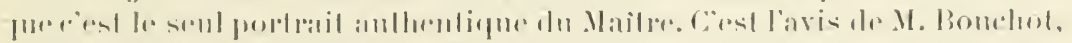

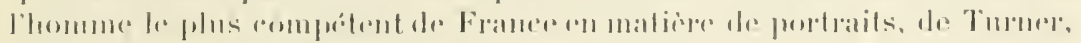

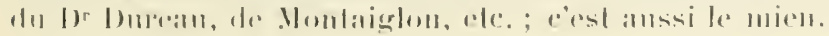


"Sapience (1), a-t-il éreril, n'entre point en ame malivolu $(2)$, et seirnce sans ronseience n'esl que ruine de l'ame... Le premier debvoir des gens doctes est de penser au peuple... sols servialole a tous tes prochains el les aime comme loimème... " (oue demande-t-il dans sa supplique an pape Paul III (:3)? Trois choses : l'absolution publique de s'alre enfui de chez les moines, la permission de pouvoir, an besoin, rentrer dans une abbaye de bémédictins el l'antorisilion d'exereer en tous lienx la médecine gratis, par pilié, aux senles conditions de ne se servir jamais ni du lere ni

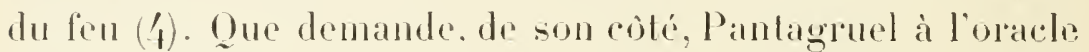
de la dive bonteille, yu'il est renu consulter de si loin? Curei : "Sonne le beau mol, je l'en proce, qui doibt nous uster le misires." Ce mut, c'est vérité, mais c'est aussi anour. "Ciar, commone est l'apologue d'Fsopet. fouls un naissent un sac au col, sonffreleux par nature et mendiants l'un de l'autre. Rog sous le ciel tant puissant n'est qui puisse se passer d'anllui; pauve n'est lant arrogant qui passer se puisse du roche voire ful-er Hippias (j) le philosophe qui laisoit tout. "Et voilà pourquoi, sal vir duraut, depuis la rave peinte de Cloinon jusifuaux hojpitaux de Montpellier el de Melz, Maitre Francois sest complu

(1) Instruclion, capacité, du latin sapientia.

(2) Malveillaute, méchante, du latin mulevolus of anch. malivolus.

(3) Voy. Introduction.

(1) En rertu de eet aphorism dollippocrate: "Les malaties pui ne pouront itre enterées par le ler, quon y emploie lo leu, sles médecins du moyen age coupaicut, taillaient ef brulaient à tort el à lavers.

"Les chirurgiens de notre sicele, pour avoil ru une fois le boucher éventrer un vean on un pore, sans aucme leçon d'anatomie, s'en vout brùlant ef taillant sur le corps des mortels... Lemir maxime, cest qu’il liaut sonffrir pour guérir. " (Jean LANGE.)

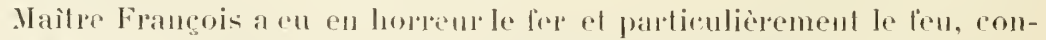
sidéré alop comme un élément mystérieux el purificateur.

(5) Hippias, sophiste d'Elis, contemporain de Platon et de Probagoras. On lui doit un dialogue intitulé les Troyens, dans lecpuel Nestor donne des conscils a véptolème pour vive homètement et sans le secours de personne. 
parmi les humbles, les déshérilís et les malades. Du junr wì il s'est penché sur l'humaine soutfrance, il lui a alplartenu sans réserve, obéissant à un idéal supérieur de juslice, de charité et de dérouement.

Il śest adomné spécialement a l'iblude de la diathèse quiont cóblorée Barthélemy et Fracastor et au traitement de cenx qui en étaient atleints (1) of que les nédecins du XVte siecle

(1) On sait que le nombre en étail grante Epistemon con al compté rent millions " en Euler of par les Champis-Elysées ". Les gramds persomalges nen étaienl pas exempls, pas plus le pape que le saeré rollege, que les rois. la noblesse. Ie penple. "Wadrantage, dil Rabelais, le pape sixte ecest

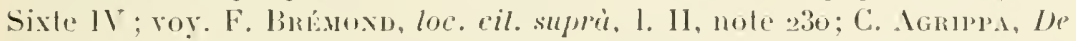

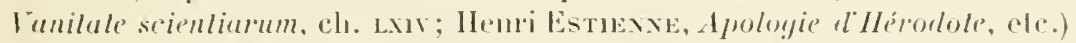
me domna quinze cants lives de rente sus son domaine et thrésor acelé-

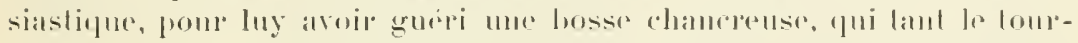

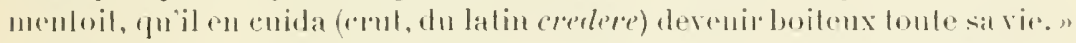

La bosse chancrense, cest le bubou inguinal dont las suppuralion stat regandé alors commore linorable.

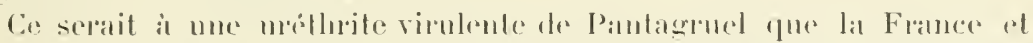

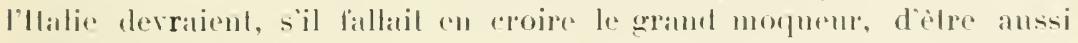
riches en stations thermales. "Panlagrodel tomba malade, el lut tant prins

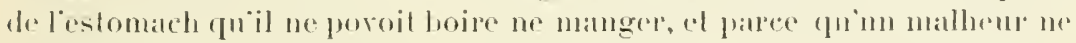
vienl janais seml, lui print une pisse chaulte, qui te tommenta plus que

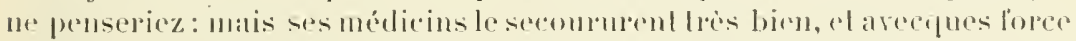

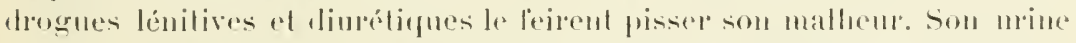

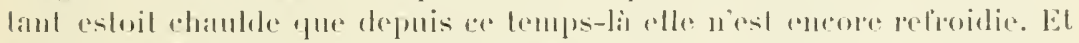

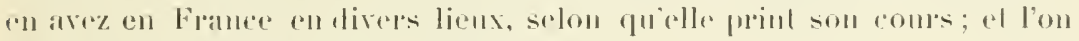
lappelle les hains chatulds, enmme :

1 Cordereds (Cinu'erels),

A Limons ("?),

A Datsl (Dote ).

I Billerue (Ballarac),

1 Veric (Novis),

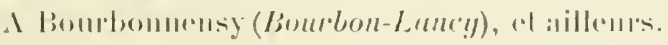

Eill Ilali, :

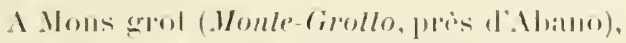

1. Аppone (Abuno r'u Pónilie).

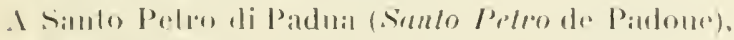

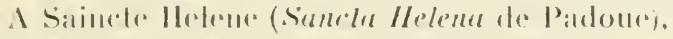

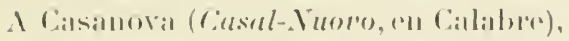

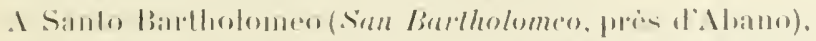

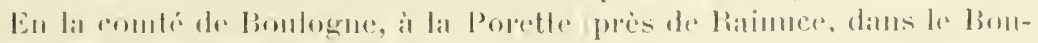
forlais) el mille anteres lienx.

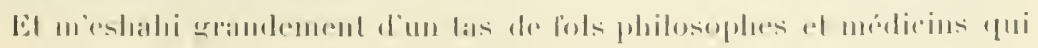


perdent temps a disputer dond (d'oin) vient la chaleur de res dictes caux, ou si ceest a rause du baurach (borax), ou du soulphre, ou de J'alum, on du salpestre qui est dedans la miniere. Lesiliets bains sont chanlds paree que ils sont issus par une chanlile pisse du bon Pantagritel.,

Jai dil antérieurement que Maître Francois a listingué l'uréthrite virulente de l'uréllupite nou virulente. (Voy. Anatomie deseriptive, Aplareil génital : La prenilispe, comme une dariole). Quant an traitement antiblemnorphagicue preseril par ses méderins à Pantagruel, il étail encore preseril il y a quelques années ef ronnu sous de nom de méthode du lessivage. En 18\% , quand j'étais interne a lhòpital du llibli, on ordonnail an individus atteints de gonocorcie méthrale des boissons "lénitives el diurétiques qui leur faisaieul pisser lem matheur ", puis des médicaments astringents intus et extrì.

Lolsfue Rabelais a commencé ses durles médieales, il n'y arail pas quarante ans qu'on s'ocempait de la syphilis. Les uns prótendaient quelle avait pris naissaner an siege de Vaples, les autres qu'elle avail rité apportie d'Améripue en Europe par les matelots de Chrislophe Colomb, cerux-ci qu'elle blail causé par la conjonction des astres, cenx-la par lusagre de la chair humaine, yuelques-mus par la bestialité d'où le nom

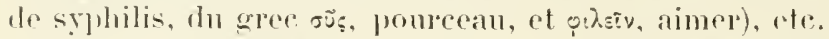

Antant d'lyypothises, autaul d'erreurs. Des epòues et des libias humains provenant des chambres sépulerales des dolmens de l'Ammede (Lozíre) ot de Léry (Eure), des fombelles do l'Hermis (Oise), du cimetirie frane de Bréby (Aisne) ef des lypogées de Lima (Pérou) purtent des stigmales de la hidense maladie.

En cela, la science n'a fait, au sumplus, que contirmer des dommes de thistoile, dont on nia plas assez tenu comple. Oviedo y Valdez of Grook assment que les araïles de l'Amérique el Jes insulaires de taïti étaient imprégnés du mal infertienx avant l'an rive des Conquisludores. Sangarassiar et Jlessianambi, médecins malabares qui visaient il y a neul sircles, eu disent autaut des populations des Indes Orientales et de la Malaisie. Ins ortonnances de police en vigueur il Copruhague en lquo, à Venise en 1302, a Londres en 1162 , laissent croire que longtenus arant lo retour de Christophe Colomb en Enrope les Européens nétaient pas moins contamines que les Polynisiens, les hudous et les Américains. Vérilable protée pathologique, ce mal a été décrit par les mires et les physiciens du moyen age sous les noms divers de pian de Vérace, bouton d amboine, radezyge, cte. C'est, à eoup sùr, le Morbus campanus des Romaius ot peut-être Ir Baral-Pehor des llóbreux.

Le Chinois Hoang-li, qui virait il y a quarante sireles, a mòme blabli la dualité de laecident primilif el elassé à part la blennom ragie. Enfin, d'iltustres savants allemands almettent la spécificité de certaines dermaloses yui ont pongé les tégunents de momies du musée de Boulâq.

si la sypluilis a pris un si grand developrement au moment de la decourrote de l'Amérique el du siege le Naples, e'est pare fue les mouvements do troupes que provougerent ces deux frénements la firenl sortir des domaines où elle était en quelque sorte cantonuée.

Rabelais ell a plus su sur les affections rénériennes que Bettencourt. 
Utrich de Hullen ef Gaspard Torella, les phe ceilibres sprécialistes de som

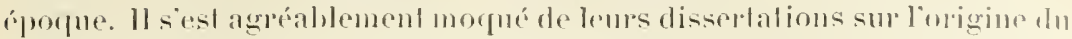
mal le Fracastor en en gratiliant Elion, wn des ancetres de Pantagruel,

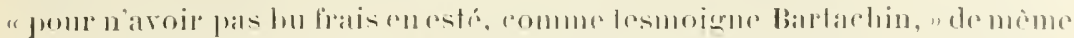

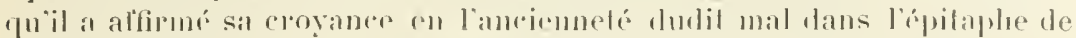
Thubal Holoferne, " un des préceptemes de Gargantua, mort en

... lian mil quatre rents ringt,

De la vorole qui luy vint ".

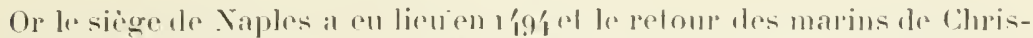

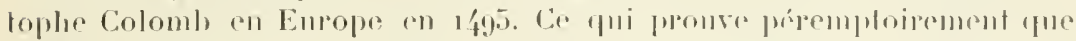

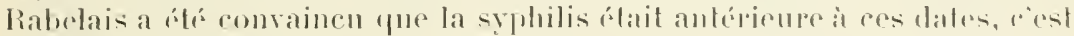

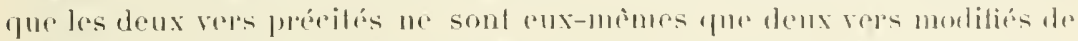
l'eppitaphe composée par Clément Harol pour un moine l'Orléas nommé

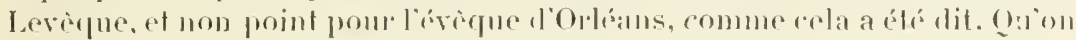
ell juge :

\section{幽}

Cy gist, repose et dort lians

Le finl revestye d'Orléans:

lentends linvsque en son surnom

Et frive Jean en propre nom

()ui mourut l'an riny cent et vingl

Ine lis verole yui lui vint.

Qui oserait prélendreque la substibulion ne soil pas voulue?

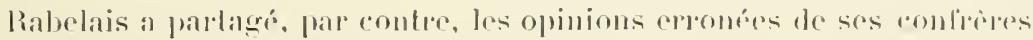
du mogen atge sur le mode de lamsmission de la syphilis of des anders

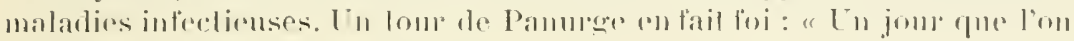

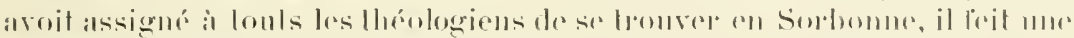

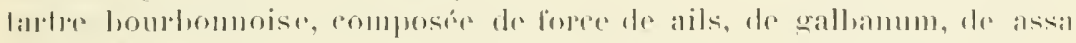

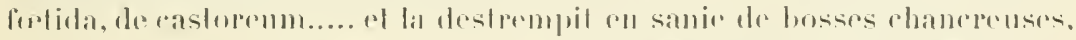

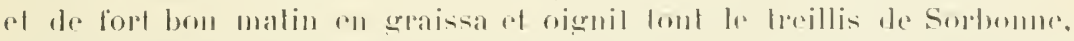

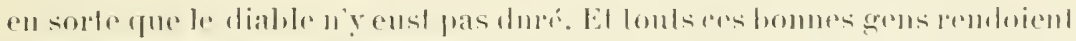

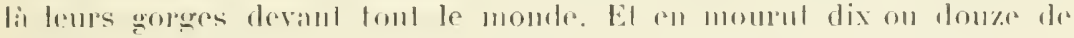

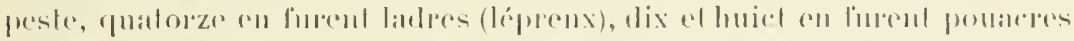

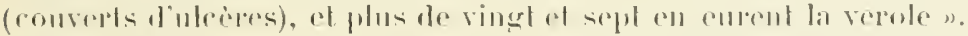

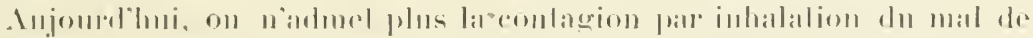

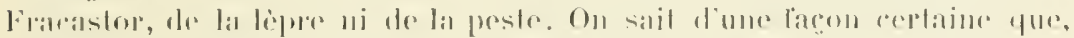

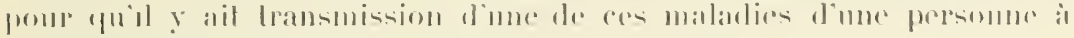

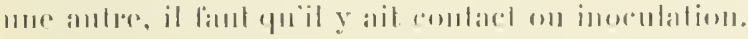

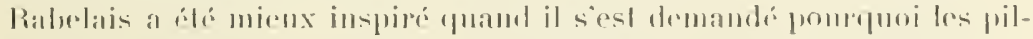

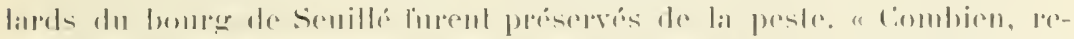

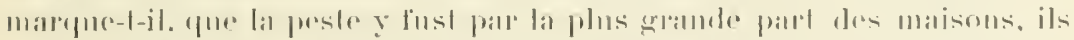

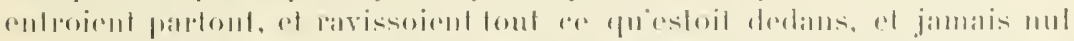

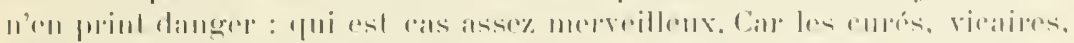

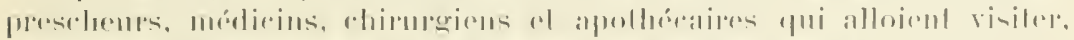

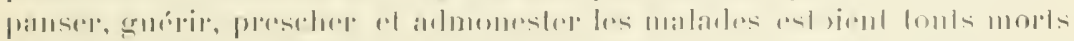

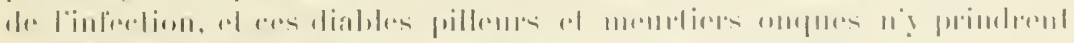

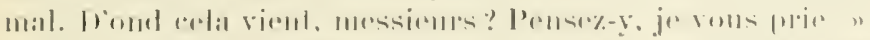

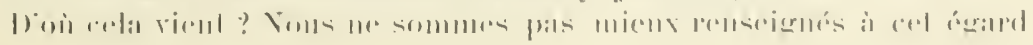




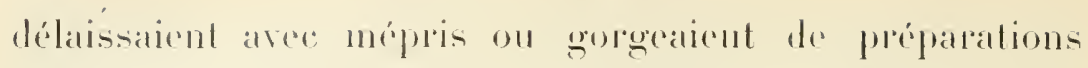
mereuriefles, aprós les aroir enfermís à jem pendant pilu-

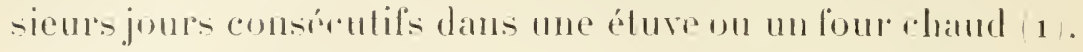
11 a plaidé chalemerusement la cause de ees viclimes des

que Mâtre Frangois. Allitire de germe ef de termin, assment les micro-

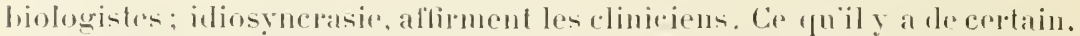
$\therefore$ est qüil y a des professions qui semblent preserver du féall, an cours

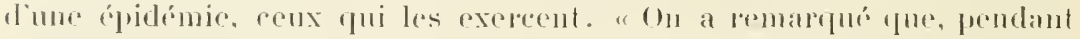
la peste dre Marseille, les portents donile avaicht étr généralemenl garantis, et, de nos jours, on a constalé que les filles publiques nétaient gue tres rarenent atteintes du choléra. "(I) Brámoxu.)

Pour elore ce qur Rabelais a dit de la syphilin, il me resterait i opposer il l'énmmération des qualités des organes grónitaux de forere Jean (Voy. Aplabeil génital : Les c..., comme une guedonfle) celle des détauts des

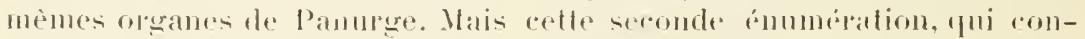
firme ce que jai déja avancé des commaissances en anatomie patholo-

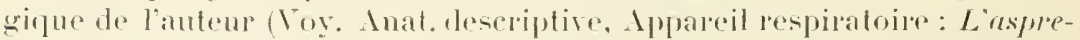

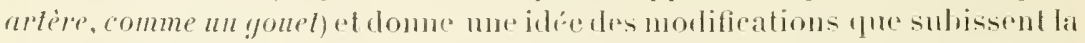
glande génitale et son produit de sécertion che' un lomme d'un certain ìge et spphilitique. compremel, comme la première émumration, un grand nombre de termes ef ne rentre qüincidenment dans mon sujet. Je men fientrai donc à ceux de ces temes qui sont les plus caractérisliques. Les roiri:

C... Es:REXÉ, avint perdu sa graine. La liquide sícrétí par les glandes génitales d'un individu atteint de sareoride syphilitique est moin- aloondant et contient moins de spermatozoïles.

C... DYscriste, fle manvaise contitution.

C... Bafatté. On ilonne, en Touraine, le nom de baraltí an petit-lait aigre qui reste quand le beurre est fat: baratté signifie donc ici : distillant un liquide séreux et acide. A létat normal. le sperme est épais et alcalin.

C.... spritcélé, mortifié, gangréné

C... Bıstoní. incisé par le histouri.

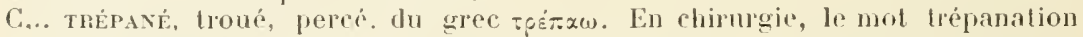
$\therefore$ applique surtout à l'ouverture du cràne.

C... estmonéxé, déformé, ulcéré, purulent. On apprelle aujonrdhi esthiomène ou lupus une malarlie chronique tuberculeuse siégeant presrue toujour à la face. Autrefois on appelait également ainsi une dermatose serpiginoulcéreuse de nature syphilitique.

C... CHOL-TELEVÉ, couvert de croùtes. Les eroùtes vénériennes solsservent de próférence à la tête, dans le cuir chevelu. Elles ont été très bien décrites prar lracastor dans son live De .Horl, is contuyiosis.

C... GRE-LÉ, ayant des cicatrices semblables à celles qui suivent la variole.

C.... sucopé, ayant des défaillances.

(... conxeté. etr., etr., ventousé. Dans le Boubonnais, les rentouses sont encore de petites cornes de lois percées à leur sommet. A Bourbonlirchambault, jai entendu sonvent dire : mettre des cornets " pour mettre des ventouses.

(1) Pour Gaspard Torella le meilleur moyen de guérir les syphilitiques cétait de les laire suer, dans une étuve ou mu four chand, pendant quinze 


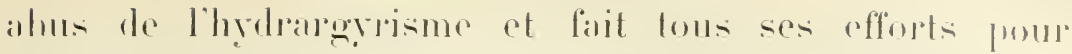
diminuer leur nombre a o puantesforis (1) nous les aroms vus. dit-il, a themre quils estoint bien oingts. ot anglaissis a a poinet; of le visage leme reluisoit comme la chover 3 diun charnier et les dents leurs tressailloient

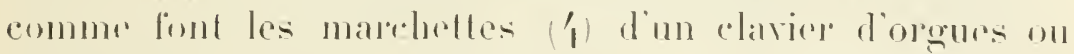

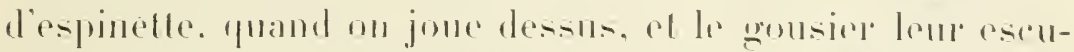

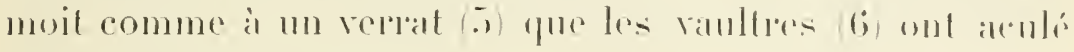
entre les toiles $(\boldsymbol{y})$.

Il a reeonnu et proclané bien haut la nécessike impérieuse quil y a pum lihomme, ausi bien pour son perfece-

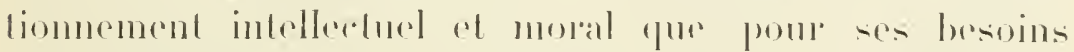

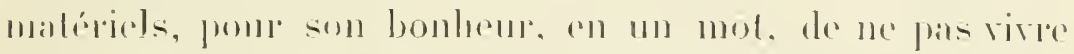

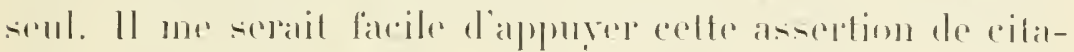

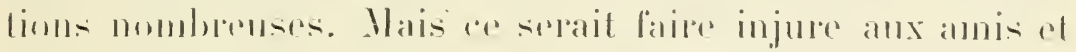
anx adminalents de Rabelain qui me lisent: je me hormerai dente is lat slivinnte:

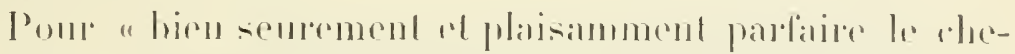

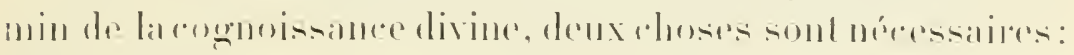

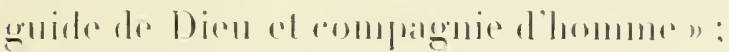

Lit is relle-ri (s) :

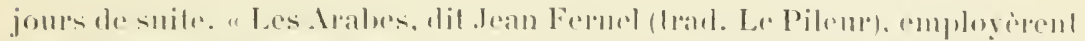

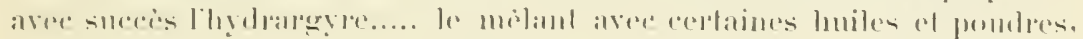

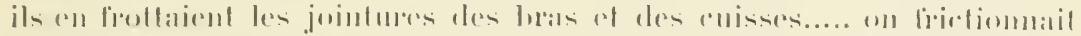

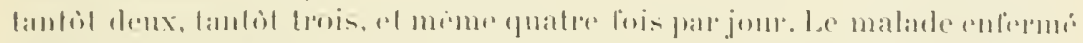

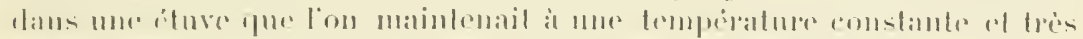

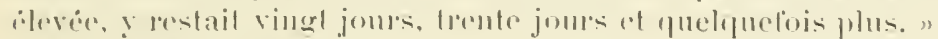

(1) Combien de luin.

(2) Cilaisisin.

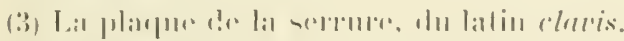

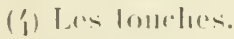

(i) Sillerlix'l.

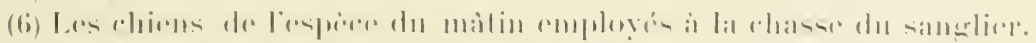

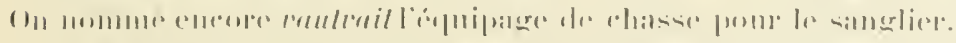

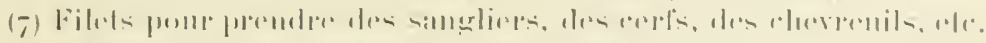

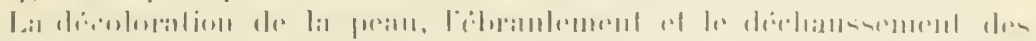

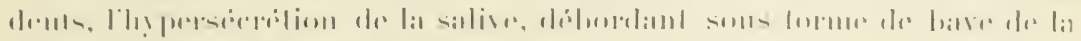

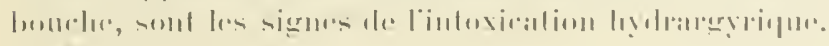

(s) $1 . .111,1 \cdot 1,11$ 
"Qnille et non marié, je n’ai personne qui tant de moi se sonciast. ch amour tel me portast, qu'on diet estre amour conjugal. Et si par eas lumbois en maladie, laricté ne serois fu'au rebours. Le Sage diet (1) : Là où n'est femme j'entunds mère-familles, el en mariage légitime), le malade ent cu grand estril" (2). J'an ai vu claire expérience en papes, légals. cardinaulx, avesques, abbés, prieurs et moynes. "

Les femmes n'ont pas changé depuis trois sieveles. Elles sont encore lidéale évocalion de la chandité ici-bas. Si, avece les àges et l'évolution sciontilique, les procédés de l'art médical se sont moditiés, leur cour, qui ressent les misères lumaines, et leurs gonts, quiles portent invinciblenenta les soulager, sont restés les mêmes. Ouel déronement égale colui d'une mère pour son enfant ạlité par la lievere!

(Onel tendre soin: Dort-il, attentive, celle chasse

Linsecte dont le rol ou le bruil le menace;

Elle semble défendre au réveil d'approcher.

La nuil mème d'un fils ne peut la délachor:

Son oreille de l'ombre écoute le silence,

On, si Morphée endort sa tendre vigilance,

Au moindre bruil ouranl ses yeux appesinlis,

Elle vole, inquiète, au cheret de son fils.

bans le sommeil longtemps le contemple immobile,

Lit rentre dans sa couche, à peine encore tranquille (3).

1il. L'aménilé de caraclère, de yestes el de langarge, le soin de sa personne. - Rabelais abhorrait " le minois dn médicin chagrin, tétrique (4), reubarbatil (5), calonian (ij),

(1) Mllusion anx paroles du Sage, de Salomon: Lbi non est mulier, ingemescil egens.

(2) Printe, chatgrin.

(3) Legoevé, Mérite des femmés.

(4) Tristr, du latin tetricus.

(5) Rébathbalit." Ny a-t-il pals, se demandent Burgaud des Marels el Rathery, daus celle manière d'écrire rébabbatil une allusion à la reubarber, comme on rerivail alor's?"

(6) Tel que celui de Caton le Censcur. 
malplaisant, malcontent, qui contriste le malade ". Il voulait qu'il ent cette " face joyense, sereme, plaisante, riante, ouverte ". qui réconforte celui qui souffre (1). Il a écrit, dans l'ancien prologute et dans la dédicace du live IV: "Ilippocrates ha laict mu livre exprès, lequel il hat intitule lle l'estat du parfaict médicin (口) Galen lha illustré de doetes commentantes), ampued il ha commandé rien n'estre au mérlicin qui puisse offenser le patient : gestes. touchenent (:3), contenance, vestements, barbe, chereulx, mains, bouche, voire justues a particulariser les ongles, comme s’il denst jouer le role de quelque amourenx ou

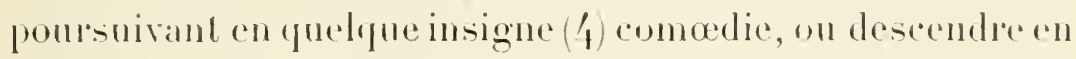

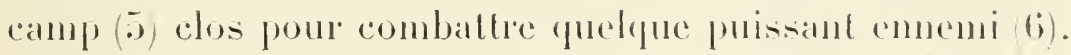
linsy laire en mon endroict et à mon lomedois (7), je me poine (s) ef efforee enver's eenlx que je prend en cure."

Nest-ee pas là nu résumé des dochlines pastemriennes régnantes, qui ventent yu'un ehirmegien ne puisse ouldeprendre uneopérationavant d'aroir changrí de costume el nettoyé soigneusement el à plusienrs reprises, avee la brosse el des liquides antiseptiques, ses avant-buas, ses mains of ses ongles. eomprés allssi ras que possible?

"De linet, la pratieque de médicine bien puoprement est

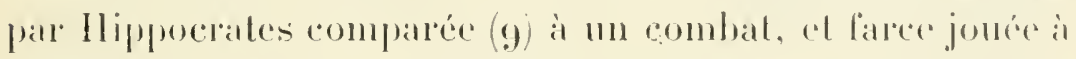
Lois persomnages : le malade, le médicin, la maladie. I atpuelle composition lisant quelque fois, nest soubrem

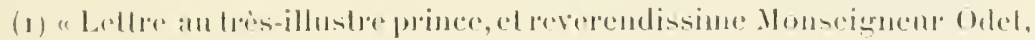
cardinal de cilastillon.

(2) Dians ses Preceptes el sou live de la Bienséance, Hippocrate ent

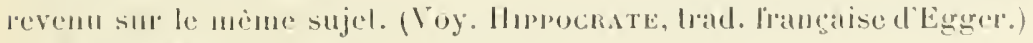

(3) Tourhere, contart.

(1) liemar(jualdr, du lat tiu insignis.

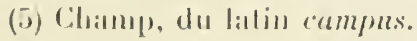

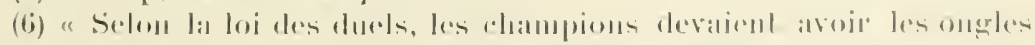

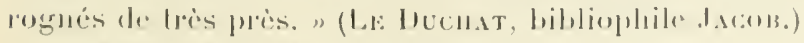

(i). Arece lianchise, nairement.

(s) Peine.

(9) Hupuckite, Mes Épilimies, 17. 
diune parole de Julia is Oelavian Auguste son pere. Un jour. elle sestoil derant luy presentée en habils pompenx, dis-

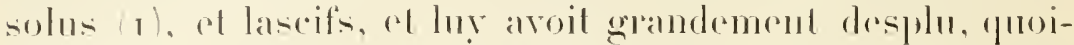
yuil non sonnats mot (2). An lendemain (3). clle changea dr restement et modestement se habilla, comme lorss restoit la eoustume des rlastes dames romaines. Ainss vestue, se présenta devant huy. II /), qui le jour précédent

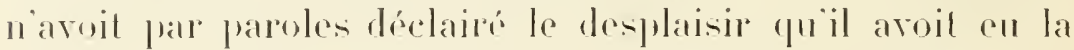
voyant en habits impudiques, ne put célel le plaisir qüil prenoit en la voyant ainsy rlangée, ol luy dist : "O combien cestuy (i) restement plus est séant ot lomable (ii) en (7) la lille de Auguste!" Elle eut son exense prompte el luy respondit: "Huy me suis-je vestue pour les arils de mon piore (s) ; hier je l'estois pour le gré de mon mari."

"Semblablement ponroit le médicin, ainsy desguisi en liner el habits, mesmement revestu de riche et plaisante robe it quatre manches [eomme jadis astoil l'estal (9), al estoil appelée Philoninm 10, comme diel Petrus Alexandri-

(1) Reritchés, Hotlants. du batin dissolulus.

(2) N'en dil mot.

(3) Lce lendemain.

(1) Cehin-ci, Augustr.

(i) Ce.

(6) Digne dóloge, du latin lundubilis.

(7) 1 .

(8) "Hodie enim me palris oculis ornavi, heri riri; anjould'un jo me

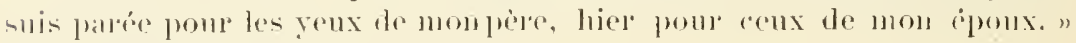
(Voy. Mlacrobe, Salurnales, II, i.)

(9) Lil moele.

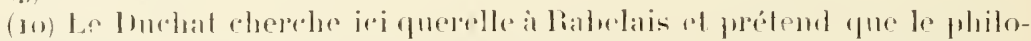

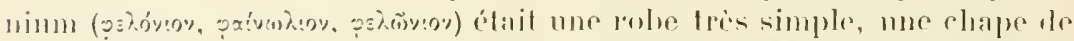

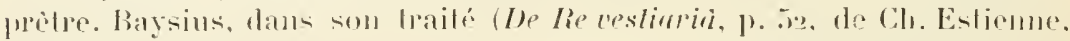

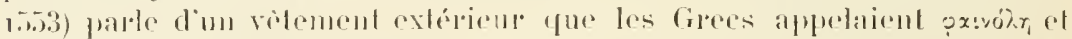

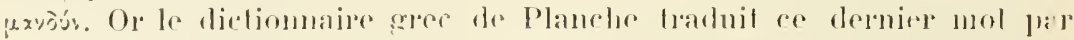

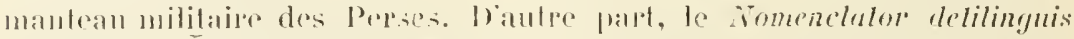

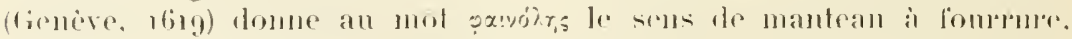

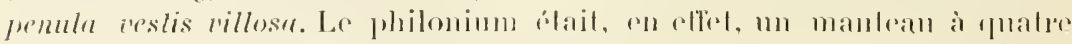
manches, dont drux restaient sims rmploi.

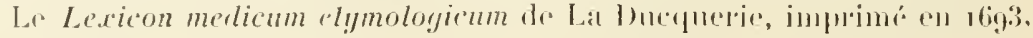


uus, in 6 Epid.] (1), respondre à ceulx qui trouveroient la prosopopée (2) estrange : ". linsy me suis-je accoustré, non pour me gorgiaser (3) et pomper (1) ; mais pour le gré du malade, leyuel je visite, auquel seul je veulx entièrement complaire, en rien ne l'offenser" (5) ne fuscher. "

N'est-ce pas là le conseil déontologique paraphrasé du Dr Dechanbre : "La dignité d" médecin est le corollaire obligé de la noblesse de son art. Ciette dignité se montrera dans toutes les actions de sa vie publique ou privée."

11 est non moins indispensable que le médecin lasse bien attention "aux paroles, propos, abouchements (i) et conlabulations ( $\boldsymbol{7})$, qu'il doibt tenir aveeques les malades. de la part desquels seroit appelé.

"Comme grandement est par Herophilus blasmé Callia$11 \mathrm{dx}$ (8), médicin, (qui, a un patient l’interroguant et demandant: "Mourrai-je?" impudentement (y) respondit:

Et Patroclus ì morl succomba bien :

Qui plus estoil que n'es, homme de bien (10).

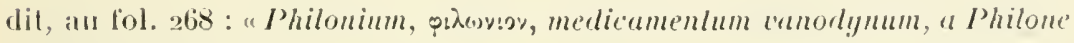
medico authore."

Lar robe nomméc philonium a peut-ètre été inventér anssi prar le médrcin Pliilon.

(1) An lien de Petrus Aledundrinus, il fiut lim Jounnes Aledumbinus,

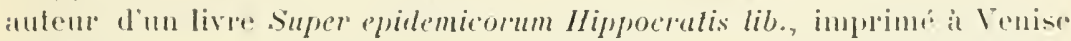
1'11 1 83.

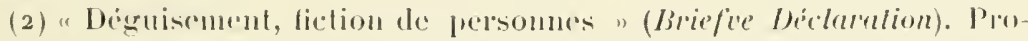

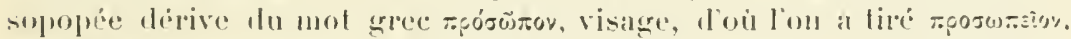
tII:siflete.

(3) Faire lo lueant.

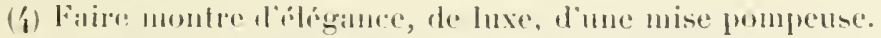

(i) Le blesser et aussi lui nuire, du latin offendere.

(6) Premier's mots de la couversation.

(7) Entretiens, du latin confabulari.

(8) J'al dil antrieurement (Voy. Anat. descriptive, Appareil urinatre,

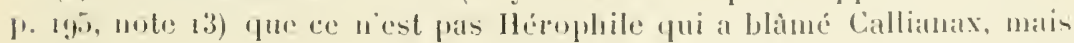
Biacelinis.

(9) Effountemont, du latiu impurtenter.

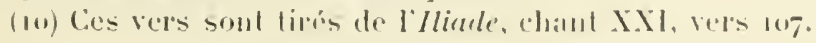


"A un aultre voulant entendre l'estat de sa maladie. et l'interroguant à la mode du noble Patelin : "Et mon urine vous dict-elle poinct que je menre? (1) " il (2) follement respondit : "Non, si t'eust Latona (3) mère des beaulx enfants Phobus et Diane engendré. "Pareillement est de Cl. (ialen, lib. 亿, comment. in 6 Epid. grandement vitupéré (1) Quintus son précepteur en médicine, lequel à un certain malade en (5) Rome, homme honorable, luy disant: "Vous avez desjeuné, nostre maistre, vostre haleine me sent le vin! "arroganment respondit: "La lienne me sent la fiebre : duquel est le flair et l'odeur plus délicieux, de la fiebrre ou du vin?"

Il importe, enfin, à celui qui est chargé de rendre la santé aux autres, de commencer par veiller soignemsement sur la sienne, de prècher d'exemple. "Me demandez-rous pourquoi? Response irréfragable. Tel est le vouloir du trèsbon, tris-grand Dieu : onquel (6) je acquiesce (7), onquel je obtempère (8), duquel je rérère la sacrosaincte (9) parole de bonnes nouvelles. C'est l'Evangile, onquel est dict, Lur, 4 (10), en horrible sareasme et sanglante dérision, au médicin négligent de sa propre santé : Médicin. o. guéris toi-mesme.) Cl. Gal., non pour telle révérence (11), en santé soi maintenoit, quoique quelque sentement (12) il eust des

(1) Vers de la farce le Maistre Pierre Pathelin.

(2) Celui-ci.

(3) Latoné, fille de Cóos it de Plorbé, fit aimée de Jupiter dont elle eut deux enfants, Phoelus-Apollon ef Diane.

(4) Réprimandé, blàmé, du latin vituperare.

(5) A.

(6) Aurquel.

(7) Je crois, je consens, du latin acquiescere.

(8) Auquel jobéis, du latin obtemperare.

(9) Tris sainte, sainte et sacre, du latin sacer. sacré, et sanctus, saint.

(10) Évangile sten saint Luc, ch. w. On sait que saint Luc, yui a publié in gree l'Érangile lo plus estimé, élait médecin, et à ce titre est avec saint Come, elc., un des patrons des médecins.

(11) Considération, du latin reverentia.

(12) Opinion. 
sacres Bibles (1), el eust cognu (2) et liéquenté les saincts christians (3) de son temps, comme appert lib. II. de I'su partium (9). lib. II. de Differentiis pulsumm (5), cap. 3. el ibidem lib. $11 \mathrm{I}$ (i) cap. 2. el lib. de Rerum affectibus (7) (s'il est de Cralen); mais par crainte de tomber en ceste. rulgaire et silyrique moquerie:

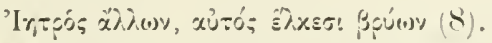

Médicin est des aultres en effect :

Toutesfois est d'ulceres tout infect.

"De mode qu'en grande braveté (y) il se rente, et ne venlt estre médicin estimé, si, depuis l'an de son age vingt et huictiesme jusques en sa haulte rieillesse, il n’ha reseu ensanté entiere exceptez quelques tiebres äphémères (10) dr peu de durée: combien (11) que de son naturel il ne lust des plus sains, el eust l'estomah évidentement (12) dyscrasió (1:3). "Cart dict-il. lib. V. de S'anit. tuend. (19), difficilement selar eru le midicin avoir soing de la santé d'anttrui, qui de la sienne propre est négligent. "Encore plus

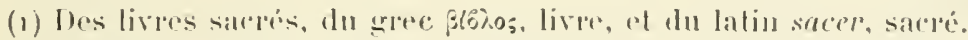

(2) Collut1.

(3) Chrétirns.

(i) L. II. De ll Lenge des prarlies.

(6) L. II. Ines Itiflérences du pouls el des Pulsations du come, ch. 3.

(ii) El live $111,1 \%$. 2, du mine ourage.

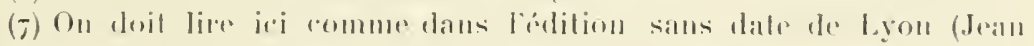

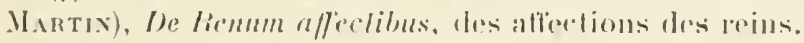

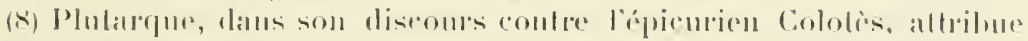

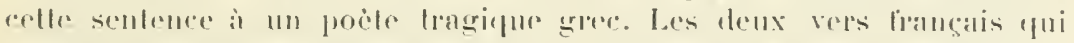
suivent, ot qui en sont la traduction, sont vaisemblablement de Rabelais.

(9) En grande havade, bravemont.

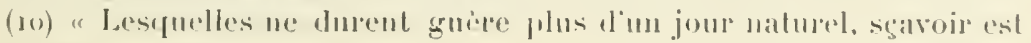
s' lieures. "(Briefine Déclarelion.)

(1) Bursidpue.

(12) Evidomment.

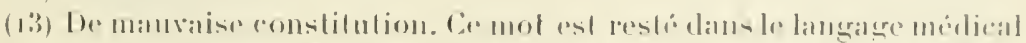

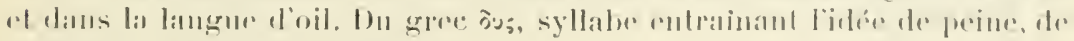

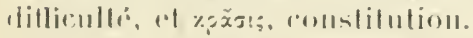

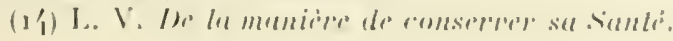


bravement se rentait Asclepiades (1) médicin avoir avecques Foilune convenu en ceste paction (2), que médicin réputé ne fust, si malade avoit esté depuis le temps quil commencea pratiequer en l’art, jusques à sa dernière vieillesse. I laquelle entier il parvint et vigoureux en touts ses membres, et de la Fortune triumphant. Finablement (3), sans maladie auleune précédente, feit (4) de vie à mort eschange, tombant par male garde (5) du hault de certains degrés mal enmortaisés (6) et pourris (7)."

Il arrive, malgré tout, qu'une maladie progresse et que tout espoir de guérison disparaisse. Alor's "le prudent médicin, royant par les signes prognostics (8) son maladeentrer en decours de mort, par quelques jours devant advertit les lemmes, enfants, parents et amis du décès imminent du mari, père ou prochain, alfin qu'en ce reste de temps qu’il ha de vivre, ils l'admonestent (g) donner ordre à sa maison, exhorter et benire ses enl'ants, recommender la viduité de sa femme, desclairer ce qu’il sçaura estre nécessaire à l'entretenement (10) des pupilles; et ne soit de mort surprins (11) sans tester et ordonner de son ame et de sa maison " (12).

(1) Asclépiate, médecin de Billynie an commencenent du Ier siècle avant Jésns-Christ, rint exercer son art à Rome, où il se fit me grande réputation et foucla une secte de médecins appelés Asclépiens.

(2) Traté, arcord, du latin pactio. Consult. Puxe, I. III, ch. xxxren.

(3) Finalenent.

(1) Fit.

(5) Pas mégarde,

(6) Mal emboîtés. (Noureau prologne du livre IV.)

(7) Dans le chapitre xxix du live III, Rabelais avait déjá écrit : "les bons médicins donnent tel ordre à la partie prophylactique et conservatrice de santí en leur endroict, qu'il n'ont besoing de la llıérapeulique et curative par médieaments."

(8) Pronosties.

(9) L'engagent instamment, du latin ad, augnentatil, et monere, avertir, prévenir:

(10) I l'entretien.

(11) Sinpris.

(12) L. IV, ch. xxvil. 
C'est ainsi que Rabelais se comportait vis-it-ris de ses clients et de la famille de chacun d'eux. Quant à ceux qui souffraient loin de lui, il leur destinait son live comme un remède sourerain. "En composant par esbat (1) ces mythologies pantagruéiiques (2), a-t-il mandé an cardinal de Chàtillon (3), je ne prétendois gloire ne louange auleune : seulement arois esgard et intention par escript donner ce peu de soulagement que porois és (4) affligés et malades absents $(5)$ : ee que voluntiers, quand besoing est, je lais es présents qui soi aident de mon art et service (6). "

Il ne les guŕrissait pas, mais il s'estimait heureux de leur procurer quelques instants d'oubli. Et il en a connu "par" le monde (ce ne sont fariboles) qui estants grandement alfligés... n'ont trouvé remède plus expédient que de metlre lesdictes chroniques entre deux beaulx linges bien chaulds, et les appliquer au lieu de la douleur, les sinapizant aveeques

(1) Distraction, eomme passe-temps.

(2) "Fabulenses narrations; cest nu tirton gree, "lit-on dans la Briefere Déclaration, attribuce à juste litre ì Rabelais.

(3) Dédicace du live IV.

(1) Aıx.

(5) "C'est, disent Burgand et Rathery, le fímoignage que remd ì Ritbelais Louis Rouzean, lorsque, apres avoir fait son éloge, il ajoute : IIoc ployium homini debui quia non raro abeo melancholia luto, ciló et jucunde liberalus sum. Je dois cet éloge a cet homme paree qu'il n'est pas ralre qu'il m’ait délivé de mélancolie entièrement, raphidement ot joyeusement."

(6) Dans lancien pologue du live IV, le doete medecin chinntais a alfirmé non moins catégoriquement que cest pour essarer de distraire les malades qu'il ne pwovait tirectement soigner quil a serit Garganlua of I'antrygruel. Voiei en quels termes : "Ifes calumuiateurs les ont follus (enlevés) és malades, es goutteux, is infortunés, pour lesquels en leur mal esjouir (réjonir) les avois taicts ef composis. Si je prenois en cure tous ceulx qui tombent en meshaing (emmi, chagrin et anssi mutilation) et maladie, ja besoing ne seroit methe tels livess en lumiere et impression.

"... Puis donc que possible n'est que de louts malades soye appelle, que touts malades je prenue en cure, quelle envie est-ce tollir is langoremx ef malades le plaisir et pasor temps joyeulx sans oflense de Dien, du roy

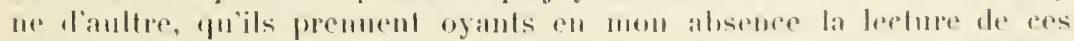
liveres." 
13 peu de pouldre d'oribus (1)... Est ce rien cela? Trourezmoi live en quelque langue, en qurlyue faculté et seience que ce soit, qui ait telles vertus, propriétés et prérogatives et je payrai chopine (2). ")

Ce n'est pas un paradoxe de soutenir qu'il y a, en effet, dans la verve joyeuse, dans la puissante fantaisie, dans le franc et large rire du médecin philosophe, une vertu curative qui rassérène l’àme of fortilie le ceur. Montesquieu déclare qu’il n’a jamais pen de chagrin qu'me heme de lecture n'ait dissipé. Il est difticile de l'en croire sur parole; mais n'est-il pas bion des soncis que le tète-à-tète arece un chef-d oeure de l'esprit peut tout au moins nous fare oublier? Et quel écrivain est plus capable d'opérer ce charme que Rabelais?

Souvenons-nous des préceptes de Maîlre François. Si nous n'arons pas en nous cette source vive de belle humeur qui lui suffisait pour guérir " les langoreux et les mélancholiques par la transfusion en eulx de ses esperits joyeulx ", essayons du moins de ranimer leur courage par des paroles consolantes el par un risage qui inspire la sympathie et la confiance, comptons avee l'amour instinctil de la vire, prenons garde de faire naître

- . . . ce fisson de morl

Qui contracte la chair sur le cour le plus fort.

Agir autrement, ést retrancher ì la douleur son meilleur palliatif, l'espérance. Pour le médecin comme pour le malade, pour celui qui lutte comme pour celui qui souflie, l'optimisme est une grande forer (3).

(1) Ceftepondred'orihus, dont ancun commentatem n’a pu déterminer la nature, est fout simplement l'espèce de colophane que laisse tomber en brùlant la chandelle de résine on oribus dont on se sent encore dans les villages du centre de la France.

(2) Prologne du live Il.

(3) On no me samra pas maurais gré, jespète, tle m’ètre écarti momentanément te mon sujet pour tracer le morlele du parlait médecin, daprès Rabelais. Je ne l'ai fait que pour préciser certaines particularités de la vie médicale de laitre Francois restées obscures ou mal interprétées. 
ANATOMIE COMPAREEE 



\section{ANATOMIE COMPARÉE}

Quand on lit les ourrages des auteurs anciens, on est stupélait de constater combien les choses les plus évidentes, les plus faciles à voir, ont été mal vues. Pline a ajoulé foi mon seulement aux récits fintastiques de tels ou lels royageur's hàbleurs, mais encore à des assertions dont il eùt pu contròler aisément l'inexactitude. En owrant au hasard l'Hisloire naturelle de ce naturaliste, j’apprends : "Que la langouste a me telle frayeur du poulpe quielle meurt de peur des qu'elle l'apereoit, et que les pourceaux cherchent les écrevisses et les mangent quand ils sont malades."

Et ee n'est pas seulement chez les auteurs anciens, cest aussi chez les écrivains du xvie, du xvir el mème du xrine siècles quion trouve de ridicules fables.

Clande Duret, de Moulins (1), a décrit minutieusement. avec des dessins a l'appui, deux arbres dont l'un est couvert de feuilles, pourves chacune de deux pieds pour pouvoir aller se promener, et dont l'autre est chargé de fruits qui sont transformés en oiseaux quand ils tombent sur le sol, en poissons quand ils tombent dans l'ean.

(1) Cl. Duret, hisloire arlmirable des planles el herbes esmerveillubles el

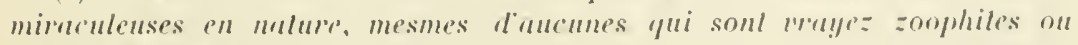

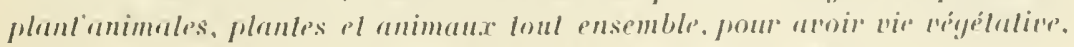
sensiliu' rl animule. In-12; Paris, chez Vicolas Buon, llow. 
Le mème auteur a écrit ailleur's (Cil. Duret, Disconrs de la mérité des canses ol effects des divers conrs, flux el refun.r el salenre de la mer Océane, mer Méditerranée et antres mers de la terre.-In-12; Paris, chez Jacques Reze, 1 (boo) :

"Il s'engender dans la mer deux lois plus de soptes d'animaux que sur la terpe: non seulement les poissons. mais aussi quelques oiseaux nommés bernaches. Meme on roit plusiemes autres oiseaux naitre du sel qui est dans les navires."

Ce mode de génération semble une absurdité colossale. Qu'on ne s'indigne pas trop rite! Au temps de Louis XIV. Ir célibse médecin alchimiste van IIelmont a aftirmé que les somris étaient engendrées par le linge sale: beaucoup plus récemment. Réanmur a prélendu que le seorpion placé sur des charbons ardents se suicidait en senfongant son aiguillon dans le rentre pour se soustraire au marlyre de samt Lament; on croyait encore, il y a cinguante ans, a la génération spontanée des champignons et des moisissures.

Voici, a titro de spéeimens de niaiseries, quelques citations extraites d'un petit live fort rurieux, datant de 157 et intitule La Irescriplion plibsophale forme el nature des bestes:

"La chair de l'ones étanl cuite croît. L'ours n'a point de sang yu'autour du ceur. Quand il a la vue troublée, il cherelre des mouches à miel et les mange, et les monches poignent (1) l'ours de leurs aignillons, le faisant saigner, el sa vue s'en éclaircit.

"Quand la singesse a deux faons, elle porte entre ses bras celui qu'elle aime le mieux, le serrant par grand amour si fort quelle le tue, et, quand elle le voit mort, elle nomrist l'autre plus simplement.

(1) Piquent, du latin pungere. 
"Le singe se réjouit quand la lune est nouvolle, et est triste quand clle est pleine ou vieille (1).

"Le cerf, quand il est grévé de maladies, attire un petit serpent par le vent des narines, et le mange, et il est guéri.

"Le bouc est de si chaude nature que son sang chaud brise la pierre du diamant qui ne pent être briséc ne par fer ne par feu, etc., ete."

Ambroise Paré, qui a eu l'idée simple et admirable de lier arec un fil l'artere coupée qui donne du sang. Anbroise Paré, un des plus grands chirurgiens francois, a subi luimême l'unfluence des préjugés de son tempes, raconté les histoires les plus extraordinaires et donné l'image au naturel dètres étonnants.

"L'an mil cinq eent-dix-sept, dit-il dans le chapitre de ses WEures consacré à l'étude des monstres, en la paroisse de Bois-le-Roi, sur le elemin de Fontainebleau, nasquil un enfant ayant la face d’une grenouille, qui fust vo et visite par

(1) On a prólendu de meme. jadlis, que la lome a ses diverses phases avail une inhuence diflérente sur lorganisme humain.

"Quoiqu’il semble démontré, dit Zimmermann dans son Trails de lexprérience, que la lune n'a point l'inlluence sensible sur la lerpe, on croit cependant puxoir proure qu'elle en a sur l'homme. La disseplalion que

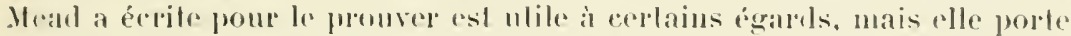

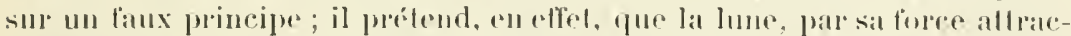
live plus grande lorsque la lune est pleine ou nouvelle, élive molpe almosphere: que par la lan qui nons envirome immediatement derient

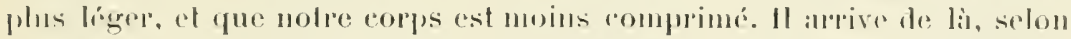
lui, que les lluides se portent en plus grame quanlilé vers la sujertiede,

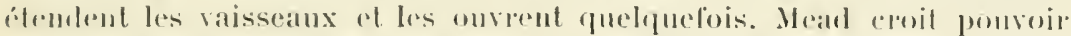

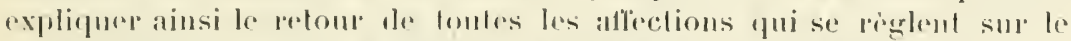
cours de lat lune, et que ce phenomine arelien est la cause des beoulements príriodirpes des femmes."

"La lune estaul humide (lor's principalement quille est pleine) pemplit

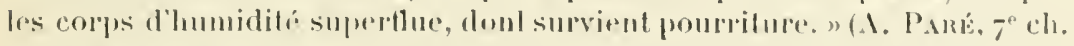
ale le lessle.)

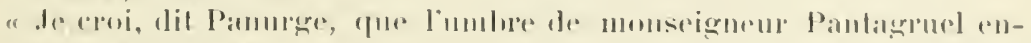

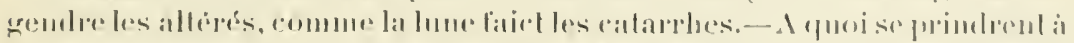

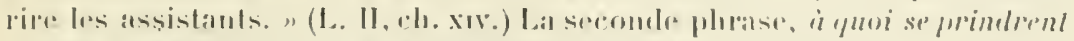

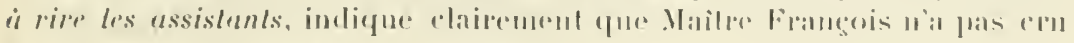
¿l l'action de la lune sur l'humanilé. 
Maistre Jean Bellanger, chirurgien en la suite de l'artillerie dı rni. Ledit Bellanger, homme de bon esprit, désirant sçavoir la cause de ce monstre, s'enquit au père d'où cela ponvait procéder, lequel lui dit qu'il estimait que sa femme ayant la fièvre, une de ses voisines lui conseilla pour guarir sa fievre qu'elle print une grenouille vive en la main, et qu'elle la tint jusques à ce que ladite grenouille fust morte... Et par la vertu imaginative, ce monstre avait été ainsi produit."

Selon Ambroise Paré : " La première cause des monstres est à la gloire de Dieu; la seconde est la colire de Dieu; la troisième, la trop grande quantité de semence; la quatrième, la trop petite quantité; les autres, l'imagination, l'angustie ou ćtroitesse de la matriee, les maladies héréditaires, l'arlifice des méchants bélìtres, les démons et diables, ete."

En 1720, an lendemain de la peste de Marseille, Manget, docteur en médecine, médecin de S. M. le roi de Prusse et membre de plusieurs sociétés savantes, s'est btomné de voir certains hommes n'avoir ancm soin de leur santí. Et il s’en est étonné en ees termes vraiment miriliques :

"Je prie ces hommes de considérer que les animaux même condamment cette folle opinion du destin en suivant l'inslinct naturel que Dieu leur a imprimé, dis leur naissance, pour chercher les remedes qui leur sont convenables et nécessaires. L’hirondelle prend la chélidoine (1) el l'applique sur les yeux aveugles de ses petits, afin de leur rendre la rue; la cigogne se donne elle-même un clỵstìre arec son bec qu'elle remplit d'eau salée, afin de purger son ventre des humeurs qui l'incommodent (2); le cheval ma-

(1) Chelidonium majus, la grande éclair, plante de la famille des Papaiéracées. Du grec y Ėıóóv, hirondelle, parce que, dit-on, cette plante fleurit an retour des hirondelles.

(2) La croyane que c'est l'ibis et la eigogne qui ont enseigné aux lommes l'usage du lavement, et l'hippopotame l'usage de la saignée, a été générale dans l'antiquité et au moyen âge. On trouve encore un reflet 
rin (1) se saigne arec la pointe d'un roseau dont il s'ouvre la veine, atin d'évacuer une partie du sang qui cause son mal; la belette mange de la rue (2), afin de se guérir de la morsure du serpent. Et nous rerrons après cela des hommes si brutaux el si stupides qui, étant attaqués, ne se mettront point en mesure de prendre les médicaments qui leur sont nécessaires. C'est ce que je ne puis comprendre. "

Il ne tiendrait qu’i moi de multiplier à l’infini ces sottes légendes el croyances. Mais je pense que eelles-ci et celles

Au premier de ces prejugés dans la cigogne quon roit dans la vilrine de la devanture de quelques vieilles pharmacies. Pline, qui a altrilsué a l'ibis l'invention du lavement, n'a tait que copier Diodore de Sicile. le nom du roi Toth s'écrit au moyen de l'hiéroglyphe de cet oisean. Prenant libis pour sa valeur figuralive el intaginant le bec pui sert de canule, le narrateur grec aurail, selon fuelyues-mus, glotesquement travesti une tradilion sérieuse, celle de l'antiquité du nelè halapa, antremenl dit du remède cher a II. de Pourceangnae. Selon quelques autres, et M. Maspím est de ce nombre, löbis amait été, dans lancienne Égypte, parfaitenenl bien considéré conme linventeur th laventent, el cela par suite de Thabitude qua cet oiseau de recueillir la maliere graisscuse qui se troum aux envirous de sa puene, pour lustrer ses plumes.

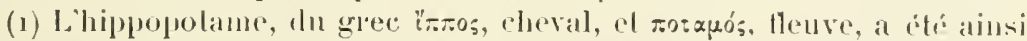
dénommé par les Grecs, a cause : $1^{\circ}$ de sa course lapide el du séjont quil fail dans les llenves: $2^{\circ}$ de son eri qui a quolque rapport aree colui du eheval. Quod fuen ail dit Pline, ce parhyderme amphibie fuil lean salob.

"Cet animal, qui est très sanguin, sait se tirer lui-nème du sang diune

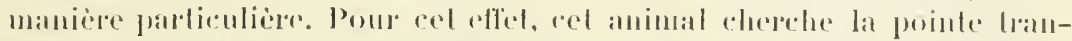

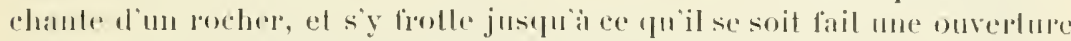

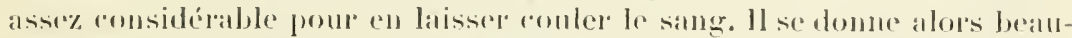
coup de monvement pour le laire sortir an phus grame duantilí; et

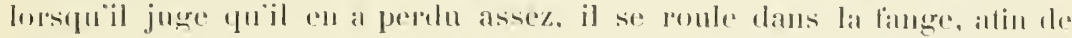

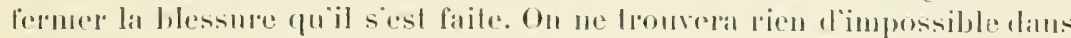

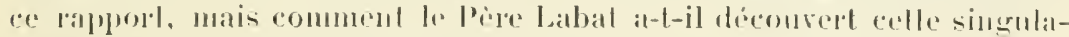
lili:?" (Burrox, Misloime naturelle.)

(2) Inulu graveolens, plante de la lamille des liulacées.

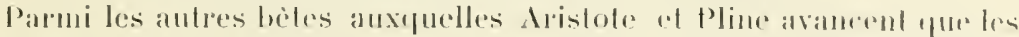

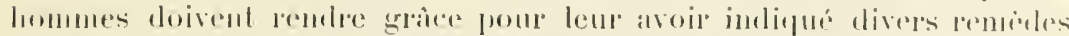

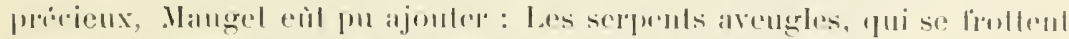

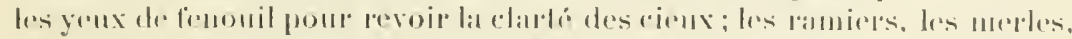

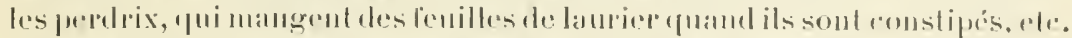

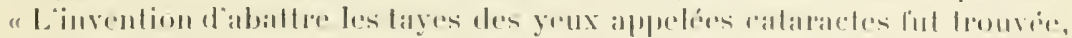

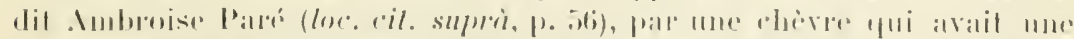

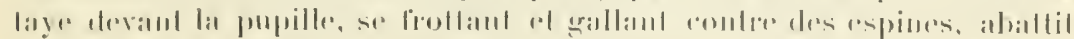

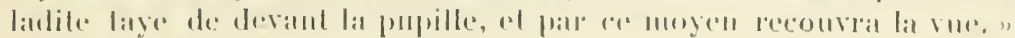


que j’ai indiquées en parlant des reptiles énumérés par Eusthenes (Voy. Anatomie descriptive, Appareil digestif: La salive comme une navette) donnent une idér plus que suffisante de la crédulité sans borne de la plupart des anciens naturalistes.

Dans Crargantua et dans Pantagrnel, on tronve également, a coté d'observations très fines et très judicieuses, des observations singulieres. En volei quelques-unes présentées sous forme de considérants.

"Messer Gaster (1), premier maistr és arts du monde, ne tronvoit difficile de laire les boullets arrière retourner contre les ennemis :

"Altendu que l'herbe nommée éthiopis ourre toutes les serrures quion luy présente (2); et que echineis, poisson tant imbécille, arreste contre touts les vents, et relienten plein fortumal (:i) les plus fortes navires qui soient sus mer : et que la chair d'icelluy poisson, conservée en sel (4), attire l'or hors des puits, tant profunds soient-ils qu'on pourroit sonder $(5)$.

(1) Voy. Anatomie descriptive, Physiologie de l'apprareil digestil.

(2) Voy. Pline, l. XXIV, ch. xir, et l. XXVl, ch. is.

(3) En pleine tempète.

(4) Dans du sel.

(5) Voy. liemores dans la liste des reptiles d'Eusthenes.

Dans un vienx livre assez peu comm (le Vicrocosme, fig., avec une briefie exposition en vers françois, in-12 de la collection E. Louvet, de Fontaineblean), ie trouve, an milien de heancoup d'autres choses réjouissantes, ces trois slances :

Il se trouve un poisson, le remore nommé. Es écrits des anciens grandement renonmé Pour la grande vertu qui dans son corps habite. Ors que de ce poisson la force soit petite.

Ce poisson merveilleux, attachant son museau Contre le gouvernail de quelque grand vaisseau, Quoi qu'il ait vent en poupe et ait un bon pilote Larrête tout d'un coup au milieu d'une flotte.

Et quoique de ramer on fasse tout devoir, On ne verra la nef pour cela se mouvoir Non plus que si la dent de quelque ancre fichée Bien avant la tenait fortement accrochée. 
"Attendu que Democritus escript. Theophrast l'ha eru et esprouré, estre une herbe par le seul attouchement (1) de laquelle un coin de fer profundement et par grande violence enfoncé dedans quelque gros et dur bois, subitement sort dehors (2). De laquelle usent les pies mars (vous les nommez pivars), quand de quelque puissant coin de fer. l'on estouppe (:3) le trou de lemes nids, lesquels ils ont accoustumé industrieusement laire et caves (4) dedans le tronc des fortes (.5) arbres (6).

(1) An seul contact.

(2) Pline a emprunte. en eltet, eettr lable a Dómocrite el à Théo-

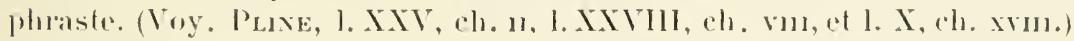

(3) Bomelie.

(a) Crenser. Le pie-vert, pivert on pigrolier (I'icus nurtius), est mu oisean grimpeur qui crense soll nid a 5 ou 6 metres an-dessus du sol,

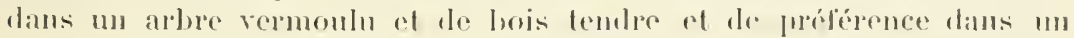
tremble. Il peree aver son hee long, anguleux, comprimé en coin, la par-

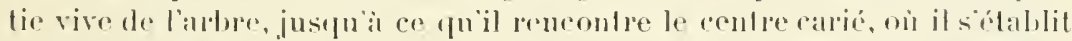

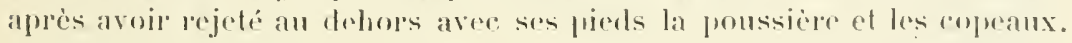
I lapproche des pluies, il jette un col plaintif qui yeul or rember par la répútition du monosyllabe plien a quon entend de très loin daus la

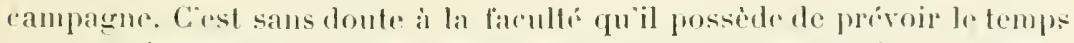

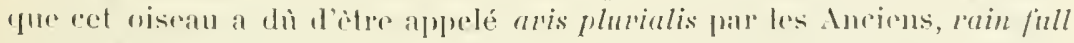
parr les dnglais, procureur de meunier par les liourguignous, et daroir

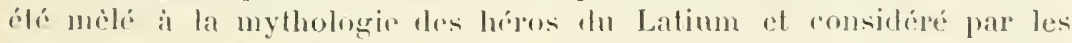
Romalus conme un ètre mystérieux dont les momvements étaiont significatifs el les apparitions labales.

(5) Ral,elais a conservo aux substantifs dérivis du latin on du gree le genre qüils ont dans la langue dou ils sont fires : arbere est pour lui léminin comme arbor, navire comme natis, ete.

(6) On retroure tes läleces de celte légende dans divers paysallemands. "En Fanconic, il existe, dit Musorus, une racine magique qui permet de

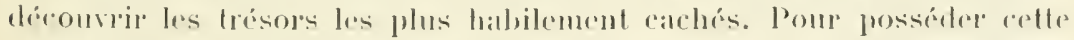

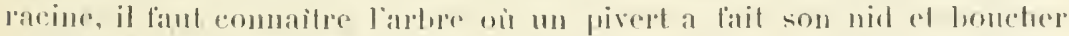

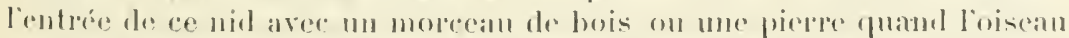

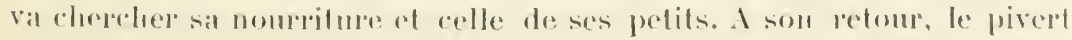
pousse des eris doulourenx, puis semvole tout à comp à tire-el'ate ver's

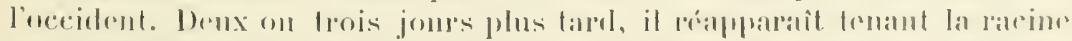

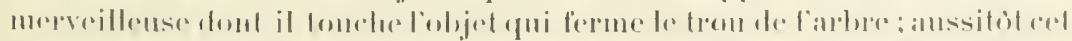

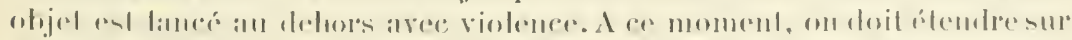

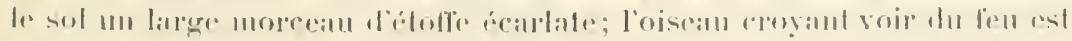
eftraye el latise tomber la racine. Arant de seon servir, il esl imlispren-

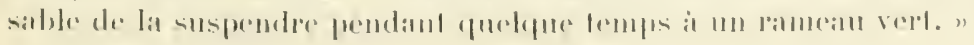


"Altendu que les cerfs el bisches, navrés (1) profundément par traicts de dards, flesches ou garrots $(2)$, s'ils rencontrent l'herbe nommée dietame, fréquente en Candie, et en mangent quelque peu, soubdain les flesches sortent hor's (3), et ne leur en reste mal aulcun (4). De laquelle Venus guérit son bien aimé fils Eneas, blessé en la cuisse dextre (5) d'une flesche tirée par la soeur de Turnus juturna (6).

"Attendu qu'au seul tlair (7) issant (8) des laurier's, ligniers, el reaulx marins (9), est la fouldre destournée, et janais ne les férit (10).

"Attendu qu'au seul aspect d'un belier les éléphants

(1) Blessés.

(2) Bitons.

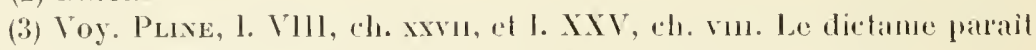
être lorigran, Origanum diclamus, plante de la fanille des Labiées.

(1) Aucun mal.

(5) Droite.

(6) Voy. Virgile, Énéide, 1. Xll.

(7) Odeul:

(8) Émanant.

(9) Le Calocéphale, vean marin (Calocephulus vilulinus), mammifïre carnassiel amphibie du groupe des Pinnipèdes ef de la lamille des Ploques. Comme le phoque pousse de temps an temps un mugissement qui ressemble à celui d'une vache on d'un reau, les Anciens lui avaient donné le som de vean marin.

Au xise sibele, Romdellet, le maitre de Rabelais, voyid encole dans le Phoca cristala un moine on un évèque main: "be nostre temps, a-t-il écrit, en Nortuege (en Norvège), on a prois mu monstre de mer après une grande Iommente, lequel tous cenx qui levirent incontinent lui donnèrent le nom de moine, cal il avait la lace d'homme mais rustique et mi-grat lienx, teste lise et lize; sur les espantes, comme un capuchon de moine, denx longs ailepons au lien de bras, le hout du rorps finissant en une quene large. Entre les hestes marines, Pline fait mention de l'homme marin of du friton comme choses non leinctes. Pausanias aussi fait mention du trilon. Jai va le pourtrict d'un autre monstre matrin à Rome, où il aroit été envoyé aree lettres, par lesquelles on assuroit pour certain que, l'an 1531, on avoit veu ce monstre en habit d'eresque, comme il est pourtraict, pris an Pologne ef porté au rey dudict pays, faisant certains signes pour montrel qưil avoil grand désir de retournep daus la mer, où estant anené se jecta incontinent dedans." (Roxuellet, De l'is(ibus.)

(10) Ve les frippe, ne les alteint, du latin ferire. (Plase, l. VIII et LV.) 
enragés retournent à leur bon sens (1); les taureaulx furieux et forsenés approchants des figuiers saulvages (2), dicts caprifices (3), s'apprivoisent et restent comme grampes (4) et immobiles; la furie des vipères expire par l'attonchement d'un rameau de fouteau (5).

"Attendu aussy que en l’isle de Samos, avant que le temple de Juno y fust basti, Euphorion (6) eseript avoil vu bestes nommées néades, à la seule voix desquelles la terre fondoit en chasmates $(\boldsymbol{z})$ et en abysme.

"Attendu pareillement que le suzeau (8) croist plus canore (9) et plus apte (10) au jeu des fleutes en pays onquel (11) le chant des coqs ne sera ouï, ainsy qu'ont escript les anciens sages (12), selon le rapport de Theophraste, comme si le chant des coqs hébéstat, amollist et estonnat (1:3) la matière et le bois du suzeau : anpued (19)

(a) Voy. Plutargle, Propos de lable, I. II.

(2) Saurages.

(3) Figuier's de chères.

(4) Surpris par une crampe. (Voy. Plixe, l. XXllI, ch. xxrru.)

(5) Hètre. Pline a écrit que l’odenr du frène lait également fur les serpents of surtoul les viperes. Est-il nécessaire dajouter que Redi a mis des fenilles de cette plante dans une cage renfermant des viperes el que ces reptiles, foin de fuir ces feuilles, se sont cachés sous elles.

(6) Poète et historien du pays de Chalcide qui vivait 27ł ans arant Jésus-Christ. (Voy. Elrex, IIisl. des animaux, l. XYII, ch, xwrur.)

(7) Gouffres, du latin chasma. "Tum chasmala aperiuntur, alor's la terre s'entrourre. "(Síxéce.)

Les renseignements foumis sur les néales par Euphorion et Elien

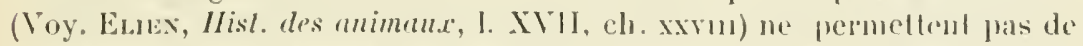
les raltacher exactement it mo groupe quelconque des animanx conmus aujourl'lui.

(8) Le sureau. Le sureau est encore appelé suzeau dans quelques villages de la Normandie et de l'Aujou.

(9) Harmonieux, mélodienx, du latin canorus. "Ales canorus (Hordce), loisean mélodieux, "Ir cygne.

(10) Convenable, du latin aplus.

(11) Dans lequel.

(12) Daus le sens de savaut, du latiu sapiens. On dit encore daus lis: campragnes ardennaises : "sage comme un notaire ".

(13) Voy. Anatomire chimurgicale, p. 309, note 4.

(1/) I.'(9)11. 
chant pareillement onï, le lion, animant (1) de si grande force et constance (2), devient tout estommé et consterné (3).

"Et d'oresenavant soyezplus faciles à croire ce qu'asseure Plutarche (4) avoir expérimenté : si un troupeau de chères s'enfuyoit courant en toute loree, mettezun brin d'érynge (5) en la gueule d'une dernière cheminante (6), soubdain toutes s'arresteront."

Est-ce à dire que Maître Francois a été aussi crédule que les savants, même lesplus réputés, de son temps? Non. La raison d'être des considérants sus-indiqués, ces considé-

(1) Animal. (V'oy. Pline, I. XVl, ch. xxrin.)

(2) Hardiesse, assurance, du latiu conslantia.

(3) S'il lallait en croire Théphraste et aussi Pline ef Lucrèce, le chanl du cor mettrail en tuite le lion. Il ue serait pas absurde de croire qui] rexiste quelefur antipathic de nature entre ces demx animaux, mais le fait est loin d'ètre contirmé par lexpérience. Les lions nomris dans les mónageriesne manitestent ancume frayem yuand reteutit aupes d'eus la voix duceq. Il est rai quils y sout pent-itre accoutunés ; et il ne serait pas impossible que ces lions, vivant en liberté clans le désert, aient pris peur en entendant pour la première fois ce cri percant of raiment belliqueux. Qnoi qüil en soit, la terrem que le coy est censé inspirer au roi des animanx est devenur un des titres de gloire de notre oisean national. Nos ancètres se plaisaient à le représenter debout sur un lion el, dans celte position périlleuse, entonnant aux oreilles de son ennemi humilié sa fanfare triomphante. Cette image s'est perpétuće jusqu'à nous, ef le coq hurdi est eneore ilans quelques-mes de nos provinces une des enseignes ordinaires des cabarets et des auberges.

De tous les coqs, le coq blanc est celui cui a passé el passe encore dans quelques contrées pour ètre le plus redouté du lion. Pourquoi? Eeoutez rillustre écrivain : "Aiusy que le dict Proclus, libro de Sacrificio et Magja, cest parce que la présence de la vertus du soleil, qui est lorgane et promptuaire (du latin prompturtium, source) de toute hunière terrestre et sidérale, plus est symbolisante el compétente an coq blane: lant pour celle couleur, que pour sa propriété et orlie spécifique, qu’au lion. Plus dict, quen forme léonine ont esté dialoles somvent vus. lesquels à la présence d'un coq blanc soublainement sont disparus." (L. I, ch. x.) Proclus est un philosophe du ve siecle qui sintitulait : le: Prètre le la nature entière.

(4) Plutarque, loc. cil. suprà.

(5) Panicant, espèce de chardon.

(6) Dime de celles qui cheminent li's dernières. 
lants eux-mêmes, plus surprenants les uns que les autres. la doctissime explication de la terreur du lion en présence d'un coq blanc, tout dénote ici encore un jeu de l'esprit du joyeux satirique. Rabelais a poussé si loin le seepticisme, en tout ee qui a trait aux scicuces naturelles, quil a mème mis en doute lexistence du singe vert (1), des cheraux polydactyles (2), du mouton i large queue, et relégué dans

(1) "Lorsque Quaresmeprenant subloit (sifflail), cestoient hollées de singes rerds. "Sous les Valois, on disait proverbialement en France d'un ricit invaisemblable que éétail hollée de singes verts. Par cette mélaphore, il liut done entemdre, dans le cas actuel, que, lorsque Quaresmepre. nant silthail, on l'entendait à peine, si on l'entendait. Cést une nourelle confirmation de l'útat débile, du manque de sonlthe du persomnage en question.

"Les thrípiaclenrs de Channys, en Pieardie,... sont de nature grands jaseurs, ef heaulx baillemes de bailliverues en matiere de singes verils.." (L. I, cl. xxr.)

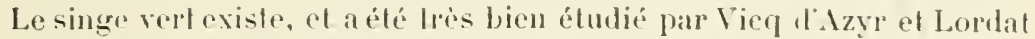
(V'ico d'Azrr et Loruat, Observations sur yuelyues points de lanalomir th singe berl; Paris, 18u'.) Ciest le Simia sabae de Linné, le Cercopitherus sabitus de Cuvier, le Cercopithecus ex cinereo flatescens genis longis pilis obsilis de briss, ele. Il a le corps vert, la gorge et le ventre diun bean blanc et la lace noire. Les marins l'appellent singe de Saint-Jacyues, parce quion le troure surtout dans cetle île. (Glammes d'Enwams, p. ro, ligr. ibid.) On le reneontre aussi au Sénégal (Awnsox, Voyerge au Sénérget, p. 178) et sur le territoire de l'ancionne Carthage.

(2) A ses contemporins, qui aceptaient avenglément les récits des royageurs menteurs, lo savant Chiunonis a présente la jument de Gatrgantua, dommé par Fiyoles, quart roy de Numidie, it Gramlgousiep : " La plus énorme et la plus grande que fut onques vure et la plus momstruense: comme asser scavez, que dipique apporte tousjours fuelque clase

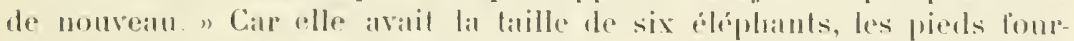
chus du cheral de Jules César, immortalisé par Sućtone, lesoreilles aussi perubutes que celles des chères du Launguedoe, le poil alezan brilá mélé de gris, une corme sur la croupe et la queur semblable a la pile de Cinq-llars, pres de Langeais en Tombine, cest-it-dire rarré, longue de 22 mètres et large de $4^{\text {m }}, 17$.

"Si de ce vous esmerveillez : esmerveillez-rous diulvantage de la quene"

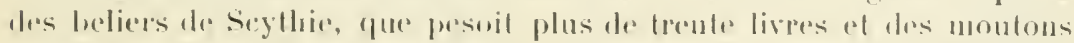

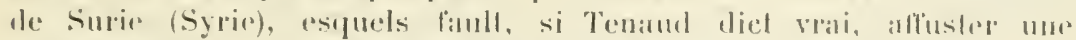
charretle all c.... frour la portere, tant elle est longue et pesante. "

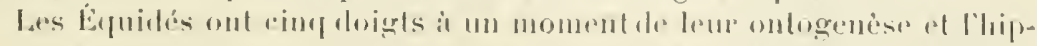

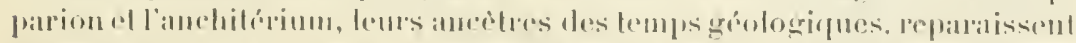

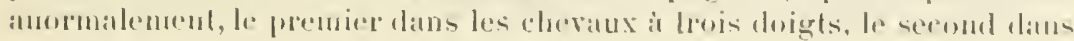


l'île de Firize, au payss de Satin, dont les bètes et les oiseaux étaient de tapisseries, et où "Ouï-dire tenoit eschole de tesmoignerie ", les animanx lantastiques, voire même la girafe, les léopards, les dorcades. les pélicans, ete.

Je lui rends la parole. Il n'a jamais mieux manié le fouct de la satire. A tout seigneur tout honneur, d'abord le portrait de Ouï-dire el de ses disciples : " II avoit sept langues, on la langue fendue en sept parties : quoi que ce fust, de toutes sept (1) ensemblement (2) parloit divers propos et langages divers ; avoit anssy parmi la teste el le reste du corps aultant d'aureilles comme jadis eut Argus (:3) d'reulx; au reste estoit areugle, et paralytique des jambes (4). Autour de lui je vid nombre innumérable (5) d'hommes et de

les chevaux à cind doigts, dont on a observé phusienr's exemples, sans compter Bucéphale, le lameux coursier ditexandre.

Le mouton à large quene n'est pas davantage un mythe. Désigné en zoologie sous le nom d'Ovis laticandala, il est remarruable par la loupe graisseuse qui entoure sa queue.

Ses principales variétés sont: le stertopyga (ovis sleatopyga), de la Perse, de la Russieméridionale et de la Chine; le monton à grosse queue, qui habite la haute Egypte; le mouton dAstmakan, qui fournit une très belle fourrure, le mouton du Cap, ete.

Non seulement Tenaud, dont la personnalité est toujours à déterminer, mais encore Hérodote (1. III, ch. 113), Aristote (8, Animal., 28), Etien (ch. 4 du I. 10 des Animaux), Marco-Polo, Chardin, Boitard, etc., aftirment que chez certains de ces quadrupedes la quene est si lourde qu’il laut la soutenir.

(1) Ce ehiffre latidique était tout indiqué à l'impitoyable railleur. N'y a-t-il pas les sept jours de la création, sept ordres d'anges, sept plaies d'Égypte, sept sacrements, sept péchés capitaux, la bète à sept cornes de l'Apocalypse, le chandelier is sept branches, etc.?

(a) Ensemble, en mème temps.

(3) Argus Panoptos, prince argien, époux d'Ismène, fille de l'Asope, avait cent yeux, dont cinquante veillaient pendant le sommeil des cinquante autres. Chargé par Jupiter de garder Io, il fut endormi puis tué par Hercure, et ses yeux répandus sur la queue du paon par la vindicative Junon.

(4) On n'a pas besoin d'yeux ni de jambes, mais seulement d'unc langue bien délice et de beaucoup d'oreille quand on n'est que le porteparole des autres.

(5) Innombrable, du latin innumerabilis. 
femmes escoutants et attentifs, et en recognut aulcuns (2) parmi la trouppe faisants bon minois, d'entre lesquels un pour lor's tenoit une mappemonde, et la leur exposoit sommairement par petits aphorismes, et y devenoient cleres el scrarants en peu dheures, et parloient de pron (:i) de choses prodigieuses élégamment et par bonne mémoire : pour la centiesme partie des quelles scavoil ne sulfiroit la vie de l'homme: des pyramides du Nil (4), de Bahylone (5), des Troglodytes (6), des Hỵmantopodes (7), des Blemmyes ( 8 ), des Pygmées (9),

(1) Reconmul.

(2) Queleues-uns. En langage juridipge, aucuns a encore ce sens.

(3) Beaucoule.

(4) Pyranides d'Egyple.

(5) Ancienne capitale de la Chaldie, sur l'Euphrale.

(6) Les habitants de lat Troglodytique, contrece située an delit de l'Ethio-

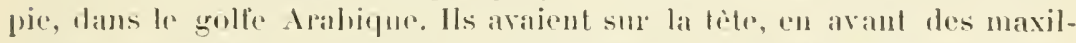
laires, des cornes fui descentaient jusquä lere (Albert Le Grand), couraient plus vile que des cheraux (Crates de Pergamre, et logeaient

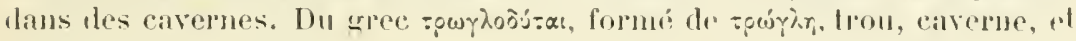

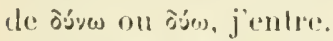

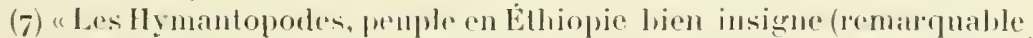
du latin insignis), sont Andonilles selon la description de Pline." (L. IV, (ch. xxxrils.)

Les Hymantopoles blainut des penples d'Ëhiopie qui avaienl les jambes of les pjeds raguens, of qui progressaient en rempant, di la ma-

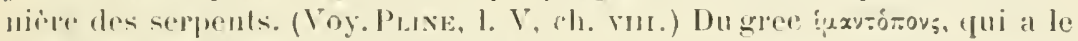
pied tordu comme un exp de vigme.

(8) Les Blemmyers on Blemyes sont des peuplades sallvages qui oceu. pairnt la partire septrutrionalde de l'Ëhiopie. Les Anciens les contondacienl

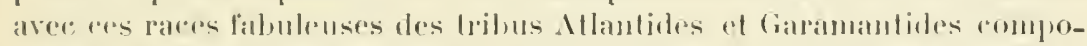
sien de monstres ayant la lide daus la poitrine ef lommant, are les Pyg-

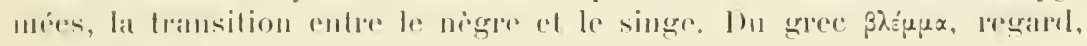
asperet, visitge.

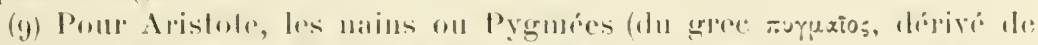

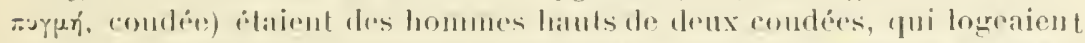

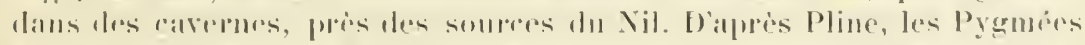

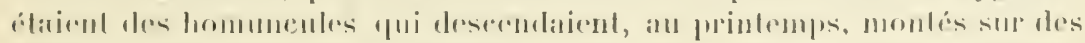

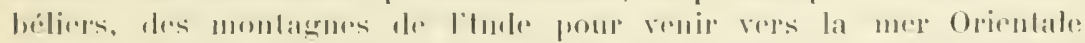

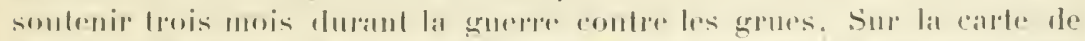

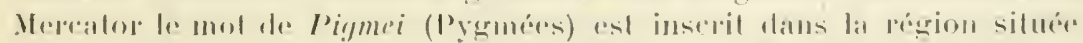

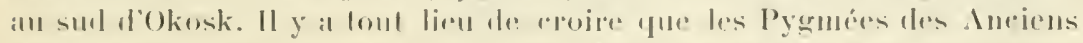

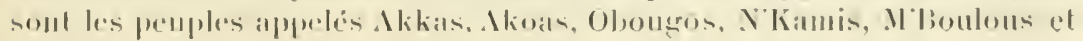


des Canibales (1), des monts Hyperborées (2), des Egipanes (:3), de touts les diables, et toul par Ouï-dire.

"Là je vid, selon mon advis, Ilerodote, Pline, Solin (4), Berose (5). Philostrate (6), Mela (7), Strabo (8), et tant d'aullees autiques: plus Albert le jacobin grand (9), Pierre

Baboukos, qui habitent au centre et sur le liltoral de l'Afrique. Leur taille ue dépasse pas celle de nos adolescents de quinze ans. Le muséc du Trocarléro posside quelques-unes de leurs armes; ce sont des armes d'enfant, mais non des armes de Lilliput.

(1) " llabitenl dans l'Amérique, an deça ef au delà de lÉquateur; gens crucls of thangeurs d'hommes, principalement leurs ememis." (Mphabed le lautemr.)

(2) Des monts aurlelì do Borér (voy. p. 233 , note 亿). Les Grecs appelaimut ainsi les monts Ripsies :

Vers les champs hyperborens,
Jai vu des rois dans la retraile
Gui se croyaient des Antonins.

(Voltallie.)

(3) "Le Nigris prend sa source entre les Ethiopiens el les Ecaliques... viendraient ensuite les Allantes, les Egipans, demi-animaux, moitié homme et moitié bone. "(Pline, I. V, eh. vin.) Du gree xis, chève ef Pan, le promier des dieux champietres.

(4) Solin (C.-Jules), contemporain d'Héliogabale, a laissé, sous le nom de Polyhistor on le Sarant, une compilation de cinquante-six chapitres. Elle se compose de notices, Ia plupart géographiques, tirées de divers auteurs ot principalement de Pline le Naturaliste.

(5) Prêtre de Bélus ef historien qui vint, ver's l'an 263 avant Jésus Clnist, à Athènes, où il fit comnaitre le cadran solaire. On trouve dans Flavius Josciphe ruelques tragments de ses wurres. La plus importante dentre elles ast me IIistoire de la Chaldée, où il est question de la création de l'homme el d'un dílnge universel.

(6) Nom commun ì deux sophistes grees, natils de Lemmos. le furemier a composé plusieurs ouvages dont les plus connus sont la Vie des sophistes, les Hépoüdes el la V'ie d'Apollonius de Tyane. Le second, neven du précédent, a écrit un live intitulé Images on Description de Iableaux.

(7) Mela Pomponius, grographe, né en Espagne vers la fin du $\mathrm{I}^{\mathrm{e}}$ siecle, a laisse me Descriplion de lunivers (De Silu orbis) en trois lives, oì l'on remarque beancoup d'exactilude et de discernement.

(8) Cólèbre grograplue qui vivait sons Auguste el Tibire. Il reste de lni une grongraphiopleine d'érudition. Arant de la publier, Strabon avail parcouru la majemre partic du monde eomm, afin de sinstruire el te rassembler des documents anthentiques.

(9) "Albert le Grand ", dit le Bibliophile Jacob. Peut-ètre Alberti de Bologne, savaul religieux $(1479-1502)$, 
Tesmoing (1), pape Pie second (2), Volaterran (3), Paulo Jovio (4), le Vaillant homme (5), Jacques Cartier (6), Chaïton arménian (7). Mare Paule vénitien (8), Ludoric ro-

(1) Pierre Martyr d'Xugiclat, anteur diune des premicres descriptions de l'Anérique sous re tilpe: De natigalione el pebus Ocerani el terris suo tempore apertis. "Il est ici désigne sous le nom de Piere Tesmoin, parce

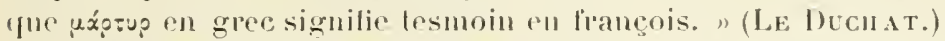

(2) Eneas Sylvius Piecolomini, pape de 1/48 à 1/464. 11 a composé divers ouvages giographiques mis a contribution par 11. Schedel dans le lameux Liber chronicorum mundi. Cilons parmi enx le De orlu regione ac gestis Bohemorum et la Descriplio de situ, ritu, moribus el conditione Germanise.

(3) Raphä̈l Maffey, dit Volatermuns, it cause de son lien de naissance (Volatrpes), anteur d'un gros volume grographipue : Commentarii rerum urbenaram, libri XXXVtt, impromé an commencement du $\mathrm{xvi}^{\mathrm{e}}$ siecle.

(1) Paul Jove, suruomume: Plume dor, historien latin molerme, ué a Còme en 1483, mott en 15\%2. Ses principans livers sont un Trate des poissons of un manuel géngraphique : De Piscibus romanis libellus, 15 f5. iu-s, el Descriptiones yuolyuol exslant regiontm alyue locorum.

(j) "Cest Andri Theret, dit le bibliophile Jacol, qui navait rien publis du vivant de Rabelais, mais qui voyageait alors dans le Levant."

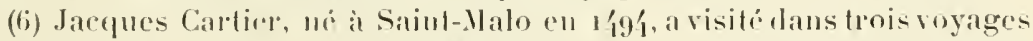
successils Teme-Neuve, les iles Madeleines, les baies Le Caspé el des Chalenrs, le Saint-Laurent, elc. Unr maison quil fit hilir wes de SaintMalo salpelle encore anjourdhui les Portes Cartier. Il a résumé les avenlures de ses longues pépregrinalions daus un live intitule : Briép

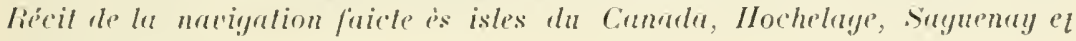
aulleses, 15 亿彳.

Des deux pilotes de Ponlagruel, l'um, Jamet Brayed, est Jacques Cartire. Rabelais lappedte Brayed parece que Cartier, Breton bletommant, porfait la culotte mationale hretonne, la braye, en luagon-baz. Guaut it

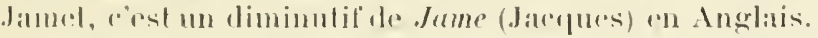

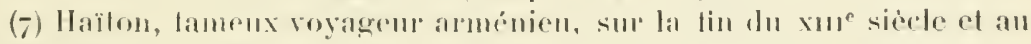

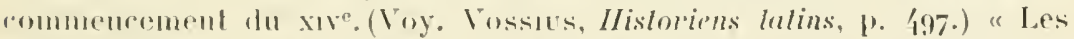

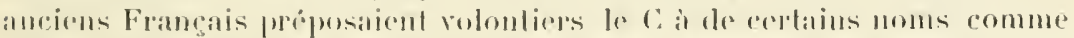

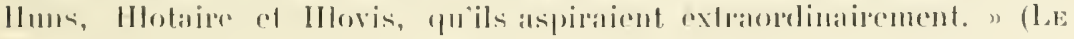
()сналт.)

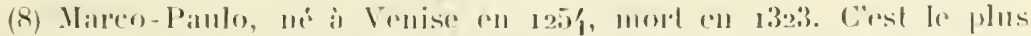

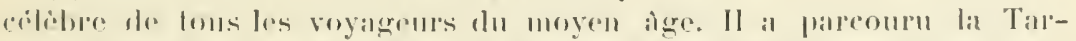

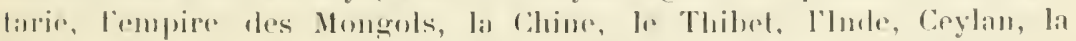

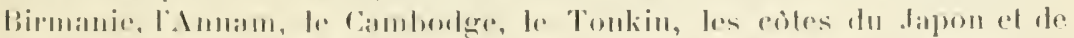

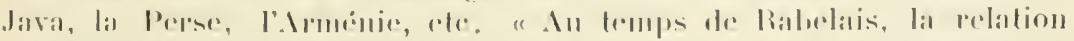

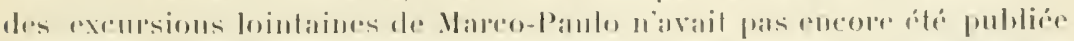

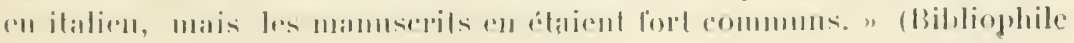
Jacess.) 
main (1), Pierre Alvarez (2), et ne sçai combien d'aultres modernes historiens eachés derrière une pièce de tapisserie, en lapinois escripvant de belles besognes, ef tout par Ouïdire.

"Derrière une prèce de velours liguré à feuilles de menthe (:3), près d'Ouï-dire..., nombre grand de Pereherons et Manceaulx (1), bons estudiants, jemes assez..., apprenoient à estre tesmoings, et en cestuy art profictoient si bien que, partants du lieu et retournés en leur province, vivoient honestement du mestier de tesmoignerie, rendants seur tesmoignage de toutes choses à ceulx qui plus domnoient par journée, et tout par Ouï-dire. "

Après cela, on conegit que les tapisseries du pays de Satin soient décorées de dessins et de monstres hideux, burlants, grimaçants, inconnus en zoologie, et d'animaux connus en zoologie, mais merveilleusement dressés pourle plaisil des yeux.

Ainsi " y vismes, poursuit le romancier-médecin, que n'avions encores vu; entre aultres y vismes divers éléphants, en diverse contenance (.)) : sus touts jy notai les six masles et six femelles, présentés a Rome au théatre par leur instituteur (i), au temps de Germanicus, nepveu de l'empereur Tibere, éléphants doctes. musiciens, philosophes, danseurs, paraniers ( $\mathbf{7})$, baladins : et estoient à table assis

(1) "Ludovic Vartomanni de Bologne, anleur d'un royage dans l'Arique et l'Asie seril en italien. "(Bibliophile $\mathrm{J}_{\mathrm{Acos}}$.)

(2) Pierre Alvarez Capral, Portugais qui fil, en 1550, un voyage à Calcutla fuon trouve daus le $1 l^{\circ}$ volume des Vavigalions pecueillies par Ramusio. Dans plusien's des áditions anciennes ce nom est écril Alliares, Alliates.

(3) "Jeu de mots sur menthe et menterie. " (Biblioplite Jacos.)

(4) Le's Pepcherons ef les Mlanceaux ont, comme les Gascons, la réputation d'etre très hablems.

(5) Posture, maintien, du latin continentia.

(6) Celui qui les avait dressés.

(7) Danseurs de pavane on de padunane, espiece de lanse cullivée ou inventée à Padone, selon Ménage. La pavane se dansait encore au $\mathrm{xW}^{\mathrm{e}}$ siecle- 
en belle composition, burants et mangeants en silence, comme beaulx-pères (1) au rélectoir (2). Ils ont le museau long de deux coubdées (:3), et le nommons proboscide (4), avecques lequel ils puisent eau pour boire, prennent palmes (5), prunes et toute sorte de mangeailles, s'en deftendent et offendent ( $\mathbf{j})$ comme d'une main $(\boldsymbol{z})$ : et au combat jectent les gens hault en l'aer, et à la chute les font crever de rire ( 8 ). Ils ont moult (9) belles et grandes aureilles de la forme d'un ran. Ils ont joinclures el articulations és jambes : eeulx qui ont escript le contraire, n'en virent jamais qu'en paincture (10). Entre leurs dents ils ont deux grandes

(1) En tite du No livre de Panlagruel on lit: "Composé par M. François Rabelais, docterur en médicine el Calloier des isles Hyères. "

Calloier, de r.x>ós et iseós, que les jésuites et les moines lraduisaient prar "bon peren, était fraduit par "bean-pè̀e " par les mauraises langues.

Or ega, Jacolsins, Cordeliers,

Augustins, Carmes, Bordeliers,

I'ou vient qu'on vous nomme beaux-pires?

C’est qüä l'ombre du crucilix,

Souvent faites filles et fils

En accointant les belles-mères.

(2) On peut avoir mue idée du hant degré d'intelligence et d'édncabilité le l'élépluant d'Alpiene en consulant les anualistes romains des gueres contre Pyrhus et les Cantluginois. Elien, Plutarque, Solin, Pline, Tretzes, llout mème pas eraint de domer à cet animal des mours raisomnés. une religion, elc.

Sie abluant el purifienul, dein arloranl solem el lunum.

Catavera sui generis sepeliunt.

Sagillas extruhunl tanquam rhiruryi perili, ela.

(3) Aucienne mesure correspondant a la longurme le la portion du

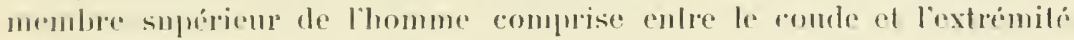
des doigts.

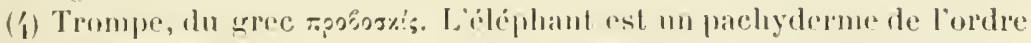
des Probosediens.

(5) Des branches trarnies de feuilles, do batin pulma.

(6) Ntlactuent, du lislin offendere.

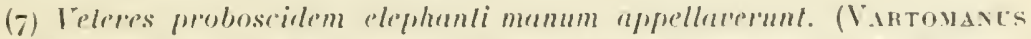
apud Gesner, cap. De Elephanlo.) Consult. alussi lastote, Ie Parl, anim. I. Il, ch. xw, of le mimre, Hist. animal. I. H, ch. I.

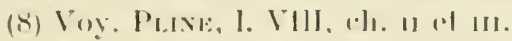

(a) Bion, trios belles, du Jatin mullum.

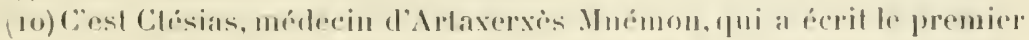
que loblephant arail les jambes sans arliculalions, qüil ne pourait se con- 
cornes, ainsy les appelloit Juba (1); Pausanias dist estre cornes, non dents (2); Philostrate tient que soient dents. non cornes (3) : ce mest tout un, pourvu qu'entendiez que c'est le vrai ivoire (4), et sont longues de trois ou quatre coubdées, el sont à la mandibule supérieure (5), non inlérieure.

"Si croyez ceulx qui disent le contraire, vous en trourerez mal, voire fust-ce Elian, liereclet de menterie (6). La, non ailleurs, en avoit vu Pline, dansants aux sonnetles sus chordes, el funambules ( 7 ) : passants aussy sus les tables en plein banquet sans offenser ( 8 ) les buveurs buvants.

". Jy vid un rhmoceros. du tout semblable a cestuy que Ilenry Clerberg (9) mavoit aultrestois monstré : et peu différoit d'un rerrat qu'aultresfois j'avois vu a limoges, exceptez qu'il avoit une corne au mufle longue d'unc coubdée, et poinctue. de laquelle il ausoit entreprendre un éléphant en com-

cher ni se reflesser, et qne, lorsquil étail blessé, ils'appmyait contre un arbre prour se sontenir, etc. Celte fable a dé acceptée par Aristote, Diodore deSicile, Strabon, saint Ambroise, Cassiodore, etc. Ce qui a pu laccréditer, cést sans doute:

1) La forme cylindrique des jambes de l'bliphant qui ont l'air d’ètre tout d'une piece et sur lestuelles on aperegoit difficilement la trace des jointures ;

B) Le morle de flexion des jambes qui est diflérent du mode de flexion des jambes des cheranx, parce que les jambes ne sont pas conformées sur le mème plan dans les denx espèces;

C) Le lait que l'éléphant, appuyé sur ses quatre membres comme sur quatre colonmes, dort sonvent debout.

(1) Noms de denx rois de Ifauritanie, dont le seeond, vaincu par les Romains, a érrit à Rome les onvages sml lhistoire, la grographie, etc.

(2) Patsaxias, les Élinques.

(3) Phllostrate, Vie dipollon, II, 13.

(i) Voy, Anat. descriptive, Appareil digestil: Les dents, comme un tonge.

(5) La uakchoile supépieure. Cette observation est exacte, ainsi que celli concernant livoire des dífenses des éliphants.

(6) Triple menteur. L'IFisloire des animanx d'Elien est pleine d'erreurs.

(z) Et marchant sur la corde, du latin funis, corde, ef ambulo, je marehe.

(8) Sans attayuer, du latin offendere.

(9) Encore orthographic Hans Cleberg et Hane Clebeir, personnage inconnu, 
bat, el diecelle le poignant (1) soubs le ventre (qui est la plus tendre et débile partie de l'éléphant) (2), le rendoit mort par terre. J'y vid trente-deux unicornes (:3) : c'est une beste lélonne (4) à merveilles, du tout semblable a un beau cheval, excepté quielle ha la teste comme un cerfl, les pieds comme un ífephant, la queue comme un sanglier, et au front une corne aigue, noire et longue de six ou de sept pieds, laquelle ordinairement luy pend en bas comme la creste d'un coq d'Inde : elle (5) quand reult combattre, ou aultrement s'en aider, la live roide droicte. Une d'icelles je vid, accompagnée de divers animaulx saulvages, avecques sa corne cmunder (i) une fontaine... purifiant l'eau d'ordure ou venin... et ces animaulx divers en seureté renoient boire apres elle...

(1) Le piquant, du latin pungere.

(2) "Le rlunocéros, dit Pline, est rennemi né de lébéphant. Il aiguise sa corne sur une pierre; dans le combat, il vise an reulpe, sachaul que cest lentroit le phus vuhépable, et tue ainsi lélephant. "L Linimitio de

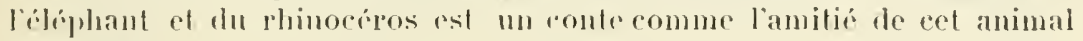
et dil tigre.

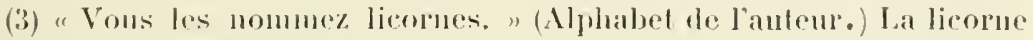
a été également appeléc muicorne ef monocíns par Pline, amunel Maitre Francois a emprumtí ces délails, ainsi que beanconp dantres qui précerdent on yni snirent. "Pline, assurent Esmangart el Johannean, est, de tous les autems anciens, celui que Rabelais a mis le plus somvent a contribution : on dirait qu'il le possédait par ceur. En effet, Rabelais était le Pline de son trmpse; of il est encore anjourdhui regardé, ansi que l'a tres bien dit Nodier, comme lo plus nniversel el le plus sivant des écrivains : cotait me encyelopedic vivante."

(i) Mrichintre

(5) Colle-ci, la licorne.

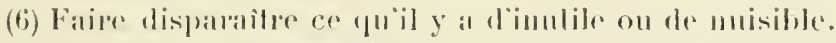

"C"est ici, préteml Le louchat, me raillerie contre l'. Jove, qui, au

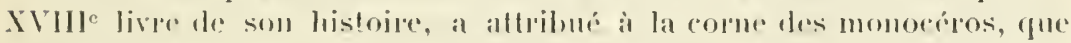

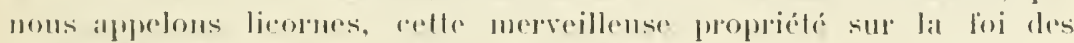

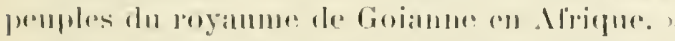

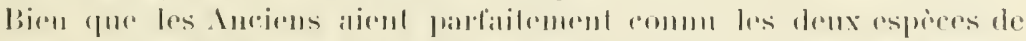

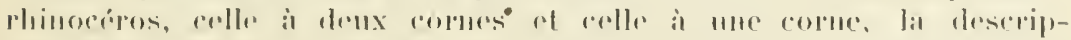

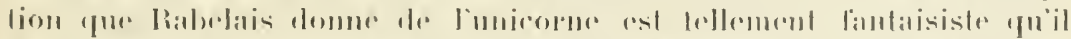

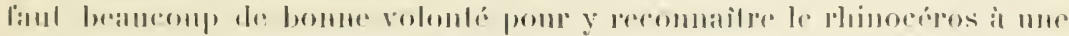

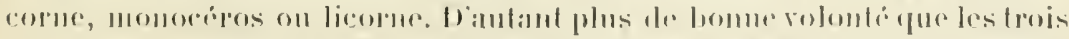

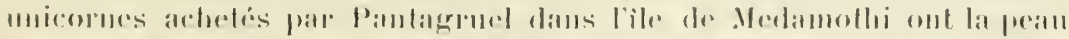

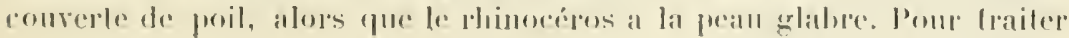


" J'y vid un chaméléon, tel que le descript Aristote, et tel que me l'aroit quelquesfois monstréCharles Marais (1), médicin insigne (2) en la noble citéde Lỵon sus le Rhosne; et ne vwoit que d'aer (3) non plus que l'aultre (4).

entierement la question de l'animal dispit ici sons le nom diunicorne ou de licorne, il me landrait entrer dans une disenssion qui mentraînerait trop loin. Jobserverai seulement quil est possible qu'il y ait en Afrique quelque espèce dintilope a une corue on plutol à deux cormes soulées en une seule, dont les Anciens aient eu connassance ef que nous ne nous soyons pas encore procurée. Jajouterai aussi fue plusieurs especes animates différentes, détinies far ce caractère de navoir qu une seute corne comme le rhinocéros, ou mème fuine sente grande dent comme la licorne marine, fe Narval monocŕpos, mammifiere de lordre des Célacés monodontes, ont été rémies sons te mème nom et ont jeté parmi les savants de la confusion. Il est singulier de voir combien il s'est débité, chrz nos peres, de poussière de la corne de la licorme dont le blason seul a grardé le dessin précis.

Ayons de l'eau de ces lycornes

Gui, sert fort contre le poison.

(Cuncheface, Recueil de poésies françaises, t. X'I, 1, 291.)

Pierre Pomel, le célebbre apothicaire du xwo siècle, a avoue, il est vrai, queles tronçous de cotte corme, ventus alors à Paris comme ailleurs, étaient des détenses de narral. (Ponet, IIist. des drogues, $2^{\mathrm{e}}$ part., ch. xxul, 1. 78 , et les Repas, Pp. 22 et suir.)

(1) Cliarles Maris dans quelrues élitions.

(2) Distingué, remarquable, dı latin insignis.

(3) Le caméléon vulgaire (Chamoeleo rulgaris, Daudin ; Lacerta Chamepleo, Limni) est un reptile saurien, propre a lancien continent. "Cet animal, dit Pline, est le seul tui ne boive ni ne mange; seulement il tumse l'ain', se tenant dehout, el ne vit d'antre chose." Solin, Orile, Stobie, saint Augustin ont souteun la mème opinion. Ce qui lui a lonné vraisemblablenent naissance, c’est que, lor'sque le camélén aspire l'air, comme ses poumons sont tris téreloppés, lair hii remptit tout le corps comme sil se versait dans ses intestins ef dans son estomac. Il faut ajouter à cela que le camélćon, the mème que la plupart des reptiles qui ont peu te sang, et le sang froill, peut, sans paraître souffrir, jeùner pendant longtemps. Bien qu'il n'y ait guère d’apparence qu'un animal anquel la nature a donné des dents, un estomar, tout un appareil digestif, ne soit destiné à ne digrerer que de l’air, il a falln les expériences décisives de Laudius, de Belon, de Pieresc ponr détruire ce préjugé. Le caméléon se nourrit dinsectes, quil saisit de fort toin arec sa langue eftilée el gluante 'tu'il darde hor's de sa bouche à une distance presque égale à la longueur de soll corjes.

(4) Dans les pages que Rabelais a consacées a lanatomie comparéc. 
"J'y vid trois hydres, telles qu'en arois ailleurs aultresfois ru. Cesont serpents, ayants chascun sept testes diverses (1).

il est une aulre errem que je tiens ì relever de suite; cest celle qui concerne le mode de déreloppement des Ursidés.

"Un procis il sa maissance première, aroue le juge Bridoye, me semble comme a vous aultres, Messienrs, informe et imparlaiel. Comme un ours naissant nha pieds, ne mains, peau, poil. ne teste : ee nest ifune pièce de chair, rude el informe. Lourse. à force de leicher, la met en perfeetion desmembres... Ainsy voi-je, comme vous aultres, Messieurs, naistre les procis à leurs commencements, informes et sans membres. Ils n'ont qu'une pièce ou denx : e’est pour lor's une laide beste. Mais lorsqu'ils sont bien entassés, enchassés el ensachés, on les peult rraiment dire membrus et formés... Les sergents, huissiers, apprarileurs, chiquancurs, procureurs, commissaires, adrocats, enquesteur's, tabellions... suceanls bien fort, el conti. nucllement, les bonrses desparties, engendrent it leurs procés, teste, pieds, gryphes, bee, dents, mains, vines, arteres, nerfs, muscles, humeurs."

Parmi les mammitëres, il ny a que les Iarsupiaux qui mellent has des petits incomplitement développés. Pline, Aristote, Elien et les poètes de l'antiquité ont supposé yüil en était de mème des Ursidés ot que èest en léchant ses petits que la femelle de l'ours parvenait à lemr donner la forme qu’ils doivent avoir. "Ce quientante lours, a écrit Ovide, ce n'est pas un petil, mais une chair mal vivante que la mère fagome en membres en la léchant el qu’elle amene ainsi à la forme quelle désire. "On dit encore proverbialement anjourdhui d'un homme mal tourné, déplaisant, que "èest un ou's mal léché ». An moyen àge, Solin a attribué lélat d'imperfection des onrsons noureaulnés à ce que la gestation de lourse ne dure que peu de temps, trente jours environ. Les oursons sont complètenent lormés dans le sein de leur mère, qui les porte pendant sept mois et non pendant trente jours, et si les jemes ours ont paru au premier coupdieil informes aux Anciens, c'est que l'ours atultr l'est lui-mème par la masse, la grosseur ef la disproporlion dn conps el des memlnes. (Pour délails eomplénenlaires, roy. Mat-

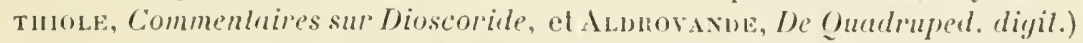

(1) Lihyelre la plus cólebro est celle qui a ravagé les environs du marais de Lerne, près d'Alegos. Elle arait sept tietes. et, quand on cu conpait une, il en revenait plusieurs autres a la place. Ciest Hercule qui les a coupres - d'aucuns disent brilées - toutes d'un seul coup. La hutte épique de linglre de Leme contre Hercule constitue le second de ses douze lavarax.

Lihydre allrense oublia d'épouvanter les morts.

(Vincile, Énéide, trad. de Delille.)

Guand je vis en sursaut ure bite efrrovable,

Chose étrange i conter, toutefois víritalsle, Gui phos qu ume hylle affreuse a sept gueules menglant.

drait les dents aciacier, l'œil horrible et sanglant.

(M. Rígxisu, Ëpitre J.) 
"J'y vid qualorze phénix. J'avois leu en divers auteur'squ'il n'en estoit quin en tont le monde, pour un age (1): mais selon mon petil jugement, ceulx qui en ont eseript n'en virent onques ailleurs qu'au pays de tapisserie, voire lust-ee Lactance Firmian (2).

"J'y vid la peau de l'Asne d'or d'Apulée (3).

"J'y vy trois cents et neul pélicans (4), six mille et seze oiseaulx séleucides (5), marchants en ordonnance et dévorants les saulterelles parmi les bleds, des eynamolges (6),

(1) "Le phénix u'Arabie, dit Pline, l'emporte sur tous les autres oiseaux. Toutefois je ne sais si ce qu'on en rapporte est labuleux ou réritable, savoir: qu'il n'y en aurait qu'un seul aumonde ef qui, eneore, ne se laisse voir que dans des circonstances extraordinaires. Du reste, on dit que le phénix est de la taille de l'aigle, jaune doré par derrière et rouge pourpre sur le reste ducorps. Il a la queue bleue entremécér de plumes incarnat ef ta tète surmontée d'un panache magnifique. Mamilius, illustre sénateur romain, est le premier qui en ait écrit avec détail. Il dit que jamais homme na vo le phénix manger, et qu'en Arabie cet oiseau est consacé au soleil et vil six cent soixante ans. 11 ajoute que, se sentant vieux, il se fait un nid avee de l'écorce de cannelle et de l'encens et meurt dessus, et que de ses cendres sort un ver qui se ehange bientôt "près en oiseau."

Celte fable égyptienne, dans laquelle on a trouvé une des preuves de la résurrection de la chair, a élé accueillie et vulgarisée par les premiers auteurs chrétiens, par saint Cyrille, saint Épiphane, saint Ambroise, Tertullien, ete.

Il est possible que ce soit la vue d'un de ces brillants oiseanx des régions tropieales qui ait fait inventer l'histoire du phénix et inspiré l'idée de forger à cet animal inconnu des mours aussi extraordinaires que son plumage. On suppose, non sans quelque apparence de raison, que ce pent ètre le laisan doré de Chine on l'oiseau de paradis.

(2) On a attribué à cet auteur, surnommé le Cicéron chrétien, un poème Du Phénix, qu’il aurait composé avant sa conversion.

(3) Apulée Lucius, auteur latin, né vers 114 en Afrique. Le plus conm de ses ourrages est la Mélamorphose ou line d'or, poman fantastique en onze livres, dont la magie forme le principal ressort. On y trouve le délicieux épisode de Psyché, si admirablement imité par La Fonlaine.

(4) Voy. plus loin Onocrolales.

(5) "On nomme séleucides ceptains oiseanx qu”à la prière les habitants du mont Cassin Jupiter envoie contre les santerelles qui ravagent leurs moissons. On n'a pas eneore découvert d'où ils viennent, ni dans quels lieux ils vont; on ne les roit que quand on a besoin de leurs secomrs." (Pline.) Apolion, comme dieu destructeur des sauterelles, avait un temple à Séleucie, en Cilicie.

(6) Oiseaux qui lont leurs nids avec des brins de cimmamome (cina- 
des argathyles (1), des caprimulges (2), des thynnumcules (3), des erotenotaires (4). voire, di-je, des onocrotales avecques leur grand gosier (5), des

molyns). "En Arabie, loiscau nommé cammellier construil son nid de brins do camelle. Les habitants abaltent ces oiseaux arec des lleches ganies de plomb; ils en font un objet le commerce." (Plixe, l. X, ch. xxxur.) On disait anssi cimnamologos, cinnamulyus, cinnamus, cinamulyos, ete.

(1) Sorte d'hirondelles (hirondelles d'ean, hirondelles de rivage, argatiles, ergatiles), selon les mis, de loriots, selon les autres, qui font leurs nids avee du chanve et des éloupes. (Voy. Plixe, I. X, ch. xxxur, addilion de Du Pinel el Gesner, De avium alura, de hirmulinibus ripariis.)

(2) Telte-chère ou engoulevenl, caprimulyus, du latin capra, chère, et mulgere, traire (Puxe, 1. X, ch.X̃L). Cetoiseau, encore appelé agothilem, caprimulyus xyothelas, crapand-volanl, fresaie, seche-lerrine, ete., se nourrit de gucipes, de scarabées, de canthariles (Klein, Charleton, etc.). C'est une variété d'orfraies. Il résulte de recherches de Schwenckfeld que jamais une ehère ne siest laissí fólrar par un oiseau puelconque.

(3) Sorles de thons, du latin thynnus ou thumnus, formé du grece 0úvos, thon. La pièche du thon s’est fiate daus la Jéditer rance dés la plus haute antiquité. Le garum retiré duthon étail tres recherehé par les gourmets le l'aucienue Rome.

"Je suis fille d'un thon, a éril Ifatial a un de ses amis, en lui envoyaut du garum préprúé avec ce poisson; si je lélais d'un seombre (maquereau), je ne l'aurais pats élé envoyé."

(4) Nolaires croltés, jen de mol arec onocrolales.

(5) Pélican. Des deax moms frílican et onocrolale que les Ancions

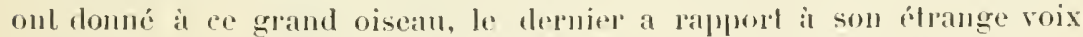

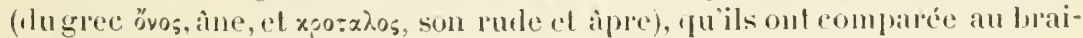
ment d’un ane. "Le premier nom pelecan, dit Bulfon, a ćlé le sujel diune

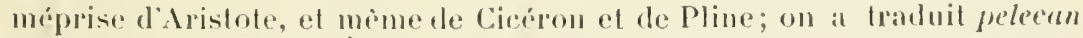
par plater, ce qui fait contombe le pélican aree la spalule, et Aristote lıj-meme, en disint du pelerin puil avile des copuillages minces of les rejelte it demi digéres pour en sífurer les aeailles, lui atlribue me habitute qui comvent mieux a la spitule, vu lat structure de son usophlage;

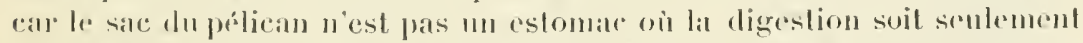
commencé el cest improperment que Pline compare la miniere dont lonocrobale (péliean) avale el reprend ses aliments a celle des animatux

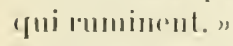

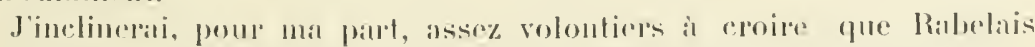
a entemdu désigner par onocrolule le pélican, ansi quen font foi

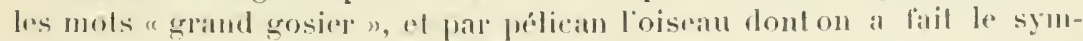

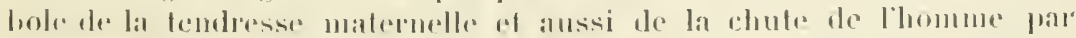

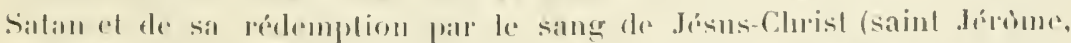

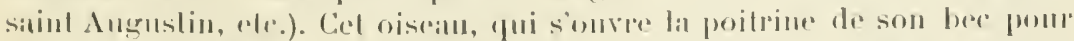

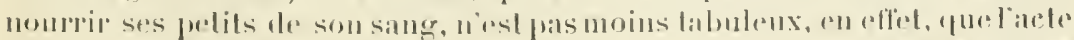

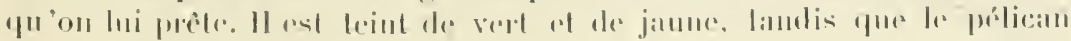




\section{stymphalides (1), harpyes (2), panthères (3), loups}

réritable est de conleur blanche; on le dessine avee un bee court et aigu, tandis que le bee du pélican véritable est large et aplati; on lui donne la grosseur d'une poule ou d'un pigeon, tandis qu’il devait avoir celle d'un eygne; on lui attribue des doigts divisés, tandis qu'il derrait avoir les pieds palmés eomme la plupart des oiseaux aquatiques; on le gralific enfin d'un cou cylindrique, tandis que le péliean véritable porte, au-dessous du bee, un jabol qui lui pend sur la poilrine.

Voici, je crois, ee qui a donné lieı à la légende du péliean.

Dis que cet oisean aperçoit le poisson qu il convoite, il s'ćlance rapide; a laide de seslongues ailes, il bat la surface de l'eau sur une assez grande f́tendue, en étourdissant par ee moyen les poissons, petits el grands. quill a des lors tont le temps de choisir et de déposer dans la poehe placée sous sa mandibule intérieure. Cette poche remplie, il gagne le rivage, où, sur un point escarpé, il va satislaire son vorace appétit.

Si c'est une mère et si, autour d'elle, ses petits se pressent affamés, elle leur dégorge la nourriture qui, dans son jabot, a subi une premicre macération. Fréquemment ces débris de poissons laissent quelques traces sanguinolentes qui tranchent avee ćclat sur le plumage blanc de l'oiseau et font eroile que celui-ei s'est blessé.

(1) Oiseaux d'une grandeur prodigieuse qui hantaient le lae Stymphale et dont le bee était si lort et si dur qu'il perçait le fer. Hereule les tua à coups de llèches.

"Slymphalidas pepull volucres discrimine quinto. Dans son cinquieme travail, Hereule a abattu les Stymphalides."

Lucrèce a fait des Stymphalides tes oiseaux de proie à ongles crochus.

".... Incisque limendx

Unguibus Arcadix volucres stymphala colentes.

Il laut redouter les oiseaux d'Areadie aux ongles reeourbés, habitant le lac Stymphale. " (Lucrèce, l. V.)

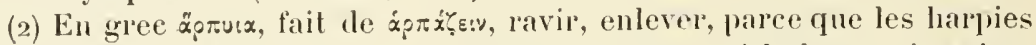
très voraces enlevaient tout. Oiseaux monstrueux et fabuleux qui avaient un visage de femme, "le col tors, les pattes pelues" (l. V, eh. 11), le corps et les ailes d'un vaulour et qui infectaient tout ee qu'ils touchaient.

(3) Depuis Aristote et Pline jusquaux naturalistes de nos jours, on s'est toujours disputé sur la détermination exacte des trois fólins auxquels on a domé les noms de panthère, de léopard el d'once, et qu'on a considérés tantôt eomme des variétés, tantòt comme des espèees distinctes.

Ceux qui considerent la panthère et le léopard comme des variétés parce qu'aucun naturaliste n’a réussi à établir les earactères qui les distinguent n'oublient qu'une chose, e'est que les Romains, qui ont donné deux noms différents à ces animaux, ont eu beaucoup plus d'oceasions de les étudier que nous. Il nous serait bien diffieile aujourd'hui de réunir un nombre de peaux de panthères et de léopards égal au nombre de ces animaux virants qui eoncouraient à un seul combat de bètes chez les Romains. 
garoux (1), onocentaures (2), tigres (3), léopards (4), hyènes $(5)$, camélopardales $(6)$, origes $(7)$, dorca-

(1) Loups dont il faut se garer. "Les loups seront loups et hommes, loups garoux et lutins, comme furent Lyeaon, Bellerophon, Nabuchodonosor, " dit Rahelais dans le chapitre mi du livre III. Par loups-garous, Inaitre François a donc entendu les hommes changés en loup. Ce qui a pu donner it croire à la translormation d'un homme en loup est vraisem-

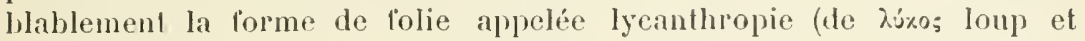
ávfowros, homme) presque inconnue de nos jours, mais très commune an moyen ìge.

(2) Bètes monstrueuses résultant de l'accouplement du taureau et de l'ânesse. Elles avaient les pieds de devant conformés comme des mains, le corps d'un homme, la tèted'un âne et cherchaient a imiter, sans y parvenir, Ia voix humaine.

(3) Les Romains semblent aroir à peu près complètement ignoré l'existence du tigre royal avant l'ère acluelle; mais lor'squ'ils étendirent leurs Irontières jusqu’à l'empire des Parthes, ceux-ci leur livrèrent des tigres qui furent conduits en Italie. Pline dit que Scaurus exhiba, le premier, én $74^{3}$ de la fondation de Rome, un de ces félins dompté, enfermé dans mine cage.

(4) Le léopard des Anciens, Leopardus Antiquorum, est le léopard d'Alrique. Les Grees l'appelaient pardulis et Aristote en a parlé souvent. Le mol pardus est plus récent. Lucain et Pline sont les premiers qui laient employé. Celui de leopardus parait avoir été créé par Julius Capitolinus à la fin du m $^{\mathrm{e}}$ siècle, oì il était admis que cet animal, b́lait un mélis provenant du lion et de la panthère. Pline a écrit "que le lion sent quand la panthère mâle s'est approchée de la lionne et en tire rengeance ".

(5) Les hyẻnes sont des animanx qui ont singulièrement prèté à la superstition. Les Anciens ont écrit que l'hyène élait alternativement male pentant six mois et temelle pendant autant de temps, qu'elle savait imiter la voix hmmaine, que la conleur de son poil el celle de ses yeux étaient changeantes, ete. Col animal est appedé lantol hycua, tantot glanus par Aristote. (IIist. anim., lib. IIt, cap. v.) Les anteurs latins ont conservé le nom de hyiena, mas celui de ganus ou gannus et celui de belbus a été employé par Gesner. (Hist. quulmup., p. :55.) Cuvier a très lien expliqué pourfuoi on a pu croire au changement successil de sexe de ee quadrupide.

(6) "Chameanmonchude" (PLISE). Ce chamean monchetí, c'est la girate, Camelopardus girafa, du littiu camelus, chameau, et pardus, panthèrer. Lai girale n'est pas seulenent un composé de panthère el te chamean, aimsi que la dit llorace, mais bien de plusieurs animanx. Elle a la tèle et le corps du cheral, le couct les épaules du chameau, Ies oreilles du bexuf, la quene de l'ane, les jambes de l'antilope, le pelage de la pantlière.

(7) C"est l'Ory.r beisu, ruminant de la lamille des Antilopidés. "Sa conleur, dit Oppian (ce pui est exacl), ressemble an lait du prinlemps ; il u’a que les joures noires. "Dans les chambers de la gramde pyramide de Chrops. 
des (1), cémades (2), cynocéphales (3), satyres (4), cartasonnes (5), tarandes (6), ures (7), monopes (8), pégases (9),

on voit souvent cette antilope représentée avec une seule eorne, et on a voulu en eonclure que c'est l'oryx qui a donné naissance à la fable de la licorne. Voiei ce que Pline en a dit: "Les déserts de l'Afrique produisent l'oryx qui ne boit jamais lans ces lieux toujours arides et qui lui-même est d'une grande ressonrce pour les voleurs gétules qui trourent dans son corps des poches remplies d'une liqueur très salubre."

(1) La gazelle commune, du latin Gazella dorcas. (Voy. Eliev, Nat. des anim., l. XIV, eh. xv.) Le dorcas d'Aristote n'est pas la gazelle, mais te cherreuil.

(2) Faons de cerfs. (Larousse.)

(3) "Animaux des Indes qui ont un corps humain avec une tête de ehien et qui aboient au lieu de parler, ") dit Elien (l. VI, cl. xuri).

(4) "Animaux qui rivent aux Indes et ressemblent aux satyres de la fable, " dit encore Elien (1. XVI, ch. xxi).

"Les eynoeéphales et les satyres sont d'un naturel plus farouche que les autres singes... Les Minisminiens, qui font partie des Ethiopiens nomades, se nourrissent du lait des animaux que nous nommons cynocéphales. Hls en lorment des troupeaux, ne réservant qu'un très petit nombre de mâles pour la reproduction, " a écrit d'autre part Pline (I. XXXI, eh. LV, et I. VII, ch. xx8I).

Sauf le cynocéphale gelada, tous les autres cynocéplıales, c'est-à-dire les singes à tète de chien (du grec \%úw, chien, et $\%: \alpha_{\alpha} \lambda \eta^{\prime}$, tète), étaient connus d'Hérodote, de Plutarque, etc. Un t'entre eux a été adoré par les Egyptiens sous le nom de Toth et Och. Ce sont les plus hideux, Ies plus grossiers et les plus repoussants de tous les quadrumanes.

Il est plus que probable que tout ce que les Anciens nous ont transmis sur les satyres, les faunes et les sylvains tire son origine de l'histoire mal connue des Anthropoïdes. La peau de satyre que saint Augustin a vue à Rome était une peau de gorille, et les peaux de satyres suspendues par Hennon dans le temple de Junon Astarté, à Carthage, des peaux de chimpanzés. (Voy. Iannonis Periplus, græce cum annolationibus, édit., J. L. Friburgi, 1803, in-4.)

(5) "Cartazanous, nom que les Indiens donnent à la licorne. " (Eries, 1. XVI, ch. xx.) Les Persans appellent carlazonon une sorte d'âne sauvage fabuleux, dont le front est armé d’une longue corne.

(6) Renues, du latin tarandus.

(7) L'aurochs, le bison européen, le tur des Lithuaniens. Lurus a été chassé dans l'Europe centrale jusqu'au temps de Jules César. On ne le troure plus aujourd'hui que dans la forèt Bralowicza, en Lithuanie.

(8) Animaux de Preonie, de la grosseur d'un taureau. "On dit que, lorsqu'ils sont poursuivis, ils lancent des déjections mortelles pour ceux qu'elles atteignent. "(Eliex, I. VII, ch. m.)

(9) Chevaux ailés. "Je mets au rang des fables, dit Pline, les pégases 
cèpes (1), néades (2), prestères (3), cercopithèques (4), bisons (5), musmones (6), bytures (7), ophyres (8), striges (9),

à tète de cheral el les griffons aux oreilles saillantes, au bec crochu, les premiers dans la Scythie, les seconds dans l'Ethiopie. Je ne crois pas plus aux sirènes, quoique Donon, père de Cléarque, auteur célèbre. affirme qu'elles existent dans l'Inde." (Plixe, l. X, ch. xur, et l. VIII, ch. xxi.)

(1) On doit peut-être lire Cepphes. Divers anteurs prétendent que les Anciens ont désigné sous ce nom la harpie. D'autres, ef c'est le plus grand nombre, traduisent cepphus par foulque. Le foulque est un oiseau aquatique appelé anssi diable, ì cause de sa couleur noire. (Voy. Histoire des animans de GesNer, l. III, de haro.)

Cèpes, néades, prestères, cercopithèques manquent dans les éditions de Hollande et dans les trois éditions de Lyon (1573-158' et i60o.)

(2) Voy. p. 353, note 7 .

(3) Stères ou prestères, serpents renimeux de Lybie quicheminaienl, croyait-on, la bouche ouverte, semant du venin autour d'eux et dont la morsure provoquait une lelle enflure du corps humain qu'il finissail par éclater. (Voy. p. 132, note 6.)

(4) "Animaux qui ont la tète noire, le poil de l'àne et qui ne difrèrent des autres singes que par la voix. " (Plixe.)

Les cereopithéques de Pline, de Varton et d'Isidorus sont les guenons

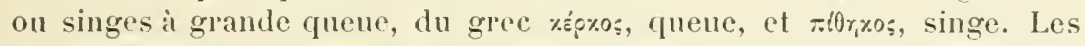
cereopithèues appartiennent tous à l'ancien contiuent. Les principales especes sont la mone, le patas ou singe rouge, l'ascagne on blanc-nez, etc.

(5) Le bison d'Amérique ou le buffle, comme lappellent les Amépicains.

(6) "Moutons d'Espagne dont la toison ressemble plutiot à du poil de chève qu"à de la laine, "dit Pline (I. VIII, ch. xux). C'est le mouflon (Musimon musmon) qui paraît ètre la souche primitive de toules les antres races de montons.

(7) Ou Biures (Biurus, de bis, denx, et ojó, quene), animanx à deux queues qui rongent les vignes, an dire de Cicéron. (Voy. Ploxe. 1. XXX, ch. Xv.)

(8) Selon Hesychins et Varimus, l'ophiurus est un oisean d’Éthiopie qui a une rquene de seppent; du grec optoupos. qui a la quene dinn serpent. (Gesser, IIistoire des animallx, l. 111.) On disait autrelois : Africa porlentosa, l'Afrique est la terre des monstres. Lorphinrus était un des plus merveilleux.

(9) Oiseaux yni se laisaient téter par les cnfants avant de les meftre en morceaux et dont le cri ol le rol avaient quedque chose delfrayant.

Quels sont ces oiseanx? C. Poinsinet do Sivri rent que ce soil notre grimpereau ou torche-pot. Brottier prose que cest le hibon d'Orient, " oisean si vorace, dit-il, qu“il entre la muit dans les maisons ef qu il déchire les enlints ". Brottier s'appuie sur l'autorité d'Asselyuis. (Voyage dans le Levant, 1. 11, 1. 19.) 
gryphes (1). J'y vid la Vi-quaresme à cheral (2), la miaoust et la mi-mar's (:3) luy tenoient l'estaphe (4).

"J'y vid une l’émore (5), poisson pelit, nommée échineis des Grees, auprès d'une grande nauf (6), laquelle ne se mouroit, encores qu'elle eust pleine voile en haulte mer' : je croi

"Ovide en a fait mention en ces termes:

Grande caput, stantes ocuti, apta rapinæ :

Canities pennis, unguilus hamus inest.

Est illis strigibus nomen; sed nominis hujus

Catusa, quod horrenda sidere solent.

"Les striges ont la tète grosse, les yenx fixes, le bec propre à la rapine, les ongles en hameçons; on les nomme striges parce qüils ont l'habitude de pousser pendantla nuit un cri àcre. " (Stridor en latin signifie craquement, grincement, bruit désagréablement entrecoupé semblable à celui d'une seie.)

A Rome, du temps des César's, les sorcières et les magiciennes élaient appelées striges ou volatices, parce qu'on supposait qu'elles pouraicnt prendre la forme de ces oiseaux.

(1) Oisean plus gros qu'un lion, aux ongles formidables, au bec long et pointu, qui déterrait l'or et le gardait dans les montagnes des lndes. Pantagruel et ses officiers furent conduits au port de Condemnation par " certains gryphons de montagnes " (l. $V$, ch. xin). Une planclie du Livre des Merveilles, de $H$. de Mandeville, représente le combat d'un griffon et d'un centanre avec une explication du motif qui anime ces denx bètes l'ume contre l'autre.

(2) L'auteur fait allusion ici à une vieille contume tourangelle et berrichonne. On s'amusait, il y a quelques années encore, en Touraine et dans le Berry, à envoyer dans un carrefour ou carroi solitaire, le soir qui précède le vingtième jour de la sainte Quarantaine, quelque nigand attendre jusquau lever du jour la Mi-Carème à cheval, en lui promettant que celle-ci le comblerait d'échaudées - gâteaux secs et triangulaires de la Mi-Carème, - en échange d'une botte de loin. J'ai connu un jeune homme qui est allé ainsi laire le guet, à deux reprises diffírentes, au même endroit, et qui, la seconde fois, est revenu chez lui roué do coups par le bon apòtre qui, le visage barłouillé de suie et déguisé en femme, jouant le ròle de la Mi-Carème, arait prétendu que la botte de foin oflerte n'avait pas le poils voulu.

(3) Mars lombant en Carème, on comprend que la mi-mar's accompagne la mi-carème, mais que vient faire ici la mi-aoùt? Est-ce un nouveau jeu de mots du grand moqueur? Est-ce, comme le prétendent Esmangart el Johanncau, parce que, les chattes étant plus amoureuses pendant le carème, on y entend darantage de miaou? Je ne voudrais pas dire non.

(4) L'étrier, on dit encore estafier, estafette.

(5) Voy. p. 133, note 5, et p. 35o, note 5.

(6) Navire, du latin navis. 
bien que c'estoit celle de Periander le tyran, laquelle un poisson tant petit arrestoit contre le (1) vent. Et en ce pays de Satin, non ailleurs, l'avoir vue Mutianus (2)...

"Jy vid des spluinges (3), des raphes (4), des oin-

(1) Périandre, tyran de Corinthe, un des sept Sages de la Grèce. Il régnait 625 ans avant Jésus-Christ ct a publié un Poème moral, dont les fragments sont édités dordinaire avec les sentences de Théogmis, les vers dorés de Pythagore el de Solon, etc.

(2) Les Anciens rapporteut qu'un navire fut curoyé a Corcyre par ordre de Périandre; l'équipage arait pour mission d'immoler une parlie des enfants nés à Corcyre; malgré un rent favorable, le navire reslait immobile, arrèté par un grant nombre de remoras, qui, en souvenir de ce fait miraculeux, furent dès lors honorés dans les temples de Vénus.

(3) Animaux dont Pline a parlé en ces termes (l. VIII, ch. xxi) : "Spinges fusco pilo, mammis in pectore geminis, Elhiopia generat, mullaque alia monstra similia. - Arec beaucoup d'autres monstres, l'Ëhiopie jroduit les sphinx au poil brun ef aux deux mamelles pectorales. "Le sphinx de Thẻbes, dont OEdipe a deriné la dernière énigme, a inspiró mainls poètes anciens et modernes.

\begin{abstract}
Né parmi les rochers, au pied du Cithéron,
Ce monstre à roix humaine, aigle, femme et lion.

De la nature entière exicrable assemblage.

Unissant contre nous l'artifice et la rage :
\end{abstract}

(Voltaike.)

(4) Loups-cerviers (chaus, mphius. Iupus cerrarius, felix lynx, le lynx ordinaire des auteurs). Les premiers carmassiers de ce genrequi aient été vus at Rome, du temps de Pompré, venaient des Gaules.

"Pompeii magni primum ludi ostenderunt chaum yuem Galli raphium rocribant, effigie lupi, pardorum maculis...

"Sunt in eo genere (scilicel luporum), qui certurii tocanlur qualem, a Callia, in Pompeii magni arenâ spectalum dirimus.

"C'est aux jeux du grand Pompée fu'on montra pour la premiere fois le claus que les Gaulois nomment raphe ef qui a la figure d'un loup aree les larhes d'un léopard.

"Parmi les lompsilenest qu'on nomme loups-cerviers lel que celui quon avu dans l’amphithétre dugrand Pompée. "(Ptixs, l. VIIl, ch. xix et xxur.)

Il est peu d'animanx qui, dans lantiquite, aient autant preté à la fable que les lomps-cerviers, el surtout, parmi cenx-ci, que le lynx. Il avait la vue si pergante flitil voyait tris bien it travers une muraille. Son urine se poitritiat of devenait une pierre prériense nomméc lapis lyneurius, qui, oute son delat, avait la propriéte de guérir une foule de maladies. Mais laissons la ces contes ridiculeste nos ä̈nx, el renons-en à la vérité. Le lyux a les merurs du chall saurage, " mais distingure sa proie à une distance leaucoup plus gramde que ba plupart des carnivores ". (MILxeEmwans.) 
ces (1), des cèphes (2), lesquelles ont les pieds de devant comme les mains, ceulx de derrière comme les pieds d'un homme; des crocutes (3), des éales, lesquels sont grands comme hippopotames, ayants la quene comme éléphants, les mandibules (4) comme sangliers, les cornes mobiles, comme sont les aureilles d'asne (5); les lencrocutes (6), bestes très légères, grandes comme asnes de Mirebalais (7), ont le col,

( 1) On lit dans l'alphabel de l'auteur: "Lynx, c'est le nom d'un once on loup-cervier qui a la rue forl aiguë. "L'once, que les Anciens ont regardé, cn elfot, les uns comme un loup-cervier, les autres comme une panthere, est un léopard. On ne pent en douter en lisant la description qu'en donne Caius daus Gesuer (IIist. quadrup., p. 825). Ce qui a pu faire eroire que c'était un loup-cervier, e'est parce qu'il se place quelquefois comme celui-ci sur une grosse branche, attendant qu'un antilope passe à sa portée, et qu'il pousse des cris semblables à ceuxd'un chien irrité, mais julus forts et plus rauques.

(2) J'ai dit antérieurement que les satyres ou hommes sylvestres de nos aïeux élaient rraisemblablement des Anthropoïdes (chimpanzés ou ggorilles). Suivant Buffon, les cèphes seraient des gibons.

"Auxjeux du grand Pompée, on vit d’abord, dit Pline, des cèphes ayant des membres avec des mains et des pieds hmmains."

Une note de Daléchamp montre que Strabon a traduit le mot cephus de Pline par keipon: "Cephos Strabo. lib. IV, Keipon rocat, esseque lradit facie salyro similem. - Strabon, I. XV, appelle Keiphon les cephes elrapporte qu'ils ressemblent aux satyres. "

Buffon pense que du mot keipon on a lait guibbon, gibon.

(3) Cirocotte, corocotte ou crocutte est un métis né de laccouplement du chien ou de la louve ou du loup et de la chienne. Buffon neen a pu obtenir, mais Daubenton en a connu un, qu'il a décrit dans l'Encyclopédie mélhodique.

(1) Les màchoires, du latin mandibnla.

(5) "Animaux de la grosseur d'un cheval marin, ayant des màchoires de sanglier et deux grandes cornes mobiles ", dit Pline (1. VIIl, ch .xxi).

"Quoique cette mobilits des cornes ne soit exactement vraie d'aucun animal, il semble cependant qu'on peut recomaitre à ces traits le rhinocéros d'Afrique, le rhinocéros bicorne, quiportedeux cornes moins immobiles que celles de tous les autres animaux. "(Encycl. mélh., Hisl. nal. des animaux, t. 1.)

(6) Animaux dont la voix pouvait, assurait-on, prendre les intonations de la voix de l'homme. Ils étaient regardés comme le produit de l'accouplement de l'hyère male arec la lionne. On trouve aussi en français léoncrocutte, leucrocotte, léoncrocolte, et en latin : leoncrocula, lconcrola, lencrocola, lentrochocha, leucurcula, ete.

(7) Les ànes de Mirebeau, en Chàtelleraudais, elceux de Meung étaient 
la queue et poictrine comme un lion, les jambes comme un cerf, la gueule fendue jusques aux aureilles, et n'ont aultres dents qu'une dessus, et une aultre dessoubs; elles parlent de voix humaine: mais lors mot ne sonnarent (1).

"Vous dictes qu'on ne vit onques (2) aire de sacre $(3)$, vraiement j'y en vid unze, et le notai bien. J'y vid des hallebardes gauschières (4), ailleur's n'en avois vu. J'y vid des mantichores, bestes bien estranges: elles ont le corps comme un lion, le poil rouge, la face et les aureilles comme un homme, trois rangs de dents, entrants les unes dedans les aultres, comme si vous entrelaciez les doigts des mains les uns dedans les aultres : en la queue elles ont un aguillon, duquel elles poignent (5) comme font les scorpions, et ont la voix fort mélodieuse (6). J'y vid des catoplèbes, bestes

el sont encore réputés pour leur beauté. Au chapitre viu du mème live, l’àne qui est le liéros de lapologue raconté par Panurge esl aussi du "Chastelleraudois".

(1) Ne dirent nol.

(2) Quon ne vit jamais.

(3) Nill de l'oisean le proie appelé sacre. Bulfon a séparé le sacre des laucons pour le mettre à la suite du lanier. "Il est rare, dit Belon, de trouver homme qui se puisse vanter d'avoir oneque ven l'endroict on il láict ses petils. "Plularque aflirme que cel endroit n’a jamais étédélepminé. (Plutargue, Demandes des choses romaines, ch. xcm.)

(1) a La hallebarde, dit Le Duchat, sied mal dans la main ganche, mais les hautelissier's n'y regatdent pas de si pres. " Hallebarde gauchère signifie, présmmons-nous, latleharde le parade. Les suisses de nos cathédrales portent la hallebarde de la main gauche.

"Derricre estoit le prieur des Jacobins en fort bon poinet traisnant unc hallebarde gauschère. "(Procession de la ligue.)

(5) P'iduent, du latin pungere.

(6) Voy. Plixe, I. Vlll, ch. xar ; (inutuen de Mletz, El liure de elergie

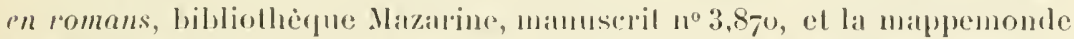
dite de Herelord. Daprés Clésias, la mantichore, de mème que l'éale, se trouvait en Ellhiopic.

En Ynde une autre beste $i$ a

Qu'on apele manchicora,

Yenx de chiève, corps de lion,

Et la kneue de l'escorpion,

Voix de serpent qui par doux chant.

Attrait et levenre les gens.

(G.AUTIER DE MET\%.)

Dans lantalomie de Diemerbroeck, imprimé à l'aris en 1797, on lit 
saulvages, petites de corps : mais elles ont les testes grandes sans proportion, à peine les peuvent lever de terre; elles ont les yeulx tant vénéneux, que quiconque les voit meurt soubdainement, comme qui verroit un basilic (1)."

Avant d'arriver dans ce pays de Satin, où se fabriquaient ces riches éloffes, toutes brochées de fleurs, de fruits, de blasons et d'animaux (2), Pantagruel avait visité l'île de Medamothi (3), où il avait acheté " trois beaulx et jeunes unicornes (4): un masle de poil alezan tostade (5), et deux femelles de poil gris pommelé (6). Ensemble un tarande que

encore (t. 2, p. 651). "Deux rangs de dents est un cas très rare. II est encore plus extraordinaire quon en trouve trois rangs, ainsi quon l'a observé d'Hereule au rapport de Rtodiginus, et que Colombus l'a remarqué en Phobus son propre fils. Les tigres et les élaphants ont souvent trois rangrs. De mème aussi la mantichore, qui est une bète féroce, et le moraxus, qui est un poisson, sont arnés d'un triple rang de dents." Quelques naturatistes croient, sans raisons suffisantes, à mon avis, que la mantichore, nommée aussi manchicore, martieore, martigore, marthicore, manticore et manicore, du persau mardicouran, mangeur d'honımes, est le tigre.

(1) Voy. Pline, 1. VIII, eh. xx. Cet animal, qui ferait bientòt périr tout le genre humain šil levait facilement la tète, n'est autre, comme l'a ćtabli Cuvier, que le Gnou(Antilope gnou, Catoplébas gnou). Lair extraordinaire du gnou - qui est un métange d'antilope, de bouf et de cheval - son regard lugubre, rendu plus effrayant encore par les longs cils blancs de ses sourcils, et enfin sa crinière sans cesse tombante sur son museau, contribuent à lui donner un aspect vraiment fantastique sur lequel s'accordent tous les naturalistes.

(2) Ce pays de Satin, je le rappelle pour la dernière fois, c'est, pour M. Duerot, le pays des drajs de Frize dont parle Thibault de Pleiguei en sa Description de ln Touraine; e'est Tours, célèbre par ses faJriques de soieries et de draps de taine.

(3) En hélureu : nulle parl. Y. Duerot croit, ai-je dit (voy. Anatomie deseriptive, Névologie: La nuque, comme un fallot), que e’est Arkangel qui, du lemps de Rabelais, était séparée de la terre ferme par la mer Glaciale et par le fleuve Pincigre, et visitée, à eause de ses grandes foires, par "les plus riches et fameux marchands d'Afrique et d'Asie ".

(4) Licornes. (Voy. p. 363, note 6.)

(5) Brùlé, del'espagnol tostar, fait de tostare dit par métaplasme pour torrere.

(6) Dans la lettre qu'il a adresséeà son père à l'oceasion de cette acquisitron, Pantagruel dit : "Je vous envoic trois jeunes unicornes, plu 
lui vendit un Scythien de la contrée des Gelones(1). Tarande(2) est un animal grand comme un jeune taureau, portant teste comme est d'un cerf, peu plus grande, arecques cornes insignes (3) largement ramées; les pieds forchus, le poil long comme d'un grand ours; la peau moins dure qu'un corps de cuirasse (4). Et disoit le Gelon peu en estre trouré par la Seythie, parce qu'il change de couleur selon la variété des lieux esquels (5) il paist et demoure. Et représente la couleur des herbes, arbres, arbrisseaulx, fleurs, lieux, pastis, rochers, généralement de toutes choses qu'il

domestiques et apprivoisées qui ne seroient petils chatons. J'ai conléré avecques l'eseuyer, et diet la manière de les traicter. Elles ne pasturent en terre, obstant leur longue come on front. Force est que pasture elles prennent és arbres fructiers, on en ratelicrs idoines, ou en main, leur offrant herbes, gerbes, pommes, poires, orge, touzelle, bref toutes espéces de fruiets et de légumages. Je mesbahis comment nos eseriprains antiques les disent lant farnnches, féroees et dangereuses, et onques vires navoir esté vues. Si bon vous semble, ferez espreuve du contraire; et lrouverez quen elles consiste une mignotize la jlus grande du monde, pourvu que maliciensement on ne les offense. "C'est la confirmation de ce que j’ai dit antériemement de l'existence possible en Afrique de quel' pue esperce d'antilope à une corne ou plutot à deux cornes sondées en une seule et ignorée de nous, mais connue des Aneiens.

(1) "Peuple de Seythie qu'on nomme aujourd"hui Tartares. " (Alphabet de l'auteur.)

(2) Le renne, larandus mongter, appeli larmndus par Pline, Gesner (Icon. quud., pl. 57-58, aree 11 dessin), Aldrovande (de Quad. bisul, PW. 859 et 861), lharmolus par Hugnes de Saint-Viclor (De Bestiis, 1. 11, lol. 2/1 des Oprerl, 1526) et Parandus par Brunetto Latini, Li liveres don Irésor, publiés par P. Clabaille, Paris, 1863). Il nólail pats comu des

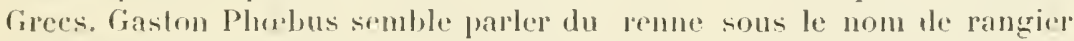
ou ranglier, enmme d'un animal qui anrail existé do son temps en France, dans les lantes monlagnes telles que les Pyrénées. (Vénerie de Jacrues du Fouillous; Paris, 1619, fenillel 971.)

(3) D'une grosiseur et d'mne grandeur remarequalses, du latin insignis.

(i) Cette drucription du renne est, ainsi quion peut sen rendre compte,

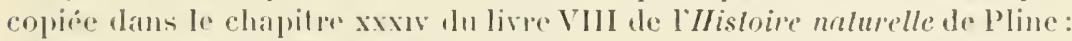

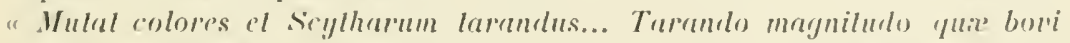
capul majus cervino, nec absimile; cornun romosa, ungulie bifiles : villus mregniludine ursortum serl cum libuil sui coloris esse asini similis est, etr... " Je ne siche pas que le mol lapandus se troure avant Pline daus aucuu auteur latin.

(5) Dans lesquels. 
approche (1). Cela luy est commun avec le poulpe marin (c'est le polype) (2), arecques les thö̈s (3), avec les lycaons

(1) La couleur du pelage du reme change, "non selon la variété des lieux esquels il paist el demoure, "mais suivant les saisons. L'animal en question est blanc en hiver et gris en été comme les ânes de Meung-surLoire.

(2) "Le polype prend la couleur des lieux où il est, surtout quand il a peur. " (Pline.)

Sous la dénomination de Polypes (du grec roxiss, plusieurs, et roüs, pied, qui a plusicurs pieds), Aristote et les auteurs grees et latins ont désigné les Poulpes et autres Mollusques rangés aujourd'hui dans le

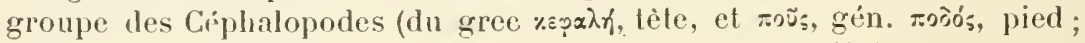
qui a des pieds à la tète). Vers le milieu du xrm siècle, après que Peyssonel et de Trembley curent publié leurs observations, le premier sur le corail, le sccond sur l'hydre d'eau douce, le terme en question fut détom'uć de la signitication qu’il avait chez les Anciens et appliqué par Réaumur et Bernard de Jussieu à tous les organismes marins que les auteurs du $x^{2}{ }^{e}$ et du $x^{\prime}{ }^{e}$ siècle avaient placés parmi les régétaux sous les noms de Lithophytes et de Cératophytes. Dans l'état actuel de la science, les Polypes constituent dans l'embranchement des Colentérés la classe des Anthozoaires ou Coralliaires.

Pourquoi certains mollusques céphalopodes, la pieure, la seiche, entre autres, quisont habituellement d'un blanc gris, deviennent-ils subitement noirs sousl'influence de la peur? 11 y a lì un phénomène nerveux. Sous la peau des mollusques, on trouve un grand nombre de corpuscules sphériques, élastiques, remplis d'une substance noire. Lorsque l'animal est an repos, ces petites boules restent distantes les unes des autres, de telle sorte qu'elles foncent seulement la conleur de la peau et la font paraître grise. Lorsqu il est effrayé, ces corpuscules tirés par des fibres musculaires, dont la mise en jeu est sous la dépendance du système nerreux central, sagglomèrent et leur réunion en masse donne aux téguments une teinte noire. Lorsque la canse qui a provoqué la contraction des fibres musculaires cesse, les corpuscules se séparent et la teinte pâle de lanimal reparaît.

(3) Le Thoës, Thos ou Thaos des Anciens est le chacal ou loup doré (Canis aureus). Homère a comparé Ajax se précipitant au milieu des Troyens pour délivrer Ulysse, à un lion fondant sur des thos attroupés autour d'un cerf aux abois. Le scoliaste d'Honère, en traduisant le mot oús par celui de panthère, a commis une erreur. En traduisant ce mème mot qui figure dans l'Iistoire des animanx d'Aristote (I. II, ch. xvir) par celui de lupus cervarins ou loup-cervier, Gaza en a commis unc autre. Voici ce qu’a éerit Pline de ce Manmifère (l. VIII, ch. xxxiv et I. X, ch. Lxw, trad. Guérault) : "Les thos, espèce de loup dont le corps est plus long, les jambes plus courtes, agile au saut, vivant de chasse et nattaquant jamais l'homme. Ils changent de fourrure et non de couleur; couverts d'un long poil pendant thiver, ils sont nus pendant l'élé..., ils sont cnnemis des lions." 
de Indie (1), avecques le chaméléon, qui est une espèce de lizart tant admirable que Democritus ha faict un livre entier de sa figure, anatomie, vertus et propriétés en magie (2). Si est ce que je l'ai vu couleur changer, non à l'approehe seulement des choses colorées, mais de soi-mesme, selon la paour (3) et affections (4) qu'il avoit. Comme, sus un tapis verd, je l'ai vu certainement verdoyer; mais y restant quelque espace de temps, devenir jaune, bleu, tanné (5), riolet par

(1) Buffon considère comme très rraisemblable que le lycaon des Indes dont il est question dans les livres des naturalistes romains et dans ceux des naluralistes du moyen àge n'est autre que lhyène. Tout ee que ceux-ci ont dit de fabuleux au sujet du lycaon convient a thyenc. On donne aujourd'hui le nom de lyeaon on cynhiène (du gree ж'sw, chien, et hyène, chien-hyène) à un animal qui tient ì la fois de l'hyène et du chien. Le poil de l'hyène n'est pas plus sujet à varier de couleur que ce carnassier n'est sujet à varier de sexe (roy. p. 369, n. 5).

On sait que Lyeaon, looi ('Areadie, fut, selon la fuble, changé en loup) pour avoir essayé d’assassiner, pendant son sommeil, Jupiter qui lui avait demandé l'hospitaliti.

(2) Lire Diogène de Lacree eflélude magistrale de L. Leclere sur les médecins arabes et aussi Plixe, l. XXII, ch. vill.

(3) Aristote, dont le nom se retrouve dans l'histoire de toutes les branches des connaissinces humaines, na pas ignoré les ehangenents de couleur du caméléon. Il a cru que ces changements de coulenr coüncidaient avec le gonflenent du corps ou la mort de l'animal. Théophraste est le premier qui les ait attribués a la peur. Lopinion si populaire que le eamélíon prent la couleur des objets qui linvironnent remonte au philosophe Antigonus Carystius. Ovide la exprimé dans le rers suivant :

\section{Protinus assimilal tetigit quoscunque colores.}

Vengeons le camélíon. (irace it MM. Paul Gervais, Milme Edwards et Brucke, il est acquis aujourd'hui que l'animal dont il s'agit n'indopte pas, comme le courtisan, les couleurs dominantes. Il ne change que soms lintluence de la lumiere : lobscurite le lait pàlir; le leni-jour marbre son corpes des couleurs les plus variées; le soleil le noircit romme la peau des lates negres tropicales et fiat naitre a la surlace de son éphiterme des conleurs irisées. Cés moulifieations sont dues a un jen de pirment quon retrouve chez divers autres reptiles, les Agamides, les Iguanidés et plusiens Batraciens.

(i) Tourments, du latin affectere. On dit encore ithe allowi pour ètre tompmenté, clangrimé.

(5) De couleur semblable a peu pris il celle du tan. 
succès (1), en la façon que voyez la creste des coqs d'Inde (2) couleur selon leurs passions changer. Ce que sus tout trouvasmes en cestuy tarande admirable est que non seulement sa face et peau, mais aussy tout son poil telle couleur prenoit qu'elle estoit és choses voisines (3). Près de Panurge restu de sa togebure (4), le poil lui derenoit gris; près de Pantagruel vestu de sa mante (5) d'escarlate, le poil et peau luy rougissoit; près du pilot vestu à la mode des isiaces (6) de Anubis en Égypte (7), son poil apparut tout blanc. Lesquelles deux dernières couleurs sont au chaméléon desniées (8). Quand, hors de toute paour et affections (9), il estoit en son naturel, la couleur de son poil estoit telle (que voyez és asnes de Meung. "

(1) Par succession, successivement, du latin successus.

(2) Le Dindon. Gallus Indiz. "Une tradition populaire tixe dans le xvie siecle, sous François f $^{\mathrm{e}}$, l'époque de la prenière apparition du dindon en France; car cest dans ce temps que vivait lamiral Chabot. Les auteurs de la Zoologie britannique avancent comme un fait notoire quil a été apporté en Angleterre sous le règne de Henri VII, contemporain te François I ${ }^{\mathrm{er}}$." (Buffox, IIisloire des animaux.) C'est, en effel, du temps de Rabelais que ce volatile a été ramené des nouvelles Indes ou Amérique en Europe. II n'en est pas question dans les ceurres de Clytus, d'Athénée, d'Elien, de Columelle, ete.

Quand le dindon est en colère, la crète qu'il porte sur son bec supérieur s'allonge, se déploie et change de couleur.

(3) Des choses qui étaient auprès, qui l'aroisinaient.

(4) Toge (de) bure.

(5) Vètement long enveloppant tout te corps.

(6) Les prètres disis étaient vètus de grandes robes de fin lin. Ce qui fait qu'Ovide les a appelés linigera turba.

(7) Ce Dieu à tète de chien (roy. p. 37o, note 4), considéré comme fils d'Isis et d'Osiris, avait son image placće à la porte de tons les temples d'Égypte. Il était honoré principalement à Hermopolis la Grande (Chemnis on Ouchmonnein, en arabe moderne).

De ses temples quand Rome, Isis, t'ouvrit la porte

Des dieux à front de chien laboyante cohorte Suivit.

(LtCaIN.)

On adore Anubis dans des cités entières,

Mais lautel de Diane, hélas! est sans prières.

(8) Voy. Plutaroue, Trailé des callses naturelles.

(JUVÉXAL.)

(9) Désirs. 
Pantagruel était occupé à faire l'achat de ces animaux quand "furent ouïs du mole dix coups de verses (1) et faulconneaux ". C'était un des céloces (2) de "Gargantua, nommé la Chélidoine (3). pource que sus la pouppe estoit en sculpture de aerain corinthien (4) une hirondelle de mer eslevée (5). C'est un poisson grand comme un dar de Loire (6), tout charnu, sans esquames $(\boldsymbol{7})$, ayant ailes cartilagineuses (quelles sont és souris-chaulves) (8) fort longues et larges. moyennant lesquelles je l'ai souvent vu voler (a) une toise au-dessus l'eau plus d'un traict d'are. A Marseille on le nomme lendole. Ainsy estoit ce vaisseau léger comme

(1) "Les verses dont parle Rabelais pourraient bien ètre, dit Le Duchat, des faucons, et mème des doubles berches plus grosses que des simples berches ou fauconneaux."

(2) Petit bitiment à marche rapide, brigantin ou aviso, destiné à porter des dépèehes, tı latin celox.

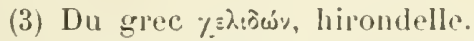

(4) Le plus précieux de tous les airains. C'était un alliage de cuivre, d'or et diurgent, dont les Anciens se servaient pour fabriquer des objets de luxe. lis croyaient quil était le résultat d’un mélange accidentel produit par la fusion des vases et des statues des temples de Corinthe, lor's de la mise à sac de cette ville par Mummius (' 6 t ans avant Jésus-Christ).

(5) Les poissons volants, rougets volants, apparticnnent à l'ordre des Télostéens et au genre Dactyloptère. Le plus connu est le Dactyloptère volant, appelé vulgairement, depuis Aristote, fancon de mer et surtont hirondelle marinc. Les ichtyologistes du moyen ìge, Belon, Rondellet, Salviani Tont nommé arondelle de mer et en ont donné de bons dessins. On ne doit pas le confondre ave l'exocet on Muge volant.

(6) Un dard de la Loire. Le darel est un poisson du genre cyprin, plus connu sous le nom de vandoise. Sa chair est très estimér el il uage avec une telle vitesse qu'il ressemble à un trait décoché. D'où ces expressions proverbiales en Touraine : sain comme un darel, vif comme un dard.

(7) Saus écailles, du latiu stuuma : on dil encore squammeux.

(8) La membrane alaire des chaures-souris, mammiteres de l'ordre des Cheiroptires, est lormée de dems feuillets dermigues trés fius, sous-tendus par des phalanges, ef des mritararpiens ossenx, non curlilayineux.

(9) Rabelais ne s'est pas tromuri. Les larges nageoires pectorales des Dactylopteres et des Exocets ne sont plus regardées aujourthui comme de simples parachutes, des appareils de sontien immobiles. Pettigrew ef de Tesison ont constate le ballement de ces nageoires. Swainson rapporle ce latit important que le poisson volant pent chinger son pareours, apres

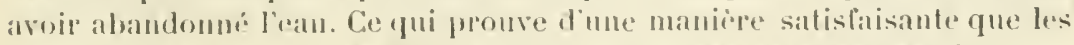
nagevires en equestion ne sont pas simplement des orgines passits. 
une hirondelle, de sorte que plustost sembloit sus mer voler que voguer."

A bord de ce battiment était un écuyer de Gargantua nommé Malicorne (1), chargé de remettre au Prince des lettres de créance et " un gozal (2) emmailloté dans un panier... C'estoit un pigeon (3) prins (4) au colombier de Gargantua, esclouant (5) ses petits sus l'instant que le susdict céloce despartoit (6). Si fortune adverse (7) fust à Pantagruel advenue (8), il y eust des jects noirs attaché és pieds (9): mais pource que tout luy estoit venu à bien et prospérité, l'ayant faict desmailloter, luy attacha és pieds une bandelette de tafetas blanc; et, sans plus différer, sus l'heure le laissa en pleine liberté de l'aer. Le pigeon soubdain s'envole haschant (10) en incroyable hastiveté (11), comme vous sçavez qu'il n'est vol que de pigeon,

(1) “ Le procès-verbal de la coutume de Touraine, dressé en l'an 1559 , parle d'un Marc de La Rue, sieur de la Couste et de la Marelle, de la Bérengerie, de Malicorne et du fief de Roche-Corbon. "(LE Ducint.)

(2) Pigeon, en hébreu.

(3) Un pigeon yoyageur. Le pigeon voyageur, columba migratoria (ordre des Colombins, intermédiaire entre les Passereaux et les Gallinacés, appartient aux deux races de pigeons cravatés et volants.

(4) Pris.

(5) Faisant éclore, couvant par conséquent.

(6) Partait.

(7) Contraire, mauvaise, du latin adversus.

(8) Arrivée, du latin advenire.

(9) Tournure latine: il lui eut attaché aux pattes les.

(10) Fendant l'air comme avec une hache.

(11) Des expériences établissent cette précipitation incroyable du vol des pigeons voyageurs et en particulier du vol de ceux d'origine arabe (gozal).

Des pigeons arabo-belges - des pur-sang - lancés de la dernière plateforme de la Tour Eiffel ont parcouru jusqu’à 130 kilomètres à l'heure, en planant à une hauteur de 400 mètres, alor's que nos pigeons ne s’élèvent guère au-delà de 150 mètres et ne franchissent, en moyenne, que jo à 80 kilomètres à l'heure.

Et ce n'est pas un maximum. "En 1884, quatre pigeons arabo-belges firent le trajet de Paris à Buda-Pesth en sept heures. La distance entre les deux villes est de 1.293 kilomètres. Les royageurs araienl done fait $184^{\mathrm{km}}, 7$ par heure, $5 \mathrm{~km}, 06$ par minute, et 51 mètres par seconde. C'est 11 mètres de plus que l'ouragan." (Coustier, les Pigeons voyageurs el leur emploi en lemps de guerre; Paris, 1891.) 
quand il ha œufs ou petits (1), pour l'obstinée sollicitude en luy par nature posée de recourir (2) et secourir ses pigeonneauk. De mode qu'en moins de deux heures il franchit par l'aer le long chemin qu'aroit le céloce en extrème diligence (3) par trois jour's et trois nuicts parfaict (4), voguant a rames et à vèles (5), et luy continuant (6) rent en pouppe. Et fut vu entrant dedans le colombier on $(\overline{7})$ propre nid de ses petits.

"Adoneques (8) entendant le preux (9) Gargantua qu'il portoit la bandelette blanche, resta en joye et seureté du bon portement (10) de son fils.

"Telle estoitl'usance (1 1 ) des nobles Gargantua et Pantagruel, quand sçavoil promptement rouloient nouvelles de quelque chose fort affectée (12) et véhémentement (13) désirée, comme l'issue de quelque bataille, tant par mer comme par terre, la prinse (14), ou défense de quelque place forte, l'apoinctement $(15)$ de quelques différents d'importance. l'accouchement heureux ou infortuné de quelque reine ou

(1) QQui n'a pas lu la fable des Deux Pigeons du bon La Fontaine? Elı bien! chez les Colombins, l'amour de la femelle pour sa couvée et ses petits égale, si elle ne le dépasse, l'amour conjugal. "Une femelle, dont le panier avait été placé trop près de la lenètre d'une volière, ne quitta sa couvée que lorsque ses petits furent éclos, bien que ses pattes lussent gelées et tombées par l'excès dn l'roid. " (Buffox.) Quelles que soient les espèces de pigeons, c’est dans les conditions indiquées par Rabelais que leur vol est le plus rapide.

(2) De revenir en toute hâte vars, du latin recurrere.

(3) Empressement, du latin diligentia.

(4) Aceompli, du latin perfeclus.

(5) Voiles, du latin velum.

(6) Ayant continucllement lo vent en poupe (en arrière), c'est-it-dire lavorable.

(7) Au.

(8) Done.

(9) Le prudent, le sage et aussi le courageux, le vaillant.

(1ii) État de santé.

(11) Lihabitude, lissage; du lilin usus.

(12) Mème sens à pen près que lésirer, souhaiter, du latin affecture.

(13) Vivement, du latin vehemeuler.

(1/1) Lal prise.

(15) La négociation, l'accord. 
grande dame. la mort ou convalescence de leurs amis et alliés malades, et ainsy des aultres. Ils prenoient le gozal, et par les postes (1) le faisoient de main en main jusques sus les lieux porter dont ils affectoient (2) les nouvelles. Le gozal, portant bandelette noire ou blanche, selon les occurences (:3) et accidents, les ostoit de pansement (4) à son retour, faisant en une heure plus de chemin par l'aer, que n'avoient faict par terre trente postes en un jour naturel (5). Cela estoit rachapter et gagner temps. Et eroyez, comme chose vraisemblable, que par les colombiers de leurs uassines (6), on trouroit sus œufs ou petits, touts les mois et saisons de l'an, les pigeons à foison. Ce qui est lacile en mesnagerie (7), moyennant la salpestre en roche et la sacre herbe verveine (8)."

Sans remonter jusqu'au déluge, c'est-à-dire jusqu'à la colombe de l'Arche, ilest certain que, depuis bien longtemps, les pigeons sont au service de l'homme. Leurs aptitudes spéciales étaient connues des Grees et des Romains. CharlesQuint s'en est servi au siège de Metz. En Égypte, les Khalifes et les Sultans les utilisent depuis plusieurs siècles pour porter des dépéches et assurer des communications

(1) Les courriers.

(2) Désiraient.

(3) Les événements, du verbe latin occurrere.

(4) De réflexion, d'inquiétude.

(5) On distinguait chez les Latins le jour naturel (dies naturalis), dont la durée était comprise entre le lever et le concher du soleil, et le jour civil (dies civilis), qui était de 24 heures. Les premiers courriers, se reposant la nuit, on conçoit l'utilité de l'épithète que Rabelais aceole au mot jour.

(6) Maison, de l'italien casina ou plutòt casino, lait, dans la mème signnification, du latin casa, clont il est un diminutif.

(7) Le mot ménagerie signifie exactement : lieu oủ on nourrit les animaux rares, et ici colombier.

(8) La verveine a été considérée comme une plante sacrée par les Grees et les Latins, qui lappelaient hierobante ou herba sacra. On s'en servait pour purifier les autels de Jupiter, pour les orner pendant les sacrifices, etc. Au lieu du moyen indiqué par Rabelais, on emploie anjourd'hui, en Suisse, pour ramener les pigeons an colombier, une boule, composée de grains d'anis, d'argile et de sel. 
suivies entre les villes. Ils ont mème obtenu, par la sélection continue des sujets, les gozals, qui sont les pigeons voyageurs les plus réputés pour l'élévation et la rapidité de leur rol. Ces gozals, Maìtre François en a entendu parler, et a dù par conséquent, ainsi que nous l'avons déjà dit, se trouver en rapport à Montpellier avec quelques étudiants ou savants arabes (1).

L'écuyer de Gargantua avait quitté Medamothi et la flottille de Pantagruel, regagné, depuis cinq jours, la haute mer, quand elle fut accostée par un bâtiment contenant un troupeau de moutons. Ces moutons marchandés par Panurge, puis noyés, par un stratagème de celui-ci, avec leur propriétaire Dindenault et leurs bergers, sont plus célèbres que ceux de II $^{\text {me }}$ Deshoulières et de Rosa-Bonheur. Ils le méritent doublement: ils nous prémunissent contre les dangers d'une imitation servile et sont de noble race.

"De leur toison seront faicts, dit Dindenault ì Panurge, les fins draps de Rouen; les louschets (2) des balles de Limestre, au prix d'elle, ne sont que bourre. De la peau seront faicts les beaulx marroquins, lesquels on vendra pour marroquins turquins (:3), ou de Montelimart ou de Hespaigne (4) pour le pire. Des boyaulx, on fera chordes de violons et harpes, lesquels tant chèrement on vendra, comme si fussent chordes de Munican (5) ou Aquileie (6).

(1) Voy. Anat. descript., Appareilgénital: La génilure, comme un cenl de' clous i lalle.

(2) Ancienne espice de serge croisíc quion appelait aussi drap de Limestre.

Combien, pour aroir mis leur honneur en sequestre.

Ont-elles en velours échangé leur Limestre.

(M. Régriler, sat. X'II.)

(3) Ture, diun bleu turc. Le marbe turquin et les turquoises se trouvent en Turquir.

(4) D'Espagne.

(5) "On pourrait croire que ce serait ici Municken, capitale de la Baviere: mais cest plulot Monaco, daus la Ligurie. Les meillempes comes de luth vienment allalie. "(I.e I) Ucast.)

(6) Apuilere, ville d's slrir. 
"S'il rous plaist, dist Panurge, m'en vendrez un.

" Mon ami, respondit le marchand... ce n'est viende que pour roys et princes. La chair en est tant délicale, tant savoureuse, et tant friande que c'est basme (1). Je les ameine d'un pays, onfuel (2) les pourceaulx... ne mangent que myrobalans (3). Lestruiesen leur gésine (4) (saulve l'honeur de toute la compagnie) ne sont nourries que de fleurs d'orangers. - Mais, dist Panurge, vendezm'en un, el je vous le payerai cn roy... Combien? - Nostre ami, respondit le marchand... ce sont moutons extraicts de la propre race de celluy qui - porta Phrixus et Helle. par la mer diete Hellesponte (5)... Par touts les champs esquels (6) ils pissent le bled y provient (7) ... Il n'y faut aultre marne ne fumier. Plus y ha. De leur urine les quintessentiauls (8) tirent le meilleur salpestre du monde.

(1) Baume, $\beta \dot{x} \lambda$ sxuor en grec, bulsamum en latin.

(2) Oì.

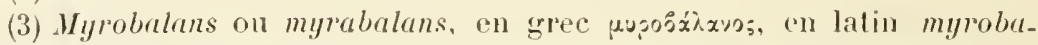
lanum (Plixe) et myrobalanus (Julius Vallerius), sorte de noix aromatique, moixde ben. "Myrobalans, que les Arabes appellent Been, car ils semblent à glands et sont metueux." (L. III, ch. L.)

(4) Festin de relevailles et aussi les couches, le temps des couches.

"L'exposant oï dire que icelle lemme avoit esté à une gésine, aultrement nonmée au pays. " (Coutuxces, 1多, arch. J. J. 167, p. 89.)

(5) Athamas, roi de Thílies en Béotie, iponsa en premières noces Néphélé ou Themisto, dontil eut, entre aulres entants, Phryxus et Hellé, et, en secondes noces, Ino, fille de Cadmus, qui le rendit père de Léarque et de Mélicerte. Cettr deuxième épouse, irritée des dédains de Plıyxus, détermina Athamas à le sacrifier aux dieux avec Hellé. Mais, la veille du jour désigné pour le sacrifice, Jupiter envoya à Phryxus un bélier à toisom d'or, sur lequel il s'enfuit avec sa sour. Celle-ci tomba dans la mer en passant l'Hellespont (le détroit des Dardanelles, mer d'Hellé); le jeune homme arriva sain et sauf en Phocide, où il devint le gendre du roi Aétés.

(6) Dans lesquels.

(7) Le fumier, lirine et la chaleur du corps de ces animaux raniment en peu de temps les terres épuisées, moides ou infertiles. Cent montons améliorent en un été huit arpents de terre pour six ans.

(8) Les savants du noyen àge qui cherchaicnt la quintessence. "Tous les corps, a écrit Cornelius Agrippa (Philosophie occulle, I. I, ch. xiv) sont composés de quatre éléments: le feu, lair, l'eau et la terre. Ces corps ainsi matériellement formés possèdent des propriétés diverses, selon leur diverse composition.

"L'esprit est essentiellement et spontanément mobile : la matière ne 
De leurs erottes (mais qu'il ne vous en desplaise) les médicins de nos parss guérissent soixante et dixhuict espèces de maladies (1). La moindre desquelles est le mal sainct Eutrope de Xaintes (2), dont Dieu nous saulve el gard (3)... Aussyme coustent-ils bon...

"Vendez m’en un, le payantbien, respondit Panurge.

" Nostre ami, dist le marchand... considérez un peu les

l'est pas. Donc il lant un certain medium, ni àme tout à fait, ni corps tont à lait, qui relie ces dilférents éléments comme ce qui unit l'àme au corps humain.

"Ce médium, les philosophes l'appellent l'esprit du monde; nous l'appelons, nous, Quintessence, parce que ce n'est pasun des quatre éléments, mais un cinquième, subsistant au-dessus et en dehor's d'eux.

"C'est cette quintessence qui distribue à toutes choses les propriétís de l'âme du monde. Par la quintessence, tontes sortes de propriélés occultes sont distriluées aux animanx, aux plantes, aux métaux, par le soleil, la lune, les planètes et les étoiles."

C'est cet esprit du monde, cette quintessence, quiont cherchée avectant d'opiniâtreté les alchimistes, les astrologues, les magiciens, sous le nom de pierre philosophale.

(1) Les crottes de moutons ont été, en effet, employées autretois en médecine contre l'hydropisie.

(2) De Saintes. Dindenault, qu'on ne loublie pas, était de Saintes.

(3) Une conversation tenue entre Lasdaller, le chef d'une bande de pèlerins, et Grandgousier nous apprend quel est ce mal :

Doù venez-rous et oì allez-rous ? demande Grandgousicp anx pélerins (I. I, ch. XLv). "I Lastaller pour touts respondit: "Seigneur je suis de Sainct Genou en Berry, cestuy-ci est de Paluau; cestuy-ci de l'Onzay... Nous venons de Sainct Sébastian près de Nantes et nous en retournous: par nos petites journées. - Voire, uais dist Grandgousier, qualliez-rous faire i Sainct Sébastian? - Nous allions, dist Lásdaller, lui offrir uos votes (verux, prières et anssi offrandes, du latin tolum) contre lit prote. - $\mathrm{O}$, dist Grandgousier, paures gents, estimez-rous que la peste vienne de Sainet Sebastian? - Oui, raiement, respondit Lasdaller... - Aiısy preschoit à Sinays un caphar, que Sainet Antoine mettoit le len és jambes; Sainct Eutrope laisoit les hydropiques; Sainct Gildas les lols; Sainct Genou les gomttes. »

Saint Entrope lait partie de cette série d'blus qui ont lait dire it 11. Eugène Vö̈l gue, dutemps de Rabelais, " le culte des Saintscitait sonrent basé sur des jeux de mots et - loon est honteux de le dire - sur

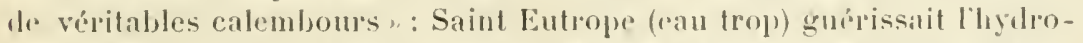
pisie; saint Genou, la gontte; saint Inam, la gale aux mains, la rogno; saint Cloud, les clous; saint Eustange on Eustanche, les hémorrhatgies, ete., 'tr. 
merveilles de nature consistants en ces animaulx que voyez, voire (1) en un membre que estimeriez inutile. Prenezmoi ces cornes-là, et les concassez un peu arecques un pilon de fer, ou arecques un landier, ce m'est tout un. Puis les enterrez en vue du soleil, la part que vouldrez, et souvent les arrosez. En peu de mois vous en voirrez naistre les meilleurs asperges du monde (2). Je n'en daignerois excepter ceulx (3) de Ravenne (4)... A propos, si vous estiez elere, vous sçauriez que, és membres plus inférieur's de ces animaulx divins, ce sont les pieds, y ha un os, c'est le talon, l'astragale (5), si vous voulez, duquel, non d'aultre animal du monde, fors de l'asne indian (6) et des dorcades de Lybie $(\boldsymbol{7})$, l'on jouait antiquement au royal jeu des tales, auquel l'empereur Oetavian Auguste un soir gagna plus de cinquante mille escuts (8)... Et quand... vous aurai-je, nostre ami... dignement loué les membres internes: les espaules, les esclanches, les gigots, le hault costé, la poictrine, le foie, la ratelle, les trippes, la gogue (9), la vessie, dont on joue à la balle; les costelettes, dont on faict en Pygmion les beaulx petits ares pour tirer des noyaulx de cerises

(1) Oì vous voudrez.

(2) Invenio (sylvestrem asparayum) nasci et arietis cornibus lusisque alque defossis. Je trouve que l’asperge sylvestre est née des cornes broyées et enterrées d'un bélier. "(Pline, I. IX, ch. vill.)

(3) L'auteur, l. V, ch. vil, lait encore asperge du maseulin.

(4) Mollis in rquorea quæ crevil spina Ravenna, non erit inaultis gralior asparagis. (Martal, épigr. xxi du l. III.)

(5) L'astragale est un os court situć entre les os de la jambe et ceux du pied et dont la forme rappelle celle de la petite moulure ronde qui entoure

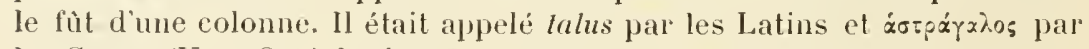
les Grecs. (Voy. Ostéologie : Les rasselles, comme des échasses.)

(6) L'àne saurage, l'onagre (?). Pline avance qu'on le rencontre sur les bords de l'Indus (aujourd'hui le sind).

(7) La gazelle dorcas.

(8) Voy. Suétone, ch. Lxin, de la Vie d'Auguste. Les tales sont les dés en or, en argent ou en ivoire ayant la lorme de l'astragale, dont les Anciens se servaient pour jouer.

(9) Le ventre. Le mot gogue est encore employé en Touraine pour désigner le gras-double qu'achètent les malheureux. 
contre les grues; la teste dont, areeques un peu de soulphre, on faict une mirifique décoction pour faire viender (1) les chiens constippés du ventre... Par le digne voult de Charrous (2), le moindre de ces moutons vault quatre fois plus que le meilleur de ceulx que jadis les Coraxiens (3) en Tuditanie (4), contrée de Hespaigne, vendoient un talent d'or la pièce (5) $)$.

Les moutons, dout la lame, la chair, la graisse, les os, les entrailles, les résidus de la digestion, la litière fournissent tout à la fois à l'homme de quoi se vètir, se nourrir, s'éclairer, fumer ses champs, réparer ses instruments de musique (6), sont les animaux les plus sots de la création. La domesticité, en achevant de les dépouiller de la faible part d'instinct qui leur avait été dérolue par la nature, en a fait des espèces de machines vivantes. Abandonnés à euxmèmes, dans les climats les plus farorables, ils périraient avant deux mois de misère ou par la dent des carnassiers. Lor'squils sont en troupe, si celui qui va en tète s'arrète

(1) "Viander c'est ici fienter." (LE Dechat.)

(2) Labbaye de Charroux, cn Poitou, était célèbre parses reliques, les pèlerinages el les vornx quin y laisait :

Par la foy tue je toy la couronne et li clou

Que dans Challe et Chaux apporta à Charou.

(Dow de Naxteull, cité par Fauchet. Lang. el poés. franç., p. 114.)

On jurait par l'image ('ullus) de Charroux.

(3) Coraxi (Plixe); les habitants de la Colchirle.

(1) En Andalousie.

(5) Strabon, 1. III de sa Géographie, cité par Budé, I. IV de son De Asse. Il y a loin de la Colchide in Mondalousie. "C"esl ce qui rendait, dit Le Juchat, si prodigieusement chers los montons des Conviens parmi les Anfalons, qui, ayaut d'ailleur's chez eux une grande quantiléd'or, comptaient pour peu de chose ce que leur contaient ces moutons dont ils voulaient avoir la race."

(6) " El pour conchusion les brehis sont grandement profitables pour linsage des hommes. Aussi Irouverons-uons en l'Escrilure Saincte que

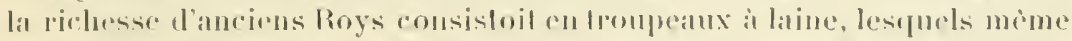
ils daignoint bien gander en lents propres personnes (pour le profit et exellence de ces leestes), conme nous lisons d'Abuaham, Isaac, Jacob,

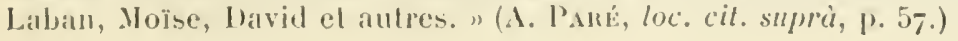


devant le plus léger obstacle, tous les autres en font autant, et on les tuerait plutot que de les faire avancer: le berger, dans ce cas, n'a qu'une ressource, c'est d'en prendre un et de le porter au delì de l'obstacle, et alors les autres passent. Mais si, au contraire, poussé par quelque imbécile frénésie, le premier mouton se jette dans un précipice ou dans une rivière, les autres s'y lancent après lui sans la moindre hésitation.

C'est en tablant sur cette particularité que Panurge a lait noyer Dindenault, ses moutons et leurs bergers. "Soubdain, je ne sçai comment (le cas feut subit, je n'eu loisir le considérer), Panurge, sans aultre chose dire, jecte en pleine mer son mouton criant et beslant. Touts les aultres moutons, criants et beslants en pareille intonation, commencearent soi jecter et saulter en mer après à la file. La foulle estoit à qui premier y saulteroit après leur compagnon. Possible n'estoit les en garder. Comme vous sçavez estre du mouton le naturel, toujours suivre le premier, quelque part qu'il aille. Aussy le dict Aristoteles lib. 9, de Ilistor. anim. estre le plus sot et le plus inepte animant (1) du monde. Le marchand, lout effrayé dece que devant ses yeulx périr voyoit et noyer ses moutons, s'efforcoit les empescher et retenir de tout son povoir. Mais c'estoit en vain. Touts ì la file saultoient dedans la mer et périssoient. Finablement (2), il en print (3) un grand et fort par la toison sus le tillac de la nauf, cuidant (4) ainsy le retenir, et saulver le reste aussy conséquemment. Le mouton fut si puissant qu'il emporta en mer avecques soi le marchand, et fut noyé, en pareille forme, que les moutons de Polyphemus (5) le borgne cyclope emportarent hors

(1) Animal.

(2) Finalement.

(3) Prit.

(4) Croyant, du latin credere.

(5) Polyphème, le plus grand, le plus célèbre et le plus hideux des 
la caverne Ulysses et sés compagnons. Aultant en firent les aultres bergers et moutonnier's, les prenants uns par les cornes, aultres par les jambes, aultres par la toison. Lesquels touts feurent pareillement en mer portés et noyés misérablement. "

Les grands Cétacés (baleines, cachalots, ete.) étaient plus communs autretois qu'aujourd'hui dans les mers du Nord.

Dans leurs longues pérégrinations, Pantagruel et ses compagnons en ont rencontré trois : deux (1) entre l'île d'Oultre (2) et le royanme de la Quinte (3), un près de l'ìle Farouche (4). Cie dernier a foumi à Rabelais loceasion d'une description de la pêche pénible et dangereuse. mais lucrative, d'un de ces gigantesques mammifères. "Sus le hault du jour, approchants l'isle Farouche, Pantagruel de loing apperceut un grand el monstrueux phýsétère (5)...

eyclopes, né des amours de Neptune ef de Thoosa, halitait les còtes de la Sicile oú il laisait faitre de nombreux troupeanx. Ulysse el ses compagnons, enlermés par lui dans une caverne, en sortirent en se crampomant au ventre des bélier's qűil surveillait.

(s) An moment où te prince laisait passer des provisions aux marins d'Henri Cotiral pour les remereier d'avoir renfloué la thalamège ensablée. "denx grands physétères impétueusement abordèrent leur nauf et leur jeetèrent dedans plus d'eau que n’en contient la Virmue, depuis Chinon jusquà Sanlouant (Sant-Louant)".

(2) Lile de Jersey, pour M. Duerot.

(3) Saint-Michel-en-Grive, pour M. Duenot.

(i) "Lîle Gipimm, an nord-nord-onest de l'lskancle, de tempes immémorial rendez-rous des pechenrs de buleines, de veanx marins, quon extermine pour en aroir la graisse. the mème que kabelais fait tuer, dit M. Ducrot, $m$ grand pliysétire on haleine par Pantagruel sur lis cótes

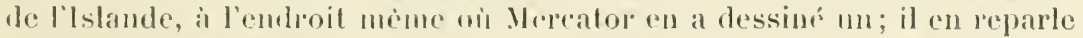
encores entre la eote normande et la cote de Bretagne, lia ou Mereator en a dessine un antre. La peneontre est lort singuliere, on en conviendra sills peine." (Ducrot, loc. cit. suprid, p. 28.)

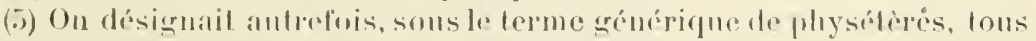

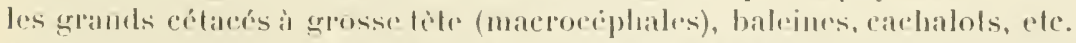
Aujonrdhui il désigne le eachalot. Dans fe hangage commereial, on dome encore le nom de blanc de baleine (spermatedi) à une substance vis-

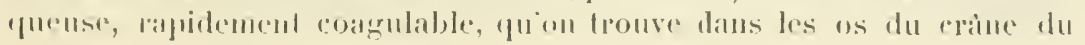


bruyant, ronflant, enflé, enlevé (1) plus hault que les hunes des naufs (2), et jectant eaux de la gueule en l'aer devant soi, comme si fùst une grosse rivière tombante de quelque montagne (3).

"Pantagruel le monstra au pilot et ì Xenomanes (4). Par" le conseil du pilot furent sonnées les trompettes de la tha-

eachalot. "Le physétère, appelé peis mular en Provence et sedenecte en Saintonge, est, dit Le Duchat, une espece de baleine quion voit quelquefois sur l'océan françois, particulièrement ver's Bayonne. Les Grees ont nommé ce poisson Physétère, comme qui diroit Soltfleur, à cause de l'ean qu'il jette comme en soufflant, par un pertuis qu'il a dans le dessus de la tète. Voy. Roxdellet, De Piscibus, 1. XVl, ch. xiv, où il cite Pline l. IX, eh. Iv. "

(1) Élevé.

(2) Le penchant inné qu'a tout homme à exagérer encore les choses extraordinaires a pu se domner un libre cours au sujet des physétères et principalement de la baleine. Dans plusieurs ouvrages anciens, il est fait mention de balcines de 50 à 60 mètres de long. De fait, les baleiniers ne parlent plus, depuis trois ou quatre sièeles, que de baleines de 20 métres de long, ce qui est déjà bien raisomnable. Arec eette longueur, la circonférence, derrière les nageoires pectorales, est de 10 à 13 mètres; le poids est d'environ 150.000 kilogrammes. Celui que représenteraient environ trente éléphants, quarante rhinocéros ou hippopotames, deux cents taureaux. (Brenn.)

(3) La respiration des Cétacés est singulière. Quand ils remontent pour respirer à la surface des flots, ils soufflent bruyamment l'eau qui a pénétré dans leurs narines incomplètement fermées, et cela avec une telle force que cette cau, réduite en poussière, sélève à 5 ou 6 mètres, à 13 mètres mème chez les grandes baleines, et peut ètre aperçu de plus d'un mille marin de distance. On dirait un jet de vapeur séchappant d'un tuyau stroit; le bruit quelle fait ressemble aussi au bruit de la vapenr. Ce n'est donc pas un jet d'eau, semblable à celui d'une fontaine, et tel que le représentent les dessinateurs et que l'ont décrit quelques naturalistes.

(4) Jaai déjà dil que l’un des pilotes de Pantagruel était Jacques Cartier et lautre Alphonse le Saintongeois. Ce dernier est indiqué elairement par ees deux phrases de Rabelais : "Panurge l'amena du pays de Lanternois " (e'est La Rochelle) et "icelluy... aroit à Gargantua laissé et signé, en sa grande et mniverselle liydrographie, la route qu'ils tiendroient. " (L. IV, ch. I.) Or c'est précisément l'ouvrage de Jean Alphonse. qui a habité avec Pierre Séealar en la rue de Saint-Jean-de-Prez, à La Rochelle, devant l'église de Saint-Jean-du-Perrot, près la tour de la Lan1erne. Son Hydrographic a été imprimée à Poitiers en 1559 par Jean de Nlarnef, libraire. 
lamege en intonation de gare serre (1). A cestuy (2) son, toutes les naufs, gallions, ramberges (3), liburniques (4), sclon qu'estoit leur discipline navale, se mirent en ordre et tigure...

"Lephỵsétère, entrant dedans les brayes (5) et angles des naufs et gallions, jectoit cau sus les premieres à pleins tonneaulx, comme si fussent les catadupes (6) du Nil en Ethiopic. Dards, dardelles, javelots, espieux, corsiques ( 7$)$, pertuisanes, voloient sur luy de touts costés.

"Frère Jean ne s’y espargnoit.

"Panurge mouroit de paour (8).

"L'artillerie tonnoit et fouldroyoit en diable, et faisoit son debroir de le pinser (9) sans rire. Mais peu profictoit (10): car les gros boullets de fer et de bronze, entrants en sa peau, sembloient fondre, à les voir de loing, comme font les luiles au soleil (1 1 ). Alor's Pantagruel, considérant l'occasion et

(1) Pour avertir de se mettre en garde et de se serrer l'un contre lautre, de faire la scie (serra), manceuve navale stratégique ancienne 'fui consistait à avancer el à reculer tour à lour. (Vegetius, Aulus-GelLies.)

(2) Ce.

(3) Vaisseaux longs.

(1) Navires léger's des Liburniens. Liburna (Horace, Lucies, Tacrte). Liburnica (Plixe, Suétoxe).

(5) Les écoutilles.

(6) "Lien en Ethiopie onquel le Nil tombe de haules montaignes, en si horrible bruyt que les roisins du lieu sont presque tous sours, comme eseripl Cl. Galen. Levesque de Caramith, celluy qui en Rone fut mon préceptenr en langue arabique, mha diet que lon oyt ee brugt it plus de trois journeses loing, qui est aullant que de Paris à Tours. " (Voy. P'Tol. Cicérox, In Som. Scipionis, Plixi, 1. V, ch. ix, et Strabox.) (Brictre Díclaration.) J'ai temu it reprodure in extenso cettenote. Elle proure: $1^{0}$ que Rabelais est bien lauleur de la Briefve Declaration; $2^{\circ}$ que c'est à Rome quil a appris larabe.

(7) Javelines.

(8) Panurge navait pas absolument tort. On eite des cachalots qui out attaqué sans motil des navires el les ont coulés las.

(y) Pincer.

(10) Mais cela ne servait guère, elat pren utile, du latin proficere.

(11) Le tissu graisseux qui double la peau de la baleine est tellement mollasse quil se laisse déprimer par la moindre pression et par cela 
nécessité, desploye ses bras et monstre ce qu'il sçavoit faire...

"Car avecques ses horribles piles (1) et dards (lesquels proprement ressembloient aulx grosses poultres sus lesquelles sont les ponts de Nantes, Saulmur, Bergerac, et a Paris les ponts au Change et aux Meusniers (2) soustenus, en longueur, grosseur, poisanteur (3) et ferrure)... au premier coup, il enferra le physétère sus le front, de mode (4) qu'il luy transperça les deux maschoires et la langue, si (5) que plus ne ouvrit la gueule, plus ne puisa, plus ne jecta cau. Au second coup, il lui creva l'œil droict. Au troisiesme l'œil gausche. Et fut vu le physétè̀e, en grande jubilation de touts porter ces trois cornes au front, quelque peu penchantes d'arant, en tigure triangulaire éfuilatérale; et tournoyer d'un costé et d'aultre, chancellant et forvoyant (6), comme estourdi, aveuglé et prochain de mort.

"De ce non content, Panlagruel luy en darda un aultre sus laqueue, penchant pareillement en arriere. Puis troisaultres sus l'eschine en ligne perpendiculaire, par équale (7) distance de queue et bee (S) trois fois justement compartie (9). Entin luy en lancea sus les flancs cinquante d'un costé et cinquante de l'aultre (10). De maniore que le corps duphy-

mème "cède et ue rompt pas ". Ce tissu graisseux forme, d'autre part, une gaine de 20 a 50 centimètres d'épaisseur antour du corps qui doit ètre entièrencnt traversée, ainsi que les muscles, avant que les parties nobles soient alteintes.

(1) Javelots, traits; rìo; en grec, pilum en latin.

(2) Le Pont-aux-Meuniers n’élait éloigné du Pont-au-Change que de quelques toises. Il fut détruit, avec tous ses moulins, sous le règne de Henri II.

(3) Pesanteur.

(4) De sorte que.

(5) Tellement, à tel point, si bien.

(6) Reculant, du latin foras, dehors, et via, chemin.

(7) Égale, du latin xulualis.

(8) Alias bac.

(9) Partagée, divisée.

(10) Le physétère de Pantagruel n’est pas une exception. Quand un animal de ce genre était harponnó el entrait en agonie, on achevait autretois de le tuer à coups de lance, principalement dirigés entre les côles. 
sétère sembloit (1) à la quille d'un gallion à trois gabies (2), emmortaisée par compétente (3) dimension de ses poultres (4), comme si fussent cosses (5) et portehaubanes de la carine $(6)$. Et estoit chose moult (7) plaisante à voir. Adoneques mourant le physétère se renversa ventre sus dor's (8), comme font touts poissons morts; et ainsy, renversant les poultres contre bas (9) en mer, ressembloit au scolopendreserpent ayant cent pieds, comme l'ha descriptle sage ancien Nicander (10). "

Alors les matelots "amenarent le physétère lié en terre de liste prochaine, dicte Farouche, pour en faire anatomie, et recueillir la graisse des lognons, laquelle disoient estre fort utile el nécessaire à la guérison de certaine maladie qu'ils nommoient faulte d'argent (11). "

(i) Ressemblail.

(2) Màls.

(3) Convenable, approprice, du latin compelens.

(4) Ce sont les tleches grosses comme des poutres.

(5) Anneanx

(6) De la carcine, du latin curine.

(7) Tres, bien plaisanl, du latin mullum.

(8) Après la mort, les nageoires pectorales qui maintiennent la bakeine en équilibre cessant l'agrip, lanimal tombe aussitot sur le dos ou sur le flanc.

(9) De haul en bas.

(10) Dans le Trailé des animatax d'Albert de Bollsbadl (Opera, I. VI, edilion de 1651) on lit: "Cenlupeda est de genere draconum, mullos valde hubens perles. Je cenlipes est du geme des dragons, mais a beaucoup plus de pieds. "Le scolopendre marin des Anciens ressemblait an cenlipes lerrestre el élat pépulí jonir de l'élrange laculté de jouroir romir ses intestims perés par un hamegon, puis de les ravaler quand il les avail débariassés de cel hamegon.

En problike, le seolopendre est un annélide qui appartient a l'ordre des Myriapodes ou Ville-pieds. Il est pourvu d'une lrompe charme somvont

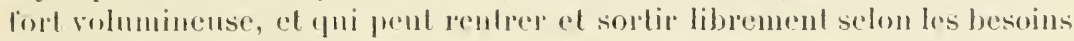
le l'animal. C'est ee pui al lail dire qu'il rendail ses intestins et les avalait de nomvan (Cuvian).

Sins nier absolumenl lexistenee de grands srpents marins, Brehm

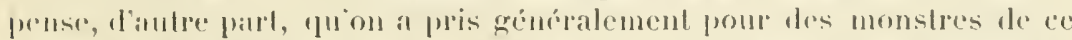
genre des algues gignalespues rourertes de Barnacles, des Congres on des Murénidés ćnormes.

(11) De fous les manmilères marins, ce sout bes baleines dont la peche 
Parmi les animaux, les uns (Vertébrés) ont un squelette intéricur osseux ou cartilagineux; les autres (Invertébrés) en sont dépourvus. Les Mammifères, les Oiseaux, les Reptiles, les Poissons, les Batraciens sont des animaux vertébrés, les Articulés (Insectes et Ver's), les Mollusques, les Zoophytes ou Rayonnés sont des animaux invertébrés. Dans les Articulés, il est nécessaire, surtout au médecin, de connaitre les Insectes diptères (1) et hỵménoptères (2) et les Entozoaires (3) en raison des accidents morbides qu'ils causent aussi bien à l'état de larves qu'à l'élat de complet développement.

..... L'homme tout entier respire en ses tableaux (1).

Le docteur Rabelais n’a parlé, dans son Gargantua et son Pantagruel, que des insectes et des vers dont il est question dans les traités de Zoologie médicale.

Jadis " au-dessus d'Aurelians estoit une ample forest de la longueur de trente et cinq lieues et de largeur dix et sept, ou environ. Icelle (5) estoit horriblement fertile (6) et copieuse en mousches bovines (7) et fres-

est, quand elle est heureuse, la plus lruclueuse et la plus productive. Une haleine de 20 mètres de long et pesant 78.400 kilogrammes fournit 1.680 kilogrammes de fanons et 33.600 kilogrammes de graisse, qui domnent près de 27.000 kilogrammes d'huile. Une tonue (1.120 kilogrammes) d'huile coùte de 3 í 4 livres sterling (75 à 100 lranes); une tomne de fanons se vend de 160 à 180 livres sterling (4.000 à $4.500 \mathrm{fr}$.). Des baleiniers ont gagné près de 300.000 francs dans ane seule campagne. S'ils étaient atteints avant de la maladie qu'on nomme "faulte d'argent ", ils ont dù en ètre, à coup sùr, rapidement et complètement guéris.

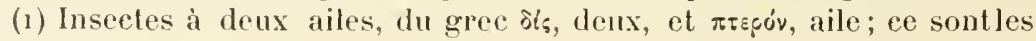
mouches.

(2) Insectes à ailes membraneuses, du grec juriv, membrane, et $\pi \tau \varepsilon p o ́ v$, aile; ce sont les abeilles, les guèpes, etc.

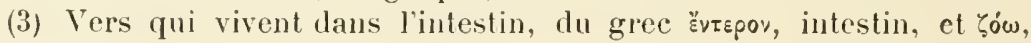
je vis.

(4) La HARPE, épître an comte de Schowalow.

(5) Celle-ci.

(6) Féconde, du lalin fertilis.

(7) La mouche des boul's est un insecte diptère très voisin de la mouche domestique. Elle s'en distingue par les còtés de la lace et du front qui 
lons (1), de sorte que c'estoit une vraie briganderie pour les paurres juments, asnes et cheraulx. Mais la jument de Gargantua vengea honestement touts les oultrages en icelle (2) perpétrés sur les bestes de son espèce, par un tour duquel ne se doubtoient mie (:3).

"Carr soubdain qu’ils (Gargantua, son précepteur Ponocrates et ses gens) furent entrés en la dicte forest, et que les freslons luy eurent livré l'assaut, elle desgaina sa quene, et si bien s'escarmouchant (4), les esmoucha (5), qu'elle en abattit tout le bois: à tords, à travers, de çà, de lì, par ci, par lì, de long, de large, dessus, dessoubs, abattoit bois comme un fauschem laict d'herbes. En sorteque depuis n'y eut ne bois ne freslons : mais fut tout le pays réduict en campagne.

"Quoi royant, Gargantua, y print plaisir bien grand, sans aultrement s'en vanter, et dist ì ses gens: "Je trouve beau ce. "Dont fust depuis appelé ce pays lì Beauce. "

A la fin du combat livé par Gargantua à Picrochole, les troupes de ce dernier, en proie à une terreur panique, "fuyoient comme vous voyez un asne, quand il ha au c... un

sont blancs, par son abdomen à bande dorsale noire et par l'absence de jaune chez les miles. Cette mouche, très commune en France, se jette sur les narines, les yeux et les plaies des bestiaux.

(1) La gruèpe on frelon (uescr crubro) est min insecte hyménoptère de la tribu des Vespides. Elle a le caractère taunin, agressil, et la locution latine crabrones irrilare et la locution française "tomber dans un guèpier " en témoignent. Le phlegmon, la gangrène, les uleères rebelles sont les complications ordinaires des blessures qu'elle cause. On comprend apres cela que les anciens Pharsalites aient quilté leur pays où elle sétait multipliée outre mesure; on s'explique les chapitres du lirre de Josue et de l'E.rode (Exode, 111,28) oil il est dit "que le Seigneur dirigeait des essaims de guejpes contre les Ilethiens et les Chananéens pour leur fare graduellement abandonner la terre qu’il deslinait it son peuple ".

(2) Celle-ci.

(3) Ne se doutaient pas.

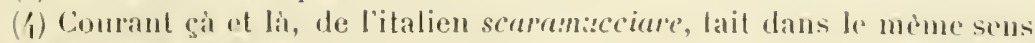
de l'allemand schuramen.

(i) Chassil cens mouches. 
astre junonique (1), ou une mousche qui le poinct (2), courir çà et là sans voie ni chemin, jectant sa charge par terre, rompant son frein et rènes, sans auculnement respirer ni prendre repos, et ne sçait on qui le meut (car l'on ne veoit rien qui le touche)."

Dans le chapitre xxı du livre III, il est fait mention en ces termes des connaissances de Raminagrobis (3) en parasitologie : "Il parle alssolument et proprement des pulces, punaises, cirons (4), mousches, culices (5), et aultres telles bestes : lesquelles sont unes (6) noires, aultres faulves, aultres

(1) Les cestres sont des inseetes diptères qui forment, sous le nom d'OEstrides, une famille proehe de eelle des Museides; ce sont de grosses mouches très velues qui déposent leurs aeufs dans l'épaisseur de la peau, sur les lères, dans le nez, lorifice anal, etc., des animatux lierbivores. Les larves qui en uaissent vivent sons la peau (euticoles) ou dans les cavités bnceale, nasale (cavicoles), on s'attachent aux parois de l'estomac et des intestins (gastricoles) jusqu'à leur complet déreloppement, puis descendent dans le rectum avec les matières excrémentitielles et s'échappent par lanus lorsqu'elles sont devenues aptes à de nouvelles métamorphoses. On distingue l'cestre du cheval (gastrophilus hemorrhoüdalis), celui dı beruf (hypoderma bovis), celui du mouton (cephalemyca oris). de l'àne, du chamean, etc. La piqùre d'une senle de ees pelites bètes cause d'horribles souffrances.

Dans l'édition de Rathery, il est écrit que Rabelais appelle l'œestre "junouique "par allusion à celui que Jumon mit après Io, que Jupiter avait changé en vache.

(2) Le pique, du latin pungere.

(3) En breton ra mine a chrobiz, il fait mine d'important. On pense avec raison que Rabelais a voulu sous ee pseudonyme désigner Guillaume Grétin. En effet, les vers qu’il fait écrire à ce poète mourant sont tirés presque littéralement d'un rondeau te Crétin adressé à Christofle de Refuge, maistre d'hôtel de Monseigneur d'Alençon qui l'avait consulté pour savoir s'il devait prendre femme. (Voy. Audiger, les Héros de Rabelais, p. 12, Saint-Antoine-Marseille, 1886.)

(4) Par ciron il faut entendre ici le sareopte de la gale.

(5) Les cousins, du latin culex, culicis. Il y a une lamille de Diptères monocères qui a pour type le cousin. La famille des Culicides se compose des genres cousin, anophète, etc. "Ces petites mousehetles qu'aulcuns appellent aussi cincelles " étaient, disait-on autretois, "engendrées de vapeurs corrompues et d'ordure. "Dans les pays chands, les piqûres; parlois assez nombrenses, des cousins, déterminent des intlammations violentes.

(6) Dont les unes sont. 
cendrées, aultres tannées (1) et basannées, toutes importunes, tyranniques el molestes (2), non és malades seulement, mais aussy à gents sains et rigoureux. Par adventure ha-rl des ascarides, lumbriques (3), et vermes (4) dedans le corps. Par adventure pastist-il, comme est en Égypte et lieux confins de la mer Erythrée (5) chose vulgaire et usilée, és bras ou jambes, quelque poineture (6) de draconeaulx grivolets, que les Arabes appellent vènes Meden (z). "

(1) A peu près de la couleur du tan.

(2) Insupportables, du latin molestus.

(3) L'asearide lombricoüde est un entozoaire vivant principalement dans le tube digestil des enfints. Connu dès la plus haule antiquité, signalé par Hippocrate lui-mème, il a été pendant tort longtemps considéré conme nélant autre que le lombric terrestre on ver de terre, un peu modifié par son séjour dans les intestins. On sait maintenaut qu'en dépit de la ressemblance il y a entre les lombrics terrestres et les vers ascarides des ditrérences d'organisation qui cn lont des espéces animales tout à tait distinctes.

(1) Vers, dn latin vermis. Outre les lombries, on peut tronver dans le lube digestit d'autres rers : l'oxyure et le trichocéphale, lielminthes ì corps cylindrigue et strié conme celui des lombrics, les ténias armés ou inermes et le botriocephate, helminthes a corps plat.

Dans le chapitre xxv du livre IV il est dit qu'Hérode, moi de Judée, eut " une mort horrible et espouventable en nature (car il mourut d'une phithiriasis, mangé des rermes et des poulx, comme pararant estoient morts I.. Sylla, Pherecides syrien, précepteur de Pythagoras, le prötegrégeois avec Alcman, et aultres). "Les Pediculi corporis, quand ils sont très nombreus et infestent depuis longtemps un individu, s'aceompagnent de diverses altérations de la peau, telles que pustules, papules el pelites lumeurs lolliculeuses, indépendammenl des exeoriations et des égratignures produites prar le grattement. Portée à ce deglé, la présenee des poux constilue une maladie véritable nommée maladie pédiculaire, phthiriasis ou phthiliase (du gree plsto, pou), sur laquelle on a délité plusieurs opinions mronces on eontrstables. Quoi quion en dise, il r’est pas probable que la malatie péliculaire ait jamais rausé la mort.

(5) La mer Rouge, mare Rubrum des Latins, mare Erylhrarum des Grecs, la mer des Jones de l'Eeriture.

(6) .Morsure, piquire.

(7) Le dracommean grivolel, encore nommé Venes menden, Gopelius medinensis, Filuriu Drucunculus, Dragonnean, Petit dragon, Ver ou Veiue de Médine, Ver de Guluée, Vra du Sénégal, Ver cutane, ele., est un ver

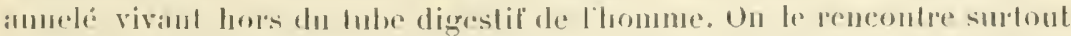
dans l Arabie Pétrée, an Sénégal et an Congro. Galien en a en connaissance. (Voy, Galaex, l. VI, Des parlies.) 
Bien qu’Avenzoar cût écrit dès XII siecle " qu'il s'engendre sous l'épiderme, dans une certaine maladie, des animaleules semblables aux poux, qui en sortent vivants quand on écorche la peau et qui sont si petils que l'œil a peine à les apercevoir" "; que Moufet, en 1654 (Insectorum minimorum animalium theatrum, ch. xxıI, p. 26), et après lui Redi, Linné, Morgagni, Latreille et plusieurs autres eussent établi la réalité de l'existence de ces animalcules; que Mikmann, en $\mathbf{1 7 7 6}$, eùt déterminé de la manière la plus exacte le mode de contagion de la gale, cette maladie était encore rangée, en 1842 (voy. Compendium de médecine), parmi les vices, les cachexies ou les phlegmasies par beaucoup de médecins.

L’ami et le médecin du cardinal de Bellay était mieux renseigné. ll a connu non seulement le siège de prédilection et de début de la gale, mais encore sa nature parasitaireet son caractìre contagieux.

"D'ond me vient ce ciron ici entre ces deux doigts (1)?" demande Panurge à Her Trippa. "Cela disoit tirant droict vers Her Trippa les deux premiers doigts ouverts en forme de cornes, et fermant au poing touts les aultres. ") (L. III, ch. xxv.)

Un des ancêtres de Pantagruel, "Enay, fut très-expert en matière d'oster les cirons des mains ". (L. II, ch. I.)

Quenelault, " médicin normand, subitement à Monspellier trespassa par de biais s'estre avec un trancheplume (2) tiré un ciron de la main ".

L'entrée de l'abbaye de Thélème était interdite aux

(1) La gale occupe et commence presque toujours dans l'intervalle des doigts ; aujourd'hui encore les médecins font ouvrir les "deux premiers doigts en forme de corne $n$ anx individus quils croient ètre atteints de cette maladie.

(2) Sorte de canif. On lit dans l'édition de 1548: "Guignemauld, normand médicin, grand avaleur de pois gris et brelandier très insigne, lequel subitement à Monspellier trespassa par laulte d'avoir payé ses dettes, et par de biais, etc..." 
"galoux" et aux individus atteints du mal de FracasLor (1).

C'en est assez.. Ne ressort-il pas amplement de ces citalionsmultiples, de colle exégèse minutieuse usque ad calcem, que Rabelais a aimé la trature a la fois commo l'aiment les poètes el les rêveurs, et comme l'aiment les savants: comme ceux qui venlent la saisir" et l'adminer dans la magnifique variélé de ses formes, et comme ceux qui veulent la pénétrer dans les secrets de ses lois éternelles? En formulant un ensemble de laits positif's, au lieu de nes'appuyer que sur des préconceptions lictives, en ne se bornant pas à brasser la matiore ductile de l'esprit d'autrui, en s'oceupant avec un égal bonheur de l'éléphant el du ciron, Mailre François a préparé el annoncé Buffon, Larépède, Daubenton et Cuvicr.

(1) En plus de l'Acare de la gale, des Oxyures. dn filaire do llédine, des Reptiles ot des Annélides muisibles, on relève dans Gargantua et dans Pantagrael les noms danimaux qui lompnissent des produits médicamenteux: le castor (I. II) ; la civelte (1. I, ch. I el 1. II, ch. vi), le chérotain porle-muse (I. I, Prol.), el, daus un autre ophle didlés, ecux des chuls de mars.

Quand "Onaresmeprenant grondoit, c'esloient chuls de mars". Garkantua

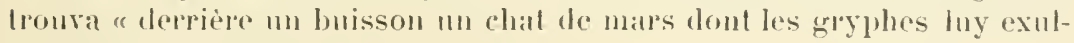
cirarent tont le pérince $n$.

Les chats de mars, ce sout les martres, disent fous les commentaten's. Pourguoi? Les chats de matrs, ce sont les challes qui ne sonl jamais si amoureuses que pendant le catène. 

ANATOMIE DES FORMES 



\section{ANATOMIE DES FORMES}

Lianatomie des formes, encore appelée Analomie artistique, Anatomie des peintres el des sculpteurs, a pour objet la description du modelé de telle ou telle région du corps humain, l'explication anatomique de ce modelé, de ses modifications à l'état de repos et de mourement. C'est elle qui permet à un arliste d'analyser à travers la pean, comme a travers un voile transparent, le jeu des parties qui produisent les formes arec leur variété infinie de caractère. Tous les grands peintres et les grands sculpteurs du xve siecle, Albert Dürer, Poussin, Jean Consin. le Titien et Jean Calcar son élive, quiontillustré l'ouvage (De Corporis humanifabricâ) de Vésale (1), Michel-Ange (3), Raphäël (:3).

(1) Dans la préface de l'élition publiće à Bate en 15.j3, il est dil que la plupart des figures ont éti exículées par d. Calcar.

(2) Nichel-Ange a lait à Florene de longurs éturles de dissertion el laissé divers dessins anatomiques dont plusiend's onl ble repoduits par

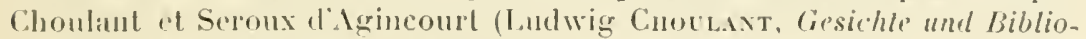
graphic des anatomischen Abbildungen, Leifzign, 1852; Seroux d'Agncount, Ihisloire de larl par les mommenls, Paris, 1811, 1. V1, pl.177).

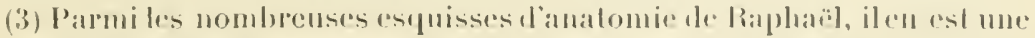
qui est particulierement remarquable, ceest celle du squelelte gui a foumi

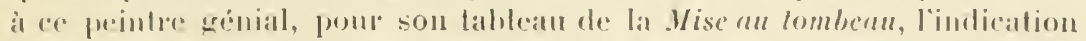
précior de la direction des neembres et de bit disposition des jointures de la Vierge ivanonie. 
Léonard de Vinci (1), ete., ete., ont élé de grands anatomistes.

Dès la fondation ì Paris, en 16 4, par Louis XIV, d'une académie de peinture et de sculpture - aujourd'hui l'École des Beaux-Arts - deux enseignements ont été institués a còté des atelierss proprement dits, l'enseignement de la perspective ef celui de l'anatomie.

Depuis celtecration. Lelorun, Camper, Lavater, Ch. Bell, IIumbert de Superville, Gratiolet, Gerdy, Darwin, Duchenne, de Boulogne. Fau, Lemoine, Pideril, Mathias Dural, Sterens, Richer, Guyer, etc., ont noté et cooldonné, en une sorte d'ensemble doctrinal, les rapports intimes qui existent entre l'ouverture de l'angle fiecial el l'intelligence, entre la contraction de tel ou tel muscle facial et telle ou telle expression de la physionomic, entre les délormations permanentes apparentes et la profession, ete.

En anatomie artistique, comme en analomie descriptive, en anatomie chirurgicale et en anatomie comparée, Rabelais a été un précurseur. Il a anatomisé d’abord Quaresmeprenant, " quant aux parties internes ", puis "quant aux parties externes ». Ėt, comme un maître de l'art, alliant à la commaissance de l'organisme l'habileté de la composition et la profondem de la pensée. il a laissé de Quaresmeprenant un portrait si ressemblant qu’il suffit de l'étudier un instant pour deviner non seulement l'àge, l'état de santé habituel, la valemr intellectuelle et morale, mais encore la parenté du modìle. Pour ètre mieux compris, l'ineompa-

(1) "Je suis absolument parsuade, a dit William Ilunter. pur Léonard de Vinci doit ètre considéré comme le meilleur el le plus sqund anatomiste de son époque. De plus, il est rertanement le premier qui ail inauguré l"usage des dessins anatomiques. " Qui a lu les manuscrits de Lionard

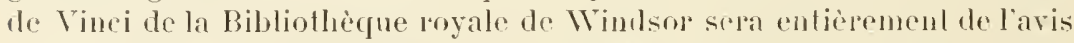
de I'illustre chirurgien anglais. (Voy.les Manuscrits de Lronard de Vinci de la Bibliothèque royale de Irindsor. D. lanatomie. lentllets A, publiés par Theodore SAbacnsikorf, ave tratuction en langue franegise, transcrits et ammotís par Giovanni Pinmati; précédés diune élude de Mathias I)ual, Paris, 1897.) 
rable satirique a fait, 'n effet, réapparaintre par atavisme, chez l'observateur fidèle des lois du Carème, diver's caraclìres anatomo-physiologiques de deux de ses aïcux, Amodunt et Discordance, qüil a dépeints en ces termes dans le chapitre xxxu dı live IV :

"Voila, dist Pantagruel, une estrange et monstrueuse membrure d'homme (1), si homme le doibs nommer. Vous me réduisez en mémoire (2) la forme of contenence de Amodunt (:3) el Discordance.

"- Quelle forme, demanda frìre Jean, avoicnt-ils? Je n'en ouï jamais parler': Dieu me le pardoint (4).

"- Je vous en dirai, respondit Pantagruel, ce que j’en ai leu parmi les apologues antiques (5). Physis (6) (c'est Nature) en sa première portée enfanta Beaulté et Harmonie sans copulation charnelle: comme de soi-mesme est grandenent féconde et fertile. Antiphysic ( 7 ). laquelle de tout lempsest partie adverse de Nature, incontinent eul envie (S) sus cestuy tant bean el lionorable enfantement : et an rebours enfanta Amodunt el Discordaner par copmlation de Tellumon (9).

(1) II sigit de Quaresmejrenant.

(2) Vons ne rappelez.

(3) Sans forme. Ce mot est dérivé peul-ètre du latin ", modo et ens, ètre sans forme.

(1) Me pardome.

(5) La Nonnoye dit que Rabelais a emprunti cet apologue i Corlius Caleagimus, antem dui n'est ni antique, ni tres connu, ef dont les wures

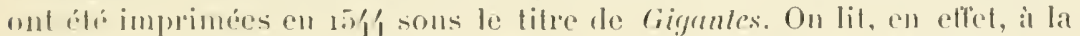

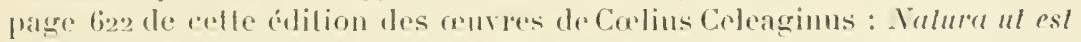
pere se feras, primo pratu, Decorem alyue IIarmoniam edidil, nulla opera

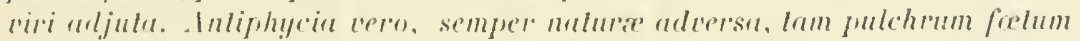
prolinus invidit, usque Trllumonis amplexu, duo ex adleeso monstra peperil fmodunlem ar Jiserepenlinm nomine, si formum indicaro, pxcilabo risum

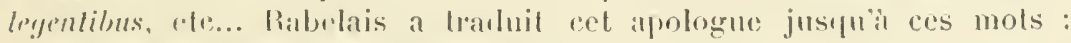
" Depuis alle enecoudea les malagols... "

(6) Lal Halulre, púses an greec.

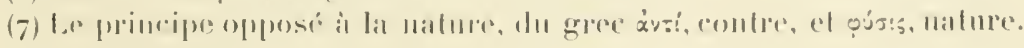

(8) Ful jallollst.

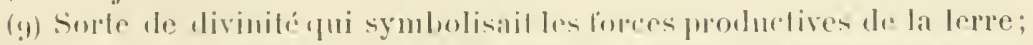
Valoun et sainl dugnstin ont usé de cedle expession. (Voy. Plphabel de l'ant1.111.) 
Ils avoient la teste sphérique et ronde entièrement comme un ballon : non doulcement comprimée des deux costés, comme est la forme humaine. Les aureilles avoient hault enlevées, grandes comme aureilles d'asne: les ails hor's la teste, fichés (1) sus des os semblables aux talons, sans sourcilles, durs comme-sont ceulx des cancres (2); les pieds ronds comme pelottes; les bras et mains tournés en arrière vers les espaules; et cheminoient sus leurs testes continuellement faisants la roue, $c . .$. sus leste, les pieds contremont (3). Et comme vous scavez que és singesses (4) semblent leurs petits singes plus beaulx que chose du monde. Intiphysie louoit et s'eftorceoit prouser que la forme de ses enfants plus belle estoit eladvenente (5), que des enfants de Physis : disant que ainsy avoir les pieds et teste sphériques, et ansy cheminer circulairement en rouant (6), estoit la forme compétente (z) et parfaicte allure retirante (8) à quelque portion de divinité, par laquelle les cieulx el tontes choses éternelles sont ainsy contournées. Aroir les pieds en l'aer, la teste en bas, estoit imitation du Créateur de l'univers, vu que les chereulx sont en l'homme comme lacines, Jes jambes comme rameaulx. Carles arlores plus commodément sont en terre tiehés sus leurs racines, que ne seroient sus leurs rameaulx. Par cetle démonstration alléguant que trop mieulx et plus aptement (9) estoient ses enfants comme une arbre droicte (10),

(1) Fixés.

(2) Crabes, du latin cancer. Les yeux des Cirustacis sont supportés par un pédoncule, dit pérloncule oculaire.

(3) Les pieds en lair.

(4) Aux femelles des singes.

(5) Plus convenable, mieux adapté à ses fonctions; du latin adenire.

(6) Lu roulant, en faisant la roue.

(7) Convenalile, du latin compelens.

(8) Approchante. Selon Platon, la forme la plus belle et la plus parfaile est la forme ronde. (Voy. Moxtagxe, Essats, l. 11, ch. xil.)

(9) Justement, du latin aple.

(ı) Je rappelle que Rabelais a conservé aux sulsstantif́s dérivés du latin ou du gree le genre quils onl en latin ou en gree. 
que ceulx de Phỵsis, lesquels estoient comme une arbre renversée. Quant est des bras et des mains. prouroit que plus raisonnablement estoient tournés rer's les espaules; parce que ceste partie de corps ne debroit estre sans deflenses, attendu que le devant estoit compétentement muni par les dents, desquelles la personne peut non seulement user en maschant sans laide des mains, mais aussy soi deffendre contre les choses nuisantes. Ainsy. par le tesmoignage et stipulation (1) des bestes brutes, tiroit touts les fols et insensés en sa sentence (2), et estoit en admiration à toules gens esecrvelés et desgarnis de bon jugement et sens commun. Depuis elle engendra les matagots (:3), cagots (4) et papelars (5) : les maniacles pistolets (6) : les démoniacles Calvins imposteurs de Geneve (7): les enragés l’utherbes (\$),

(1) Approbation, du latin stipulatio.

(2) Opinion, du latin sententia.

(3) Moines riveurs, du gree $\mu x \dot{x}=x 10 \xi$.

(i) Hypocrites.

(j) Fins, rusés el aussi papistes.

(6) Les maniaques de Pistoir. Le Duchat estime que Rabolatis reul lésigner jei des lémoniaques on sechares. appelés noirs et blancs, qui parment vers lian 1300 dans la ville de Pistoir. Selon le dirliomatre de Trévonx, cest de Pistoie, oil ils anraiont éte inventés, que les pistolets tirent leur nom. Pontr. M. A. Yemmin, eependant, le mot pistolet dériverail de pis tallo, prommeatu, ganilure, en ilalien, el non de Pistoire, ville.

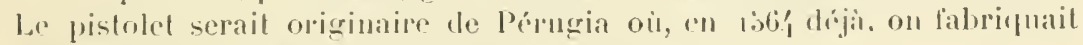
des canous à mains de la longueme diume palnte.

(7) Les calvinistes. On ćrivait autrofois démoniacle pour démo-

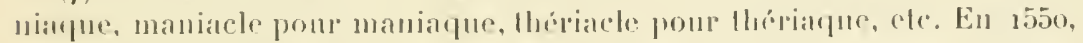

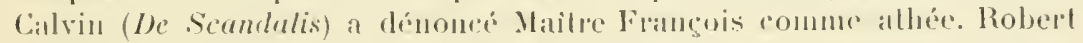
Estienne a demanté (In Prafal. ad Glossar., nor. 153i) quion te brulat avec son live, al le carlinal de Tommon funon lemprisonnàt.

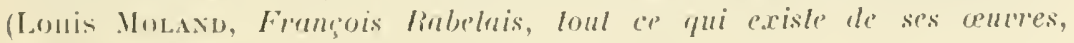
[ए. 29 (1) 30.)

(8) Ciabriel de Puy-llowant (Pulherberus), moine de Fonterrault, a

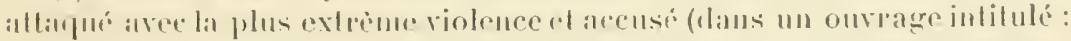

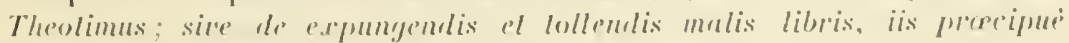

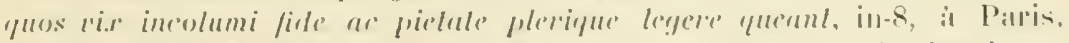

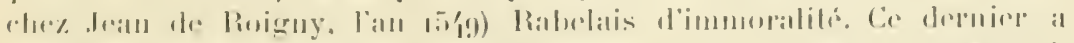

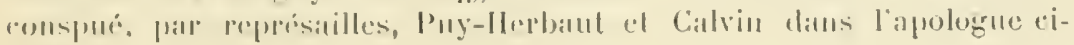
lessils. 
briffaulx (1), caphar's (2), chattemites (:3), canibales (4) et aultres monstres difformes et contrefaicts en despit de Nature (5). $)$

Par moment, entraincé rers l'idéal, Rabelais a parlé avec saggesse et élévation, en homme qui a conseience de son génie: ailleurs, il s'est laissé aller ì une extravagance de fantaisie, à une débauche de plaisanteries, à un déluge de bons mots ou de gros mols. On a essayé d'explipuer ces contradictions, ce bizarre assemblage du sublime el du bouffon. On a dit que, ne roulant pas renoncer à son franc-

(1) "Frères lais tondés en bref par le Pape, dit Moland, of entretenus par des religieuses non rentées, afin de quèter pour elles."

"Chartreux, Jacopins, Carmes, Augustins,

Tous morjues blanes, louges, noirs ou vers,

Corteliers, Bonshommes et tous Celestins,

Procureurs, Briffaulx aussi convers

Tout ra ne scay comment a revers."

(Le Resveur aver. ses resveries. Recueil de poésies françoises, L. XI. p. 1of),

(2) Souruois, moines affublés d'un capuchon, caphardum, en basse latimté. Les Turcs appellent cafar un renégat. Ce mot parait venir du verbe hébren erophar, cacher, courrir.

(3) Gens qui acendent en riant, en faisant les bons apôtres; du latin calla, ehalle, et milis . douce. Chalte qui lait la palte de velours.

Un chat faisant la chattemite.

\section{LA Foxtaise)}

\section{Ah: Ghattemites}

Je scay bien que en riant vous accordez.

(Grétiolre, Moralité du jeu des Princes des Sots et mère Solte.)

(1) "Yoines qui, comme ì belles dents. déchiraient l'auteur par leurs écrils el dans lems discours. " (Le Duchat.) Pendant toute sa vie, Rabelais a été violemment attaqué par lesécrivains de la Rélorme, jaloux de ne pas sentir à lenrs còtés un homme qui aurait pu lenr attirer des parlisans, el par les moines mécontents de voir élaler au grand jour lems mours licencieuses. Il a falln an técond ef intarissable satirique, pour ne pas subir le sort de son ami Étienne Dolet, lappui des áripues de Paris, du Mans, de Maillezais, de Pierre Duchatel, svinue de Tulle, lectem ordinaire tu roi, du cardinal dismagnac, cle., etr.

(5) Les fripes fredons araient " les genoils contrepoinctés (pointus it robours)... deux liraguettes en forme de pantophle. lime drant. of l'aulte derrière... des souliers ronds conme bassin,... le calunel (l'extrémité) de leur capuchon altaché devanl... les chereulx en devant croissants en liberté et Iondus à la partie postérieure de la leste, ctc." 
parler, mais averti par des exemples journaliers du prix de la prudence, l'auteus de Gargantua et de Pantagruel a caché, sous le mastfue el les greluts de la folie, les témérilés de la raison. On a dit qu il n’a lait que suive les traditions de liberté, de licence mème, d'allures, de gestes et de langage admises par les mours deson époque 1). Quoi quil en soit. il r a, lans l’épopéc pantagruélique, des expressions el des ganduiseries qüil est difficile de reproduire. Je vondrais laire pour les " eontenences externes " de Quaresmeprenant ee que $j$ ati fait pour ses "contenences internes ". les analyser minutieusenent et me à me, mais plusieurs d'entre elles ont prèté á des comparaisons si risquées de la part de Maitre Francois que cela n'est impossible. Je me bormerai donc à esquisser à gnrands trails le portrait du roide

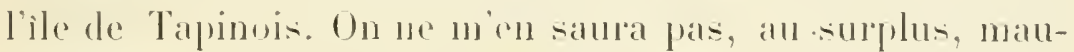

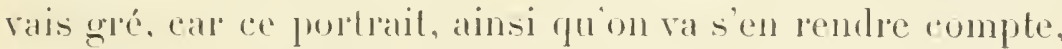
est luin dêtre siduisint (.2) :

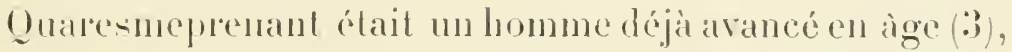

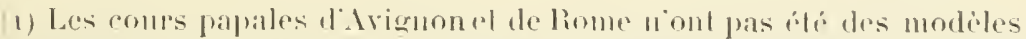

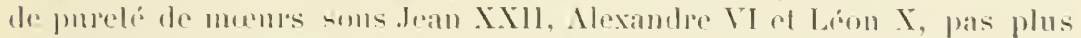
gue les couls de Toseane el de France sous les Mrdieis, sous Francois fer

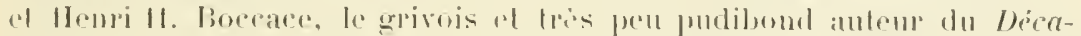

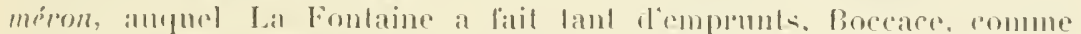

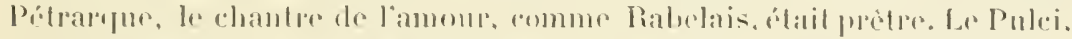

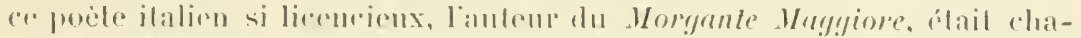

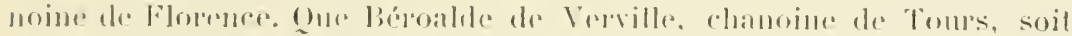

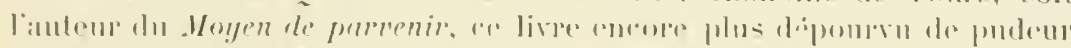

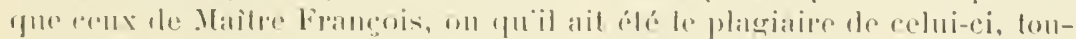

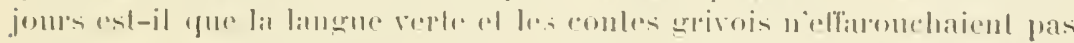

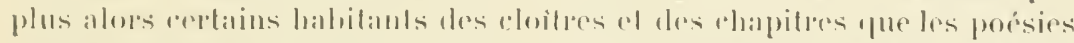

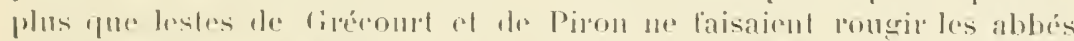

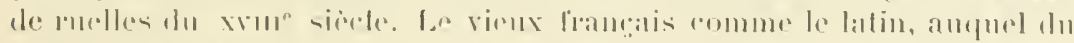

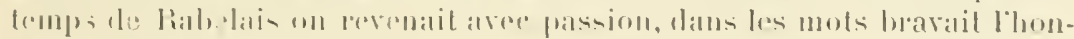
nimleti.

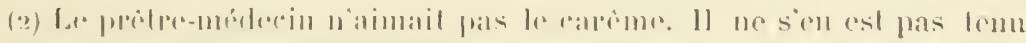

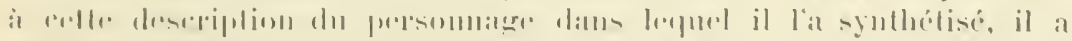

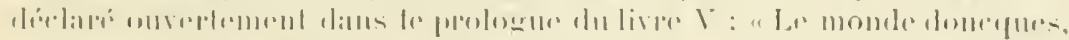

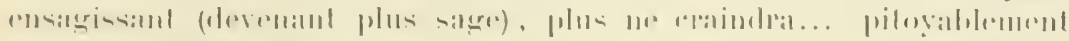
choire, 101 quatrestme.

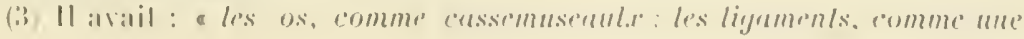


d'une taille élevée (1), maigre (2), débile (3), tourmenté moralement par le repentir (4) des fautes qu'il arait commises el physiquement par une maladie constitutionnelle honteuse (5) el quelquefois aussi par une gonorihée provoquéc par une nourriture trop échauffante (6).

Il avait la tête ronde $(\boldsymbol{z})$, mais les joues creuses, la peau du visage ravagée de coutures comme si elle avait été

escarcelle; le dors, comme une arbalesle de passe, ete. v. Le dos (du latin dorsum) raboteux, arqué, difficile et long à redresser. Les exagérations de courbure de la colonne vertébrale, dues à l'inlluence de l'àge, intéressent surtout la région dorsale, tandis que celles qui dépendent des professions occupent de préférence tantôt la partie inférieure de la région cervicale, comme chez les porteurs, et tantôt la partie suprérieure de la région lombaire comme chez ceux qui s'adomnent à la culture du sol. C'est dans la région dorsale que commence l'ankylose physiologique des vertỉbres entre elles.

Larbaleste de passe est me grosse arbalète qu'on tendait an moyen dime machine et rui servait ar armer une tour roulante, dite passe, quion approchait des remparts. (Froussaro.)

"Gargantua bandoit és reins les fortes arbalestes de passe."

(1) "Un demi-géant."

(2) Il avait: "les lumbes, comme un cathenal; la poitrine, comme un jeu de regnalles; les jouss, comme deux sabbots, etc. "I.es joues creuses, profondes. Prov. pop. : Dormir comme un sabot, "dormir profondément.

(3) Il avait: "les muscles, comme"un soufllet: le sany bouillant, comme nazardes multipliées; les esperits vitaul $x$, comme longues chiquenauldes; šil subloit (sitflait), c'estoienl hotties de singes verds, etc. ".

(4) Il avait: "la repenlance, comme l'équippage d'un double canon."

(5) Il avait : " le trou du c..., comme un miroir crystallin ». Les anciens médecins domnaient le nom de cristalline a la syphilis des Ganymedes, ì la syphilis anale engendrée par des rapports contre nature. (Voy. te dictionnaire de Furetiere et le Traicté second de la maladie appelée cristalline, autrement dit maladie indienne ou rongne espagnolle, par Tammegui Guillanmet, chirurgien du roy, Nismes, 16n.) Quaresmeprenant sacrifiait en secrel à la pierre noire d'Emesse déifiée par Héliogabale.

(6) Il avait: "la penilliere, comme une dariole " el pitissait "quelyuefois "lune lourde pissechaulde, etc. "

(7) Il avait: "la leste contournée, comme un alumbic, " c'est-it-dire comme un ballon d'alambic. Les anthropologistes ont établi que toutes les races humaines préhistoriques, protohistoriques el historiques peurent elre ramenées à deux types: au type des tèles longues ou dolichocéphales (du grec

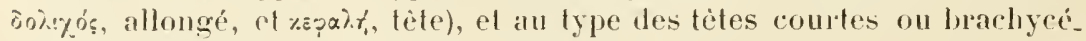

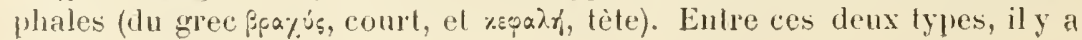


incisée arec le bistouri (1), les reux les trois quarts du temps inondés de larmes (2), de hautes oreilles velues, mal ourlées (3), un nez à la Cyrano (4), surplombant sensuellement (j) wne bouche tries ourerte, garnie de grandes dents jaunes et pointues (6). Il n'avait pas de

de's transitions nombreuses, mais il est bien cerlain que, quelle que soit actuellement et quelle qu'ait étí primitivement la contormation du erâne humain, il est et a toujours dé plus ou moins aplati sur les tempes. Il n'y a eu que Quaresmeprenant et ses ä̈eux qui aient eu " la teste sphérique, ronde entièrement comme un ballon : non doulcement comprimée des deux costés" pour pouvoir " cheminer circulairement en rouant".

(1) Il avait: "le visage bistorié, comme un bast de mulet". S'étnit-il labouré, se labourait-il encore, en signe de deuil, la face avec ses ongles, inconsolé et inconsolable, comme Rachel daus Rama ?...

(2) 11 "plourait les trois parts du jour".

(3) Il avait: "les aureilles, comme deux milaines ". Mitaines, "gros gants tourrés où il n'y a pas de séparation pour mettre les doigts, à la réserve d"l pouce. "(FuRETIÈRE.)

(1) Il avait: "les narines, comme un béyuin; le nez, comme un brodequin eulé en éscusson ". On appelle écusson un morceau d'écorce portant un ceil ou un bouton, qu'on détache d'un arbre pour l'insérer entre le bois et l'écorce d'un autre arbre. "Le nez, comme un brolequin enté e'n escusson "signifie: donc le nez comme un brodequin.

Grandgousier" "feit faire i son fils des bottes faulves: Babin les nomme brodequins ". Dans l'ádition de Garnier, il est dit que "Babin parait désigner une république fictive élablie antrelois en Pologne eomme le royamne de la llise solte en France !... " Babin est tont simplement le nom pillonymique d'ume limille de cordomiers chinonas.

(5) "Ad formam nasi cognoscilur al te levavi" (1. I, eh. xL), s'écrie fière Jean.

Les dames romaines favorisaient, enproportion de la longueur du tuez les gladiaten's. L'exemple, il est rai, venail de loin el de haut. I. grand nez de Vuleain avail séduil Vénus, - Vénus qui devait s̀y comathere

Nosrllur a pedis quanlum sil virginis antrum.

Noscilur a naso quanta sil hasta viri.

(O)IDE.)

Quya-t-il de seientitique daus ae disticque proverbial du poète, dont les licentieux alages italien et prevengal : Al nazzo rognoscele il cazzo, -1 Gros nas, gros dabas, ne sont que des réminisences?

(6) 11 avail: "les dents, comme un vouge. De se's telle's deuls de laict lous troucerez une a Colonges-les-royaula, en Poictou, el de'ux it la Brosse en Xrainlonge, sus la porte de la curee ".

11 arail : "la bouche, comme une housse ". Selon Furetiere, " la housse 
barbe (1), el son crâne était orní de la double tonsure des moines. bordée d'une couronne de cheveux roides (2), poudeenx (:3), agglutinés, ainsi que les sourcils, les cils et les poils des autres parties du corps (4). par des humeurs at des crontes gluantes ou desséchées de nature suspecte (5). Son cou étail déformé par un goitre rolumineux (i) et aussi, selon toute probabiliti, par des écrouelles $(7)$, el sa

était une couverture que les paysannes meltaient antretois sur leur tèle pour se défendre de la pluie ef du rent $\%$

Il ny avait pas que les paysannes. Un règlement de lancien Senonais interdisait aux lépreux de sortir de lenr borde sans èlre vètus de leur lionsse.

(1) Soit quil en fùt naturellement dépourvu, soit qưil la rasât de prics. Dans le ehapitre xxix du live $\mathbb{T}$, Rabelais a écril que Quaresmeprenant ćlait $u n$ " demi-géant à poil follef et double fonsure " (la tonsure monaeale), ct, dans le chapitre xxx du mème livre, qu’il avait "la barbe, comme une lanterne", scilicel comme le parchemin on le papier huilé qui remplacail les ritres dans les lanternes primilives, ou comme la pean glabre des docteurs an théologic el des moines lítéquentant les conciles el qui sont appelés plaisamment, di diverses reprises, lanternes dans le roman pantagruélique. Quaresmeprenant álait. lui-mème ", un extraict de Lanternois, bien grand lanternier" ".

(2) Il avait : les chevenlx, comme un décrollonoire". On donnait jadis le nom de déerottonoire à unc brosse grossière de chiendent on de crin qui servait à netloyer les ehanssures.

(3) Dautaul plus poudrenx que Quaresmeprenant avait reçu les cendres sur sa donble fonsure le premier jour de son règne.

(4) Il avait: "les sourcilles (sourcils), comme une lichefrelle (lichefrite); les aeils, comme un estui de peignes; la penilliere, comme une drariole, ete..:

(5) Engendries par la manvaise alimentation et par la malpropreté, la syphilis on la scrotule.

(6) 11 avait : "le menton, comme un potiron; la gorge, comme une chansse dhypocras; le noa, comme un baril, anquel pendoient denx yoitrous de bronze bien beaul.x et harmonieux, en forme d'une horloge de sable, etc. ". Avec udeax goitrons de bronze sibeanlx et si harmonicux ", on comprend pourquoi quand Quaresmejrenant "dodelinoit de lateste, c'estoient charretles ferrées ", pourquoi il avait le nenton comme un poliron, la gorge comme un pain de sucre.

Chausse d'hypocras. Chansse fentrée de forme conique dont on se sert encore aujourd'hui pour filtrer, passer et clarifier le vin, les sirops, les licplieurs.

"Sur la tèle les Circassiens ont un bonnet de fenltre lait tout ainsi qu'une chanse à hipocras ou qu'un pain de suere. "(Bebleforest, Cosmogr., part. 11, col. 855.)

(7) Il avait: "les adènes, comme une serpe". 
poitrine, dont les cotes, au nombre de sept (1) peregaient les téguments, contrastait d'une laçn étrange aree son gros ventre (2) logé dans un pourpoing " houlonné selon la mode antirque et ceinct i l'antibust (?) ".

Ses members patauds (4) étaient terminés par

(1) Allısion aux sept semaines du Carème, "Quaresmeprenant, disoit Xenomanes continuant, quant anx parties externes, estoil un peu micux proportionmi, exceptez les sept contes quil avoit oultre lat forme commune des humains $"$.

(2) Il avait : "le ventre a poulaines " of le " miruch, comme un chapeau albanois ". Les ventres a poulaines blaient des gipons ou pourpoings rembourés. Le grand satirique a, par suite, comparé ì ces prourpoings ef feint de les croire postiches les ventres de certains moines. "Un grand tas de sarabaitles (moines déprglís el vagabonds)... qui se sont desguisés comme masturs pour tromper le monde... au contraire font chèe, Dien sçait quille... Vons le povez lire en erosse lethe el enluminure de lems rouges museaulx et ventres it poulaines. " (L. It, ch. xxwr.)

"On appelle mirach en arabe, dit Leonellus Favenlinus, en son traté De Medenelis morbis, ch. L, la partir extérieure du ventre compusée de peau, de graisse et de huit muscles du ventre : Mirach dicilur purs ientris exlerior, composilu ex cule, pinguedine el oclo musculis ernlris."

Chapera allunois, "chapean poinctu, latult bommet " (1. HII. ch. xxe et I. I, ch. xxxir). "ll a mu ventre aussi poinlu "est me phrase encor"

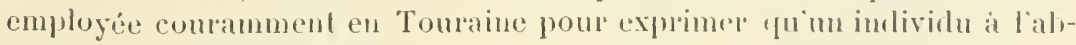
domen très proéminent.

Il est me maladie consislant dans l'engorgement des ganglions abduminanx sous l'influence de la scrofule ou de la luberculose, le carrean. dont un des principaux symptomes est li distension du ventre. Quaresmeprenant état-il atteint de cettr maladie : Ses "rils, comme un eslui de peignes; "ses "alenes, comme une serpe "porteraient a lectoire. Il est it fomarequer cependant que le carreatu, assez enmmun chez leulant, est

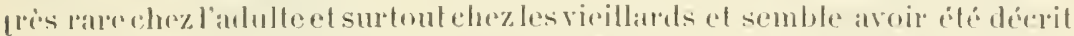

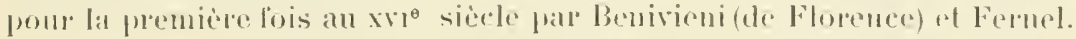

(3) Ceint is la poitrine: du lating anle, devint, alde l'ilalien busto, partie supérieure du corps. "lit eroyez quils burent ì rontre desboutumé

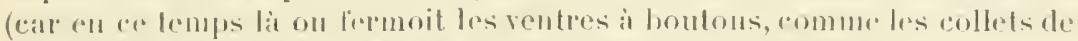
prosent) jusyues it dire: Dond remez-yous?" "(L. II, ch. x.)

(4) Il avait: "leshanches, comme un vibrequin; le's cuisse's, comme un crenequin; les genoils, comme un escubenu; les jumbes, comme un leurre; less bras, comme une barbule: les coubles, comme ralonoires, rete. ".

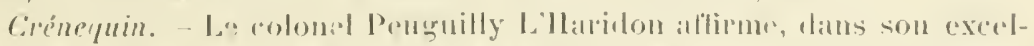

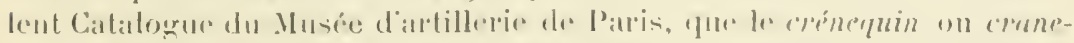

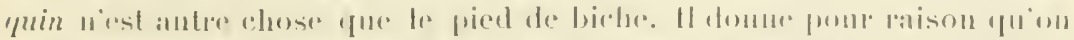

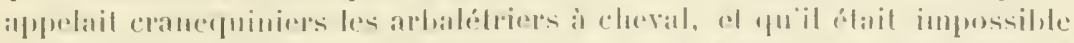

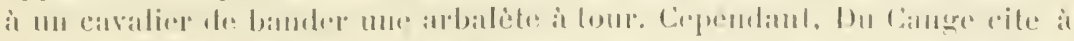

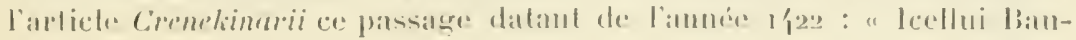


doin prist une arbalète nommée eréuequin, qui est dire arbalète à pré. " Or, l'arbalète à pied est bien l'arbalète à étrier dont l'arcest bandé, non par le pied de biche, mais par la moulle. On pent done admettre arec Viollet-Le-Duc quan commencement du xvie siècle le erénequin était la monfle dont nous donnons le dessin au trait ei-dessons et qui a la configuration générale de la euisse.

Le leurre, dont la formen'a pas changé depuis le moyen àge, est un morceau decuir rouge façonné en forme d'oiseau, disent lestraités de rènerie, - faconné en forme du gras de la jambe, du mollet, dirons-nous avec Maitre François, - et dont les faucomniers se servent pour appeler les tiercelets au réclame. Il est rembouré pour prepuettre aux serres des lancons de s’y

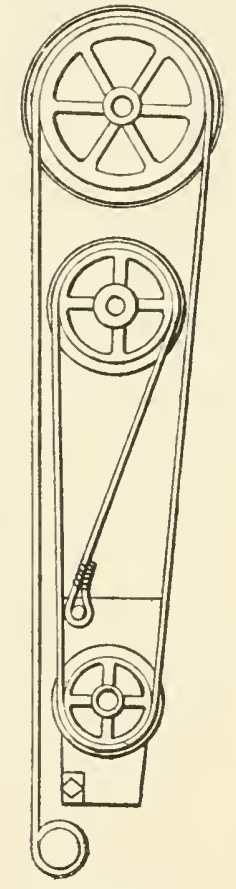

Crènequin.

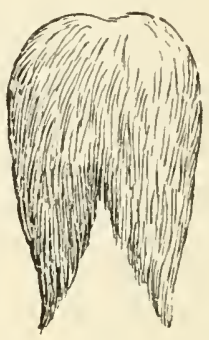

Lenre.

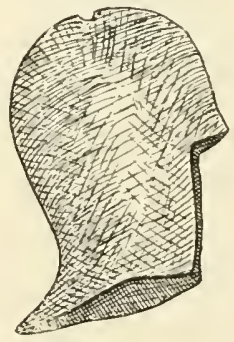

Burbule.

fixer.(Voy. le Livre du roy Modus; TARdF, Arl de la fauconnerie; Reliqnia librorum cit. suprà et Magasin pittoresque, t. XI, 18f3, p. 253, fig. 5.)

Barbule. - Casque deseendant très bas en arrière, "quo capul tegebant milites el equites in prælits, " dit Du Cange. Les bras, par conséquent, déjetés en arrière comme ceux des enfants d'Antiplysie. Pour prouver cette assertion, jai fait dessiner au Musée dartillerie de Paris la barbute qu'on a sous les yeux. Les areher's à pied sont restés fidèles à cette coiffure que les argoulets, eavaliers du xrie siècle, portaient encore.

Les coubles, les coudes, du latin cubilus.

Ratonoires. - Piège à prendre les rats. Il y a des ratonoires de toutes les formes, mème de la forme du coude. 
des mains rudes d'une propreté douteuse (1) et par des pieds dont la plante convexe était imprégnée d'une sueur huileuse (2). Ses doigts et ses orteils étaient armés

(1) Il :vait: "les mains, comme une estrille". Abstraction fiate des doigls, la main est carréce comme est dordinaire une étrille. L'étrille, dont on ne se sert plus que pour eulerer la crasse atlachée au poil el it la pean des cheraux, a lait partie du matériel des éluves. A Rome, la peau des haigneurs était racléce au moyen d'un racloir oustrigille par les aliples, triclionnce par les fricalores, massér par les tractalores, cndnite de parfums par les nnclores. En Grice, la strigille était employéc apres les exereices du gymmase.

Valentin et Orson "servoient aux estures d'enters et estoient rascletorets (aliples) $).($ L. II, ch. xxx.)

Parmi les termes de la litanie célébrant la puissance virile do lrère Jean figmre celui d' " estrillant ", frottant vigoureusement.

Des mains comme me étrille convenaient ì Guaresmeprenant qui avait "les cheveuls, comms un décrollonoire; la peau, comme une gravaldine, etc. ", et qui était méchant.

(2) Ilavait : "les pierls, comme nne guileme ; les talons, comme une mussue; la planle, comme un crezion $"$.

Guilerne, gainterne, guisterne, quilerne. instrument it cortes pincérs qui est un dérivé de la cithare dol de la rote.

Harpes el gigues et rubèbes

Si ia gruiternes et leus (luthes).

(Roman de la Rose.)

La table d'harmonie, échancréc de chaque côté, de coptanes guiternes a les eontoms amplitiés du pied. La ressemblance de cette tahle avee lepied est léjì évilentesur la guileruedont jour avee mo plectrum, pendant qu’un jongleur exécute mu pas, le ménestrel debout figmé sme l'un des entomrages du mamuserit de Trislan el Yseull (ver's 1260 , manuserit de la Bibliolh. nat.). Le mot guiterne ne semble pas toutelois avoir eti enjuloyé avant le xivo sibcle.

L'extrémité libre d'unc massue est poutle.

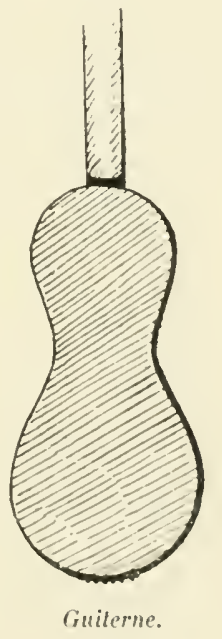

Daus le Poiton el le Chinonais, on appelle eneore crézion, erézien on eré-

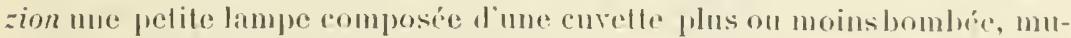

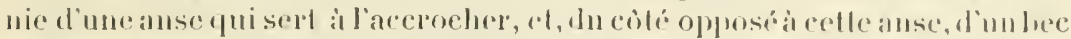

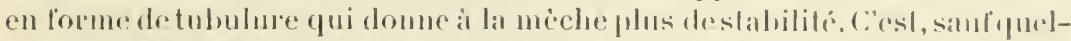

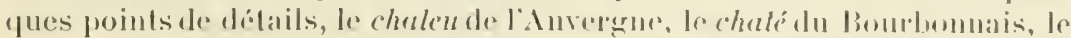

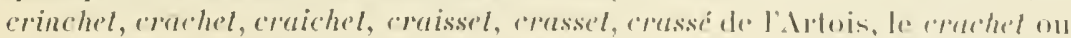

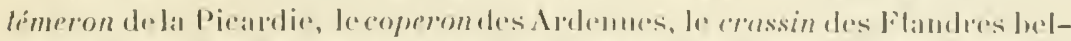

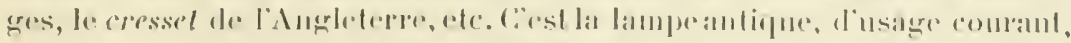

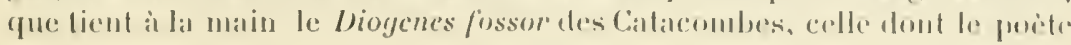


d'ongles acérés enroulés plusieurs fois sur eux-mêmes (1).

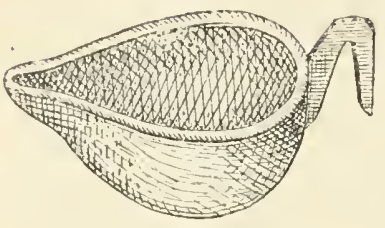

Creziutl.

Prudentius a dit : Pendenl mobilibus lumina funibus, et qu'un personnage sculpté sur un cippe gallo-romain du Muséc d'Amiens porte it la ceinture, celle dont on a tromé de nombreuxspécimens lans l'Allier el qui n'est peut-ètre elle-mème qu'une imitation de l'appareil d'éclairage rudimentaire, de la simple feuille plice suivant son grand axe contenant l'huile et la mèche, dont ont usé les hommes des âges de la pierre taillée. Le creziou permet aux paysans du Centre de la France d'utiliser l'huile de noix, devenue absolument impropre à la consommation lorsque le pot tire à sa fin, et fournit ainsi un éclairage économique. Celui dont nous donnons le dessin appartient à la mère d'une de mes domestiques habilant Richelien, près de Chinon.

"Il avoit aussi préparé une salade composíe de plusieurs especes d'herbes, y jetant un peu de sel dessus et du vinaigre et quelques goutles d'huile d'un créziels. " (IIisloire macaronique, I. Il. Trad. anonyme.)

(1) 11 avait: "les ongles, comme une vrille ». S'il n'y a guère en France que des vieillards qui aient des on-

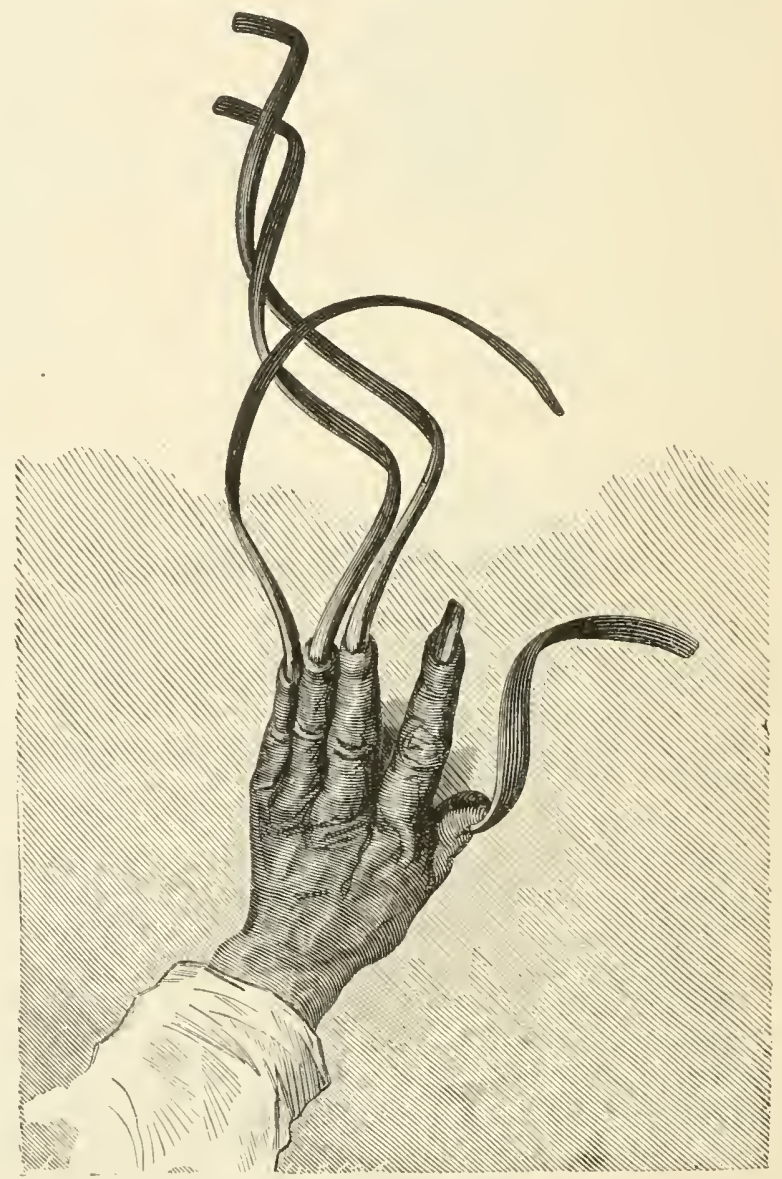

Ongles en vrille. gles en rrille, il n'en est pas de même dans l'Extrème-Orient. Les dandys de Bangok et de Hué se font honneur de leur oisiveté en s'agrémentant d'ap- 
pendices unguéaux quils enlerment, pour les préserver de toute araric, dans des éluis d'or on d'argent. Sur le dessin ci-joint, qui est la reproduclion fidèle de la main d'un seigneur annamite, on roit des ongles ne mesurant pas moins de fo el mime 45 cenlimctres de longuenr. Un seul lail exception, cest celui de lindex, mais il a étí brisé.

Les formes dites anormales de lonychrogryphose (du gree övog, övoyos, ongle, et ypurós, coupbé, crochu) ne sont que l'exagération des formes normales que prendraient les lames cormées des doigts si nous obéissions à des modes aussi excentrifues que celles qui rignent au Tonkin et en Cochinchine. Les pathologistes, je le répète, ont décrit chèz les vieillards des ongles en grifle, en spirale, en vrille, etc. Jajonterai que, chez les cagots ou goitreux des Pyrénées, la lèpre est líćquente el caractérisée par thypertrophie des ongles el des doigts, le teint blafard, ele. (Voy. Progrès médical, 1892. De l'existence de la lèpre atténuée chez les cagols des I'yrénées, par Lajard et F. Regrault.) En domnant à Quaresmeprenant, qui était déjà àgé el doublement cagot, des ongles "comme une vrille", Rabelais a donc été bien inspiré.

En mettant en parallèle la conlormalion physique de Quaresmeprenant et celle de ses arrière-aïeux, on peut juger maintenant du degré de ressemblance qu'il avait avec eux.

Quaresneprenant avait :

"La leste conlourné, comme un alumbic (un ballon d'alambic);

"Les aureilles, comme denx milaines;

"Les paulpieres, romme un rebee (l'cxlrémite libre renflee du manche d'un rebce); "Les sourcilles, comme une lichefrelle (lechefrite)

"Les bras, comme une barbute;

"Les Inlons, comme une massne; la plante, comme un creziou, etc."
Amodunt et Discordance, Jes fils l'Antiphysie, avaient

"La tesle spherique el ronde comme un ballon et non doulcement comprimée des deux costés, comme est la forme hamuine;

"Les aureilles haull enlevies, grundes eomme rureilles d'usne;

"Les ails hors ln teste, fiches sus des os semblubles au lalon, suns sourcilles, durs comme ceux des cuncres;

"Les bras tonmess en arriere lers les espanles;

"Les pieds ronds, comme pelulles, ele. "

Daus sa lougue énumération des "contenences de Quaresmeprenant. Maître François n'a liait mention que de la marelue il reculous de ce personnage. Eh bicn! celle marches'eflectuat en loulanl, ainsi que celle des fils d'Antiphysie : "s"il reculoit, cestotent corpuecigrnes de mer." "On appelle coequecigrues, dit Le Duchat, les coquilles des hérissons de mar, et, suivant ce passige, M. Ménatge a crutule lexpression proverhiale dont il s’agit dins le premin venait de ce que, selon qu’il liat parl a Rondellel, les hérissons de mer, an lieude mareher, ne font que tourner daus leurs coquilles, rui sont tontes hérissées dre pointes. Mais il n’a pats birn entendu Rondelled, dont roiei les lermes, lib. 18, De P'iscibus, "ap. 19.

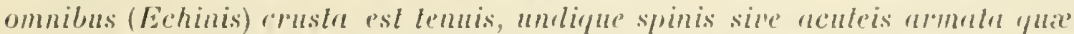

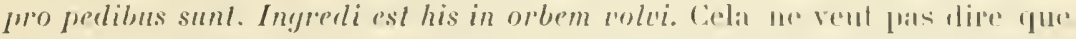

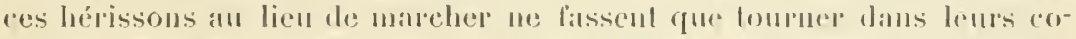

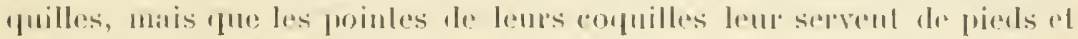
qu'ils matrelent en roulant." 
Il étant sale (1), inintelligent (2), grossier (3), indiscrel (4), cupide (5), débauché (ij), adonné anx pratiques contre nalure en honnem a Sodome, somrnois, chicaneur ( 7 , méchanl $(S)$, entiché du passé (9), manquail d'ini-

Je suis d'autant plus heureux d’invoquer ici l'autorité de Le Duchat, qưil n’a pas soupconné la parenté de Quaresmeprenant et des enfauts d'Antiphysie et que l'erreur de Ménage, quil corrige dans la note ci-dessus, en s'appuyant snr le meilleur ouvrage du maitre de Rabelais, est provoque par cette phrase du chapitre xux de Gargantua : "que son royaulme luy seroit rendu (i Picrochole) à la venue des cocquecigrues."

(1)ll avait: "le poil, tel comme ha esté lict; les mains, comme une estrille; la plunte des pieds, comme un crezion; lepidermis, comme un belutean; la peau, comme une gaerulaline, ctc.". Gaervaldine, galvardine, sarrau, jaquette de paysan. La peau aussi pude el aussi mal soignée que te vètement d'un rustre.

(2) Il avait: "la cervelle cn grandeur, couleur, substance el vigneur, semblable au c... gausche d'un ciron masle; les esperits animaul.r, comme grands conps de poing: less pensées, comme un vol l'estourneaulx; l'enlendemenl, comme un bréviaire déssiré (déchiré); le sens commun, comme un bourdon; les délibéralions, comme une pochée d'orgues (un sac d'orge); les inlelligences, comme limus sortanls des fraires (des fraises, clu latiu fraya); le jugement, comme un chanssepied, etc.".

(3) "S'il parloil, c'esloil gros burean d'Auveryne, lanl s'en failloit que fust saye cramoisie, de laquelle vouloit Parisalis estre les paroles tissues ceulx de yui parloient à son fils Cyrus roy des Perses. C'étaient paroles dures et grossières comme la bure qui se fabrique an Auvergne; entièrement opposées anx paroles donces et moelleuses comme la soie dont Parisatis roulait qu'on usât avec son fils Cyrus. " (Voy. Plutarole en ses Apophthergmes.)

(4) Il avait: "la discrélion, comme une moufle ". Il laut entendre ici par moulle, comme Oudiu, "converele de marmite". Quel pue soil le poids de son convercle, me marmite, mise sm le feu, laisse toujours s'éraporer, à un moment donué, une parlie de son contenu. "La sapience (la science, le savoir, du latiu sapienlia) des premiers précepteurs de Gargantua n'estoit que moulles, abastardissant les bons et nobles esperits." (L. I, ch. Xr.)

(5) "S'il resvoit, c'esloient papiers rentiers; si rien donnoit, aultant en avoit le brodeur (le bourdem, le trompeur). " (Voy. Pasguer, I. Vill. 1). 753 .)

(6) Il arait: "La crystalline; le nez, comme un brodequin enlé en escusson, et s'il sonypoit, c'estoient vils volants el rampanls, ctc. ". Dans le chapitre intitulé Défaul, de Béroald de Verville (t. II, lol. 427 de l'édit. de la Mon. noye) est relaté un lait qui montre le langer de pareils songes.

(7) "S'il marmonnoit (marmottait), c'estoient jeux de la bazoche."

(8) "Rioit en mordant, mordoil en riant."

(9) "S"il disconroit, c"esloienl neiges d'antan." 
tiative (1), perdait son temps à rien (2) et laisait tout à rebour's des autres (:3).

Signes particuliers : il avait an-dessus du sourcil gauche " un seing en forme et grandeur d'un urinal " et dormait les veux ouverts (4).

En face d'un pareil personnage, qui ne se serait écrié comme Pantagruel : "Voili une estrange et monstrucuse membrure d'homme, si homme le doilss nommer!"

(1) Il avait: "les entreprinses, comme la sabourre (le lest, du latin saburra, gros sable) thun gallion".

(2) "Cas estrange : Iravailloit rien ne frisant, rien ne forisoil trataillant.

(3) Il "se brignnoit dessus les huulls elochers, se seichoit derlans les estangs et rivieres. Peschoil en l'aer... Chassoil on profund de la mer, etc."

(4) "Corybantioil dormant, dormoit corybantiant. "Corybantier veut dire dormin les yeux onverts a l’imitation des Corybantes, pretres de Cybile, rluareges de veiller sur Jupiter enlint pour l'empécher d'etre dévoré par Salurne, son piere. 

GONGLUSIONS 



\section{GONGL US I O N S}

Je suis arrivé an but que je m’élais proposé en commencant à écrire ces pages.

J'ai expliqué les chapitres xxx el xxxi du live IV de l'épopée pantagruélique, qu'il est prudent et sage, prétendon depuis trois sioeles, de ne pas chereher à échancir. J'ai prouvé que "relle insipide énuméralion qui n'a pas d'aulve but, selon le bibliophile dacob (1), que de rassembler la lechnologie anatomique ", el "qu'il y anrail de la puérilité, selon Burgaud des Marels ot Rathery, à prendre anx sérienx" (2), a an contraire un sens précis, dénote me eonnaissance approfondie de l'. Inatomie deseriplive de la part de celui 'juil l’a écrite. J'ai établi, on m'appuyant sur des lextes d'une auterite irrélagable, que Mailre Frangois a lait mon des fremiers, sinon le premier, des démonstrations publiques d'anatomie sur le caddave. Et il est désormais acquis sans conteste - el cette découverte que j’ai faite ne comble de joie el de patrioligue lierté - que Rabelais a été l'émule de Vísile.

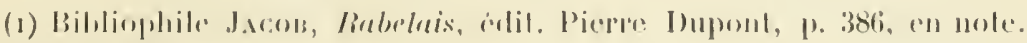
Ellition de 181.

(2) CEncres de liabeluis, 1. 11, p. 162, Paris, 1858. 
J'ai montré que le médecin ordinaire du cardinal du Bellay a possédé assez bien son Anatomie chirurgicale pour pouvoir indiquer d'avance le degré de gravilé d'une blessure d'après son siège et sa profondeur, inventer un instrument de chirurgie ingénieux et un appareil de fracture qui a été copié par Ambroise Paré ; a fait preuve, à une époque oì les contes les plus ridicules enfantés par l'imagination des, voyageur's hâbleurs étaient universellement acceptés, d'un esprit scientifique sérieux, en appliquant dans toute leur rigueur les règles de la méthode baconienne à l'Anatomie comparée : en ne tenant pour vrai que ce qu'il avait vu ou ce que plusieurs autres avaient ru avant lui.

J'ai tracé, d'après ses indications, l'Anatomie des formes d'un des personnages de son immortel roman.

Je me suis arrêté sur les descriptions qu'il a laissées du goitre et des déformations de la trachée qu'il provoque, du sarcocèle vénérien el de la stomatite mereurielle, descriptions qui témoignent que l'Anatomie pathologique n'a pas été plus étrangìre au "tant docte el gentil médicin chinonois", que l'Anatomie descriptive, l'Anatomie chirurgicale, l'Anatomie comparée et l'Anatomie des formes.

J'ai noté qu'il a signalé l'action physiologique des principaux aliments et des principales boissons pris modérément, avec excès ou en quantité insuffisante, le rôle de la veine rénale dans la sécrétion urinaire, les conditions qui activent ou diminuent la spermalogenèse, la corrélation qui existe entre l'intégrilé et la quantité de substance cérébrale et l'intelligence, l'aftlux d'une plus grande quantité de sang dans les artères du cerveau pendant un travail intellectuel, la vertu rétentrice des nerfs des orifices naturels, ete.

J'ai mentionné les divers préceptes d'hygiène qu'il a formulés, notamment ceux concernant le jeu des muscles et le soin de la peau (balnéation, hydrothérapie). 
J'ai appelé l'attention sur le modìle du parfait médecin qu’il a tracé, d'après Hippocrate et Galien, et qu'il s'est appliqué lui-mème à suivre; sur des incidents mal interprélés, peu connus ou ignorés de sa vie de praticien; sur ses connaissances étendues en pathologie el en thérapeulique; sur sa grande réputation médicale, attestée par les médailles frappées en son honneur et les ácrits en rers ef en prose de ses malades reconnaissants; sur les hautes fonctions qu'il a oceupées dans les hôpitaux et dans l'enseignement de la médecine.

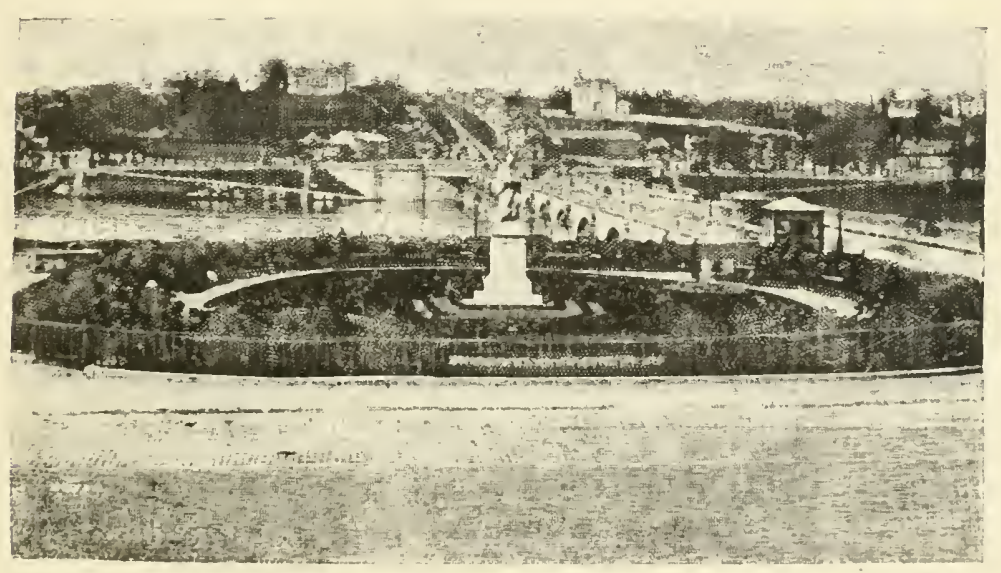

square Rabelais, is Tours.

Dans ce "bean et plaisant pays de Touraine. vu abondent bus les avantages de la vie intellectuelle el matérielle,

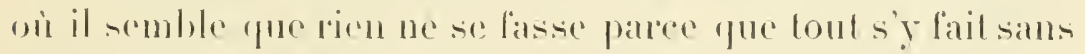

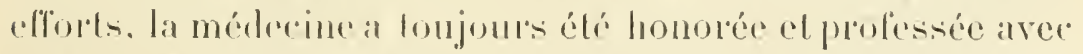
stecés. Esit-il nódessaire de ciler parmi les médecins toulangeanx bien commus qui ne sont plus :

Le moine Iluges de la collégiale de samb-Martin; Guil-

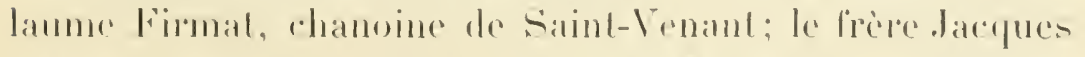

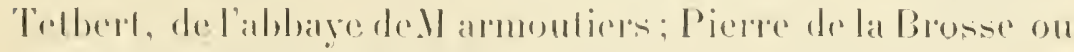
plus correctement de Broce. chambellan de sinint-Lonis el 
de Philippe le Hardi: Robert le Poitevin qui, de concert avec Coictier, soigna Louis XI ; Adam Fumée, maître des requêtes et garde des sceaux de Charles VIlI; Nicolas Provost, auteur du premier Codex medicamenlarius l'rançais; Grégoire Martin, helléniste distingué; Thibault de Pleini, qui a publić la Ilécoration du pays de Touraine el un promptuaire des médecines simples en rythmes joyeux; Louis Burgensis, premier médecin de François Ier et de HenrilI; Sébastien Collin, qui a écrit, vers 1553, une Jéclaration des abus el des tromperies que font les apothicaires; René Thionneau, médecin ordinaire de la suite du roi, à la fin du règne des Valois; Laurent Feau, qui a composé un traité latin sur l'Epicrasse et soutenu une longue controverse avec Vietor Pallu, de l'Université de Paris, au sujet de la saignée; Poirier, premier médecin de Louis XIV; Heurteloup, premier chirurgien de la Grande Arméc, puis Inspecteur général du service de santé; Tourlet, professeur à l'École des Chartes, le docte traducteur des odes de Pindare, de la guerre de Troie de Quintus de Smyrne et des ouvres de l'empereur Julien, le zélé propagateur de la vaccine en France; Baillarger et Moreau, de Tours, éminents aliénistes de la Salpêtrière: Lorain, prolesseur d'histoire de la médeeine à la Faculté de médecine de Paris; Cottreau, professeur agrégé à la même Faculté; E. Labbé, Archambault, médecins des hôpitaux de Paris; Vidal, aneien président de l'Académie de médecine; Bretonneau et ses deux immortels élèves, Trousseau et Velpeau; Giraudel, l'historien érudit de la ville de Tours; Tonnelé, qui a laissé le plus rare et le plus précieux des trésors, un trésor que la rouille ni les ver's ne sauraient détruire: l'amour des malheureux;

Et, parmi ceux qui virent et qui vivront pendant longtemps encore, il laut l'espérer, pour le plus grand bien de la science et de l'humanité:

MM. Raymond, de Saint-Christophe, qui a suecédé ì l'illustre Chareot dans la chaire de clinique des maladies 
nerveuses de la Faculté de médecine de Paris; R. Blanchard, également de saint-Christophe, prolesseur d'hishoire naturelle à la mème Faculté, membre de l'Académie de médecine, fondatem et scerrétaire général de la Société zoologique de France; 1. Robin, de Saint-Flovier, professeur agrégé à la Faculté de médecine de Paris, membre de l'Académie de médecine, médecin de l'hoopital de la Pitié, à Paris: X. Gouraud, médecin de l'hòpital de la Charité, à Paris; Beaunis, d'Amboise, ancien professeur de physiologie à la Faculté de médecine de Strasbourg, directeur du laboratoire de psychologie physiologique à la Sorbonne; Léon Marchand, de Tours, pour lequel le Ministre de l’Instruction publique a eréé, en 1881 , une chaire de crọptoganie régétale à l'École supérieure de pharmacie de Paris; Verneau, de la Chapelle-surLoire. professeur d'ethnographie à l'École coloniale, assistant au Muséum d'histoire naturelle, où il est chargé d'un enseignement spécial pour les royageurs naturalistes; Renaut, de La Haye-Descartes, prolesseur d'histologic a la Faculté de médecine de Lyon, membre associé de l'Académie de médecine; Boisseau, de l'lle-Bonchard, professeur agrégé an Val-de-Gritee, médeein-inspecteur de l'armée; Madamet, d'Huismes, sous-directern de l'École de médecince el de pharmacie militaires, membre du Comité technique desanté; Moussu, de Saint-Laurent-en-Gatines, prolesseur i l'École vétérinare d'Mlfort, ete, etc.

Dans cette brillante plédade. il fant placer Rabelais au premier rang. Maîle François est une despersonnitications les plus éclatantes de la Touraine, une desplus rayonnantes manilestations de son génie médical. Inventem précoce de toutes les idées et de loutes les euriosités modernes, esprit universed

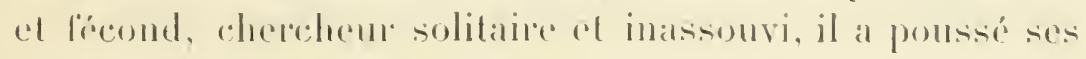

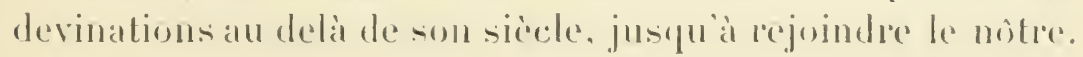

Pour la plupart d'entre nous. la mort est plus que la lin; 
c'est l'oubli. Pour quelques-uns, e'est en quelque sorte une apolhéosc. Les amis de l'humanité, les servileurs de la science laissent une trace durable de leur passage ici-bas; les frivoles el les inuliles, qui nont pas su consacrer au bien les facultés dont ils élaient doués, tombent comme les feuilles d'automne et disparaissent comme elles.

Nul n'a mieux mérité de la postérité que le Martial des bords de la Vienne. La scolastique ne développait que le raisonnement. Elle tendait à faire de l'homme une machine

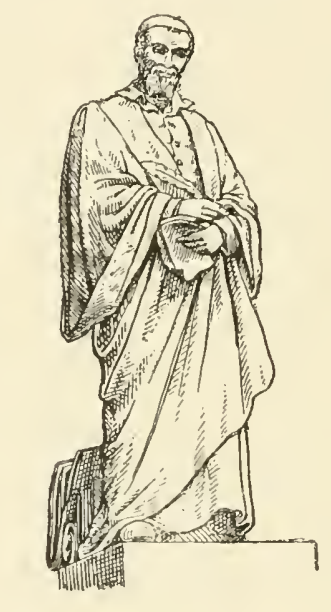

Slalue de Rabelais, it Tours.

à syllogismes et, pour ainsi dire, un automate dialecticien. Or, l'homme n'est pas seulement un être qui raisonne, e'est aussi une intelligence qui a soif de connaître et un cour qui aspire à ainer. Rabelais l'a senti, ou du moins - et e'est là un de ses plus beaux titres de gloire-énoncé le premicr.

Le meilleur moyen d'honorer et de perpétuer la mémoire des hommes de génie, e'est de leur élever des statues.

La Ville de Tours - pour ne parler que d'elle - s'est conformée à cette obligation.

Le 10 juillet 1881 , la cité tourangelle était en fête. La 
Municipalité, entourée des délégués du chef de l’État, du Sénat. de la Chambre des députés, de l'Armée el de la Presse, inangurait la statue du grand railleur, Maflee François Rabelais. Seule, la médecine offieielle, oubliant que l'auteur de Ciaryanlua et de Pantagruel a été l'orgueil de notre phus vieille Faculté de médecine, n’était pas représentée. Cét oubli fiut remarqué, il devait l'ètre.

Ce livre est un hommage et une réparation.

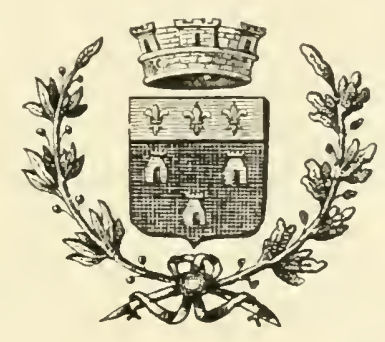





\section{ADDENDA}

Page 56. - Les rassettes, comme des échasses. Dans le livre d'Esticnne de la Riviere intilulé la Dissection des parties du corps, Paris, 1546, le carpe et le tarse sont représentés (pl. 10), le premier arec cetle indication : le brassellet ou rassetle, le second avec celle-ci : le tarse ou rasselle.

Pages 126 et sunantes. - Lisle desieptiles d'Eusthenes. Dans le De Vratura animalium, de la Nalure des Animaux, d'Albert de Bollstadt (Opera, 1. VI, pages 5-6 ì 68, édit. de 1651, 21 vol. in-folio), quelques-uns des repliles cités par Eusthenes, ou dont le nom se rapproche de ceux cilés par Eusthenes, sont décrits en ces termes:

Ahedisimon. - ... Est de genere draconum et habet dentes vehementes (Est du genre des dragons el a les dents forles).

Alhartraf: - Il est de la famille des dragons et a jusquà cinq coudées de longueur. Sa blessure est partois guérissable.

Armène. - Il est de la mème famille que le basilic. Tout animal qu'il approche tombe mort, sans mème avoir été piqué par lıi.

Cafazelus. - Serpent de petite taille at de conlenr ronge qui se cache dans les arbres.

Canhares. - De la mème nature que l'Arunducus, c'est-ìdire long d'une coudére et amenant parr sa molsure la mort all bout de trois is sept jours. 
Celidrus. - ... Hic serpens ante in magna quantitate erectus ambulat, quia si se multum torserit, crepat (Ce serpent progresse ayant la majeure partie du corps dressée, parce qu'il craque lorsqu'il se tord de trop).

Cerastes. - Il a huit cornes. C'est six de plus qu'il n'en a.

Haudion. - Ressemble beaucoup à l'Allıartraf.

Ilicinus. - Est serpens qui habitat in ilicibus (Est un serpent qui habile dans les ruisseaux et les rigoles). Sa piqùre est mortelle. Esmangart el Johanneau se sont donc trompés en traduisant ilicinus par serpent charmeur.

Phareas. - Serpent cilé par Lucain. "Quasi totus erectus graditur super caudam. II s avance presque entièrement droit sur sa queue. "Ceci conviendrait au Naja ou serpent à lunelles qui se redresse dès qu'il aperçoil quelqu'un. Mais le Naja, c'est, pour moi, le basilic.

Sabrin. - Serpens coloris arenosi habens puncla nigra el alba, et longitudo ejus est longitudo serpentis cornuti (Est un serpent de la couleur du sable, mais ponctué de noir el de blane el d'une longueur égale à celle du Cornuta). Le Cornuta est un reptile analogue au céraste.

Selphir. - Est de genere viparum (Est du genre des vipères). Le Sabrin et le Selphir d'Mlbert de Bollstadt sont-ils le stabin et le selsir de Maitre Francois?

Pour clore ce qui a trait aux animaux venimeux indiqués par Eusthenes, il me reste à dire :

(a) Gue nombre de naturalistes pensent que l'Icle et l'Acontias des Anciens sont un seul et mème animal, el que, pour Cuvier, "il faut reconnaître dans l'Acontias quelqu'une de ces couleuvres minces qui montent sur les arbres et s'entortillent à leurs branches ".

( $\beta$ Q Que les commentateurs qui ont traduit Miliares par millo pieds, mille pedie, etc., el qui ont vu dans ce mille-pieds, en invoquant l'autorité de Galien, de Pline, ele., les uns, le scolopendre terrestre, les autres, le forficule ou perce-oreille, etc., se sont mépris. Miliares est serpens qui, propter suam citrinitatem, 
est quasi coloris milii et ideo etiam a milio nomen accepit (Est un serpent dont la couleur citrine se rapproche de celle du millet, d'où le nom de millet qui lui a été clonné). C'est notre millet (Crolalis miliaris).

(y) Que les scorpène's, vulgo scorpions, crapauds, diables de mer, sont des poissons, que leur grosse tète épineuse et la peau molle el spongieuse qui les entoure le plus souvent rendent hideux, dégoutants ef redoulables. Pline, Dioscoride, Rondellet, Salviani ont fait mention de la grande scorpène ou scorpène truie (Scorpena scrofa). Du vin dans lequel esl mort ee genre de scorpène est, au dire de Pline, très efficace contre les douleurs du foie.

La Rascasse (Scorpena porcus) est un des poissons indispensables pour la confection d'une bonne bouillabaisse.

Ce plat phocéen accompli, sans délaut.

(MÉr.)

Page: 260. - Les nerfs opliques, comme un fusil. Panurge avait " un f'usil garni d'esmorche (amore), d'allumettes, etc." Les allumettes de Panurge étaient des petits bouts de bois blane ou de chanve soul'rés a leurs rxtrémités. Stace, Juvénal el surtout le satirique Vartial ont fait allusion à des allumettes de ce genre auxquelles Aggricolal, auxvi" siorele, a consacré également quelques lignes dans son De Re metallict. Cent ans plus lard, Boyle a conté, dans l'Artificial phosphori, avee quelle shupéfaction il a vu se produire un mélange explosif en associant les fleurs de soufre au phosphore, ce philtre magique dont l'influence élait si redoulér. C̈rest sculement rn $18 \% 31$ qu'un médecin de Saint-Lothain (Jura), le Dr Sauria, a imaginé de fabriquer des allumelles avee du soufre, du phosphore et ilu chlorate de potasse.

Page z91, Note 1. - Aux béros du roman rabelaisien cilés dans er volume el dont l'existence est hien élablie el la personnalité nellement délerminér: a Mleofribats Nasior et Séraphin Cialobarsi (Francois Rabelais), a scurron et Rondibilis (Schyrron 
et Rondellet, professeurs a la Faculté de médecine de Montpellier), Hor Trippa et Henry Cotiral (Henri Corneille Agrippa), Thaumaste (Thomas Morus, chancelier d'Angleterre), Raminagrobis (Ir poète Crétin), Janotus de Bragmarlo (l'orateur Janotus), Xenomanes (Jean Alplionse le Sainlongeois), Jamet Brayer (Jacques Cartier), Fayoles, quart roy de Numidie (Louis de Brezé, grand sénéchal de Normandie, seigneur de Fayoles en Auvergne), Malicorne (Mare de La Rue, sieur de la Couste et de Roche-Corbon), Pierochole (Scévole ou Gaucher, médecin de Renée de Bourbon, abbesse de Fontevrault), Marquet, beau-père de Picrochole, Grippeminaud d'Oppède, le bourreau des Vaudois, Jean des Entommeures, procureur des fermiers de l'abbaye de Seuilly, Babin, corlonnier a Clhinon, etc., etc., il faut ajouter: Ulrich Gallet, bourgeois de Chinon, parent de lahelais, Jean Denyau, charron ì Chinon, Jean Gaymard, receveur de l'ablaye Seuilly, II. de la Bellonière (René I)upuy, auquel a appartenu jusquien 1.534 la terre de la Bellonière, située sur la commune de Cravant, à 7 kilomètres de Chinon), II de Maulevrier (Guillaume de Ballan, dont la maison seigneuriale, située à Lerné, subsiste encoreen partic), le capitaine Chappuys (le poc̀te Ciaude Chappuis d'Amboise, valet de chambre de François I ${ }^{\mathrm{er}}$ ), Breton Villandry (Claude Breton, seigneur de Villandry, un des officiers de la cour de François Irr), Don Philippe des Marais, vice-roi de Papeligosse (Philippe Chabol; seigneur de Brion, comte de Buzançais), l'abbé de Tranchelion (Antoine de la Garde. de la famille des Tranchelions du Limousin, abbé de Saint-Genou, de Déols et de Vermusse en Berry, vicaire général de René, cardinal de Prie), Tinteville, évèque d'Auxerre (François 11 Dindeville, évèque d'Auxerre), le tavernier Guillot. d'Amiens, Geoffroy à la Grand Dent, le persécuteur des religieux de Maillezais, fils de Geoffroy de Lusignan, cle.

Sćraphin Calobarsi, le nom dı savant médecin chargé par Ponocrates de remetlre "Gargantua en meilleure voie", est, en effel, comme Alcofribas Nasier, l'anagramme de François Rabelais. Pour en ètre persuadé, on n’a qu'à reconstituer cet ana- 
gramme en changeant l'F de François en ph, ce qui, au point de rue philologique, n’implique aucune différence:

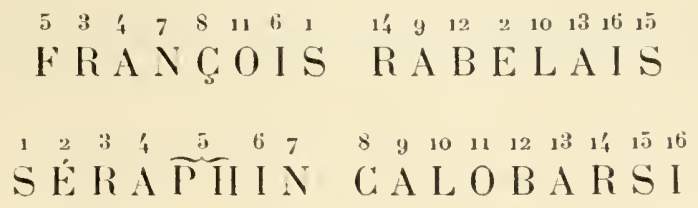

Pour de plus amples détails, voy. de Busseroless, Dicl. géograph., hist. et biog. d'Indre-et-Loire, et Bullet. de la Soc. archéol. d'Indre-el-Loire, I. IV, 1879 ; Cih. Anvaubs, Histoire de Maillezais; Le Ducint, Esmangart el Johanneau, Burgaud des Marets el Rathery, Aubiger, Ducrot, Dubouchet, H. Grinaud, elc., passim, etles Coustumes du Duché et Bailliage de Touraine en 1.50o; la Gallia Christiania, 1. II, col. 147; Menagiana, p. 429 de l'édition de 1693 ; la note écrite de la main du sieur Bovgnereav, érudit lourangeau du commencement du xvir siècle, dans les Manuserits Dupuy, à la Bibliothèque nationale; le vol. II (carton de l'abbé de Seuilly) et le fol. 407 duvol. F des Archives du département d'Indre-et-Loire: l'Hisloire chronologique de la grande Chancellerie de France, I. I, p. 95 , etc. 



\section{TABLE DES MATIERES}

Préface de M. le Professeur Matuin d til . . . . . v AvertissemeNt. . . . . . . . . . . . . . I

INTRODUCTION . . . . . . . . . . . . . . . . 3

ANATOMIE DESCRIPTIVE

OSTÉOLOGIE

Anatomie. . . . . . . . . . . . . . . . 39

Physiologie. . . . . . . . . . . . . . 58

ARTHROLOGIE . . . . . 60

MYOLOGIE

Anatomic . . . . . . . . . . . . . . . 62

Physiologie. . . . . . . . . . . . . . 70

ANGÉIOLOGIE

Anatomie . . . . . . . . . . . . . . . 79

Pliysiologie . . . . . . . . . . . . . . . . . 93

SPIANCIINOLOGIE

Appareil digestif. - Anatomie . . . . . . . . . . . . 99

Physiologie . . . . . . . . 147

Appareil respiratoire. - Analomic .......... I74

Physiologie . . . . . . . . 182

Appareil urinaire. - Anatomie ........... . 184

- Physiologic .......... 192 
Appareil génital. - Anatomie . . . . . . . . . . 200 Physiologie. . . . . . . . . . 221

Organes des sens. - Anatomic . . . . . . . . . . . 253 Physiologie .... . . . . . . . ${ }_{2} 65$

NÉVROLOGIE

Anatomie . . . . . . . . . . . . . . . 274

Physiologie... . . . . . . . . . . . . ${ }_{2} 91$

ANATOMIE CHIRURGICALE . . . . 303

ANATOMIE COMPAREE . . . . 345

ANATOMIE DES FORMES . . . . 405

Conclusions. . . . . . . . . . . . . . . . . . 425

AdDENDA . . . . . . . . . . . . . . . . . . . 433 



\section{ERNEST LEROUX, ÉDITEUR \\ RUE BONAPARTE, 28}

\section{VILLEGAGNON, ROY D'AMERIQLE \\ ( 15 I O-I 572 ) \\ UN HOMME. DE MER AU XVI SIECLE \\ Par Arthur HEULHARD}

Un beau volume in-t raisin, avec cartes, figures et planches.

Exemplaire sur papier rélin .

$40 \mathrm{fr}$.

Le même, avec les miniatures de LE TESTU coloriłes

$60 \mathrm{fr}$.

Exemplaire de grand luxe, sur papier vergé de Hollande, avec les miniatures coloriées $100 \mathrm{fr}$.

\section{Docteur G.-A. LESSON \\ LES POLYNESIENS}

LEUR ORIGINE, LEURS MIGRATIONS, LELR LANGAGE

Ouvrage rédigé d’après le manuscrit de l'auteur

Par L. MARTINET

4 forts volumes in 8 , avec cartes

$60 \mathrm{fr}$.

\section{Docteur L. LECLERC}

HISTOIRE DE LA MÉDECINE ARABE

2 volumes in -8

$20 \mathrm{fr}$.

\section{LA CHIMIE AU MOTEN AGE}

Par M. BERTHELOT

Secrétaire perpétuel de l’Académie des Sciences

3 volumes in. 4

\section{Aloxandre BERTRAND \\ De l'Institut \\ NOS ORIGINES}

Volume d'introduction : Archéologie celtique et gauloise. In-8, dessins, planches et cartes en couleurs.

Io $\mathrm{fr}$.

1. - La Gaule avant les Gaulois, d'après les monuments et les textes. Nouvelle édition refondue et augmentée. In-8, nombreuses illustrations et cartes.

Jo fr.

II. - Les Celtes dans les vallées du Pô et du Danube, par A. Bertrand et

S. ReInACH. In-8, nombreuses illustrations . . . . . . . 7 fr. 50

[11. - La religion gauloise. In-8, nombreuses illustrations. . . . 10 fr. 






$$
\text { MAR } 181986
$$




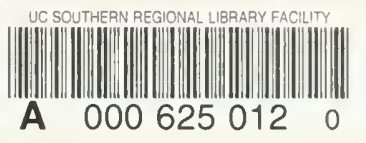




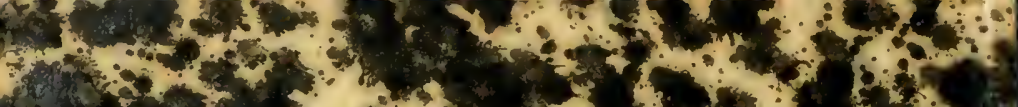

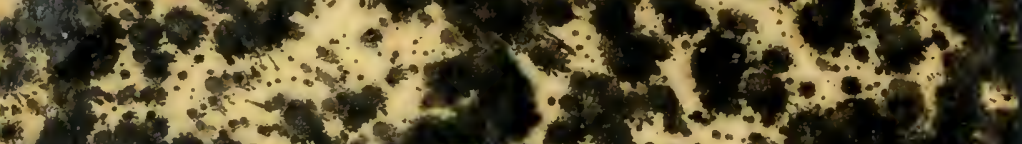

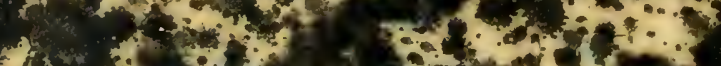
ats

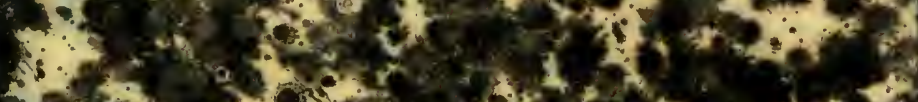

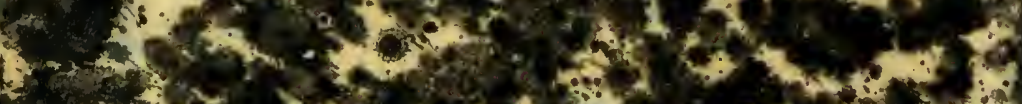

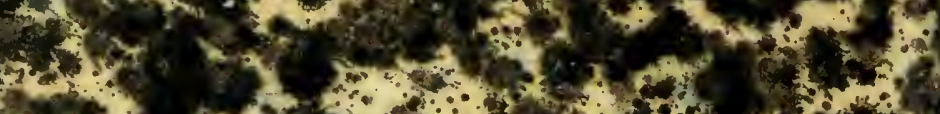

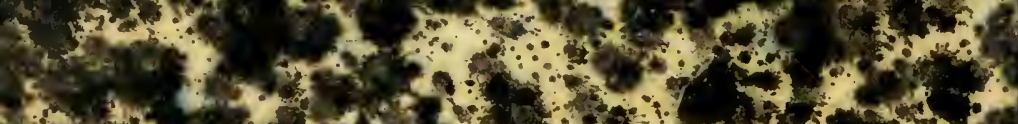

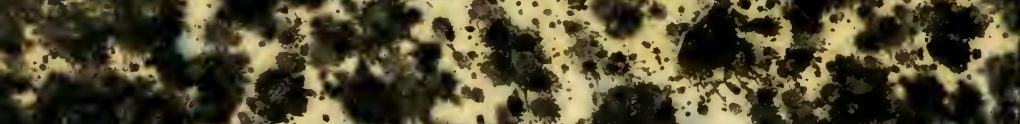

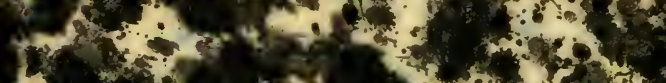

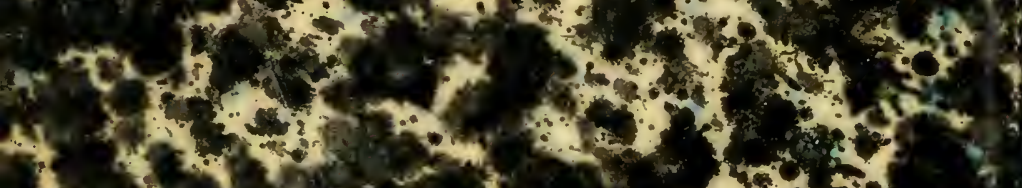

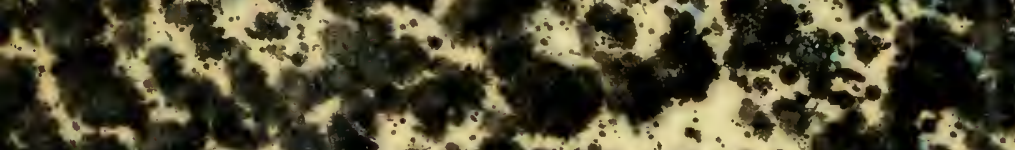

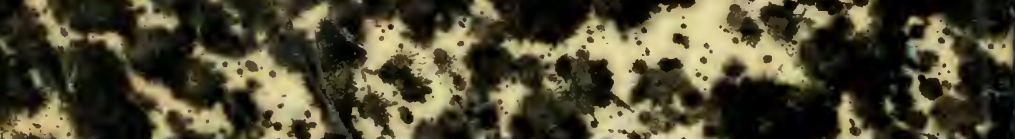

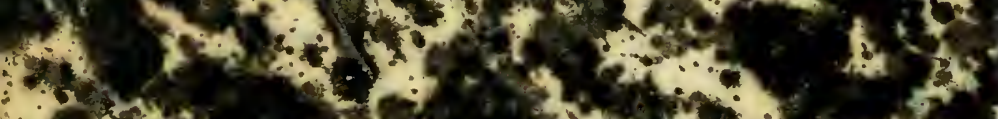

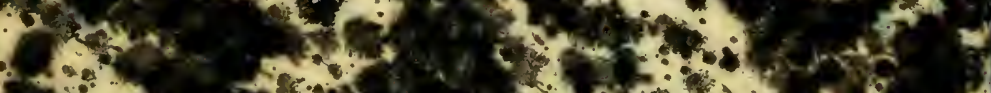

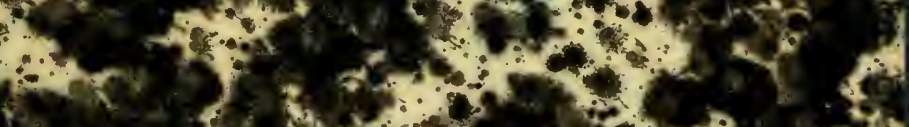

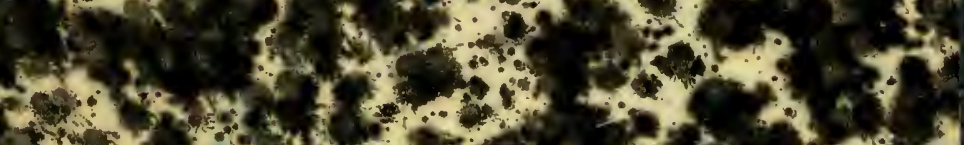

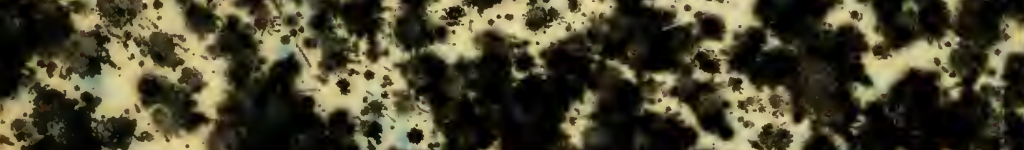

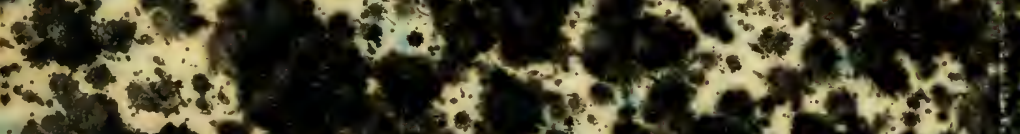

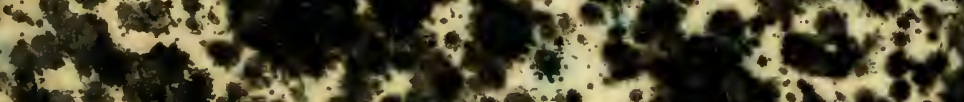

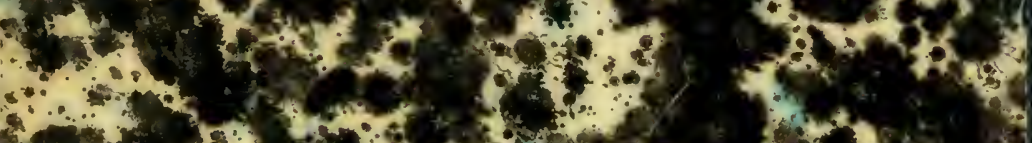

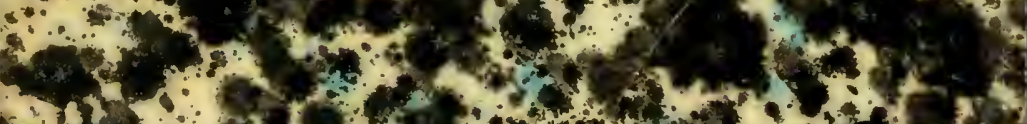

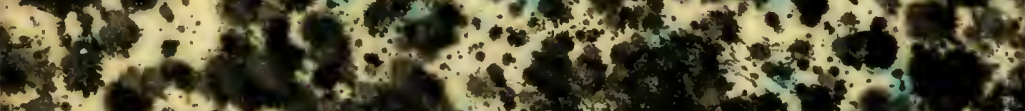

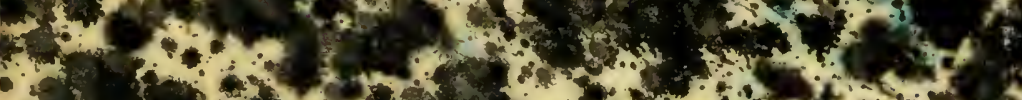

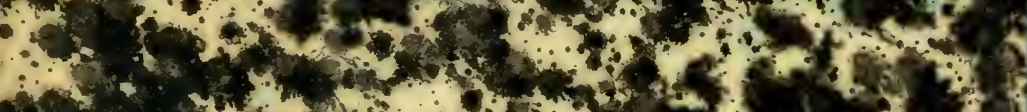

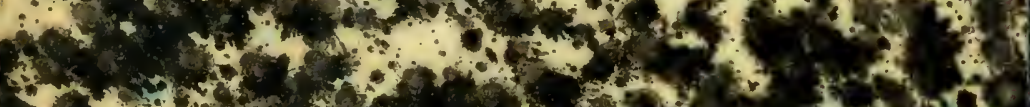
1.

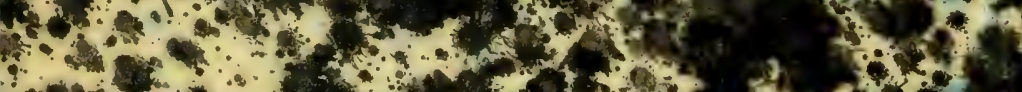

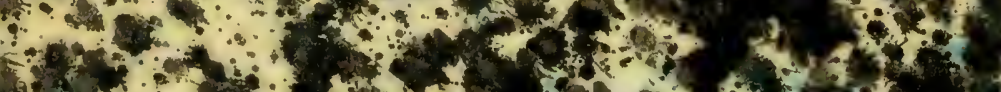

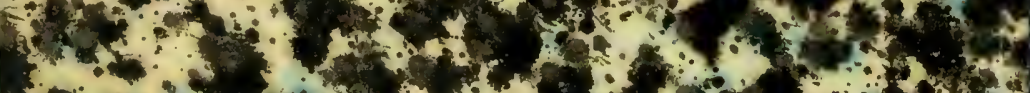

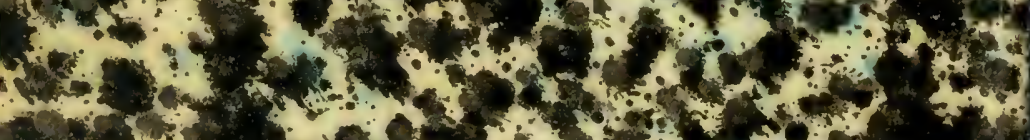

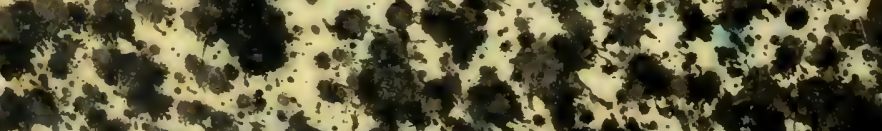

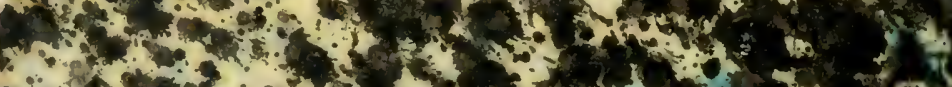

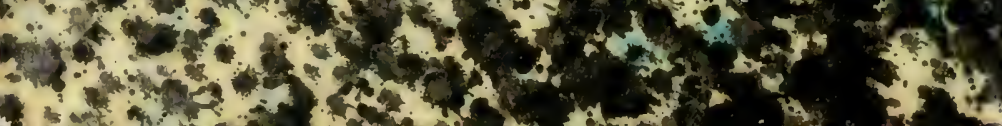
$y-4=2$ 